

\section{DISCLAIMER}

This report was prepared as an account of work sponsored by an agency of the United States Government. Neither the United States Government nor any agency Thereof, nor any of their employees, makes any warranty, express or implied, or assumes any legal liability or responsibility for the accuracy, completeness, or usefulness of any information, apparatus, product, or process disclosed, or represents that its use would not infringe privately owned rights. Reference herein to any specific commercial product, process, or service by trade name, trademark, manufacturer, or otherwise does not necessarily constitute or imply its endorsement, recommendation, or favoring by the United States Government or any agency thereof. The views and opinions of authors expressed herein do not necessarily state or reflect those of the United States Government or any agency thereof. 


\section{DISCLAIMER}

Portions of this document may be illegible in electronic image products. Images are produced from the best available original document. 


\section{UNCLASSIFED}

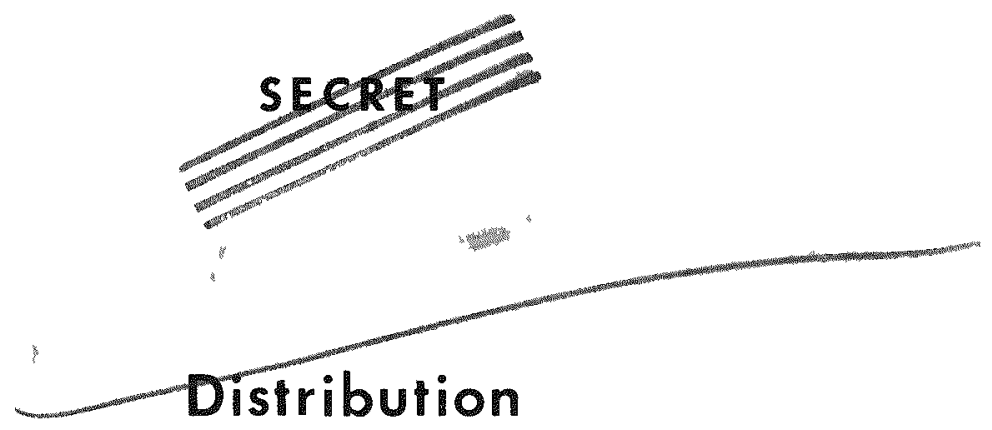

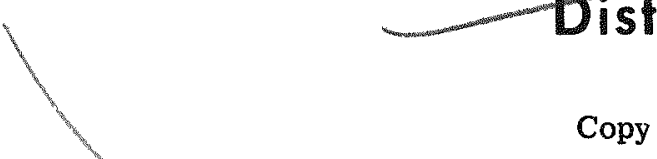

DEPARTMENT OF DEFENSE

Armed Forces Special Weapons

Project (Sandia)

Armed Forces Special Weapons

Project (Washington)

\section{ARMY}

Army Field Forces

Assistant Chief of Staff, G-3

Assistant Chief of Staff, G-4

Chief of Enginners

Chief of Ordnance

Chief of Transportation Corps

Operations Research Office

(Johns Hopkins University)

\section{NAVY}

Bureau of Aeronautics

35

Bureau of Ordnance

Bureau of Ships

Bureau of Supplies and Accounts

Bureau of Yards and Docks

Chief of Naval Operations

Chief of Naval Research

Commandant, Marine Corps

Naval Radiological Defense

Laboratory

\section{AIR FORCE}

Air Force Cambridge Research

$$
\text { Center }
$$

Air Research and Development

$$
\text { Command }
$$

Air Targets Division, Directorate

of Intelligence (Phys. Vul. Branch)

Assistant for Atomic Energy

Assistant for Development Planning
$52-53$

\section{$55-58$}

$59-60$

\section{AIR FORCE}

Assistant for Materiel Program

Control

Deputy Chief of Staff for Development

(AFDRD)

Director of Operations (Operations Analysis Division)

Director of Plans (AFOPD-P1)

Director of Requirements

Director of Research and

Development

Eglin Air Force Base, Air

Proving Ground

Ent Air Force Base, Air

Defense Command

Copy

Kirtland Air Force Base, Special Weapons Center

Langley Air Force Base, Tactical Air Command

Maxwell Air Force Base, Air University

Offutt Air Force Base, Strategic

Air Command

1009th Special Weapons Squadron

Rand Corporation

Scott Air Force Base, Air

Training Command

Wright Air Development Center

Wright Air Materiel Command

63

64

65

66

$67-68$

$69-70$

71

$72-73$

$74-76$

$77-78$

$79-80$

$81-83$

$-84$

$85-86$

$87-88$

$89-91$

$92-93$

\section{ATOMIC ENERGY COMMISSION}

Division of Military Application,

$$
\text { Washington }
$$

Los Alamos Scientific Laboratory, Report Library

Sandia Corporation

Technical Information Service, Oak Ridge (surplus)

University of Cailfornia Radiation

Laboratory, Livermore

Weapon Test Reports Group, TIS
$94-97$

$98-102$

103-104

$105-148$

149

150

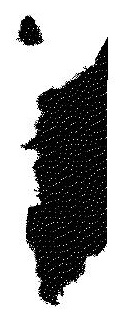




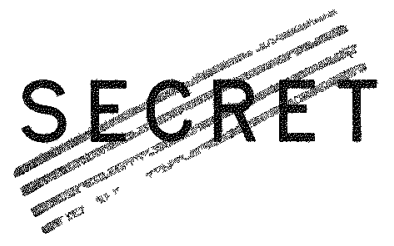

\section{U. S. NAVY STRUCTURES}

by

CHARLES L。 HAYEN

LT, CEC, USN

Approved by: SHERWOOD B. SMITH

Director, Program 3
Approved by: ALVIN C. GRAVES

Scientific Director

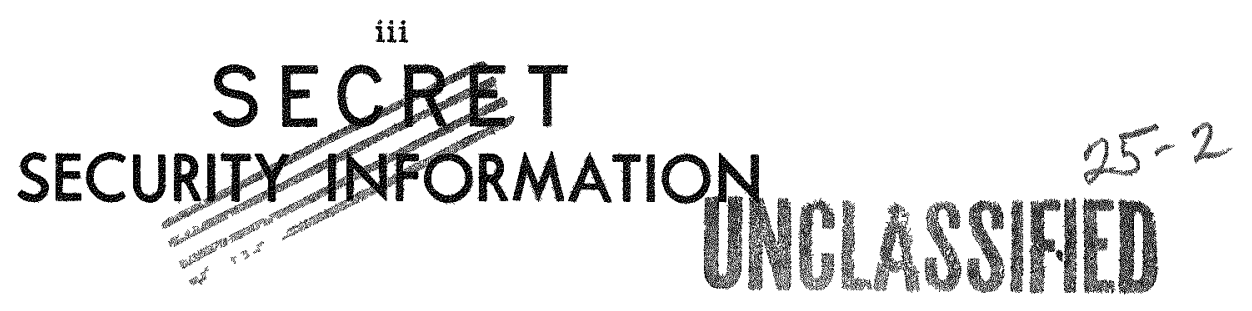




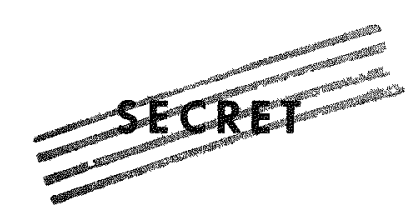

The following portions of the Operation Greenhouse Navy Structures report have been printed in 27 copies and given limited distribution to reference libraries as indicated in the distribution list below.

WT-23 (REF.)

Appendix E Details of Construction

Appendix F Soil Test Data

Appendix G Concrete Test Data

Appendix $\mathbf{H}$ Instrumentation

Appendix I Transit Survey Data

Appendix J Permanent Deformations

WT-24 (REF.)

Appendix K Preshot Photographs

WT-25 (REF.)

Appendix L Postshot Photographs

Reference Library Distribution

Atomic Energy Commission, Washington

Los Alamos Scientific Laboratory

$1-3$

$4-5$

Sandia Corporation

Armed Forces Special Weapons Project, Washington

Armed Forces Special Weapons Project, Sandia

Air Materiel Command, Wright-Patter son AFB, Dayton, Ohio

Air Research and Development Command, Baltimore, Maryland

Air Targets, AFOIN, Headquarters, USAF, Washington

Air University, Maxwell AFB, Alabama

Bureau of Xards and Docks, Navy Department, Washington

Engineer Research and Development Laboratories, Fort

Belvoir, Virginia

Naval Civil Engineering Research and Evaluation Laboratories,

Port Hueneme, California

Office, Chief of Engineers, Department of Army, Washington

Weapon Test Reports Group, TIS 


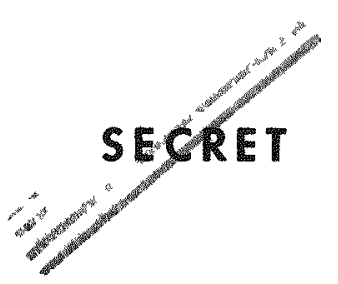

\section{Acknowledgments}

The preparation of this report was accomplished through the combined efforts of personnel of the Bureau of Yards and Docks and of officers of the Civil Engineer Corps.

RADM J. F. Jelley, CEC, USN, was Chief of the Bureau; CAPT E. E. Saunders and CAPT E. B. Greey, CEC, USN, were Assistant Chiefs for Plans and Research; CDR J. Koleszar and CDR F. F. Kravath, CEC, USN, were Directors of the Research Division during the operation.

The report on the design and analysis was prepared by A. Amirikian, Consultant on Special Structures for the Bureau. He was assisted by E. G. Odley. LTJG D. G. Iselin, CEC, USN, the field representative during construction, prepared the construction report. The pre- and postshot surveys were conducted and draft reports prepared by LT C. L. Hayen, LTJG D. G. Iselin, and LTJG P. J. McEleney, CEC, USN. A. Amirikian was technical consultant during the survey. Lieutenant McEleney was field representative during the TItem Shot and was responsible for the interim and final reports published after lreutentints Hayen and Iselin were detached from the project.

LCDR S. Rockefeller, CEC, USN, represented the Bureau and served as Project Officer during the planning and initial construction phases. He was also a consultant to the Project Officer during the entire operation. 
-

F

.

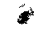

9

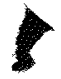

$+$

6 

4.1 General

4.2 Foundation Conditions

4.3 Construction Materials

4.3.1 Concrete.

4.3.2 Structural Steel

4.3.3 Reinforcing Steel

4.3.4 Anchor Bolts .

4.3.5 Assembly Hardware

4.3.6 Brick

4.3.7 Lumber and Formwork

4.4 Construction Methods

4.4.1 Placement of Concrete

4.4.2 Setting of Anchor Bolts

4.4.3 Erection of Precast Structures

- 20

20

- 20

- 20

20

- 21

- 24

- 24

24

24

- 24

- 25

- 25

- 25

- 25

4.5 Construction Problems

- 25

CHAPTER 5 METHODS OF OBTAINING EXPERIMENTAL DATA • . . . . . . . 26

5.1 Objective.

5.2 Required Data

5.2.1. Loading

5.2.2 Response

5.3 Methods

5.3.1 Measurement of Permanent Changes

5.3.2 Selected Transient Measurements .

5.3.3 Photography

CHAPTER 6 EXPERIMENTAL DATA

6.1 General

6.2 Blast Loading

6.3 Structural Response (Observed).

6.3.1 Structure 3.2.1a (Bombproof Roof).

6.3.2 Structure 3.2.1b (Cellular Roof)

6.3.3 Structure 3.2.2a (Panels on Bents).

6.3.4 Structure 3.2.2b (Panels on Brick) .

6.3.5 Structure 3.2.3a (Matchbox)

6.3.6 Structure 3.2.3b (Matchbox)

6.3.7 Structure 3.2.4a (Gable Bent) .

6.3.8 Structure 3.2.4b (Gable Bent) .

6.3.9 Structure 3.2.5 (Cylindrical Arch)

6.3.10 Structure 3.2.6 (Dome)

6.3.11 Structure 3.2.7a (Conventional Poured in Place)

6.3.12 Structure 3.2.7b (Conventional Poured in Place)

6.4 Structural Response (Recorded)

- 30

- 30

- 30

- 30

- 30

- 45

- 53

- 61

- 69

- 82

- 92

. 102

. 114

.127

. 141

7.1 Comparison of Test Results with Pretest Predictions

viii 


\section{CONTENTS (Continued)}

7.1.1 Loading .

7.1.2 Response

7.1.3 Structure 3.2.1a

7.1.4 Structure $3.2 .1 \mathrm{~b}$

7.1.5 Structure 3.2.2a

7.1.6 Structure $3.2 .2 b$

7.1.7 Structures 3.2.3a and $b$

7.1.8 Structure 3.2.4a

7.1.9 Structure $3.2 .4 \mathrm{~b}$

7.1.10 Structure 3.2 .5

7.1.11 Structure 3.2 .6

7.1.12 Structure $3.2 .7 \mathrm{a}$

7.1.13 Structure $3.2 .7 \mathrm{~b}$

7.2 Critical Points in Dynamic Design

7.2.1 End Walls

7.2.2 Connections on Rectangular Structures.

7.2.3 Panel Framing

7.2.4 Roofs

7.2.5 Front Walls

7.3 Comparison of Recorded Deflections with Those Computed on the Basis of

Recorded Loading

7.3.1 Structure 3.2.5 (Quonset)

7.3.2 Structure 3.2.4b (Gable)

7.4 Comparison of Shaped with Rectangular Structures

7.4.1 Loading .

7.4.2 Structural-resistance Characteristics

7.5 Comparison of Conventional with Paneled Structures

7.6 Discussion of Comparison Panels

7.3.1 Ribs In vs Ribs Out

7.6.2 Value of Intermediate Ribs

7.6.3 Welded Panel Connections vs Bolted Connections

7.7 Effects of Earth Cover

7.7.1 Mass Effect.

7.7.2 Pressure Attenuation

7.7.3 Streamlining Effect

CHAPTER 8 CONCLUSIONS AND RECOMMENDATIONS

8.1 General Conclusions

\subsubsection{Fundamental Data .}

8.1.2 Observation of Physical Behavior .

8.1.3 Relative Merit of Types

8.2 Specific Conclusions.

8.2.1 Valiaity of the Method of Analysis

8.2.2 Modifications to Analysis in Light of Test Results.

8.2.3 Conclusions on Greenhouse Structures

8.2.4 Revised Designs Based on Analysis

8.3 General Recommendations

8.4 Specific Recommendations 


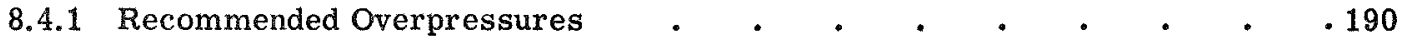

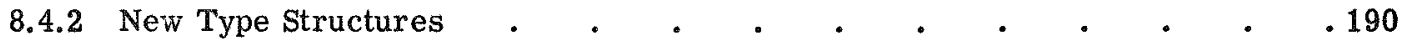

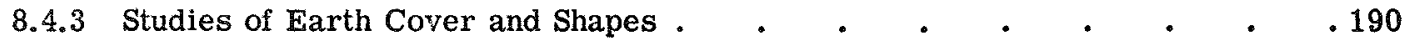

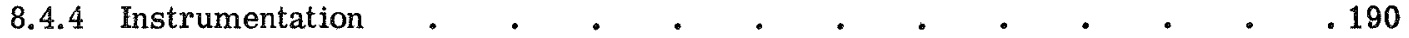

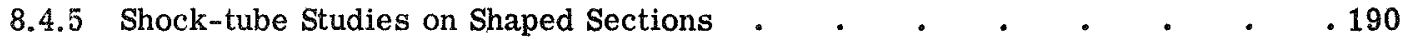

8.4.6 Laboratory

8.4.7 Theoretical Studies.

\section{CHAPTER 9 SUMMARY .}

.190

.192

APPENDIX A NOTATIONS

.193

A.1 Directions.

A.2 Notations Used in Analysis

APPENDIX B METHOD OF ANALYSIS FOR RESISTANCE TO BLAST

.197

.197

.197

B.1 Procedure of Analysis

B.1.1 General Phases of Investigation

B.1.2 Concept of Deformation .

B.1.3 Modulus of Resistance .

B.1.4 Fundamental Relation of Motion

B.2 Application - of Analysis for Resistance to Blast

B.2.1 Case I: Front Wall

B.2.2 Case II: Roof.

B.3 Analysis for Over-all Strength Against Blast

B.3.1 Stability Against Sliding.

B.3.2 Stability Against Overturning.

APPENDIX C DESIGN AND ANALYSIS OF STRUCTURES

.199

.199

.199

.199

.200

.204

.204

.207

.210

.215

.216

.217

.222

C.1 stmucture 3.2.1a

C.2 Structure $3.2 .1 \mathrm{~b}$

C.3 Structure 3.2.2a

C.3.1 Framing Arrangement

C.3.2 Design

C.3.3 Analysis for Blast .

C.3.4 Anticipated Damage

C.4 Structure 3.2.2b

C.4.1 Framing Arrangement

C.4.2 Design .

C.4.3 Analysis for Blast .

C.4.4 Anticipated Damage

C.5 Structures 3.2.3a and $b$

C.5.1 Framing Arrangement

C.5.2 Design .

C.5.3 Analysis for Blast .

C.5.4 Anticipated Damage, Structure 323b

C.5.5 Anticipated Damage, Structure 323a 
C.6 Structure 3.2.4a
C.6.1 Framing Arrangement
C.6.2 Design .
C.6.3 Analysis for Blast .
C.6.4 Anticipated Damage

C.7 Structure 3.2.4b

C.7.1 Framing Arrangement

C.7.2 Design .

C.7.3 Analysis for Blast .

C.7.4 Anticipated Damage

C.8 Structure 3.2.5 。

C.8.1 Framing Arrangement

C.8.2 Design .

C.8.3 Analysis for Blast .

C.8.4 Anticipated Damage

C.9 Structure 3.2.6 .

C.9.1 Framing Arrangement

C.9.2 Design .

C.9.3 Analysis for Blast .

C.9.4 Anticipated Damage

C.10 Structure 3.2.7a and b

C.10.1 Framing Arrangement

C.10.2 Design .

C.10.3 Analysis for Blast

C.10.4 Anticipated Damage, Structure 3.2.7a

C.10.5 Anticipated Damage, Structure 3.2.7b

D.1 General Clauses

D.1.1 General Description

D.1.2 Drawings

D.1.3 Standard Specifications

D.2 Concrete Work .

D.2.1 General Requirements

D.2.2 Additional Classes of Concrete

D.2.3 Precast Concrete

D.2.4 Concrete Surfaces .

D.3 Masonry

D.3.1 General Requirements

D.3.2 Workmanship.

D.4 Steelwork

D.4.1 General Requirements

D.4.2 Structural Steel

D.4.3 Inserts .

D.4.4 Fastenings

D.4.5 Pipe

D.5 Woodwork .

D.5.1 General Requirements 


\section{CONTENTS (Continued)}

D.5.2 Grades .

D.6 Field Painting

D.6.1 General Requirements

D.6.2 Materials

D.6.3 Lead-and-oil Paint

D.7 Design Drawings

BIBLIOGRAPHY

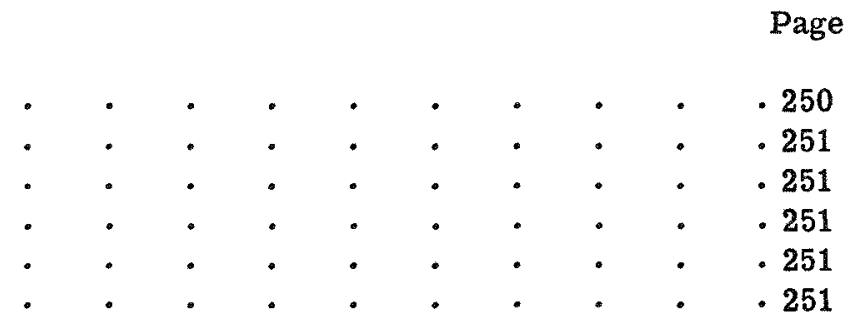

.271

\section{ILLUSTRATIONS}

\section{CHAPTER 2 STRUCTURAL BEHAVIOR UNDER BLAST}

2.1 Assumed Duration of Positive Phase of Shock Wave . . . . . . . . 7

2.2 Assumed Pressure-Time Relation for Front Face of Structure . . . . . . $\quad$. 8

2.3 Assumed Pressure-Time Relation for Roof of Structure . . . . . . $\quad 9$

2.4 Assumed Pressure-Time Relation for Rear Face of Structure . . . . . . 10

CHAPTER 3 TEST STRUCTURES

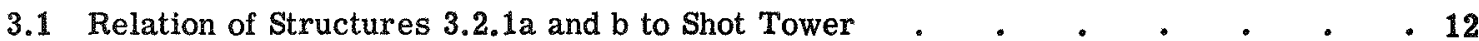

3.2 Structure 3.2.1a

3.3 Structure $3.2 .1 \mathrm{~b}$

3.4 Structure 3.2.2a

3.5 Structure $3.2 .2 \mathrm{~b}$

3.6 Type Structures $3.2 .3 \mathrm{a}$ and $\mathrm{b}$

3.7 Structure 3.2.4a (Prior to Placement of Earth Cover)

3.8 Structure $3.2 .4 \mathrm{~b}$

3.9 Structure 3.2 .5 .

3.10 Structure 3.2.6 (Prior to Placement of Earth Cover).

3.11 Type Structures $3.2 .7 a$ and $b$

\section{CHAPTER 4 CONSTRUCTION}

4.1 Quarrying Reef Coral. Coarse Aggregate after Crushing, Screening, and

Washing

4.2 Concrete Mixing Plant

4.3 Transit-mix Truck Discharging Concrete into a 1 -cu.

. 23

4.4 Steel Box Trusses and Reinforcing Steel in Place . . . . . . . . . . 24

\section{CHAPTER 5 METHODS OF OBTAINING EXPERIMENTAL DATA}

5.1 Projecting a Point Selected at the Fold to the Floor Using a Plumb Bob . . . 27

5.2 Procedure of Measuring Coordinates in a Horizontal Plane . . . . . . 28

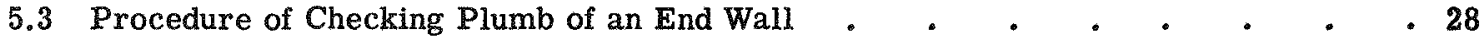

\section{CHAPTER 6 EXPERIMENTAL DATA}

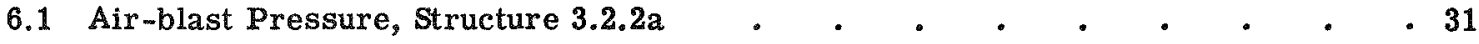

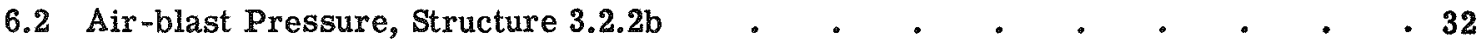

xii 


\section{SECRET}

\section{ILLUSTRATIONS (Continued)}

6.3 Air-blast Pressure, Structure 3.2.3a

6.4 Air-blast Pressure, Structure 3.2.3b

6.5 Earth Pressure, Structure 3.2.4a

6.6 Air-blast Pressure, Structure 3.2.4b

6.7 Air-blast Pressure, Structure 3.2.5, Left Half .

6.8 Air-blast Pressure, Structure 3.2.5, Right Half .

6.9 Earth Pressure, Structure 3.2.6

6.10 Air-blast Pressure, Structure 3.2.6.

6.11 Air-blast Pressure, Structure 3.2.7a

6.12 Air-blast Pressure, Structure 3.2.7b

6.13 Postshot Aerial View of Structure 3.2.1a .

6.14 Roof from Right Rear Showing Cratering, Structure 3.2.1a

6.15 Center Section of Edge of Roof Slab and Front Bearing Wall, Structure 3.2.1a.

6.16 Undersurface of Top Slab Showing Dowel Scratches When Support Wall Is Deflected Inward

6.17 Deformation of Structure 3.2.1a

6.18 Cracks on Edge of Slab from Right Front, Structure 3.2.1a

6.19 Cracks on Edge of Slab from Left Rear, Structure 3.2.1a .

6.20 Postshot Aerial View of Structures 3.2.1b and 3.2.1a

6.21 General View of Building Components, Structure 3.2.1b

6.22 Top Slab Displaced 150 Ft to Rear, Structure 3.2.1b

6.23 Failure of Weld Between Roof and Bearing Wall, Structure 3.2.1b

6.24 Filled Cell Broken Away from Roof, Structure 3.2.1b

6.25 Final Location of Structural Elements, Structure 3.2.1b

6.26 Postshot Aerial View of Structure 3.2.2a

6.27 Response History of Structure 3.2.2a

6.28 Inward Deformation of Front Panel, Structure 3.2.2a

6.29 Rear Haunch of Center Bent, Structure 3.2.2a

6.30 Panel-bolt Failure in Right Bent at Front of Structure 3.2.2a

6.31 Anchor Bolts Bent Inward Along Front of Structure 3.2.2a

6.32 Weld Failure Between Roof and Wall Panel, Structure 3.2.2a

6.33 Final Location of Panels of Structure 3.2.2a

6.34 Postshot Aerial View of Structure 3.2.2b.

6.35 Panel Footing in Uplifted Position, Structure 3.2.2b .

6.36 Typical Masonry Failures Through Brick, Structure 3.2.2b

6.37 Left Half of Roof Showing Column Type Failure, Structure 3.2.2b

6.38 Weld Failures Between Roof and Wall Panels, Structure 3.2.2b .

6.39 Roof Fracture, Structure 3.2.2b

6.40 Horizontal Deformations, Rear Wall of Structure $3.2 .2 \mathrm{~b}$

6.41 Rear-wall Crack Pattern, Structure 3.2.2b

6.42 End-wall Crack Pattern, Structure 3.2.2b

6.43 Cracks on Interior of Brick Wall, Structure $3.2 .2 \mathrm{~b}$

6.44 Response History of Structure 3.2.3a

6.45 Top Ends of Front-wall Trusses

6.46 View Along Front Edge of Foundation of Structure 3.2.3a

6.47 Edge Row of Roof Cells Still Attached to Each End Wall, Structure 3.2.3b

6.48 Top Edge of Rear Wall of Structure 3.2.3a 


\section{SERET}

ILLUSTRATIONS (Continued)

Page

6.49 Roof Edge Along Top of Rear Wall of Structure 3.2.3b Still Intact $\quad$. . . . 84

6.50 Detail of Weld Failure in Roof Truss near End Connection to Rear Wall

Structure $3.2 .3 \mathrm{~b}$

6.51 Right End Wall of Structure 3.2.3a, Showing Failure at Welds Between

Truss-chord Bars and Channel . . . . . . . . . . . 86

6.52 Left End Wall of Structure 3.2.3b, Showing How Channels Pulled Up over

Anchor Bolts

6.53 Base of Rear Wall of Structure $3.23 a$ Still Attached to Foundation

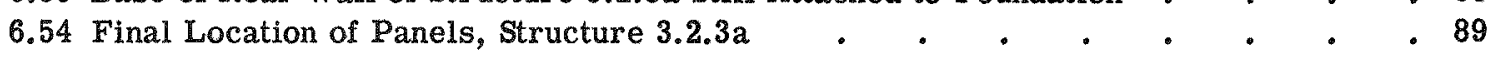

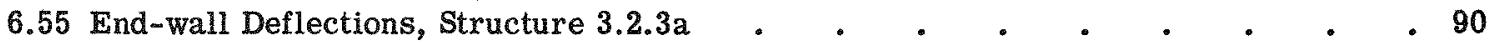

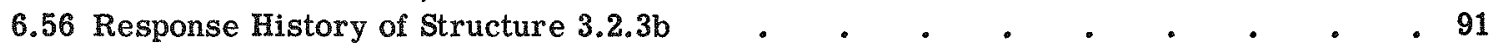

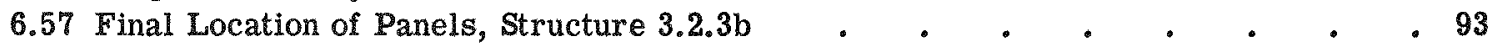

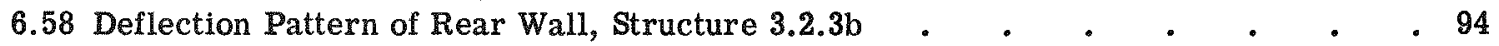

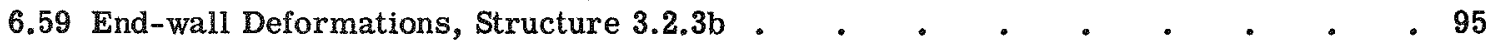

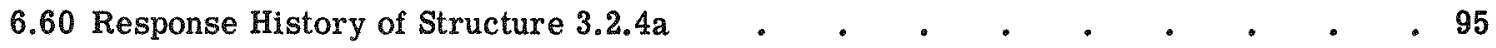

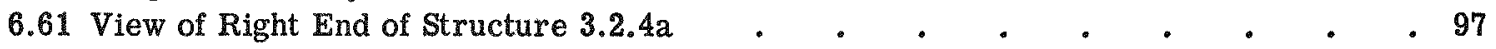

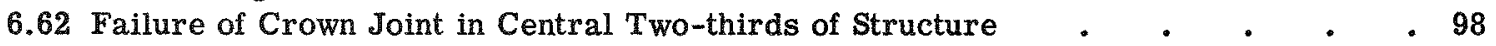

6.63 Upper Half of End Panel That Was Adjacent to Front Wall,

Structure 3.2.4a

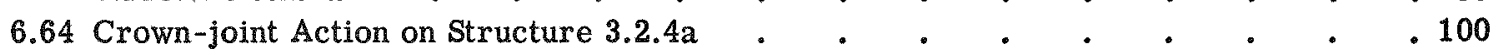

6.65 Crown Failure near Right End . . . . . . . . . . . . . . 101

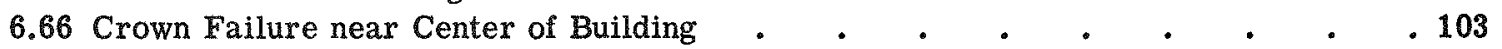

6.67 Interior View of Crown Joint After Removal of Debris and

Earth Cover

6.68 .

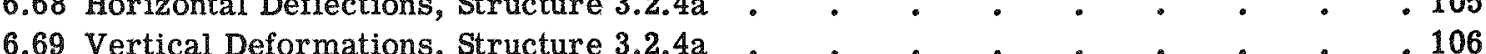

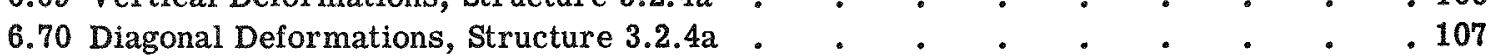

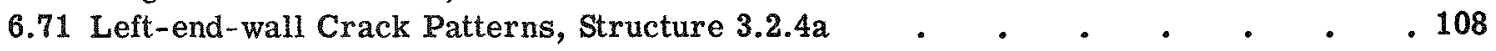

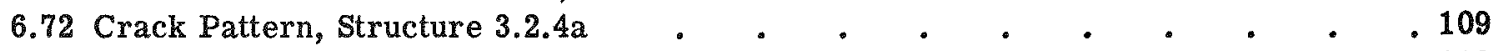

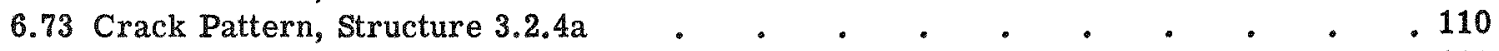

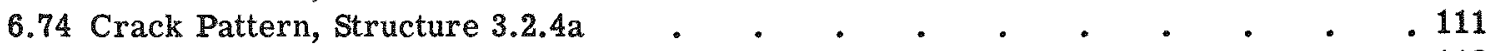

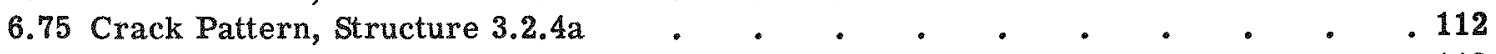

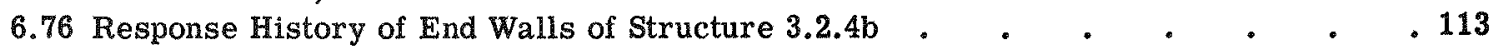

6.77 Interior View Showing Diaphragm Distortion and Concrete Spalling

After Loading

6.78 Interior View Showing Failure of Diaphragm After Loading . . . . . . 116

6.79 Right Front-wall Panel Deflections, Structure 3.2.4b $\quad . \quad$. $\quad . \quad$. $\quad . \quad$. 117

6.80 View Showing Roof Failure in Front-wall Panel _ . . . . . . . . 118

6.81 Interior View Showing Cracks in Ribs at Lower Fold of Left Front Wall . . . 119

6.82 Horizontal Deflection, Structure 3.2.4b . . . . . . . . . 120

6.83 Vertical Deformations, Structure 3.2.4b . $\quad$ - . . . . . . . . . . 121

6.84 Crack Pattern, Structure 3.2.4b

6.85 Crack Pattern, Structure 3.2.4b

6.86 Crack Pattern, Structure $3.2 .4 \mathrm{~b}$

6.87 Crack Pattern, Structure 3.2.4b

6.88 End Walls in Displaced Positions, Structure 3.2 .5

6.89 Left End Wall Nearly Severed, Structure 3.2 .5

6.90 Response History of End Walls of Structure 3.2.5

xiv 


\section{ILLUSTRATIONS (Continued)}

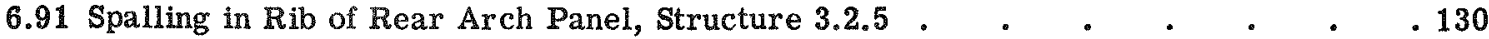

6.92 Steel in End-wall Panel, Structure 3.2.5 • . . . . . . . . . . . . 131

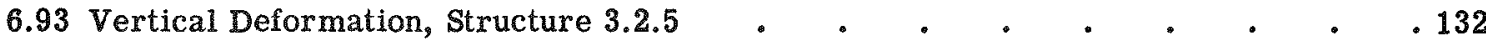

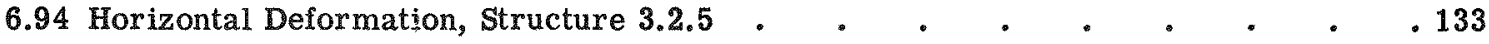

6.95 Changes in Diagonal Length of Arch Panels Between Points Indicated, Structure 3.2.5

6.96 Arch Deformation, Structure 3.2.5

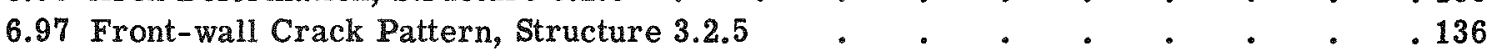

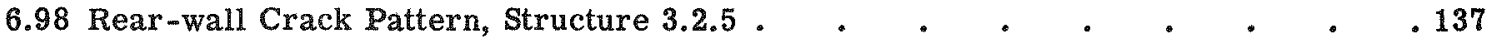

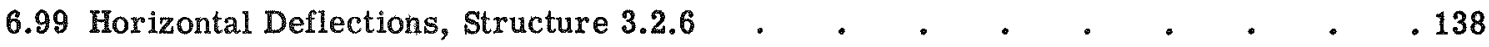

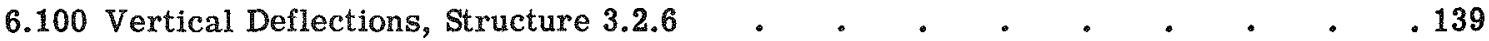

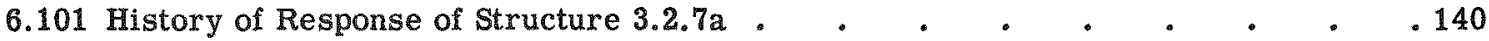

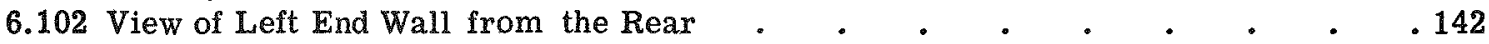

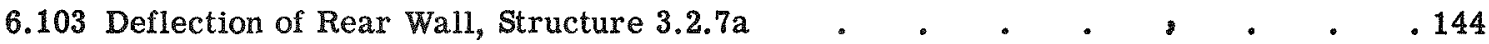

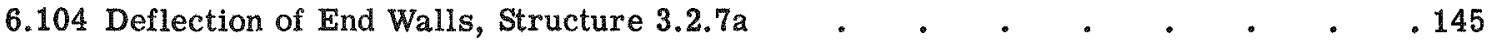

6.105 Rear-wall Crack Pattern, Structure 3.2.7a . . . . . . . . . . . . 146

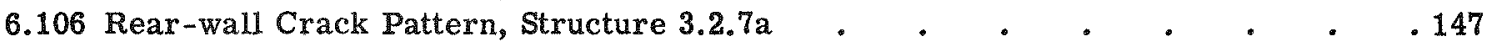

6.107 Longitudinal Stringer Beams Under Right Half of Roof . . . . . . 149

6.108 Deflection of Main Transverse Roof Girder . . . . . . . . . . . 150

6.109 Detail View of Diagonal Tension Failure of Stringer Beams at the Haunches . . . . . . . . . . . . . 151

6.110 Inward Rotation of Main-girder Haunch at Front Wall . . . . . . 152

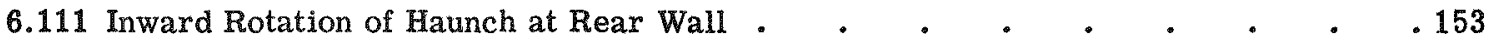

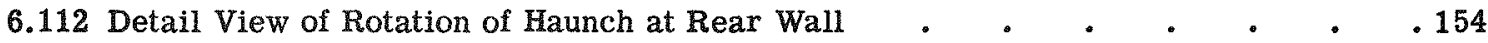

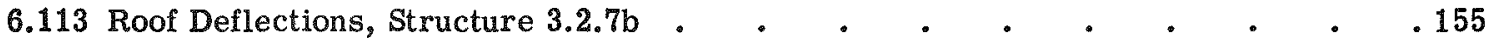

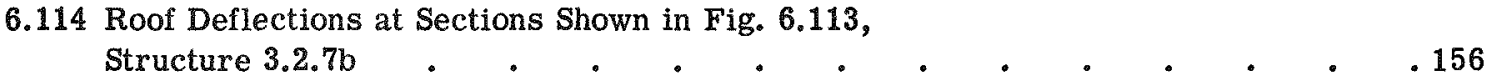

6.115 Deflection Pattern, Structure 3.2.7b $\quad . \quad$. $\quad . \quad . \quad . \quad . \quad . \quad . \quad .157$

6.116 Wall Deflections at Sections Shown in Fig. 6.115, Structure 3.2.7b . . . . 158

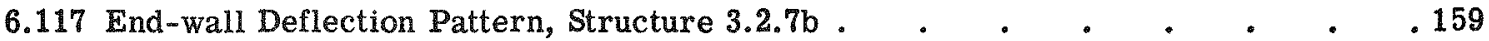

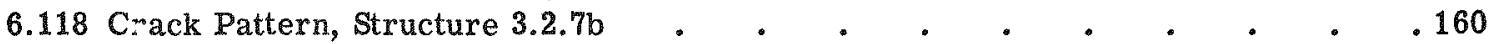

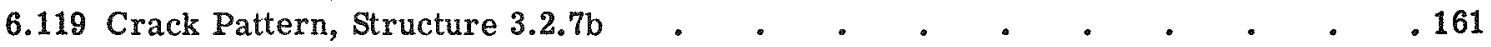

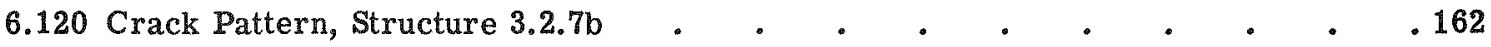

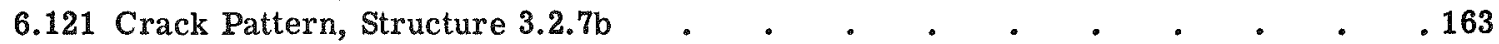

6.122 Diagonal Shear Failure in Roof Girder . . . . . . . . . . . 164

\section{CHAPTER 7 DISCUSSION OF RESULTS}

7.1 Chronological Loading Curves from Shock Tube, Structure 3.2.5 • • • 173

7.2 Recorded Chronological Loading Curves, Left Half of Structure 3.2 .5

7.3 Computed and Recorded Deflections at Gauge D3, Structure $\mathbf{3 . 2 . 5}$

7.8 Computed Deflections at Gauge D2. Structure 3.2.4b

7.9 Damage to Structure 3.2.6 After Item Shot, of Blast 


\section{ILLUSTRATIONS (Continued)}

APPENDIX A NOTATIONS

A.1 Plan View, Showing Directions. $\quad$ - . . . . . . . . . . . . 197

\section{APPENDIX B METHOD OF ANALYSIS FOR RESISTANCE TO BLAST}

B.1 Deformations of a Beam Under a Uniform Loading . . . • . . . . 201

B.2 Resistance-Deflection Relation for a Reinforced-concrete

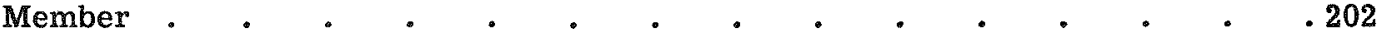

B.3 Plastic Deformation of a Two-way Thin Slab Under a
Uniform Loading $q$.
E

B.4 Reduction Factors and Resistance Factor for Two-way Slabs . . . . . 205

B.5 Pressure-Time Relation for Front Face of Structure $\quad$ - . . . . . . 206

B.6 Pressure-Time Relation for Roof of Structure. . . . . . . . . . . 211

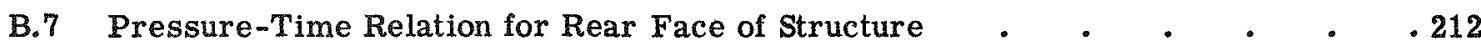

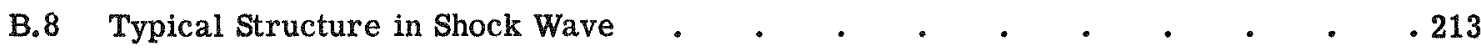

B.9 Total Roof Pressures and Movements of Total Pressures . . . . . . 214

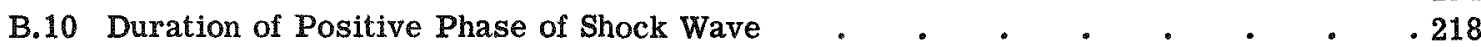

\section{APPENDIX C DESIGN AND ANALYSIS OF STRUCTURES}

C.1 Resistance-Deflection Relation for a Simply Supported

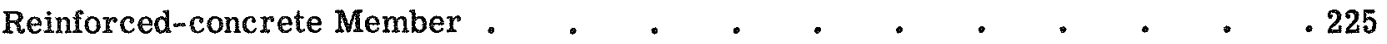

C.2 Deformations and Loadings for Bents of Structure 3.2.2a..$\quad$. $\quad . \quad$. 226

C.3 Deformations and Loadings for End Walls of Structure 3.2.2a . $\quad$ - . $\quad$ - 228

C.4 Pressure-Time Relation for Roof . . . . . . . . . . . . . 233

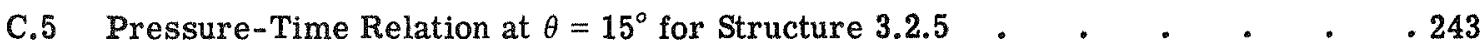

\section{APPENDIX D DESIGN DRAWINGS AND SPECIFICATIONS}

D.1 Structural Details, Type 3.2.1a

D.2 General Plans, Type 3.2.1b

D.3 Truss Details, Type $3.2 .1 \mathrm{~b}$

D.4 Foundation Plan, Type 3.2.1b .

D.5 Structural Details, Type 3.2.2a

D.6 Structural Details, Type 3.2.2a

D.7 Structural Details, Type 3.2.2b

D.8 Structural Details, Type 3.2.2b

D.9 General Plans, Type 3.2.3

D.10 Joint Details, Type $\mathbf{3 . 2 . 3}$

D.11 Panel Details, Type 3.2.3

D.12 Truss Details, Type 3.2.3

D.13 Structural Details, Type 3.2.4a

D.14 Structural Details, Type 3.2.4a

D.15 Plans and Details, Type 3.2.4b

D.16 Plans and Details, Type 3.2.5

D.17 Structural Details, Type 3.2.6

D.18 Structural Details, Type 3.2.6

D.19 Structural Details, Type 3.2.7 


\section{SERRET \\ TABLES}

CHAPTER 6 EXPERIMENTAL DATA

6.1 Maximum Displacements .

165

CHAPTER 7 DISCUSSION OF RESULTS

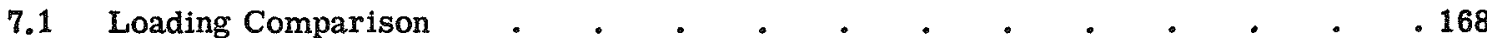

7.2 Strengths of Materials . . $\quad . \quad . \quad . \quad . \quad . \quad . \quad . \quad . \quad . \quad 176$

7.3 Effect of Shape on Reflected Pressures (Constant Range) . . . . . . 184

CHAPTER 8 CONCLUSIONS AND RECOMMENDATIONS

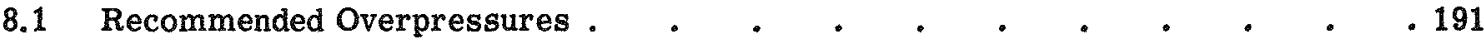

APPENDIX B METHOD OF ANALYSIS FOR RESISTANCE TO BLAST

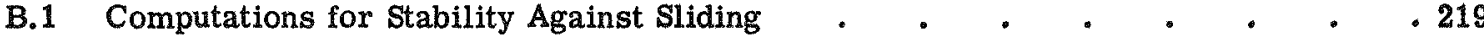

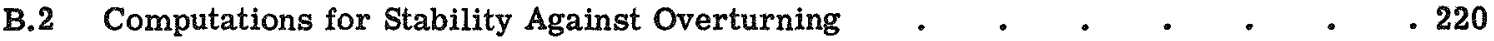

APPENDIX D DESIGN DRAWINGS AND SPECIFICATIONS

D.1 Concrete Specifications . • • . • • • • . • • . 248

D.2 Aggregate Sieve Specifications . . . . . . . . . 249

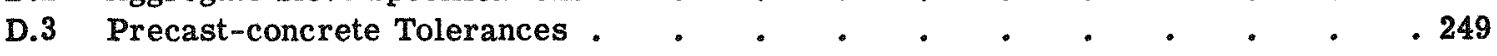

xvii 


\section{Abstract}

This volume describes all phases of the structures of Project 3.2 for which the Bureau of Yards and Docks, the sponsoring agent of the project, was responsible. All phases of the project work reported herein were accomplished by personnel of the Bureau of Yards and Docks, Navy Department, and officers of the Civil Engineer Corps, U. S. Navy.

The objectives of the test were (1) to observe the physical behavior or response of a structure under blast loading, (2) to obtain fundamental data from structures subjected to blast loading, and (3) to determine the relative merit of various structural types.

The types of structures tested are those which have been developed through previous testing and through trends in Bureau policy in protective construction.

Since protective construction is a problem common to civil as well as military installations, practical methods of design and analysis for blast loadil.gs must be developed for use by structural engineers. The method of design and analysis used in Project 3.2 was developed for practical use by A. Amirikian, Consultant on Special Structures for the Bureau. The complete postshot analysis for two of the most important structures may be found in Chap. 7. The remaining structures will be analyzed as time permits.

Test results and analysis to date have, in general, corroborated the pretest concept of structural behavior.

During the construction phase, the Project Officer was represented at the site. The field representative, LTJG D. G. Iselin, CEC, USN, was assigned certain responsibilities which are included in the Program Director's Report, Annex 3.0.

The structures were instrumented in order to provide accurate transient data. In addition, a thorough system of physical measurements was used to obtain and record the changes in the structures and the structural elements. Still photography was used extensively. The measurements data were evaluated, and a history of response is presented. This history was obtained from studies of the data and of the final positions of members which failed. Methods of failure were also determined from a study of the physical survey data.

The following brief conclusions are based upon the Project 3,2 results:

1. Enough fundamental data were obtained to reanalyze the structures tested and to correct structural weaknesses.

2. The method of analysis is accurate to within $\$ 25$ per cent in predicting structural response.

3. The loading assumptions were generally good except for the roofs, which had higher pressures than expected.

4. Shaped structures were superior to rectangular structures.

5. Standard Navy heavy bombproof structures with connection modifications can withstand an atomic burst at the edge of the fireball, for weapons of this yield $(46.7 \mathrm{kt})$.

6. Earth cover has a beneficial effect on the response of structures subjected to blast.

Further full-scale tests on similar structural types are recommended in order to test modified structures. The collection of data on the yield strengths of materials should be accelerated. Quantitative infor mation is required concerning the effects of earth cover on structures subjected to blast. Much additional information on loading of structures of varying shapes, sizes, and orientation should be obtained from scale-model tests and shock-tube tests. 


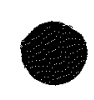

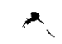

4

1 


\section{Discussion}

\section{INTRODUCTION}

\subsubsection{Protective Construction}

One of the responsibilities of the Bureau of Yards and Docks is to provide protective-construction designs for the Naval Shore Establishment. The field of protective construction covers personnel shelters and other structures designed for maximum resistance to the effects of enemy weapons. It is necessary to provide protection for vital facilities, such as power plants and certain naval industrial establishments. Further, in considering protection from conventional weapons, many functions of a naval establishment are placed in a low-risk category because of the high order of duplication within or near the establishment. When an atomic attack is considered, however, stand-by or duplicate facilities may also be in the damage area. It is necessary, therefore, to strengthen nearly all structures if feasible and to provide blastresistant features in new structures in order to ensure a minimum amount of work and time in rehabilitating the establishment.

It is readily apparent that there is a limit to the protection which can be provided. Cost, availability of materials, and labor must be measured against the importance of the facility to be protected. It is necessary, of course, to design some structures which will provide nearabsolute protection. Such structures must be safe against the impact and blast of conventional weapons. They must also be safe under the blast load imposed by an air or surface burst from a nuclear explosion. Because of the lack of information on the close-in pressures of a surface burst, the test structures designed for maximum protection in this test were designed for conventional-weapon loading.

\subsubsection{Structural Analysis for Dynamic Loading}

In conventional structural design, loadings are either static or dynamic, with dynamic loads usually converted empirically to static in a manner similar to the handling of wind load. In special designs, there are exceptions to this practice; however, in general, very few structural designers have attempted to design structures for dynamic loads. Since blast imposes a dynamic load on structures, most designs should include an analysis for this type of loading. At the present time, a dynamic analysis is a tedious time-consuming task requiring special techniques and knowledge. A method of analysis must be developed which follows conventional design methods and which is relatively fast.

\subsection{OBJECTIVES}

The general objectives of the project were (1) to test under blast loading standard and new structural types for use as protective structures in the Naval Shore Establishment and (2) to develop a practical method for the design and analysis of standard and new structural types when those types are subjected to a dynamic loading.

The first general objective was accomplished by testing selected standard structures and the latest designs of new structural types. The latter objective will be accomplished by analyzing all structures by a method developed by $A$. Amirikian of the Bureau. The pre- and postshot analyses are included in this report. The complete postshot analysis, however, will be completed at a later date, and an addendum to the final report will be written at that time incorporating the final conclusions. 
Each structure of the Navy Project was placed in the program with a specific technical objective. These objectives are listed in Chap. 3 .

\subsection{PRESENT KNOWLEDGE}

The design and analysis of the structures of the Navy Project were made by A. Amirikian, Consultant on Special Structures for the Bureau, and his staff.

Since the basic design of each structure was made using standard wind and snow loadings and standard methods, the knowledge and experience of the designing engineers comprised the necessary background. Present specific technical knowledge is demonstrated in later sections of this report where design criteria and methods are discussed. The development of the method of analysis and of certain design features was based on several research and experimental projects sponsored by this Bureau and on extensive work accomplished by the Office of the Chief of Engineers, U. S. Army, the David Taylor Model Basin, the National Bureau of Standards, and other agencies with similar interests.

\subsubsection{Concrete Tests}

Just prior to World War II, an extensive massive-concrete testing program was carried out at the Naval Proving Ground, Dahlgren, Va. ${ }^{1}$ The tests resulted in the standard Navy design for massive-concrete protective structures. The tests, in general, advanced knowledge in reinforcing-steel requirements, proved theories of this type of design, and provided data for advanced theories in design. One of the structures in the project covered by this report was designed by the standards which resulted from these tests.

\subsubsection{Precast-concrete Construction}

The Bureau has had considerable experience in the use of precast-concrete elements in construction. The techniques used in the fabrication of the structures have been used success- fully in standard building types, such as the Mechanicsburg, Pa., Supply Depot warehouses. ${ }^{2}$

A project in construction using precast and prestressed concrete at College Point, N. Y., in 1944 provided the Bureau with further information in this field.

\subsubsection{Operation Sandstone}

In Operation Sandstone, the Bureau tested a large number of precast-concrete shapes of varying outside dimensions, wall thicknesses, and geometric shapes. ${ }^{3}$ The test procedures used in Sandstone did not provide results which could be subjected to a strict analysis. However, an evaluation had been made of the damage and movement of the cubes, which was of considerable value in the design of the precast elements of the Greenhouse structures, and in the anchorage required to prevent movement.

\subsubsection{Precast Cellular Construction}

Subsequent to Operation Sandstone, a precast cellular type structure had been tested against conventional armor-piercing (A.P.) projectiles at Dahlgren. ${ }^{4}$ Scaled roof slabs were constructed and subjected to penetrating projectiles. The projectiles were then withdrawn from the slab, and a charge was placed in the crater and exploded to simulate an explosive projectile. The tests were satisfactory, and the results served as a basis of design for one of the structures included in this project.

\section{REFERENCES}

1. C. A. Trexel, CAPT, CEC, USN, "Bombproof Structures," U. S. Government Printing Office, Washington, D. C., Sept. 30, 1941.

2. A. Amirikian, Precast Concrete Storehouses, J. Am. Concrete Inst., 18(10): 1097-1116 (1947).

3. Bureau of Yards and Docks, Interim Report Participation by Bureau of Yards and Docks, Navy Department, in Operation Sandstone.

4. U. S. Naval Proving Grounds, Final Report on Model Tests of Concrete Cellular Construction, Jan. 18, 1950. 


\section{Chapter 2}

\section{Structural Behavior Under Blast}

\subsection{INTRODUCTION}

This section is based on a method of analysis developed for Project 3.2 by Amirikian. ${ }^{1}$

Unlike structural behavior anticipated and obtained in conventional design, the extent of damage due to weapons loading in protective construction cannot be fully or clearly determined. In conventional work a structure is designed to sustain a given condition of loading within limits of elastic strain. Except for rare instances the intensity of a loading sustained by a building during its service life is not appreciably surpassed by that contemplated in the original design. In contrast, there is no control of the loading which may be imposed on a protective structure. There is no assurance, except that given by the laws of probability, that the condition and the severity of loading as assumed will prevail. Consequently the extent of damage may be far beyond the range conceived in design. As a practical corollary it may be necessary to assume that a building will suffer maximum damage which, in turn, may be taken as a condition short of collapse of local or individual members of framing.

In this report the analysis of the strength of a structure under atomic blast is predicated on this concept of structural behavior. It may be considered as a limit design where use is made locally of the full dynamic resistance of members under relatively large plastic deformations. However, such local overstresses, or even some failures, may not necessarily mean a serious impairment of over-all structural adequacy of a building, since in most cases, by proper arrangement of framing, it will still be possible to retain the needed strength and stability of the structure as a whole.

\subsection{LOADING CONDITIONS}

\subsubsection{Atomic Blast}

A great deal of information has recently become available regarding the nature and effects of an atomic explosion. 2/ The destructive effects of the fission are caused by the shock wave and the thermal and nuclear radiations associated with the phenomenon. From the point of view of structural adequacy, resistance to the shock wave constitutes the primary problem in protective construction.

A shock wave is essentially a pressure wave with almost zero time of rise, initiated by the energy released during an explosion. It is characterized by a shock front where the intensity of pressure rises sharply in the positive direction, reaches a peak, then falls off and reaches a negative peak pressure with subsequent gradual return to atmospheric pressure. The intensities of the pressures decrease while their durations increase with the propagation of the shock wave. Similarly, the velocity of the shock front decreases from an indeterminate maximum near the center of the explosion to the velocity of sound at a distance of about 10,000 ft. For design purposes, in the distance range of 2000 to $10,000 \mathrm{ft}$ from the center of explosion, the velocity of the shock wave was considered as constant and equal to $1400 \mathrm{ft} / \mathrm{sec}$. The peak pressures in this range utilized for the analysis of the test structures are given in Chap. 3; the durations of the positive phase are given in Fig. 2.1.

In the analysis, the investigation was confined to the positive phase of the shock wave. Since the pressures in the negative phase are relatively small, no investigation for this period is 


\section{SECRET}

required for the type structures included in the Navy test, i.e., those with a relatively high natural frequency.

\subsubsection{Blast Pressures on a Structure}

When a shock wave encounters an obstruction in its path, such as a structure, the pressure pattern is disturbed. The extent of the disturbances will vary at the various faces of the structure in accordance with the angularity and orientation of the element or the created interference. Owing to the many variables involved, the disturbance is a complex phenomenon for which complete information is not yet available. At present one of the most convenient and practical methods of studying the disturbances caused by obstacles in the path of a blast wave is by means of shock tubes. A number of investigations in this field have been made, of which those at Princeton University constitute a valuable source of information. ${ }^{3}$ The pressure-time relations shown in Figs. 2.2 to 2.4 are based primarily on these data. In this connection, the following points are to be noted: All pressures represent an average condition over each face of the structure, As shown in Fig. 2.2, a factor of 2 was applied to peak pressure, $\mathrm{p}_{0}$, in order to obtain the maximum reflected pressure on the front wall. This corresponds ${ }^{4}$ to an angle of incidence of $0^{\circ}$. The stagnation pressure at the end of the period $t_{1}$ was taken as equal to $p_{0}$. In order to simplify the analysis, the variations in pressure in both time intervals $t_{1}$ and $t_{2}$ were assumed to be linear. This assumption was also made for the pressures shown in Figs. 2.3 and 2.4. The initial pressure at any transverse section of the roof was taken as $\mathrm{p}_{0}$, dropping to a value of $1 / 3 p_{0}$ in the time required for the vortex to reach that section (Fig. 2.3). On the basis of shock-tube studies, the vortex velocity was assumed to be constant and equal to one-seventh the shock velocity. An initial pressure of $2 / 3 \mathrm{p}_{0}$ was used (Fig. 2.4).

\subsection{ANALYSIS OF RESPONSE}

Having established the loading conditions, it is possible to analyze the response. The detailed procedure of analysis is given in Appendix B. In general, the analysis depends on Newton's second law which expresses the relation between applied force, mass, and acceleration. The forcing function is the difference between applied load and structural resistance. Linear load variations are used as explained previously. By assuming certain conditions of deformation, the resistance can also be expressed as a linear function, dependent on deflection. Resistance is a discontinuous function, however, and it must be expressed by equations corresponding to elastic, elastic-plastic, and plastic conditions of deformation. It is necessary to solve for the conditions existing at the points of discontinuity in order to proceed into the next mode of deformation. The elastic deformation of an element with a high natural frequency can be obtained directly by solving a single differential equation of motion.

By relating the motion of all points on an element to a single point, usually the point of maximum deflection, it is possible to determine the motion of all points. It is not considered necessary to lump masses to solve for motion.

\section{REFERENCES}

1. A. Amixikian, Design of Protective Structures (A New Concept of Structural Behavior), Report NAVDOCKS P-51, August 1950.

2. "The Effects of Atomic Weapons," Los Alamos Scientific Laboratory and U. S. Government Printing Office, Washington, D. C., 1950.

3. W. Bleakney, "The Diffraction of Shock Waves Around Obstacles and the Transient Loading of Structures,"' Department of Physics, Princeton Universïy, Mar. 16, 1950.

4. "The Effects of Atomic Weapons," p. 123, Los Alamos Scientific Laboratory and U. S. Government Printing Office, Washington, D. C., 1950. 


\section{STGRET}

$+$

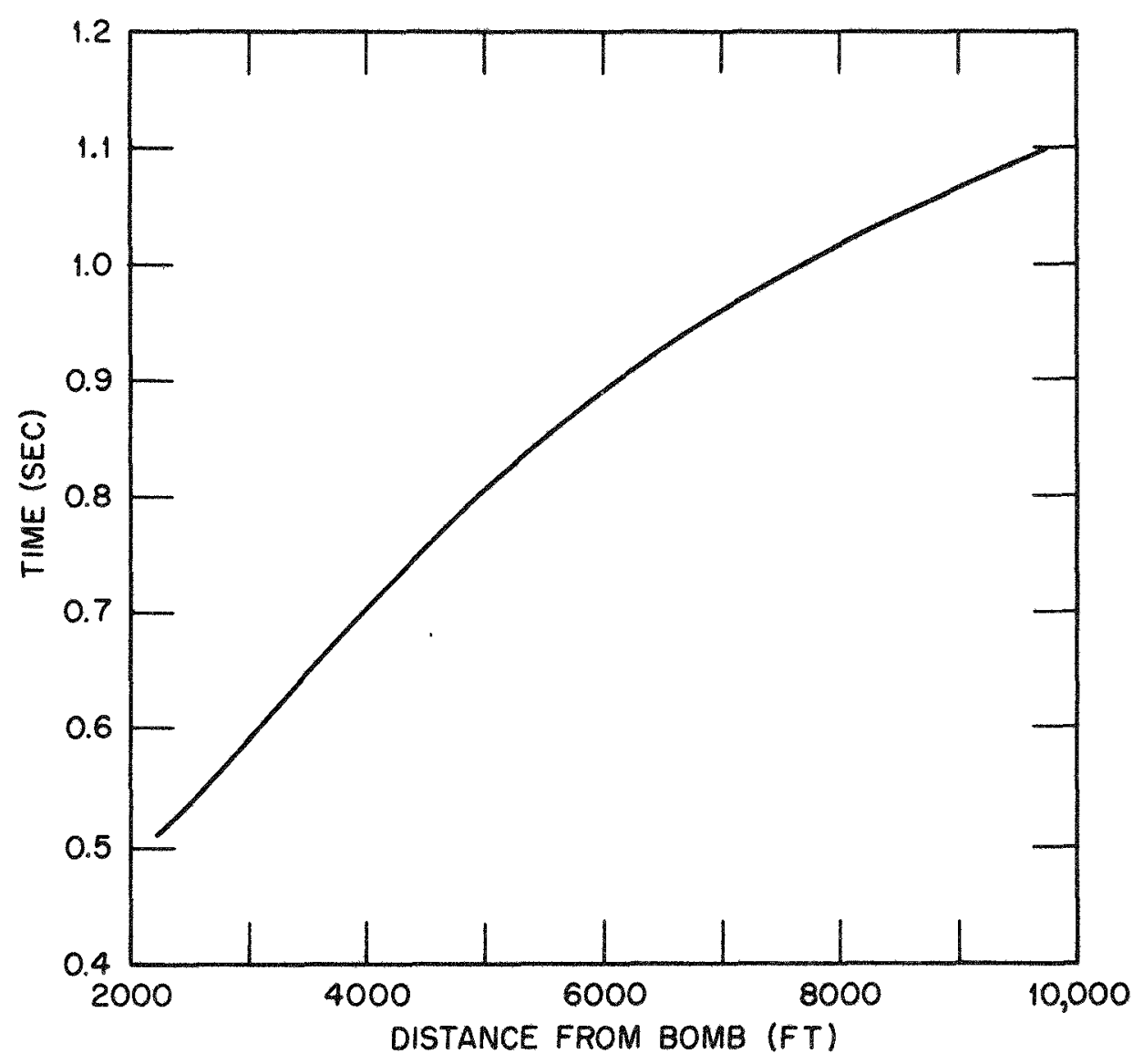

Fig. 2.1 Assumed Duration of Positive Phase of Shock Wave

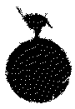




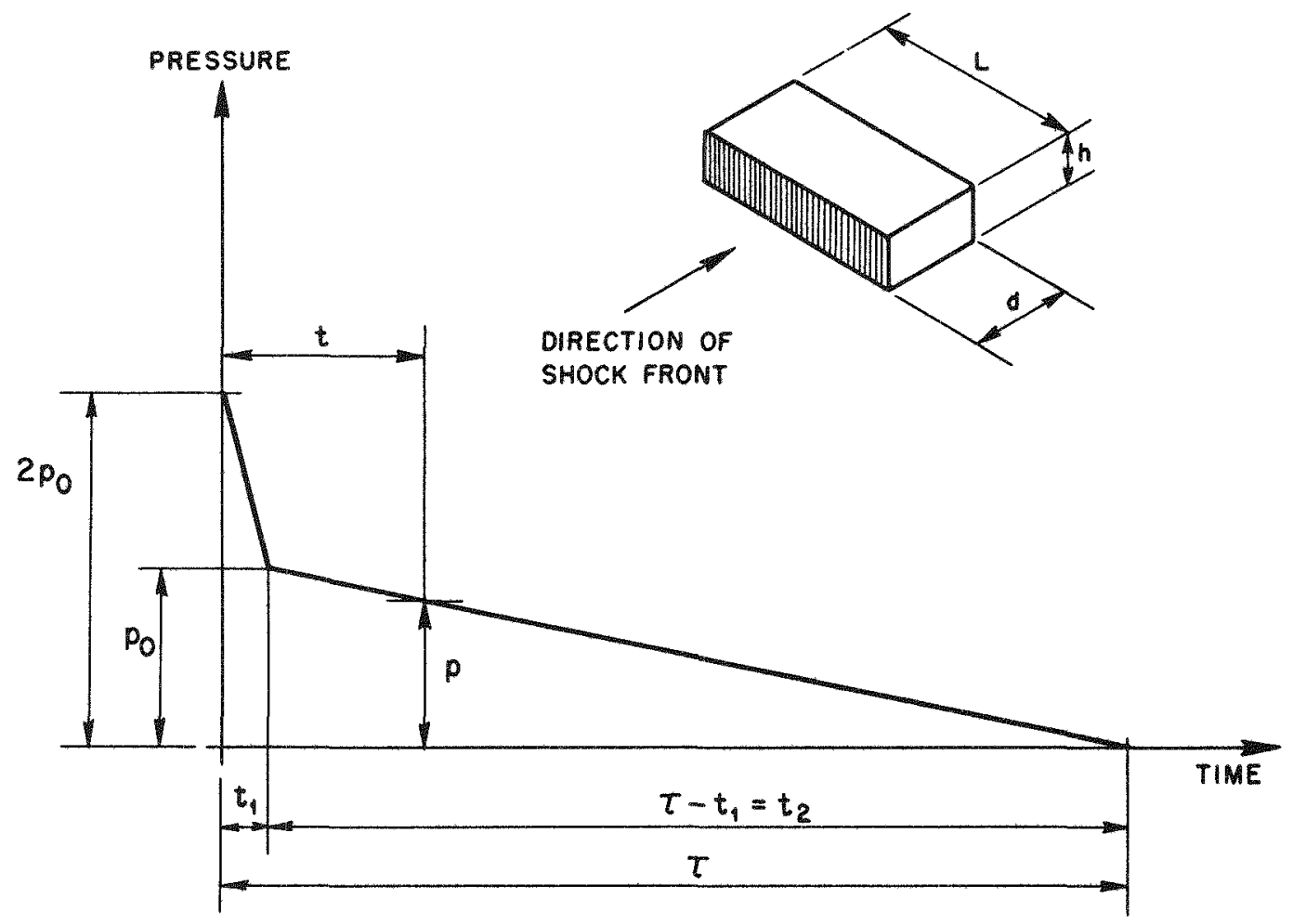

$$
\begin{aligned}
& t_{1}=\frac{4 h}{v^{\prime}}, \text { FOR } h \leqq \frac{L}{2} \\
& t_{1}=\frac{2 L}{v^{\prime}}, \text { FOR } h>\frac{L}{2}
\end{aligned}
$$

Fig. 2.2 Assumed Pressure-Time Relation for Front Face of Structure 

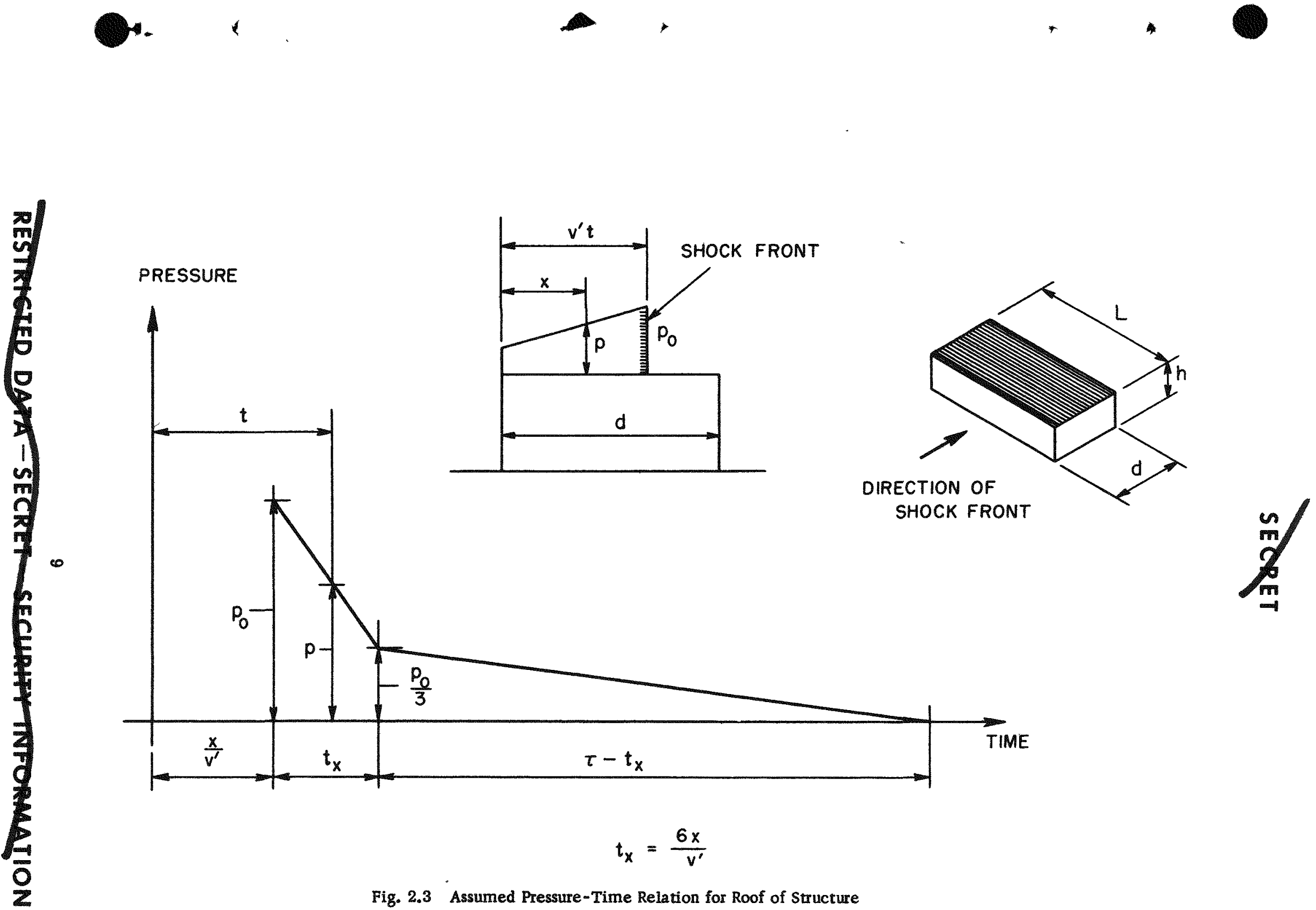

Fig. 2.3 Assumed Pressure-Time Relation for Roof of Structure 


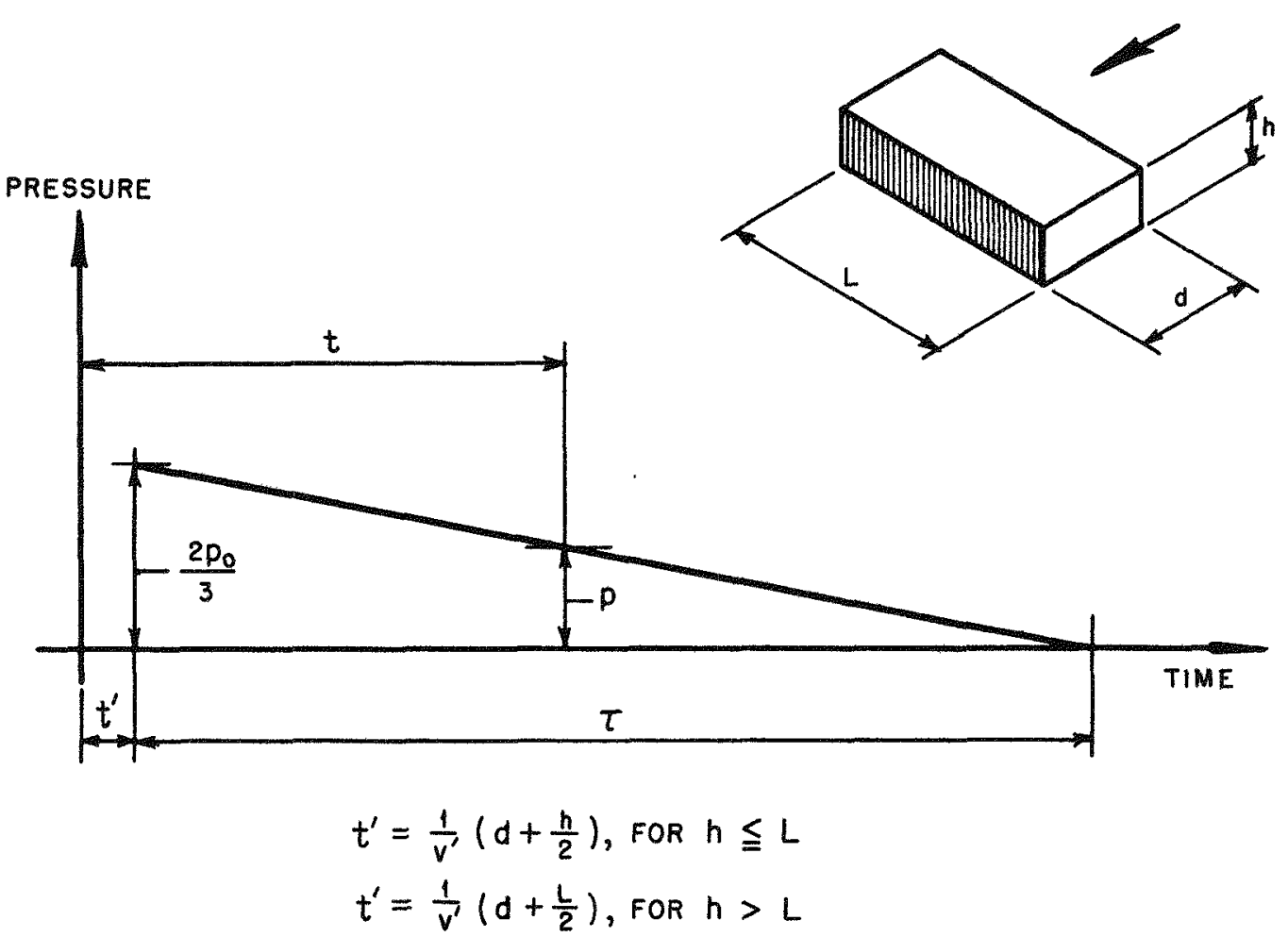

Fig. 2.4 Assumed Pressure-Time Relation for Rear Face of Stucture 


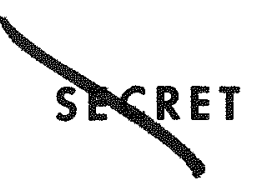

Chapter 3

\section{Test Structures}

\subsection{GENERAL}

In general, the test structures included in this program, with the exception of Structures 3.2.1a and $b$, were designed in accordance with conventional design criteria and loading conditions normally utilized for naval shore structures. The live loads used in the basic designs were a roof load of 40 psf and loads produced by winds of 70 mph velocity. Covered structures had an additional roof load corresponding to the weight of the earth cover.

Each design was then reviewed to ascertain its resistance to atomic blast and to determine the distance at which the structure was to be placed from ground zero. The determination of strength was made on the assumptions of structural behavior in both elastic and plastic ranges of stress. Except as indicated hereafter, moderate damage was anticipated in each case. The review indicated the necessity of changing certain details of the original design from normal practice in order that the elements of framing might more fully participate in resisting blast. These changes were, for the most part, confined to strengthening the connections between framing elements and making the reinforcement continuous in certain members.

In all cases, except for Structures 3.2.1a and $b$, the strength of an element or one of its parts rather than the main framing was the determining factor in the ability of the structure to resist the shock loading. For example, the end walls of Structure 3.2.7a were capable of resisting much larger loads than could be carried to them by the front wall and roof. As a criterion of damage, the deflection at the center of an element was limited to about one-tenth its span.

The basic data used in analyzing the behavior of the test structures under blast load are given in Chap. 2 and Appendix B. Owing to space limitations, certain details of analysis and design applicable to the various test structures have been omitted. The specific data and procedures used in the analysis, the assumptions made as to pressure distributions and structural behavior, and the expected damages resulting from the test are described in Appendix C. The design plans and specifications are included in Appendix D.

\subsection{DESCRIPTION OF STRUCTURES}

\subsubsection{Structure 3.2.1a (Figs. 3.1, 3.2, and D.1)}

Structure 3.2.1a, a conventional bomb-resistant structure located $250 \mathrm{ft}$ from ground zero at an unknown pressure, was a test of the ability of a massive above-ground concrete roof at the fringe of the fireball to resist the heat and blast of an atomic explosion. Command centers now in existence and other similar structures may require protection when underground construction may not be practicable. This was an opportunity to determine above-ground feasibility of protective construction.

\subsubsection{Structure 3.2.1b (Figs. 3.1, 3.3, and D.2 to D.4)}

Structure 3.2.1b was a novel cellular roofed structure located $250 \mathrm{ft}$ from ground zero at an unknown pressure; it was recently successfully tested against penetrating explosive bombs at Dahlgren, and it was desired to test its strength against the atomic bomb at Greenhouse. It is considered to be cheaper than massive-concrete structures, much quicker to construct, and minimal in logistic requirements. 

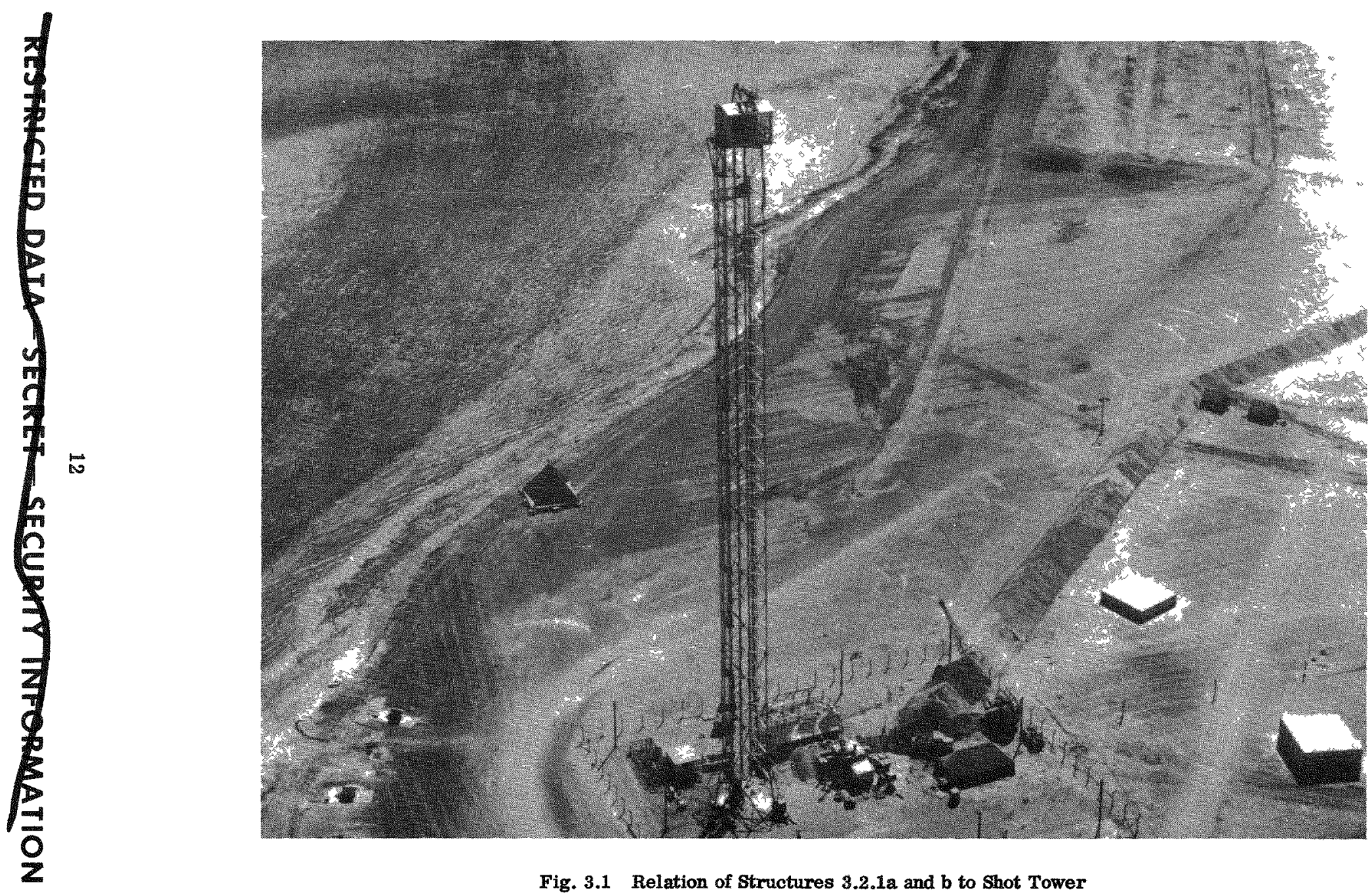

Fig. 3.1 Relation of Structures 3.2.1a and b to Shot Tower 


\section{SECRET}

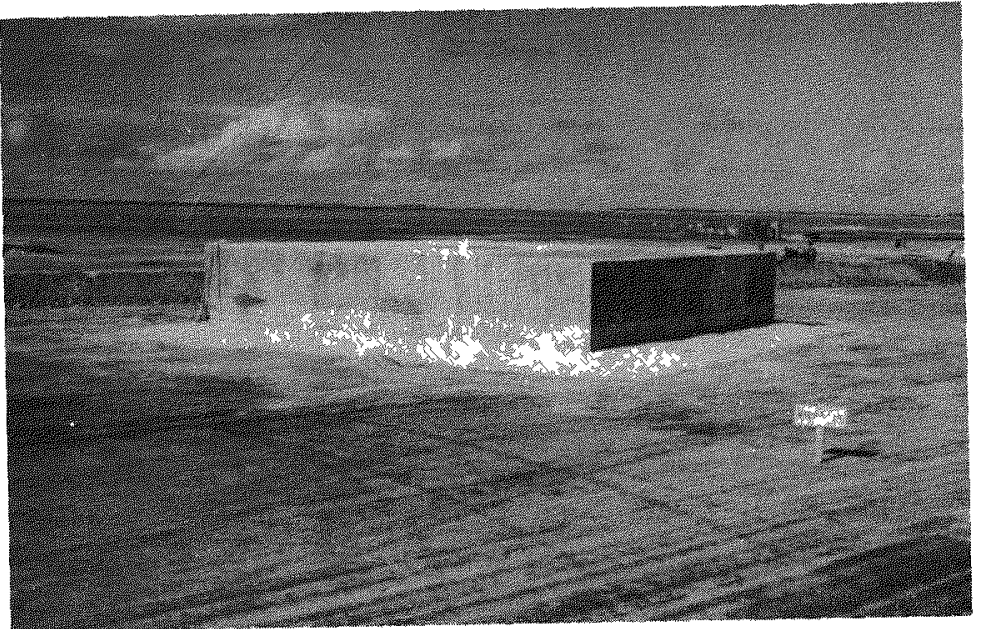

Fig. 3.2 Structure 3.2.1a

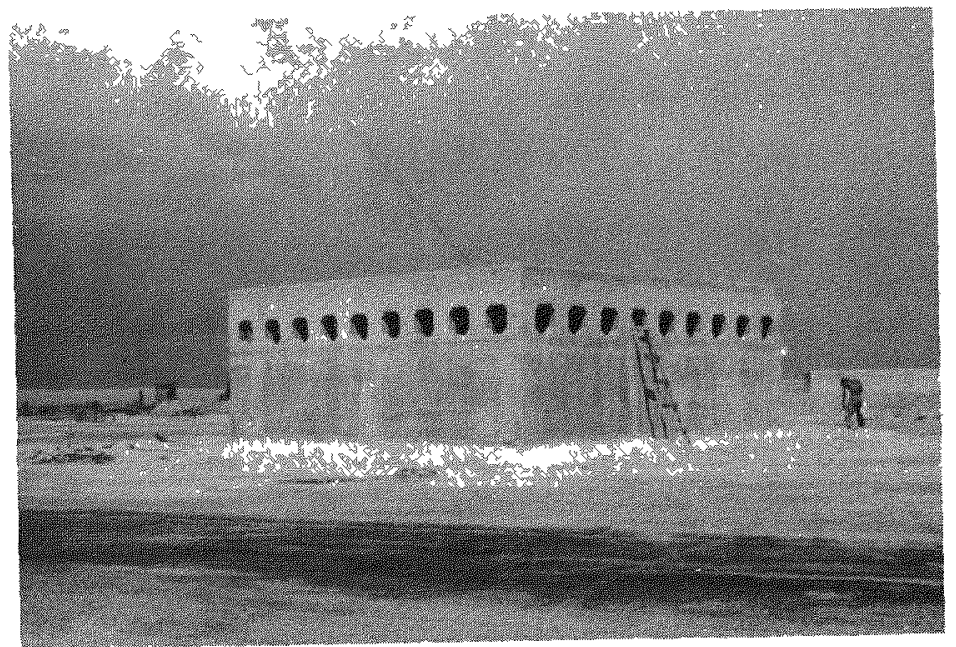

Fig. 3.3 Structure $3.2 .1 \mathrm{~b}$

13

-RESTRICIED DATA-SEGREI-SERURITY TNFQRMATION"

$25-27$ 


\subsubsection{Structure 3.2.2a (Figs. 3.4, D.5, and D.6)}

Structure 3.2.2a was a one-story rectangular building composed of precast-concrete rigid frames and ribbed panels; it was located $3630 \mathrm{ft}$ from ground zero at a predicted pressure of $11.6 \mathrm{psi}$. It was desired to test a new type of structure which would increase the construction and protection potential of the Department of Defense as well as industry. The techniques used in this structure are similar to those employed in the Mechanicsburg warehouses. The structure is designed stronger than normal onestory structures and is capable of being reinforced to almost any desired extent.

\subsubsection{Structure 3.2.2b (Figs. 3.5, D.7, and D.8)}

Structure $3.2 .2 \mathrm{~b}$ was a one-story conventional brick building covered with precast-concrete ribbed panels; it was located $3630 \mathrm{ft}$ from ground zero at a predicted pressure of 11.6 psi. It was desired to test a proposed method of protecting the lower stories of a multistoried structure. The precast panels used in this structure were of the same type as those used in Structure 3.2.2a.

\subsubsection{Structure 3.2.3a (Figs. 3.6 and D.9 to D.12)}

Structure 3.2.3a was a rectangular building of cellular (matchbox) framing; it was located 2400 ft from ground zero at a predicted pressure of 26.7 psi. The objective was to test the cellular principle utilized in Structure 3.2.1b for structures providing a lesser degree of protection. Structure 3.2.3a is the newest development in the field of precast cellular structures. The basic design is the provision of a grid framework of exceptionally strong steel trusses to withstand the blast load on the structure. This truss grid is welded to form a continuous light steel framework which will act as a unit rather than independently as in conventional construction. The wall integrity is maintained by the use of small concrete blocks whose thin reinforced walls act as strong diaphragms.

\subsubsection{Structure 3.2.3b (Figs. 3.6 and D.9 to D.12)}

Structure 3.2.3b and 3.2.3a were identical; however, Structure 3.2.3b was located $2640 \mathrm{ft}$ from ground zero at a predicted pressure of 22.0 psi.
3.2.7 Structure 3.2.4a (Figs. 3.7, D.13, and D.14)

Structure 3.2.4a was a precast-concrete magazine of rigid frame panels with earth cover; it was located $2760 \mathrm{ft}$ from ground zero at a predicted pressure of $20.0 \mathrm{psi}$. The objective was to test a magazine structure fabricated from precast-concrete elements. The design maintains the logistic standards of the arch design, but at the same time a vertical side wall is used to promote greater use of floor space. It was anticipated that this structure, with an earth cover, could be used as a shelter at the nearer intermediate distances.

\subsubsection{Structure 3.2.4b (Figs. 3.8 and D.15)}

Structure 3.2.4b was like 3.2.4a in construction, except that it had no earth cover or wing walls; it was located $3510 \mathrm{ft}$ from ground zero at a predicted pressure of 12.5 psi. Half the framing panels were constructed "skin out" as a comparison.

\subsubsection{Structure 3.2.5 (Figs. 3.9 and D.16)}

Structure 3.2.5 was a precast-concrete magazine of cylindrical shell panels; it was located $3510 \mathrm{ft}$ from ground zero at a predicted pressure of 12.5 psi. The objective was to test a precast-concrete arch, the most desirable shape for design and analysis as well as for future model tests. This structure was developed in the study of reduced use of critical materials and the search for adequate personnel shelter design. The shape of the structure is desirable from the standpoint of reduction of reflection factors and in the inherent structural resistance.

\subsubsection{Structure 3.2.6 (Figs. 3.10, D.17, and D.18)}

Structure 3.2.6 was a dome-shaped precastconcrete magazine or shelter; it was located $3240 \mathrm{ft}$ from ground zero at a predicted pressure of 14.5 psi. The objective was to test a shape common to Navy magazines and a design with the advantages of less material used, short construction time, and optimum stress conditions by virtue of shape. When covered, the structure could be made suitable for use as a personnel shelter at the nearer intermediate distances. 


\section{STERET}

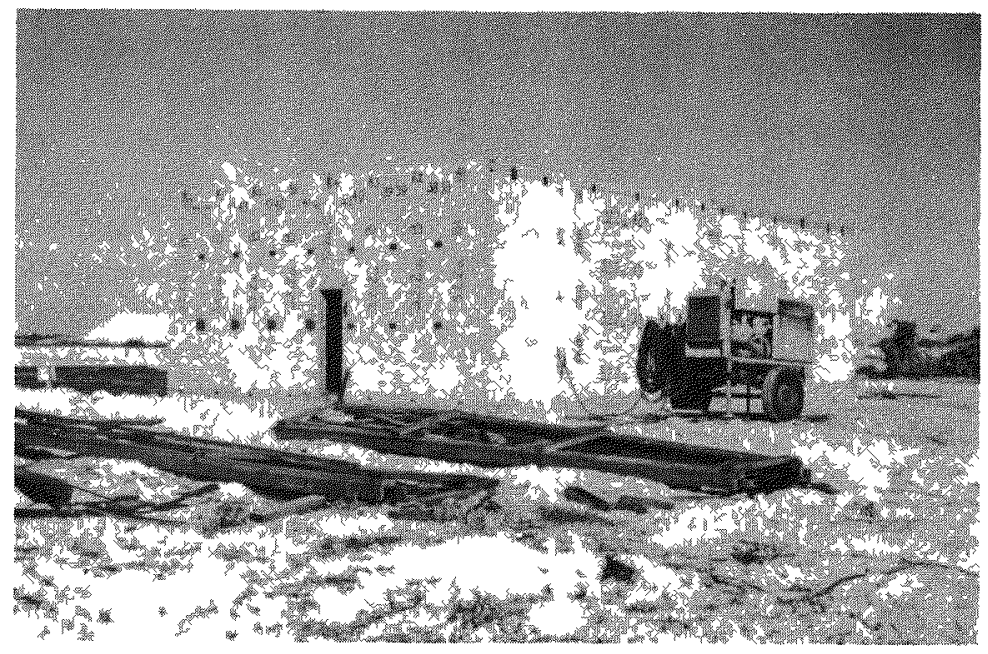

Fig. 3.4 Structure 3.2.2a

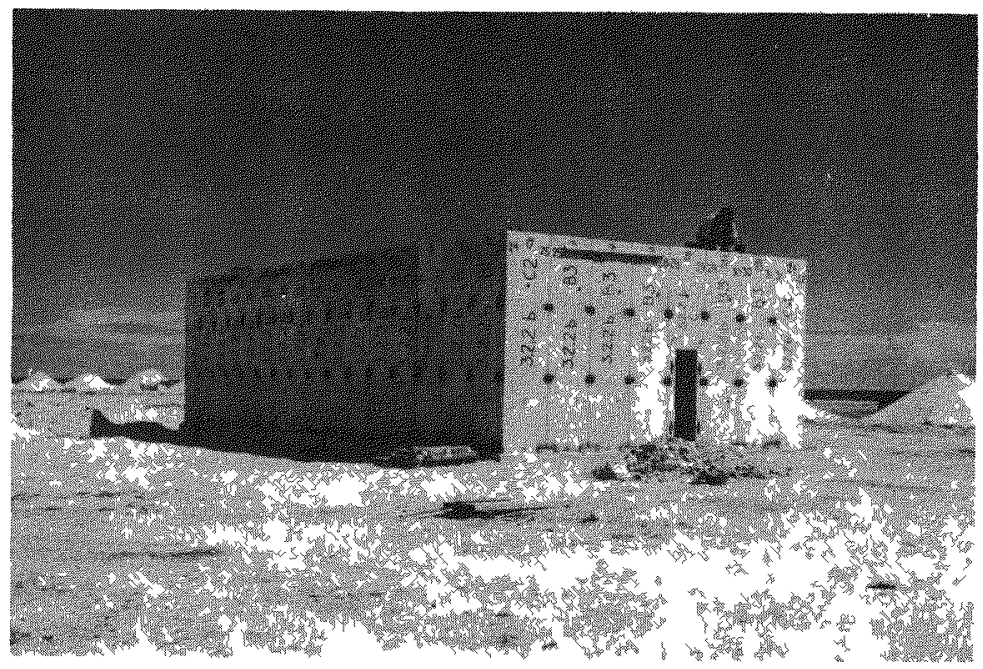

Fig. 3.5 Structure 3.2.2b 


\section{SEKRET}

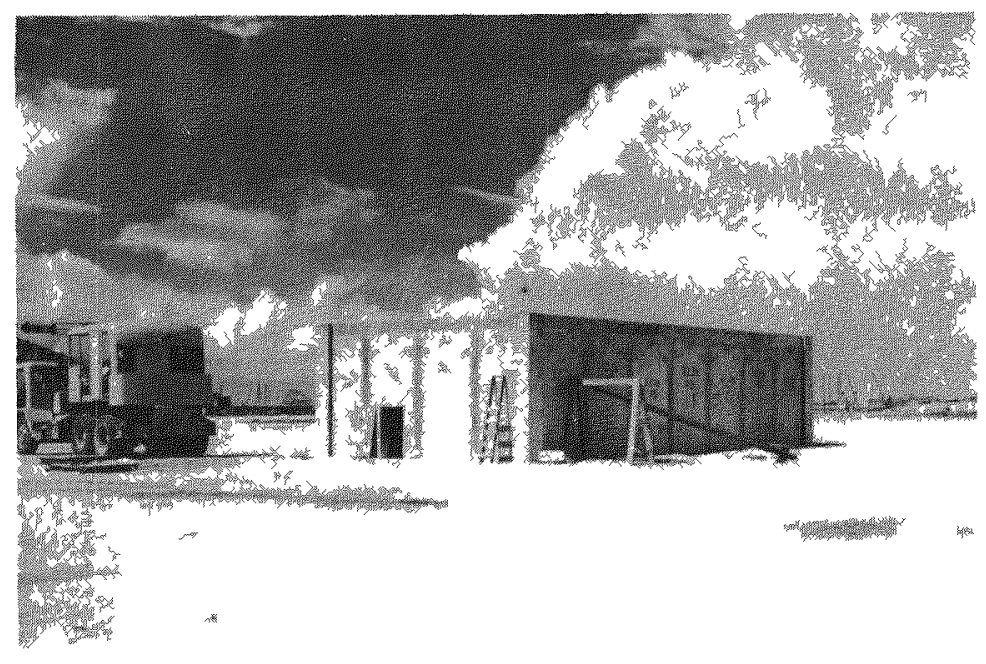

Fig. 3.6 Type Structures 3.2.3a and b

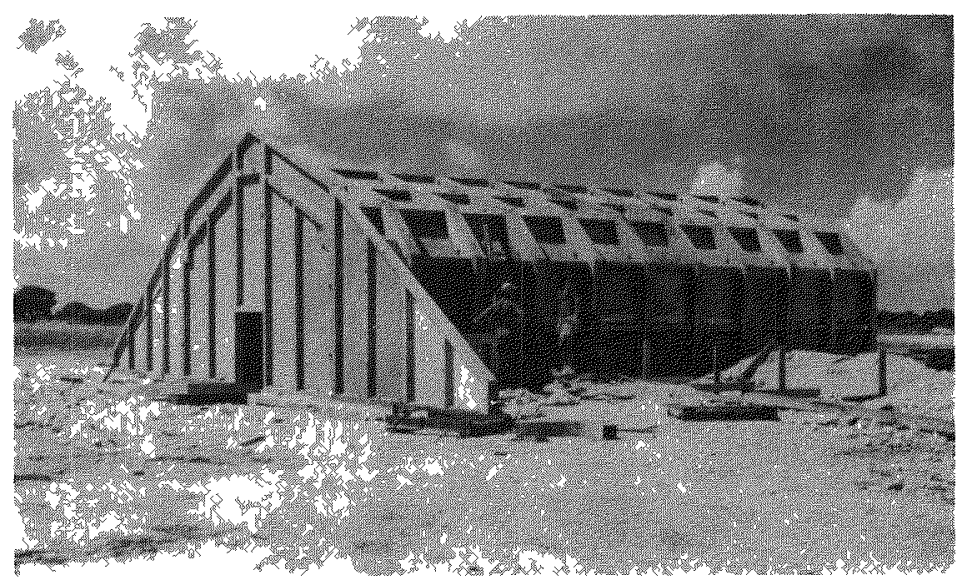

Fig. 3.7 Structure 3.2.4a (Prior to Placement of Earth Cover) 


\section{SEQYET}

1

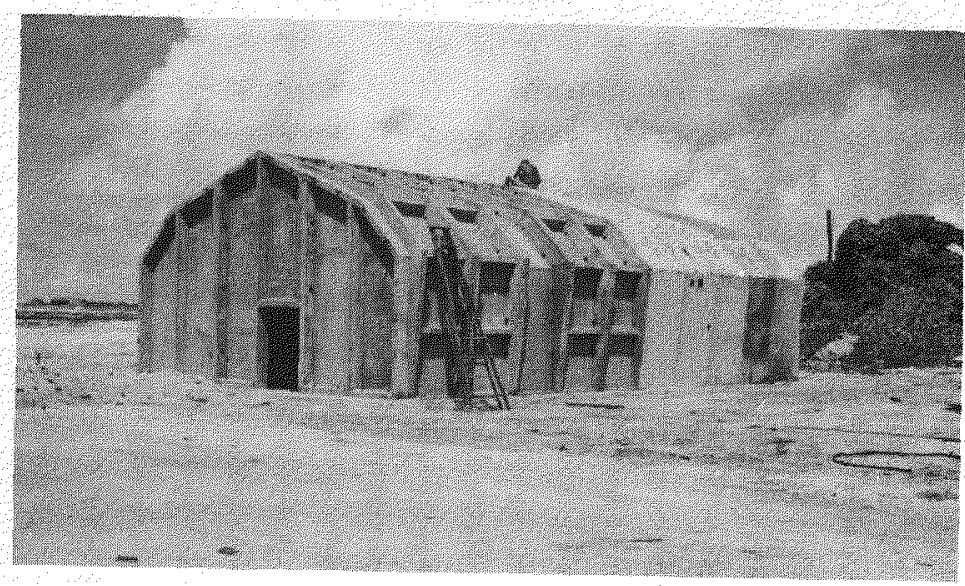

Fig. 3.8 Structure $3.2 .4 \mathrm{~b}$

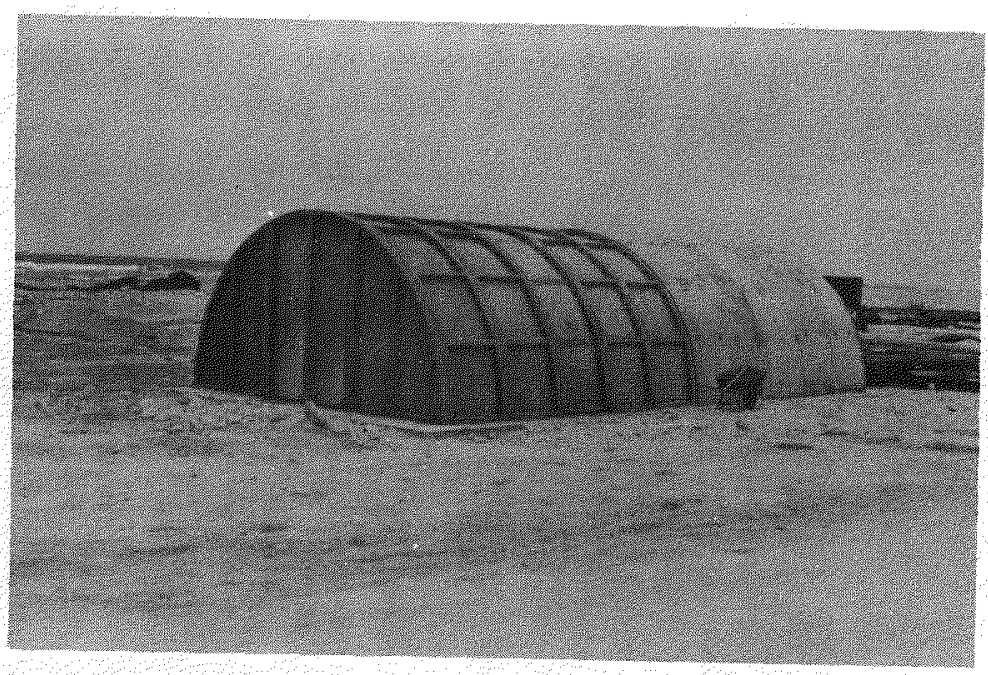

Fig. 3.9 Structure 3.2.5 


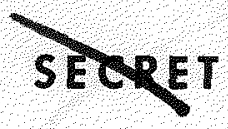

\section{f}

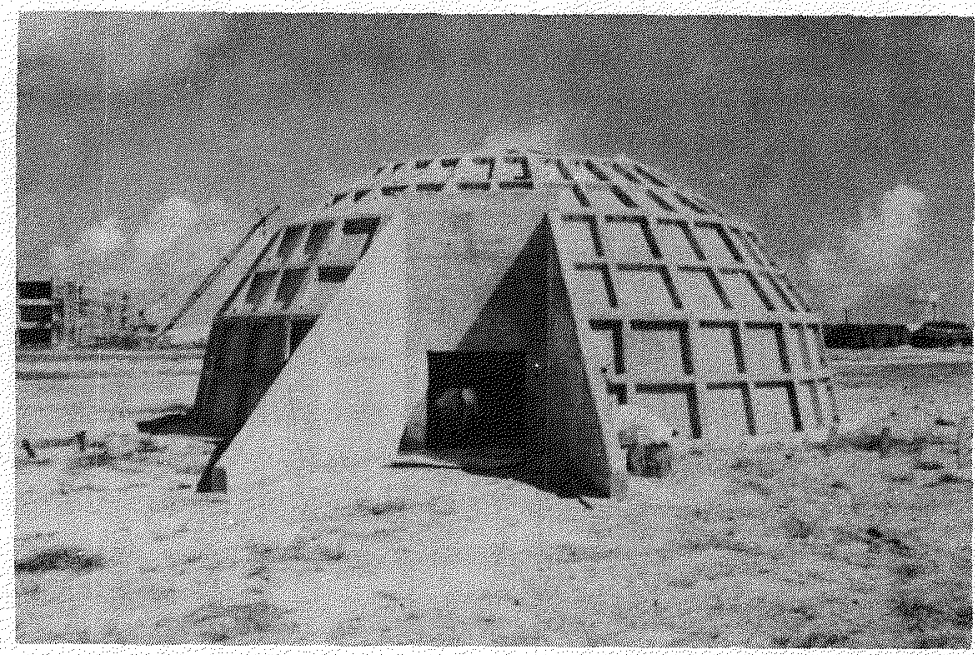

Fig. 3.10 Structure 3.2.6 (Prior to Placement of Earth Cover)

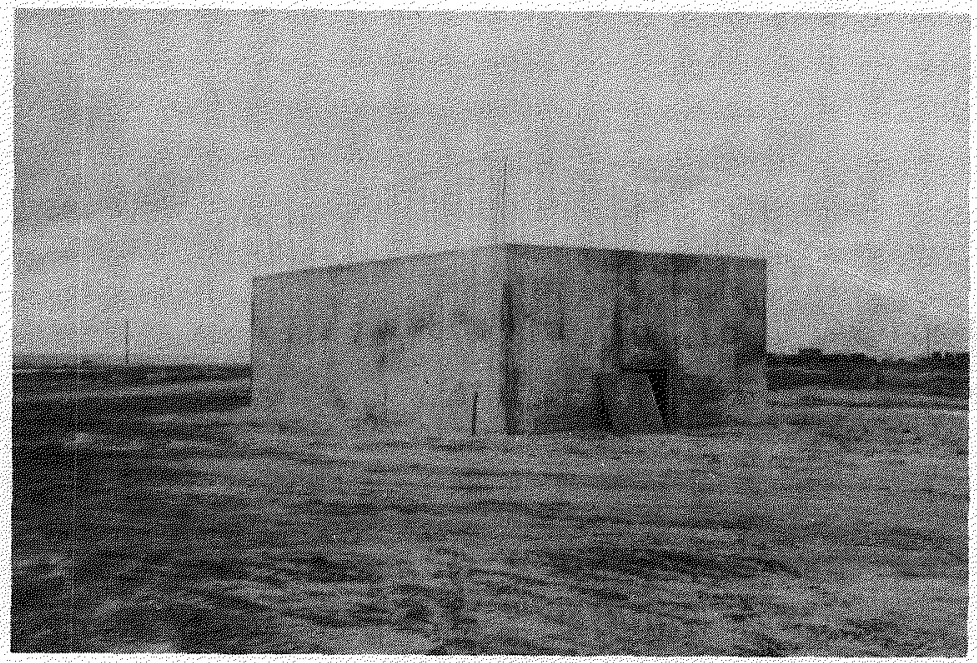

Fig. 3.11 Type Structures $3.2 .7 \mathrm{a}$ and b 


\section{SECRET}

\subsubsection{Structure 3.2.7a (Figs. 3.11 and D.19)}

Structure 3.2.7a was a reinforced-concrete rectangular building of conventional construction; it was located $3540 \mathrm{ft}$ from ground zero at a predicted pressure of $\mathbf{1 2 . 2}$ psi. The objective was to test a conventional structure as a comparison with the precast structures which have identical presentment. This structure provides the opportunity to compare the strength of normal construction with the strength of the precast structures which require considerably less material in their fabrication.

\subsubsection{Structure 3.2.7b (Figs. 3.11 and $D .19$ )}

Structure 3.2.7b was similar to $3.2 .7 \mathrm{a}$ but was located $6950 \mathrm{ft}$ from ground zero at a predicted pressure of 3.9 psi.

\subsection{BASIS FOR SELECTION OF DISTANCE FROM GROUND ZERO}

It has been pointed out that the design loadings utilized were those which are used in conven- tional design for the Naval Shore Establishment. The designs were then analyzed to determine the blast loading to which the structure could be subjected. Changes were made in the design to provide a balance in the resistance of the parts of the structure to the loads, and a loading was chosen to which the structure could be subjected without appreciable damage. A range at which the building could be placed was then taken from pressure-vs-distance curves provided by C. W. Lampson, Ballistic Research Laboratories, Aberdeen Proving Ground. Exceptions to this general procedure for the Navy project are as follows:

1. Structures 3.2.1a and 3.2.1b were placed as near as possible to ground zero in order to subject them to extreme heat and blast. As noted in the preceding section, no analysis was made of these structures for the dynamic loading.

2. Structure $3.2 .3 \mathrm{a}$ is identical to $3.2 .3 \mathrm{~b}$ which was placed at the range of moderate damage. Structure 3.2.3a was placed nearer to determine the extent of damage at that range and to provide a more complete evaluation of the methods of design and analysis. 


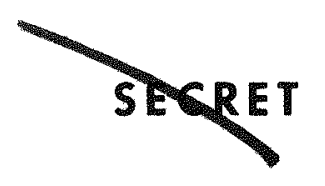

\section{Chapter 4 \\ Construction}

\subsection{GENERAL}

The construction of the structures was accomplished by the AEC, through the Santa Fe Office. The Holmes and Narver Construction Company (H\&N) of Los Angeles was the contractor.

It will be noted that, except for Structures 3.2.1a, 3.2.7a, and 3.2.7b, all the structures were fabricated for the most part from precast-concrete elements. The precast work was subcontracted by H\&N to Barrett and Hilp of San Francisco. Considering the type of units and the long shipping distances involved, the precast panels arrived at the site in excellent condition.

The field representative of the Navy Structures Project at the Greenhouse site was LTJG D. G. Iselin, CEC, USN. This chapter is based upon his report. ${ }^{1}$ The responsibilities of field representatives during the construction phase are presented in the report of the Director, Program 3.

The first excavation was commenced in May 1950 , and the last structure was completed, except for instrumentation, in November 1950.

\subsection{FOUNDATION CONDITIONS}

This section deals with the general foundation conditions common to the job site.

The first 5 or $6 \mathrm{ft}$ of soil on Engebi is medium sand in a dry or slightly moist state. Ground-water level averages about 6 or $7 \mathrm{ft}$ below undisturbed ground surface, and this water table fluctuates slightly with the tide. In certain areas a thin ledge of coral rock or cemented coral conglomerate underlies the top $6 \mathrm{ft}$ of sand. This ledge varies in thickness from about 6 in. to $6 \mathrm{ft}$, depending on the specific location. In some places there are several thin ledges of rock interspersed with sand. Below this coral ledge, or below the upper $6 \mathrm{ft}$ of sand in areas where there is no rock, the strata to a depth of $25 \mathrm{ft}$ are composed of varying layers of submerged sand and gravel in a sfate of medium compaction. Soil tests conducted by Dames and Moore of Los Angeles give more detailed information concerning the soil conditions in three different parts of the site to a depth of $50 \mathrm{ft}$.

The reports of soil investigations made at the site are collected in separate reports (see Bibliography) and in Appendix $F$ (Soil Test Data) to this report which has been given reference library distribution. These reports include bearing tests, probings, and core borings. The personnel employed in making most of these tests were relatively inexperienced; therefore some latitude must be allowed in interpreting the various results. Taken as a whole, however, the test results provide a fair analysis of the foundation conditions prevalent at the site.

\subsection{CONSTRUCTION MATERIALS}

This section deals with the various materials that are a part of the Navy structures. Among these materials are concrete, structural steel, reinforcing steel, anchor bolts, assembly hardware, brick, and lumber.

\subsubsection{Concrete}

(a) Coarse Aggregate. The coarse aggregate used in all concrete prior to Aug. 23, 1950, was "bank-run" coral. The source of this aggregate 


\section{SECRET}

was a large coral-gravel pit with quarried material ranging in size from $1 / 4$ to $6 \mathrm{in}$. This stone was then crushed to $3 / 4-i n$. aggregate, without washing, and used in the concrete. The aggregate from this source was highly porous, relatively weak, and very inconsistent in strength. Concrete made with the crushed bank run did not attain consistent strengths of over $2500 \mathrm{psi}$, and in some cases the strength reached only 2000 psi in 28 days. This aggregate in the early part of August was covered with a slick film of dust and fine sand, thus preventing good bond in the concrete mix. Consequently the service representatives took up this condition with the AEC resident engineer and the contractor. The problem was resolved by quarrying hard reef coral, crushing it to the desired gradation, and washing. This new aggregate proved to be satisfactory in all respects and was used for the remainder of the concrete (Fig. 4.1).

(b) Fine Aggregate. Beach sand taken from Engebi and Muzinbaarikku was used as the fine aggregate. However, this sand contained so many large pieces of coral that 20 per cent was retained on a No. 4 sieve. In order to reduce the content of rock in the fine aggregate, a 1-in. scalper screen was installed in the sand hopper on Aug. 15, 1950. All large pieces of coral were removed, and less than 10 per cent of the sand was retained on a No. 4 sieve. The beach sand did not possess enough fines to keep the concrete from bleeding; however, a source of fine sand was located near Rojoa, and this sand was transported to Engebi for use in conjunction with regular beach sand. This procedure was used for all concrete placed after Sept. 2, 1950 , and resulted in a workable mix with little bleeding.

(c) Cement. At no time during the progress of the structures program was the cement stored in a dry weather-tight building. Some cement was stored in buildings that had large exposures to the atmosphere and leaky roofs, but most of it was stored outside under canvas for periods of 3 to 5 months. The very high relative humidity, coupled with frequent rains, caused the cement to become lumpy and subject to deterioration. On Aug. 1, 1950, a $3 / 8$-in. screen was installed at the batch plant, and all cement was passed through this screen before being weighed. In early November of 1950 the lumpiness became excessive, and deterioration of the cement was evident. This condition was brought to the attention of the AEC resident engineer, who required that the contractor screen all cement through a No. 16 shaker screen and that daily tests be made of the cement before its use was permitted. It is probable that many of the variations noted in the concrete-cylinder tests were due to the condition of the cement.

(d) Mixing Water. Slightly brackish water obtained from a well dug on Engebi was used as mixing water. Average saline content was less than 5 per cent of that of sea water, and salt could never be tasted in the water.

(e) Batching. All ingredients were accurately weighed before mixing, except for the cement used prior to August 1, which was measured by the sack.

(f) Mixing. Mixing was accomplished in a Ransome 34E 1-yd dual-drum paver type mixer with a calibrated water-control tank (Fig. 4.2).

(g) Transporting. Most of the concrete was transported to the pouring site from the mixer in Dumperete trucks with no agitation. Some small amount of segregation occurred during transporting, but, since the elapsed time from mixing to placement rarely exceeded $5 \mathrm{~min}$, the segregation was not detrimental. In cases where the concrete was not placed within about 10 min after mixing, segregation became so excessive that the batch had to be wasted.

Transportation to Muzinbaarikku for concrete placement in Structure 3.2.7b was accomplished in Jaeger 3-cu yd Transit-mix trucks. Concrete was mixed in the paver and agitated during transportation in the transit-mix trucks. This method of transporting concrete was highly successful (Fig. 4.3).

(h) Grout Concrete. Beach sand and cement were used to make grout concrete from the commencement of the job until Oct. 20, 1950. After October 20, crusher screenings were used for aggregate and gave higher strengths of concrete. These screenings were the fine particles washed out of the crushed reef coral and were suitable for grout.

\subsubsection{Structural Steel}

Box trusses for the foundation of Structure 3.2.1b and the $\mathrm{T} 1$ carrying trusses were fabricated by Nigg Engineering Corporation. They arrived in good condition and were placed with 

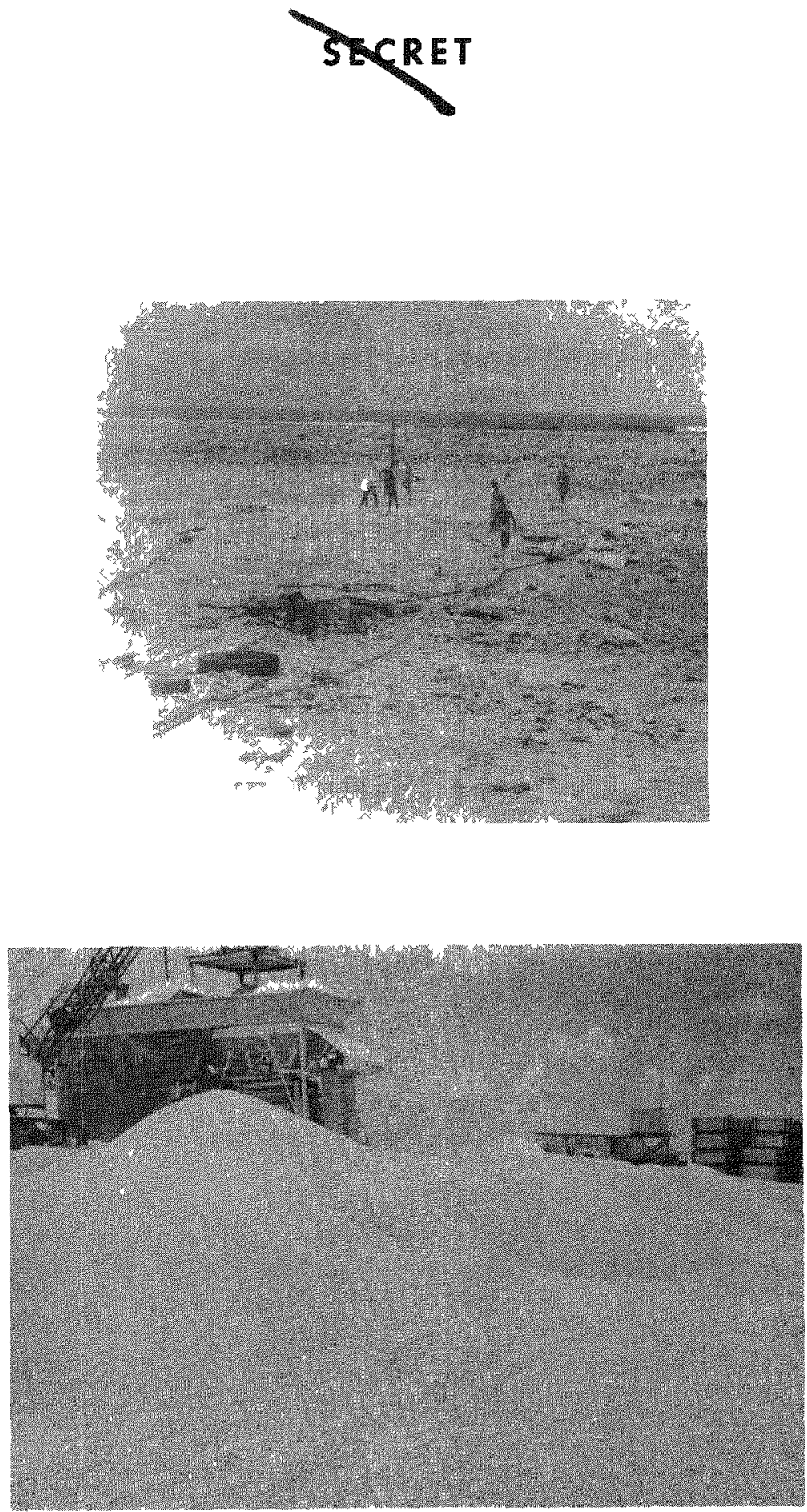

Fig. 4.1 Quarrynng Reef Coral (Upper); Coarse Aggregate After Crushing, Screening, and Washing (Lower) 


\section{SESET}

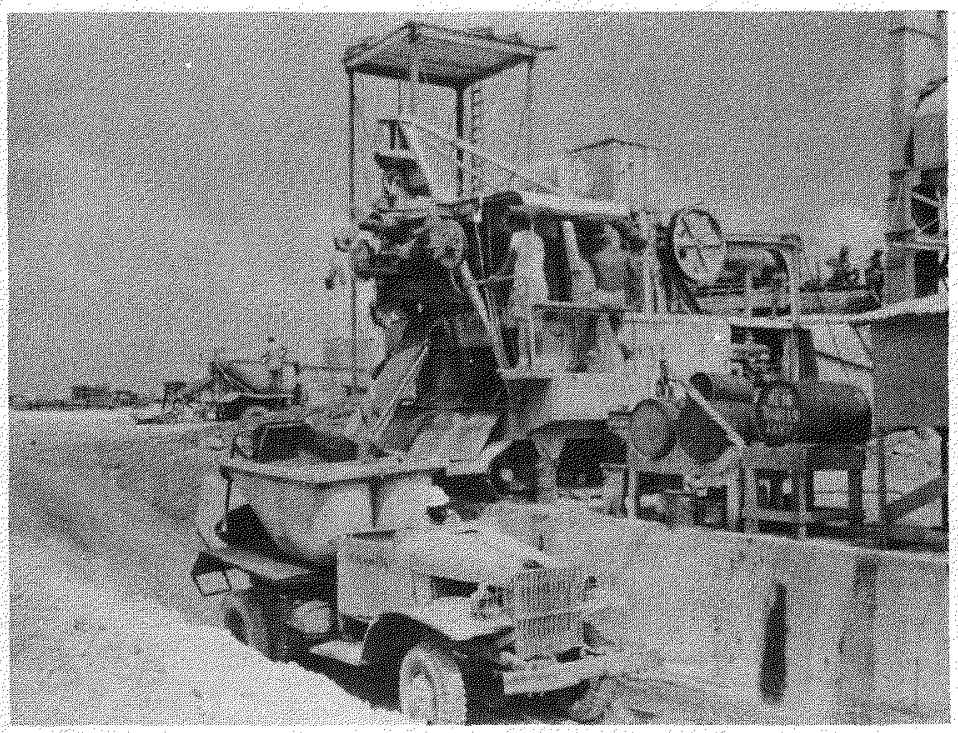

Fig. 4.2 Concrete-mixing Plant

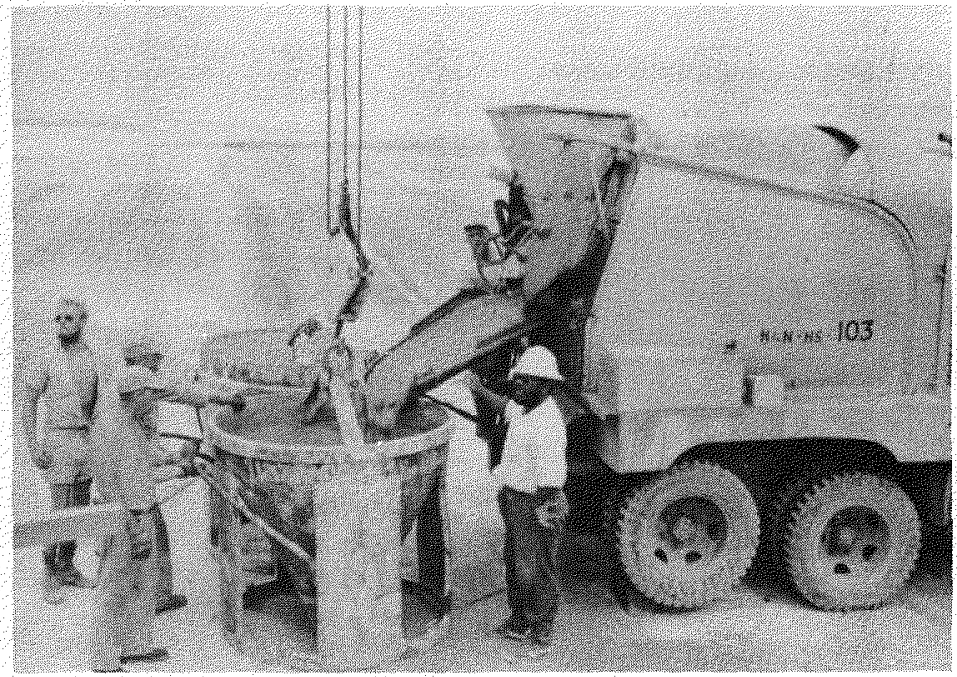

Fig. 4.3 Transit-mix Truck Discharging Concrete into a 1-cu yd Pouring Bucket 
little difficulty (Fig. 4.4). The field-placed trusses for Structures 3.2.3a and 3.2.3b, fabricated by Soule Steel Co., arrived in good condition and were also placed with little difficulty. finished commercial steel. All exposed portions of these bolts, nuts, and washers were given a coat of red-lead paint. Washers were cast iron, but steel would have been preferable.

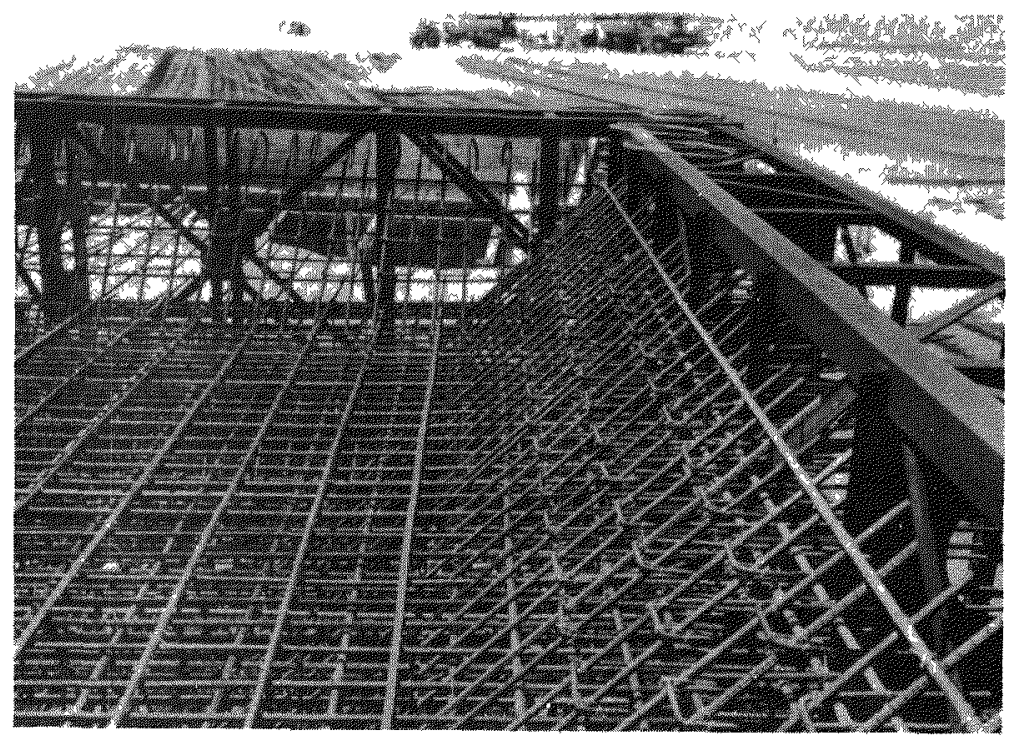

Fig. 4.4 Steel Box Trusses and Reinforcing Steel in Place

\subsubsection{Reinforcing Steel}

All reinforcing steel used in the Navy structures was intermediate-grade deformed bars. Most steel had a light coat of rust when concrete was placed. In cases where the rust was heavy or scaly, the steel was sandblasted just prior to the placement of concrete. Bends and hooks were made on a bar-bending machine. Reinforcing steel was supported on concrete blocks in the footings and on steel chairs in the superstructure.

\subsubsection{Anchor Bolts}

All anchor bolts were set according to construction drawing dimensions by use of fieldfabricated wood templates. A 1/16-in. tolerance in any direction was maintained in setting the anchor bolts, and special precautions were taken to maintain the anchor bolts in position during the placement of concrete.

\subsubsection{Assembly Hardware}

The bolts, nuts, and washers for assembling and fastening the precast structures were un-
Welding plates were structural-grade steel, and all were painted after welding. Steel doors and closure plates were structural steel and were painted.

\subsubsection{Brick}

Hard-burned clay brick $2 \frac{1}{2}$ by $3^{3 / 4}$ by 8 in. were used, laid up in common bond with a through header course at every sixth course. Joints were about $1 / 2$ in. thick, and mortar was composed of 1 part portland cement, 1 part hydrated lime, and $4 \frac{1}{2}$ parts screened beach sand.

\subsubsection{Lumber and Formwork}

Forms used for foundations were of 1-in. stock, with 2- by 4-in. strength members: Forms for concrete superstructures were of $5 / 8$ - or $3 / 4$-in. plywood, with standard walers and form bolts. Plywood forms were reused, and some sags in the concrete were evident, although not detrimental. All forms were oiled before use, but in some cases the concrete adhered tightly to the forms, resulting in a rough surface. 
Joists for Structure $3.2 .2 \mathrm{~b}$ were of select structural Douglas fir.

Sheathing for the roof of Structure 3.2.2b was straightedged 1 - by 6 -in. No. 2 common Douglas fir.

\subsection{CONSTRUCTION METHODS}

This section outlines the procedures employed in placing concrete, setting anchor bolts, and erecting precast structures.

\subsubsection{Placement of Concrete}

Placement of concrete was accomplished by use of a mobile crane and a 1-cu yd invertedcone bucket with spring-loaded pouring doors. When necessary to reduce the free fall of concrete, a hopper and fabric elephant trunk were hung below the pouring bucket. Vibration of concrete was accomplished with gasolinedriven internal vibrators. For small-footing pours, chutes on the concrete truck were used for placement instead of a pouring bucket. The sequence of placement in the various structures may be found in the construction report.

\subsubsection{Setting of Anchor Bolts}

Wood templates placed at or above concrete grade were employed to hold anchor bolts in position. These templates were usually 4 by 4 in. running parallel with the forms and secured to the forms with 1 - by 6 -in. cross strips. Templates for Structure 3.2.6 were separate sections for each sector of the footing and were trussed to vertical 2 - by 4 -in. struts fastened to the outside forms. As soon as the concrete was rough-troweled, these templates for Structure 3.2.6 were removed, and a finish troweling was applied. On the rest of the structures, the templates were left in place for several days. In some cases, the pouring operation caused the templates to deflect slightly downward, resulting in somewhat irregular concrete surfaces at these points.

\subsubsection{Erection of Precast Structures}

With the exception of Structure 3.2.6, all precast panels in contact with the building foundation were placed in a bed of fresh sandcement grout varying in thickness from $1 / 8$ to $1 \mathrm{in}$. Both the surface of the footing and the base of each panel were sprayed with a waterproof membrane to prevent loss of moisture from the fresh grout. The sequence and method of placing precast panels for the various structures may be found in the construction report.

\subsection{CONSTRUCTION PROBLEMS}

All the problems encountered during the construction phase were resolved satisfactorily on the site, and no significant effect upon the test results was caused by the problems. A complete discussion of the construction problems and other minor difficulties is given in the construction report.

\section{RE FERENCE}

1. D. G. Iselin, LTJG, CEC, USN, Field Construction Report of Program 3.2 Structures, Dec. 15, 1950. 


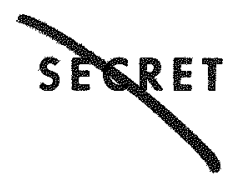

\section{Chapter 5 \\ Methods of Obtaining Experimental Data}

\subsection{OBJECTIVE}

The objective of the measurement program was to obtain data to assist in determining the validity of the assumptions made in the design and analysis and in furthering the understanding of structural response under blast loading.

\subsection{REQUIRED DATA}

\subsubsection{Loading}

One of the most important measurements required was the pressure-vs-time relation on each structure. Data on the loading of the structure with respect to time were mandatory in order to evaluate effectively the methods of analysis and the history of structural response.

The predicted maximum pressures were determined from pressure-vs-distance curves provided by C. W. Lampson. Factors were applied, as described in Appendix $C$, to those locations where reflection or reduction of the peak overpressure would occur.

\subsubsection{Response}

In analyzing the structures for a dynamic loading, theoretical transient and limiting deformations and accelerations were determined. In order to evaluate the method of analysis and to determine limit resistance, it was necessary to collect considerable data on the structural response.

(a) Complete Structure. In the analysis each structure was checked for sliding and for overturning. Therefore data were required to determine the translation and rotation of the structure as a whole. (b) Structural Elements. In order to obtain data regarding the response of each building, it was necessary to determine the action of the structure frame and the component members as well. Since some of the structures embraced new designs using precast panels with integrated framing elements, information was required as to the movement of each of a series of panels in a given structure.

\subsection{METHODS}

Two basic methods were employed to obtain the desired data. One method consisted in a detailed survey to determine the exact space location of several points on every panel or element of each structure, both before and after the shot. By calculating the changes in the 10cation of these points, the permanent deformations of all members were obtained. This program was carried out by the personnel of the Navy Structures Project.

The second method consisted in using specially designed instruments installed in various locations in each structure to measure the transient values of pressure, displacement, and acceleration for selected elements during the blast loading. In addition, it was considered that in the event of complete collapse of a structural member these transient measurements would provide the best and sometimes the only method of determining the action of the member prior to failure. This phase of the measurement program was carried out by Project 3.4.

\subsubsection{Measurement of Permanent Changes}

A preshot survey of the structures was conducted in order to check the accuracy of con- 
struction and the exact physical conditions of the structure and all component members before the shot. The space location of the structures was determined by $H \& N$, and the location of each panel within the structure was measured in a three-coordinate system by the Navy project personnel. Accuracy of measurements was $\pm 0.01 \mathrm{ft}$. A similar survey was conducted after the shot to determine what changes had taken place.

(a) Complete Structure. Several points on the foundation of each structure were selected by Project Officer 3.2, surveyed, and tied into the island coordinate system. After the shot these points were surveyed again, and comparison of the results of the two surveys provided a measurement of the change in location of the structure as a whole. One or two other points were also chosen on each structure to serve as checks on the response movements which were determined by separate means.

(b) Structural Elements. All panels of the shaped structures were located in a threecoordinate system whose base planes were located relative to the survey points. The following planes were chosen as the basis for measurements in most structures.

1. Vertical measurements: horizontal plane through the top of a nearby bench mark es tablished for the structure under consideration.

2. Longitudinal measurements: vertical plane through the inside face of the right-end foundation.

3. Transverse measurements: vertical plane through the inside face of the front foundation.

In the case of the dome, polar coordinates were used in a horizontal plane.

Four or more points on each panel in the shaped structures were located in the three. coordinate system. The difference between the pre- and postshot measurements gave the significant deflection picture in three dimensions.

Points were selected which appeared to have the best chance of surviving the blast. The number of points per panel were chosen by a study of the design and a prediction of where and how deformation would take place. After the points were selected, they were projected to the floor by a plumb bob, as shown in Fig. 5.1. These were then measured in the $x$ and $y$ directions (Fig. 5.2) and recorded. Vertical locations at each point were established by a survey

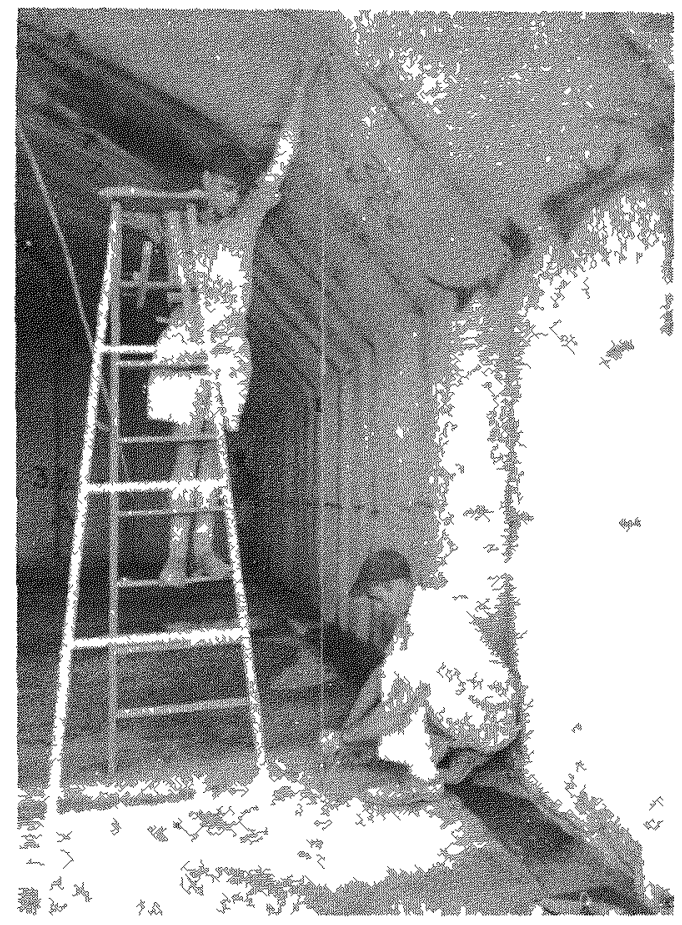

Fig 5.1 Projecting a Point Selected at the Fold to the Floor Using a Plumb Bob

level and rod. All points selected, including those projected to the floor, were marked with either keel or paint. After the shot all points still existing were remeasured and recorded.

The walls of all rectangular buildings and the end walls of the shaped buildings were checked in the vertical plane both before and after the shot, as follows: Each wall panel in the paneled structures was checked for plumb, and the eighth points along each wall of the poured-inplace structures were checked for plumb. To accomplish this, a special level was made which increased the accuracy of measurements on the 10-ft-high walls. A standard 30-in. carpenter's level was attached to an 8-ft strip of plywood. Wood screws through wood blocks attached to the board at each end of the level provided a vernier for setting the level. Accuracy of the level was within $1 / 16$ in. in $8 \mathrm{ft}$. Figure 5.3 demonstrates the use of the level.

The sag in the roof was determined, both before and after the shot, by measuring deflections at quarter points along both edges of each panel or at eighth points on the poured-in-place 


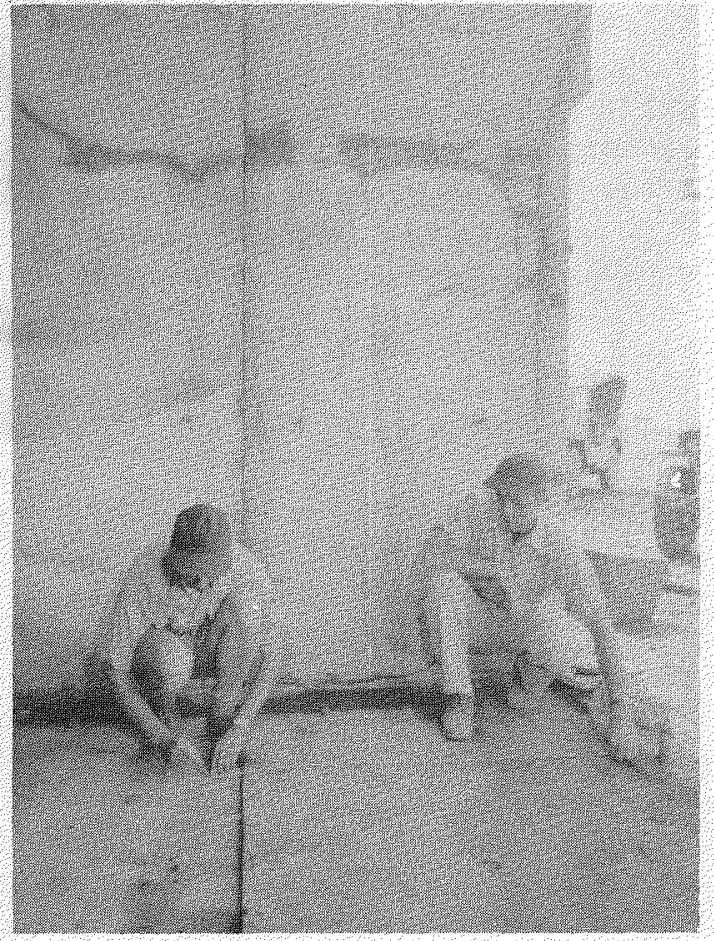

Fig, 5.2 Procedure of Measuring Coordinates in a Horizontal Plane

roofs. The level board was used for these measurements.

In each of the shaped structures, a horizontal line was established at each joint between panels. The lines were established using one instrument level setting; therefore they were all in the same horizontal plane. Vertical displacement of the wall panels was easily determined in the postshot measurements by checking with a single setup of the level, and displacement of one panel relative to the adjacent ones was determined rapidly by eye.

A short length of masking tape was placed over intersections of panels in the shaped structures. The direction of relative movement of a panel could be rapidly determined by checking the distortion of the tape.

Three of the shaped structures had bolts or steel loops cast in the panels to be used as lifting pads. The bolts were approximately at third points. Diagonal measurements between these boits before and after the shot gave a rapid measure of the shape change of each panel.

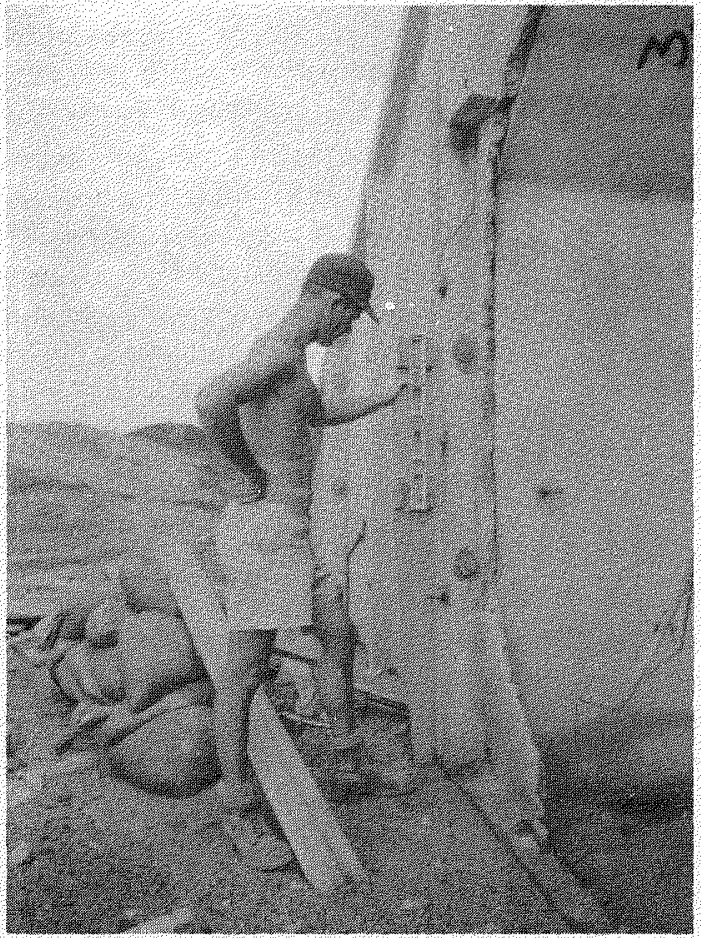

Fig. 5.3 Procedure of Checking Plumb of an End Wall

\subsubsection{Selected Transient Measurements}

It was determined early in the planning for Operation Greenhouse that the Sandia Corporation would develop the methods for obtaining transient measurements, including pressure measurements. The report of methods used is therefore included in the Sandia Corporation Instrumentation Group, Project 3.4, report. The measurements required were submitted by the Navy Structures Project. These requirements were reviewed by a panel of Sandia Corporation consultants. The Navy proposal was modified by the panel to include a larger number of instruments. Upon further study, certain instruments were eliminated in order to reduce recorder requirements. The final instrumentation program for the Navy project provided an opportunity to acquire a substantial amount of data for the analysis.

(a) Measurements Required. Displacement measurements were required with respect to time to determine the accuracy of the method of analysis. Also, since acceleration is one of 
the quantities which are determined in the analysis, experimental data on this variable were required. With acceleration and mass known, it is possible to compute the forces imposed on the element to check the loading data. The Project 3.4 report describes in detail the instruments used.

(b) Determination of Instrument Ranges. A summary of the maximum readings expected at the various instrument locations was submitted by the Navy project personnel. Maximum deflection and acceleration at instrument locations were products of the analysis. One of the criteria in the analysis was that no member should be displaced a distance of more than one-tenth the span length of the member. On this basis the displacements at the various instrument locations were determined. The maximum acceleration was also determined during this stage of the analysis. The determination of these quantities is explained in Appendix C.

\subsubsection{Photography}

Photographs were taken by personnel of the Los Alamos Photographic Laboratory, using a 4- by 5-in. Speed Graphic camera with blackand-white film. Photograph identification forms were prepared in triplicate by the field representative; the original was sent to the developing laboratory, one copy was sent to the project officer, and one copy was retained by the field representative. All developing and printing of photographs was done by personnel assigned to the Photographic Project.

The photographic record for the Navy project consists of three phases: construction photographs, preshot photographs, and postshot photographs. (a) Construction Photographs. An over-all photograph was taken after completion of each major stage of construction at each structure. Detailed photographs were made of elements of the structure where particular problems were encountered and where deviations were made from the specifications. Additional photographs were made in cases where new or unusual techniques were employed, especially in regard to the erection of precast-concrete sections. Finally, a general photograph was taken of each completed structure.

(b) Preshot Pholographs. A complete preshot pictorial record of the visual condition of each structure was obtained by taking a series of related photographs at each location. Seven exterior photographs were taken of each structure - two each of the front and rear walls, one of each end wall, and one of the roof. Interior photographs were taken of typical sections of each structure. In addition, detail views were taken of those portions of a structure, such as connections and beams, that were considered to offer good possibilities for photographic comparison with postshot results.

(c) Postshot Photographs. A complete postshot photographic coverage of all portions of each structure was obtained by use of a series of related photographs similar to those taken on the preshot survey. Wherever possible, photographs were taken from the same angle as used in the preshot photography in order to provide ease of visual comparison. Both exterior and interior surfaces were included in this program. Because of the many specific details observed in the condition of the structures after the shot, it was necessary to take additional photographs of these details in order to complete the photographic coverage and to provide permanent records for use in subsequent analysis and discussion. 


\section{SERET \\ Chapter 6 \\ Experimental Data}

\subsection{GENERAL}

This chapter presents information on loading and response, both as measured by instruments during the blast and as observed by the damage survey party later. Information on permanent distortion and crack patterns is given in Sec. 6.3.

Permanent distortions are indicated by sketches, cross sections, and photographs of the structures as a whole or of components thereof. Distortions measuring 20 per cent of the span length were measured; 5 per cent deformations were common. Transient deformations in many cases were considerably larger, but a large elastic recovery reduced the final deformation.

The sketches of crack patterns usually indicate the direction of principal stress in the structure and within the panels themselves.

\subsection{BLAST LOADING}

Data concerning transient air-blast and earth pressures recorded on the test structures are given in Figs. 6.1 to 6.12. Wherever possible the assumed pressure curves used in the preshot analysis are included for comparison.

Although no transient measurements were taken in the vicinity of Structures 3.2.1a and $b$, ball-crusher gauges indicated peak pressures of the order of magnitude of 10,000 psi.

\subsection{STRUCTURAL RESPONSE (OBSERVED)}

\subsubsection{Structure 3.2.1a (Bombproof Roof)}

(a) Damage. The roof of Structure 3.2.1a suffered a general depression in the form of a crater with maximum deflection occurring in the center. A diagonal shear plane developed near the front edge of the roof, and a vertical displacement of 6 to 8 in. occurred. The antiscour ramp and the earth in front of the structure were scoured away to the top of the footing mat, exposing the front support wall. This wall deflected severely in the center but retained its end connections. Only the roof was being tested (Fig. 6.13).

(b) Response History. The roof sustained a maximum permanent deflection of $13 \mathrm{in}$. near the center of the slab. This resulted in radial cracks around the center of the roof. The precise time during the response at which this deflection occurred is not clearly indicated (Fig. 6.14). The roof deformation caused wide horizontal cracks to open up all around the sides near the center of the slab edge, and some separation occurred along the construction joint in the front edge of the roof slab. The only other significant response affecting the roof was the front-wall action. Apparently quite early in the loading phase, the blast wave reflected off the leading edge of the roof and caused the scouring mentioned previously.

The entire surface of the front support wall was then subjected to blast pressure, resulting in bending action with a maximum permanent deformation of $30 \mathrm{in}$. at the center. The dowels connecting the front wall and roof slab ruptured when the wall moved in. The front edge of the roof slab also was deformed about $15 \mathrm{in.} \mathrm{inward}$ in the center of the span (Fig. 6.15). This 15-in. deformation is probably closely related to the diagonal tension shear plane which developed. The roof slab was axially loaded by the horizontal component of the pressure and vertically loaded by the vertical component.

The reflected pressure of the horizontal component off the front edge of the slab caused an 

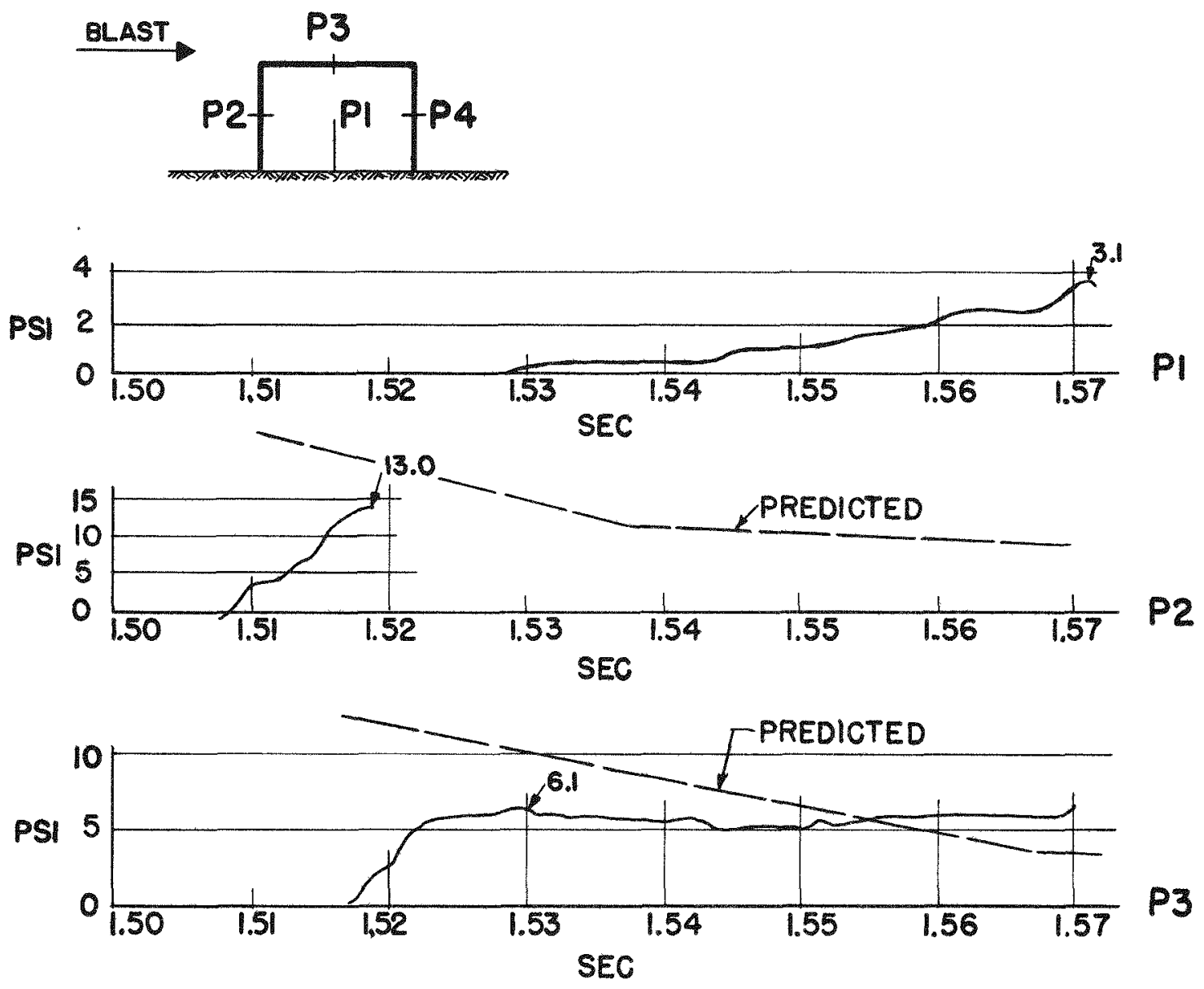

P4 NG

PSI

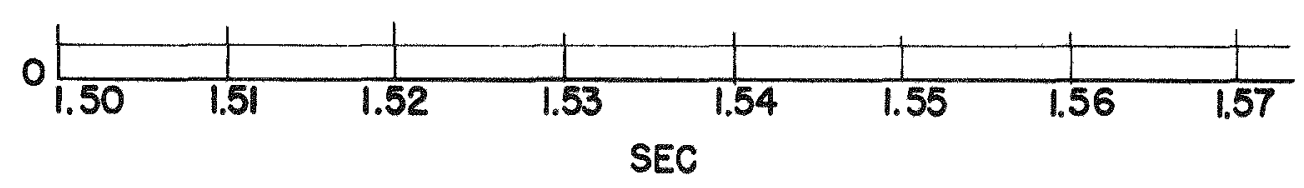

Fig. 6.1 Air-blast pressure, Structure 3.2.2a 

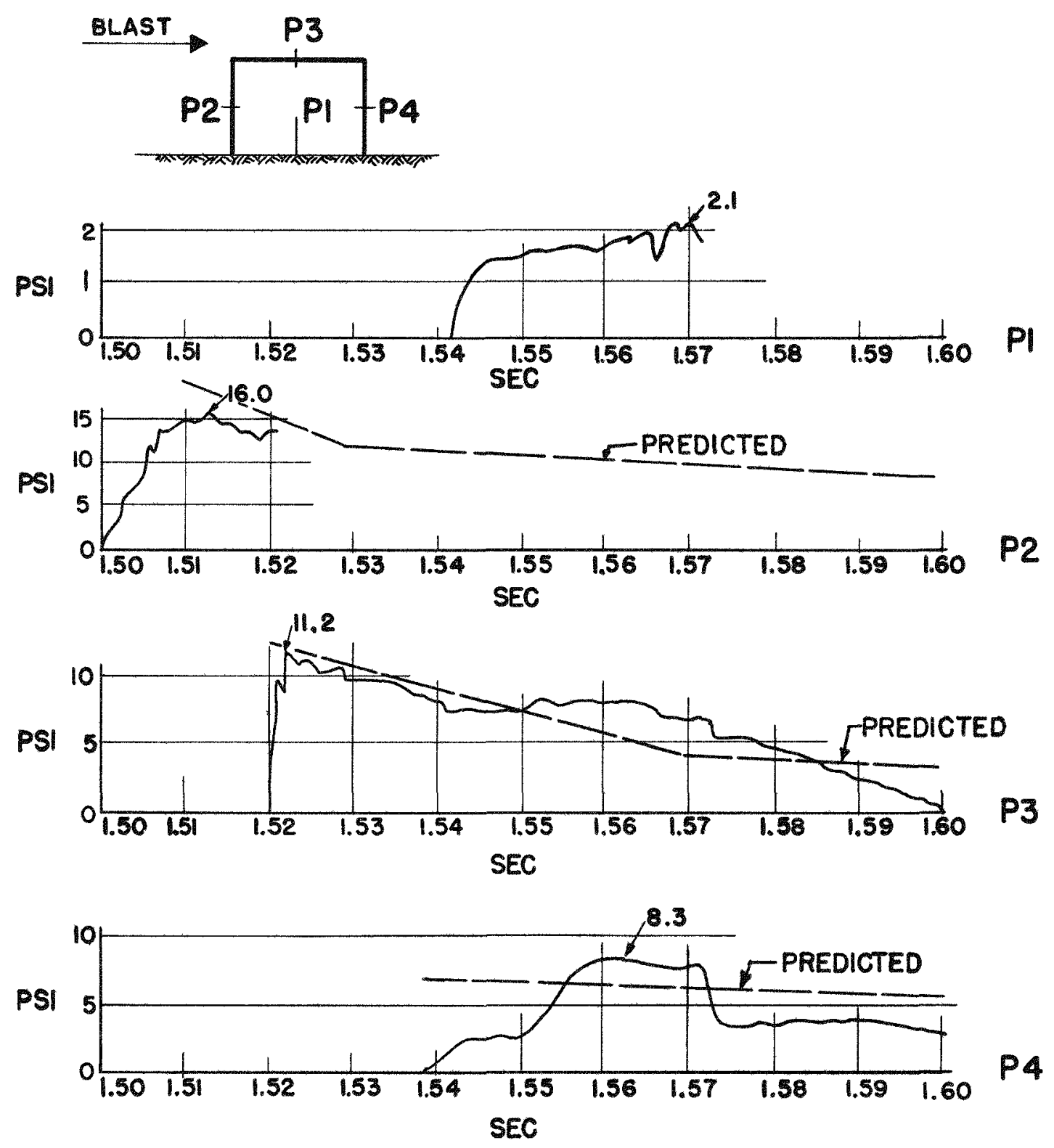

Fig. 6.2 Air-blast Pressure, Structure 3.2.2b 

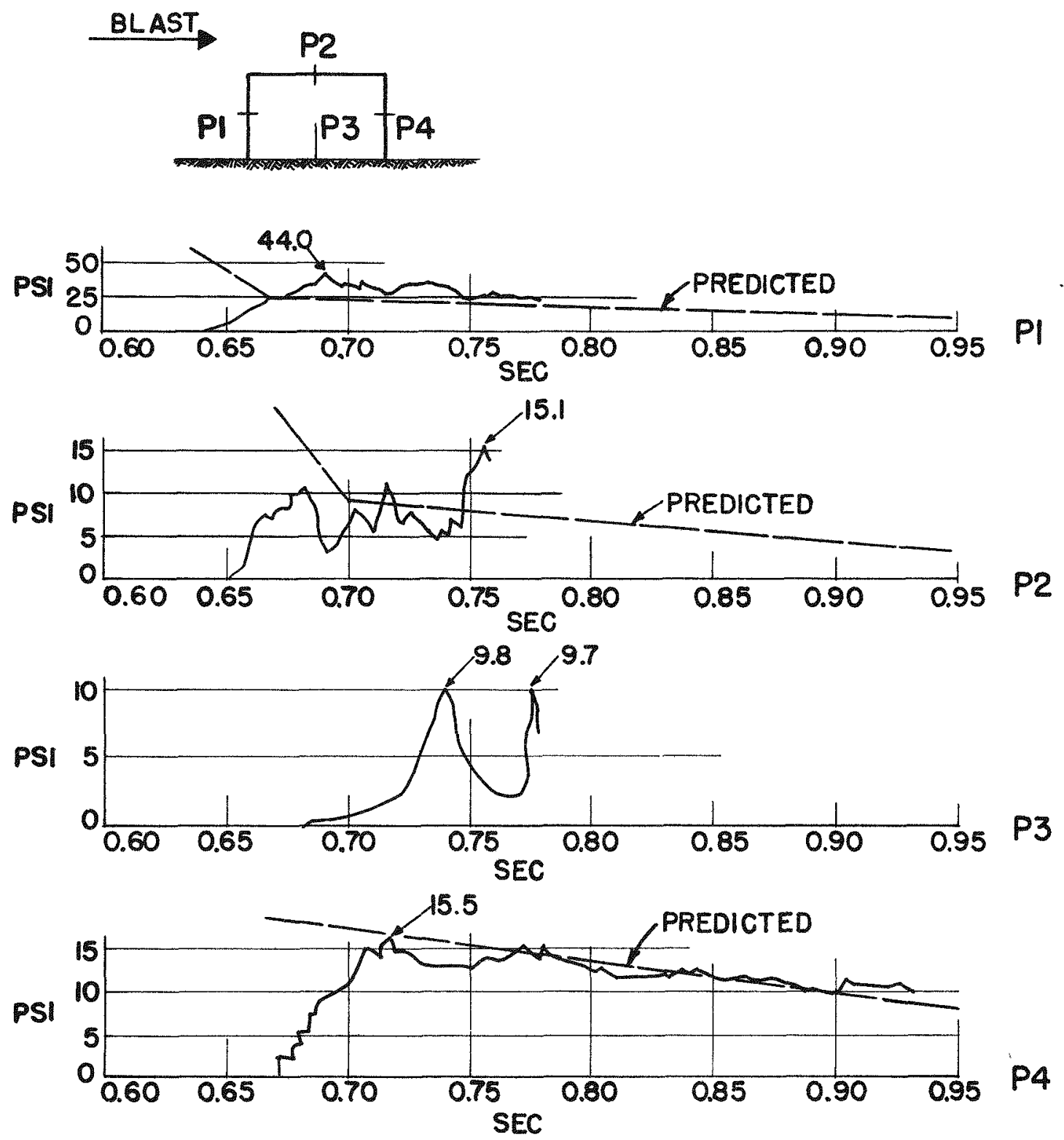

Fig. 6.3 Air-blast Pressure, Structure 3.2.3a 

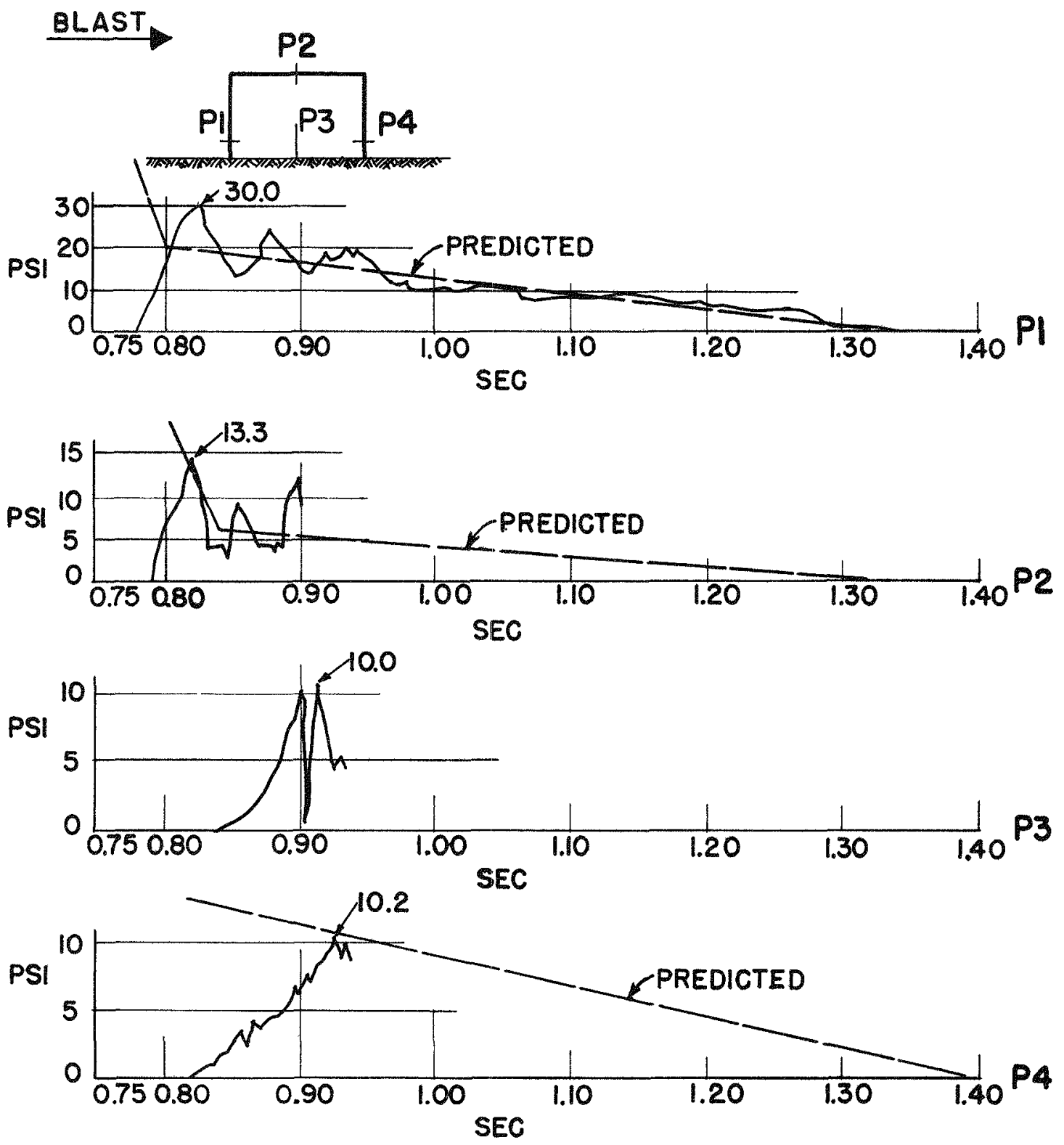

Fig. 6.4 Air-blast Pressure, Structure 3.2.3b 

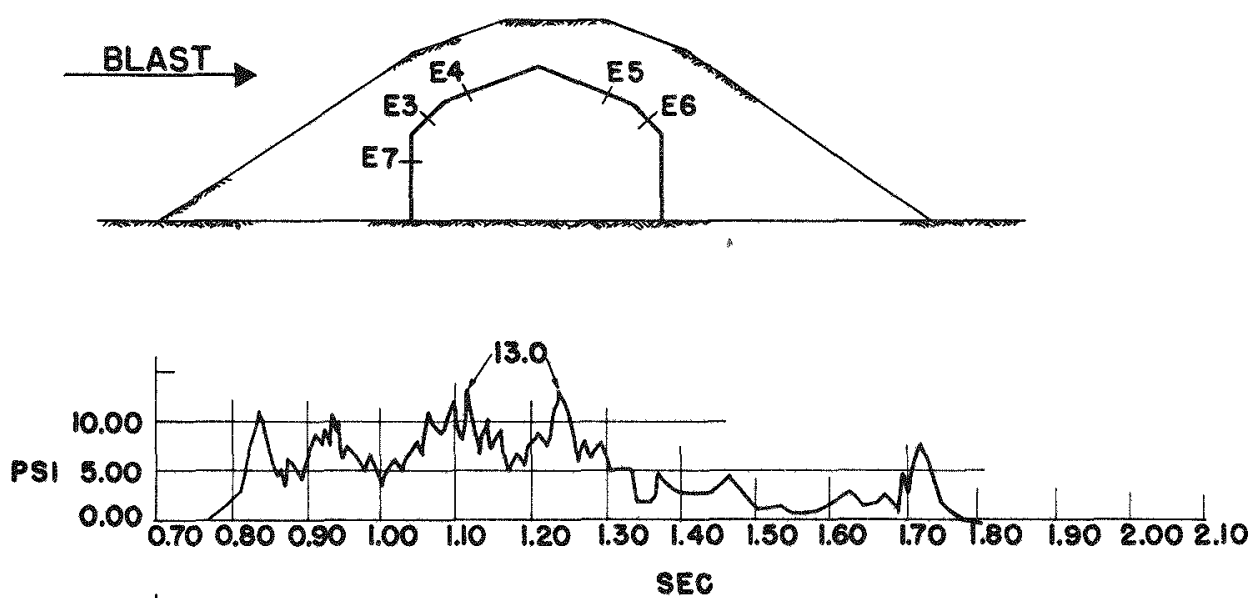

E3

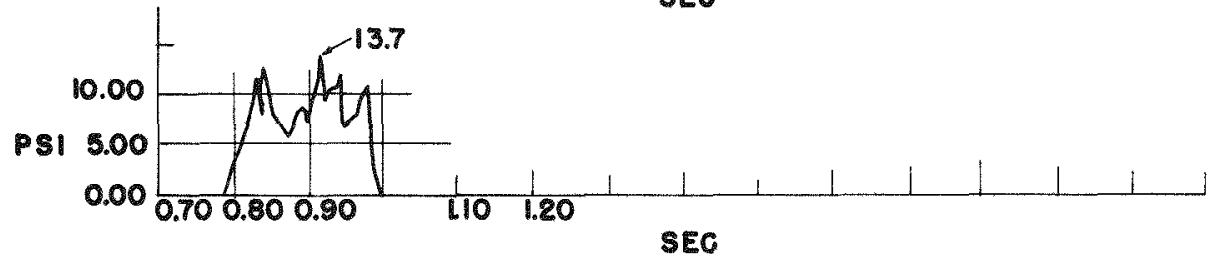

E4

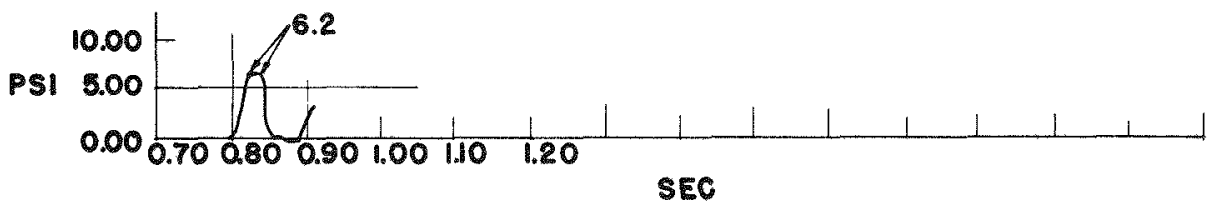

E5

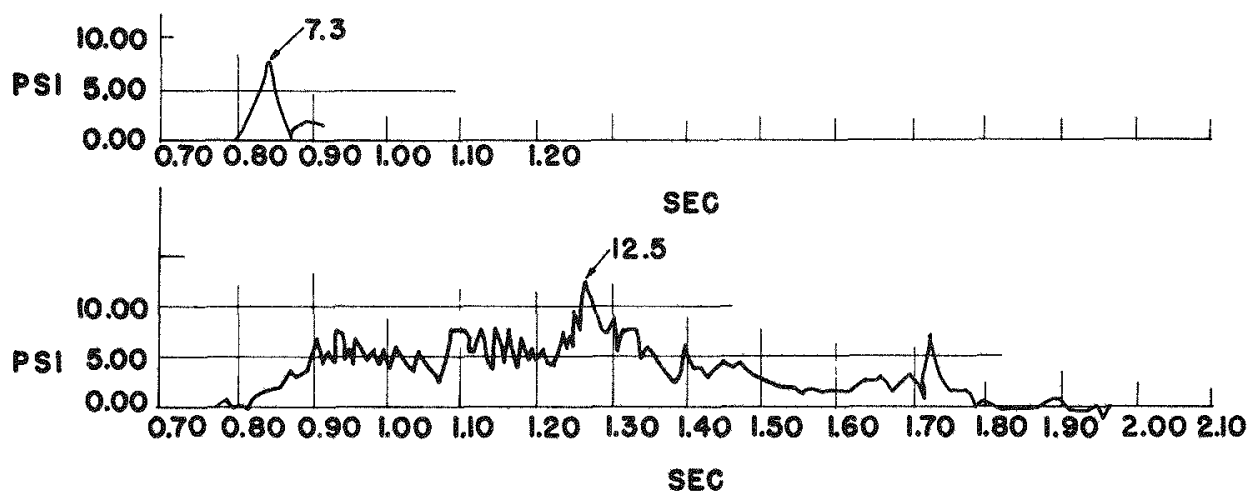

E6

E7

Fig. 6.5 Earth Pressure, Structure 3.2.4a 

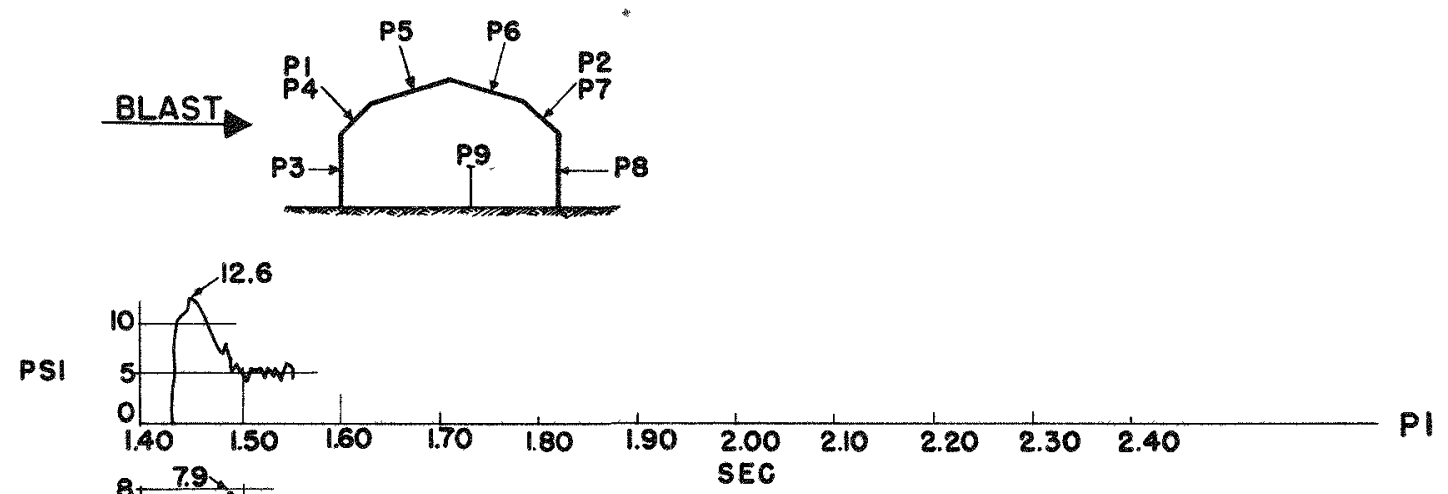

PSI

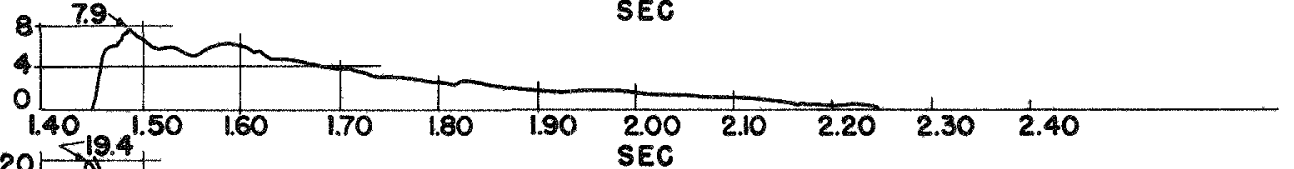

PSI

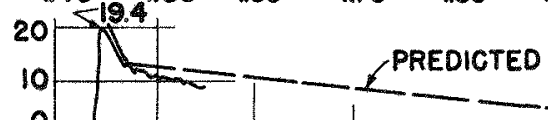

PSI
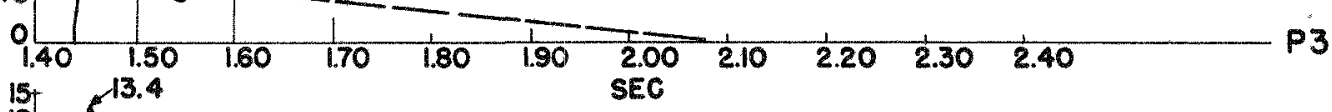

S
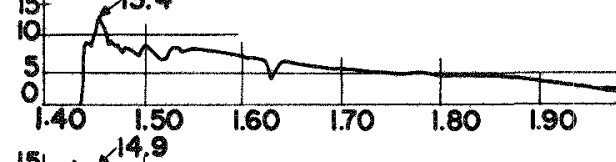

$\mathrm{E}$

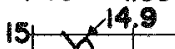

PREDICTED

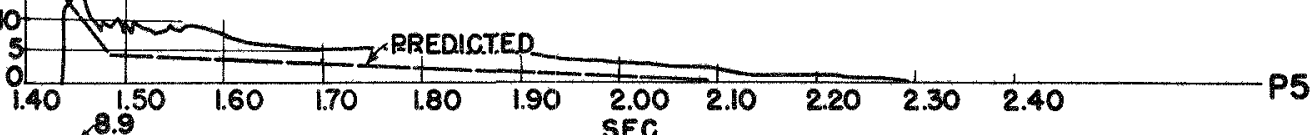

PSI

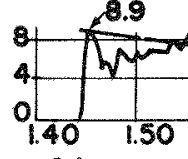

PREDICTED

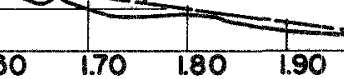

$\begin{array}{lllll}1.00 & 2.10 & 2.20 & 2.30 & 2.40\end{array}$

PSI

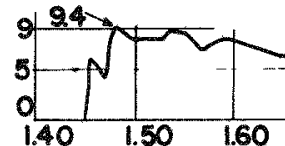
SEC

\section{3}



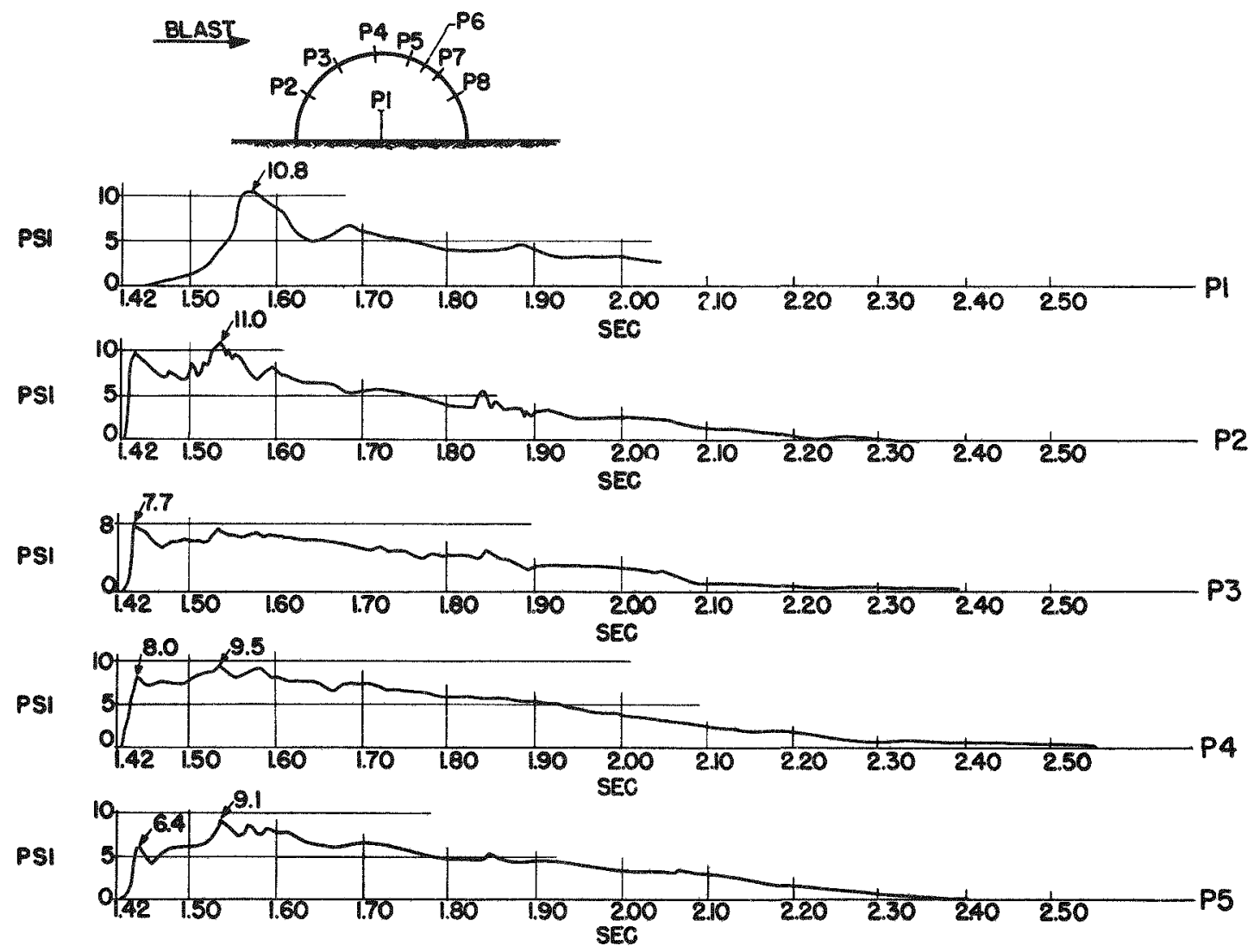

NOTE: PG NO GOOD
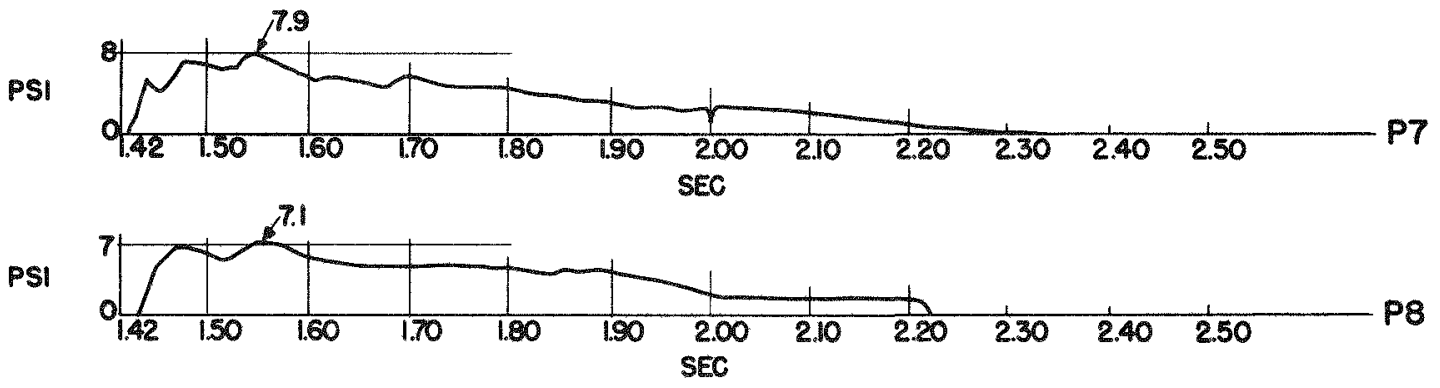

Fig. 6.7 Air-blast Pressure, Structure 3.2.5, Left Half 

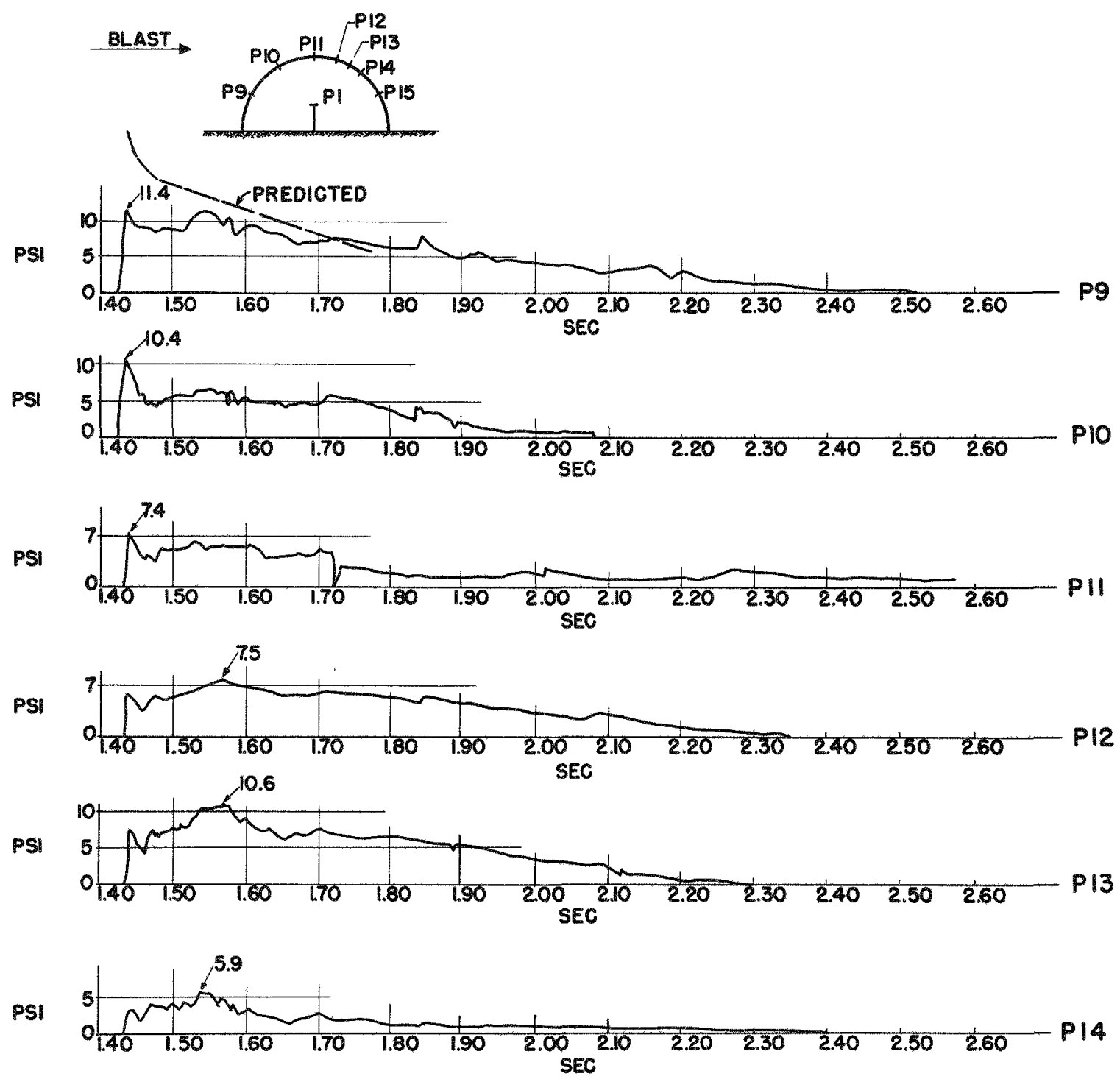

NOTE: PI5 NO GOOD

Fig. 6.8 Air-blast Pressure, Structure 3.2.5, Right Half 

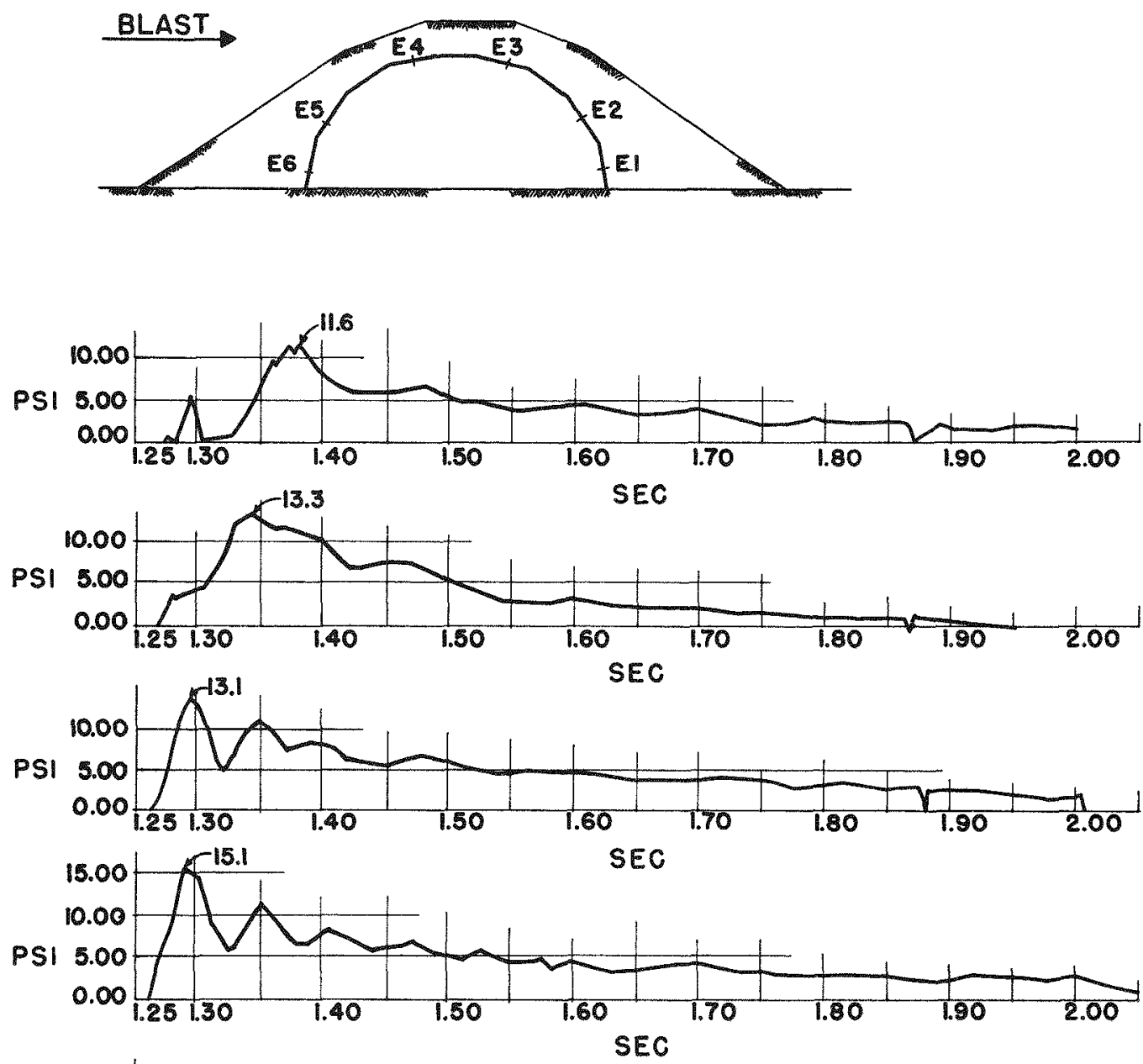

E4
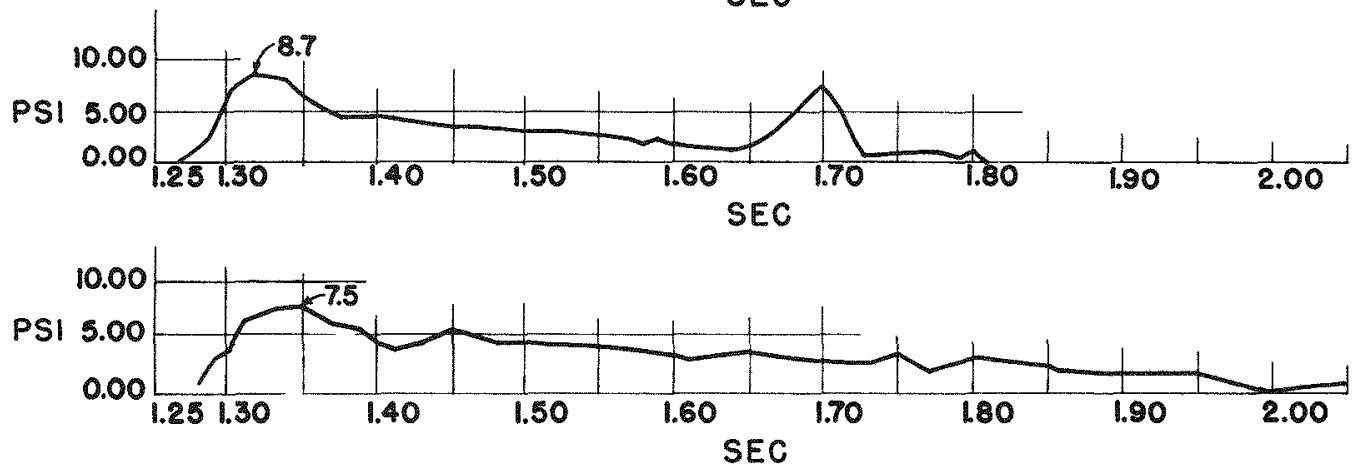

E6

Fig. 6.9 Earth Pressure, Structure 3.2.6 

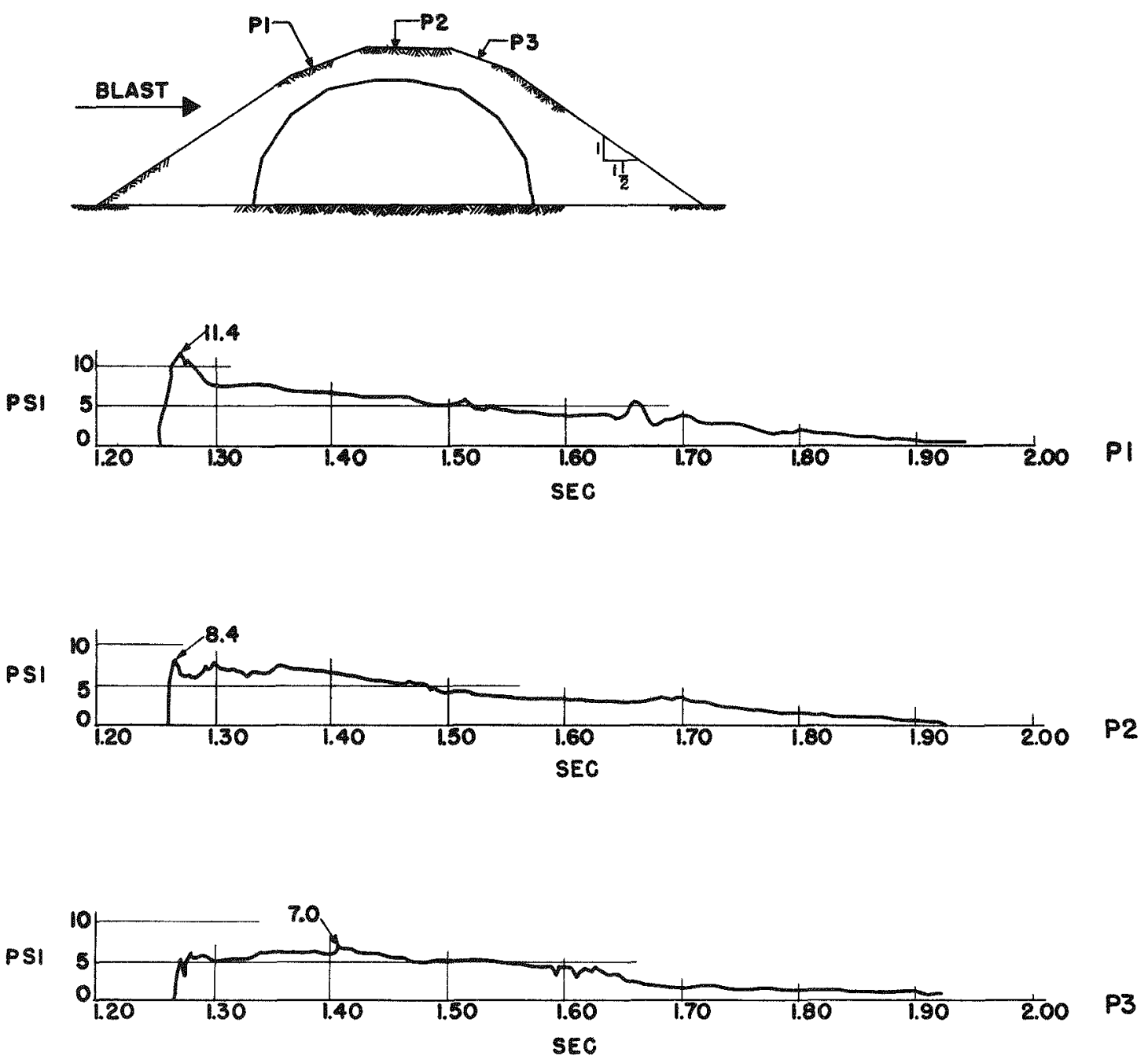

Fig. 6.10 Air-blast Pressure, Structure 3.2.6 

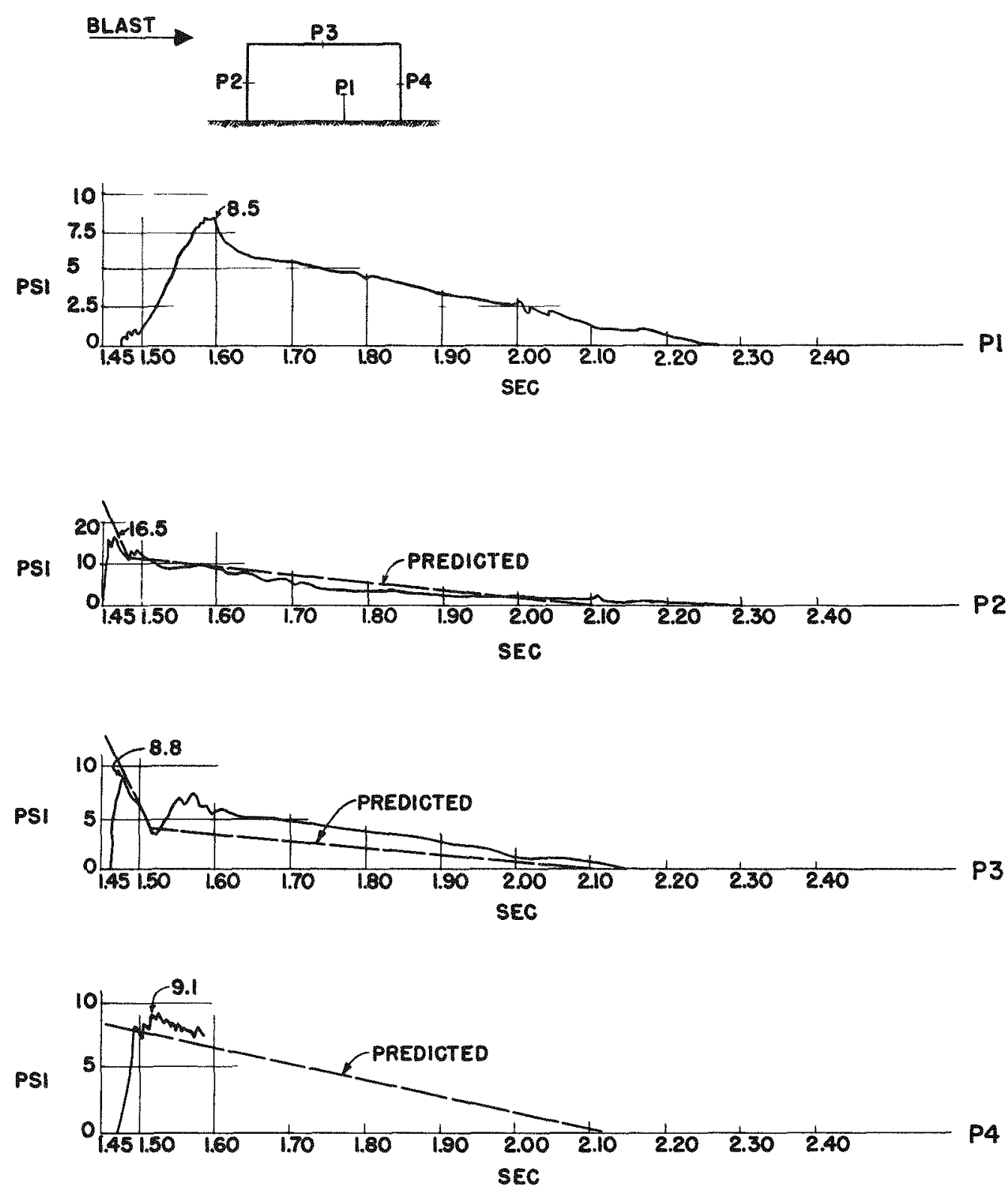

Fig. 6.11 Air-blast Pressure, Structure 3.2.7a

41 


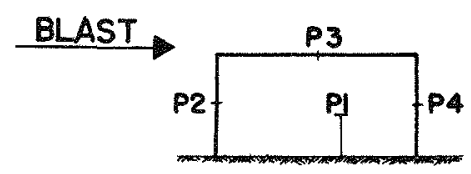

PSI
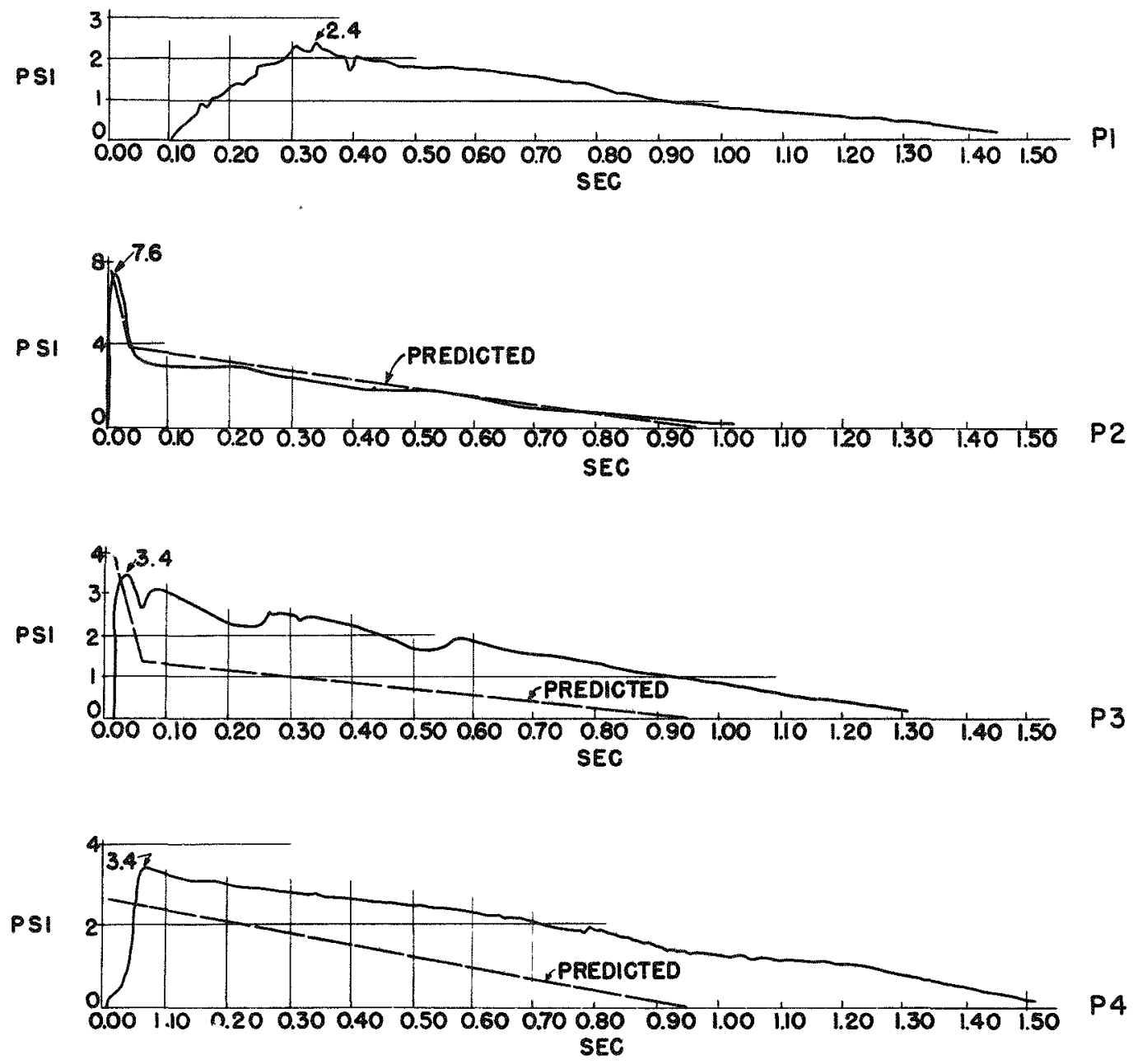

Fig. 6.12 Air-blast Pressure, Structure 3.2.7b 


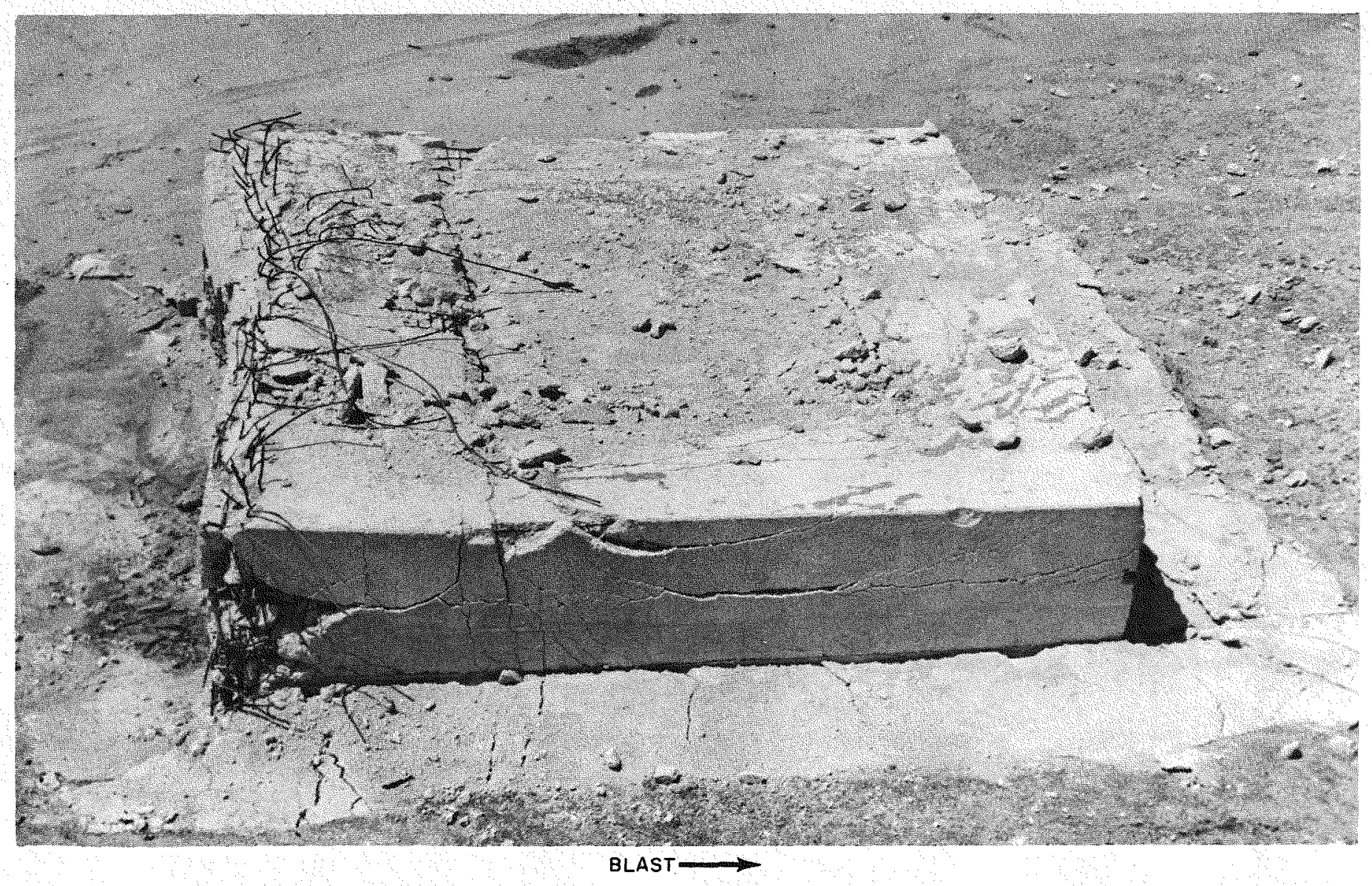

$\prod_{-1}^{n}$

Fig. 6.13 Postshot Aerial View of Structure 3.2.1a 


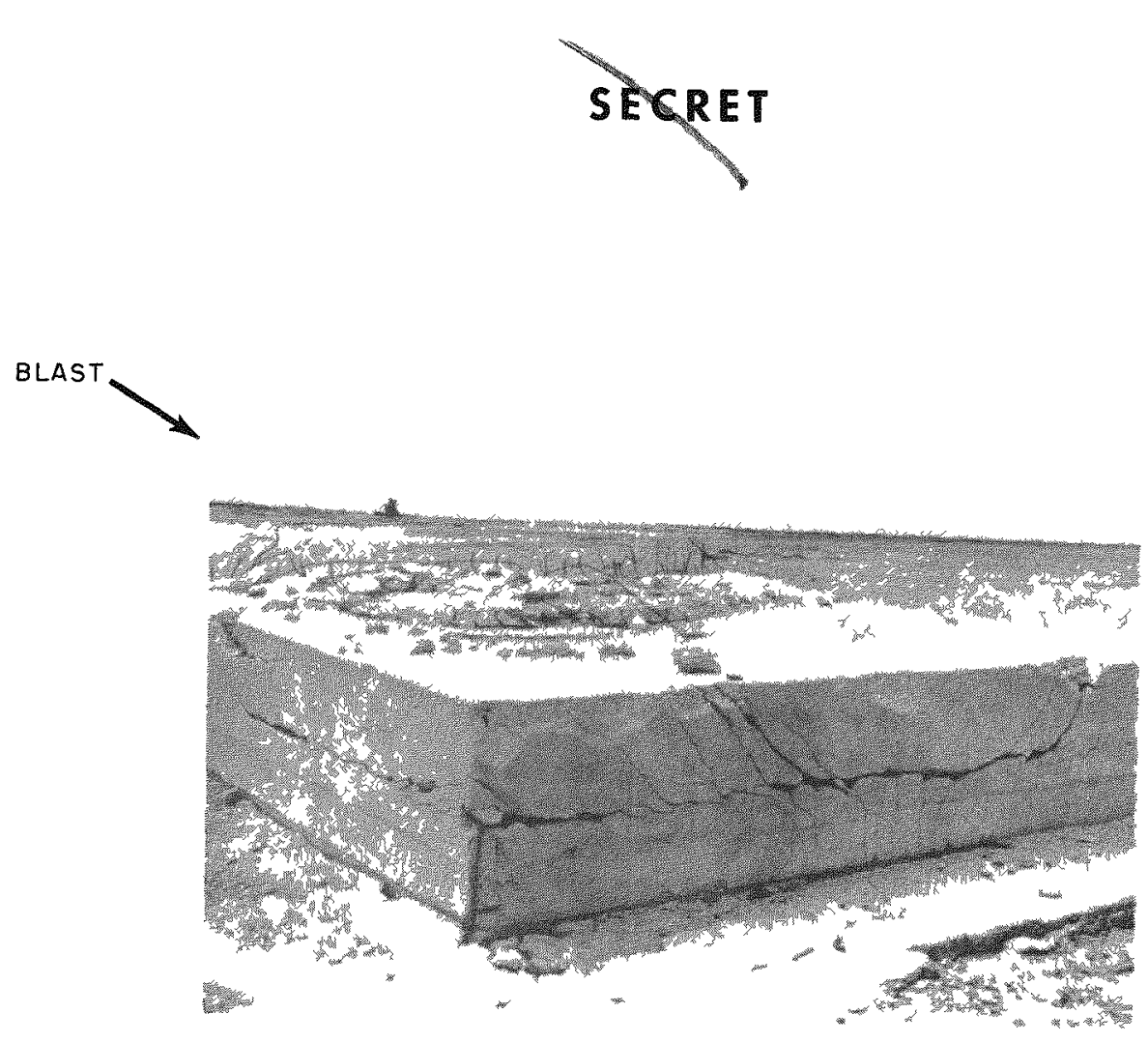

Fig 6.14 Roof from Right Rear Showing Cratering, Structure $3.21 \mathrm{a}$

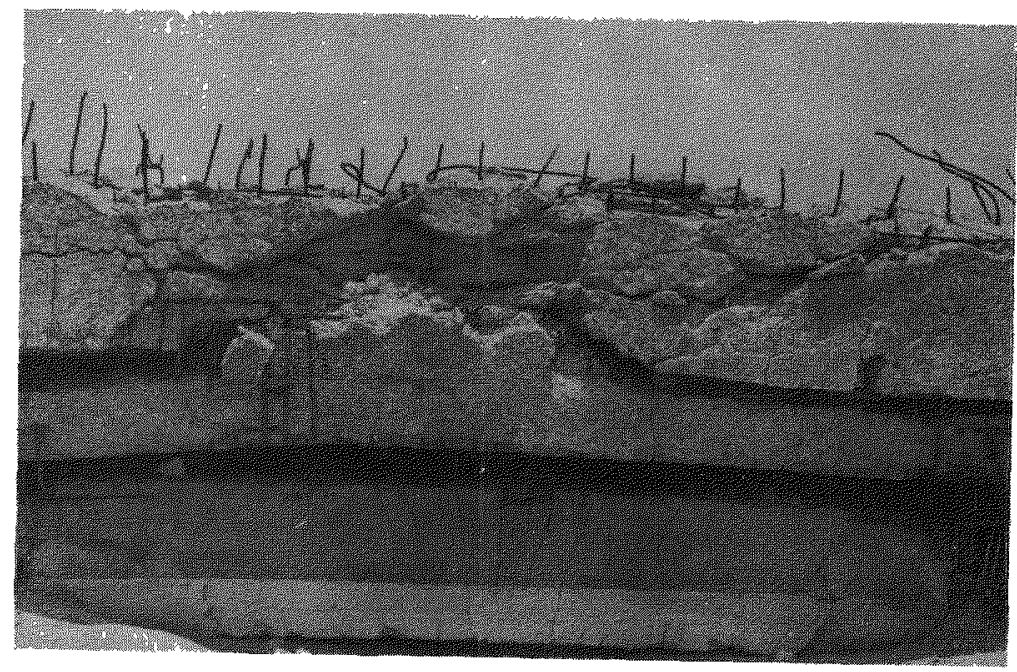

Fig. 6.15 Center Section of Edge of Roof Slab and Front Bearng Wall, structure 3.2.1a 
unbalanced axial force large enough to cause a plane of diagonal tension failure to develop. This plane extended diagonally down from a point $8 \mathrm{ft}$ back from the front edge to a point on the underside of the slab above the rear edge of the front wall in the displaced position, having a slope of one horizontal to two vertical. The section of the roof slab forward of the shear plane deformed 15 in. and moved back and up along the plane giving a 6 - to 8 -in. relative displacement between this section and the remainder of the roof slab. The reflected pressures developing in the pocket under the overhanging edge of the roof slab may have contributed to this upward motion. The entire structure was tilted back approximately $3^{\circ}$. The concrete on the front edge of the roof slab and on the front corners was badly spalled, exposing a considerable amount of steel. Despite this punishment, the slab still spanned the 22-ft gap between support walls after the blast wave had passed.

(c) Methods of Failure. Other than cracking and spalling of concrete, no significant failure occurred in the roof slab. The concrete failed in diagonal tension near the front edge, primarily because of reflection off the front face.

The vertical dowels connecting the slab to the front wall were sheared off by the wall movement, the steel failing mainly in shear. The ends of the broken dowels scratched the underside of the roof slab as the wall moved in (Fig. 6.16). The steel at the shear plane in the roof slab was badly bent but did not fail. This vertical truss steel was exposed on the top and bottom of the roof slab. The 5 per cent maximum roof deformation fell safely within the 10 per cent allowed before failure can be considered to have occurred.

\subsubsection{Structure 3.2.1b (Cellular Roof)}

(a) General Damage. Structure 3.2.1b was completely demolished (Fig.6.20). The roof section was torn loose from the foundation, broken up into pieces, and scattered over a radius of $200 \mathrm{ft}$ beyond the building. The sides were blown out and slightly to the rear. The top slab was separated from the top layer of cells and moved approximately $150 \mathrm{ft}$ to the rear, right side up, but badly cracked and spalled. The center and lower layers of cells were broken up badly and blown behind the structure. The front wall of the foundation was exposed by scouring and completely severed at the ends; it then moved straight back to the rear wall. The concrete from the United States in the precast cells which became exposed as the roof slab broke up was fused to a glassy green on the exposed surfaces by the thermal radiation from the explosion. The coral concrete was not affected in this manner because it lacked the igneous materials, such as quartz, necessary for such fusion.

(b) Damage to Components. Since this struc-m ture was a test of a roof section, the only importance which can be attached to parts of the structure other than the roof is the way in which their response affected the roof test. As will be explained in Sec. $6.3 .2 c$, the supporting elements for the roof failed, allowing the lower twothirds of the roof to overturn. Hence the roof was not properly tested but rather failed because of the failure of its supporting components.

(c) Response History. Early in the sequence of events, the base of the front wall was severed from the footing mat along the horizontal construction joint through the center of the heavy box truss. The front wall then acted as a beam supported at the ends as indicated by the 8-in. permanent deformation which occurred in this beam before it sheared off at its supports and moved to the back wall. The roof was then subjected to ballooning action due to the blast pressure trapped inside the shallow 3-ft opening underneath. The center and bottom layers, with the exception of the outer rows of filled cells on the sides, were then rotated up and back behind the building. The vertical trusses were bent up and back, and the web members were badly curled. The filled side cells at the ends of the center and bottom layers were then blown outward and back as a unit (Fig. 6.21).

Apparently the top slab and top layer of cells acted independently from the rest of the structure. The blast wave passed underneath the top slab through the ports in the top layer of cells, shearing this portion of the roof from the remainder of the building. A shearing force was also exerted against the front edge of the roof slab. Then either the free portion was uplifted by reflected pressure underneath and thrown back while rotating $360^{\circ}$ to its new location 150 ft to the rear or it was moved off horizontally. The condition of the top slab is not definitive; the numerous cracks and spalls could have occurred either before or after it tore loose. This 

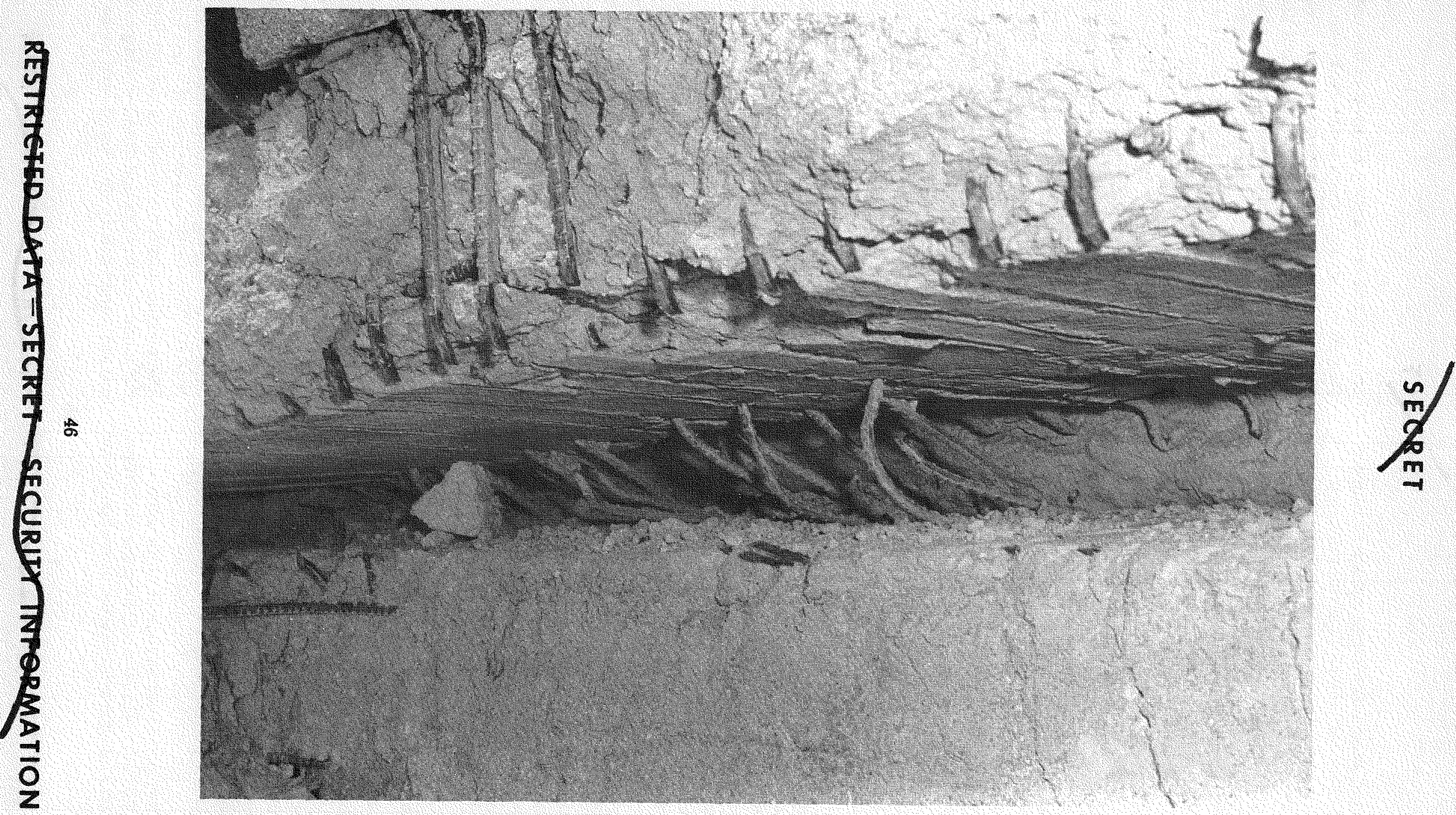

Fig, 6.16 Undersurface of Top Slab Showing Dowel Scratches When Front Support Wall Is Deflected Inward 


\section{SERRT}
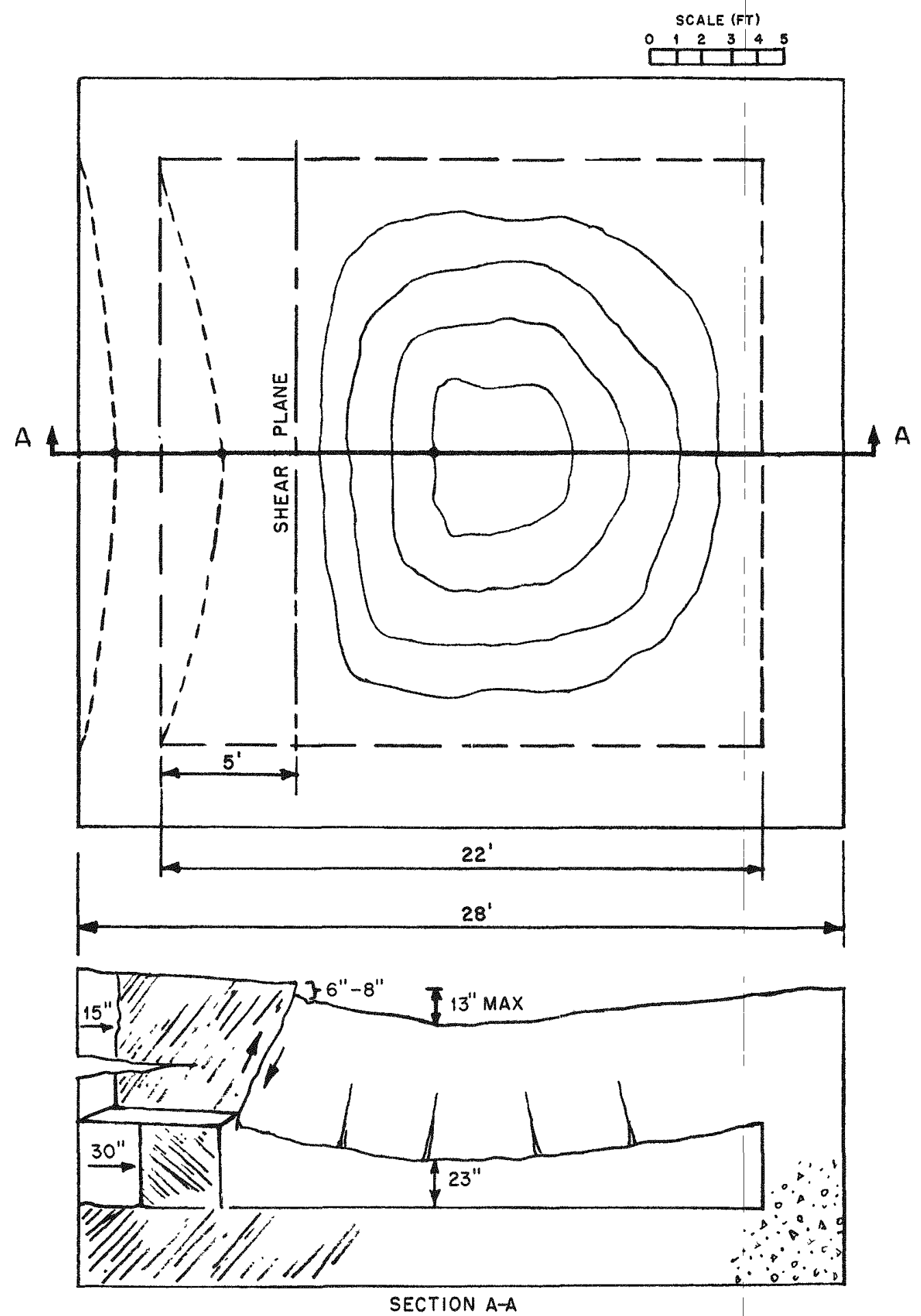

Fig. 6.17 Deformation of Structure 3.2.1a

47 


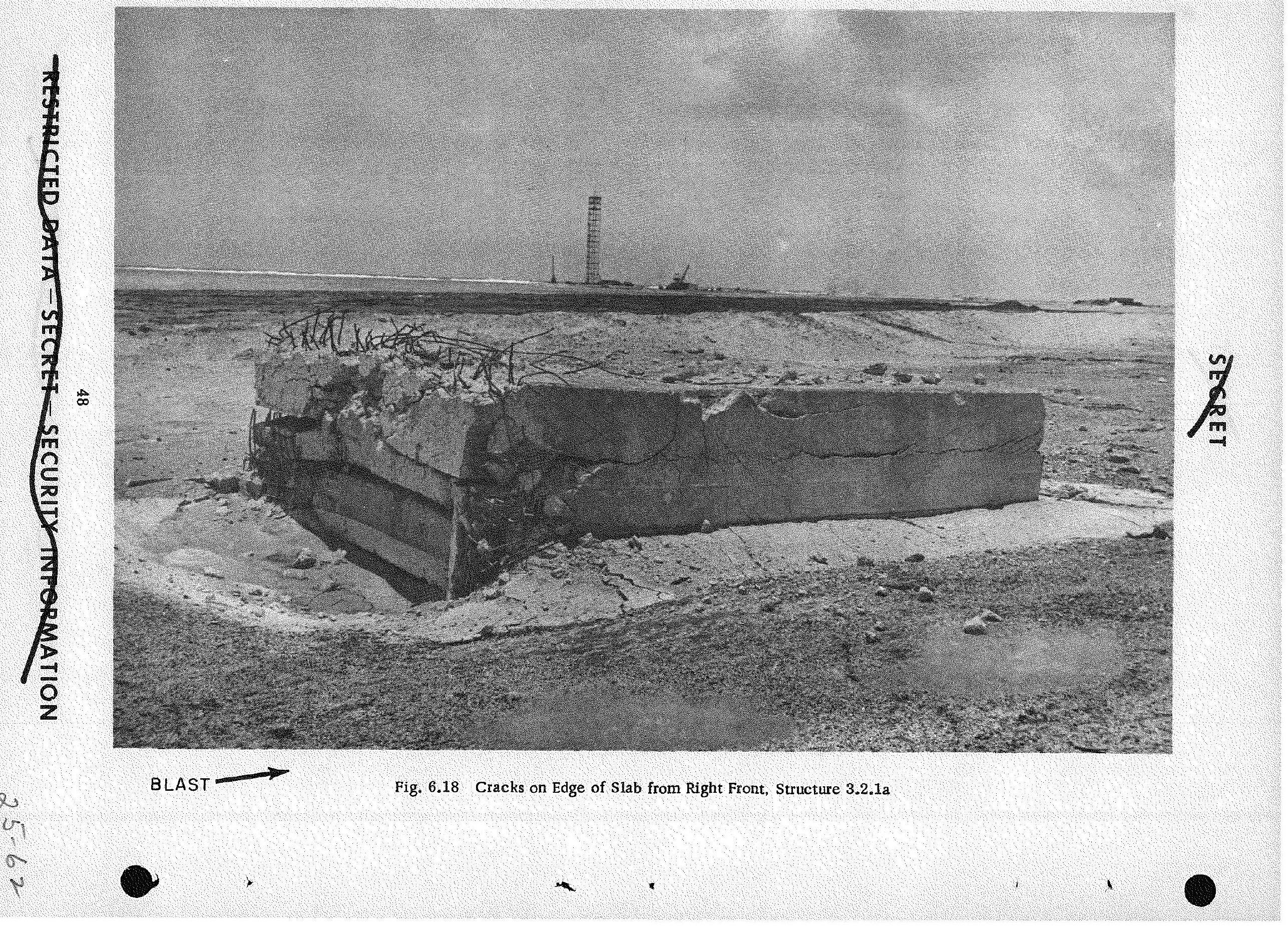




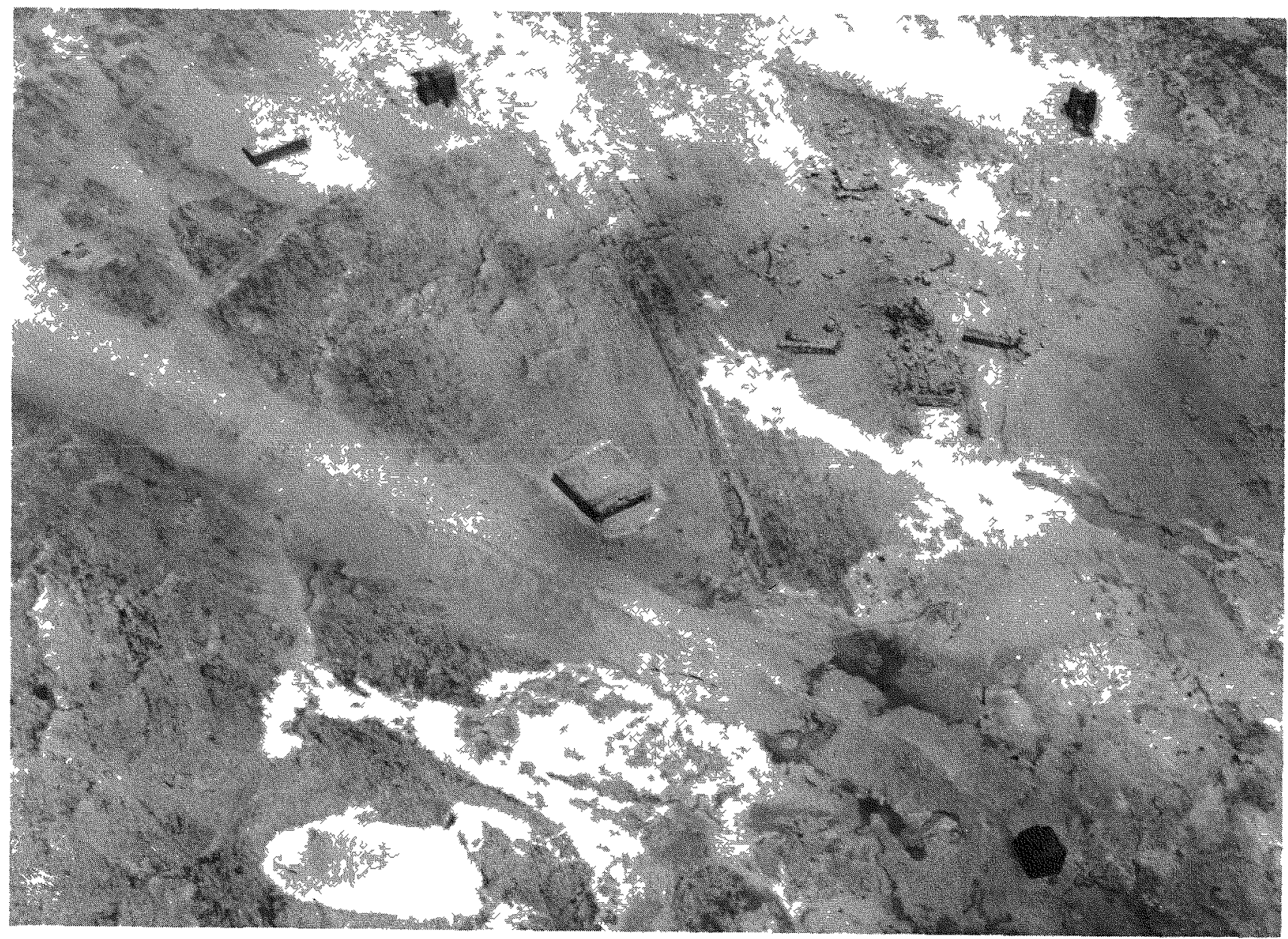

Fig. 6.20 Postshot Aerial View of Structures 3.2.1b (Upper Right) and 3.2.1a (Center)

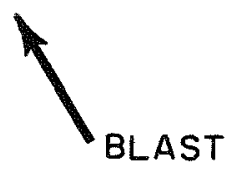



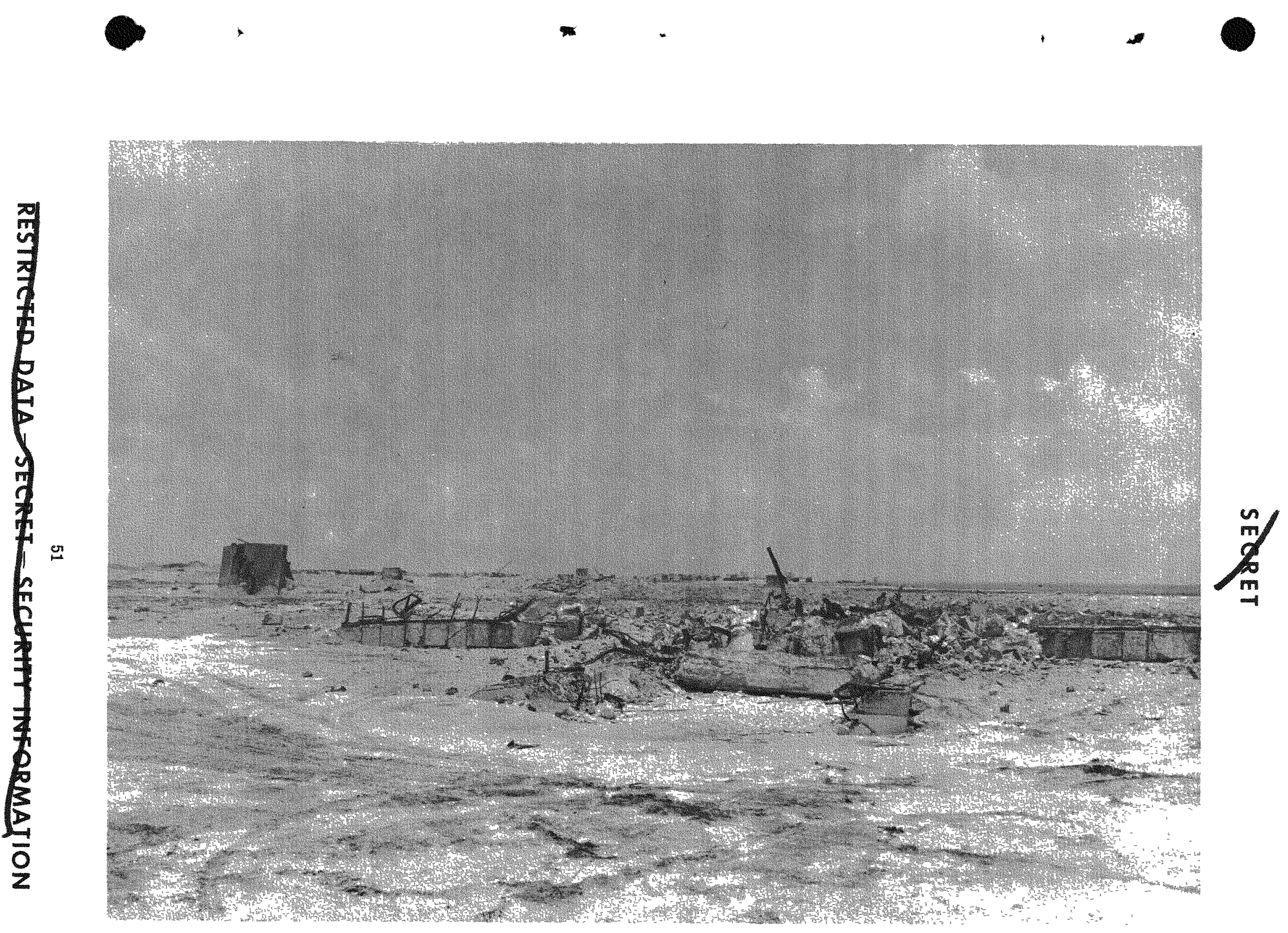


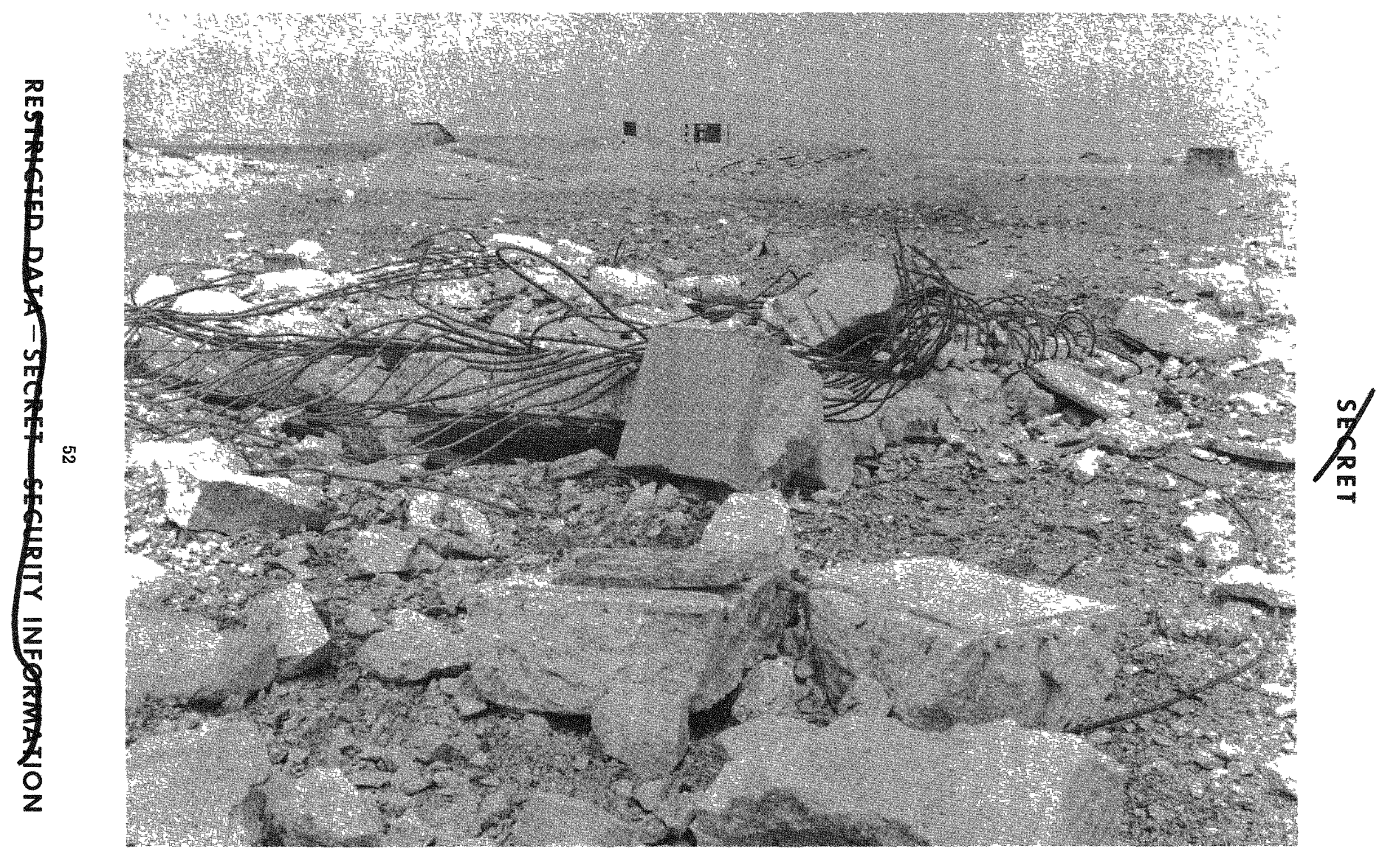

Fig. 6.22 Top Slab Displaced $150 \mathrm{Ft}$ to Rear, Structure 3.2.1b 
portion of the roof can definitely be considered weak, since the failure of the supporting components did not affect its response (Fig. 6.22).

(d) Methods of Failure. In general, the roof failed by shearing off laterally from side pressure rather than in bending from normal vertical pressure, as intended in the design. The construction joint on top of the foundation where the bottom chord of the lower steel truss in the roof was welded to the top chord of the box truss in the foundation was the principal point of failure. The $2-\mathrm{in}$. fillet welds failed, leaving the roof free to move (Fig. 6.23).

All the exposed trusses bore indications of terrific punishment. The filled cells were obviously stronger than the hollow ones and in several instances were found intact but widely separated from the building or other cells (Fig. 6.24). No hollow cells were found intact, all of them having shattered.

\subsubsection{Structure 3.2.2a (Panels on Bents)}

(a) General Damage. Structure 3.2.2a suffered general over-all failure. The panels forming the front siding were stripped off and blown in. All the remaining panels then exploded outward from the building. The side walls were split in two and moved outward and to the rear approximately $60 \mathrm{ft}$ from the building. The roof and rear walls were blown behind the structure (Fig. 6.26).

(b) Damage to Components. The horizontal front-wall panels of this structure were torn loose from their bent supports because of the failure of the end and side connections. Even though their end anchorage was insufficient, the panels held long enough to suffer considerable permanent deformation. The panels had to bend considerably to move past the bents, even after the end anchorages had failed. In effect, a simple beam condition existed. Two moment failures near the center of the panel were common, leaving the panel in a $U$ shape. These panels landed in or to the rear of the structure.

The end walls split in two along the joint between the two panels nearest the center because of moment failure. In some cases the panels were blown away from the tension steel in the ribs, leaving the steel attached to the bents. In other instances the end connections failed. The halves of each end wall moved out as a unit relatively intact.
The roof and rear walls broke loose in a manner similar to the side-wall panels. Roof panels on each half of the roof remained attached remarkably well, all ending up badly cracked just to the rear of the building but still attached to one another. One front roof panel tore loose and moved about $55 \mathrm{ft}$ to the rear of the building. The rear-wall panels were intermixed with the roof panels.

The moment failures near the haunches of the center bent and lesser effects on the end bents indicate that the bents absorbed all the load they were capable of taking before the panels peeled off. Had the panels remained in place and fully loaded the bents, they would probably have suffered complete failure.

(c) Response History. The panels of this structure held long enough for the blast wave to encompass the building. This is shown by inward deformations of all panels of up to $1 \frac{1}{2}$ in. across a 30-in. panel or a deformation of $L / 20$ (Fig. 6.28). Also the anchor bolts and reinforcing bars on the rear-wall panels generally had double or $\mathbf{S}$ curves, indicating an early pressure from the exterior followed by a greater pressure from the interior. The near failures of the bents further prove this point (Fig. 6.29).

The front wall then gave way, allowing the blast wave to enter the structure and exert pressure on all the remaining panels from their weak sides. This resulted in a general ballooning of the structure due to the entrapped blast wave reflecting off the building interior until pressures exceeding exterior pressures developed.

The end walls apparently were next to go, moving away from the structure at a $45^{\circ}$ angle. The distances covered by these panels indicate that the roof and rear walls were still in place to confine the pressure.

The roof and rear walls followed, the roof being blown up and back and the rear-wall panels being blown back. Some of the front-wall panels were blown through the building to a point 20 to $30 \mathrm{ft}$ to the rear of the building, indiçating the effect of the greater front-wall pressures.

(d) Methods of Failure. The failure of the end and side connections of the front panels is of primary importance, because this failure prevented the panels from absorbing their design load and ultimately released the blast pressure to the building interior. The bolts through the bents holding the plate, which was welded to the clip 


\section{SEDQET}

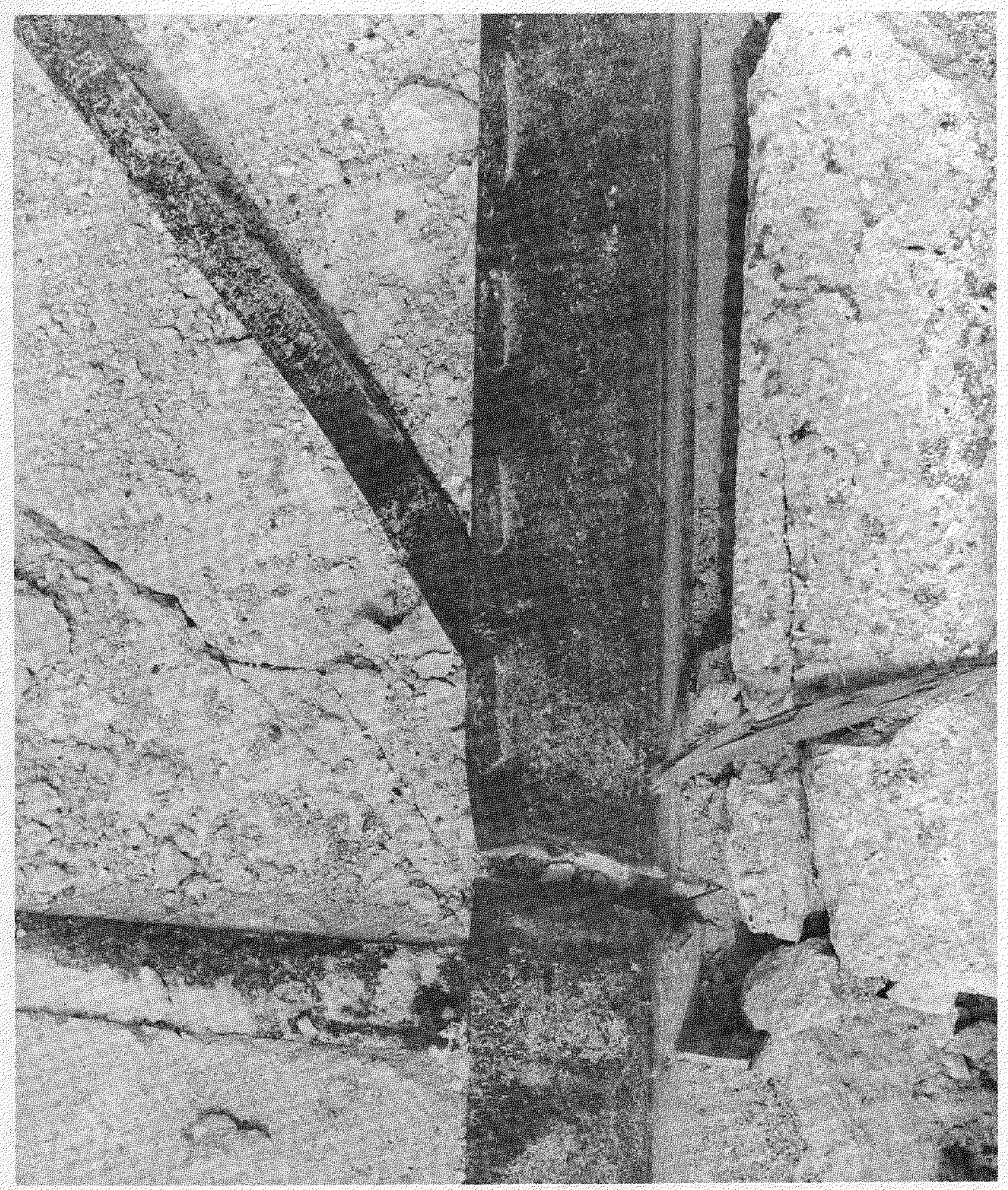

Fig. 6.23 Failure of Weld Between Roof and Bearing Wall, Structure $3.2 .1 \mathrm{~b}$ 


\section{SEQPET}

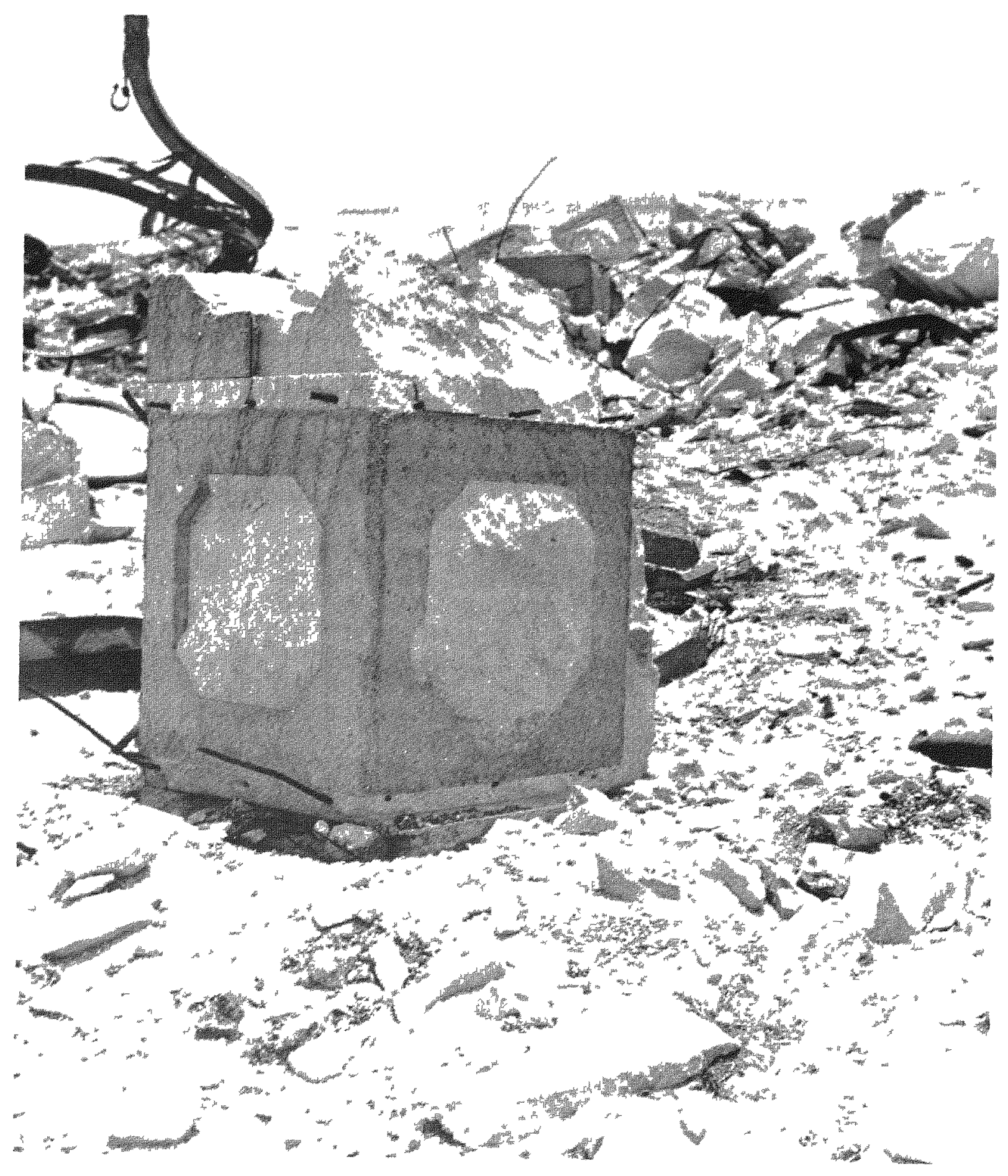

Fig. 6.24 Filled Cell Broken Away from Roof, Structure 3.2.1b 

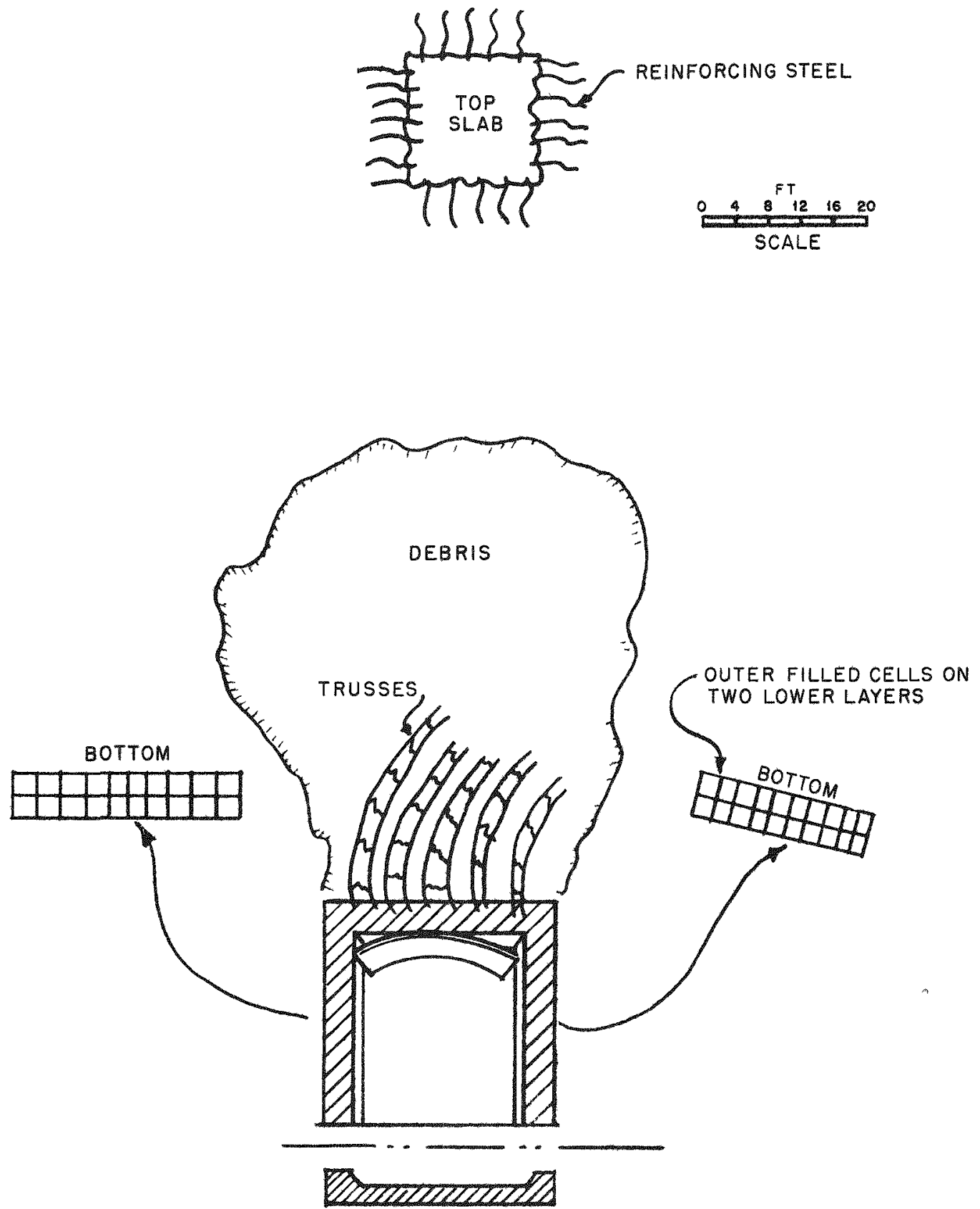

Fig. 6.25 Final Location of Structural Elements, Structure 3.2.1b 

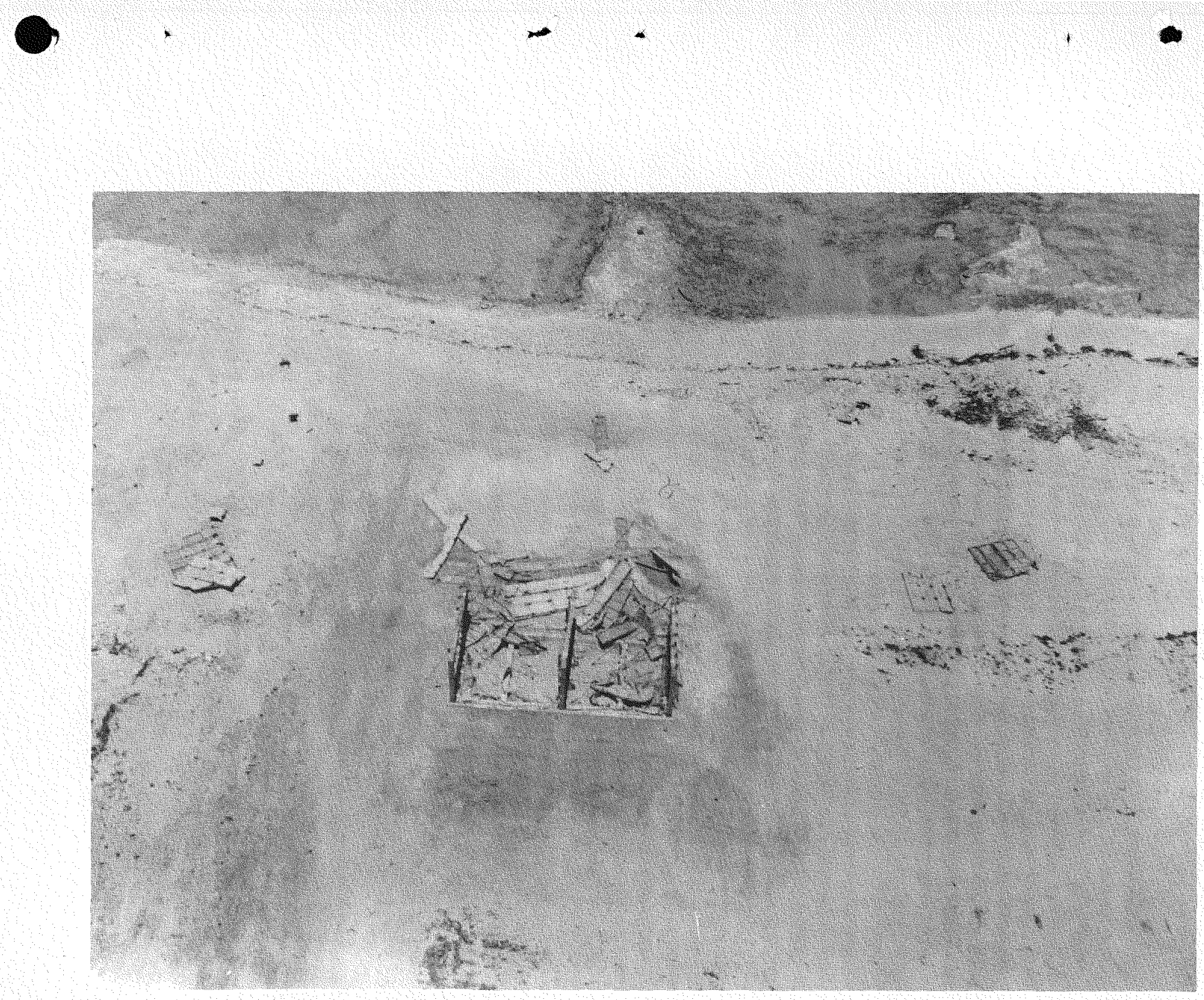

Fig. 6.26 Postshot Aerial View of Structure 3.2.2a 


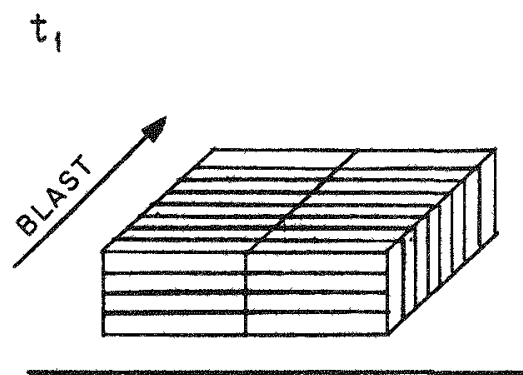

$t_{2}$
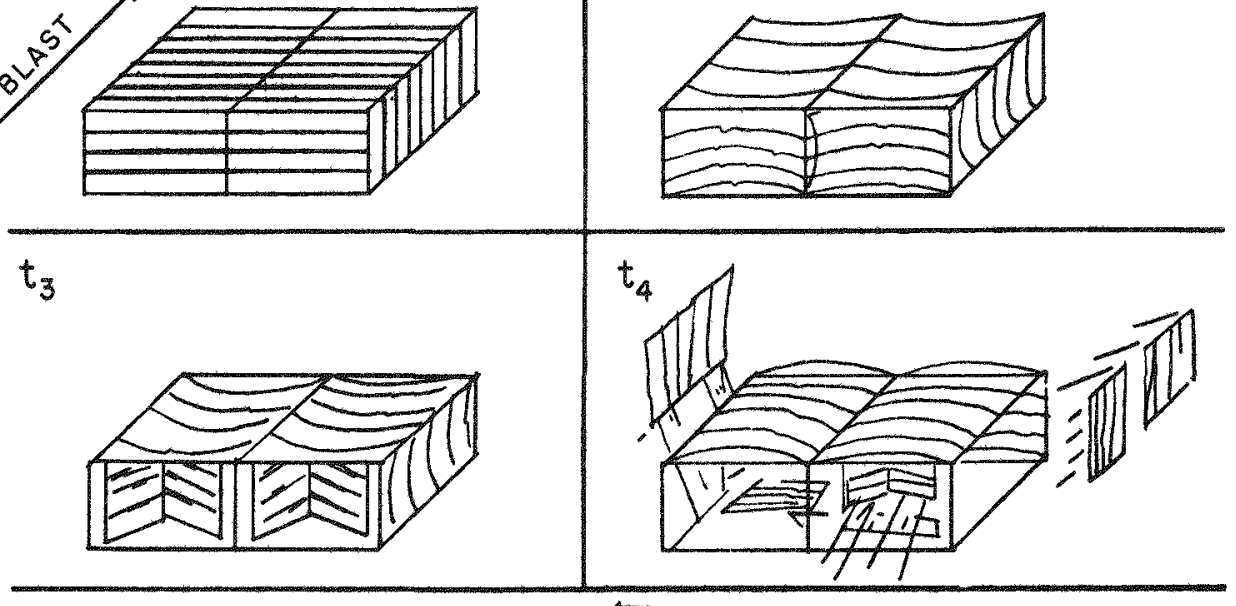

$t_{5}$
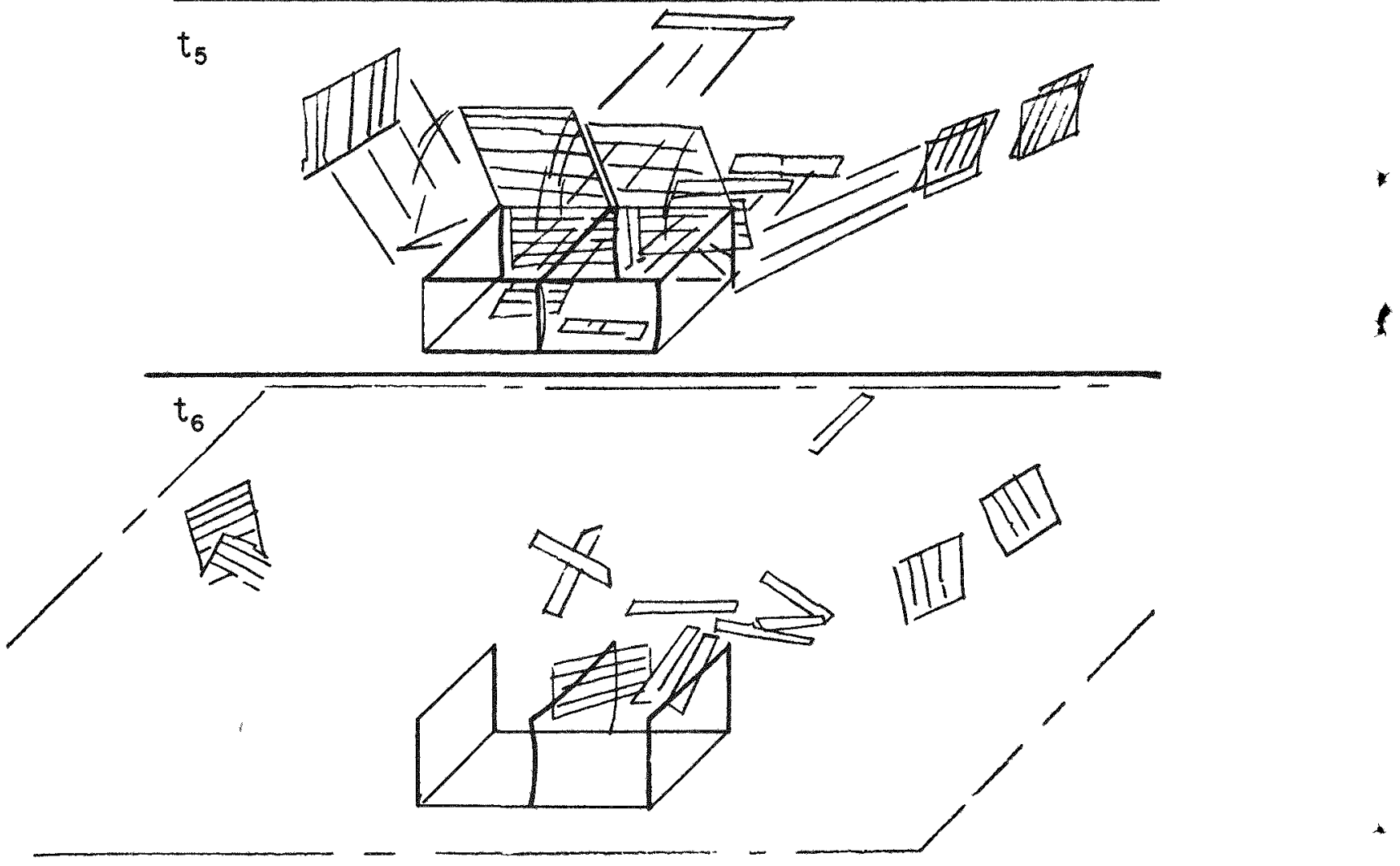

Fig. 6.27 Response History of Structure 3.2.2a

58 


\section{SEQRET}

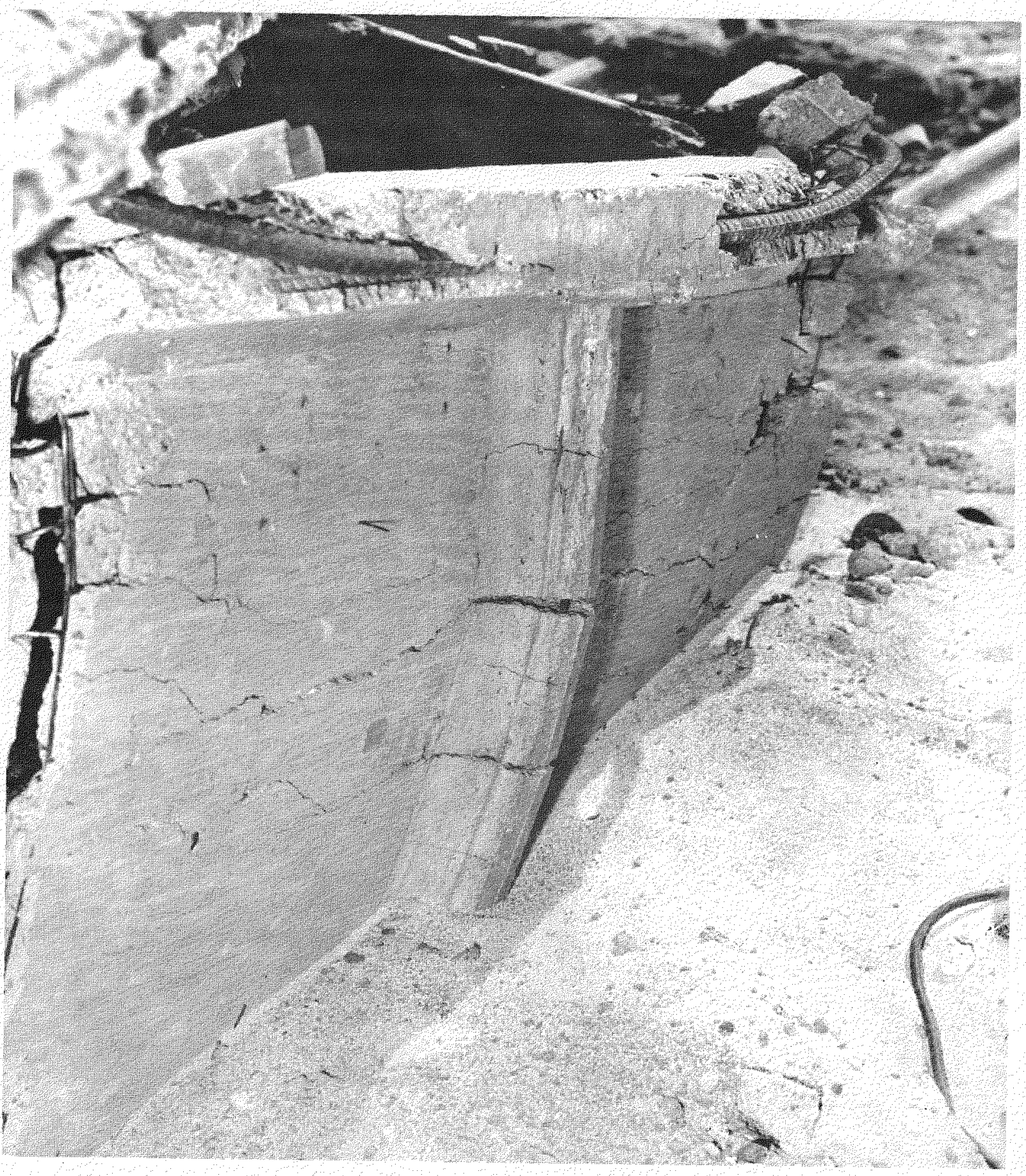

Fig. 6.28 Inward Deformation of Front Panel, Structure $3.2 .2 \mathrm{a}$ 

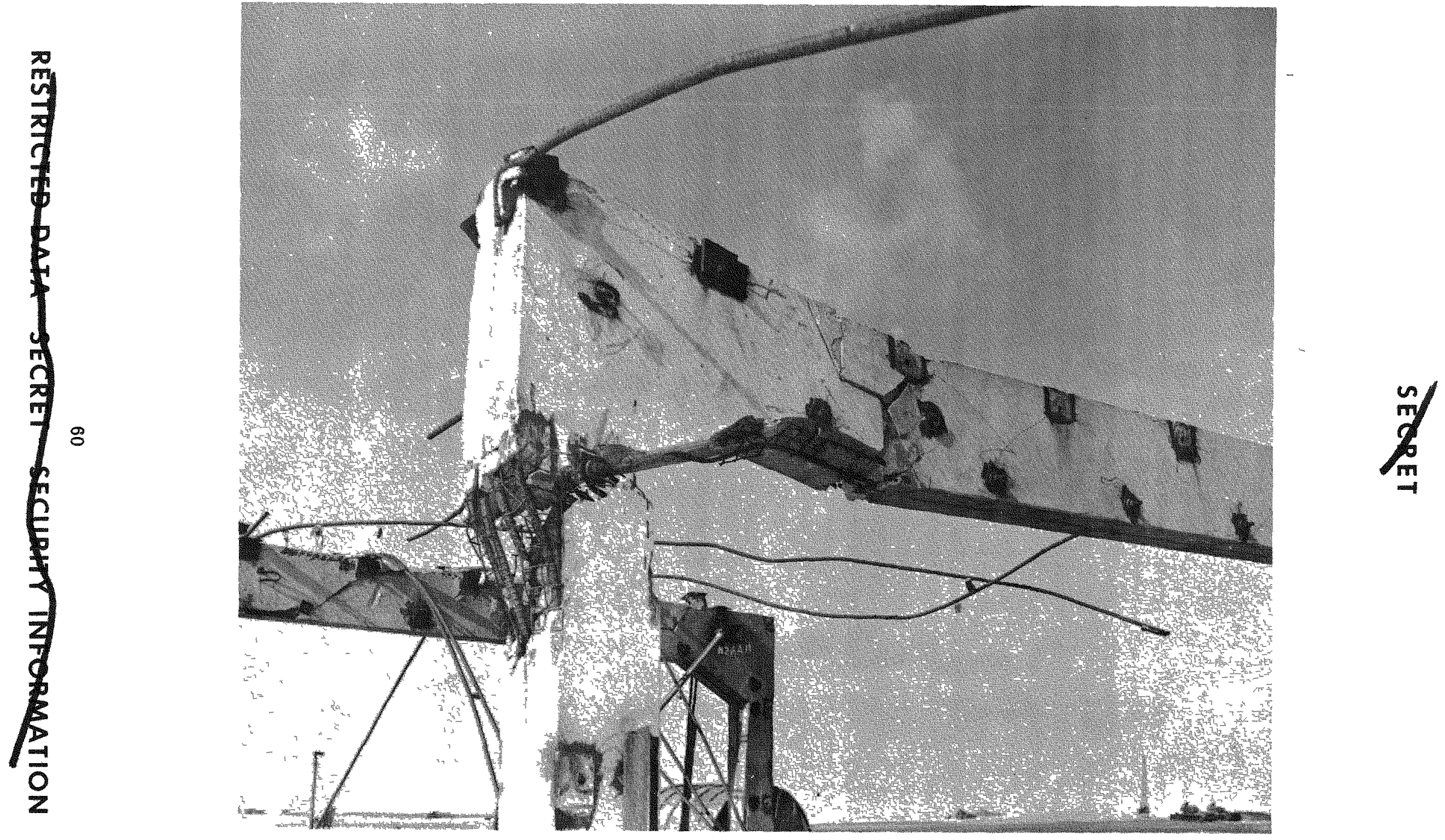

Fig. 6.29 Rear Haunch of Center Bent, Structure 3.2.2a 


\section{SETET}

on the end of the panel, failed in tension (Fig. 6.30). There were only two $5 / 8$-in. bolts at each end of each panel. The anchor bolts along the foundation were bent in severely, but there were no failures. Rather, the concrete around the pipe sleeves of these bolts failed (Fig. 6.31).

The method by which the other panels broke loose is not too important, since the pressure was on their weak side. Hence the steel designed as tension steel acted as compression steel. It was necessary only for the concrete around this steel to fail in tension to release the panel. In some instances the angle on the end of the side-wall panels separated from the angle on the end of the roof panels by breaking the weld (Fig. 6.32).

\subsubsection{Structure 3.2.2b (Panels on Brick)}

(a) General Damage. The roof of Structure 3.2.2b collapsed completely, and the timber roof joists came to rest on the floor. The front wall rotated about the foundation until supported by the roof joists at an angle of $45^{\circ}$ (Fig. 6.34). The side walls bulged out slightly, and the rear wall was deflected toward the building interior. The brick on the three sides left standing was cracked slightly as a result of the wall deformations.

(b) Damage to Components. The major part of the roof, with the exception of one or two panels on each end, failed a foot or two to the rear of the longitudinal center. The typical break was sharp with very little deformation in the rest of the panel. The timber joists fractured in the typical fashion of wood beams with a splintered jagged break and numerous longitudinal cracks running back along the joist. The roof panels and joists pulled away from their end connections. The fractured roof members finally came to rest on the floor after rotating about their end points. The roof panels retained attachment between themselves rather well except at the center where they parted to allow the roof to reach the floor.

The front-wall panels were relatively undamaged except at the points of separation near the corners. Some inward deformation occurred within the individual panels. When the wall rotated, the footing supporting the panels rotated and was lifted with the wall since it had no restraint (Fig. 6.35). This uplift caused several breaks in the footing because the ends were an- chored at the corners. The brick wall remained well attached to the panels through the bolt-andwasher connections, even on the front wall which came to rest at approximately a $45^{\circ}$ angle. The mortar work was excellent; most of the masonry failures occurred in the brick itself rather than in the mortar (Fig. 6.36).

Some cracking occurred in the brick of the left end wall, especially near the corners. Outwardly this wall was undamaged. The right end wall was cracked more generally, indicating slightly more movement than the left wall. However, the panels on the exterior were essentially undamaged. The door, although easily removed, suffered about a $2-$ in. maximum inward defor mation.

Uniformly varying deflections of up to a $2 \frac{1}{2}$ in. maximum at the top center occurred in the rear wall. This movement was not sufficient to damage the panels, except for some cracking at the weld points, but the brick wall was cracked slightly.

The angles attaching the vertical wall panels to the footing were undamaged. A typical crack pattern developed around the welded connections between panels, indicating stress concentrations in the concrete at these points. Many of these cracks had already started before the shot. A considerable number of cracks developed in the panel footing at anchor-bolt locations.

(c) Response History. In considering the response of this structure, the actions of the roof, front, and rear walls must be considered together. Assuming that no failures had time to occur until the blast wave had a chance to pass over the structure and load the rear wall, the following sequence of events occurred:

1. The blast wave reached the structure and loaded the front wall. Half of this load was passed to the rear wall by the roof acting as a strut.

2. The blast wave loaded the roof, causing some downward deflection.

3. The blast wave loaded the rear wall, tending to counteract or relieve the force transmitted to it from the front wall. This balancing of forces tended to stabilize the rear wall.

4. The roof, acting as a column with its base at the rear wall and loaded by the front-wall reaction as well as the side-on pressure, continued to deflect. The moment at the center of the roof continued to increase in proportion to the deflection. 

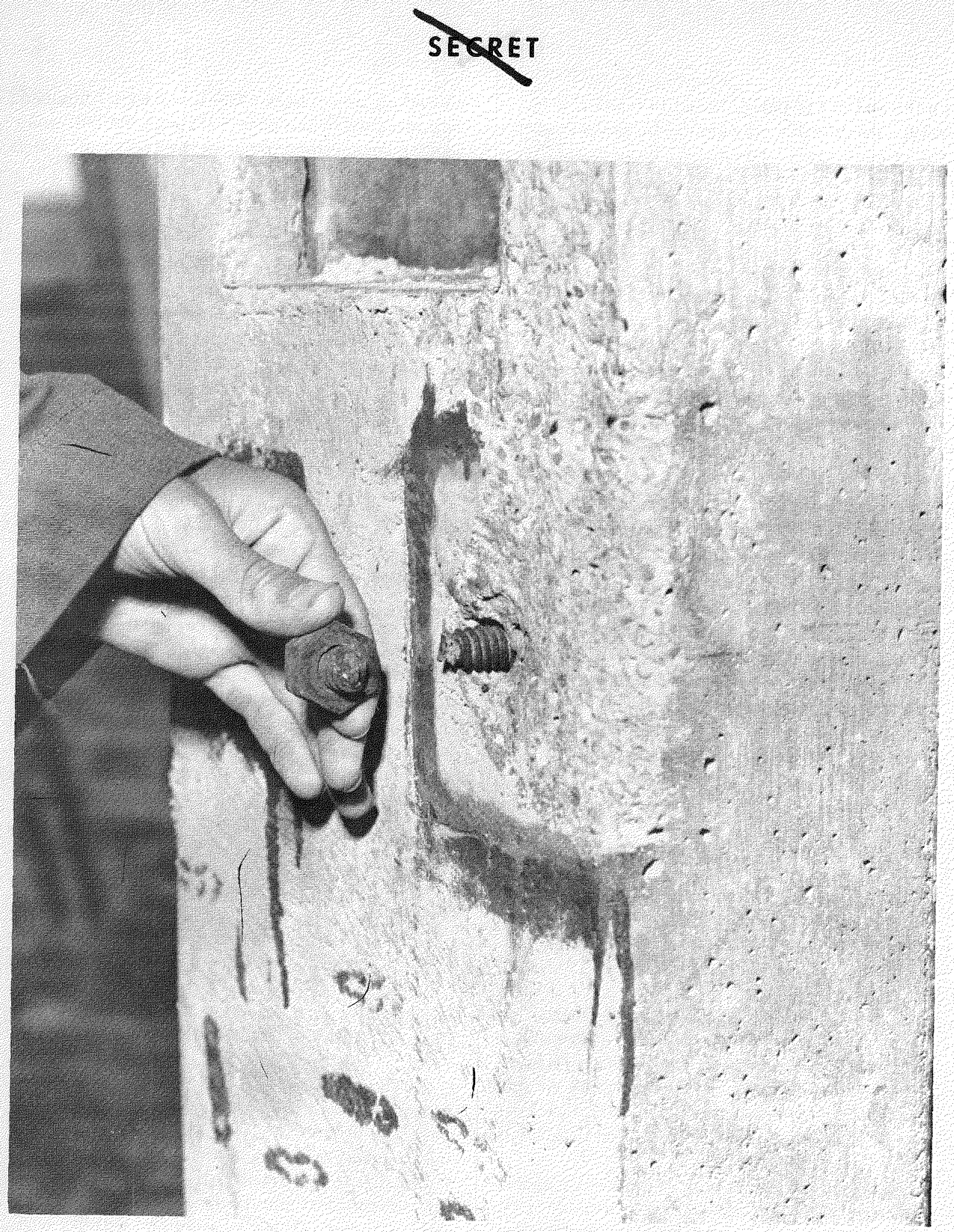

Fig. 6.30 Panel-bolt Failure in Right Bent at Front of Structure 3.2.2a 


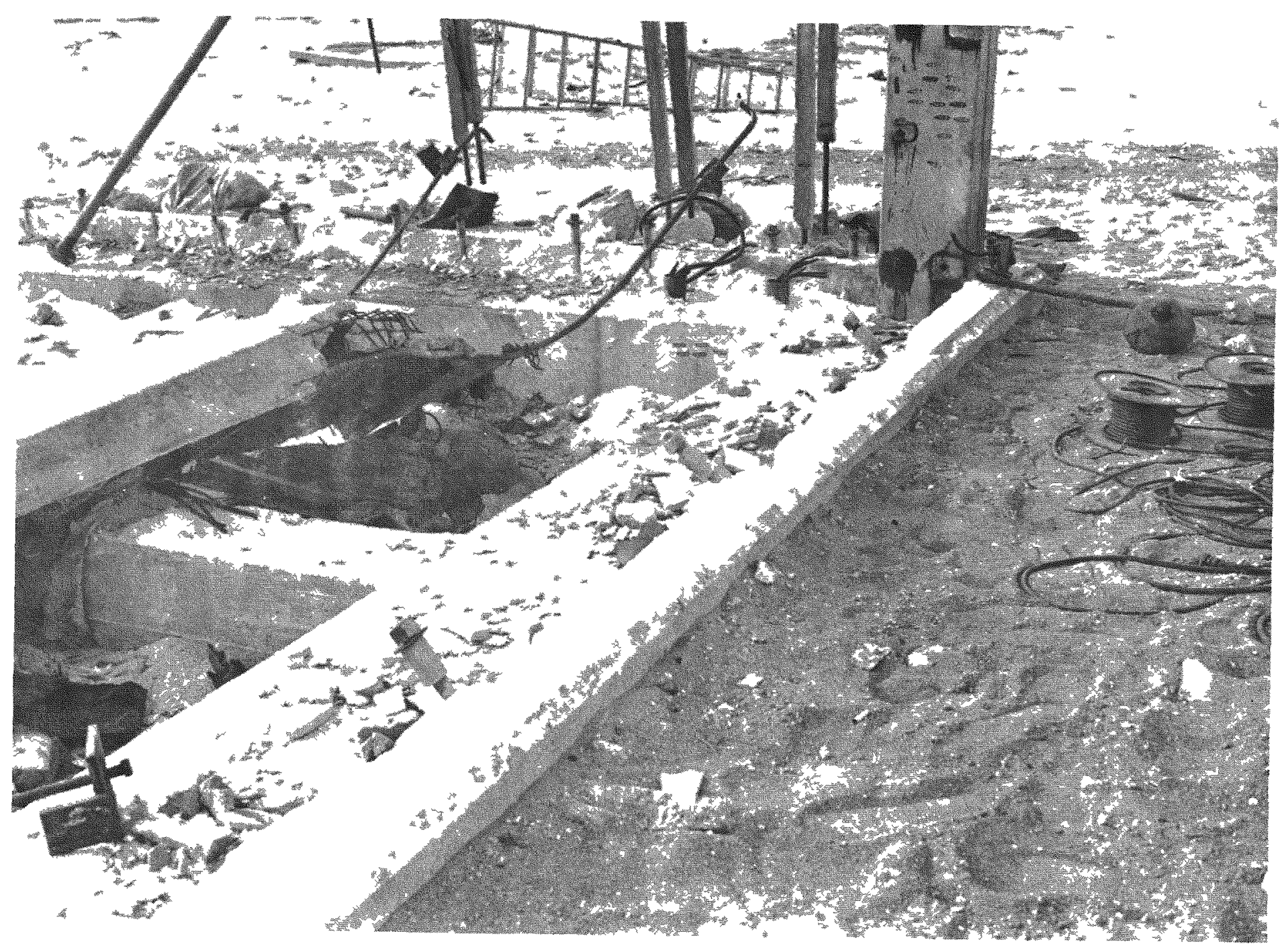

$\prod_{m}^{m}$

Fig. 6.31 Anchor Bolts Bent Inward Along Front of Structure 3.2.2a 


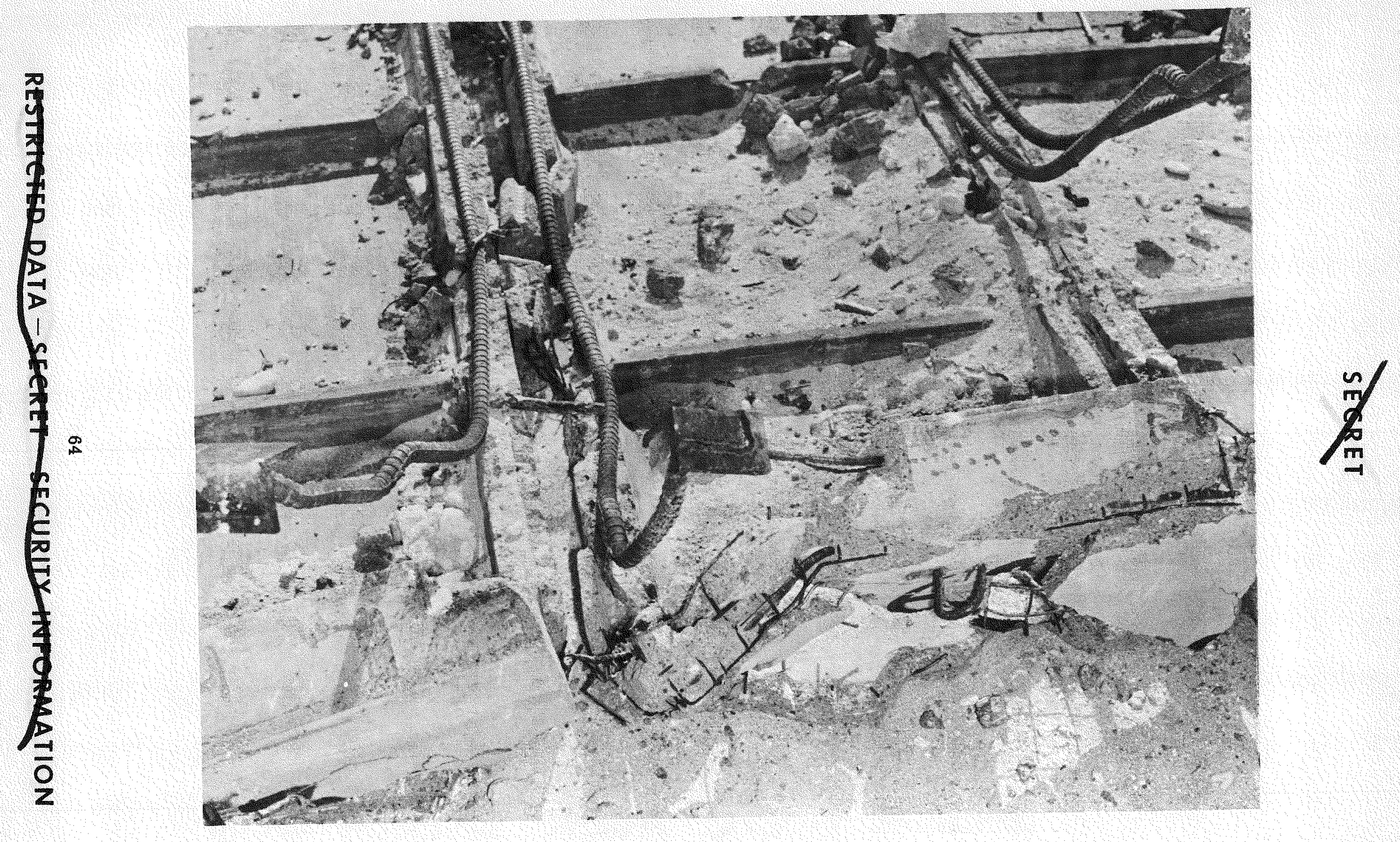

Fig. 6.32 Weld Failure Bêtween Roof,and Wall Panel, Structure $3.2 .2 \mathrm{a}$

U

On

13 


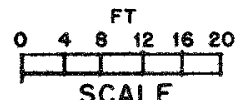

LEFT END-WALL PANELS
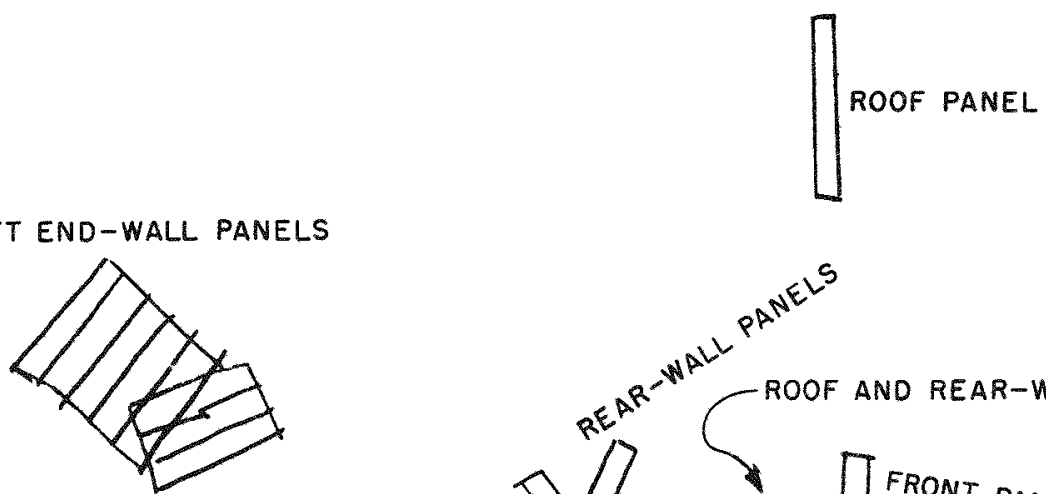

RIGHT END-WALL PANELS

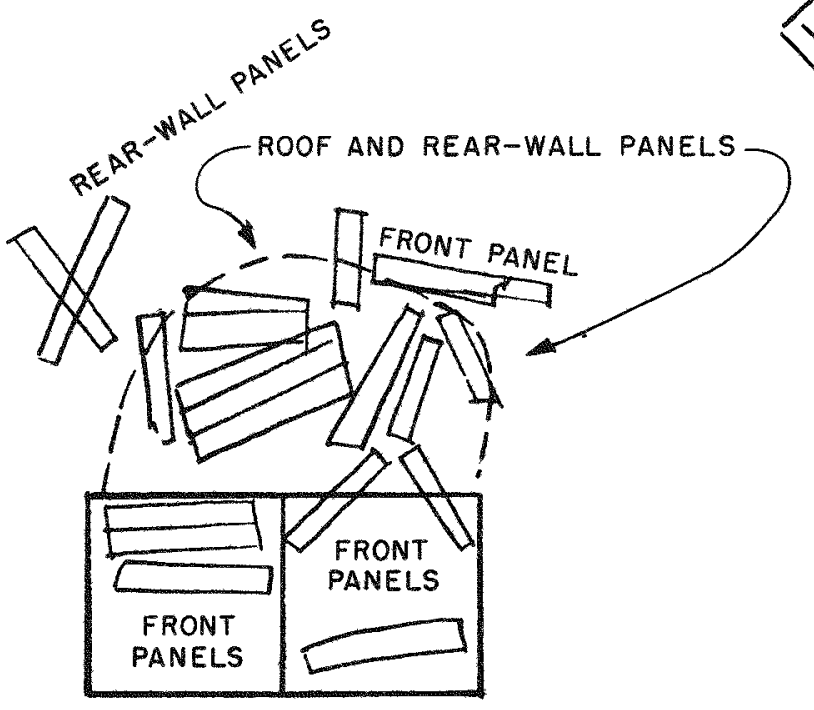

$\prod_{\pi}^{n}$

Fig. 6.33 Final Location of Panels of Structure 3.2.2a 


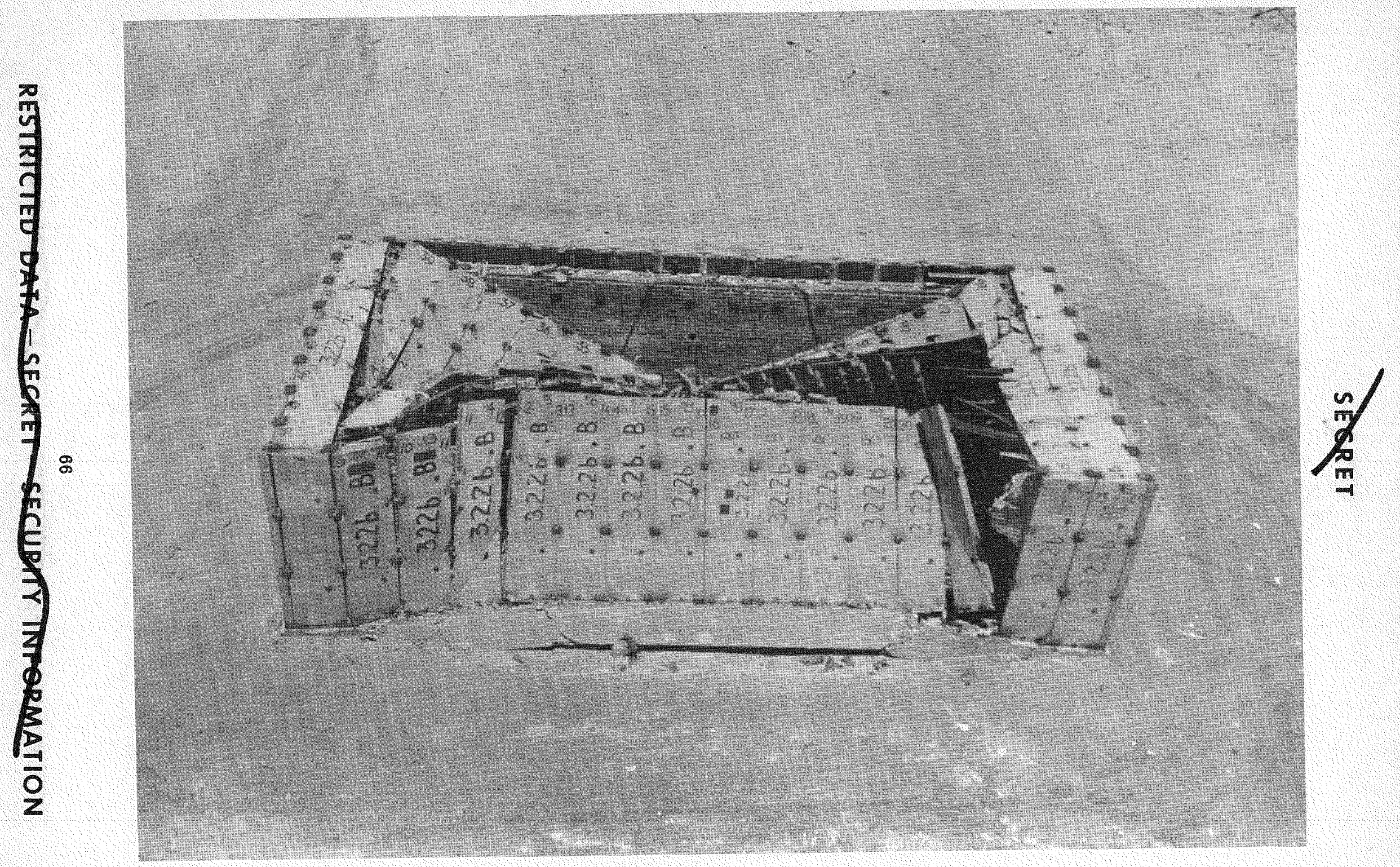

Fig. 6.34 Postshot Aerial View of Structure $3.2 .2 \mathrm{~b}$

4
1
0 


\section{8}
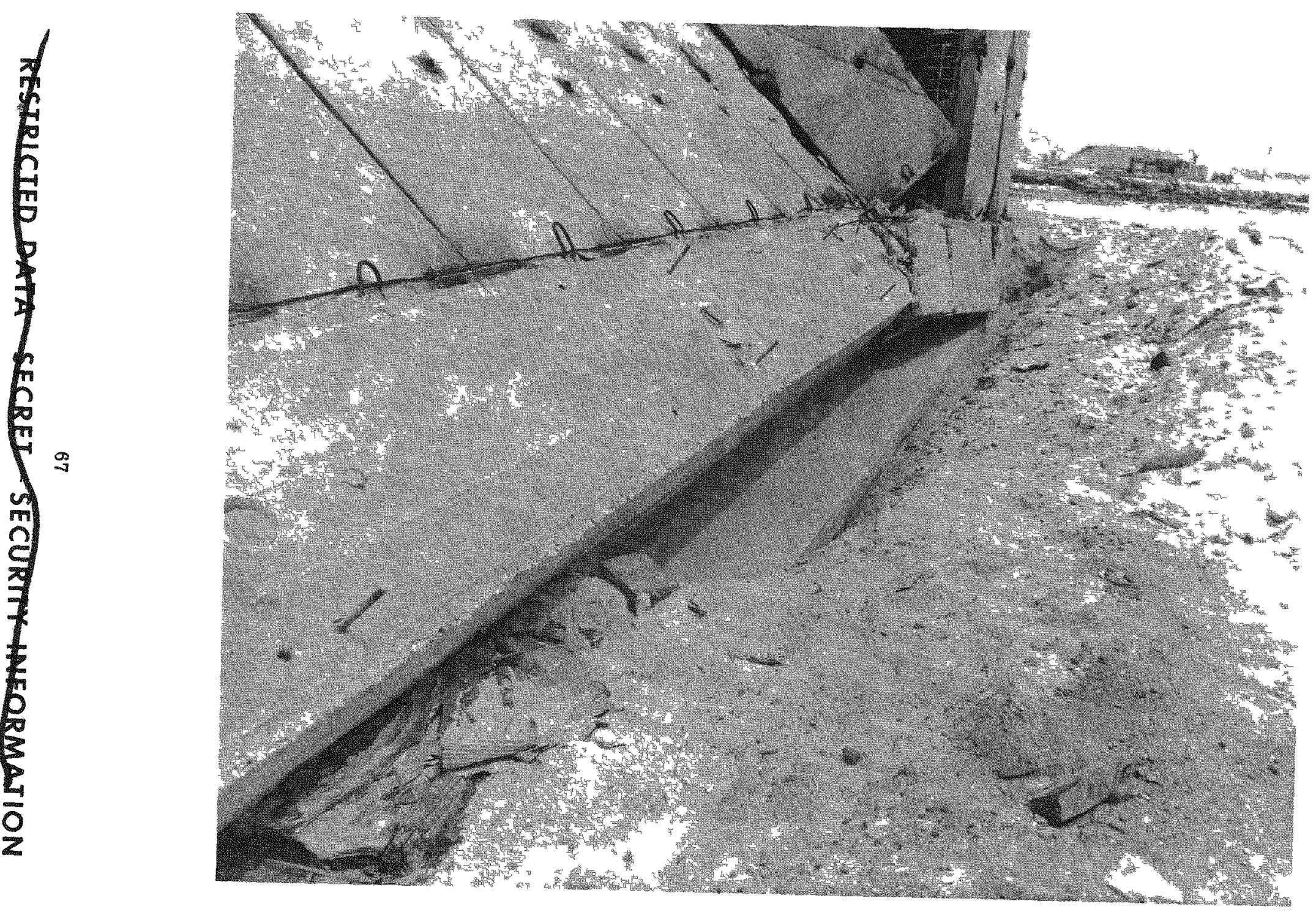

Fig. 6.35 Panel Footing in Uplifted Position, Structure 3.2.2b 


\section{SERET}

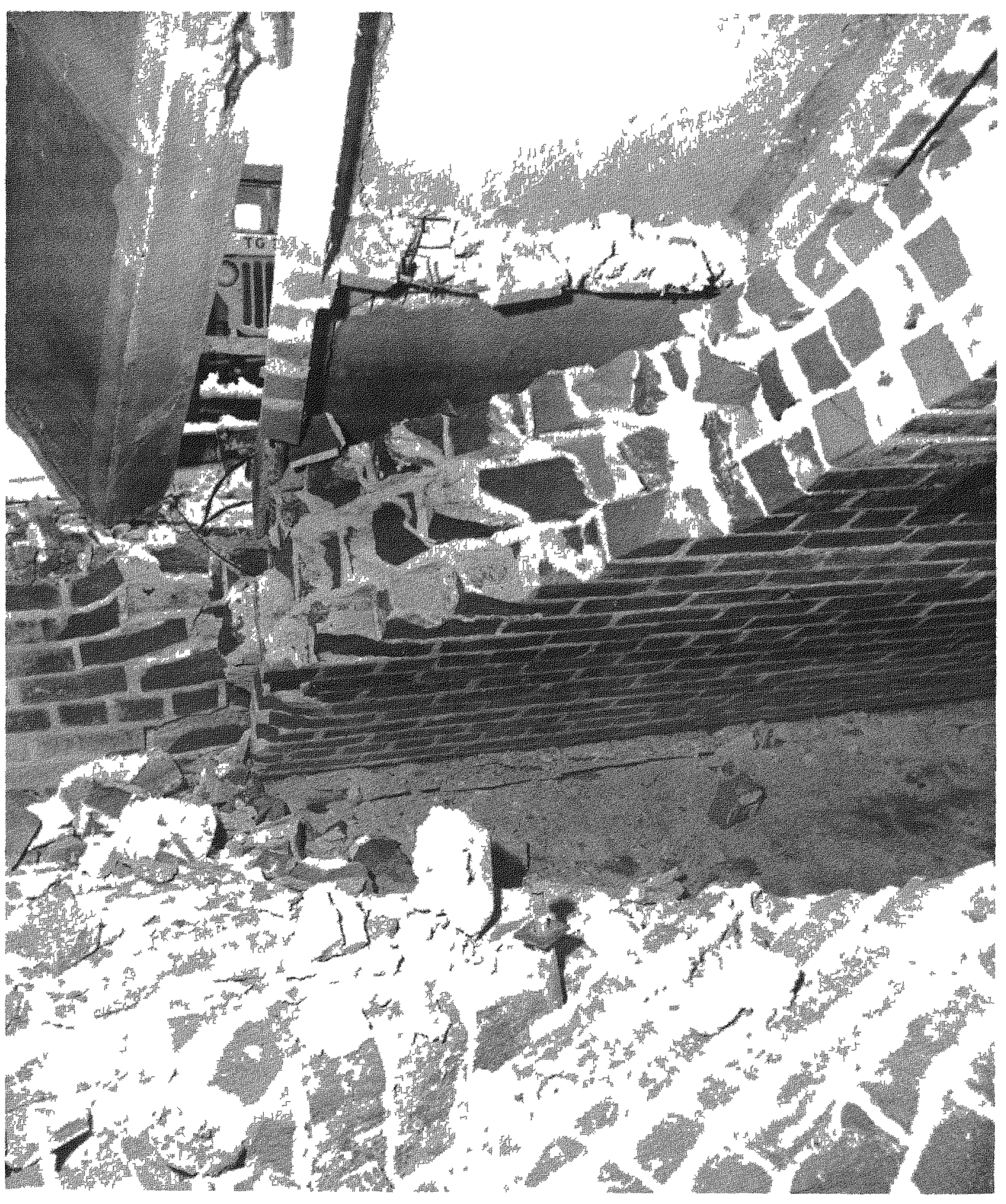

Fig. 6.36 Typıcal Masonry Fallures Through Brıck, Structure 3.2.2b 


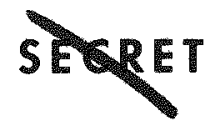

5. The roof collapsed because of excessive moment. The front wall rotated simultaneously until supported by fractured roof joists. The front wall opened slightly near corners.

6. The rear wall lost equilibrium of forces when the roof could not transfer front-wall load to it and suffered inward deformation. The blast wave passed on before serious damage devel oped.

7. After the front wall opened, the blast wave had some opportunity to enter the structure and load the end walls from the interior. The end walls bulged out at the top a maximum of $2 \mathrm{in}$. This completed the response.

Except within one or two panels of the end walls, the $\mathbf{S}$ force, or horizontal restraining force necessary to develop the upper portion of the load-deflection curve used in the design of the roof panels, was absent. Hence the roof panels were not able to develop their design strength. That the end walls did not develop as shear walls to the degree anticipated is indicated by the small amount of damage they received.

(d) Methods of Failure. The complexity of the support for the roof panels clouds the explanation for their sharp failure at the center span with very little accompanying deformation throughout the rest of the panel (Fig. 6.37). Apparently, a column failure occurred at the center of the span because of the axial loading. Further studies of the behavior of concrete panels under dynamic loading will be required.

Aside from the roof failure the connections are all that remain to be examined. As the roof deflected downward, the ends of the panels rotated inward and upward until the end connection failed. Typical $45^{\circ}$ weld failures occurred where the plates on the ends of the roof panels sheared off from the angles atop the wall panels (Fig. 6.38). There were no weld failures on the connections between panels. Instead, at the points where panels separated, the rib steel sheared or was pulled out of the concrete. There were several instances where the bolt attaching the panel to the masonry pulled through the panel when the front wall rotated. Larger exterior washers would have prevented this, but they would not be required if the wall remained near the vertical.

Rotation of front-wall footing was caused by the large moment developed at the foot of the front wall when it started to rotate inward. Some footing restraint could be provided by anchoring the structure footing to the panel footing.

\subsubsection{Structure 3.2.3a (Matchbox)}

(a) General Damage. Structure 3.2.3a suffered complete collapse. The front wall was shattered; the end walls were hurled outward as units and separated from the foundation by about $15 \mathrm{ft}$; the roof was torn off and hurled about 100 ft to the rear of the structure; and the rear wall was knocked down, its base remaining partly attached to the foundation.

(b) Damage to Components. The individual panels of the front wall were shattered. Cells collapsed, trusses were bent and distorted, and most of the panels were torn away from the foundation. The end-wall panels suffered little individual damage, and in most cases the joints between panels remained intact, even though the entire wall was displaced about $15 \mathrm{ft}$ from its original position. The roof panels sustained considerable damage, although they remained as units. Most of the damage to the panels themselves was probably due to the impact of landing on the ground, since damage was largely localized and some sections were practically intact. The rear-wall panels sustained moderate damage; however, considerable bending occurred in the lower quarter of the panels.

(c) Response History. As the shock wave struck the front wall, the panels comprising this wall deflected to a considerable extent, with a maximum dishing at the center of the wall of the order of $1 \mathrm{ft}$. The portion of the applied force that was transmitted to the roof by the front-wall panels was apparently transferred to the rear wall and end walls and thence to the foundation. Any deflections of the roof, rear wall, or end walls in transmitting this load were appar ently very small, since no evidence of significant deflections prior to direct loading of these elements was found.

As the front wall continued to deflect under load, it developed the maximum resistance that the connections at the roof could sustain. The front-wall panels then were severed from the roof at its underside and were rotated inward about their bases. The force applied to the front-wall panels during this phase was sufficient to break them loose from the foundation through a cantilever action and then to hurl them an appreciable distance to the rear of the struc- 

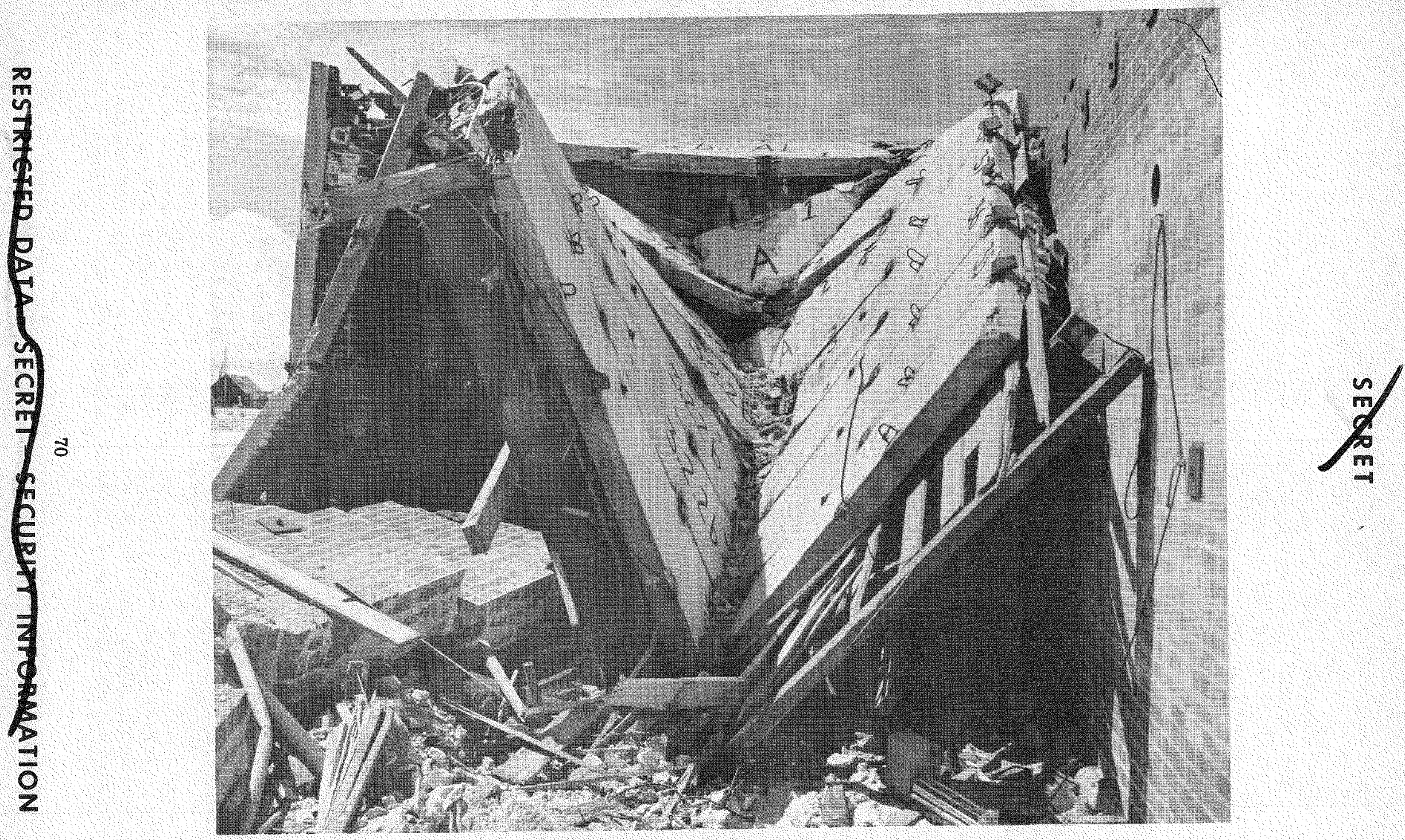

Fig. 6.37 Left Half of Roof Showing Column Type Failure, Structure 3.2.2b

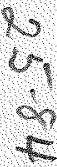

$\infty$
a
क 


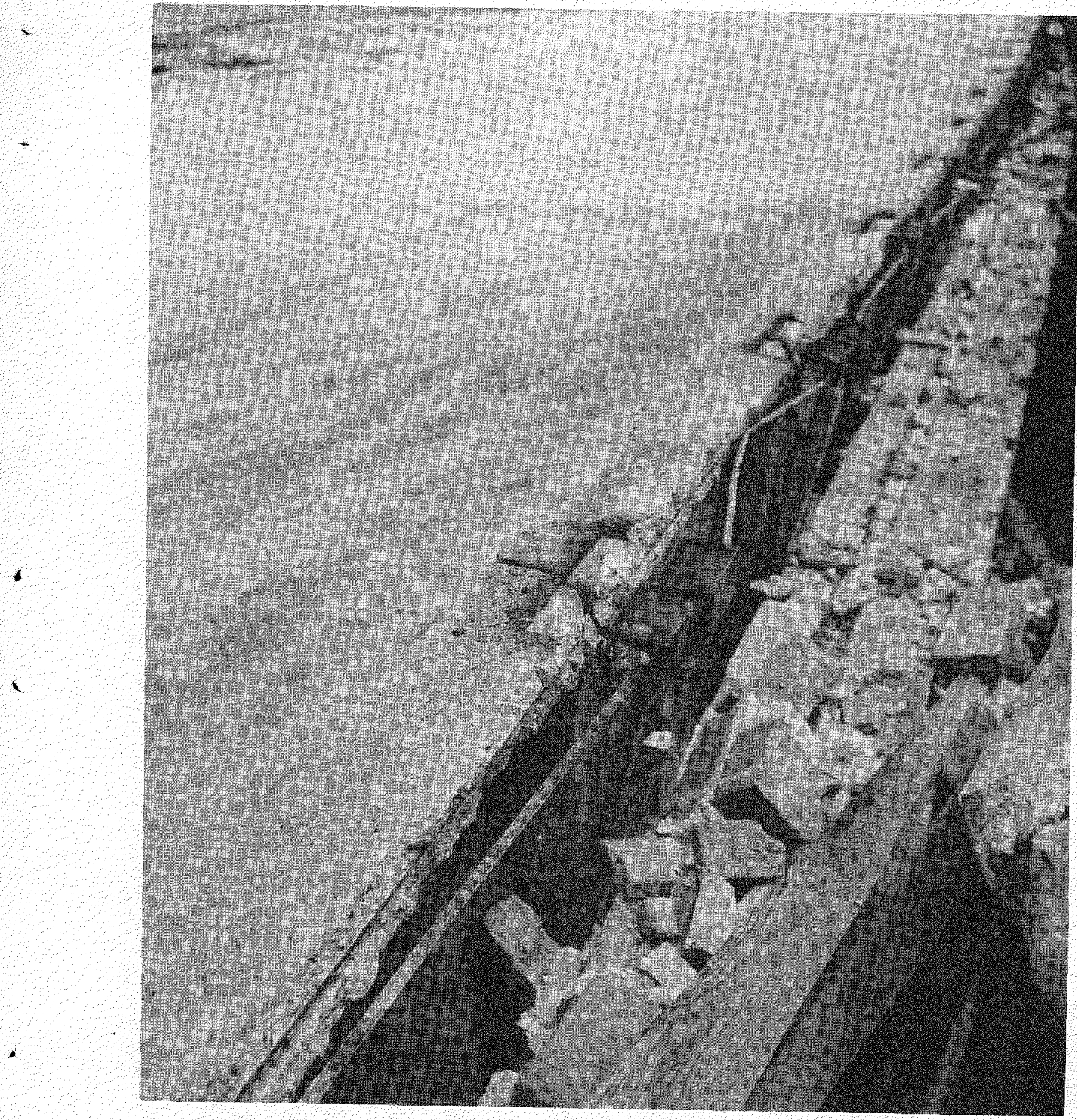

Fig. 6.38 Weld Failures Between Roof and Wall Panels, Structure $3.2 .2 \mathrm{~b}$ 
ture. Typical $S$ curves in the remaining portions of these panels indicate the combined action of initial bending between two supports (roof and foundation) and then reverse bending about the base. The front wall remained in place over a long enough period of time to receive a severe sandblasting of the exterior face, whereas there was no sandblast effect, nor any other damage, on the interior face of the rear wall, which, of course, became exposed when the front wall collapsed.

The collapse of the front wall allowed the pressure wave to enter the structure and create a condition of internal loading on the end walls, roof, and rear wall, resembling the effect of a piston compressing the fluid inside a cylinder. The resulting effect was a ballooning of the structure which developed the maximum resistance of the connections between the end walls and the roof and between the roof panels themselves.

When the load exceeded the maximum resistance of these connections, a literal explosion of the structure occurred. The roof split along its center line normal to the shock front, and at practically the same instant the end walls separated from the roof. The two sections of the roof rotated upward about the top of the rear wall, and the end walls rotated outward about their bases. The cantilever action of the roof about the top of the rear wall caused the connections to rupture, and the force then acting on the exposed underside of the roof was sufficient to hurl each of the two major sections about $100 \mathrm{ft}$ to the rear of the structure. The roof sections showed no evidence of panel deflections of sufficient size to cause permanent deformation during this dislodging action. The connections of the end walls to the foundation were also separated, allowing these units to be displaced outward from the foundation, the left wall moving out about $15 \mathrm{ft}$ and the right wall about $5 \mathrm{ft}$. The end walls had some permanent bowing in an outward direction, indicating that they underwent appreciable deflections before the roof severed from the rear wall. The pressure acting on the inside face of the rear wall caused it to bend outward about its base until it finally collapsed. The bases of these rear-wall panels did not separate from the foundation.

(d) Methods of Failure (Structures 3.2.3a and b). The basic cause of the collapse of Structures 3.2.3 $\mathrm{a}$ and $\mathrm{b}$ was the failure of the front wall.
This wall failed at the connection to the roof by pulling loose in tension as the wall deflected inward and attempted to shorten the distance between the foundation and the roof. There undoubtedly was a shear component introduced in this failure, because the horizontal force on the front wall attempted to give the entire wall a translational motion toward the rear. In almost every case the weld between the chord bars of the wall trusses and the end plate of these trusses failed. The end plate remained attached to the roof trusses and to the long bar truss $(\mathrm{T}-7)$ that ran along the longitudinal edge of the roof (Fig. 6.45). Note that, where the end plate, or top plate, of the wall truss was severed from the edge truss, the fallure was in tension. The results of the strong tension forces exerted by the front wall on the edge of the roof can be seen in Fig. 6.45 by observing the distortions of the heavy bar of the edge truss.

Once the connections of the front wall to the roof were severed, the front wall acted as a cantilever about its base, and, as the wall rotated inward, the lower ends of the wall trusses failed. Either the outside bar of each truss broke the weld to its anchorage channel or the bar itself failed in tension just above the channel. As soon as this bar was loose, the translational forces acting on the front-wall panels caused the inside bar of these trusses to fail in tension, either through the weld at the base or in the bar itself. None of the grout concrete in the footing recess broke out along the front wall (Fig. 6.46).

The rest of the structure was loaded from the inside. In each structure the roof split precisely down the short center line, right through the center of the middle roof truss. The roof was severed from the end walls along the edge row of cells, this row remaining with the end walls (Fig. 6.47). This condition is due to the short lateral trusses $(T-5)$ connecting the end roof panels to the end walls; the trusses extended through only the edge row of cells that still remained with the end walls (Fig. D.11). When the roof had split down the center line and had also severed from the end walls, the pressure inside the structure forced the roof up and to the rear so that it acted as a cantilever about the top of the rear wall. In Structure 3.2.3a, the roof severed from the top of the rear wall by breaking the welds between the wall-truss-chord bars and the end plate of each of the wall trusses - pre- 
LINE OF ROOF FRACTURE

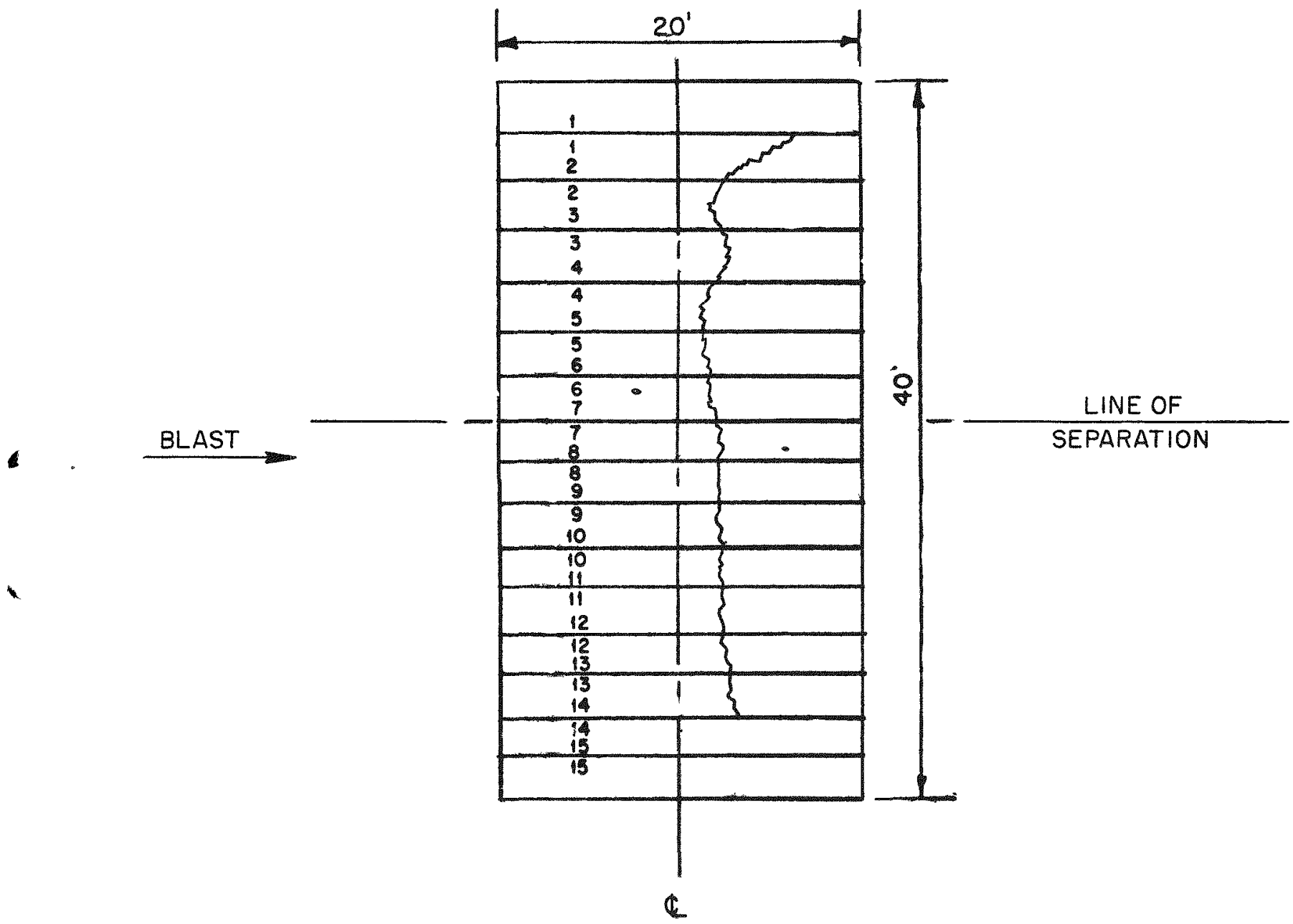

Fig. 6.39 Roof Fracture, Structure 3.2.2b 

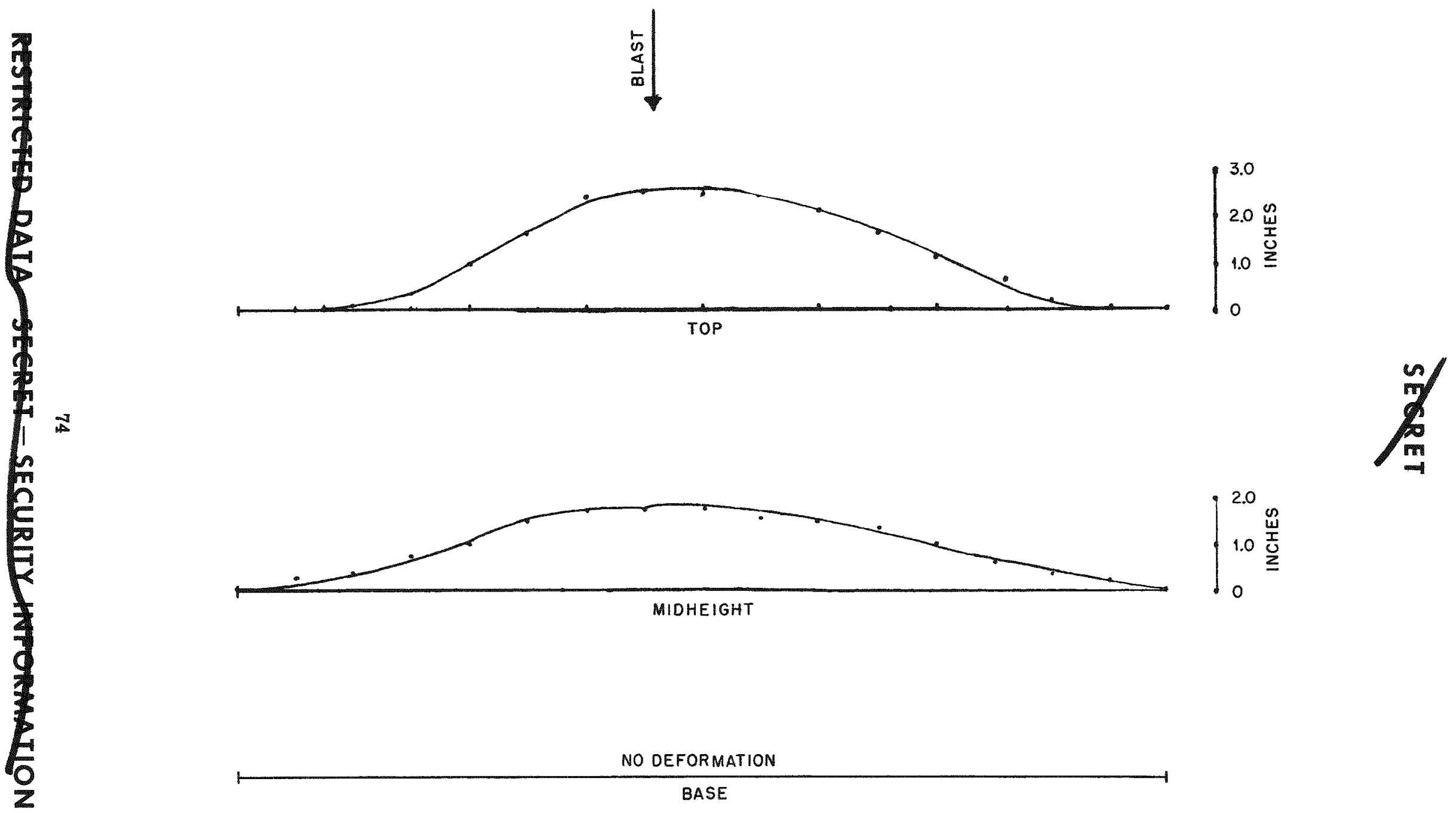

NO DEFORMATION

Fig. 6.40 Horizontal Deformations, Rear Wall of Structure $3.2 .2 \mathrm{~b}$ 


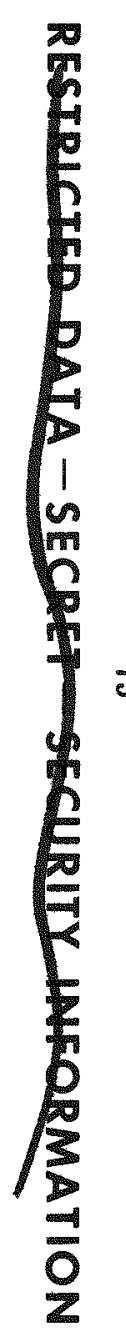

EXTERIOR

RIGHT LEFT

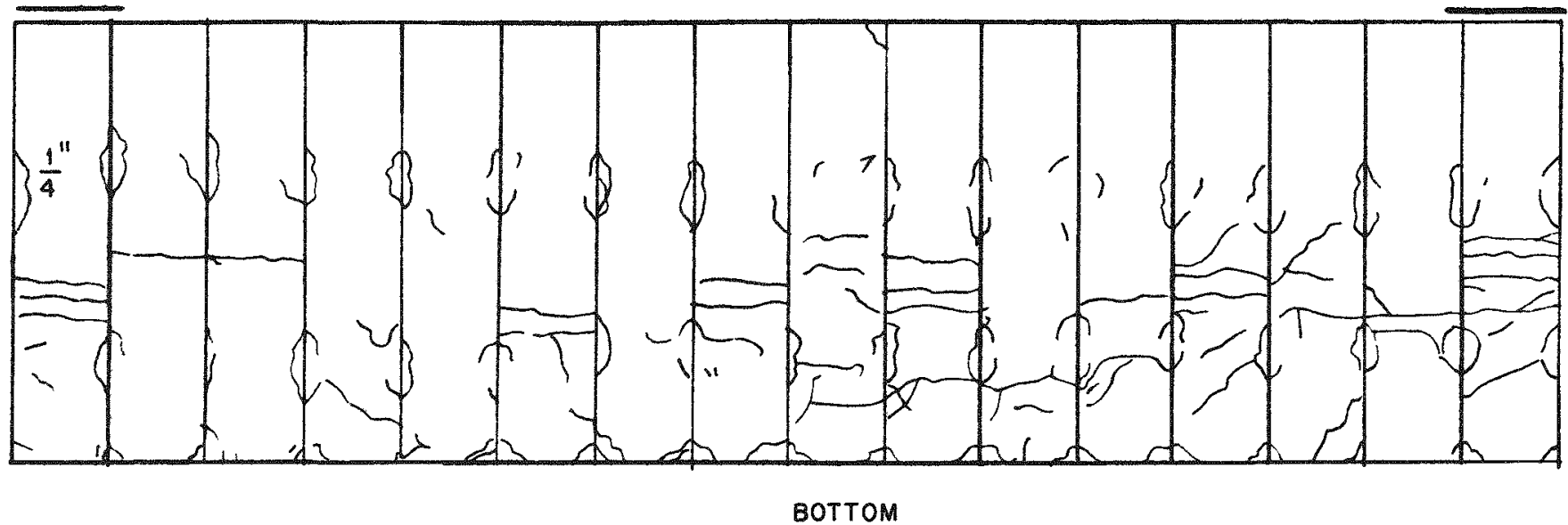

Fig. 6.41 Rear-wall Crack Pattern, Structure 3.2.2b 


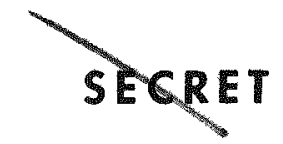

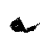

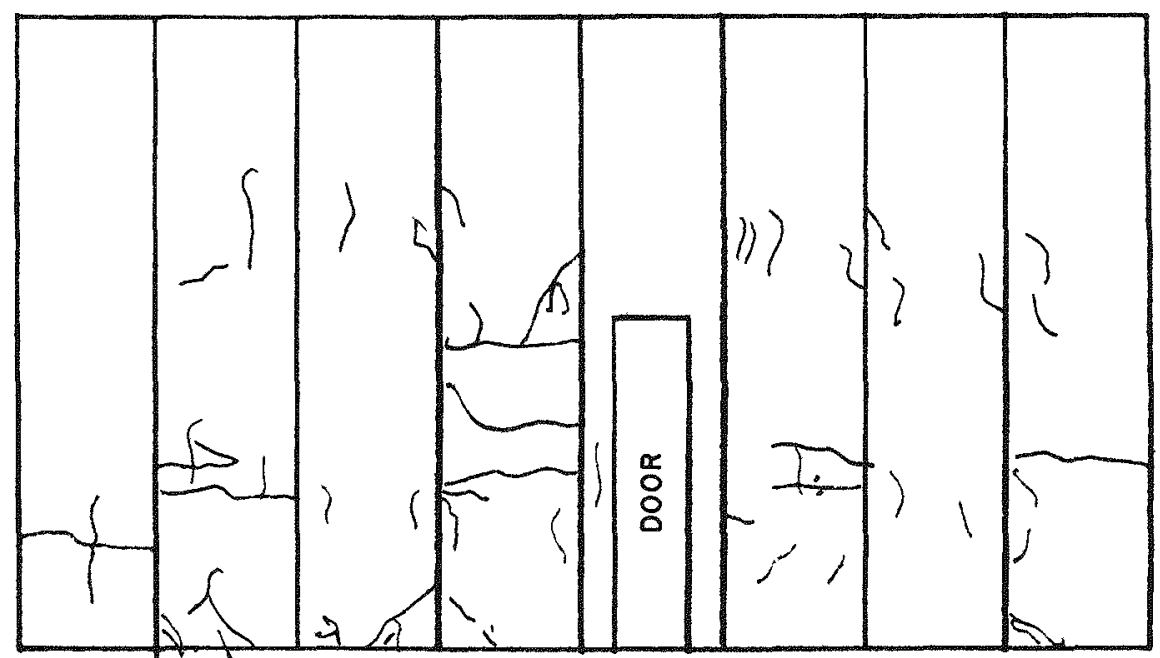

RIGHT-WALL EXTERIOR

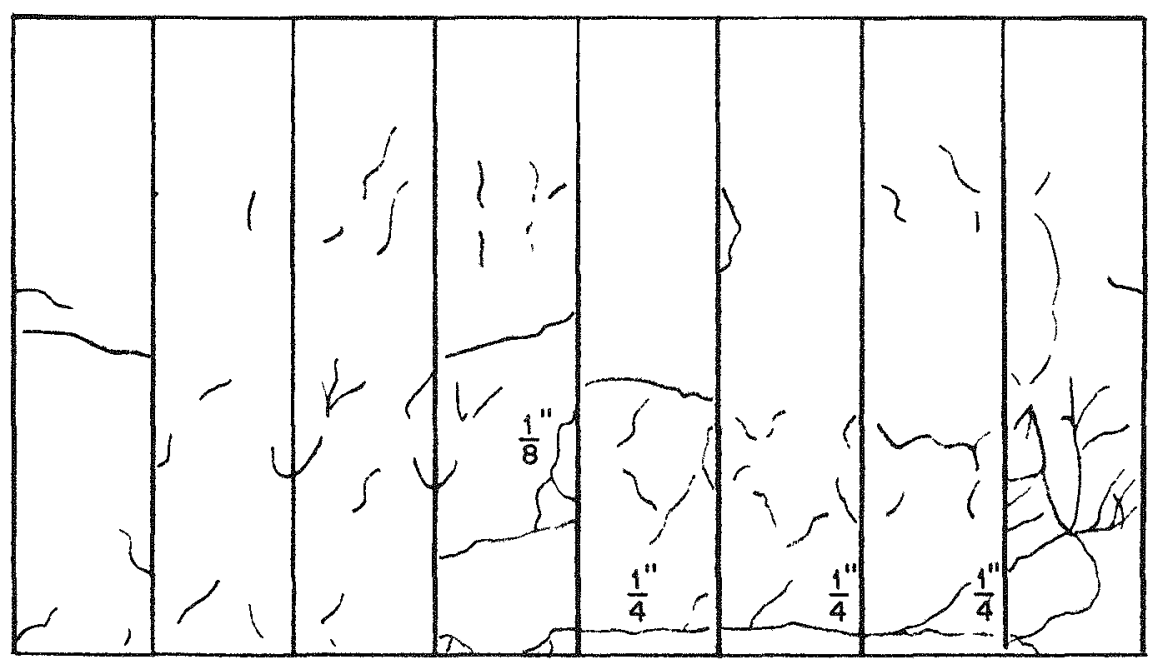

LEFT-WALL EXTERIOR

Fig. 6.42 End-wall Crack Pattern, Structure 3.2.2b. All cracks are hairline except as noted. 

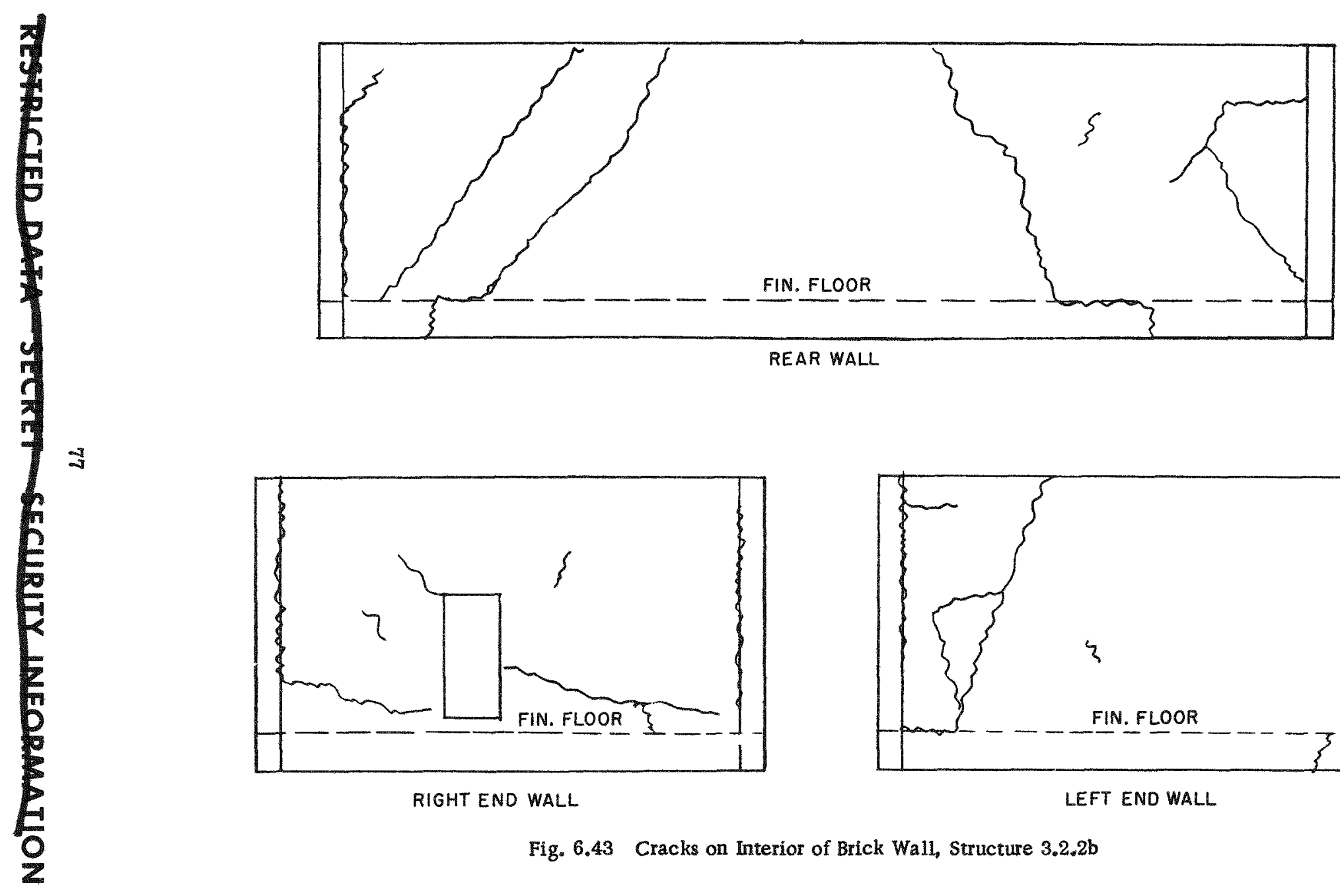

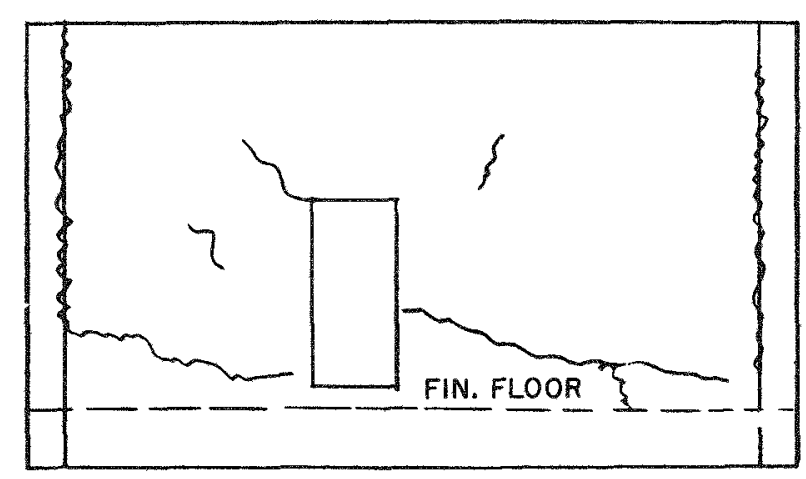

RIGHT END WALL

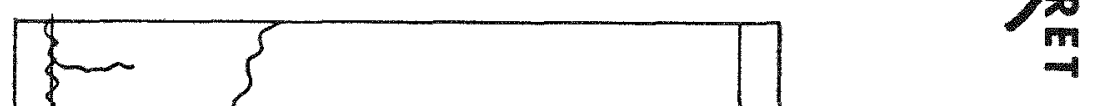

Fig. 6.43 Cracks on Interior of Brick Wall, Structure $3.2 .2 \mathrm{~b}$ 

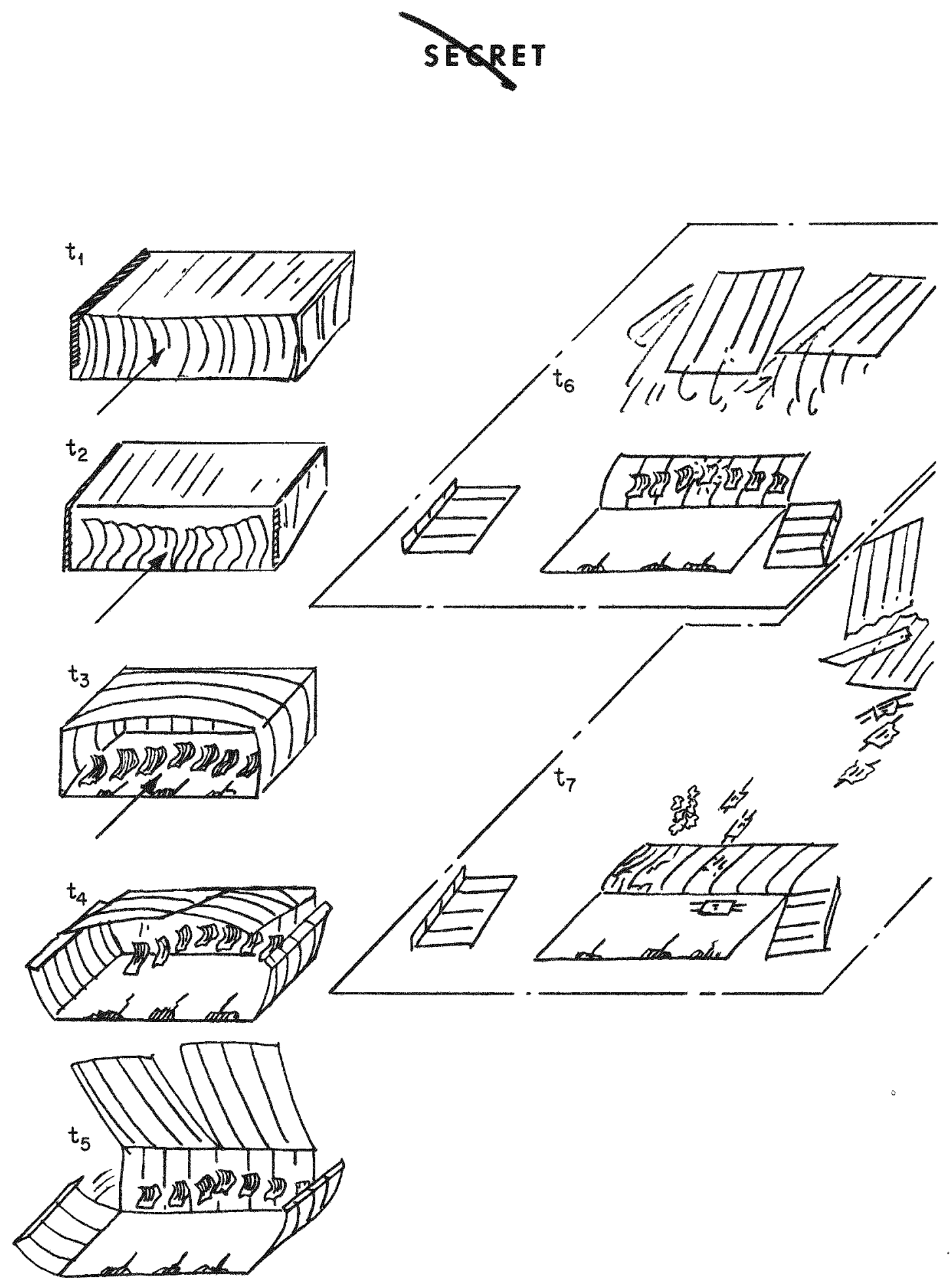

Fig. 6.44 Response History of Structure 3.2.3a 


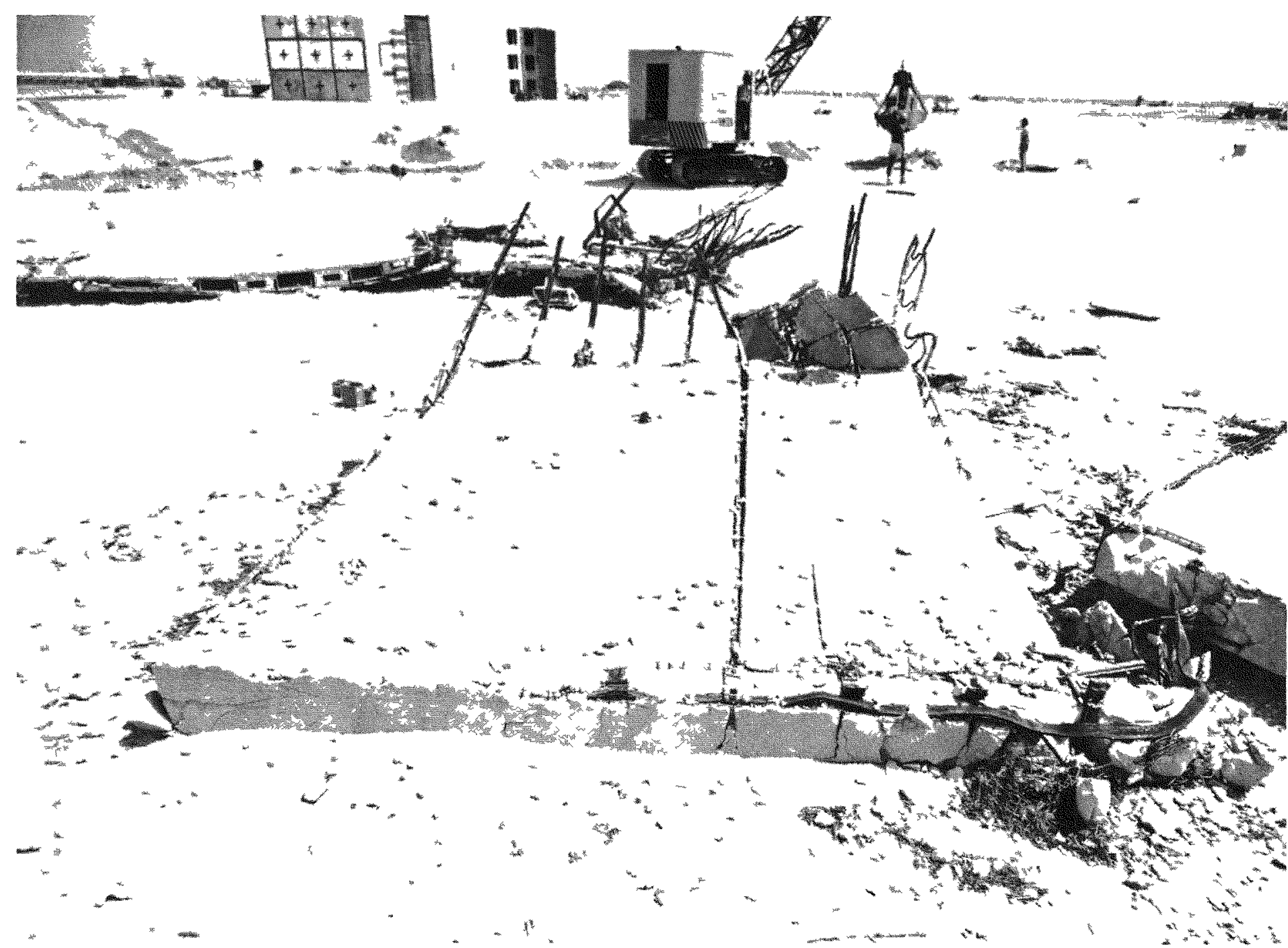




\section{SERRET}

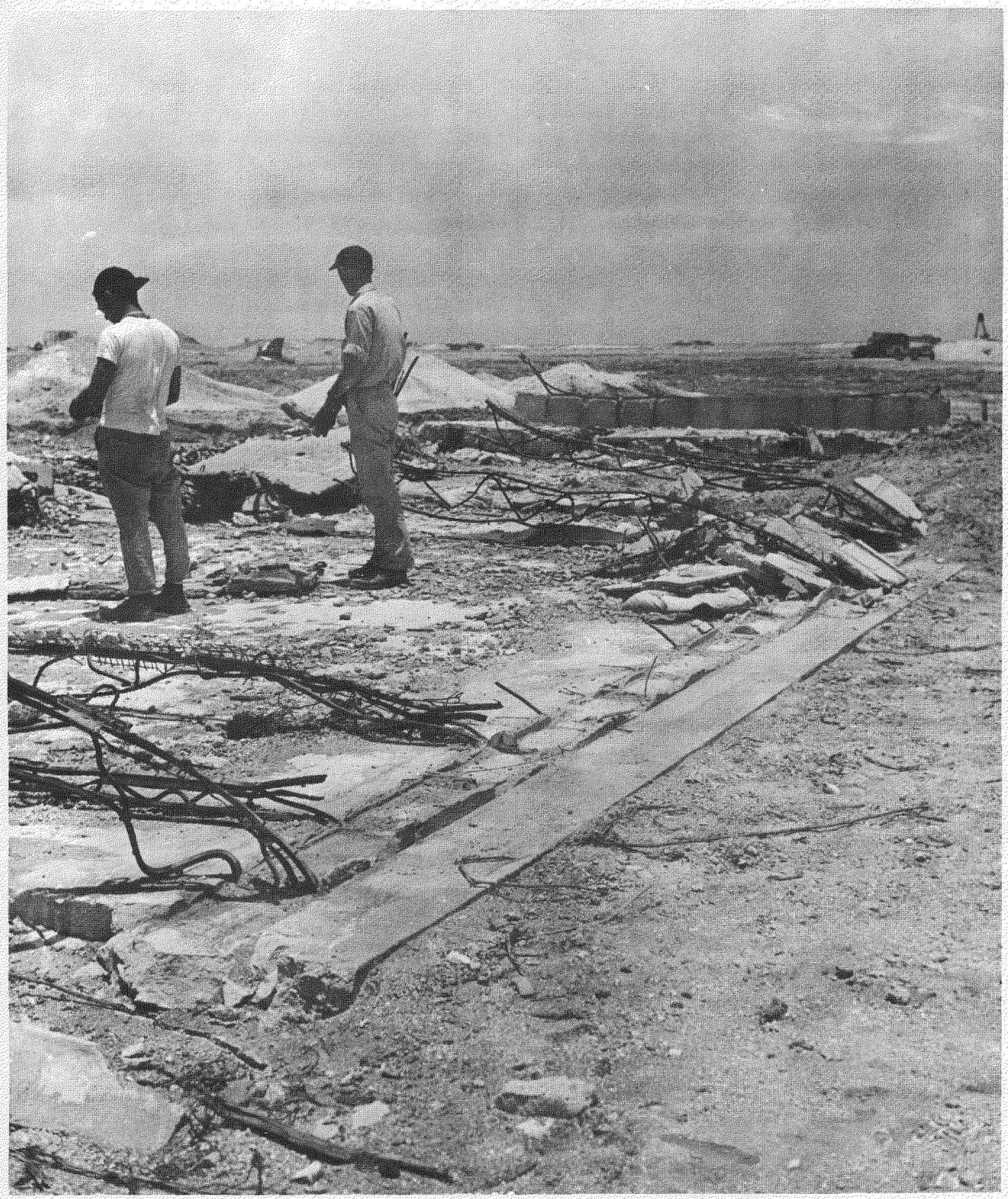

Fig. 6.46 View Along Front Edge of Foundation of Structure 3.2 .32 . Isolated trusses are only remnants of Front Wall. 


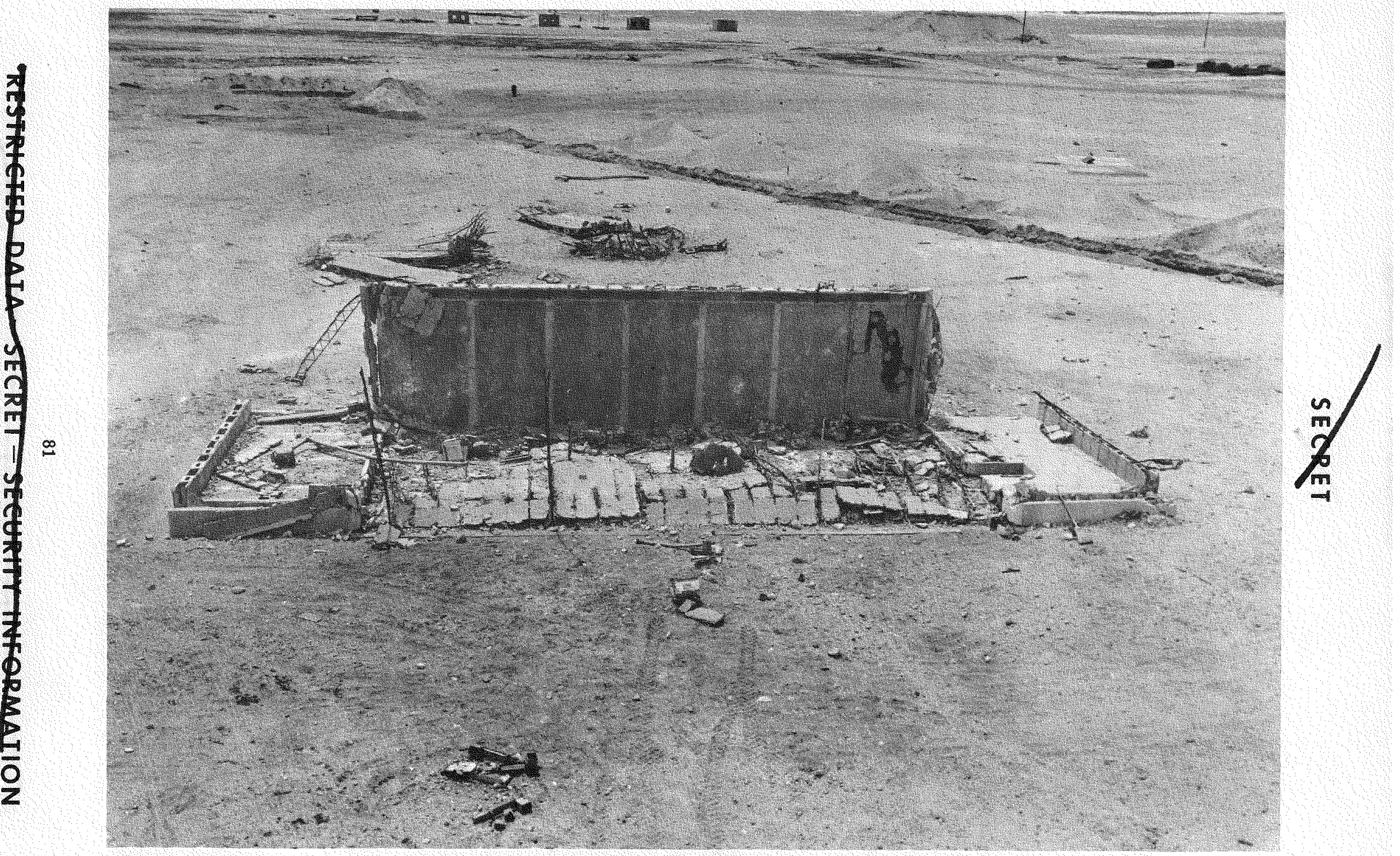

Fig. 6.47 Edge Row of Roof Cells Still Attached to Each End Wall, Structure 3.2.3b 
cisely the type of failure that occurred at the front wall (Fig. 6.48).

In Structure $3.2 .3 \mathrm{~b}$, however, the roof was severed from the top of the rear wall by a failure in the end of the roof truss. This was a weld failure at the point where the chord bars of the roof trusses were welded to the end section of these trusses (Detail A, Fig. D.12). The pouredin-place rear roof edge of Structure $3.2 .3 \mathrm{~b}$ remained intact (Fig. 6.49). A detail view of the weld failure of a roof truss in Structure $3.2 .3 \mathrm{~b}$ is shown in Fig. 6.50. The end walls were rotated outward by the pressure inside the structures and acted as cantilevers about their bases. Failure of the base connections took place in several ways. Many of the trusses pulled out of the anchorage channels by rupturing the welds at these points or by shearing the parent metal of the channel at the weld location (Fig. 6.51). Others remained attached to the channels and pulled the channels up over the heavy nuts on the anchor bolts (Fig. 6.52).

The end-wall panels suffered practically no damage in Structure 3.2.3b (Fig. 6.47) and only moderate damage in Structure 3.2.3a (Fig. 6.51).

The rear walls of both structures were loaded from inside. In Structure 3.2.3a the rear wall was rotated outward until the inside bar of each wall truss severed from the anchorage channel by failing at the weld. When this weld ruptured, the wall toppled over, with consequent crushing and shattering of the lower row of cells of the rear wall (Fig. 6.53). The outside bar of the rear-wall trusses remained attached to the anchorage channel, and all channels remained in place. The rear wall of Structure 3.2.3b remained standing and largely intact, as shown in Fig. 6.47.

\subsubsection{Structure 3.2.3b (Matchbox)}

(a) General Damage. Structure $3.2 .3 \mathrm{~b}$, which was identical in construction with Structure 3.2.3a, suffered complete collapse, although the degree of destruction was much less severe than that sustained by Structure 3.2.3a. The front wall was knocked down toward the center of the structure, but its base remained attached to the foundation. The end walls were forced outward to a horizontal position, and the bases were severed from the foundation, although no bodily lateral displacement of these walls occurred. The roof was torn off and hurled about
$75 \mathrm{ft}$ to the rear of the structure. The rear wall remained standing, basically intact; only a moderate wall deformation resulted.

(b) Damage to Components. The individual panels of the front wall were severely damaged. Some cells collapsed; others were dislodged from the panels and hurled to the rear. Only a few cells remained intact. Trusses bent considerably because of the initial heavy deflection of the front wall prior to its failure and the final cantilever action as the wall collapsed inward. The end-wall panels, with one minor exception, remained completely intact. The roof panels suffered considerable localized damage, probably due to the impact of landing, but otherwise they remained largely undamaged. The rearwall panels were practically undamaged.

(c) Response History. As the shock wave struck the front wall, the panels comprising this wall deflected to an appreciable extent, possibly in the neighborhood of 6 in. at the center. The portion of the load that was transferred to the roof by the front-wall panels was transmitted to the rear wall and the end walls and thence to the foundation. Any deflections of the roof, rear wall, or end walls in transmitting this load were apparently very small, since no evidence of significant deflections prior to direct loading of these elements was found.

As the front wall continued to deflect under load, it developed the maximum resistance that the connections at the roof could sustain. The front-wall panels were then severed from the roof at its underside, rotated inward about their bases, and continued bending until they reached the floor slab. The base connection remained intact in most of these front -wall panels, but the steel trusses sustained a $90^{\circ}$ bend in the lower foot or two, and many of the cells collapsed because of the bending action.

The collapse of the front wall allowed the pressure wave to enter the structure and create a condition of internal loading on the end walls, roof, and rear wall, resembling the effect of a piston compressing the fluid inside a cylinder. The resulting effect was a ballooning of the structure which developed the maximum resistance of the connections between the end walls and the roof and between the roof panels themselves.

When the load exceeded the maximum resistance of these connections, a literal explosion of 


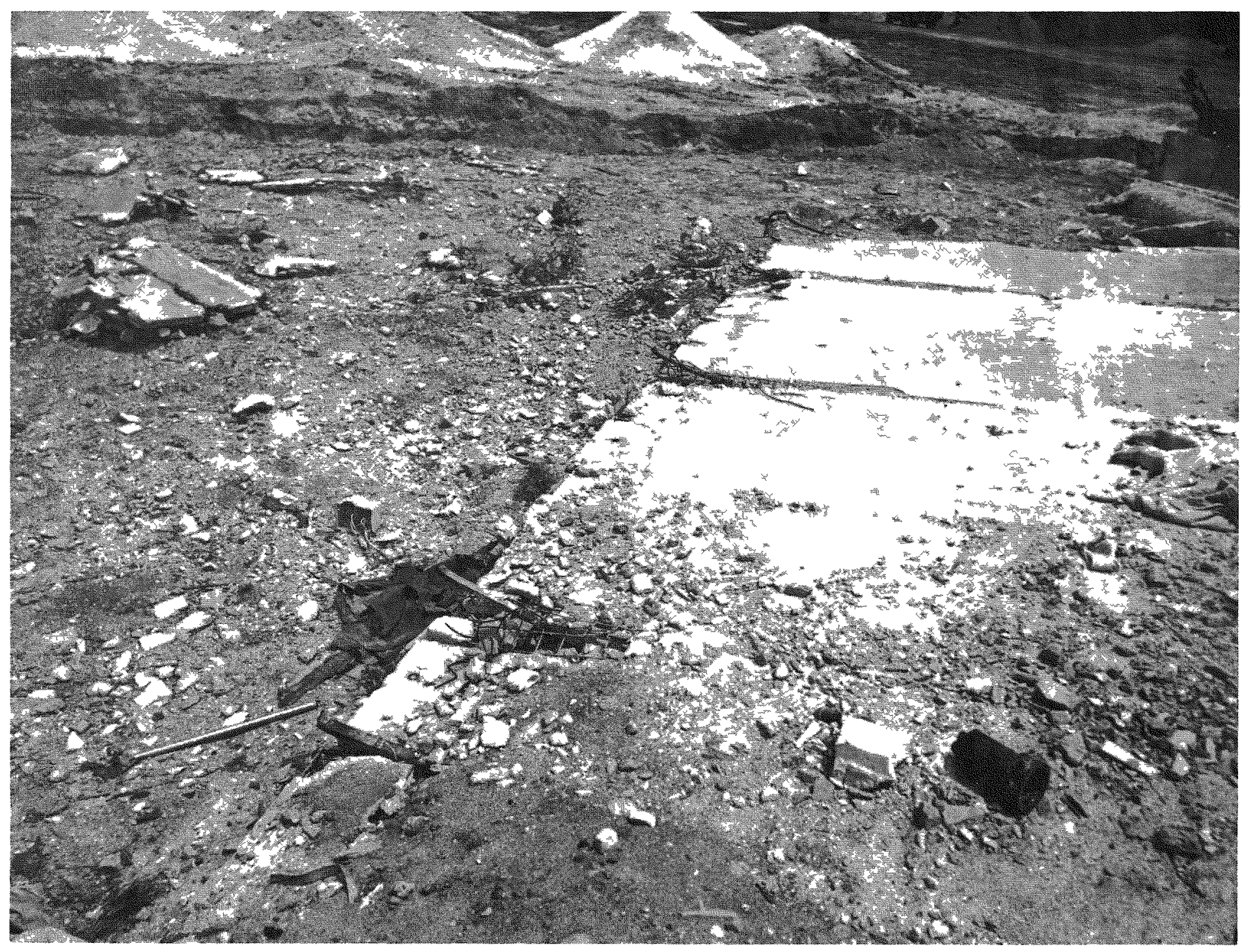

Fig 6.48 Top Edge of Rear Wall of Structure 3.2.3a. Falure of the weld at the top ends of the chord bars of the wall truss can be clearly seen. 

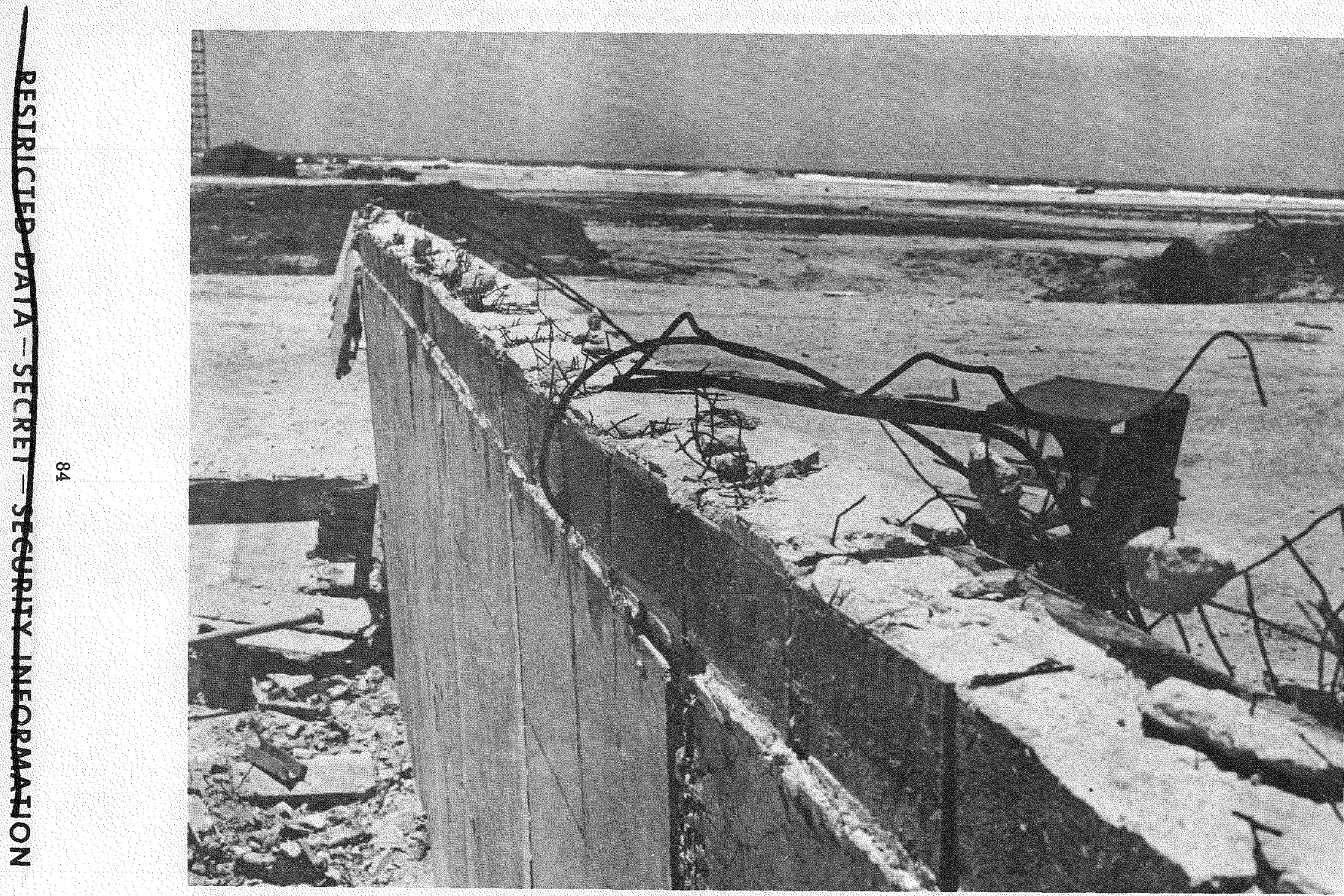

$\sum_{n}^{n}$

Fig. 6.49 Roof Edge Along Top of Rear Wall of Structure 3.2.3b Still Intact. Two roof trusses are still partially attached. 

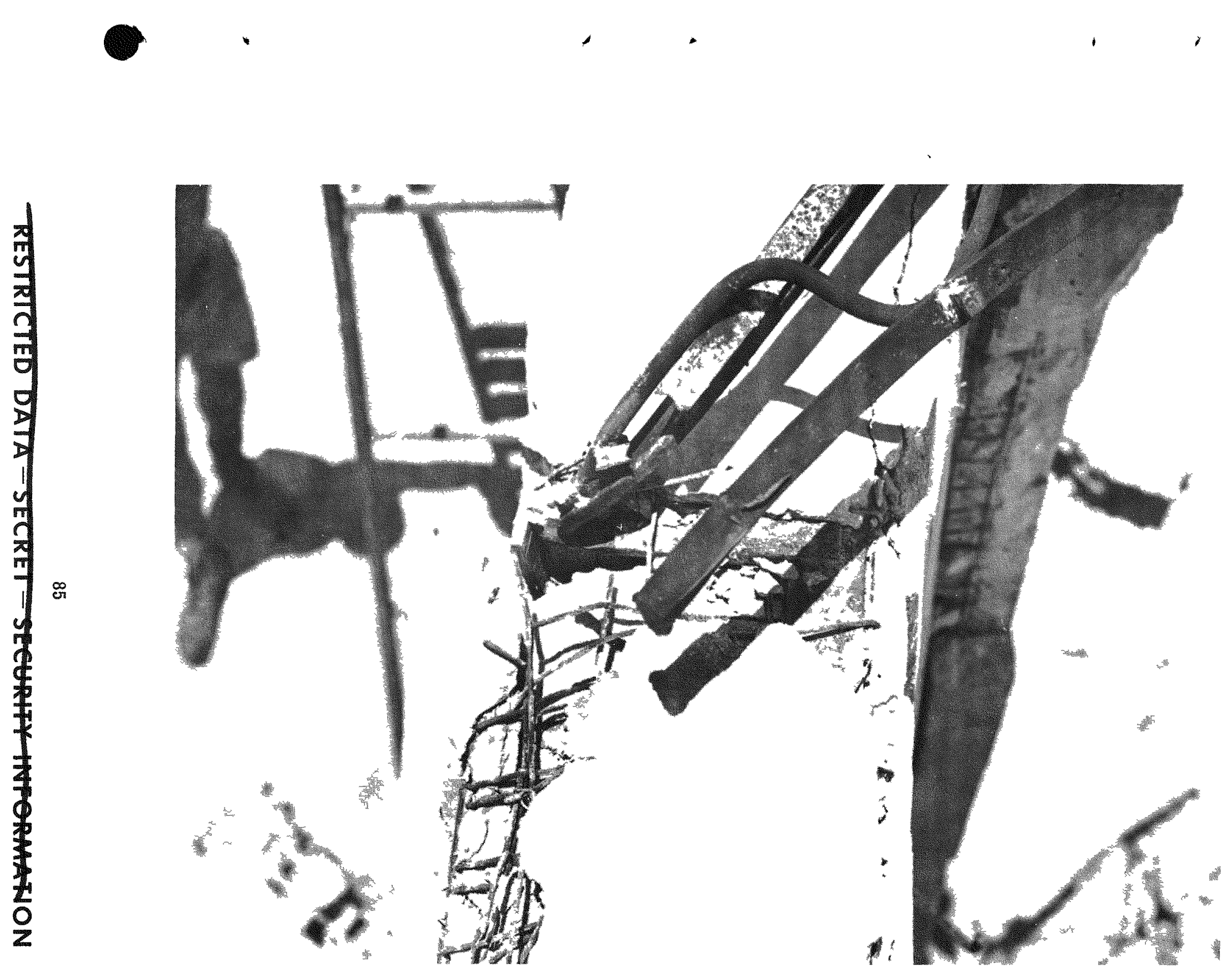

$m_{m}^{m}$ 


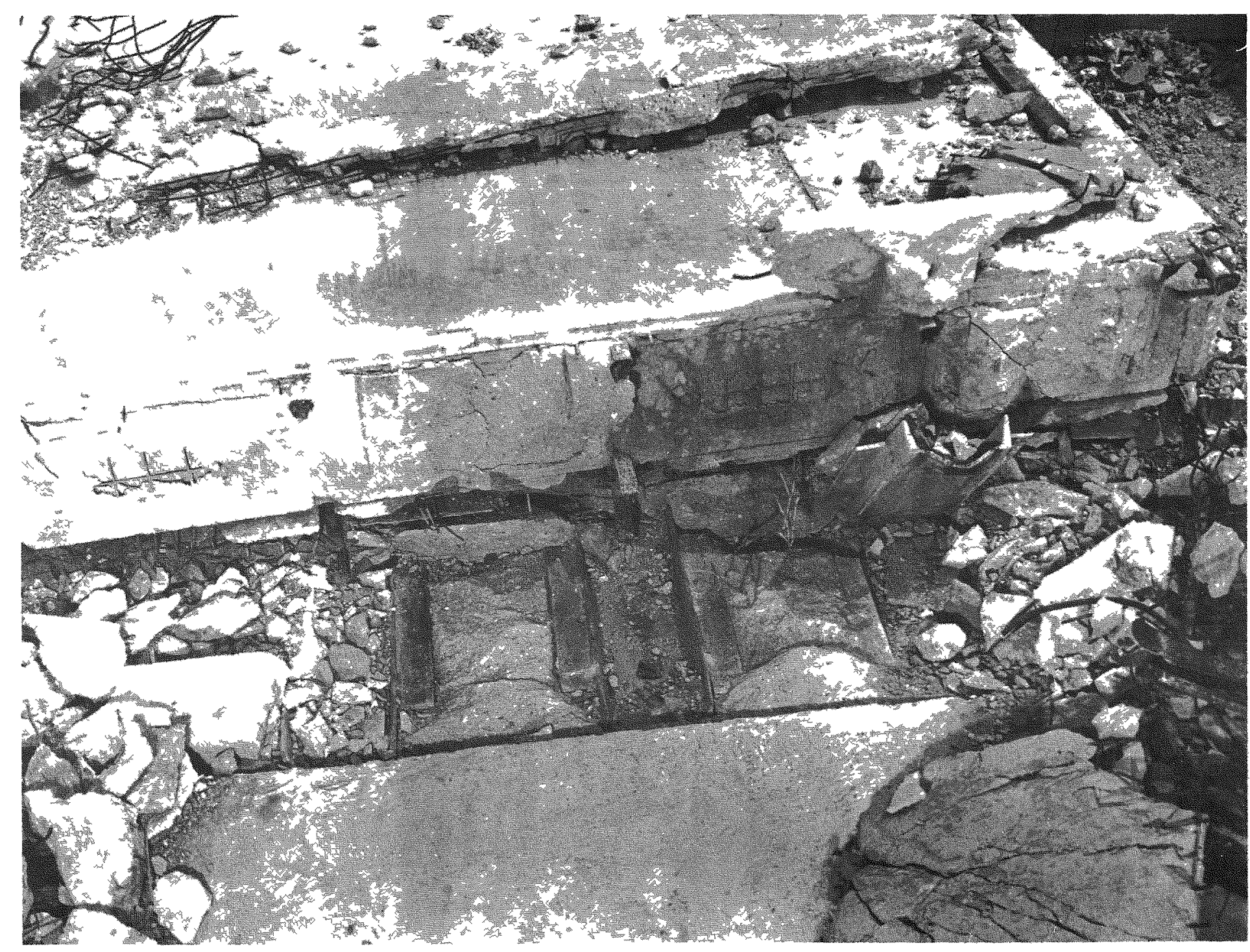

Fig. 6.51 Right End Wall of Structure 3.2.3a, Showing Falure at Welds Between Truss-chord Bars and Channel Second truss from the right fauled in the weld; the rest sheared out the parent metal of the channel at the weld location. 

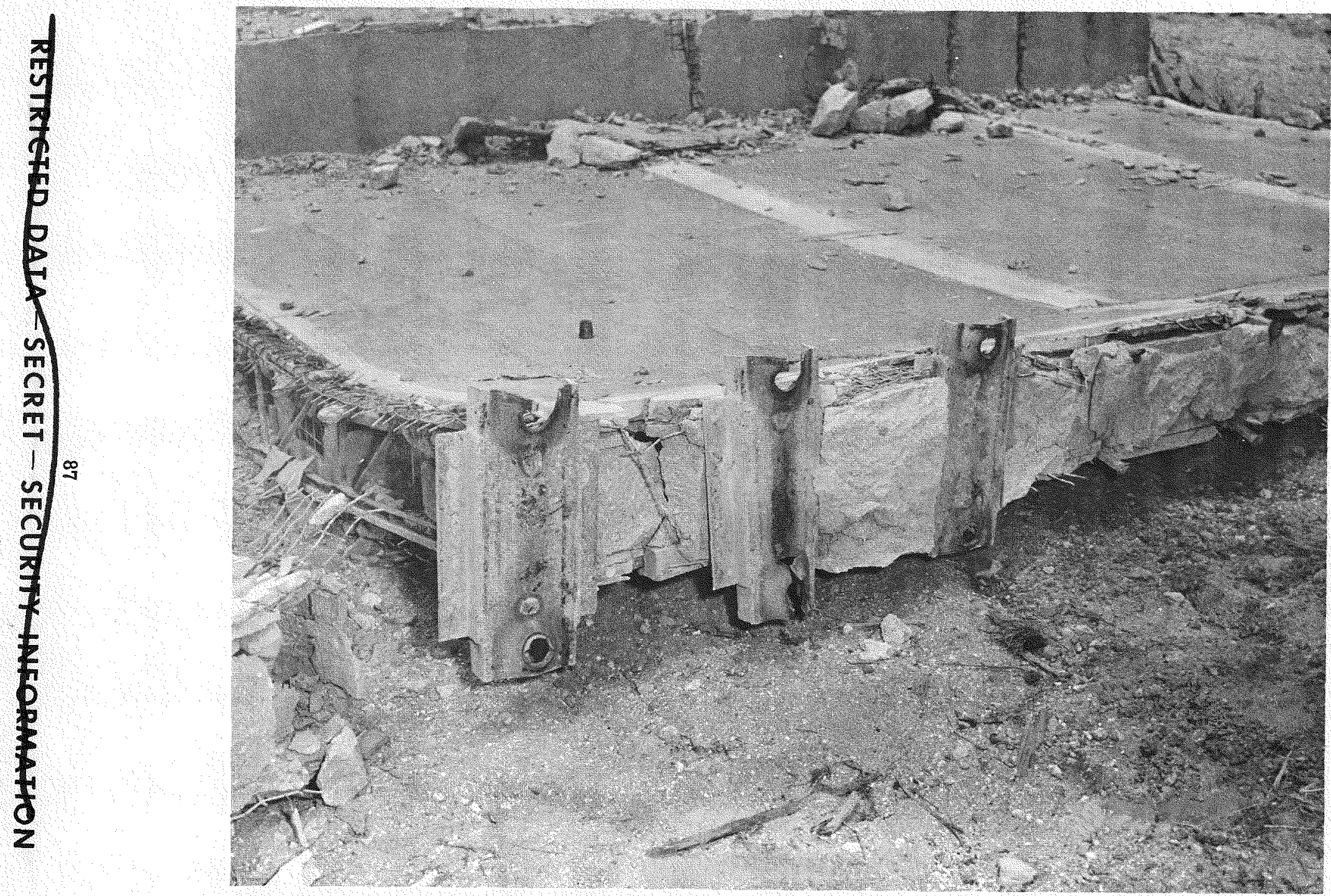

$\frac{43}{8}$

Fig. 6.52 Left End Wall of Structure 3.2.3b, Showing How Channels Pulled Up over Anchor Bolts 


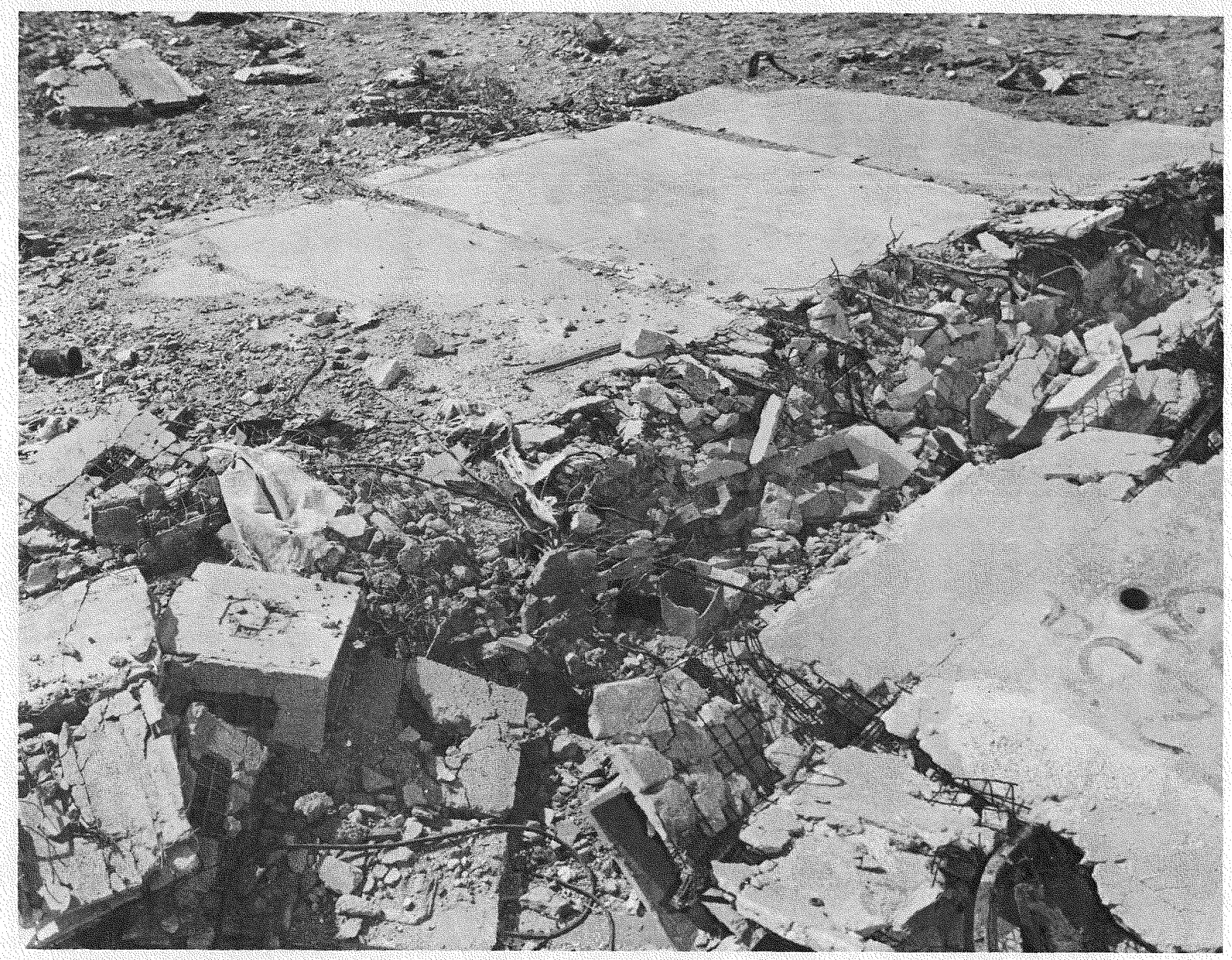

Fig. 6.53 Base of Rear Wall of Structure 3.2.3a Still Attached to Foundation. Lower row of cells collapsed. Weld failures of inside truss bars can be seen in right center of photograph. Panel in right foreground and other debris are from front wall. 


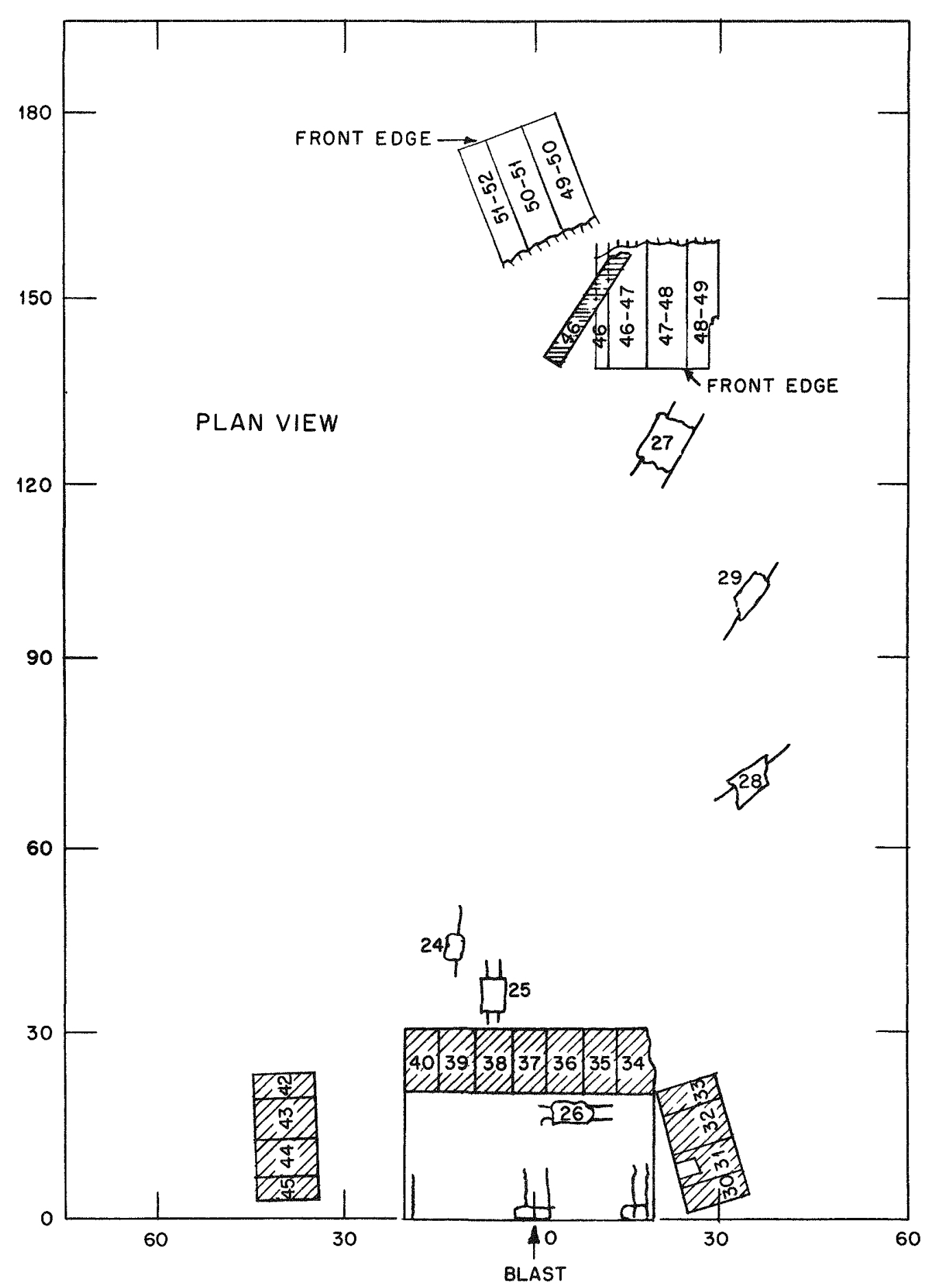

Fig. 6.54 Final Location of Panels, Structure 3.2.3a. Shaded panels indicate inside face up. 

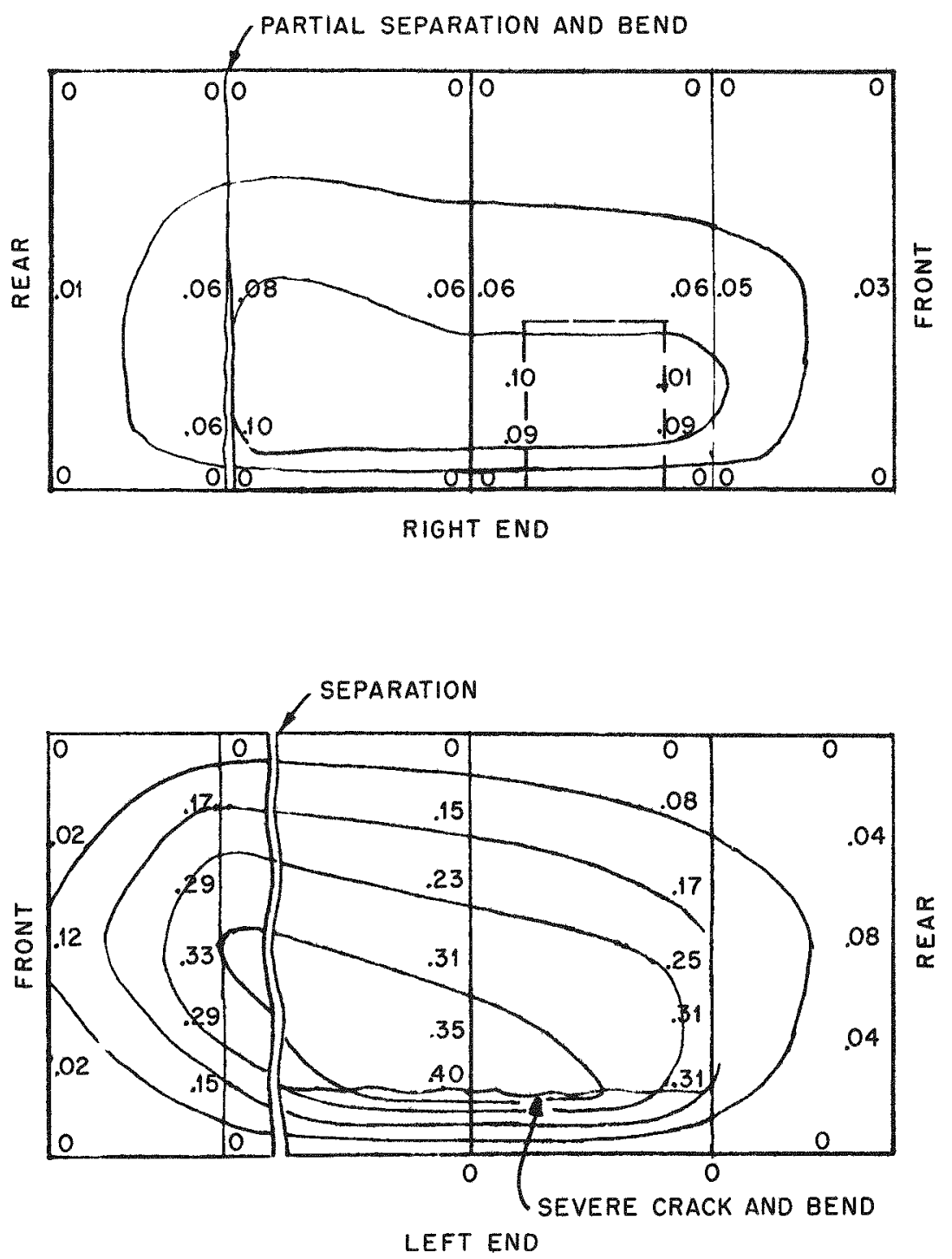

Fig. 6.55 End-wall Deflections, Structure 3.2.3a. Deflections (given in feet) are outward, 

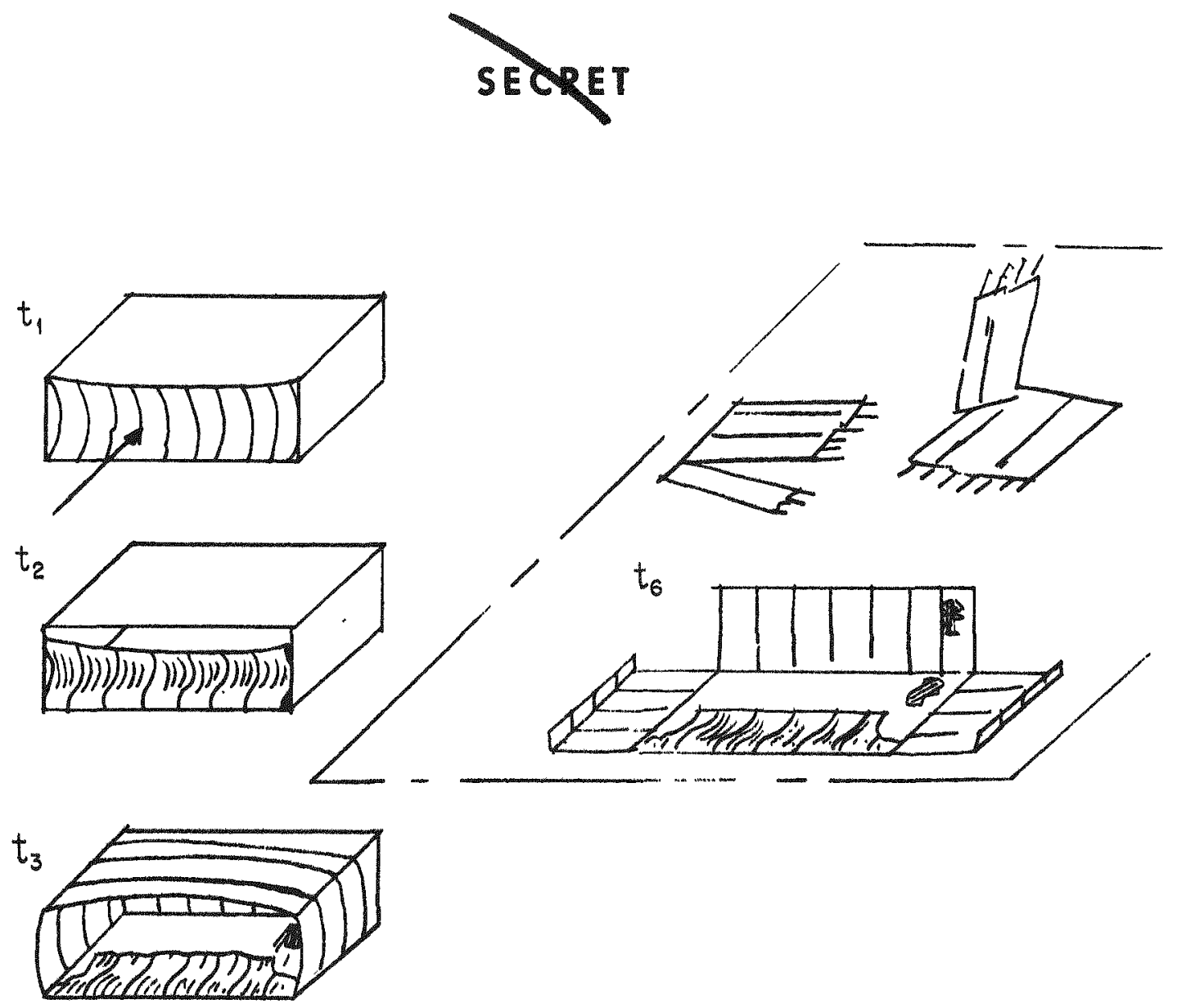

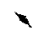
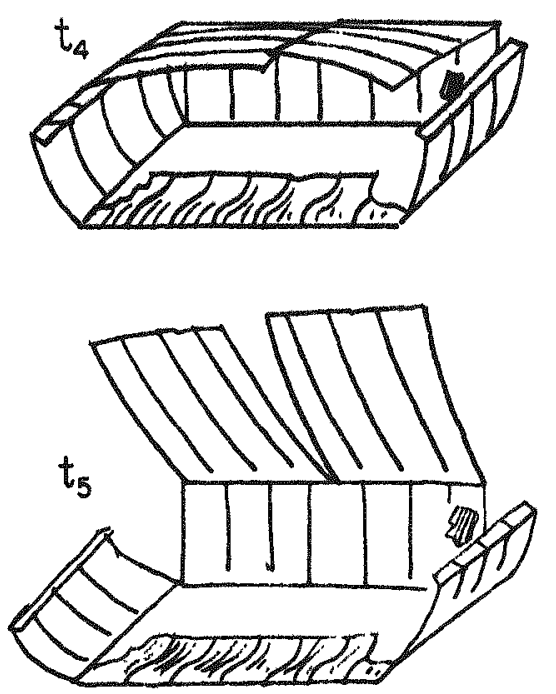

Fig. 6.56 Response History of Structure $3.2 .3 \mathrm{~b}$

91 
the structure occurred. The roof split along its center line parallel to the blast, and at practically the same instant the end walls separated from the roof. The two sections of the roof rotated upward about the top of the rear wall, and the end walls rotated outward about their bases. The cantilever action of the roof about the top of the rear wall caused the connections to rupture, and the force then acting on the exposed underside of the roof was sufficient to hurl each of the two major sections about $75 \mathrm{ft}$ to the rear of the structure. The roof sections showed no evim dence of panel deflections of sufficient size to cause permanent deformation during this dislodging action. The connections of the end walls to the foundation were also severed, and the walls pivoted about the outside lip of the foundation, rotating outward until they rested on the ground. No lateral displacement of the end walls took place. These walls showed a very small amount of permanent bowing in an outward direction, indicating that limited deflection within the panels had taken place prior to the time that the walls separated from the roof. The pressure differential on the rear wall was not sufficient to produce appreciable motion or damage to this wall, although there was an inward dishing of the entire wall, with permanent deflection most pronounced ( 4 in.) at the top edge near the center. The resultant conditions were similar to those occur ring when a diaphragm supported on three edges has its surface uniformly loaded. Whether this condition was caused by the action of the roof sections in breaking loose from the rear wall or by the pressure of the positive pressure wave while the structure was still intact was not clearly indicated.

\subsubsection{Structure 3.2.4a (Gable Bent)}

(a) General Damage. Structure 3.2.4a sustained heavy damage but remained standing. The right end wall was completely destroyed and hurled into the structure. The left end wall suffered practically no damage. The front panels suffered heavy damage at the crown connection but remained standing. Maximum permanent deformation at the peak was about $8 \mathrm{in}$. The remainder of the front panels sustained only light cracking. The rear panels were damaged only slightly, except at the crown connection, where the central portion of the front-panel crown ribs was severed from the rear-panel crown ribs and slid slightly underneath the rear panels.

(b) Damage to Components. The right end panels were destroyed. The diaphragm or skin sections of these panels pulled away from the ribs, which were firmly anchored, and each panel broke into several sections as it was hurled into the structure. The left end panels developed only small cracks in the concrete and remained basically intact. The front and rear panels, except for the failure of the crown rib, remained basically intact, developing only limited cracks along the fold lines and also along the inside base of the rear panels.

(c) Response History. As the blast load was applied to the front of the structure, the shape and thickness of the earth fill against the vertical portions of the front panels afforded a marked attenuation of the face-on pressure, so that practically no cracks developed in the diaphragm sections of these members. As the shock wave began to move over the top of the structure, it exerted a large downward force on the flatter portions of the front panels and also a considerable horizontal load tending to move the front panels toward the rear. This combined load caused the central portion of each front panel to rotate inward, thereby exerting a force through the upper portion that tended to move the crown joint to the rear and slightly upward, with the accompanying adjustment of the angles at the fold lines and at the foundation to meet this deformed condition. Local deformation of the diaphragms of the central and upper portions of the front panels also took place during this phase of the loading, as evidenced by the general cracking in these areas. No failures of the diaphragms occurred, however.

As the shock front progressed to a point just past the center line of the structure, the major component of the applied force acting on the front panels was in a downward direction, while the primary force acting on the rear panels was still the horizontal thrust being transmitted from the front panels through the crown joint. Consequently the crown rib of the front panels attempted to move downward with respect to the crown rib of the rear panels. The resisting force in the rib of the front panels consisted of the shear strength of the concrete above the connecting bolts. The resisting force in the rib of the rear panels consisted of a heavy steel reinforcing bar and the concrete below the bolts in 
PLAN VIEW
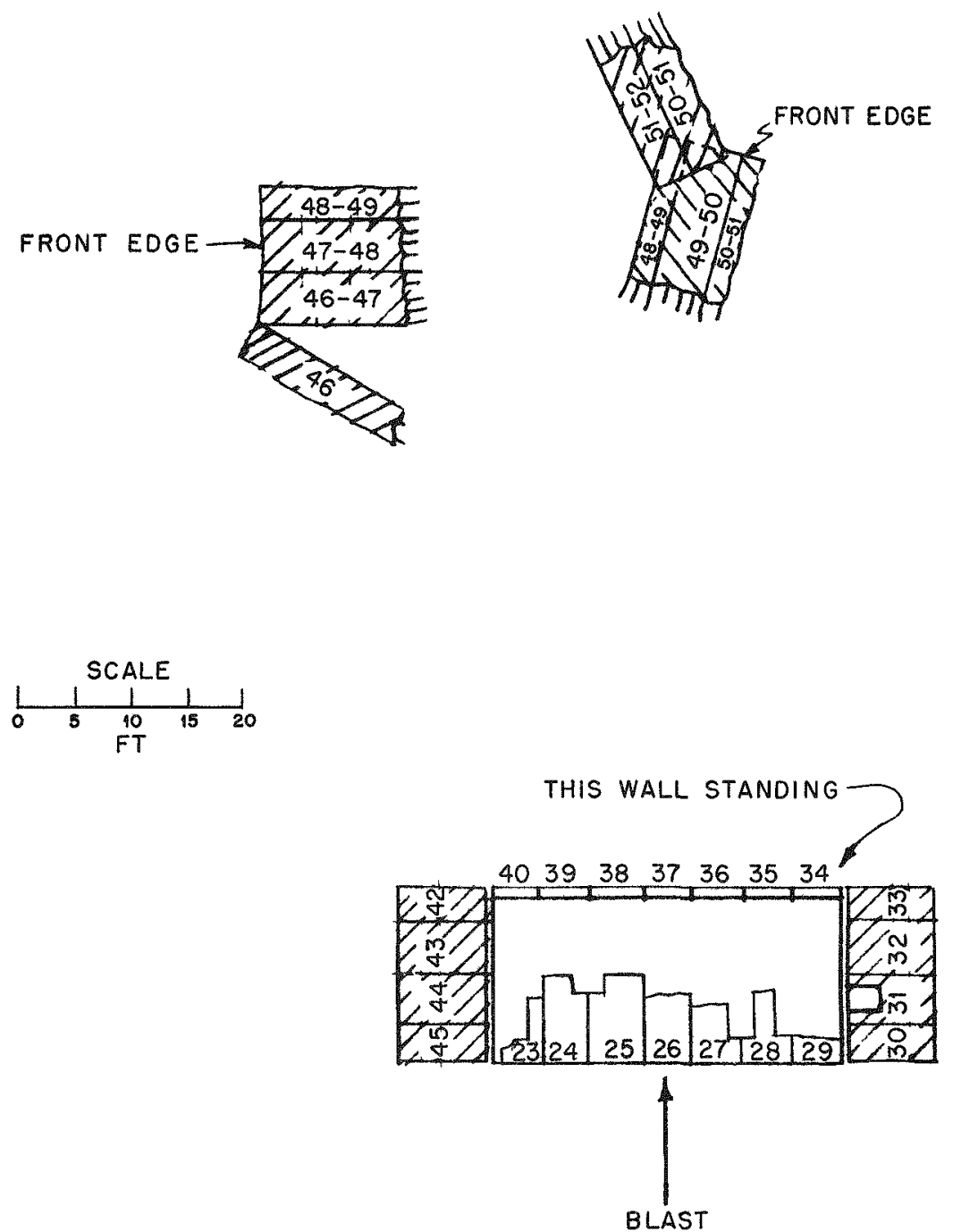

Fig. 6.57 Final Location of Panels, Structure 3.2.3b. Unshaded panels indicate outside face up. 

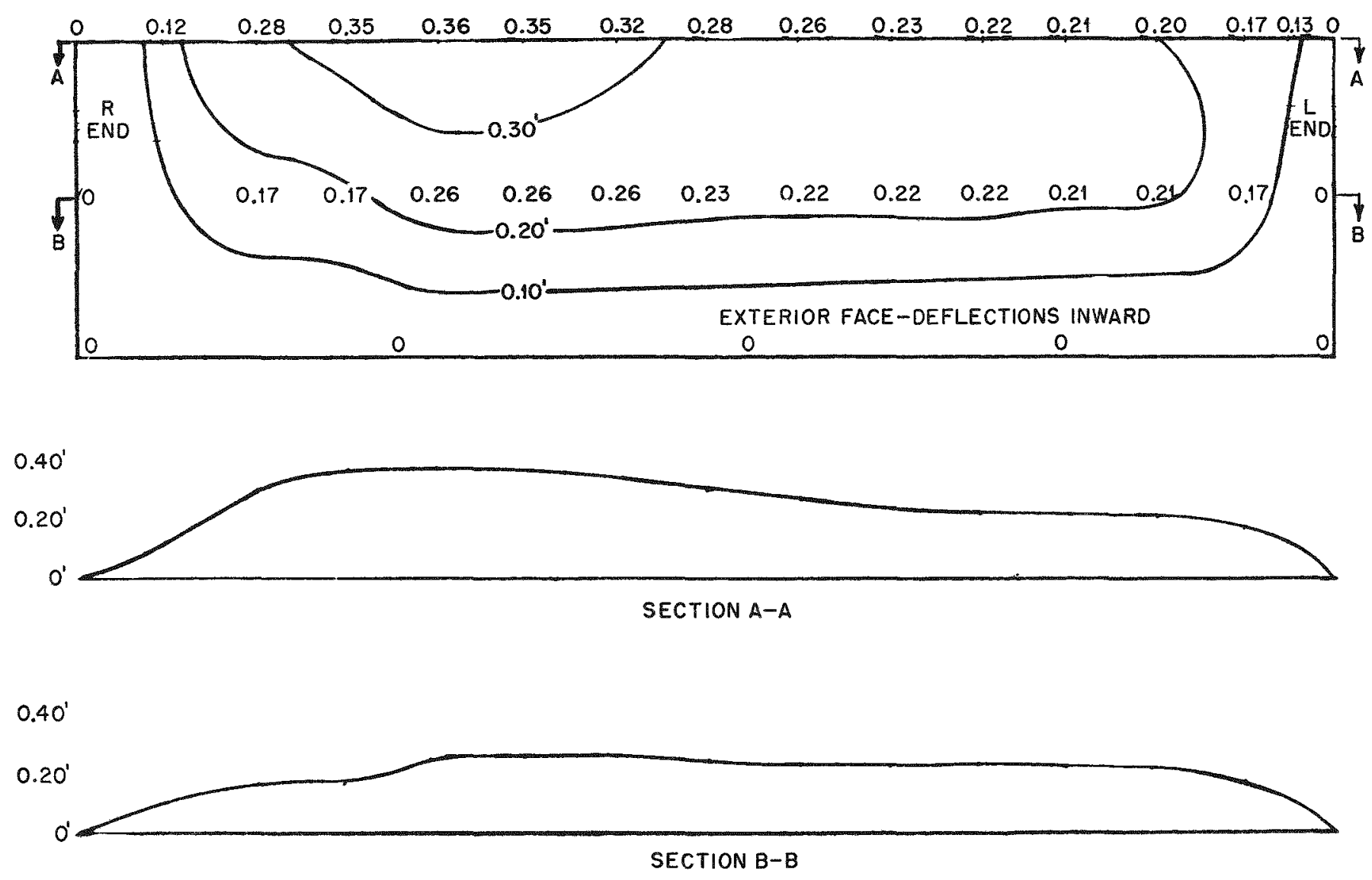

Fig. 6.58 Deflection Pattern of Rear Wall, Structure 3.2.3b. Deflections are measured in feet.

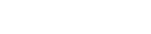



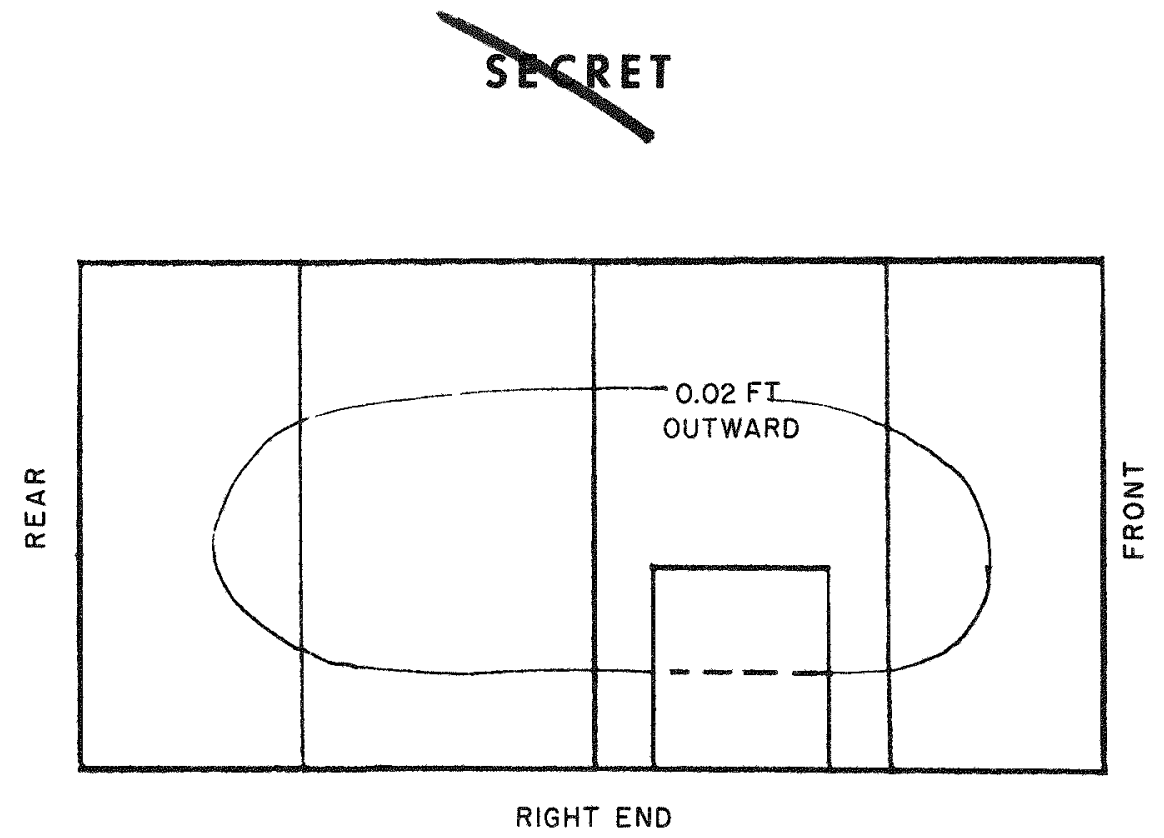

Fig. 6.59 End-wall Deformations, Structure 3.2.3b. No measurable deformations on left end wall.
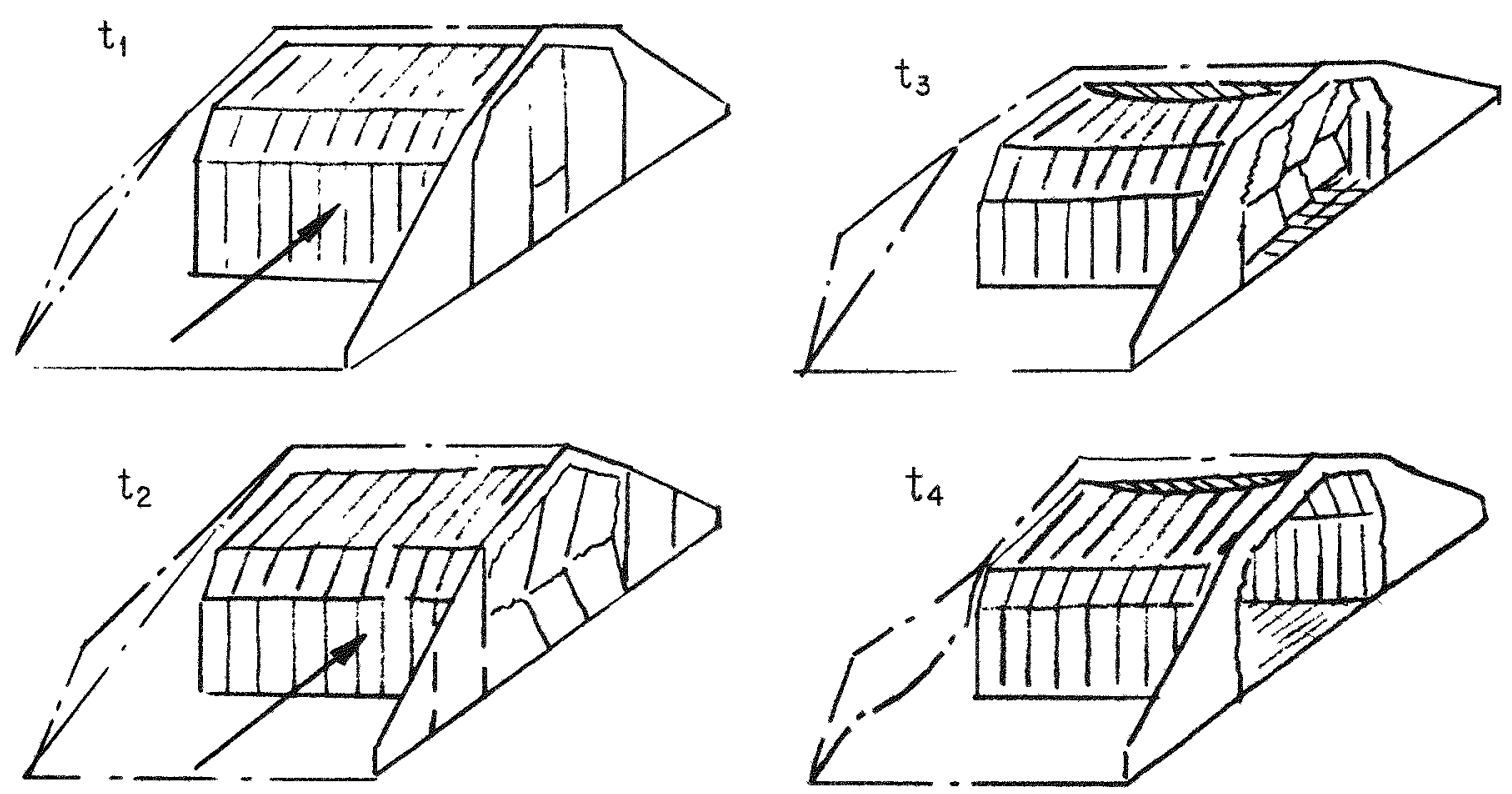

Fig. 6.60 Response History of Structure 3.2.4a 
the crown rib. This latter section was capable of developing a greater resistance than the former, and consequently the concrete above the bolts in the crown $\mathrm{rib}$ of the front panels broke out and allowed the upper end of the front panels to move downward until they cleared the lower edge of the rear panels at this point.

The shock front by this time had progressed well over the structure, so that a general crushing force enveloped the building; the front and rear panels began a telescoping action at the crown, with the upper edge of the front panels sliding underneath the upper edge of the rear panels. This action was arrested by a combination of the moment developed at the bases of the front and rear panels and also by the horizontal restraint supplied by the end walls and transmitted through the bolted connections between parallel panels. Restraint was also furnished by the front and rear panels adjacent to each end wall, because these panels did not sustain a separation at the crown joint. The maximum telescoping of the front and rear panels occurred at the center panels and amounted to about 8 in.

While this action was taking place, side-on pressure was being applied to the ends of the structure. The load reaching the left end wall had been attenuated by the earth fill against that wall, and only slight cracking of the diaphragms occurred. The right end wall, on the other hand, received the full side-on pressure, and the initial action of the loading here was to deflect the thin diaphragm sections of the wall in an inward direction. As this deflection increased, the panels cracked and bent along a horizontal line at about midheight of each panel, and the upper and lower portions then rotated inward about their respective anchorages, forming a horizontal $\mathrm{V}$ shaped pattern, with the apex of the $V$ at this crack.

As the load continued to be applied, all three panels were severed from their base ribs, and then each entire panel rotated inward about the edge of the roof. The lower half of the rearmost end panel then broke loose from the upper half and was hurled to the left side of the structure, striking the left end wall and falling to the floor. The door proper broke loose from the panel above it and moved to the left end of the structure. Then the upper half of the end panel adjacent to the front wall was severed from its anchorage and from its lower section and was hurled about $15 \mathrm{ft}$ inside the structure. The lower section of this panel was held by one $3 / 4$ in. reinforcing rod that remained anchored at the roof line. Then the upper section of the rearmost panel and that of the center panel broke loose and were hurled into the structure. Fim nally, the reinforcing bar holding the lower half of the end panel adjacent to the front wall broke loose from its anchorage, and this last remaining part of the end wall was hurled to a point about $25 \mathrm{ft}$ inside the structure.

(d) Methods of Failure. There were only two major fallures in this structure: One was the complete failure of the right end wall (Fig. 6.61 ); the other was the failure of the crown joint along the central two-thirds of the structure (Fig. 6.62).

The failure of the right end wall may be largely attributed to an error in engineering detailing. These panels were designed to receive loads applied to the opposite face from that which was actually loaded in this test. Had these panels been turned around, they probably would have withstood the pressures with only slightto-moderate damage. Some of the methods by which these panels failed are significant, however, in providing information concerning the action of reinforced concrete under dynamic loading.

The base ribs at the foundation were torn apart in tension through the line of bolt holes. The diaphragm section had developed sufficient resisting forces to cause this heavy damage to the base ribs. The vertical ribs, except those bearing against side-wall panels, failed at about center height because they had practically no tension steel. This fallure allowed the diaphragms to crack along a horizontal line at this same height and to bend sharply at this axis, finally stretching the wire mesh enough to cause it to neck down and break. Figure 6.63 clearly shows one of these lines of cracking and rupture. The left edge of the piece of the panel shown was horizontal and at midheight of a continuous panel before it failed.

The fallure of the crown joint was largely a matter of downward forces on the roof portion of the front panels, combined with the translational forces tending to move these panels to the rear (Fig. 6.65).

The heaviest loads were applied to the panels on the front side of the crown, and these are the panels that show the greatest damage and the 

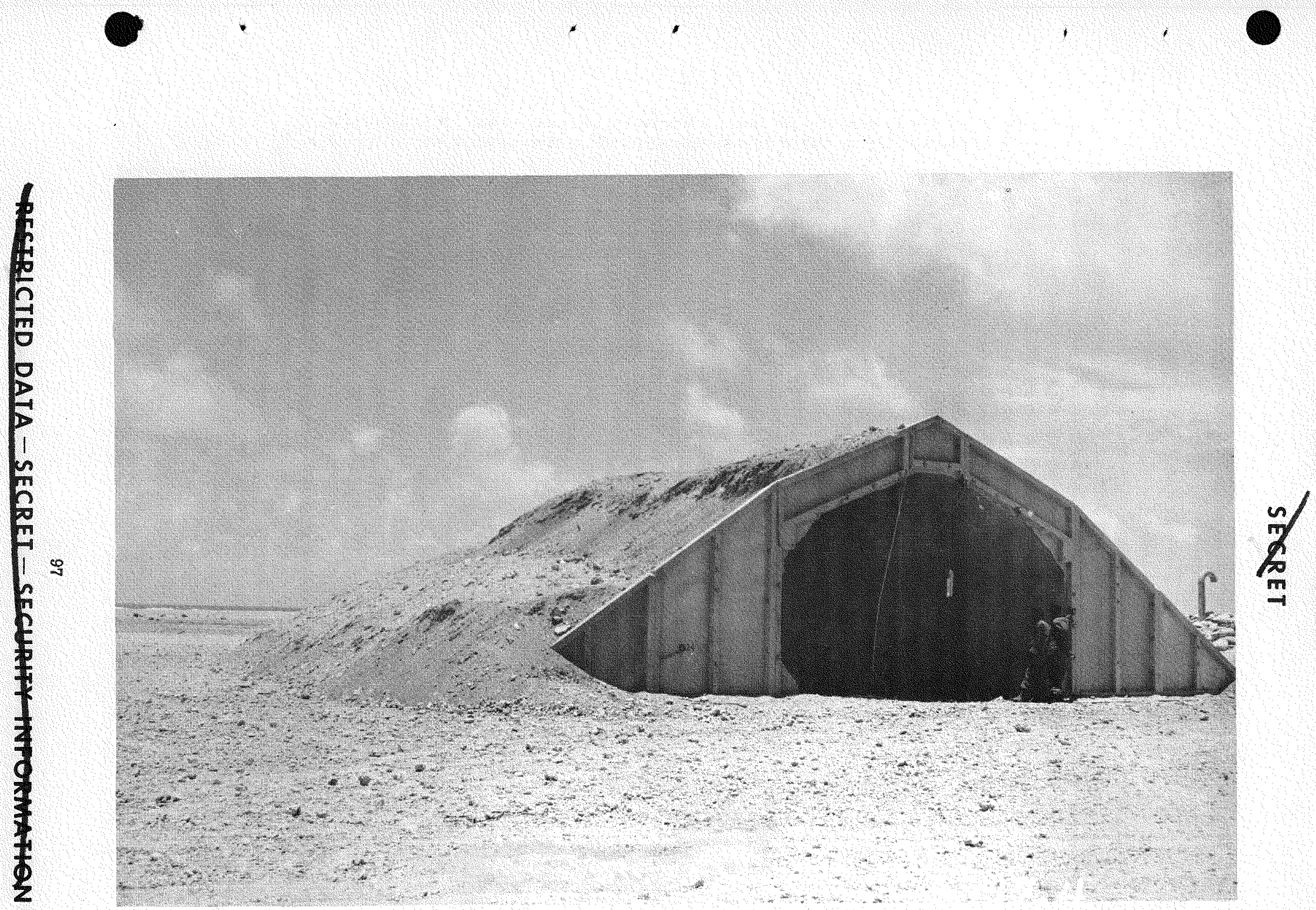

Fig. 6.61 View of Right End of Structure 3.2.4a. This end wall was blown into the building. 


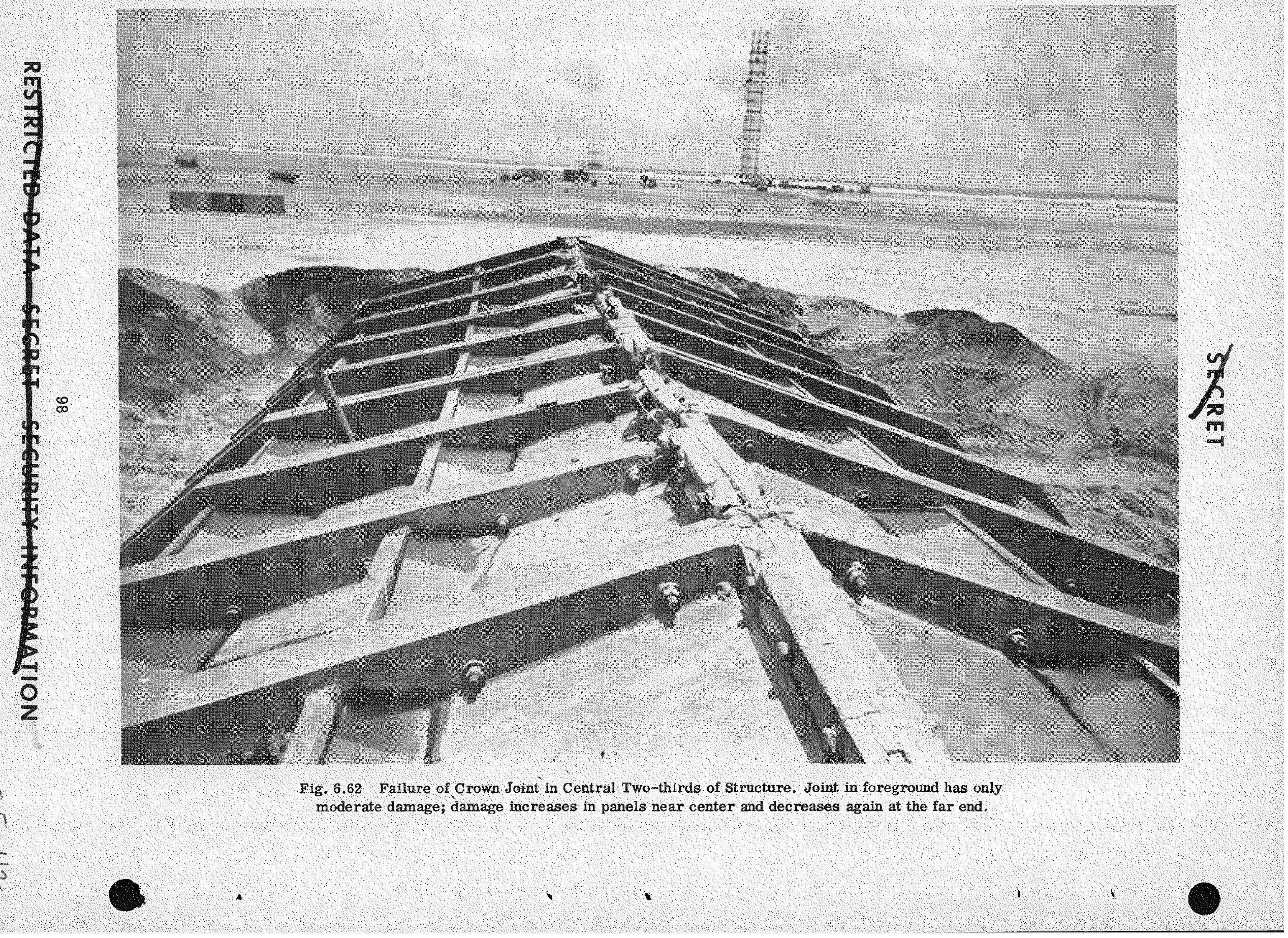



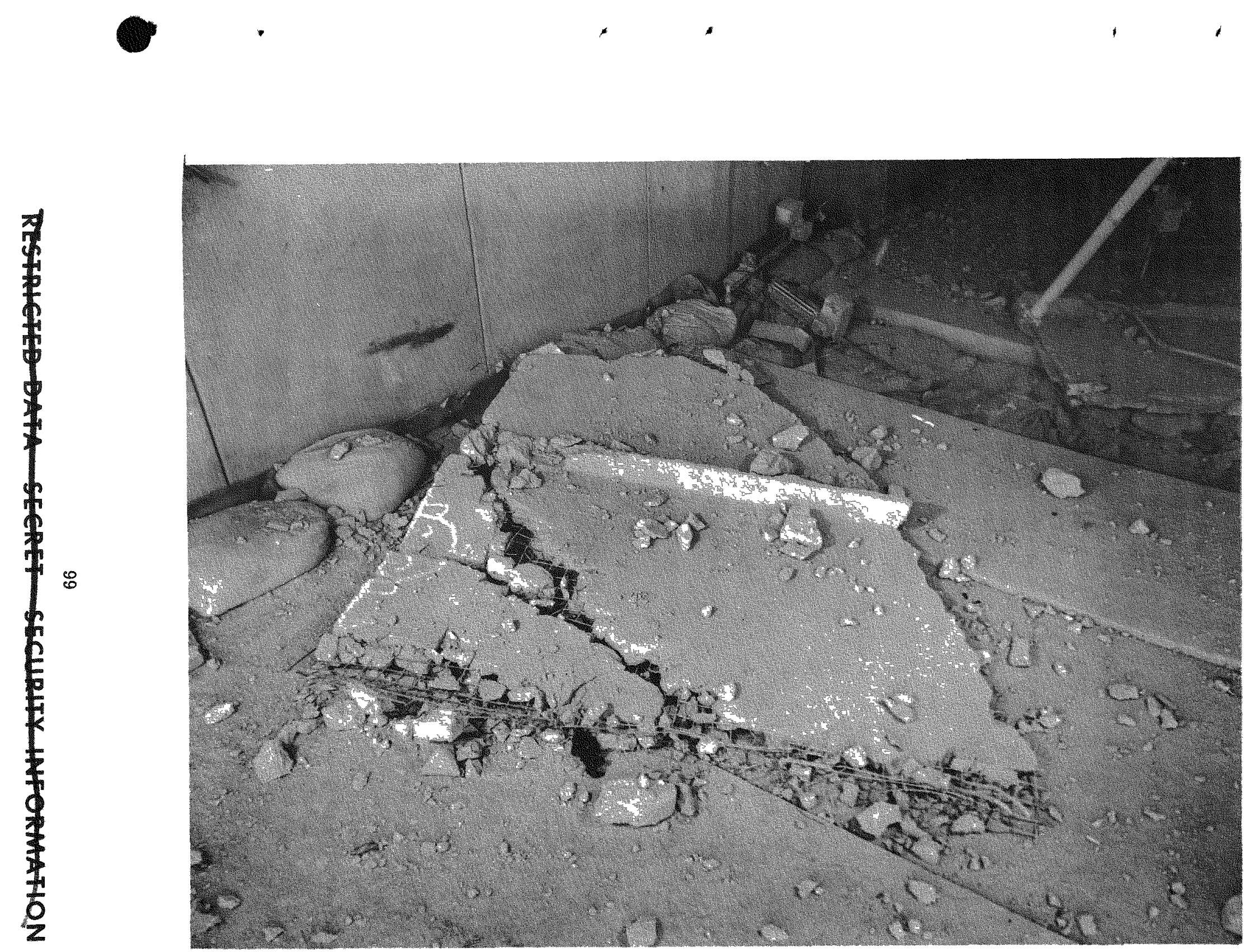

$\prod_{n}^{\infty}$

Fig, 6.63 Upper Half of End Panel That Was Adjacent to Front Wall, Structure 3 2.4a 

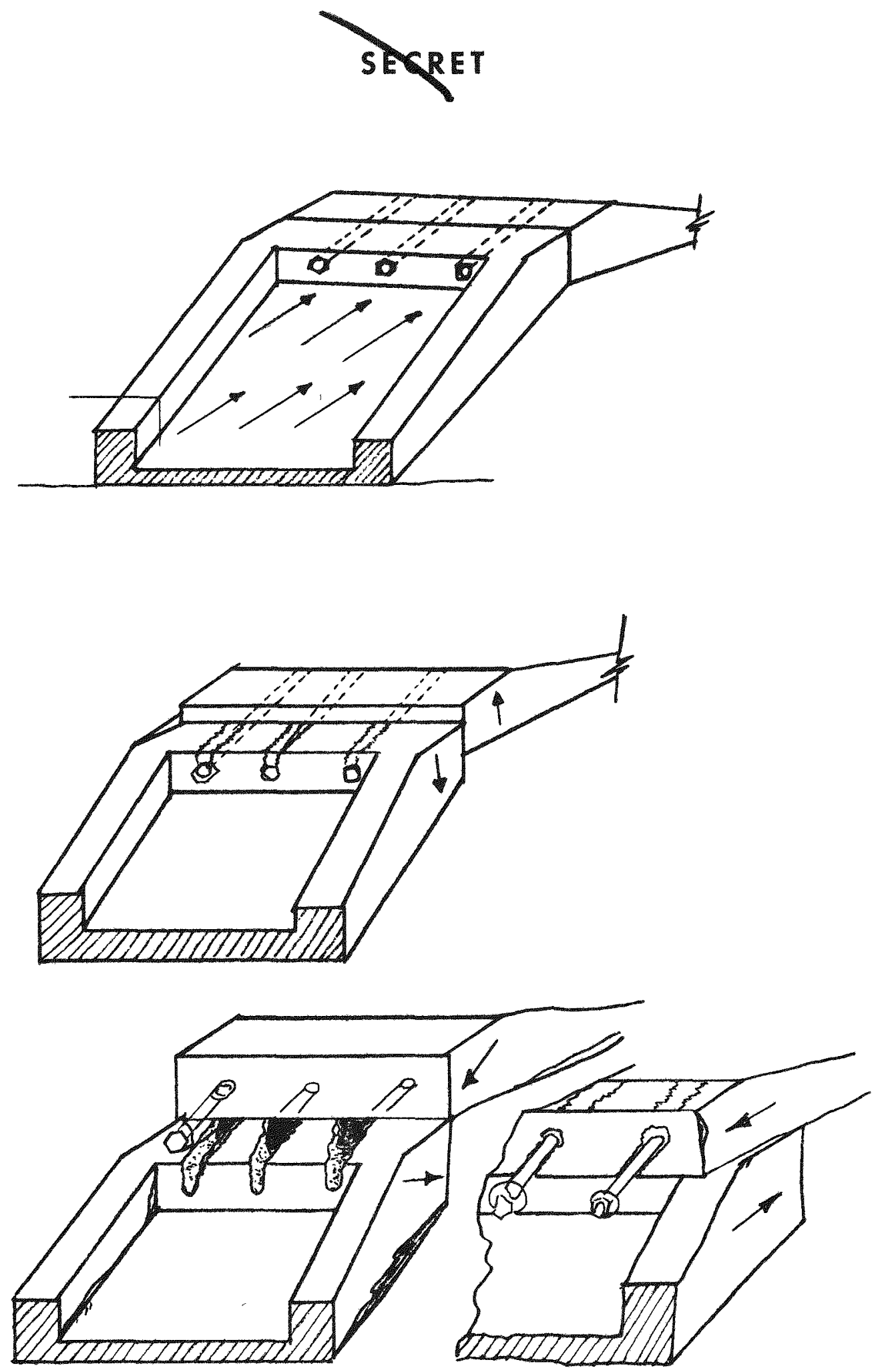

Fig. 6.64 Crown-joint Action on Structure 3.2.4a 


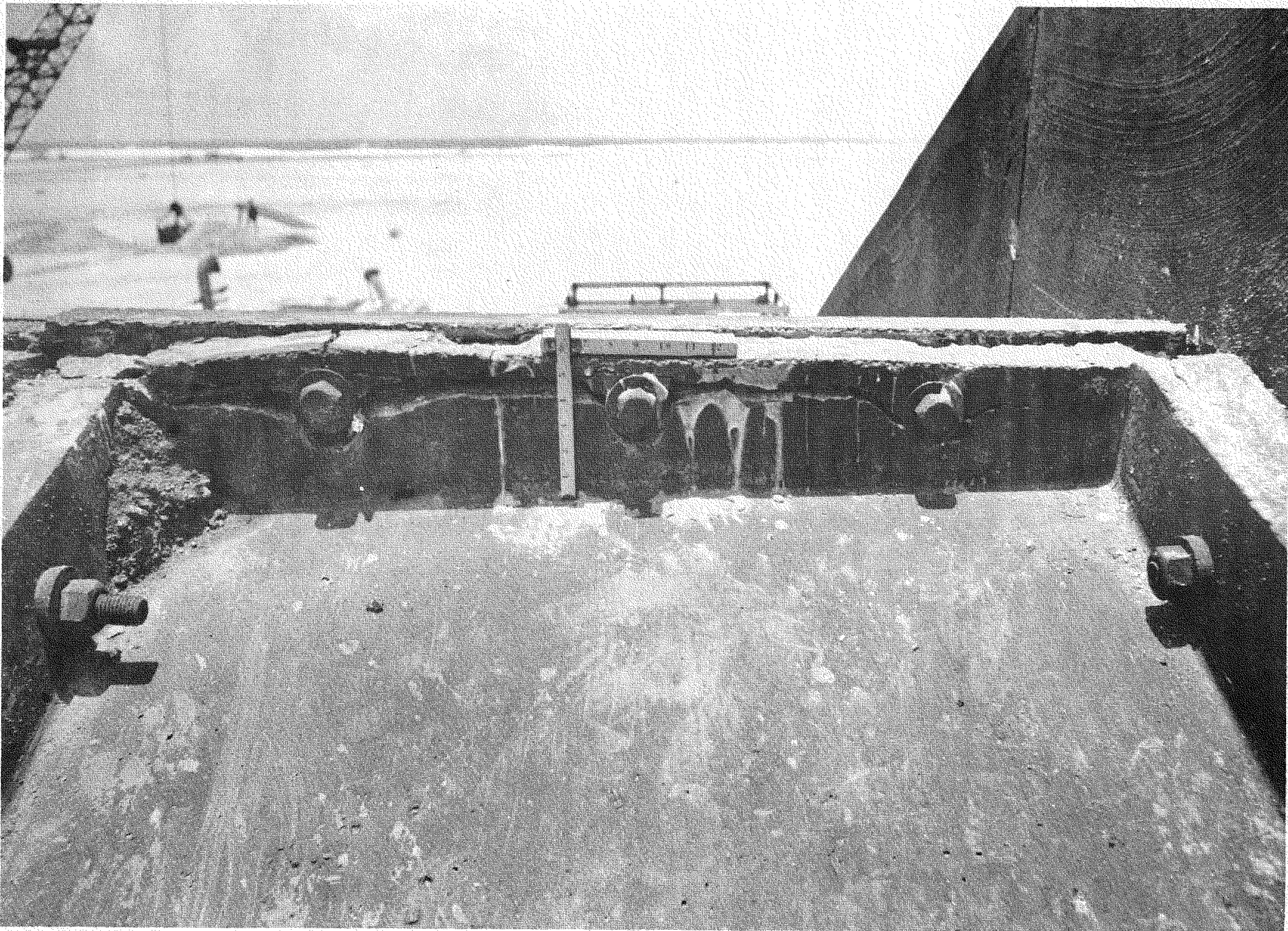


most movement downward. Had the failure been caused by opposing horizontal thrusts, most of the load would have been brought in through the heavy edge beams, with resultant crushing of concrete at the ends of these beams and a general tendency to force these beams up and over the rear panels. However, almost the opposite condition resulted. The front beams were forced downward; the rupturing of the crown ribs indicates that high forces were acting in the vertical direction; and the crown joint was pulled forward and down (Fig. 6.66). After failure of the joint, the assembly bolts between panels prevented further downward motion of the center panels by transferring the forces out to the end panels where the crown joints were not collapsed and where the end walls furnished considerable restraint.

The crushing effect of the pressures completely enveloping the structure caused the front and rear panels to telescope together at the crown after the crown joint was destroyed. This telescoping reached a maximum of 8 in. at the center panels (Fig. 6.67).

\subsubsection{Structure 3.2.4b (Gable Bent)}

(a) General Damage. Structure 3.2.4b suffered practically complete collapse of the end walls. The rear and center panels of both end walls failed and were hurled to the center of the building. The front panels of each end wall were damaged beyond effective use but were still in place with large deflections. The front panels received medium damage in those panels with the ribs outward. One of these panels failed in the vertical section. The panels with the skin outward were not damaged, except in the ribs, and this was only moderate. The rear panels received no damage except light cracking.

(b) Damage to Components. The panels with the ribs outside received the most damage throughout the structure. In the end-wall panels the skin pulled completely away from the center rib, taking with it the $3 / 8$-in. reinforcing bar. In several cases the outer portion of the rib and the heavy reinforcing bar remained in position. The skin of the center and rear panels of both end walls failed at the top and bottom ribs. The vertical ribs through which the center and rear panels of each end wall were connected failed at the top and at the bottom of the panels. The panels were broken as they were hurled and hit the sections coming from the opposite end wall. The front end panels failed in a similar manner; however, they did not break free at the top rib.

The five right-hand front- and rear-wall panels were cast with the ribs outside. In the front wall these panels received medium damage to the vertical section. The panel nearest the end wall received the least. There was increased damage to panels that were closer to the center of the building. The fourth panel received the greatest damage. The ribs in the roof sections of the fourth and fifth panels failed but did not collapse. The rear-wall panels received only light cracking in the skins.

The wall sections which had the ribs inside received only light damage. In the front wall the ribs at the first fold were cracked when the panels tended to straighten under the load. The skin in these sections was lightly cracked. The rear wall received very light cracking in the ribs of the panels near the center of the building.

The end-wall foundations were cracked near the rear third point. The crack was about $1 / 16$ in. wide at the surface, decreasing to zero about three-fourths of the way down the foundation. A $1 / 32$-in. crack was found near the center of the rear foundation. The concrete was spalled in front of the left front panel, where the keyed toe of the panel had rotated.

(c) Response History. As the blast struck the front wall, the skin of vertical sections of those panels with ribs outward deflected up to 6 in. One failed when deflected about 7 in. The spill of pressure around the end walls released the load on panels nearest the end walls, thereby causing less local damage to those panels. The structure as a whole deflected about $4 \mathrm{in}$. in the horizontal direction at the center. The heavy deflection and the roof pressure load caused failure of the roof ribs in the two panels with ribs out nearest the center. Those panels with ribs in withstood the load without local failures. The pressure on the front wall and the resistance of the rear wall caused the top of the front panels to tend to pitch upward. The ribs cracked at the first fold to provide a hinge for the movement.

The spill of pressure from the front wall caused vortices of lower pressure at the front end panels; therefore the concentration of pressure on the side walls when the structure was enveloped by the pressure was toward the rear of center of the end walls. The vertical ribs 

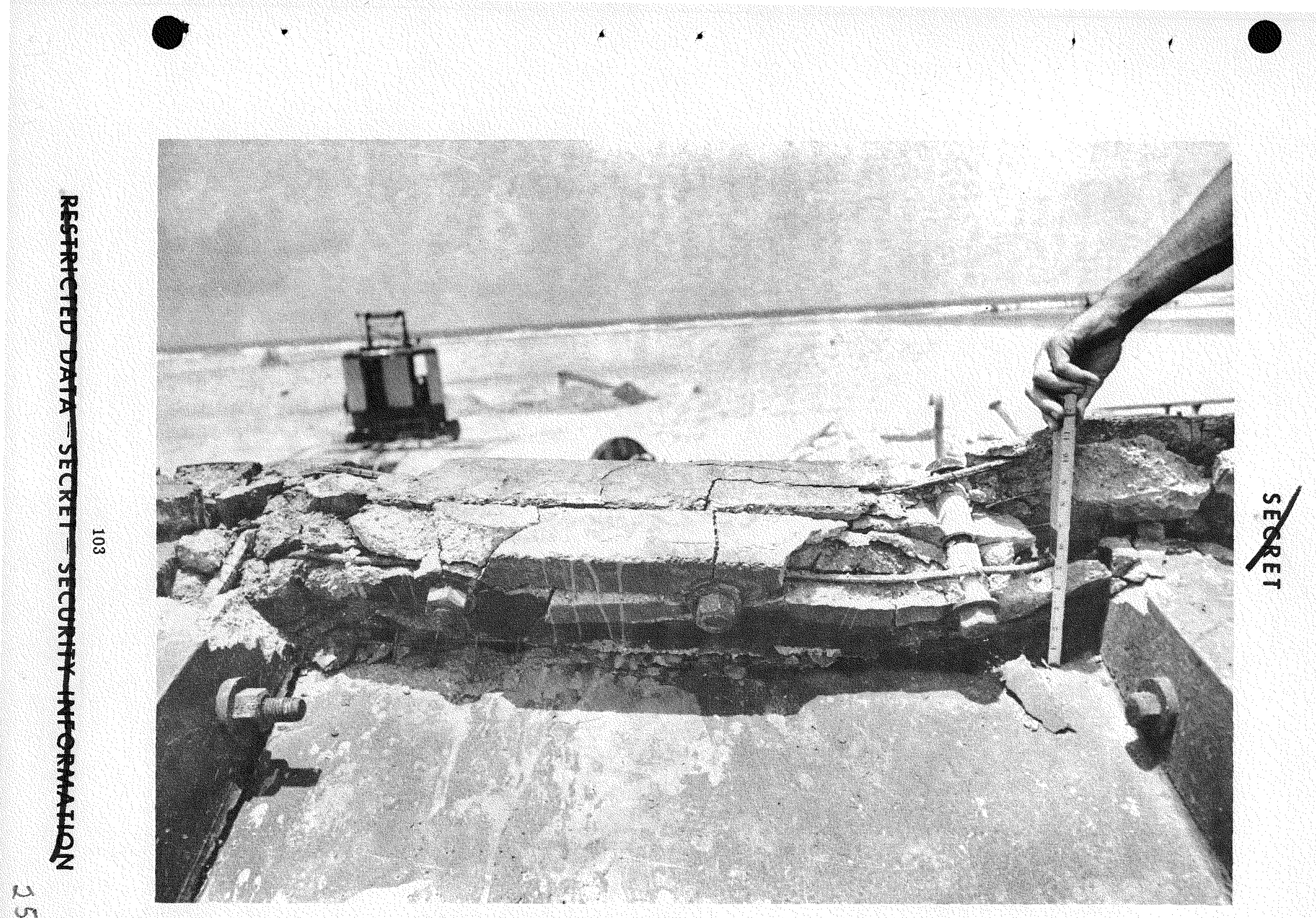

Fig. 6.66 Crown Failure near Center of Building, Showing Downward and Horizontal Displacement of 


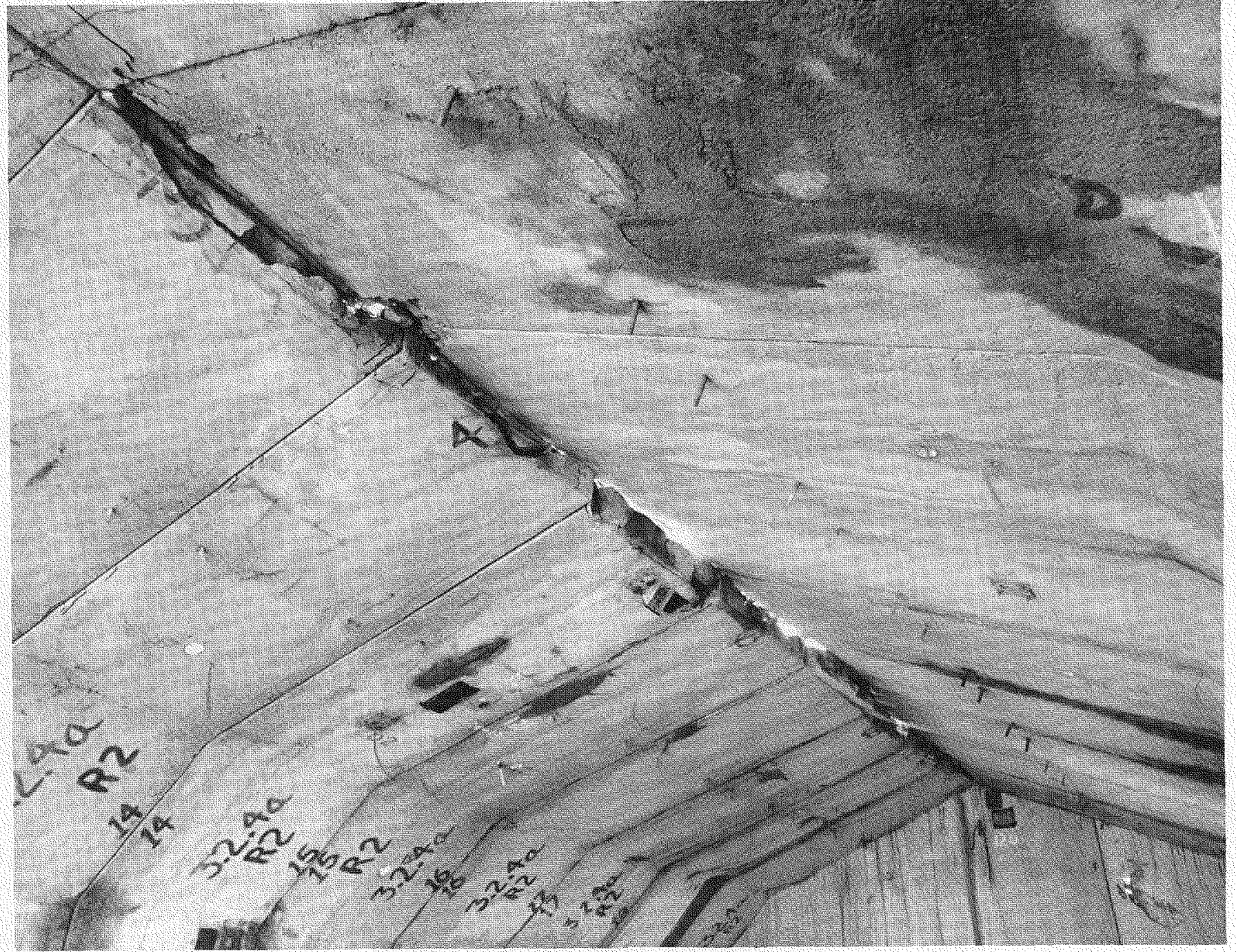

Fig. 6.67 Interior View of Crown Joint After Removal of Debris and Earth Cover 

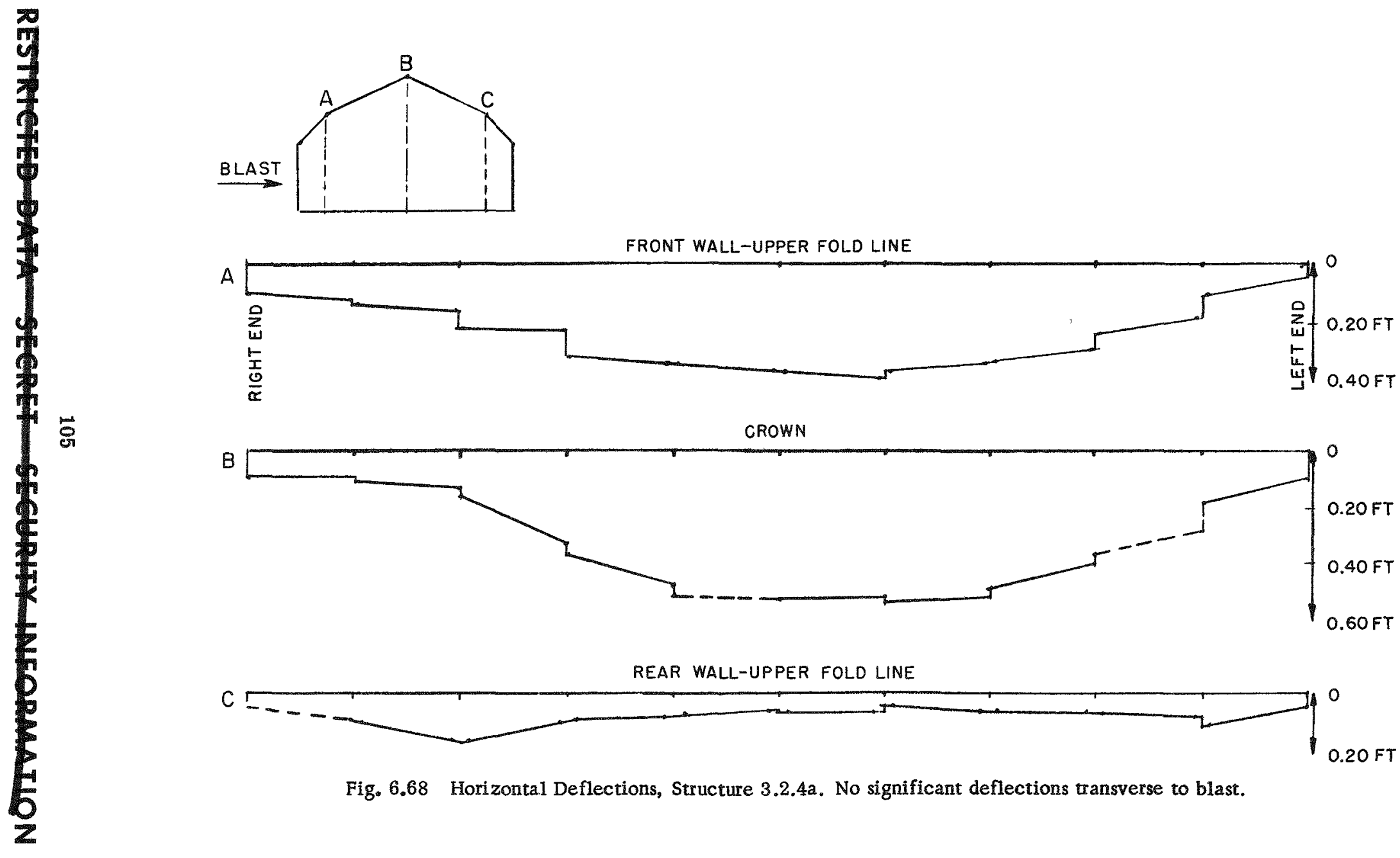

CROWN

B

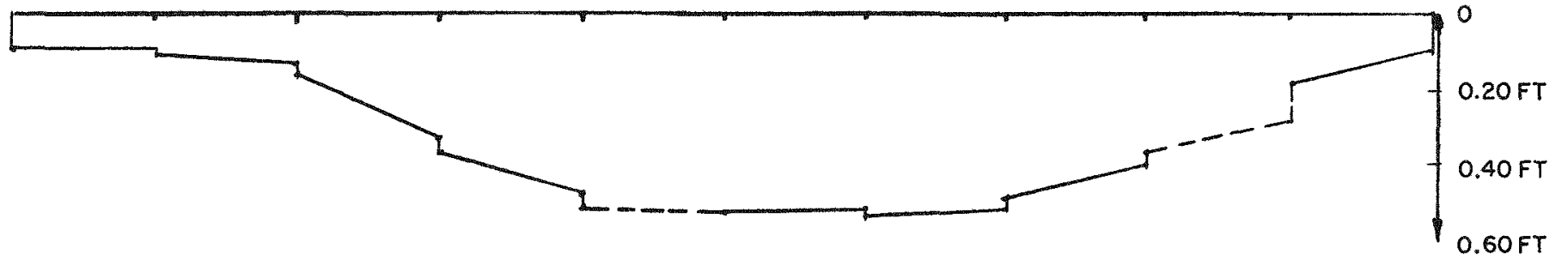

REAR WALL-UPPER FOLD LINE

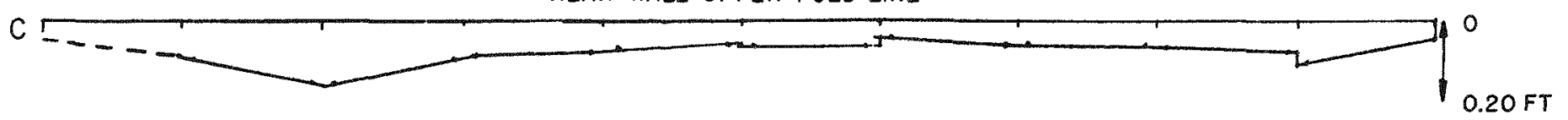

Fig. 6.68 Horizontal Deflections, Structure 3.2.4a. No significant deflections transverse to blast. 


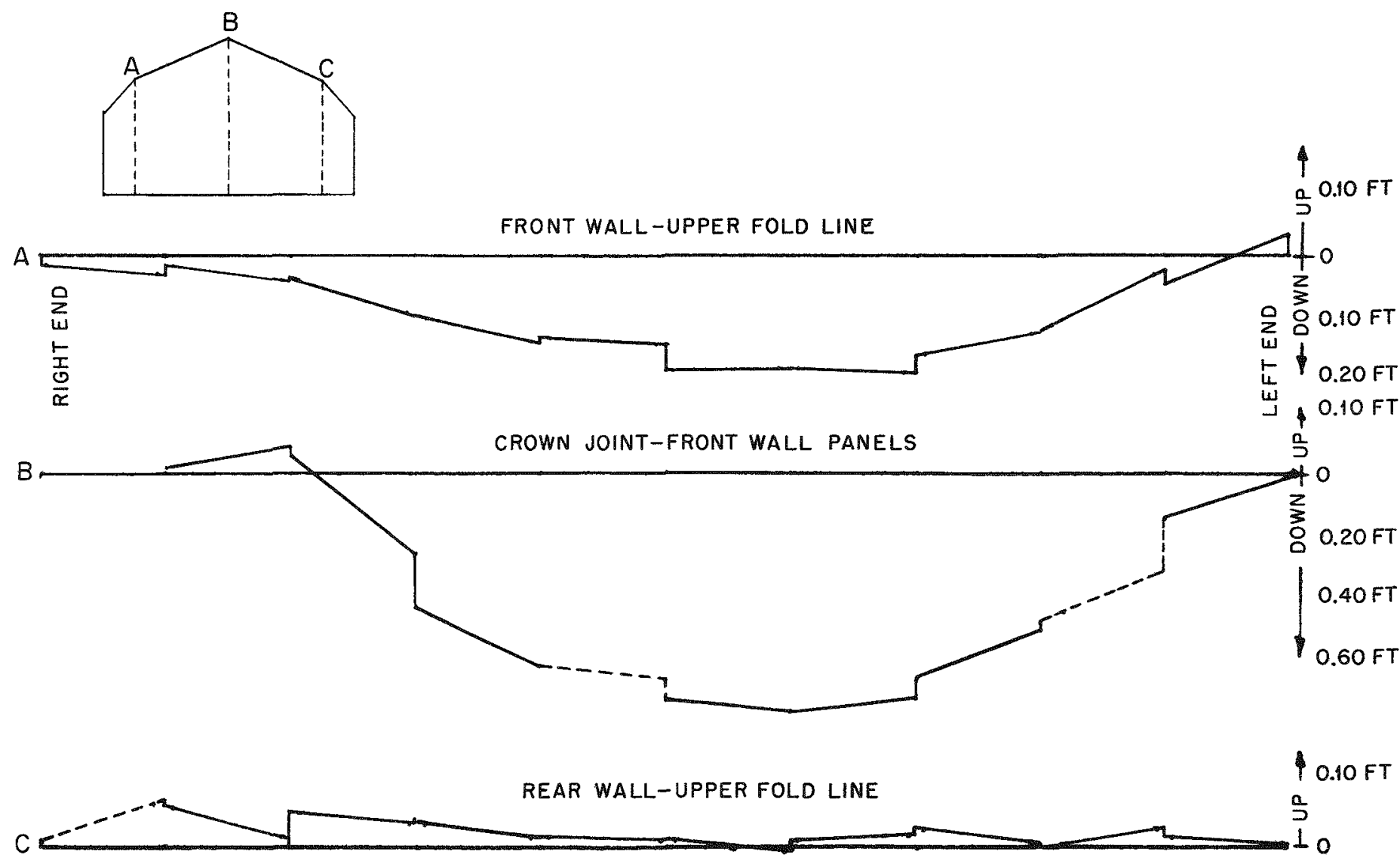

Fig. 6.69 Vertical Deformations, Structure 3.2.4a. Deflection in section B is half scale that of sections A and C. 


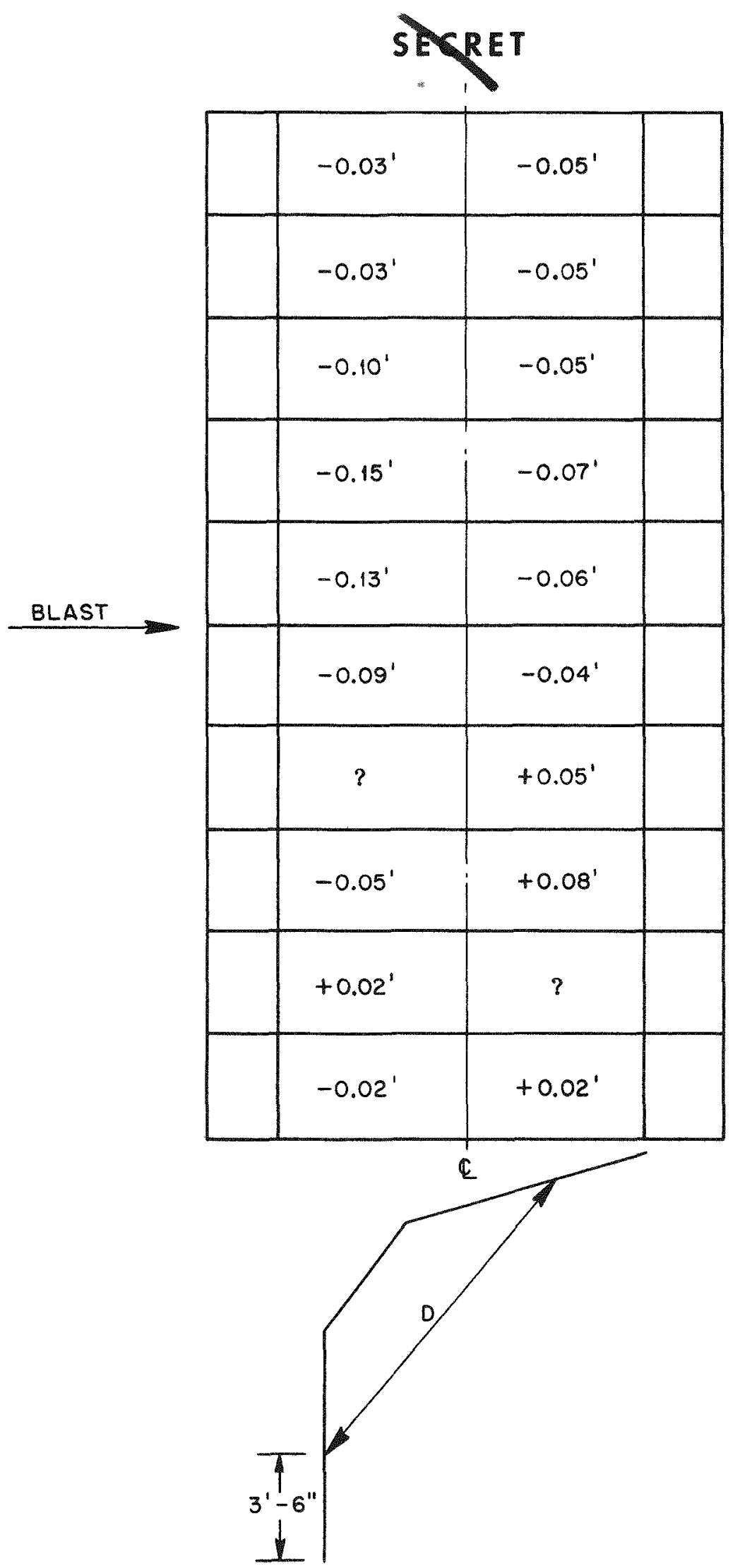

Fig. 6.70 Diagonal Deformations, Structure 3.2.4a

107 

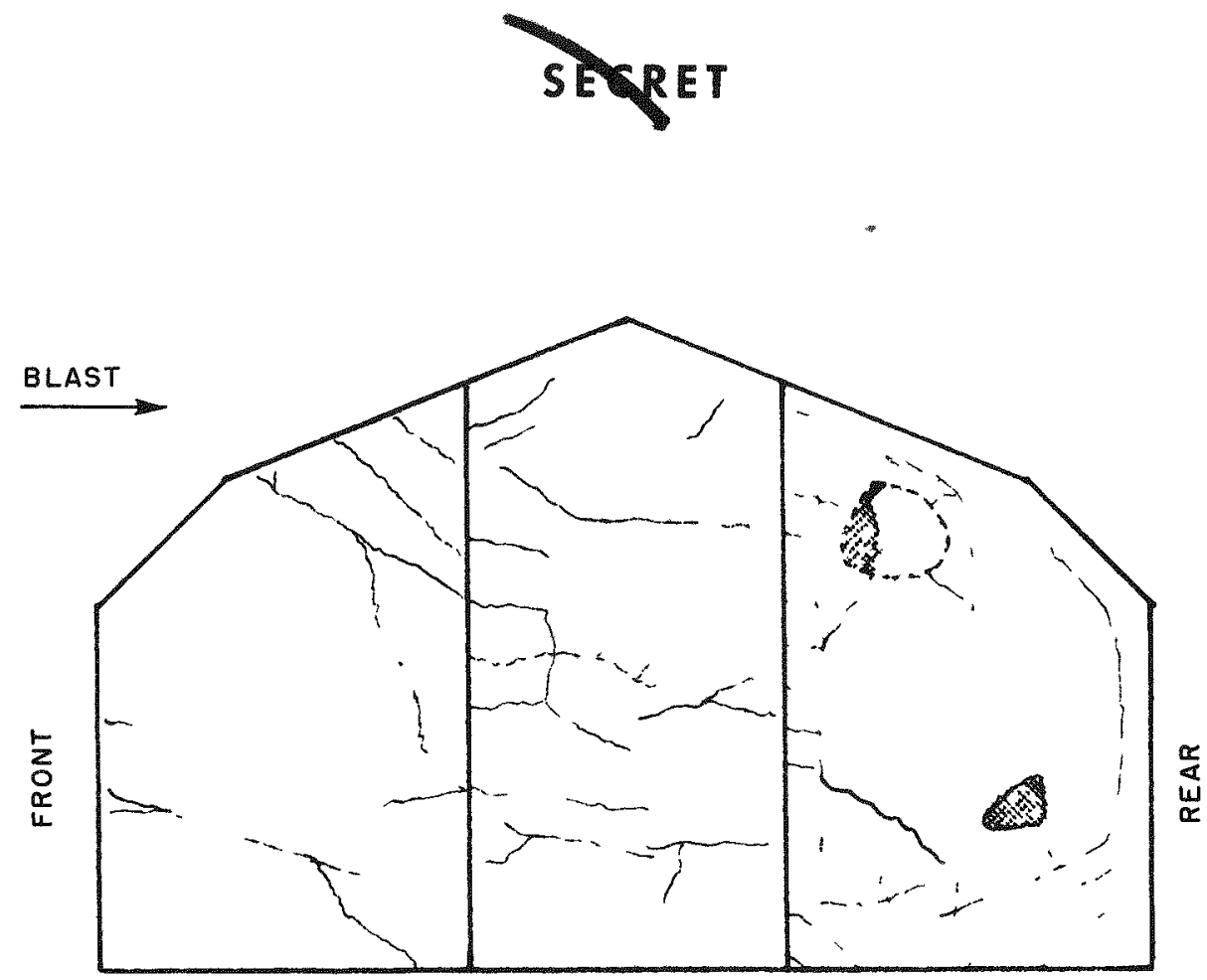

INTERIOR

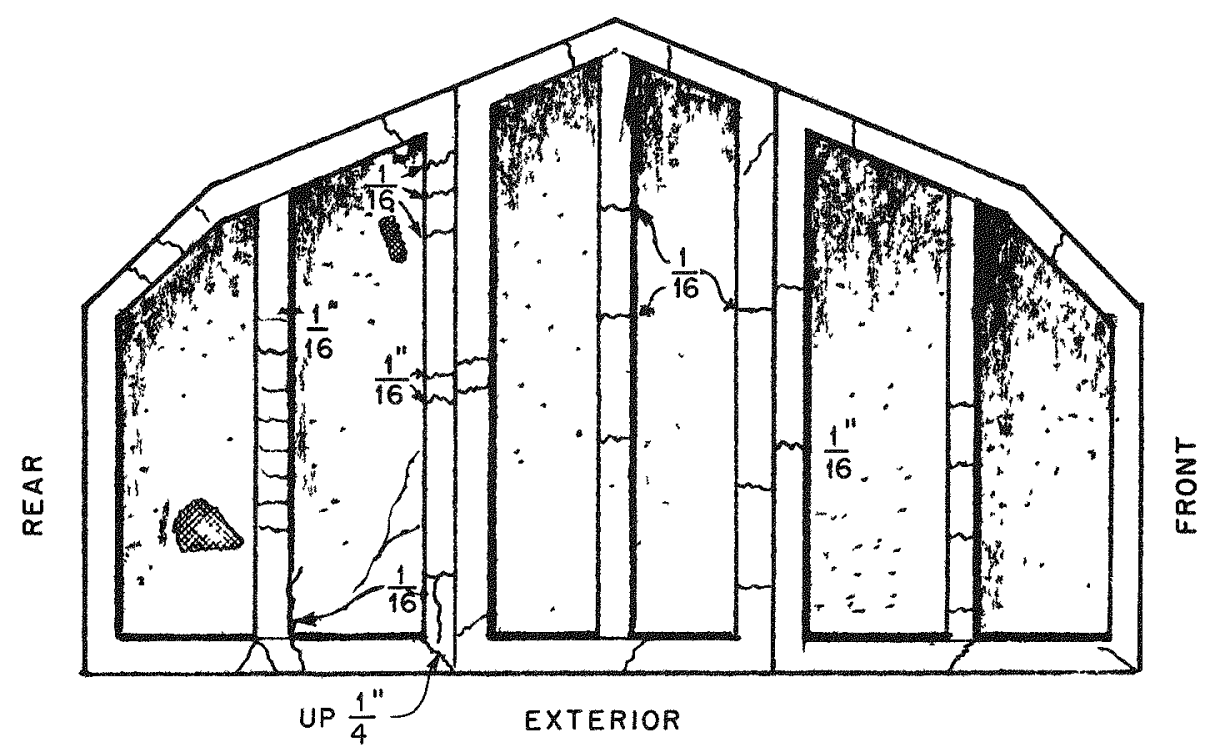

Fig. 6.71 Left-end-wall Crack Patterns, Structure 3.2.4a. Cracks are about $1 / 64$ in. unless marked. 


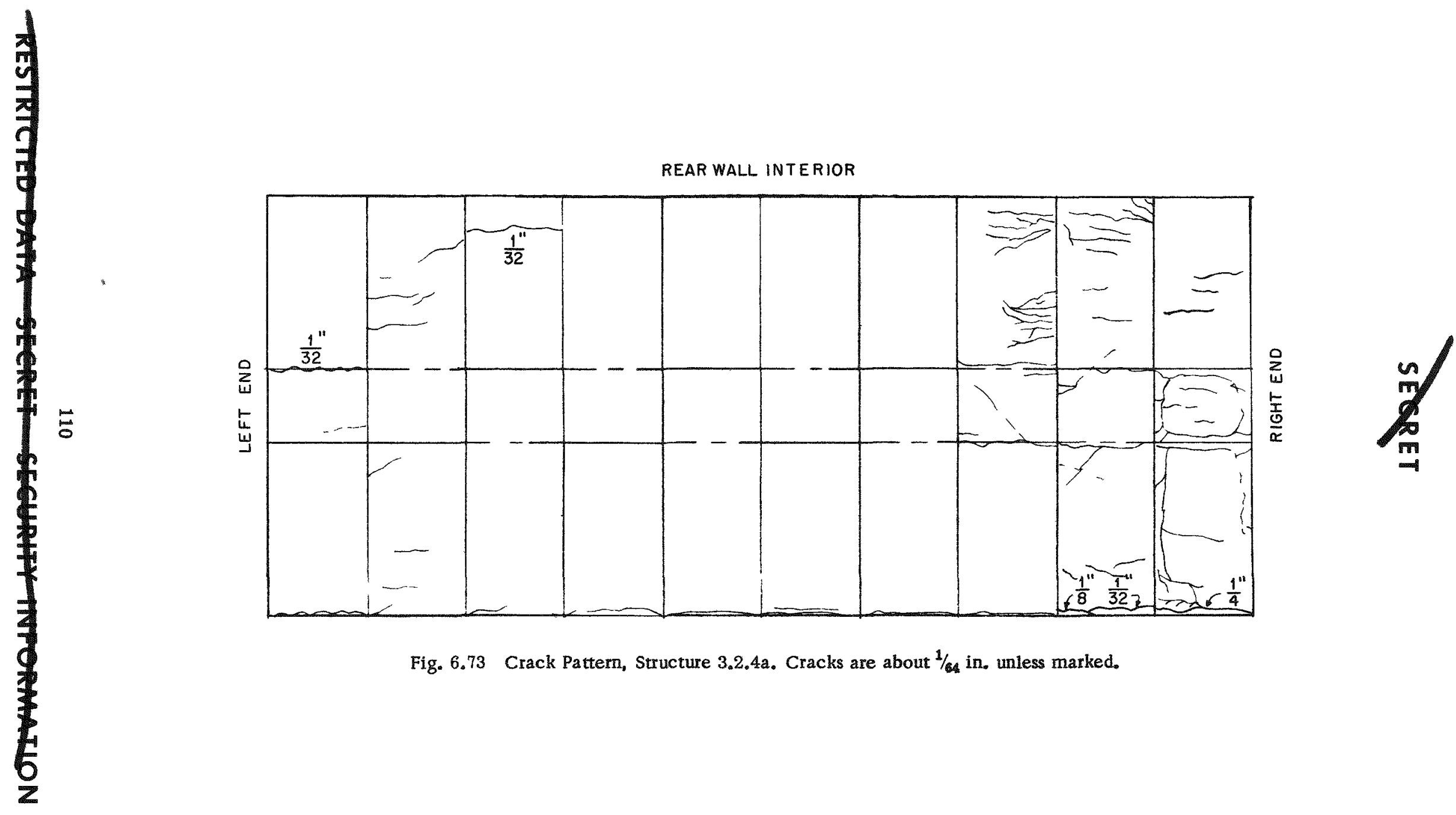

Fig. 6.73 Crack Pattern, Structure 3.2.4a. Cracks are about $1 / 6$ in. unless marked. 


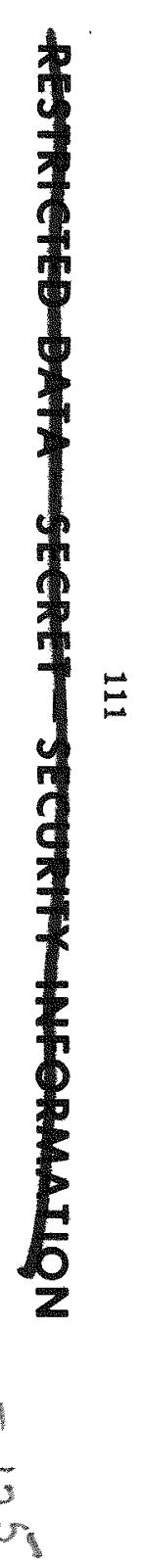

REAR WALL EXTERIOR
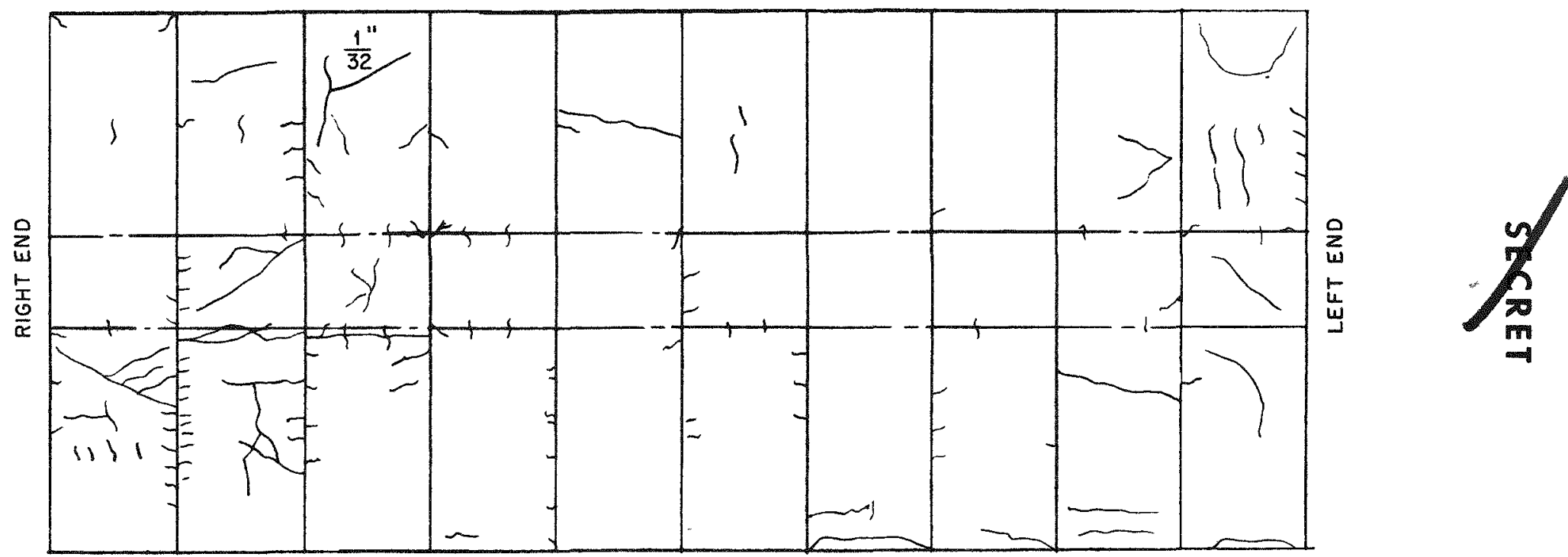

Fig. 6.74 Crack Pattern, Structure 3.2.4a. Cracks are about $1 / 6$ in. unless marked. 


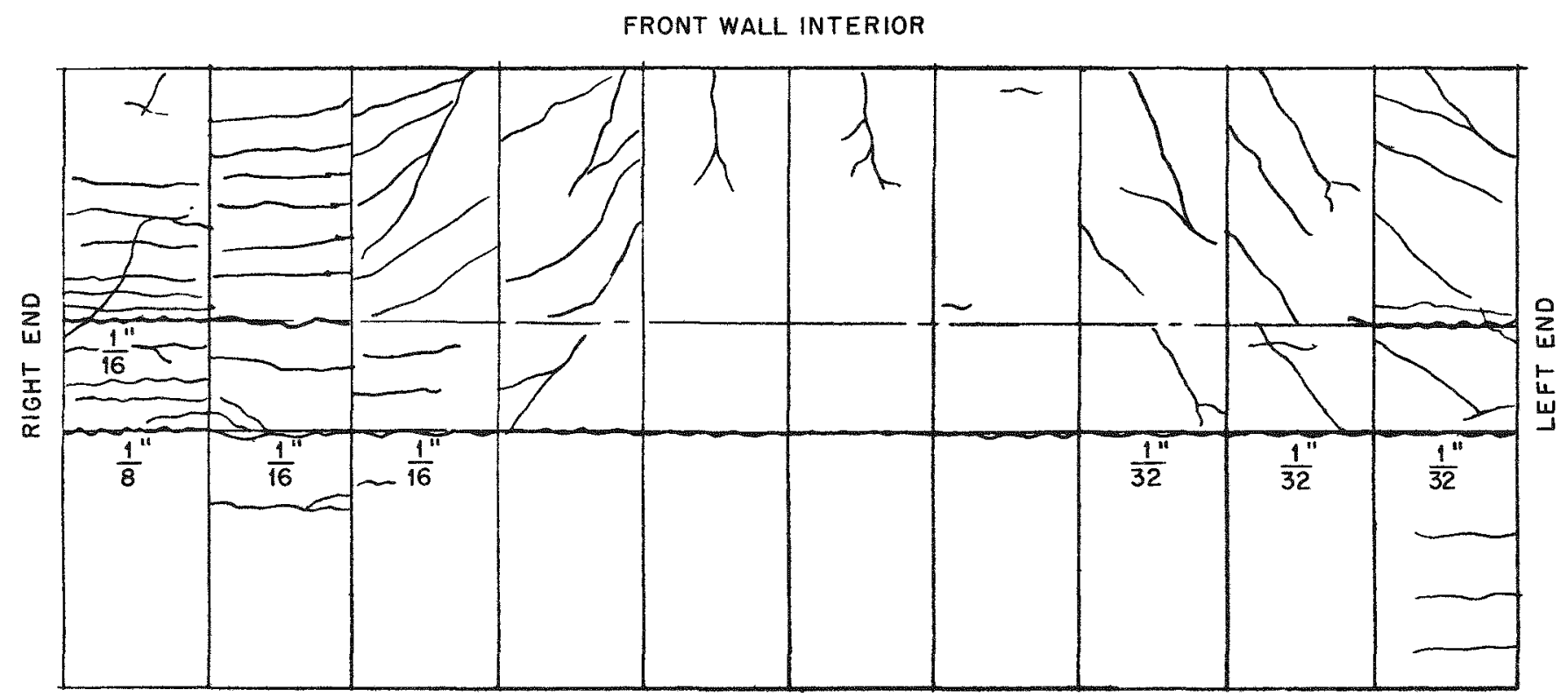

Fig. 6.75 Crack Pattern, Structure 3.2.4a. Cracks are about $1 / 64$ in. unless marked. 

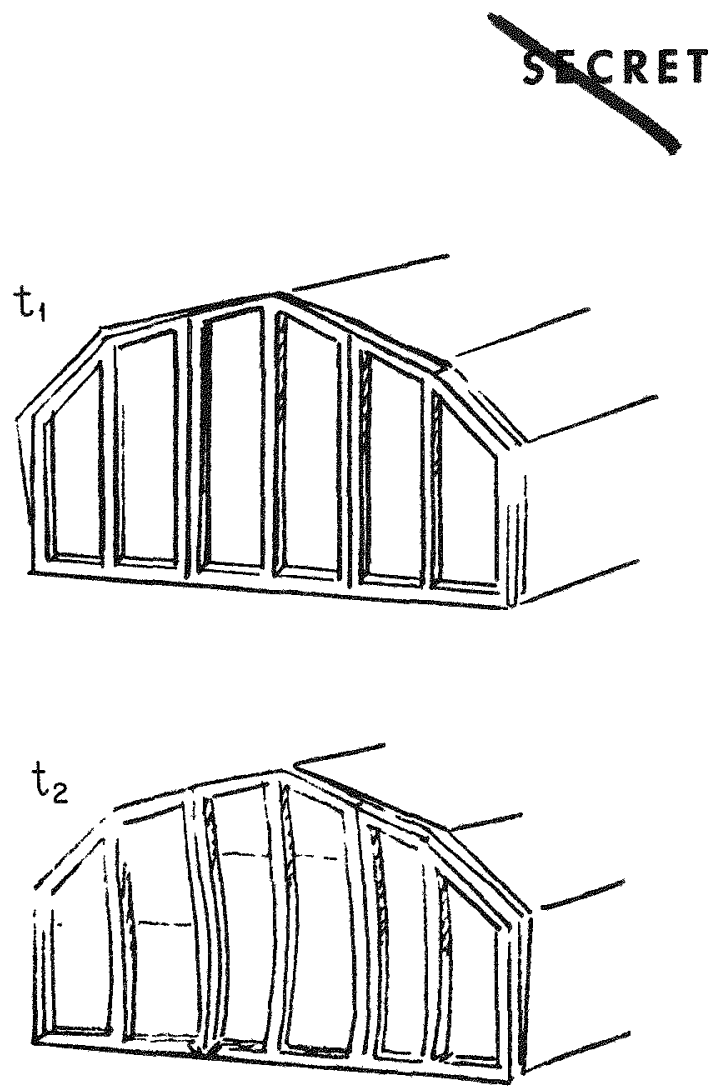

4
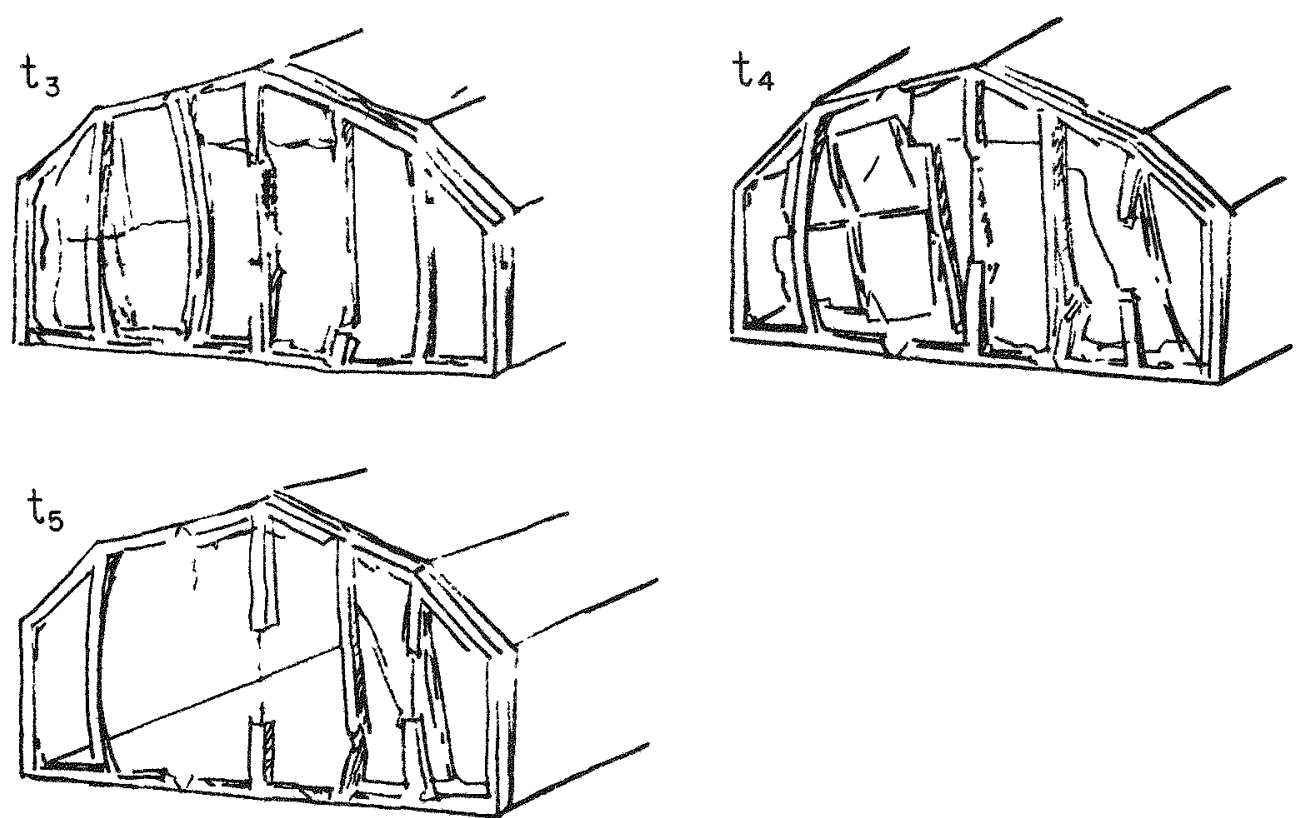

Fig. 6.76 Response History of End Walls of Structure $3.2 .4 \mathrm{~b}$ 
through which the center and rear panels of the end walls were connected failed at the base rib and deflected inward. The skin pulled away from the center ribs of each end panel, taking the $3 / 8$ in. reinforcing bar with it. The severe loading of the left rear panel caused the panel skin to fail along a horizontal line near the center; only the $3 / 8$-in. bar held the two halves together.

The left center panel failed in the same manner about $4 \mathrm{ft}$ from the top; the pieces were entirely separated. This panel also failed and separated along the vertical center line. The left rear panel and the rear half of the left center panel were forced out of position, hurling bottom first toward the center of the building. The rear half of the center panel was on the bottom of the debris with the left rear panel beside it. The top $4 \mathrm{ft}$ of the center panel fell inward. The rear and center panels of the right end wall falled, bottom first, moved inward, collided with the left end panels, and fell inside face upward, bottom toward the center of the building. The front part of the left center panel landed on top of this debris. The door which was in the right center panel remained bolted to the vertical rib of the center panel. This panel folded along the vertical center line. The right rear and center panels remained attached by one bolt.

(d) Methods of Failure. Wall panels with ribs on the outside were damaged; however, those with ribs on the inside did not fail. The gradation loading on the front wall gave a step-bystep picture of the failure of a wall panel. Figures 6.77 and 6.78 show the last two steps, the most significant in the series. The whole group is included in Fig. 6.79. Figure 6.77 show's how the concrete broke away from the rib and the skin when the mesh failed plastically at its anchorage to the rib. At this point the mesh is under high tension, and another increment of loading would have resulted in failure as shown in Fig. 6.78. It is to be noted that the rib broke up in the bottom half and that the mesh failed in tension in the top half. Since the bottom half was under the more extreme load, it is assumed that it failed first, placing an eccentric load on the mesh in the top half. The critical section therefore was the rib. The rib concrete broke up around the connecting bolts and the $3 / 4$-in. reinforcing bar, allowing the diaphragm to pull free.

The two ribs-outward panels nearest the center of the building failed in the roof section as shown in Fig. 6.80. The heaviest load was on these center panels. The restraint of the rearwall panels to the deflection of the front-wall panels caused the failure in these roof sections.

Figure 6.81 shows the cracks in the ribs in the front-wall panels at the lower fold line. "The resistance of the rear-wall panels caused the front-wall panels to tend to straighten, the top pitching upward. The tension steel was not tied to the compression; therefore, in attempting to straighten, it caused the cracks at the lower fold.

The center rib of all end panels failed in the same manner. This failure was due to an error in engineering detailing. The skin was not tied to the rib steel except through concrete. When the skin was loaded, the concrete failed in tension between the inner and outer reinforcing bars, leaving the outer bar and the concrete in original position with slight deformation.

The rear rib of the center panel and the front rib of the rear panel in both end walls failed at the top and bottom. The ribs were loaded by the skin and were in the approximate position of maximum end-wall deflection. There was no tie between the steel in the top and bottom ribs and the vertical ribs. The heavy load resulted in large deflections which caused the concrete to break up at the panel corners and allowed the ribs to move out of position.

The mesh of the diaphragms failed at the change in section, in most cases, at the ribs. All mesh was necked down at the point of failure indicating tension failure.

\subsubsection{Structure 3.2.5 (Cylindrical Arch)}

(a) General Damage. The end walls of Structure 3.2.5 were blown toward the building interior (Fig. 6.88). The main arch shell of this structure was deformed slightly in the direction away from the blast. Cracking was extensive, but no failures occurred. The front side of the arch flattened out, and the rear side bowed in. The foundation was undamaged, and little, if any, tilt was observed. The floor panels suffered permanent downward deformations from the blast pressure they received after the end walls had failed.

(b) Damage to Components. The arch panels deformed symmetrically to the rear at the center points in amounts up to $1 \% \mathrm{in}$. in the horizontal plane. Good coupling between panels caused all panels to act as a unit. Response 


\section{SERET}

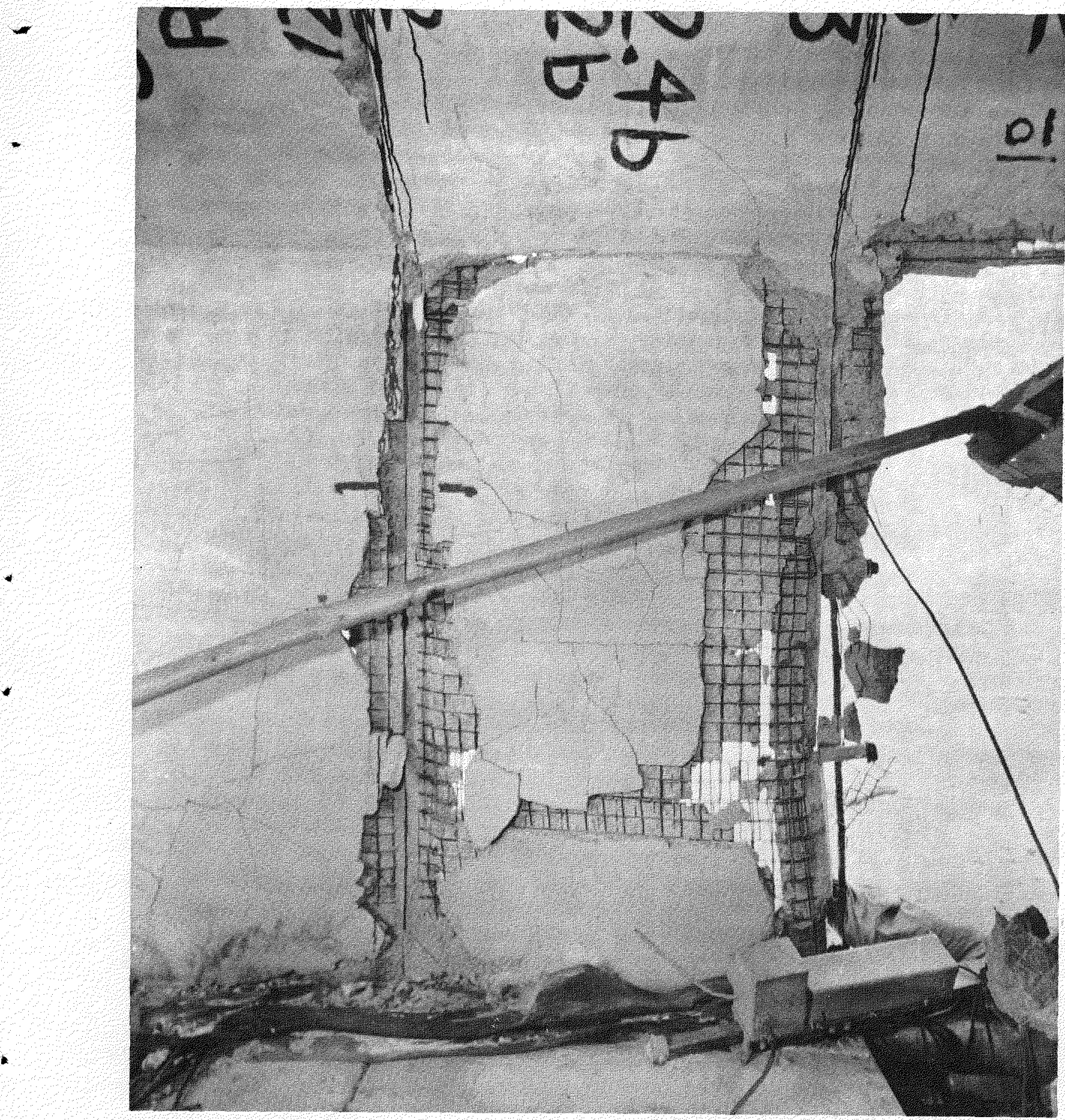

Fig. 6.77 Interior View Showing Diaphragm Distortion and Concrete Spalling After Loading 


\section{STCRET}

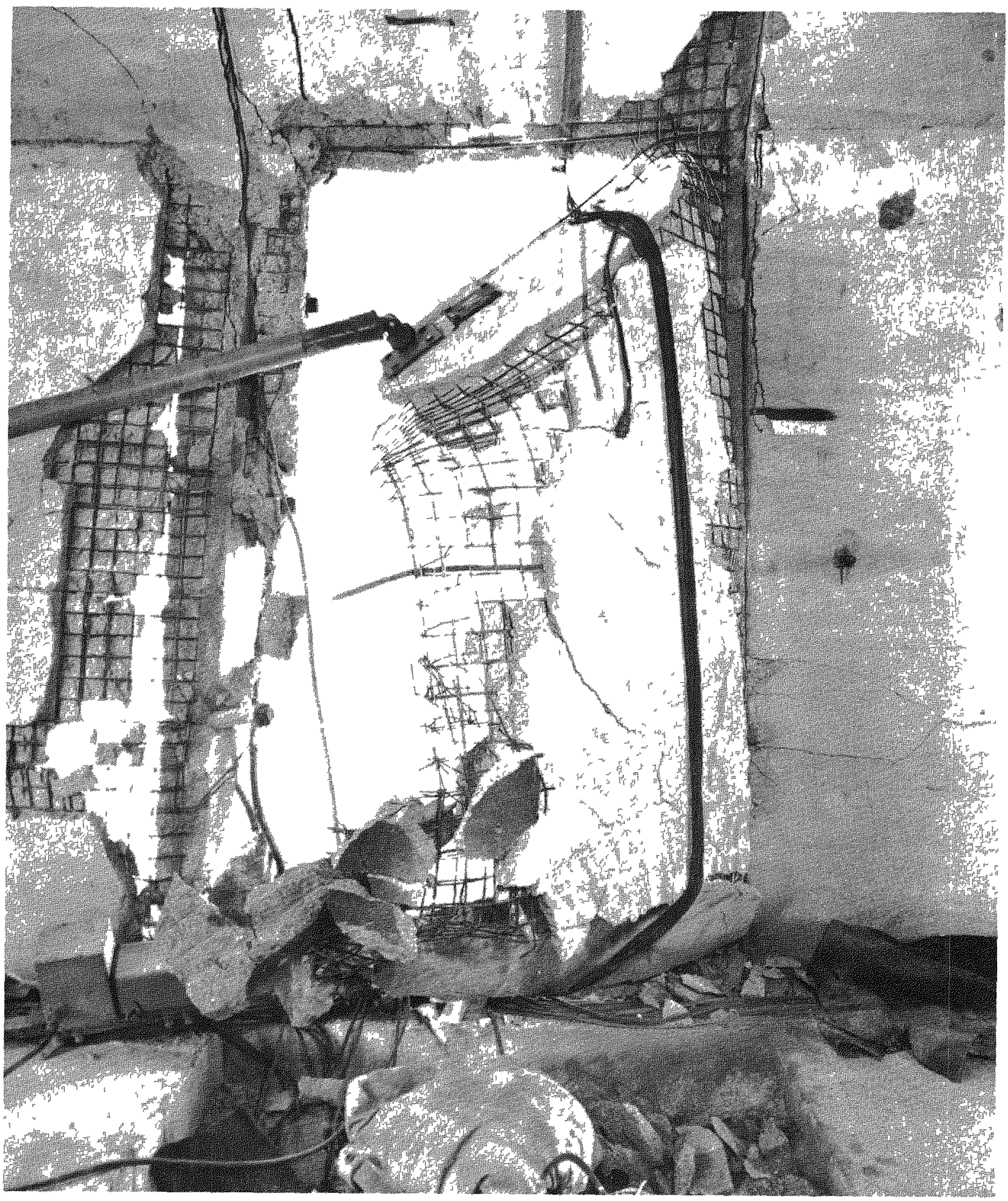

Fig. 6.78 Interior View Showing Failure of Diaphragm After Loading 

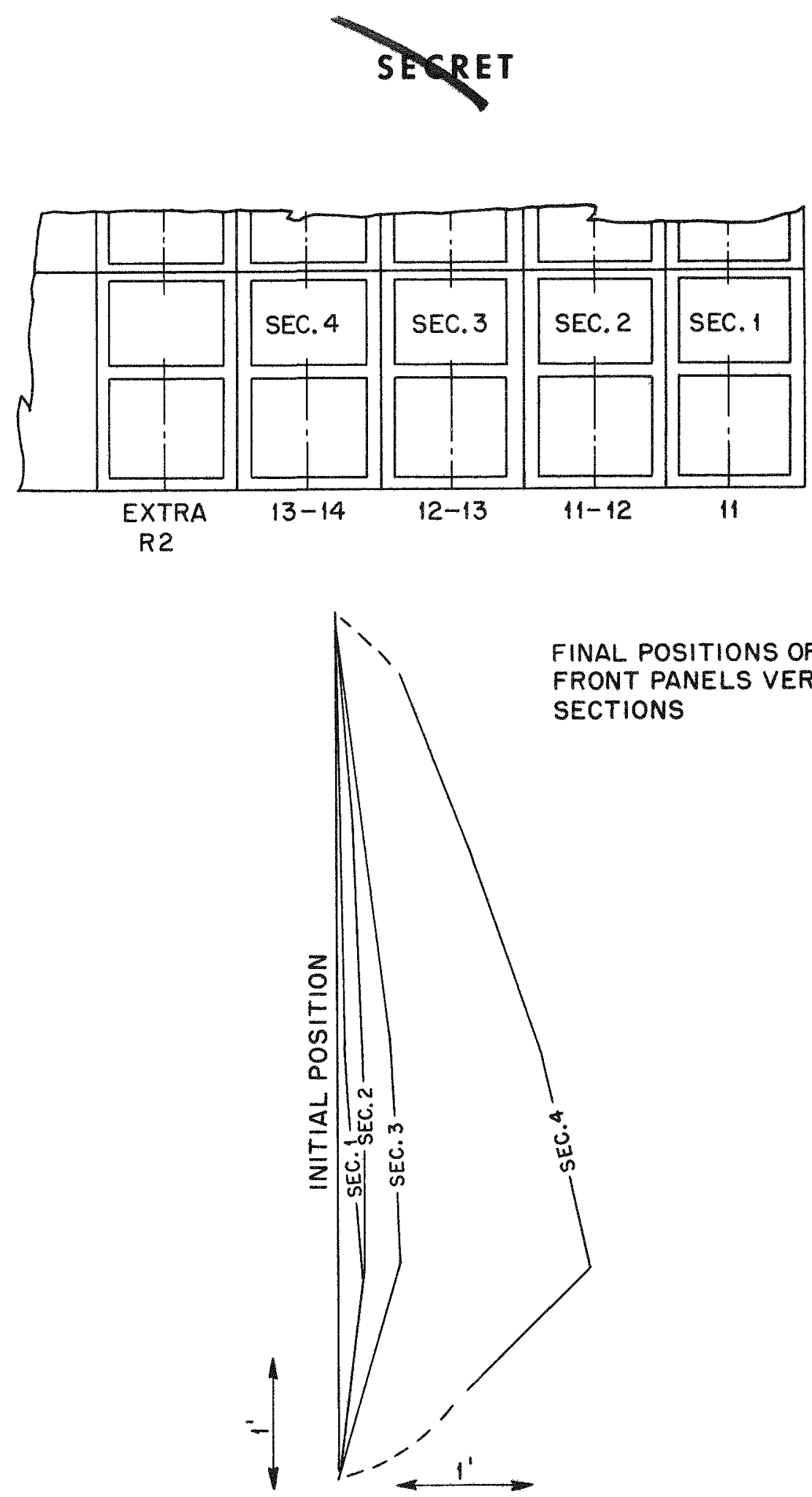

Fig. 6.79 Right Front-wall Panel Deflections, Structure 3.2.4b 


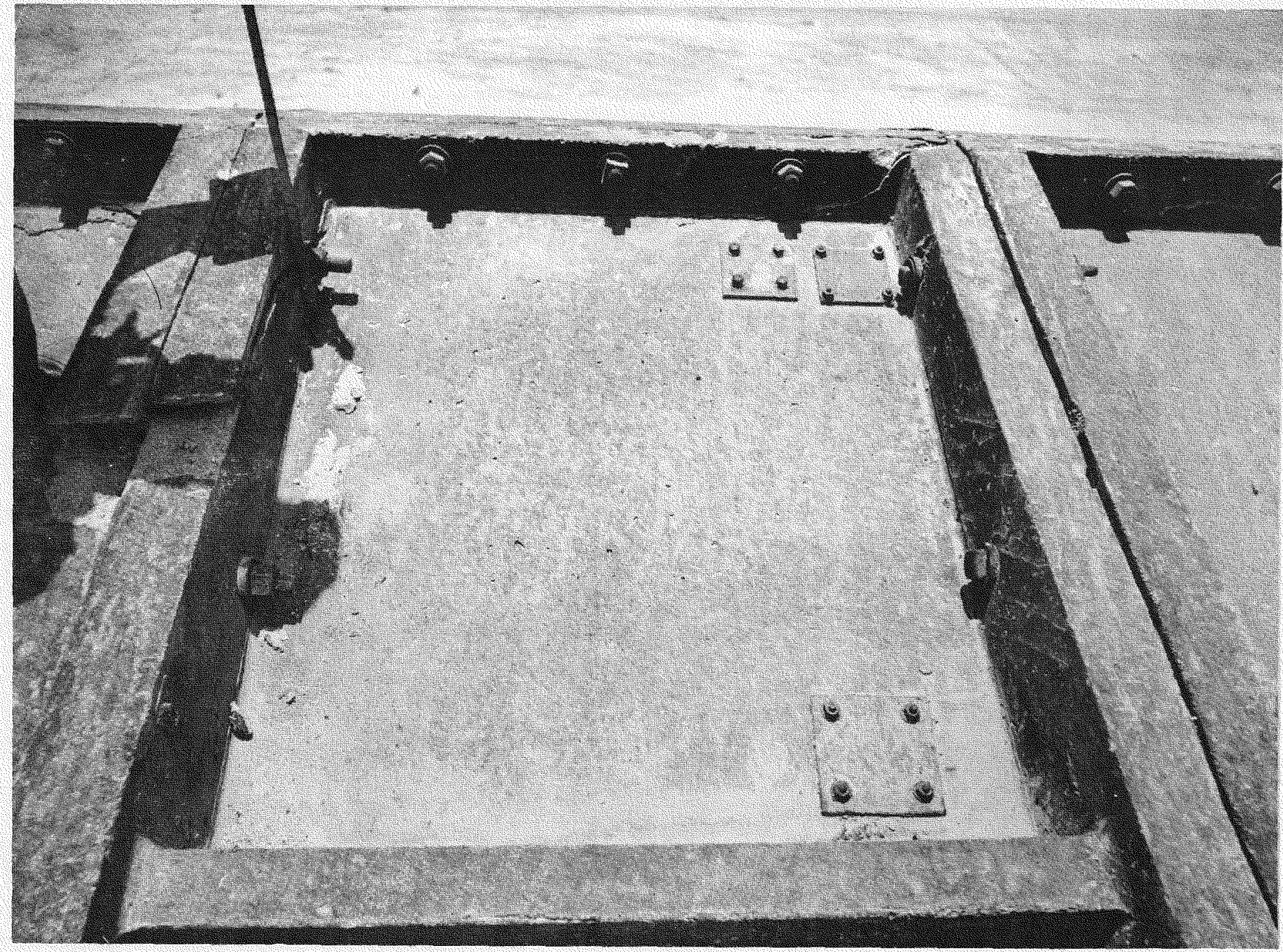

Fig, 6.80 View Showing Roof Failure in Front-wall Panel. Intersection at left is transverse center line of building. 

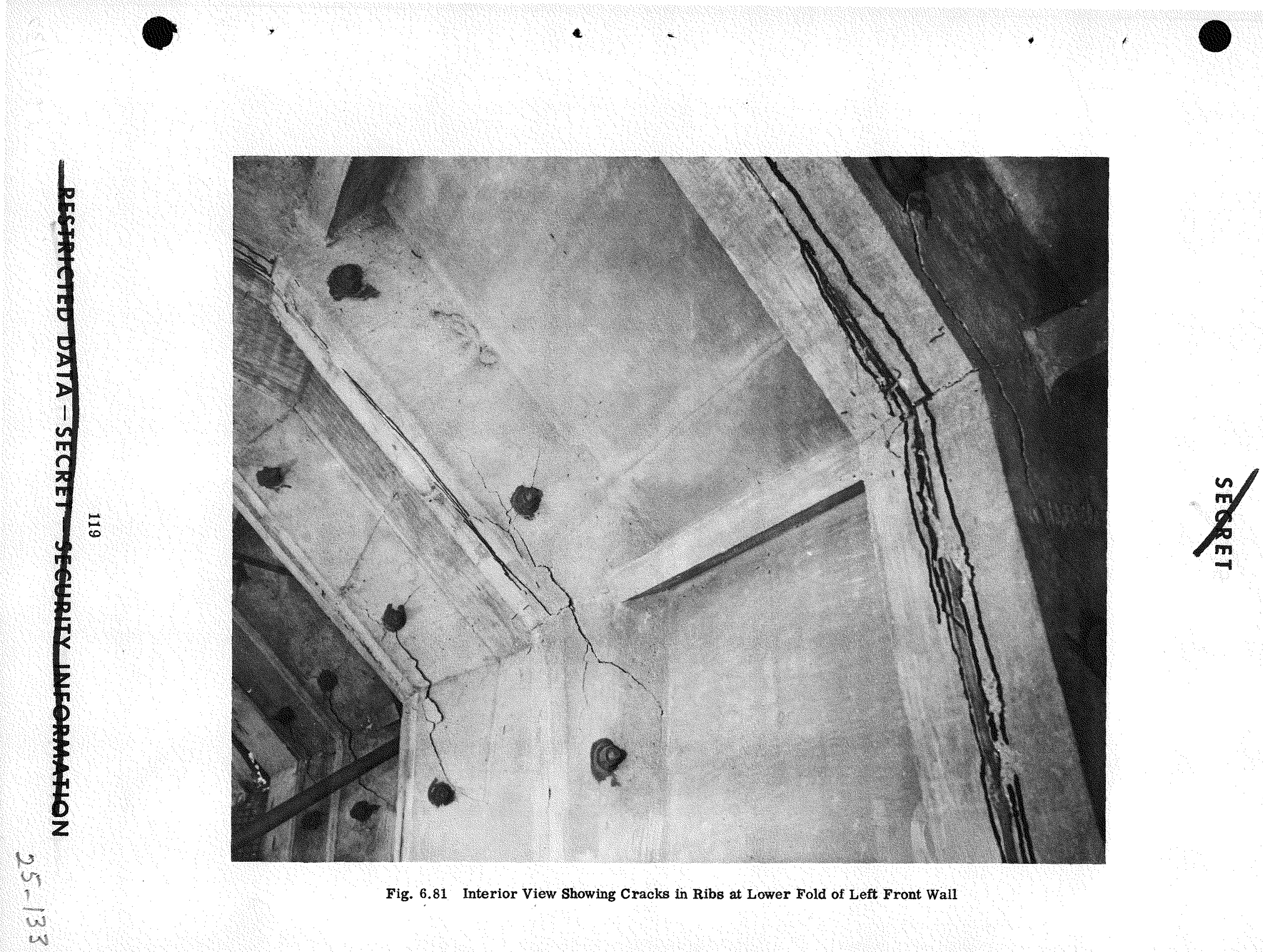

Fig. 6.81 Interior View Showing Cracks in Ribs at Lower Fold of Left Front Wall 


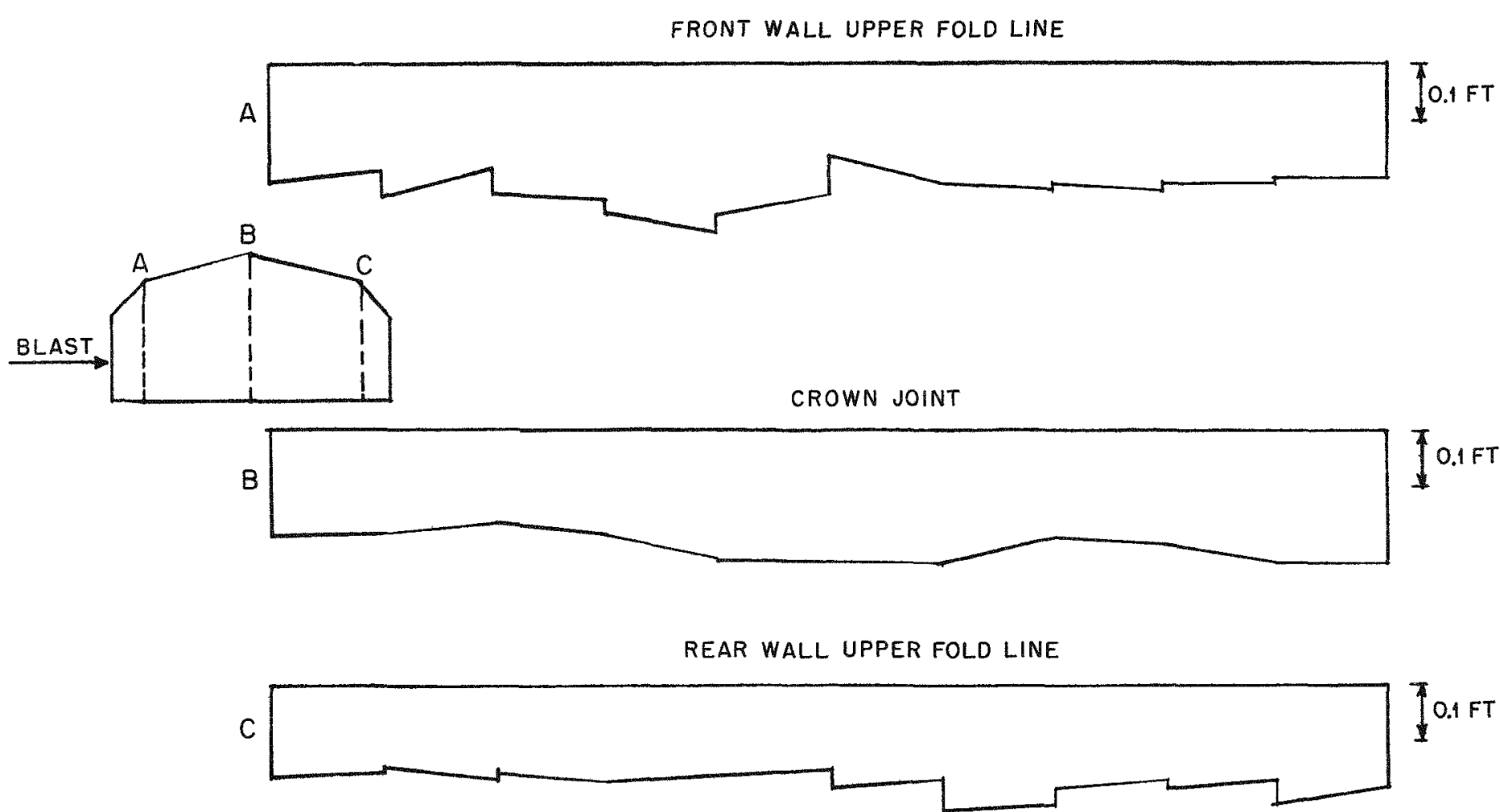

Fig. 6.82 Horizontal Deflection, Structure 3.2.4b. No significant deflections transverse to blast. 

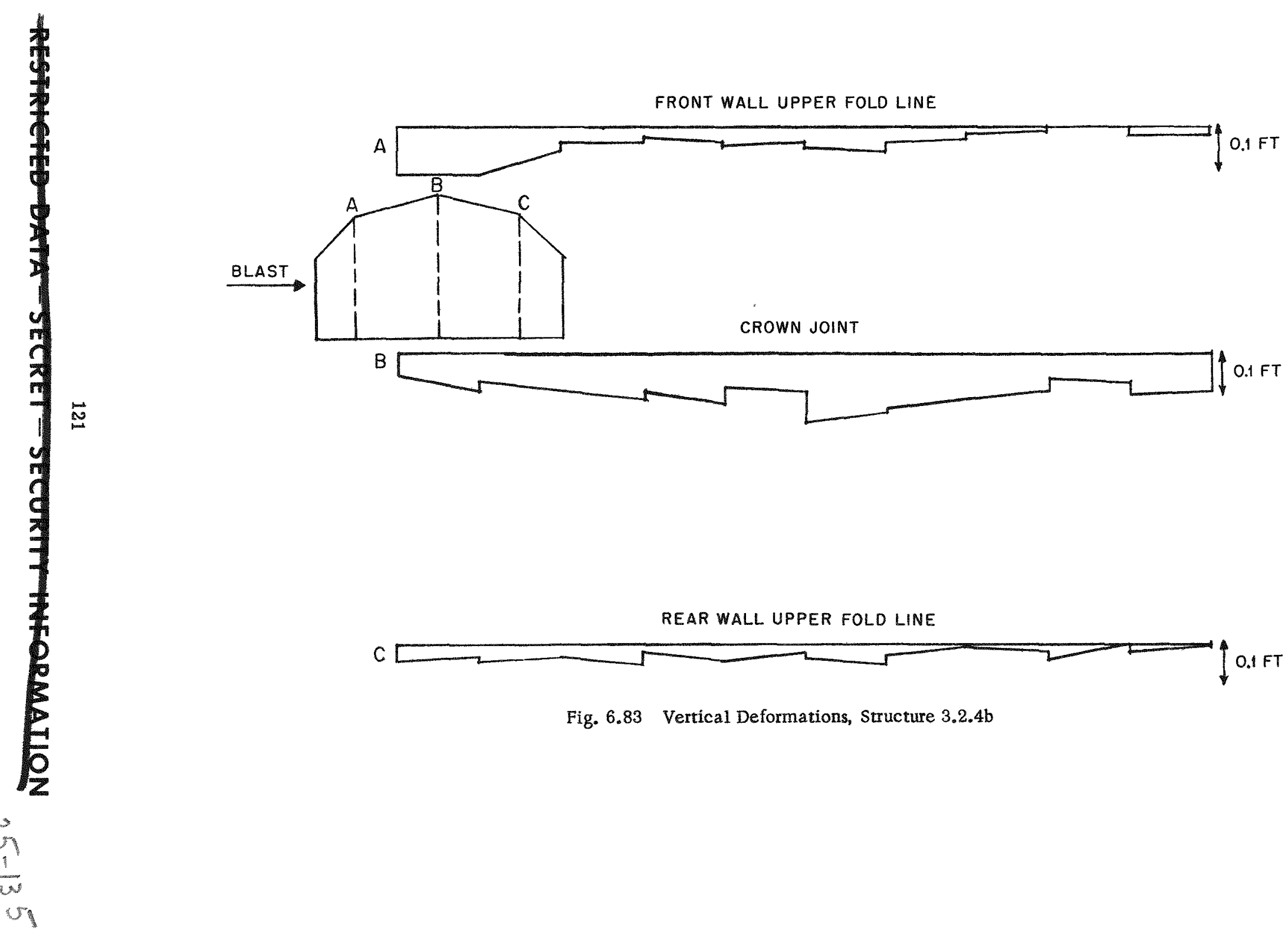

REAR WALL UPPER FOLD LINE

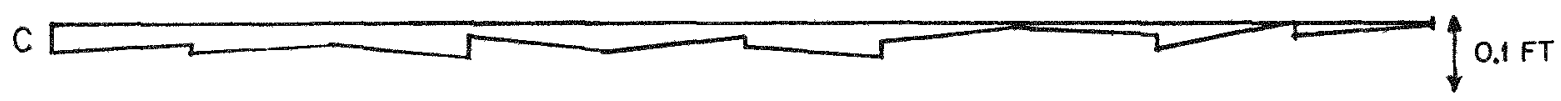

Fig. 6.83 Vertical Deformations, Structure 3.2.4b 


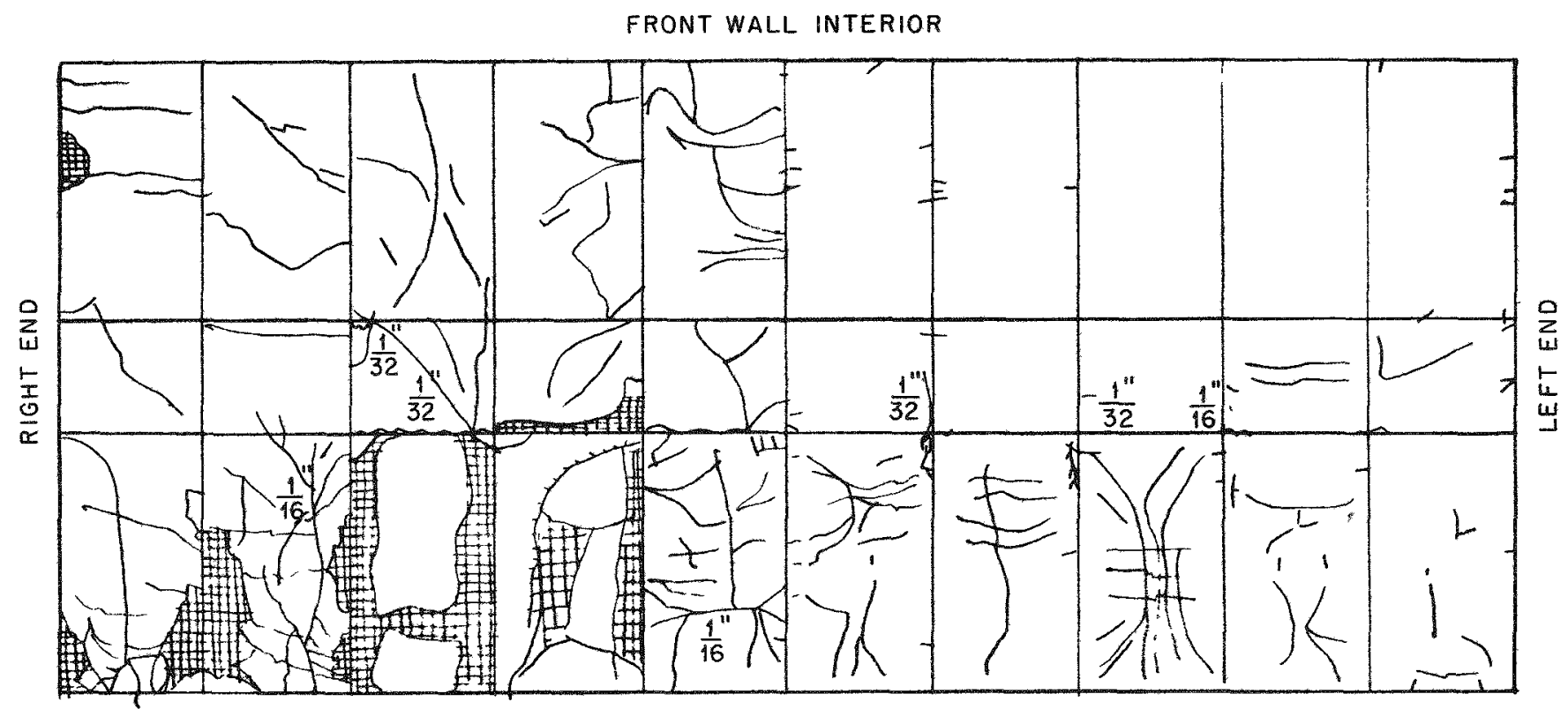

Fig. 6.84 Crack Pattern, Structure 3.2.4b. Cracks are about $1 / 64$ in. unless marked. 


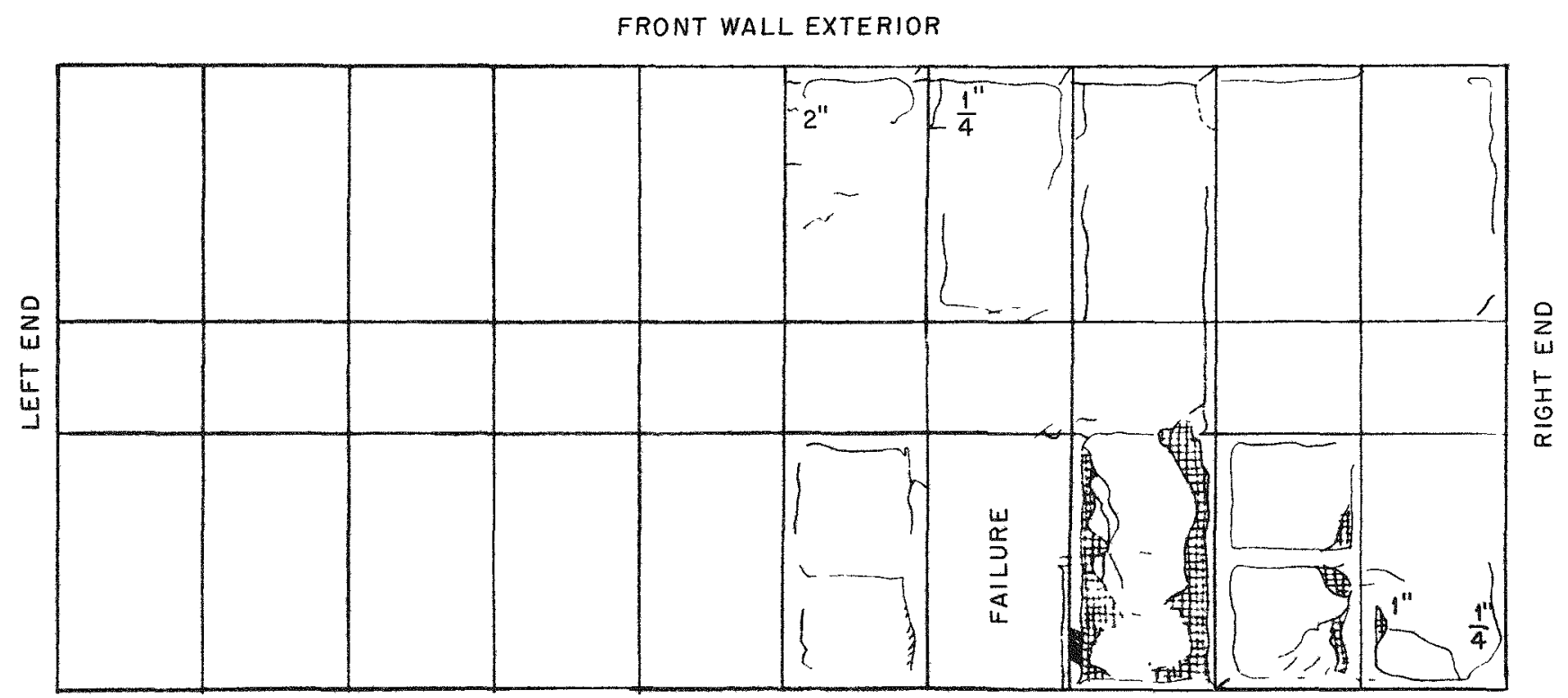

Fig. 6.85 Crack Pattern, Structure 3.2.4b. Cracks are about $1 / 64$ in. unless marked. 

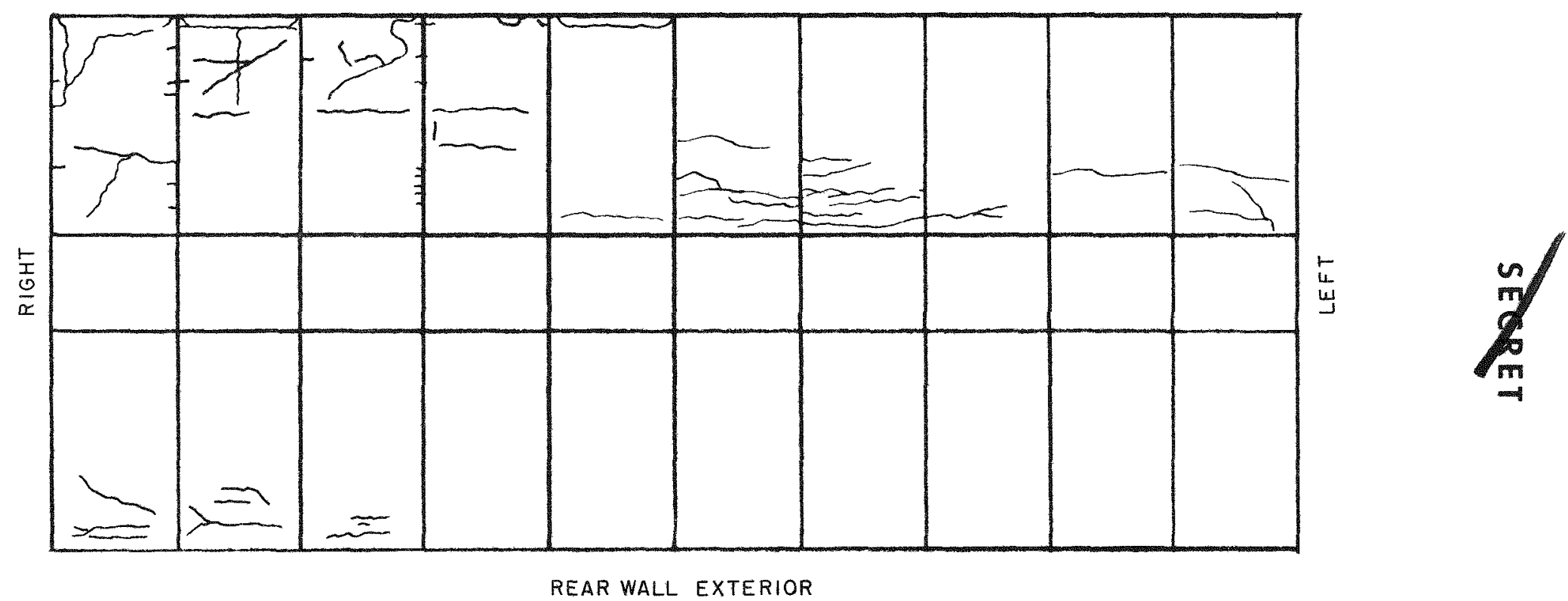

Fig. 6.86 Crack Pattern, Structure 3.2.4b. Cracks are about $1 / 64$ in. unless marked. 


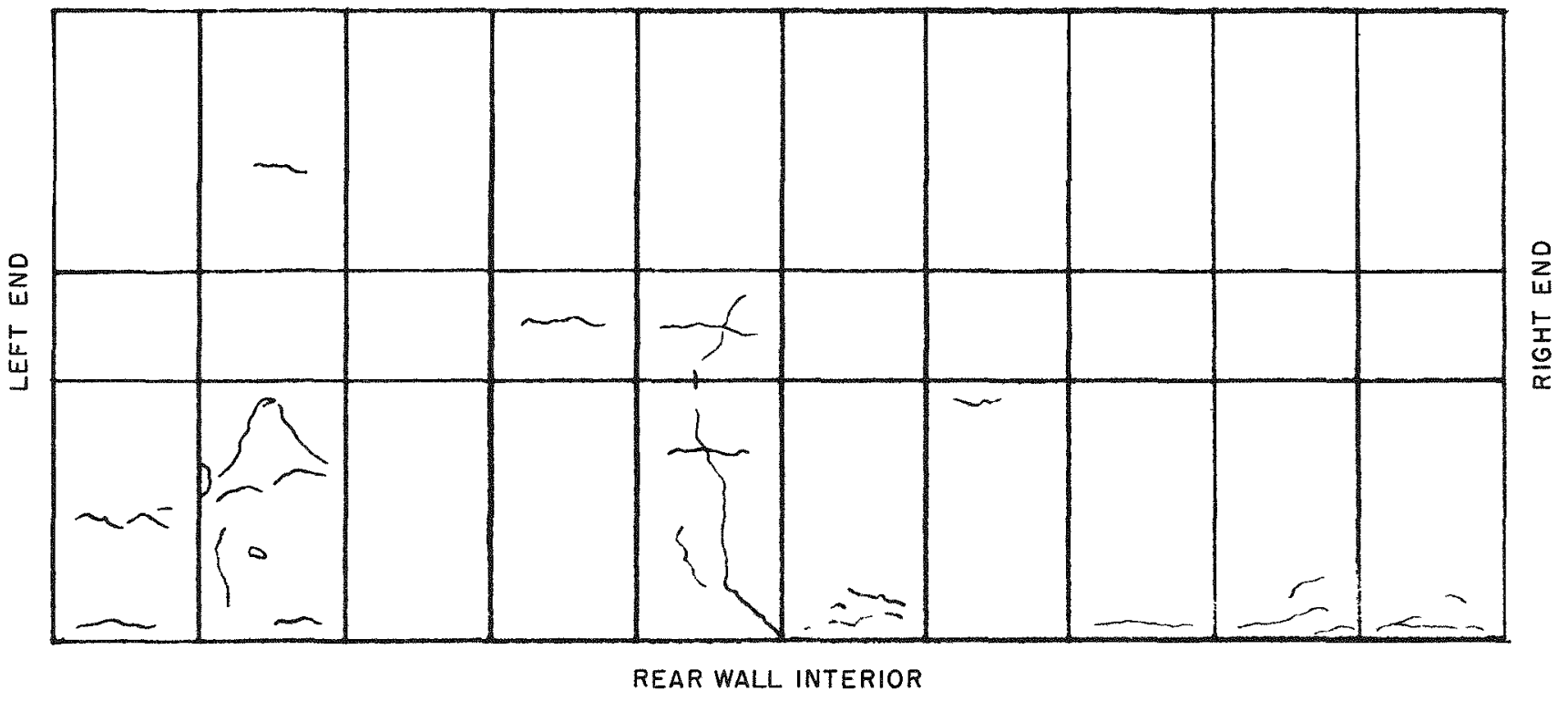

$\prod_{m}^{\infty}$

Fig. 6.87 Crack Pattern, Structure 3.2.4b. Cracks are about $1 / 6$ in. unless marked. 


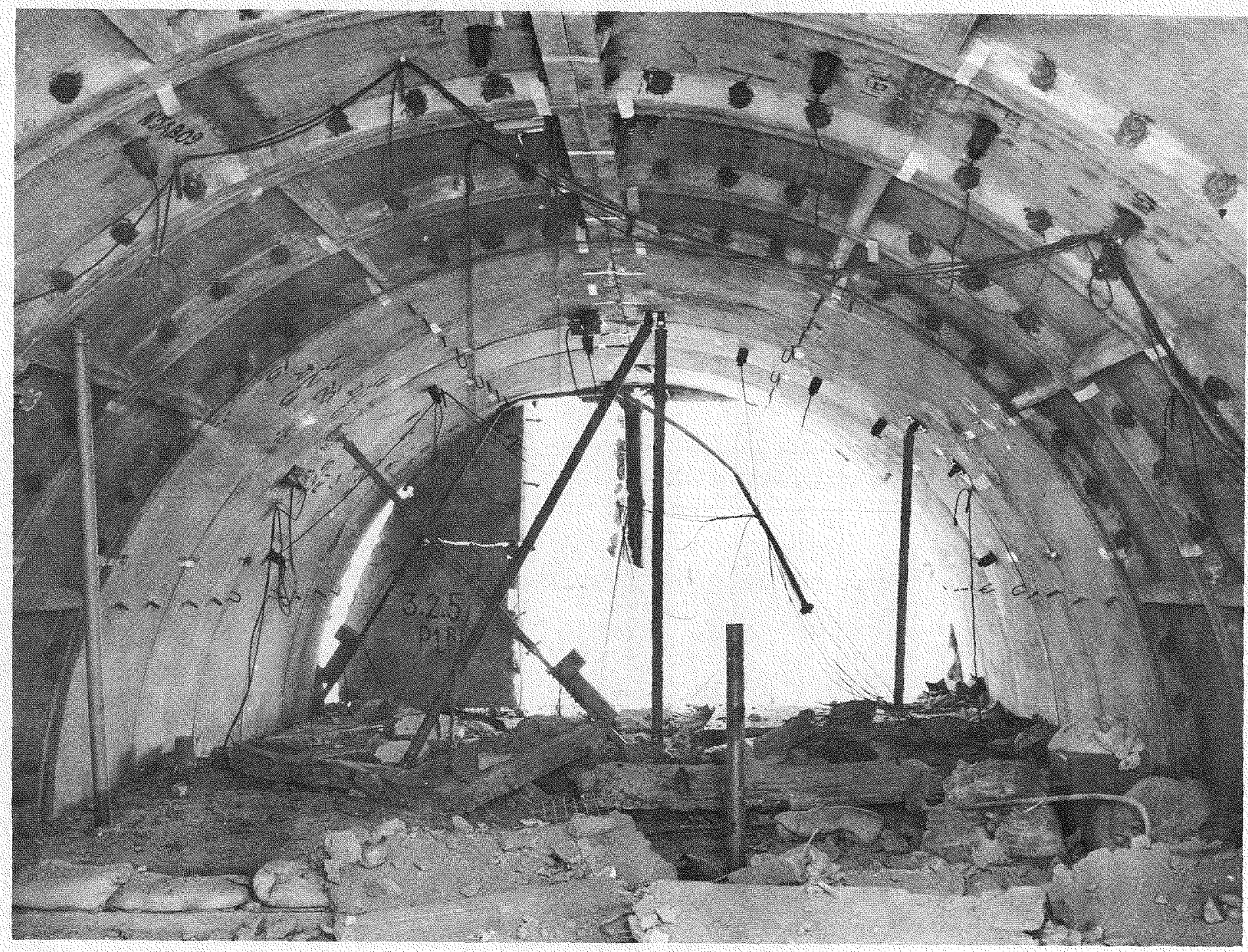

$y$
$\pi$
$\pi$

$\frac{4}{1}$

Fig. 6.88 End Walls in Displaced Positions, Structure 3.2.5

$\vec{s}$ 
within panels depended on the type of panel. Panels with skin out and ribs in exhibited the greatest strength, and few cracks or spalls were found in this type of panel. Panels with skin in were decidedly weaker because of the greater span of membrane and less edge restraint. These panels cracked considerably at the junction of skin and ribs and also within the subpanel itself. The special panels without horizontal bracing ribs suffered no more damage than the panels with horizontal bracing. Anchor-bolt connections and connections between panels were adequate; no failures were found.

The center and rear panels of both end walls failed completely and were displaced into the building. The two end walls failed similarly, and corresponding fragments were moved approximately equal distances, indicating that failure occurred approximately simultaneously. On both end walls the front panel retained its attachment to the arch shell, although it was badly damaged with much spalling and with connections nearly severed (Fig. 6.89). Those panels which became entirely detached severed in a horizontal line near the center of the panel and at the point where the skin joins the rib. In all cases the mesh failed in tension. Generally the ribs retained attachment to the arch shell. In some cases the bottom ribs broke loose from the anchor bolts. The vertical center rib in the front panels of the end walls separated from the rest of the panel. This doubled the span of the skin and reduced its resistance to moment by a factor of 4 .

(c) Response History. The end walls were blown in early in the response history as indicated by the somewhat even deformation of the arch shell to the rear. However, the front wall of the arch was somewhat restrained by the front panel in each end wall remaining in place. Vortex action is believed to have reduced the pressure on these front panels. Some pressure equalization between building interior and exterior occurred after the end walls failed, tending to reduce the deflection. On the other hand, the failure of the shear or end walls tended to increase the deflection. With the exception of the end walls, this building responded excellently under dynamic loading.

(d) Methods of Failure. With the exception of tension cracks in skin and ribs of some of the arch panels and some spalling at the panel edges
(Fig. 6.91), all failures in this building were confined to the end walls.

The end-wall failure cannot be considered too meaningful because the panels were erected with the weak side out. The heavy reinforcing normally designed as tension steel was thus on the compression face (Fig. 6.92). Placed in this position, the vertical center rib of each panel offered only the strength of concrete in tension to the over-all panel strength. Once the skin broke away from the rib, the panel was very weak in resistance to moment. Concrete tension failures also occurred at the bolts in the outer rib. Reversed, the panels would have been several times stronger in bending, the primary cause of failure, and might well have survived.

\subsubsection{Structure 3.2.6 (Dome)}

(a) General Damage. Structure 3.2.6 withstood the loading without damage. Taping at the intersections showed slight displacement of panels relative to each other. No large portion of the earth cover was blown away, but rather the middle section of earth was thrown out and down, exposing some of the B-ring panels. The door was slightly dished near the rear edge, but it was easily removed. The wing walls were undamaged.

(b) Damage to Components. There were some cracks and some spalling at all intersections of the top of the D-ring and bottom of the C-ring. At the base of the D-ring there was some spalling at corners in the panels opposite the wing walls. There were very few spalls or cracks in the other panels. The floor was cracked in a semiring opposite the wing walls. Two cracks led from the ring to D-ring panel intersections.

(c) Response History. The impact was attenuated by the earth cover before striking the structure. The impact caused the structure to vibrate, throwing off the earth cover in the middle section.

(d) Methods of Failure. Failure in the panels of this structure was limited to a plastic change at some joints. Irregularities in casting and shrinkage caused the panels to bear on each other at the corners. Further, column action of the ribs in the vertical plane during vertical deflection and of the ribs in the horizontal plane during wracking caused plastic strains at the intersections. 


\section{SEREe}

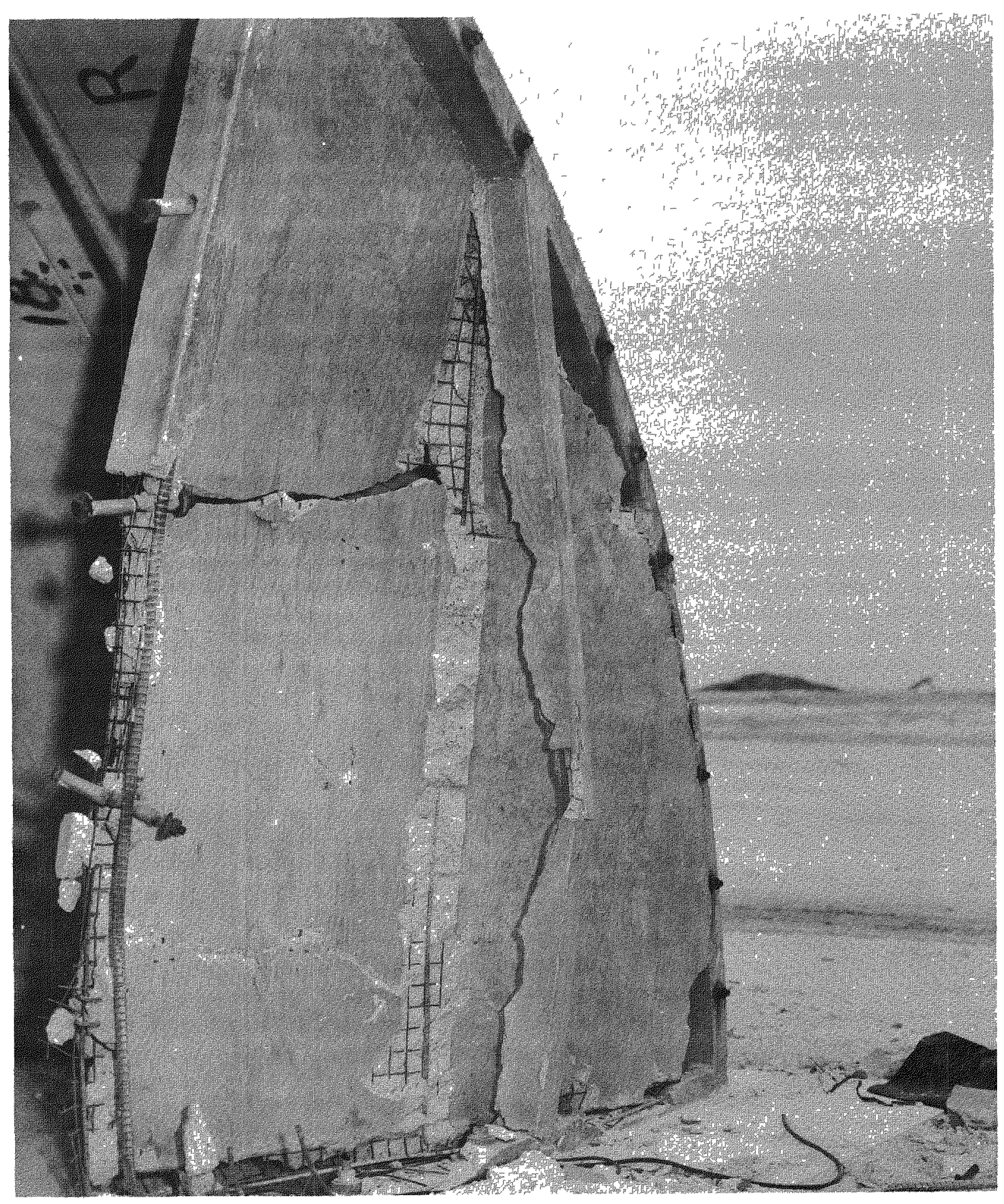

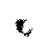
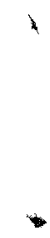

Fig. 6.89 Left End Wall Nearly Severed, Structure 3.2.5 

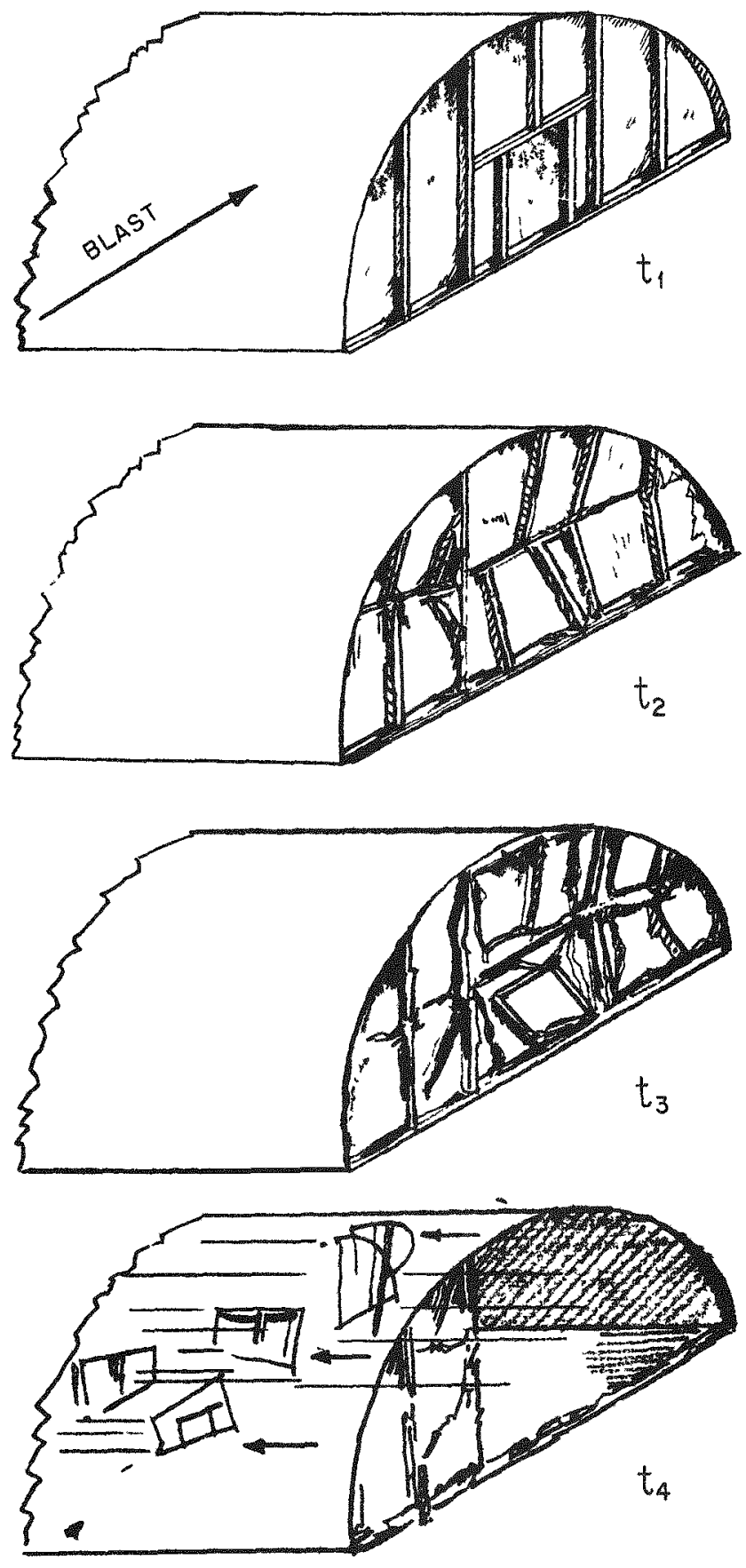

Fig. 6.90 Response History of End Walls of Structure 3.2 .5 

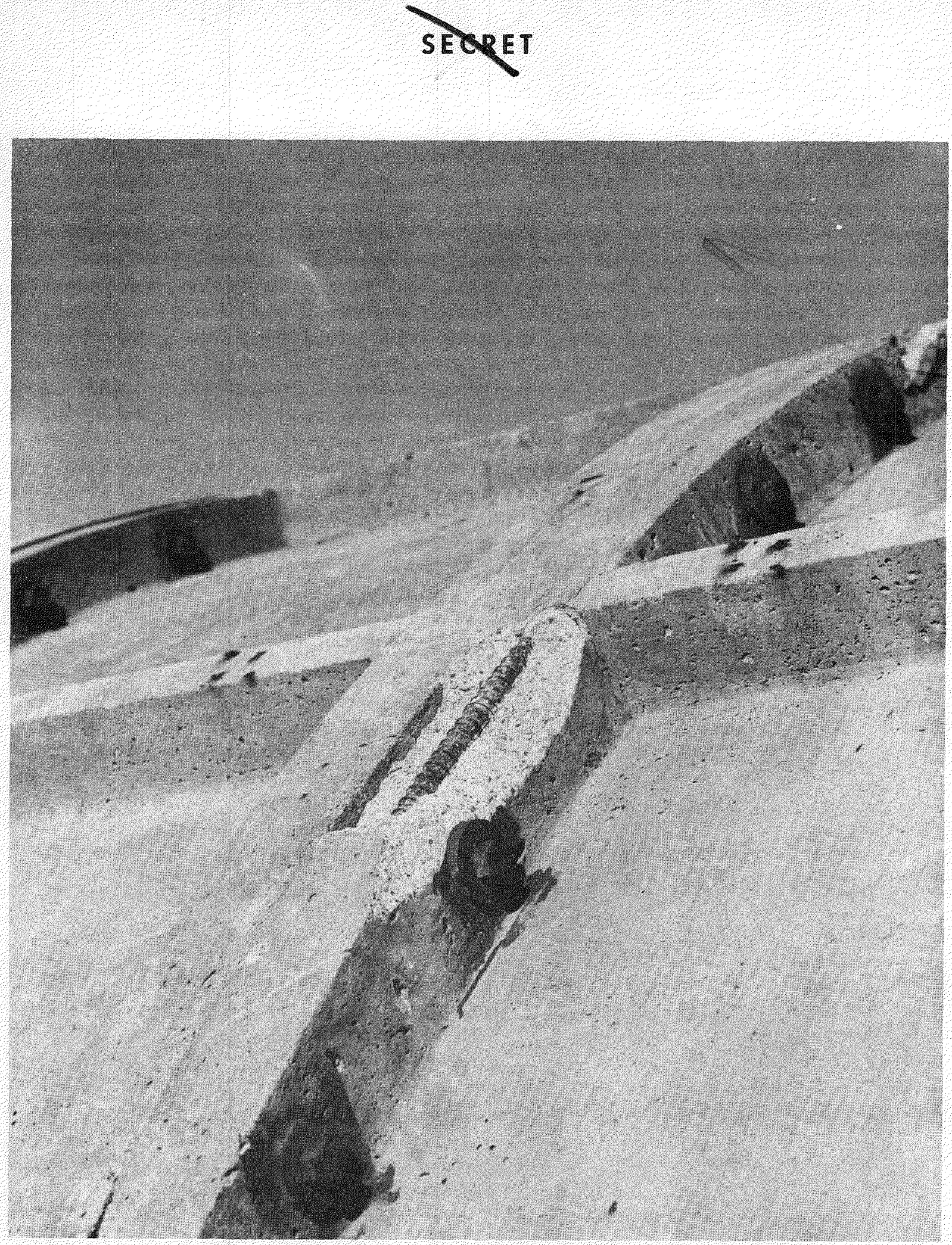

Fig. 6.91 Spalling in Rib of Rear Areh Panel, Structure 3.2 .5 

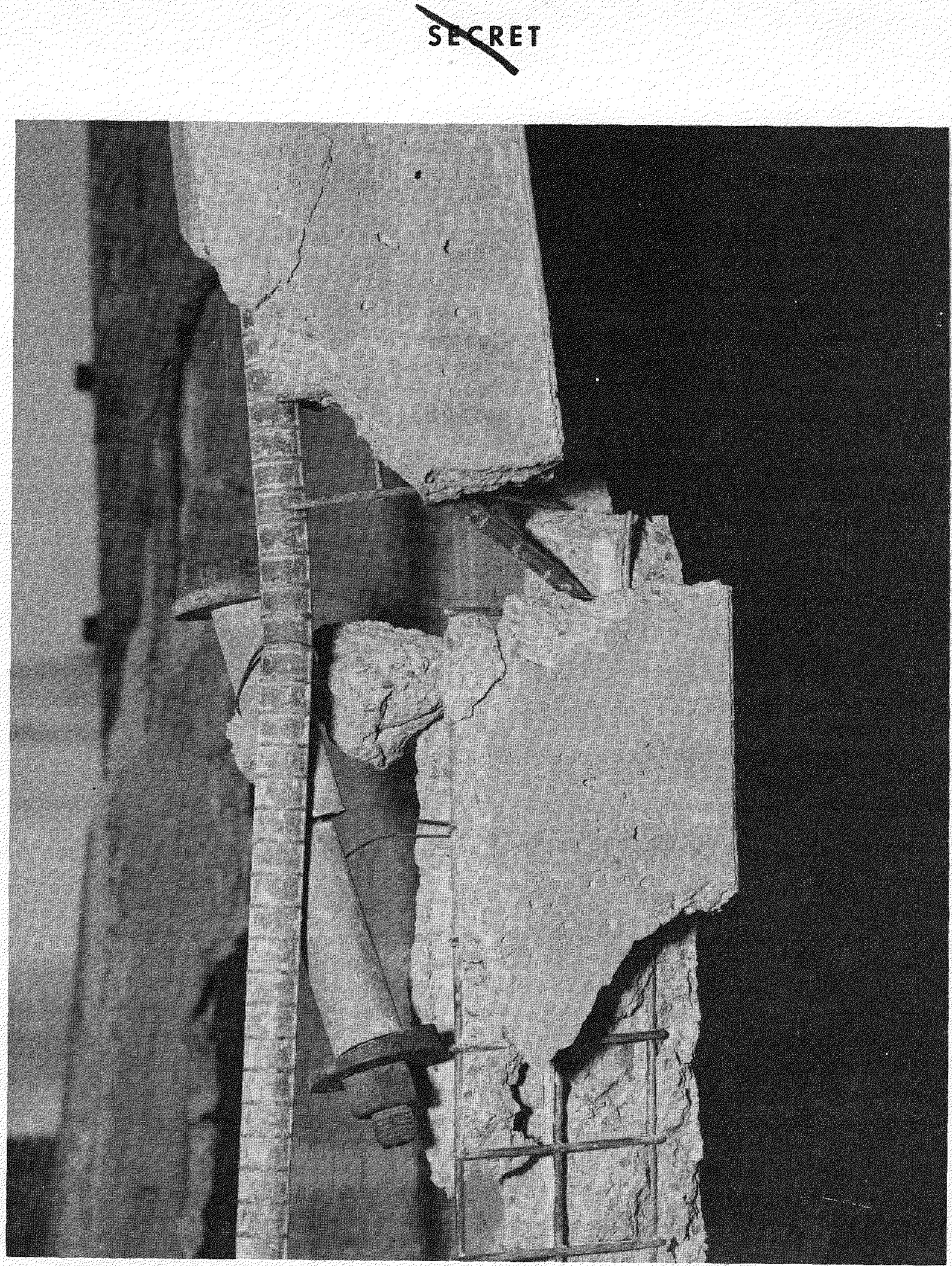

Fig. 6.92 Steel in End-wall Panel, Structure 3.2.5 

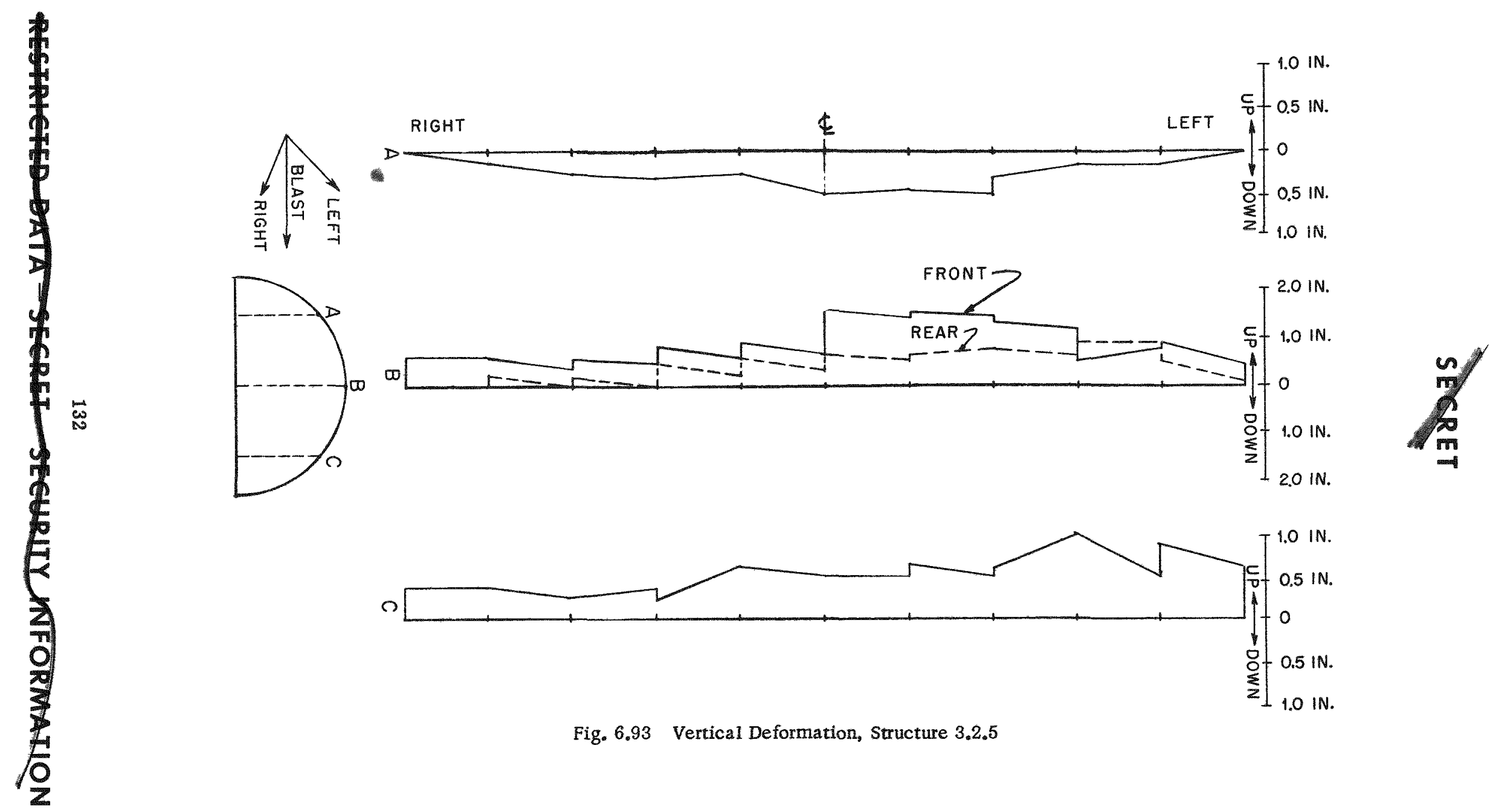

Fig. 6.93 Vertical Deformation, Structure 3.2.5

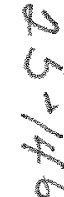




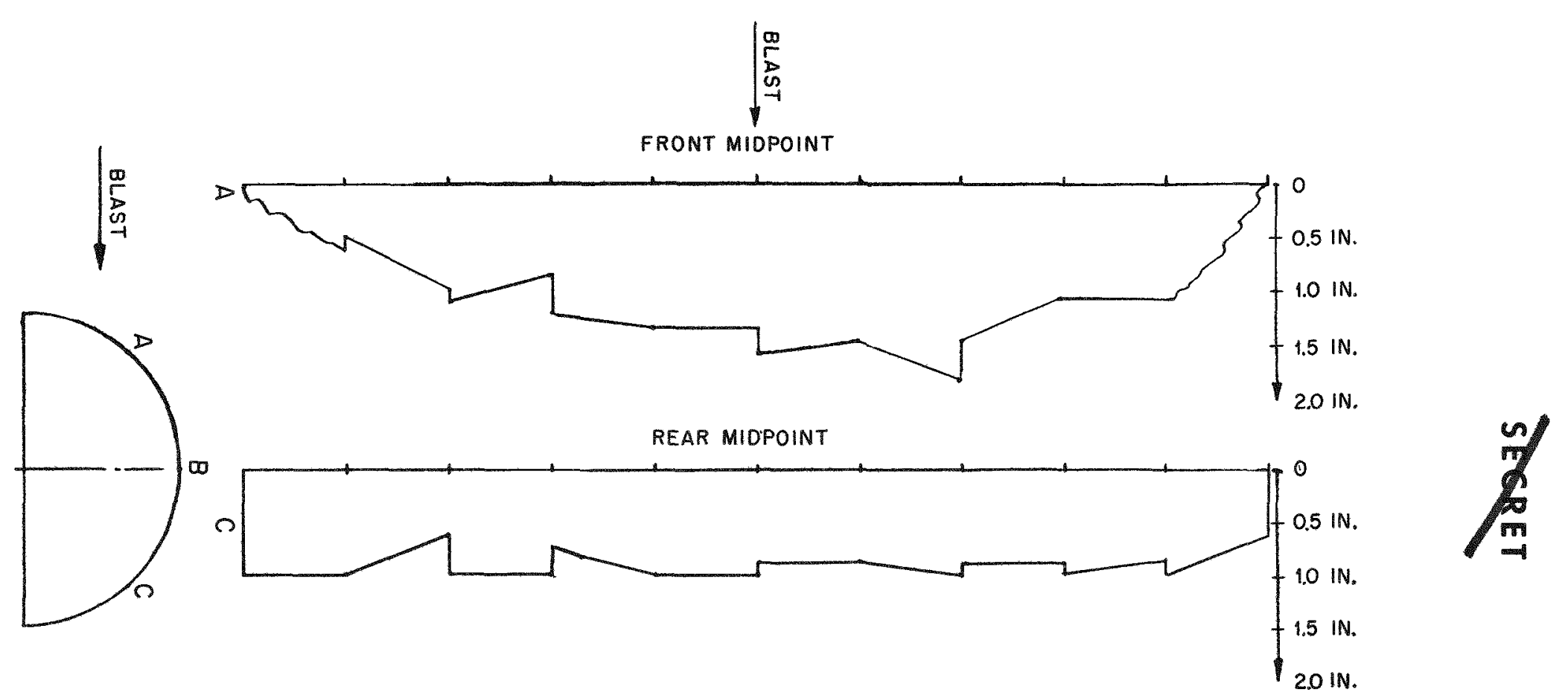

PEAK

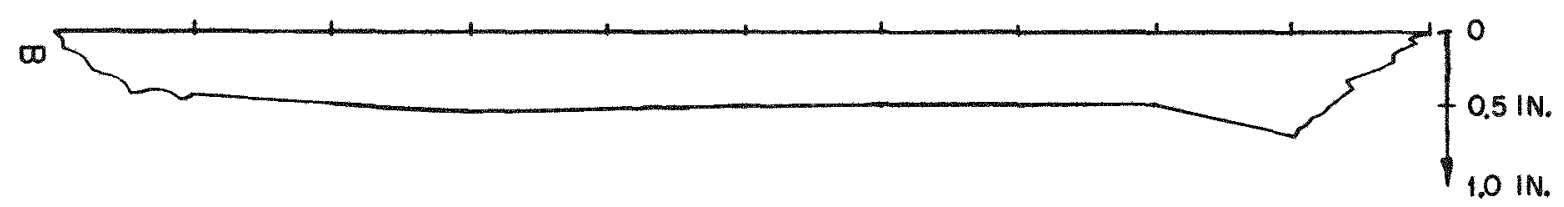

Fig. 6.94 Horizontal Deformation, Structure 3.2.5 


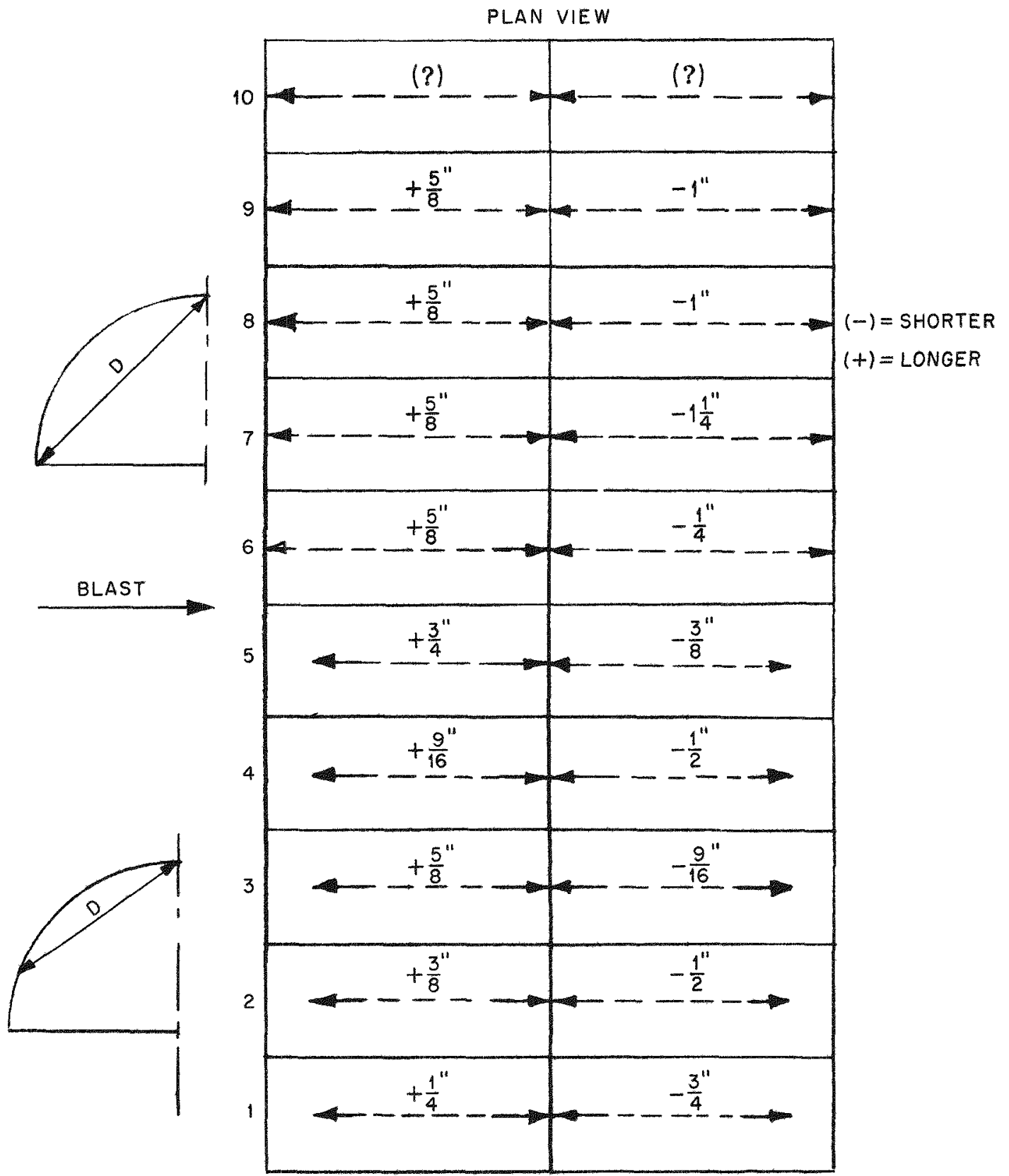

Fig. 6.95 Changes in Diagonal Length of Arch Panels Between Points Indicated, Structure 3.2.5 


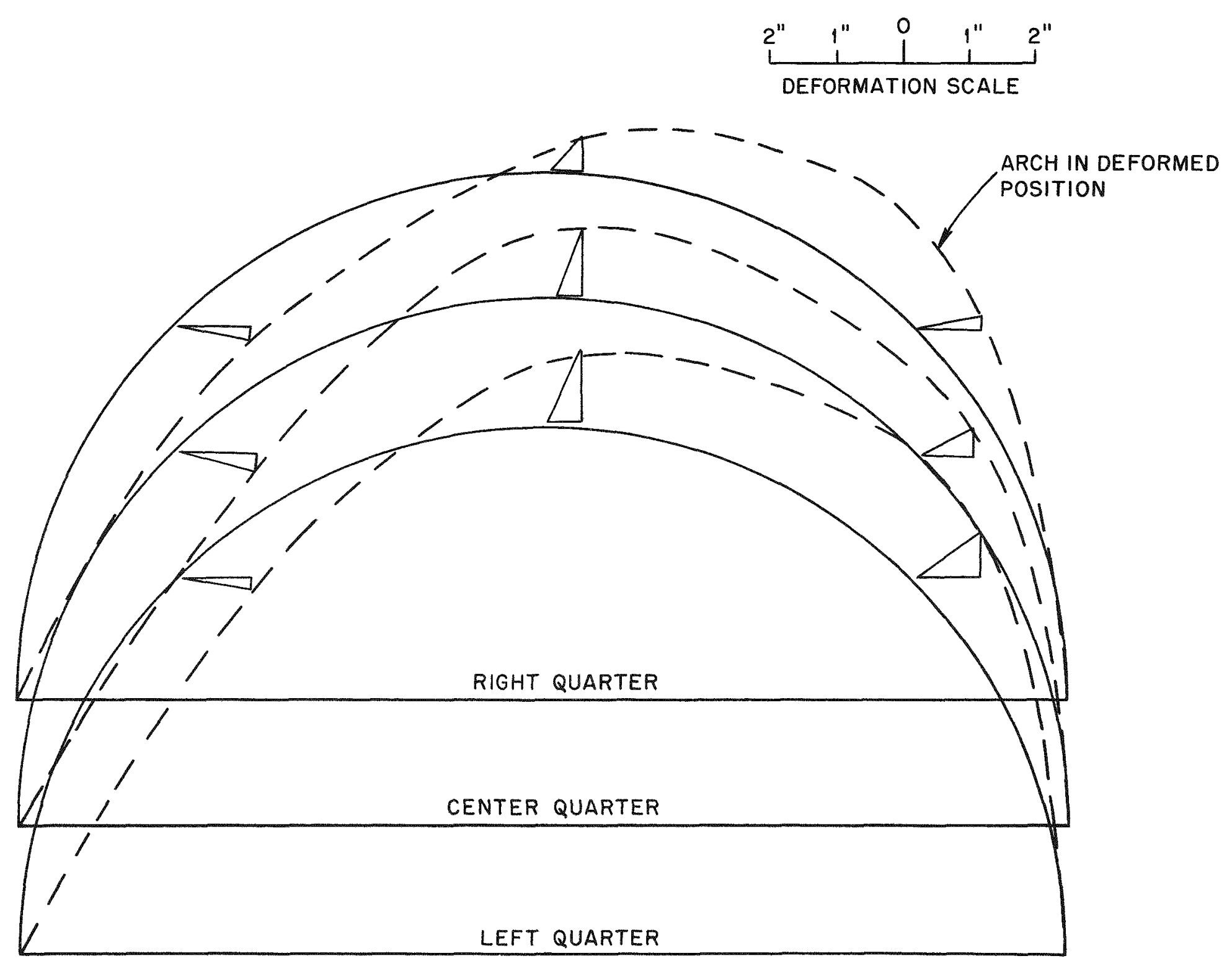

Fig. 6.96 Arch Deformation, Structure 3.2.5

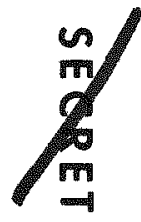



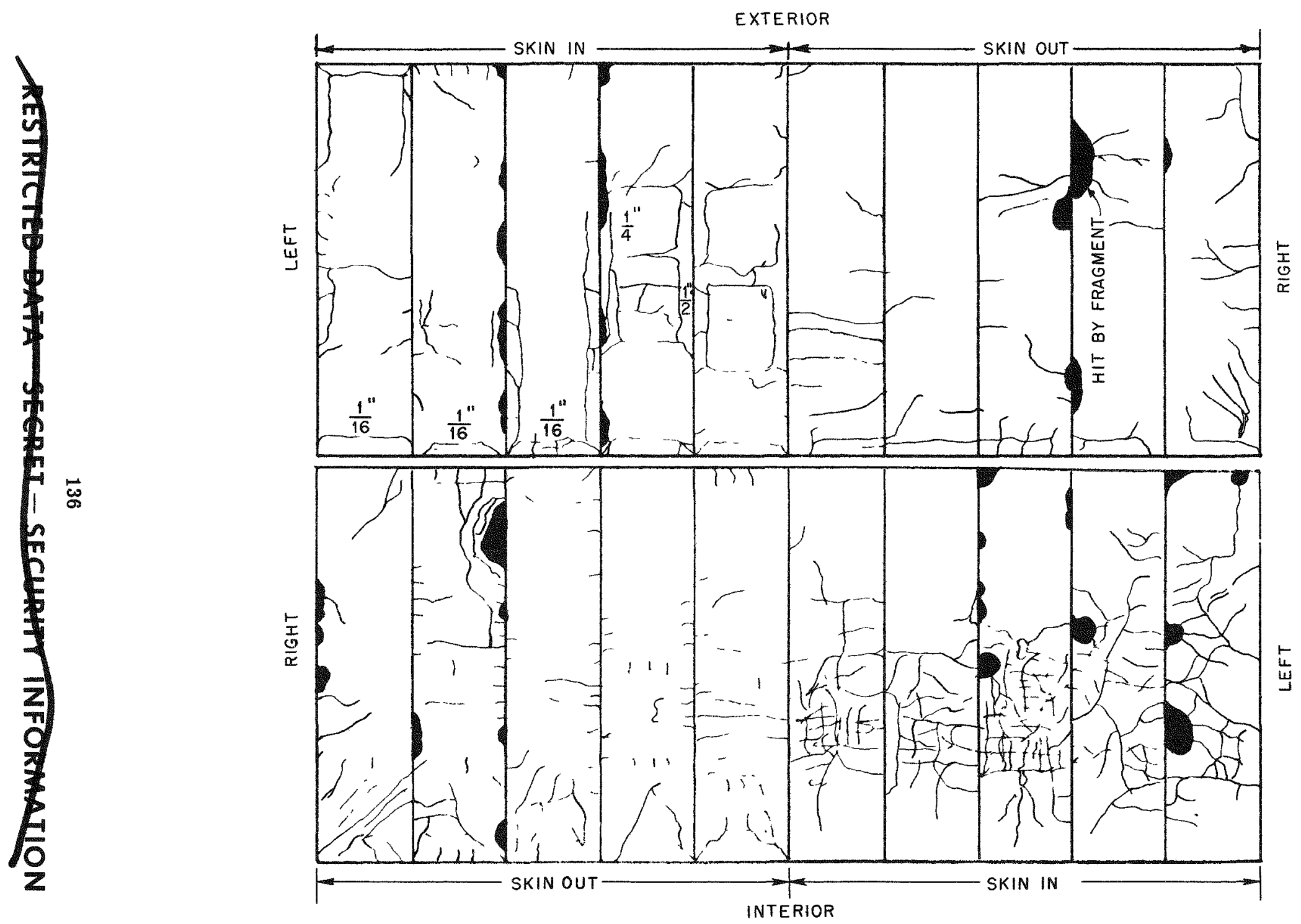

$\prod_{n}^{m}$

Fig. 6.97 Front-wall Crack Pattern, Structure 3.2.5. Panels are flattened. Cracks are about $1 / 64$ in. unless otherwise marked. 


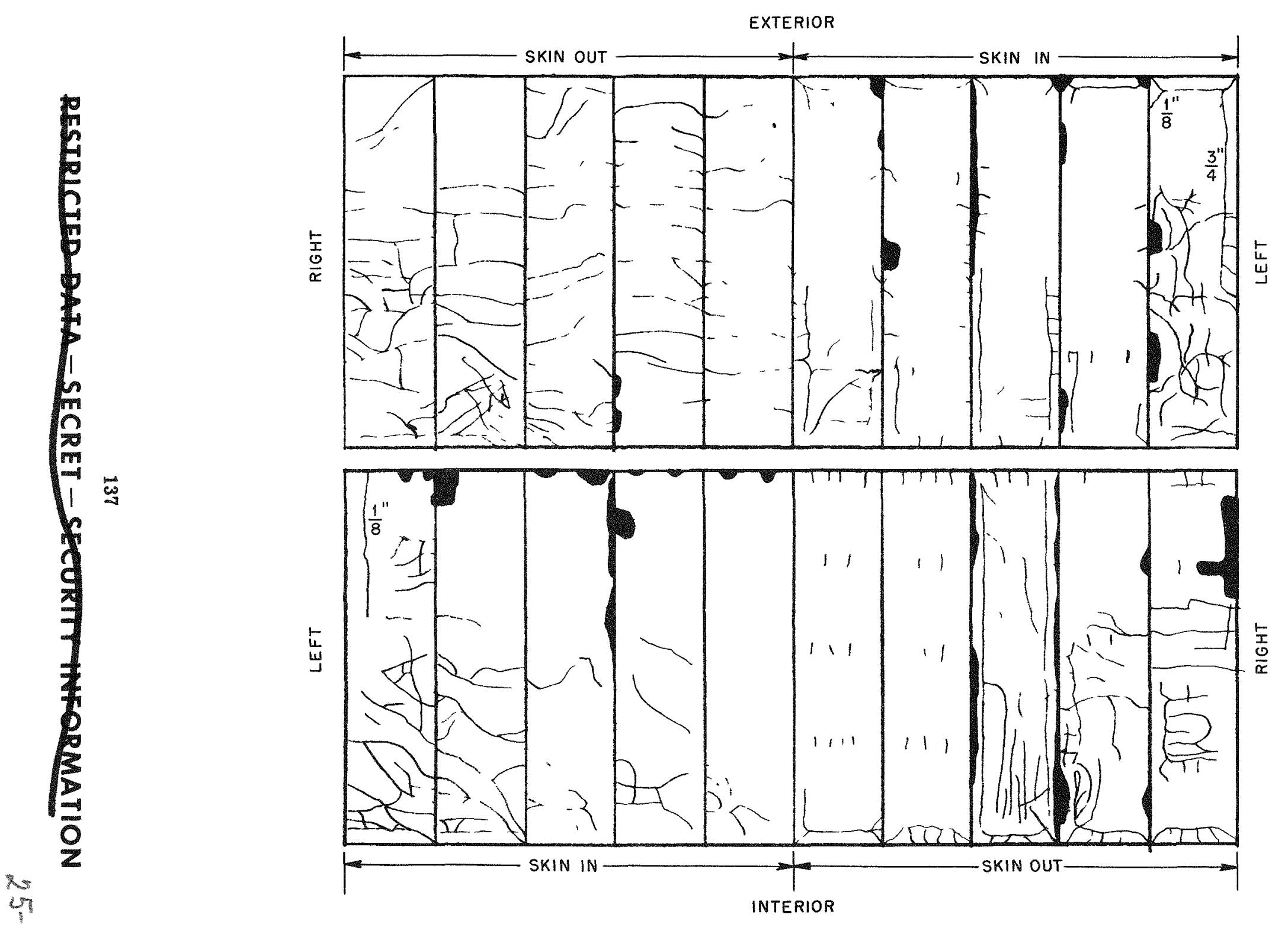

Fig. 6.98 Rear-wall Crack Pattern, Structure 3.2.5. Cracks are about $1 / 64$ in. unless otherwise marked. 


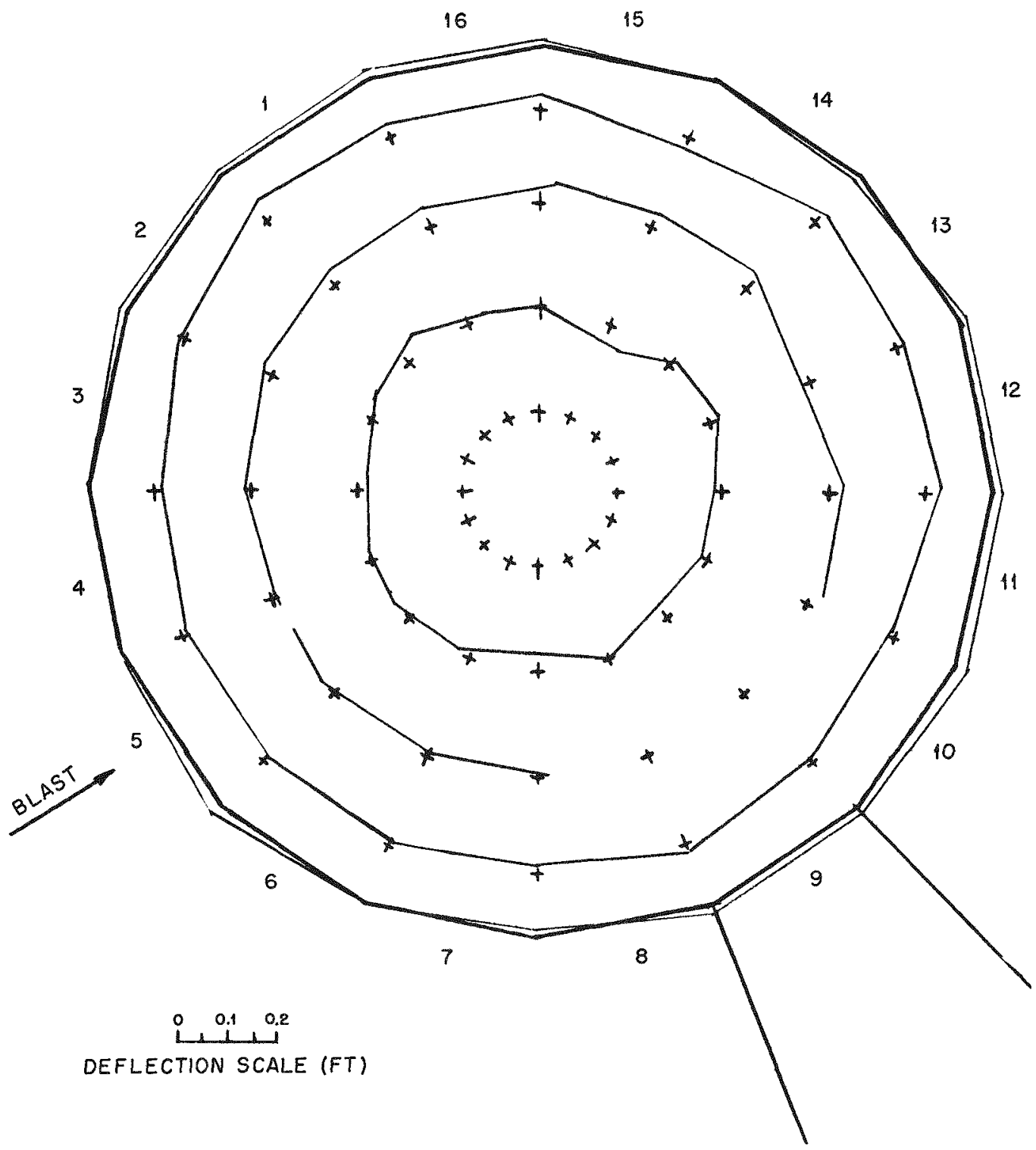

Fig. 6.99 Horizontal Deflections, Structure 3.2:6. The symbol + indicates original position of panel. 


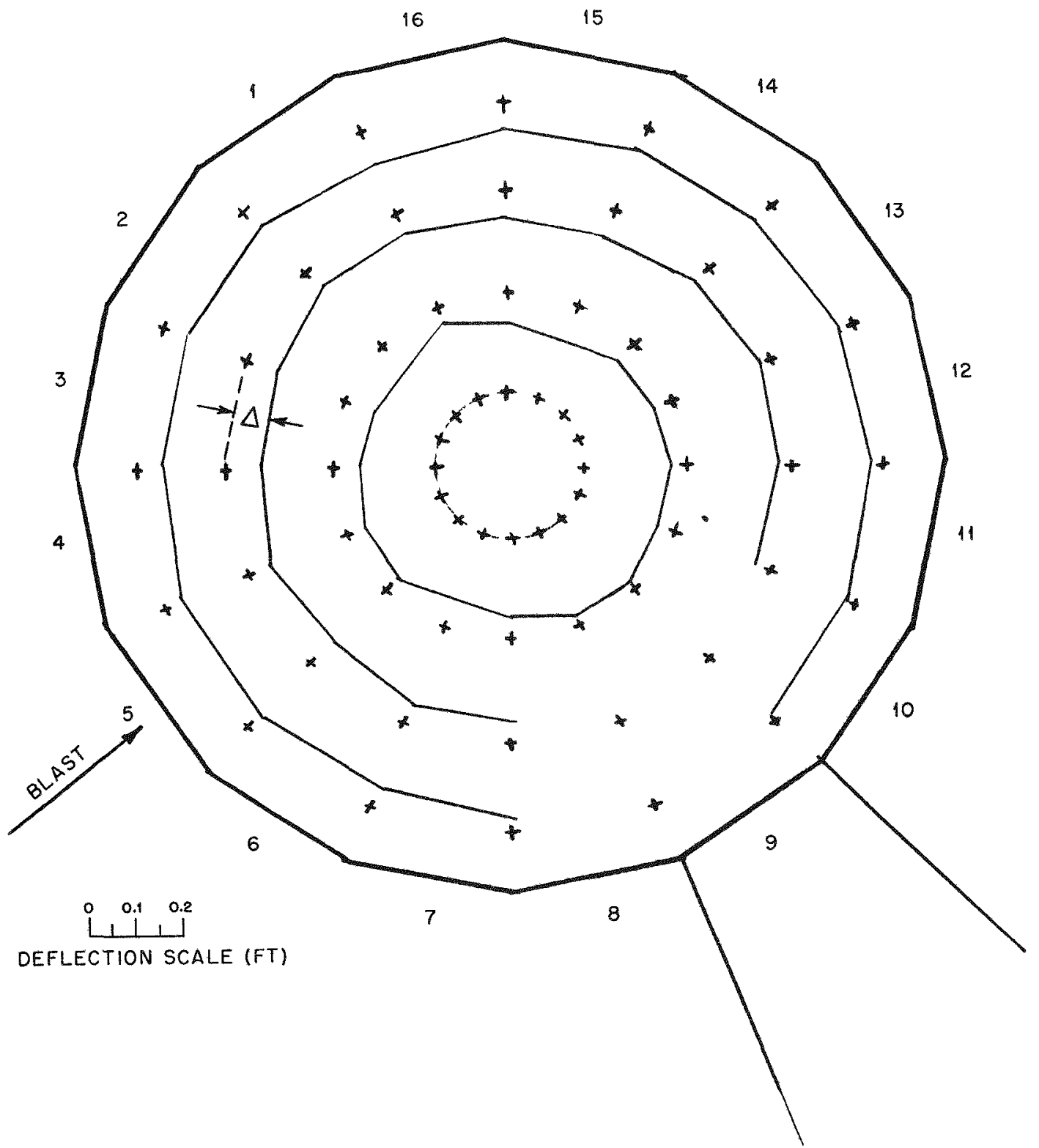

Fig. 6.100 Vertical Deflections, Structure $3{ }_{n} 2.6$. Vertical deflections are plotted in the horizontal plane; all deflections are downward. 

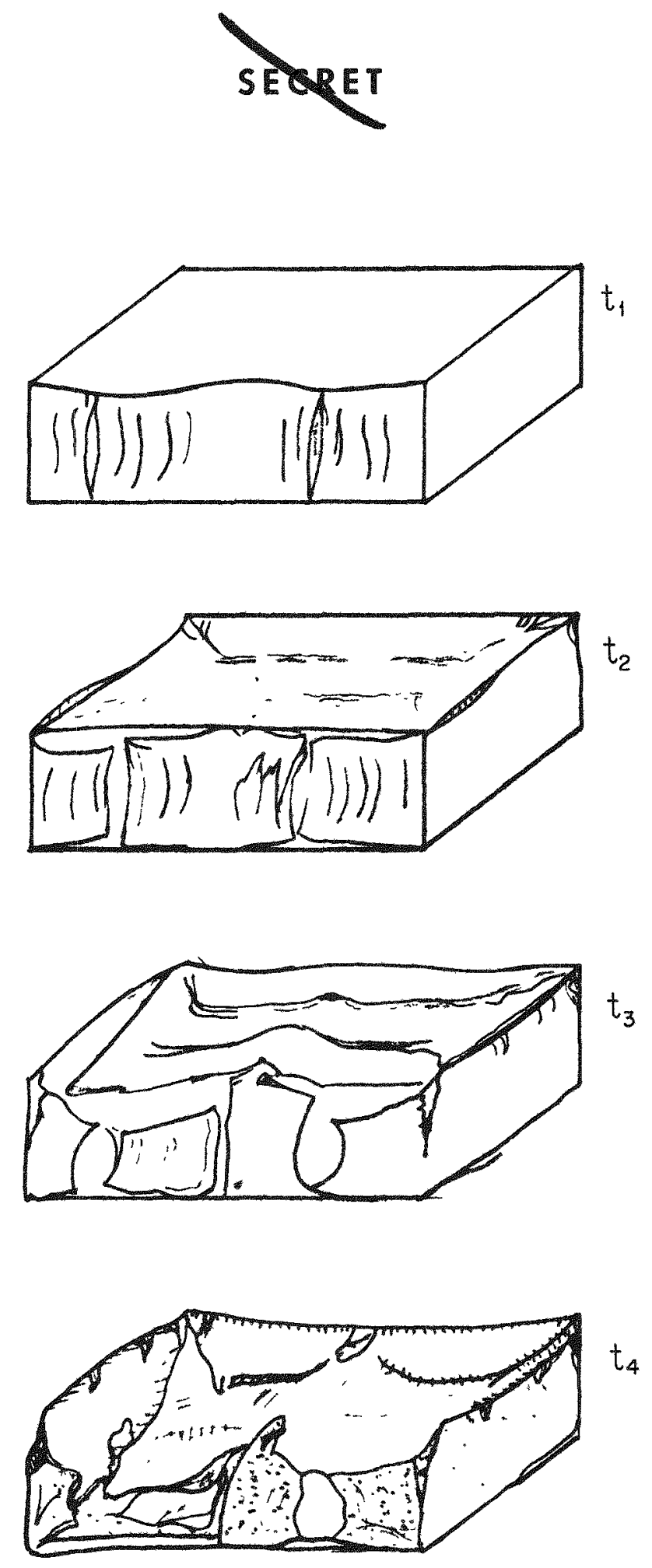

Fig. 6.101 History of Response of Structure 3.2.7a 
The vertical load on the foundation caused the foundation to settle slightly and crack away from the floor mat. This action occurred on the side opposite the wing walls. Cracks also formed from intersections to the floor mat to take up differential settlement. The increased foundation area on the wing-wall side resisted the load without settling.

\subsubsection{Structure 3.2.7a (Conventional Poured in Place)}

(a) General Damage. Structure 3.2.7a was destroyed with the end walls and rear wall still standing. The front wall falled inwardly, taking small sections of the end walls with it. The stringers and girder of the roof failed; the bottom tension bars separated completely. The roof collapsed and was pulled away from the end walls. Both columns failed at the base. The end walls were deflected outward about 12 in. The rear wall was deflected inward about $2 \mathrm{ft}$ at the center along the roof.

(b) Damage to Components. On initial impact the front wall deflected and then failed along a vertical line, each section to the left of center. As deflection increased, there was failure along the base and at the roof.

The untied bottom tension bars in the stringers dropped away. The roof failed along the stringer lines. The end-wall connections failed, and the top tension bars of the stringers pulled out, per mitting the roof to drop. The girder failed near the end of the top tension bars at the rear end and at the column face on the front end. Both columns failed at the base.

The end walls failed about $2 \mathrm{ft}$ from the front wall. The 2-ft section remained attached to the front wall. The left end wall developed severe shear stresses with localized failure near the bottom rear corner and the bottom corner in front of the door.

The rear wall deflected at the roof before the rear column failed. When the column failed, the rear wall deflected farther, but it remained standing.

(c) Response History. As the blast wave struck the front wall of the building, both front sections deflected to failure. Total deflection at failure was 30 to $36 \mathrm{in}$. at the center of the right section. Each section failed in tension on a vertical line about $3 \mathrm{ft}$ to the left of the center of the section. As the sections deflected farther, failure occurred along the base and along the roof. Extreme deflections of the front wall and bending action about the vertical corners caused failure of a narrow section of the side walls near each front corner.

When the roof was loaded, the untied bottom tension bars in the stringers broke away and dropped to the floor. As the roof deflected under the load, it failed along the stringer lines. The roof separated from the side walls, and the top tension bars of the stringers pulled free, staying with the side walls. The girder failed at both ends. At the rear it failed in diagonal tension; at the front it failed in tension at the face of the column.

As the roof was collapsing, the rear wall was loaded, and each half deflected, the maximum being at the roof line. During roof failure both the front and rear columns failed at the base. The rear wall then deflected a maximum at the center along the roof line.

(d) Methods of Failure. The front wall and both end walls failed at the roof in the same manner. The 6-in. hook of the wall reinforcing bars pulled out of the roof concrete; the same length of roof bars pulled out of the wall concrete.

The front wall failed along the base at the time of maximum deflection. The reinforcing bars were necked down, indicating tension failure of the reinforcing steel due to moment developed at the section or translational force tending to move the wall inward.

Each section of the front wall failed in a vertical line by tension failure of the reinforcing steel. The face of the front wall was badly spalled, indicating that high stress occurred in the compression face.

Both side walls failed near the front wall. When the wall deflected, the corner connection held, placing a high moment in the leading edge of the side wall. The side wall failed; however, the steel held and bent around to permit the corner and side-wall section to rotate into the building.

The left side wall failed in shear near the bottom rear corner and the bottom corner in front of the door (Fig. 6.102). This side wall acted as a deep girder with concentration of stresses at the locations of failure. Note the sharp jagged spall and crack lines. 


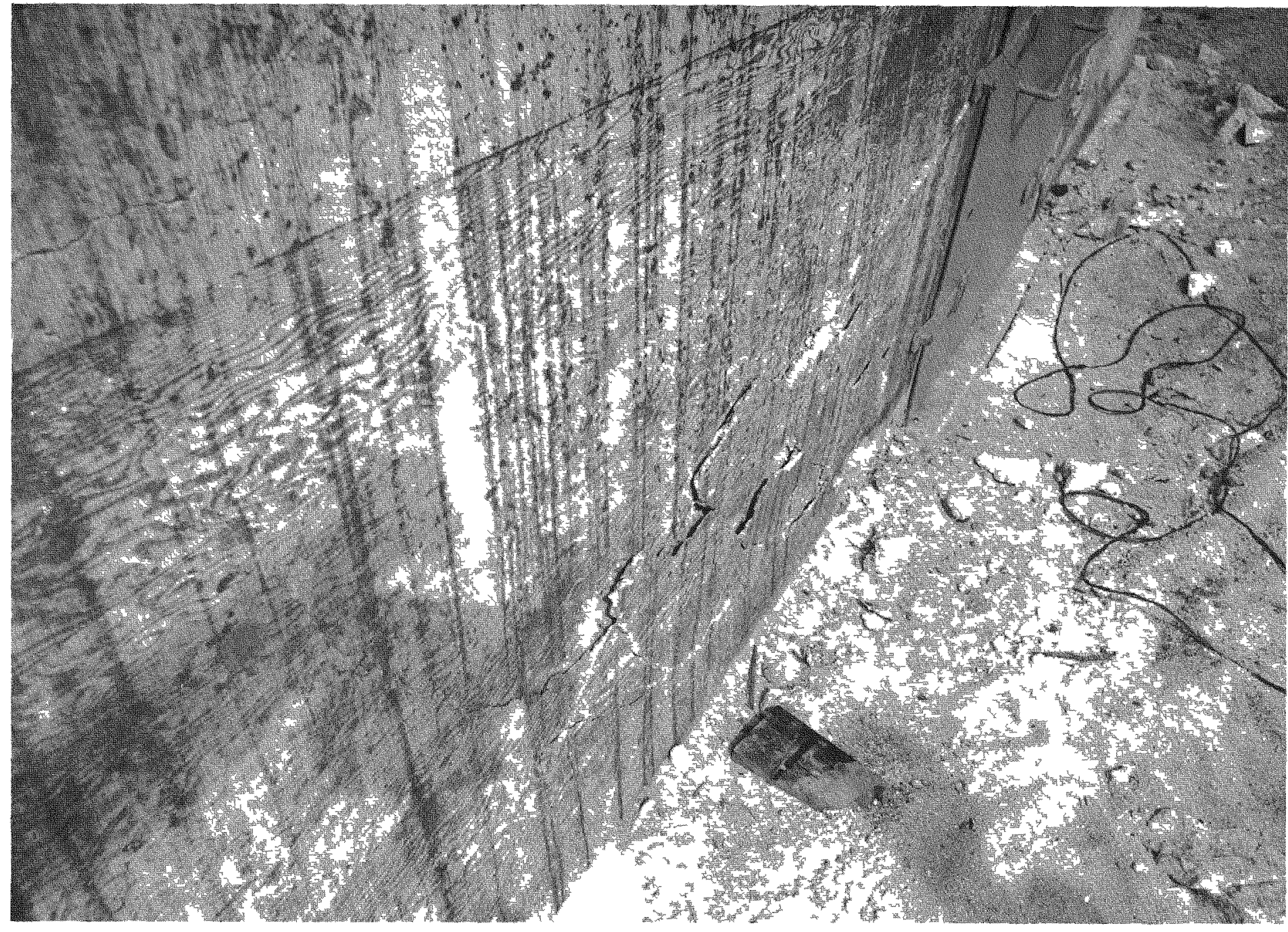

Fig. 6.102 View of Left End Wall from the Rear, Showng Shear-fallure Cracks 


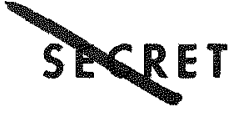

Both end walls deflected outward as a result of the high moments developed in the walls during front- and rear-wall deflections.

When the roof girder deflected, the bottom tension bars were resisting the movement. Since they were not restrained at the ends and the deflection was appreciable throughout the entire length, the concrete failed at the ends of the bars in tension and along the length in horizontal shear. The rear end of the girder failed in diagonal tension at the end of the top tension bars. The front end of the girder failed in tension at the column face.

The bottom tension steel of the roof beams failed in the same manner as in the girder, except that the tension bars dropped completely away. The haunch concrete stayed with the roof when it collapsed, leaving a hole in the end walls and leaving the top tension steel in the end walls.

The front column failed because of bending at the base. The rear column failed because of a vertical compression and a moment load at the base. The concrete spalled away, allowing the steel to fold.

The roof failed along the stringer lines, probably owing to a concentration of stresses at the change in section. The concrete spalled away from the steel, allowing the steel to bend.

\subsubsection{Structure 3.2.7b (Conventional Poured in Place)}

(a) General Damage. Structure $3.2 .7 \mathrm{~b}$ sustained very heavy damage to the roof, but the walls remained basically in a serviceable condition, with some permanent deformation.

(b) Damage to Components. The light stringer beams of the roof failed completely, and the roof slab itself then resisted the entire load, this action causing large downward deflections of the roof, extensive cracking, and localized loss of concrete. Replacement of the roof would be required to rehabilitate the structure. The transverse roof girder rotated at the haunches and failed at a point about one-third of its span from the front wall, with complete cleavage of the concrete and sharp bending of the tension steel at this location. The girder, however, remained in place in its deflected position and continued to support the roof slab. The front and rear walls were both deflected inward to a maximum of about 3 in. at the roof level; moderate cracking of concrete occurred in both walls, but they remained structurally serviceable. Both end walls were bowed outward, with a maximum permanent deflection of about $1 \frac{1}{2}$ in. at the top center of each wall. As in the case of the side walls, moderate cracking of the concrete occurred, but the end walls remained structurally serviceable. The steel door was undamaged and was easily opened.

(c) Response History. As the shock front reached the front wall, each half of the wall began to deflect inward, acting as a diaphragm well supported on three sides and lightly supported on the fourth (the roof). Support along the vertical edges was provided by one end wall and by the center monolithic bent. Support along the horizontal edges was provided at the base by a keyed construction joint and anchorage of wall steel into the foundation, and at the roof by the 3-in. roof slab. This latter support probably was effective in the initial stages of the deflection, but, as soon as the roof was loaded and began to deflect, the value of its support for the front wall was reduced to a small amount. As a result of this action the maximum permanent deformation of the front wall occurred at the roof line and reached a value of about $3 \mathrm{in.}$

As the shock wave passed across the roof, it caused a downward deflection of the roof, and the longitudinal stringers supporting the roof slab failed in diagonal tension near the beam haunches. After the beams failed at the haunches, the lower portions of each beam separated from the upper portion because of the horizontal shear developed and fell to the ground. The roof slab then acted as two diaphragms, each supported on four sides. Support was provided by the two side walls, one end wall, and the main transverse roof girder. The large span $(20 \mathrm{ft}$ ) of these slabs allowed very large deflections of the order of 2 or $3 \mathrm{ft}$ to occur.

The roof girder received loads from both the roof slabs and the compressive action of the two side walls due to the general crushing effect of the pressure wave after it had enveloped the structure. These loads caused the girder to deflect to a considerable extent, with an accompanying rotation of the haunches at the front and rear walls. This rotation produced large cracks along the outside faces of the walls at the haunch locations. Local sections of the walls bent inward with each haunch, and the steel in the tension faces of the haunches elongated considerably during the rotation. At the junction of the rear 

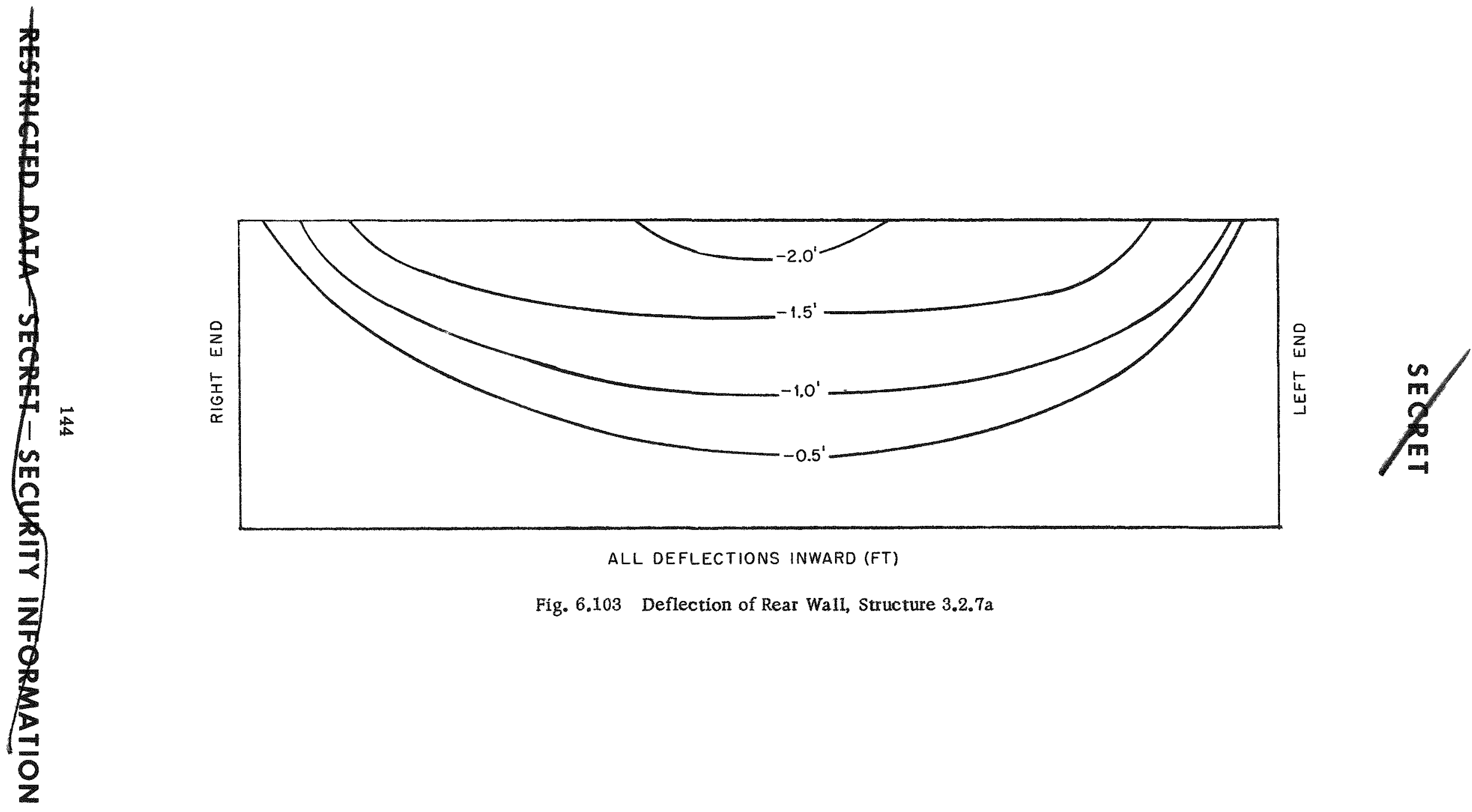

Fig. 6.103 Deflection of Rear Wall, Structure $3.2 .7 \mathrm{a}$ 

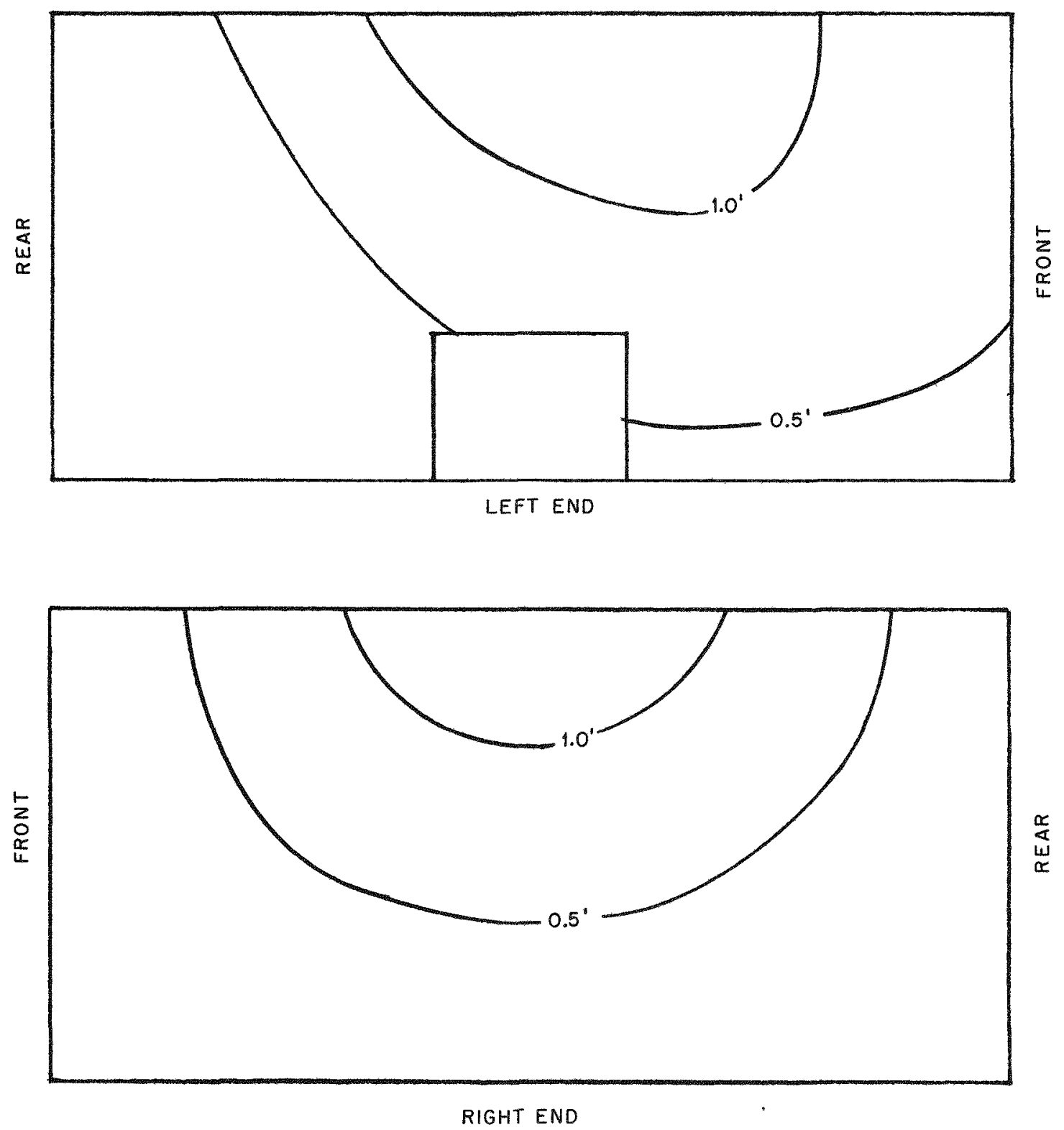

Fig. 6.104 Deflection of End Walls, Structure 3.2.7a. Deflections (given in feet) are outward. 


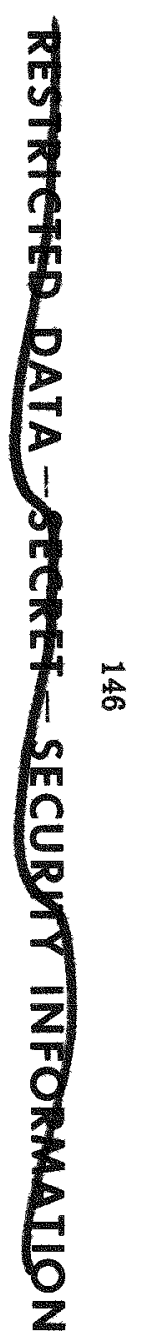

REAR WALL EXTERIOR

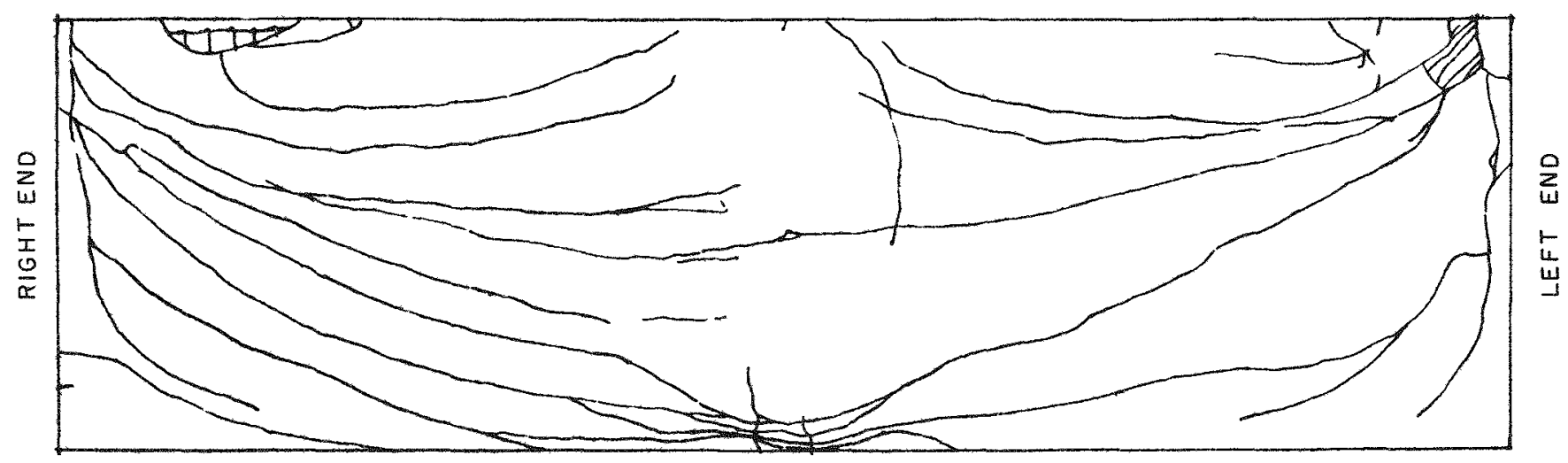

Fig. 6.105 Rear-wall Crack Pattern, Structure 3.2.7a 
SECMET
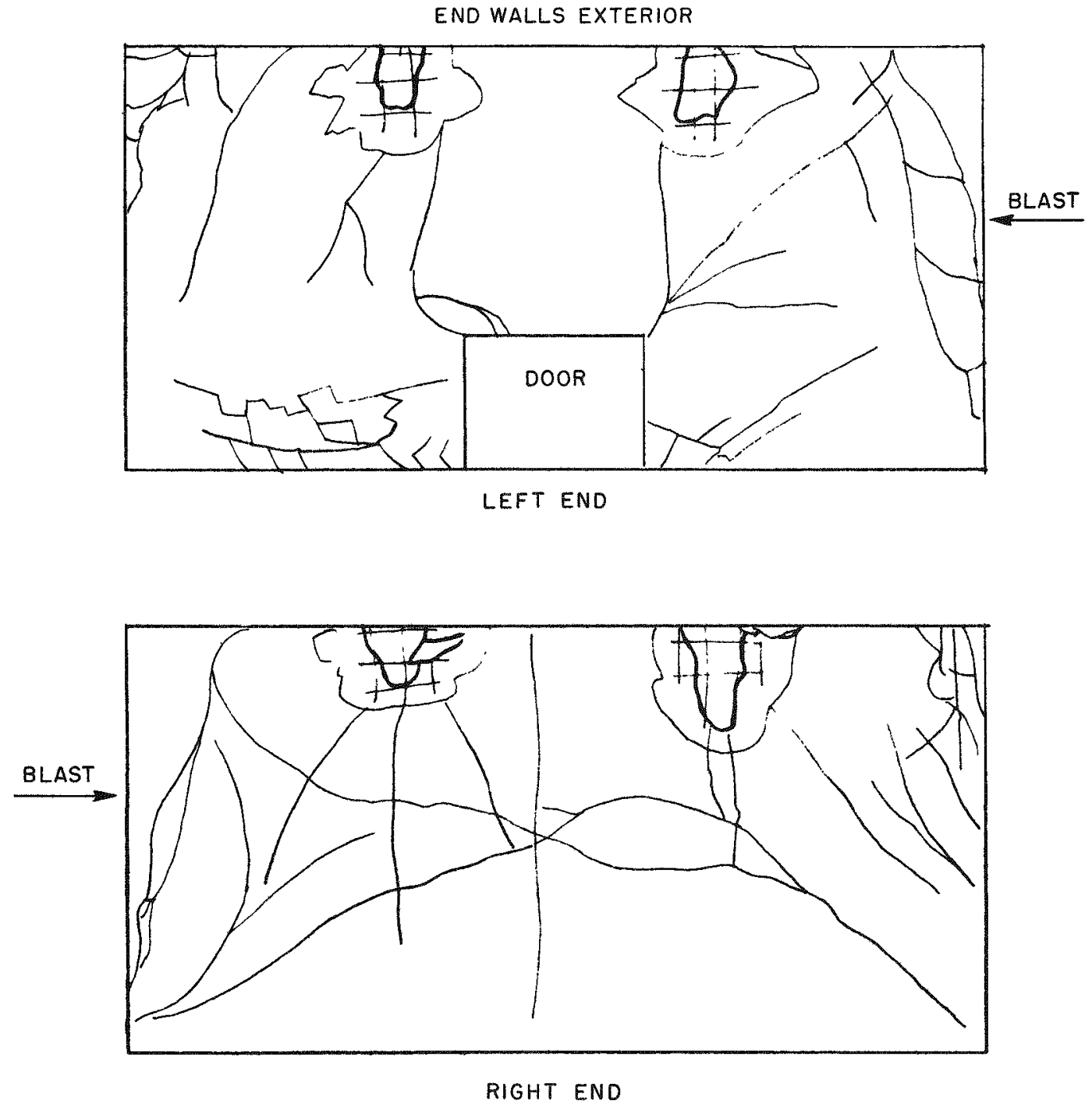

Fig. 6.106 Rear-wall Crack Pattern, Structure 3.2.7a

147

RESTRTCTED DATA - SECREF - SECURITY JHFORMATION

$25-161$ 
haunch and its pilaster, there was a definite crushing of the concrete that was in compression. The maximum deflection of the girder was about $2 \mathrm{ft}$. Localized sections of the roof-slab concrete broke out along both the girder and some of the longitudinal beams, and rather sharp bends in the roof occurred at these locations. The slab and girder, however, remained in their deformed positions and did not dislodge.

When the shock wave reached the rear wall, it caused a dishing of each of the two wall sections which was almost identical in shape and magnitude with that occurring on the front wall. The pressure acting on the rear wall was appreciably less than that on the front wall; so the equal deflections are probably due to the fact that the roof had already deflected considerably by the time the load reached the rear wall, and practically no support was afforded along the upper edge of the wall.

Side-on pressure acting on the end walls was insufficient to overcome the outward bowing effect created by the general inward crushing forces acting on the front and rear walls. This latter action apparently caused the end walls to act as struts between the front and rear walls, with the column action producing the outward deformations. The attempt of the front and rear walls to rotate the corners of the end walls outward undoubtedly contributed to the direction that the deformation assumed.

(d) Methods of Failure. Failures in this structure were limited to the roof framing, where two types of failure occurred: One was the complete failure of the longitudinal stringer beams of the roof (Fig. 6.107); the other was the partial failure of the main roof girder and its haunches (Fig. 6.108).

The walls and the roof slab proper responded approximately as predicted by the basic analysis. The stringer beams failed at each haunch in diagonal tension combined with vertical shear (Fig. 6.109). There was an insufficient lap of reinforcing steel at the haunch to carry the stresses from the beam into the haunch. Figure 6.109 shows that the beam failed cleanly through concrete only, following about a $45^{\circ}$ angle along a plane connecting the stub ends of the top and bottom steel at these locations. See Sec. B-B of Fig. D.19 for the detail of this steel reinforcing.
After the beams had failed at the haunches, the continued deflection of the roof slab and of the main portion of the stringer beams (now held to the roof slab only by tension in the concrete) caused horizontal shear to develop in the beams. This action broke the bond of the steel and sheared the concrete at that section, allowing the lower portions of the beam to fall to the ground. The tension that was developed in a vertical direction through the beam owing to the bending action must also have contributed to this latter failure, so that it became a combination of pure tension and horizontal shear on the same section.

The main transverse roof girder apparently failed because of rotation at its haunches. The knee of the haunch was not strong enough to carry the stresses that were brought to it by the girder. Both the front and rear haunches failed in a similar manner, although at the front haunch the tension steel extending down into the pilaster column broke its bond and pulled up (Fig. 6.110), whereas at the rear haunch the steel elongated without pulling loose, and the concrete on the underside of the haunch was crushed (Figs. 6.111 and 6.112).

The girder itself developed a diagonal shear failure at the third point nearest the front wall. The exact mechanics of this failure are not clear since the rupture could have occurred because of excessive loading of the beam in the normal manner, or it could have been the result of a column type failure due to the compressive axial load when the structure was enveloped by pressure. This latter condition certainly caused the beam to assume its final position (Fig. 6.122).

\section{3}

\subsection{STRUCTURAL RESPONSE (RECORDED)}

Transient displacement measurements are given in Table 6.1, which presents gauge, location, displacement value, and information as to whether or not this was a peak value. Deflection gauge readings which did not reach a peak are primarily attributed to failure of the element or cable failure caused by excessive deflection or flying debris. Acceleration measurements are not given here, since they are primarily of value in the detailed analysis. 


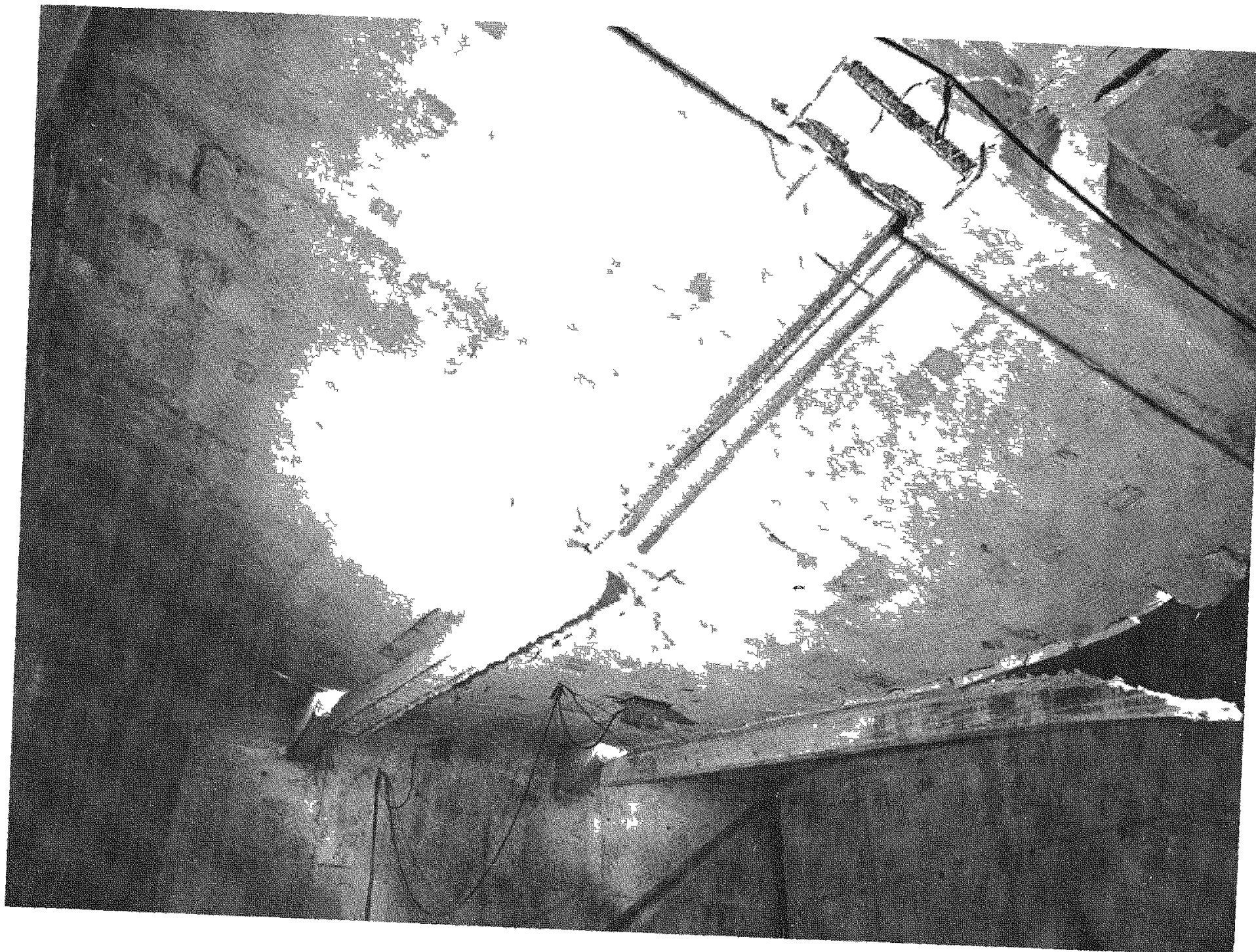

Fig. 6.107 Longitudinal Stringer Beams Under Right Half of Roof. Complete farlure occurred. 

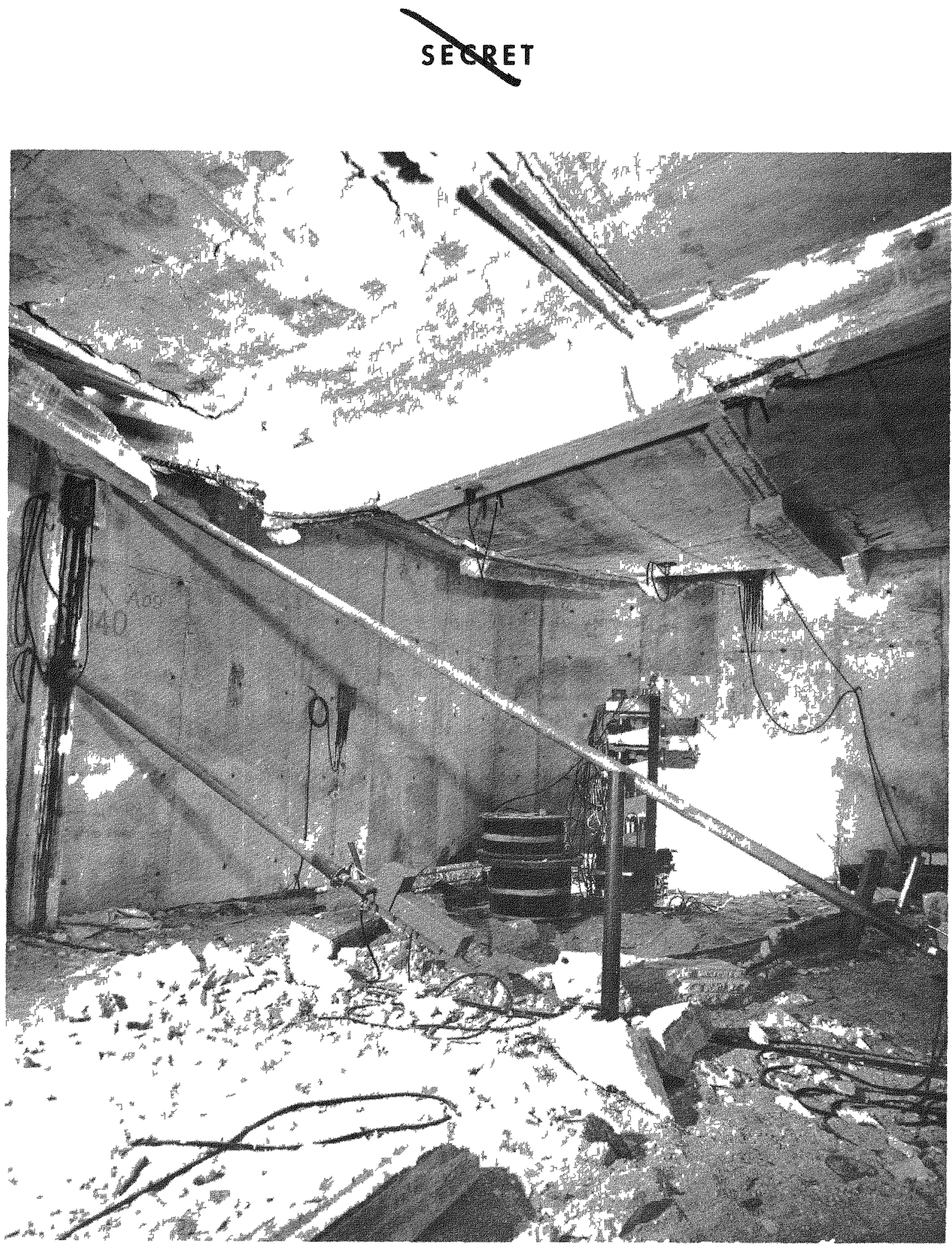

Fig. 6108 Deflection of Main Transverse Roof Girder. Lower sections of the small longitudinal stringer beams are lying on the ground below the beams. 

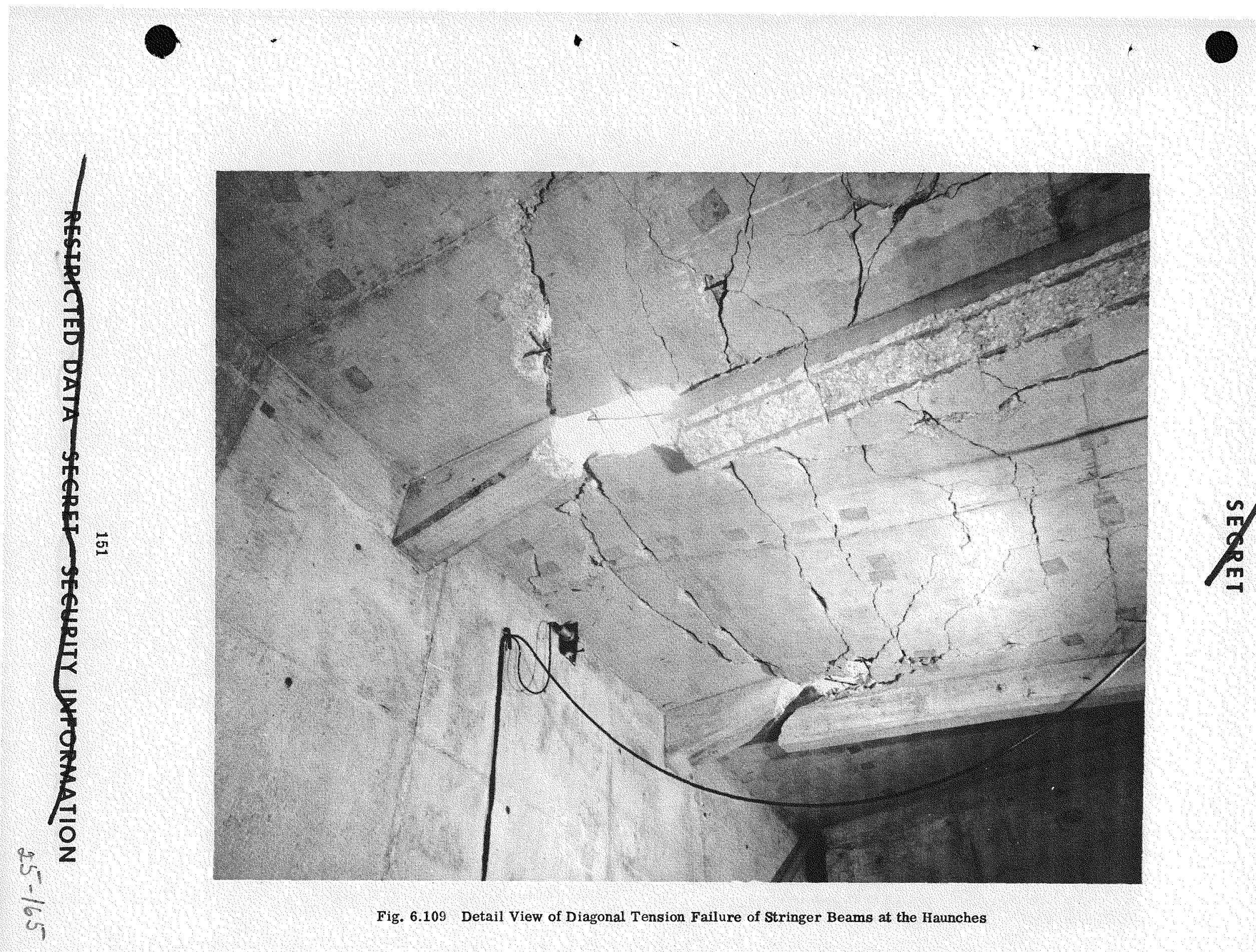

$\frac{m}{2}$

Fig. 6.109 Detail View of Diagonal Tension Failure of Stringer Beams at the Haunches 


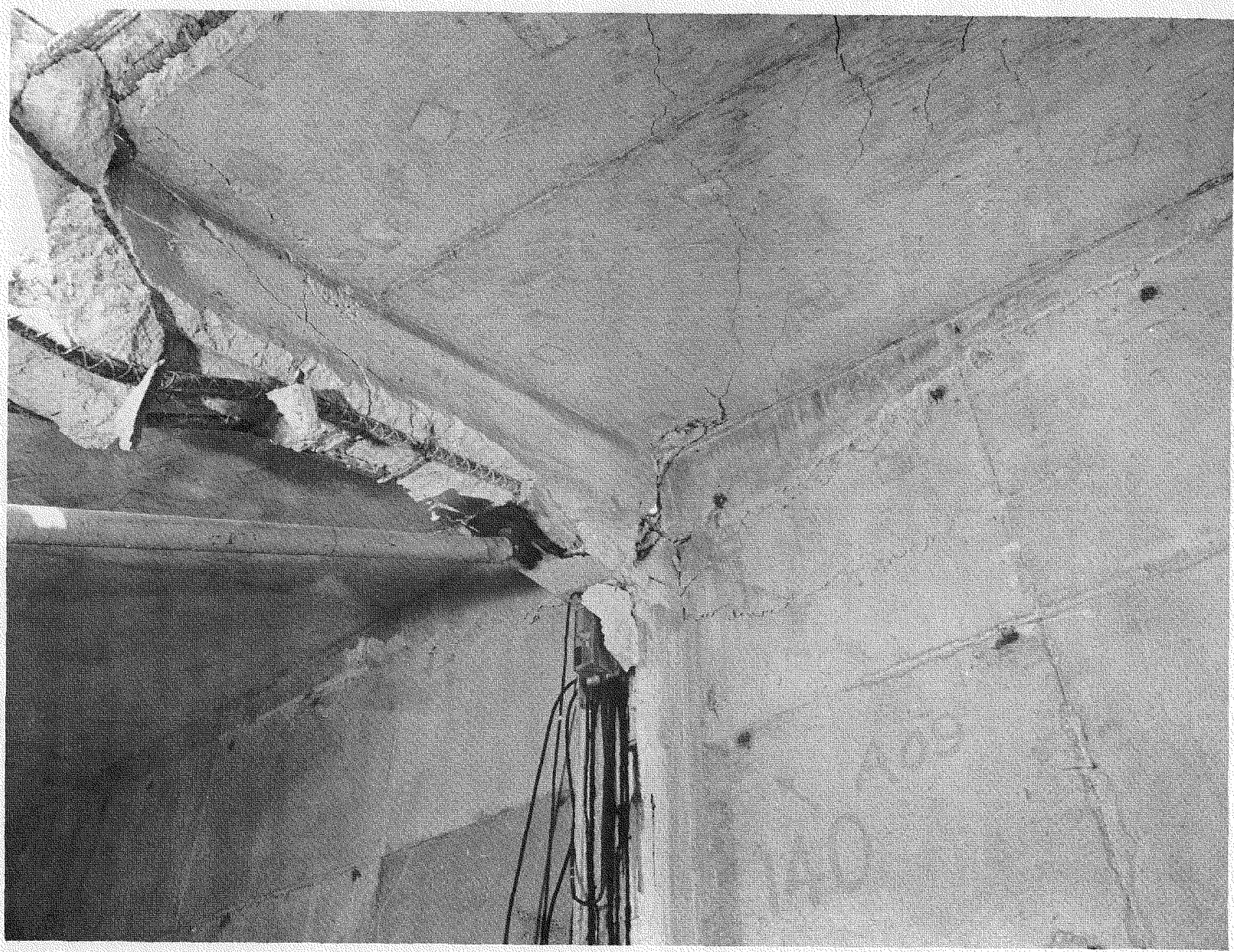

Fig. 6.110 Inward Rotation of Main-girder Haunch at Front Wall, Steel in the back of the haunch pulled up. 

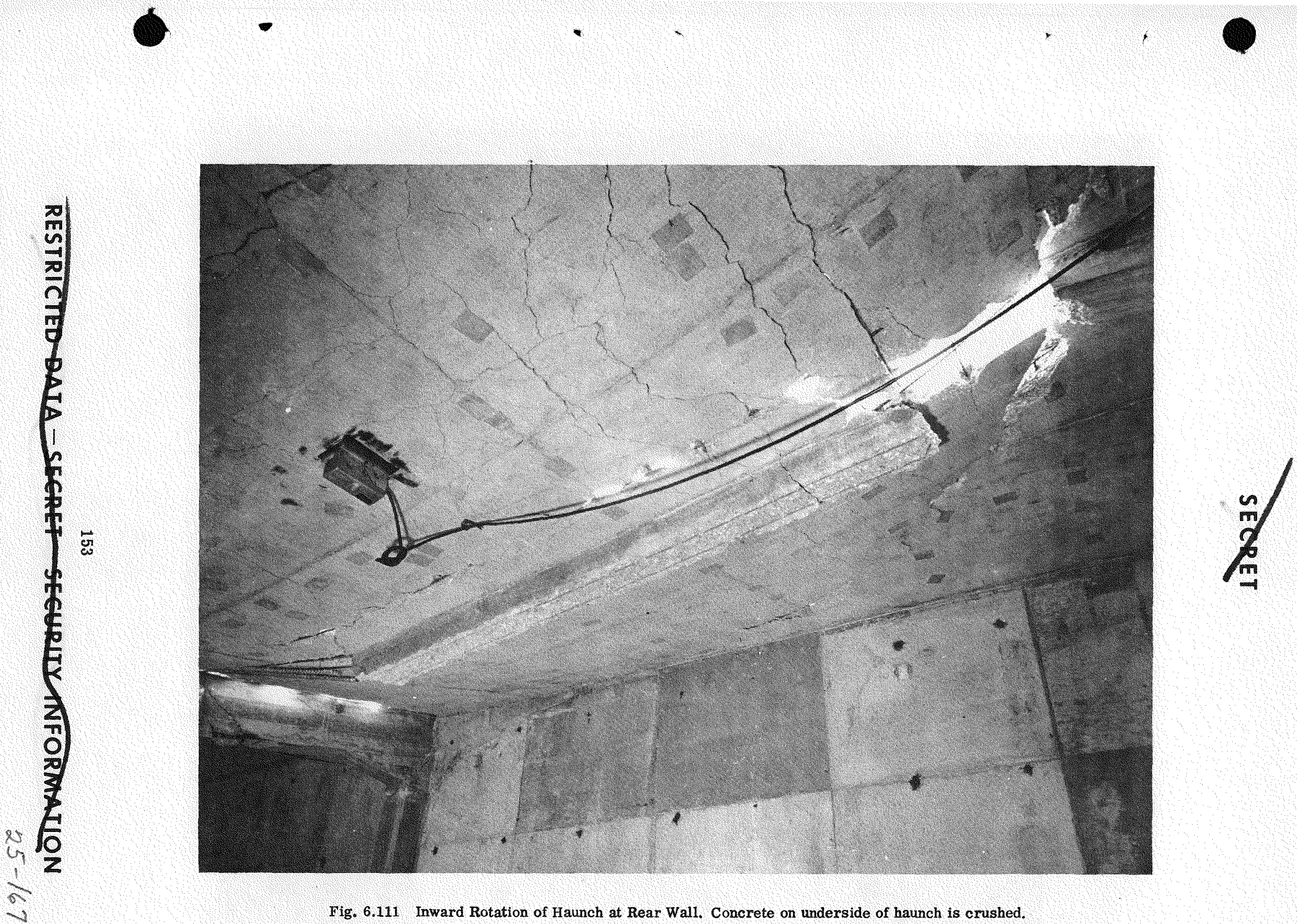

Fig. 6.111 Inward Rotation of Haunch at Rear Wall, Concrete on underside of haunch is crushed 


\section{SECRET}

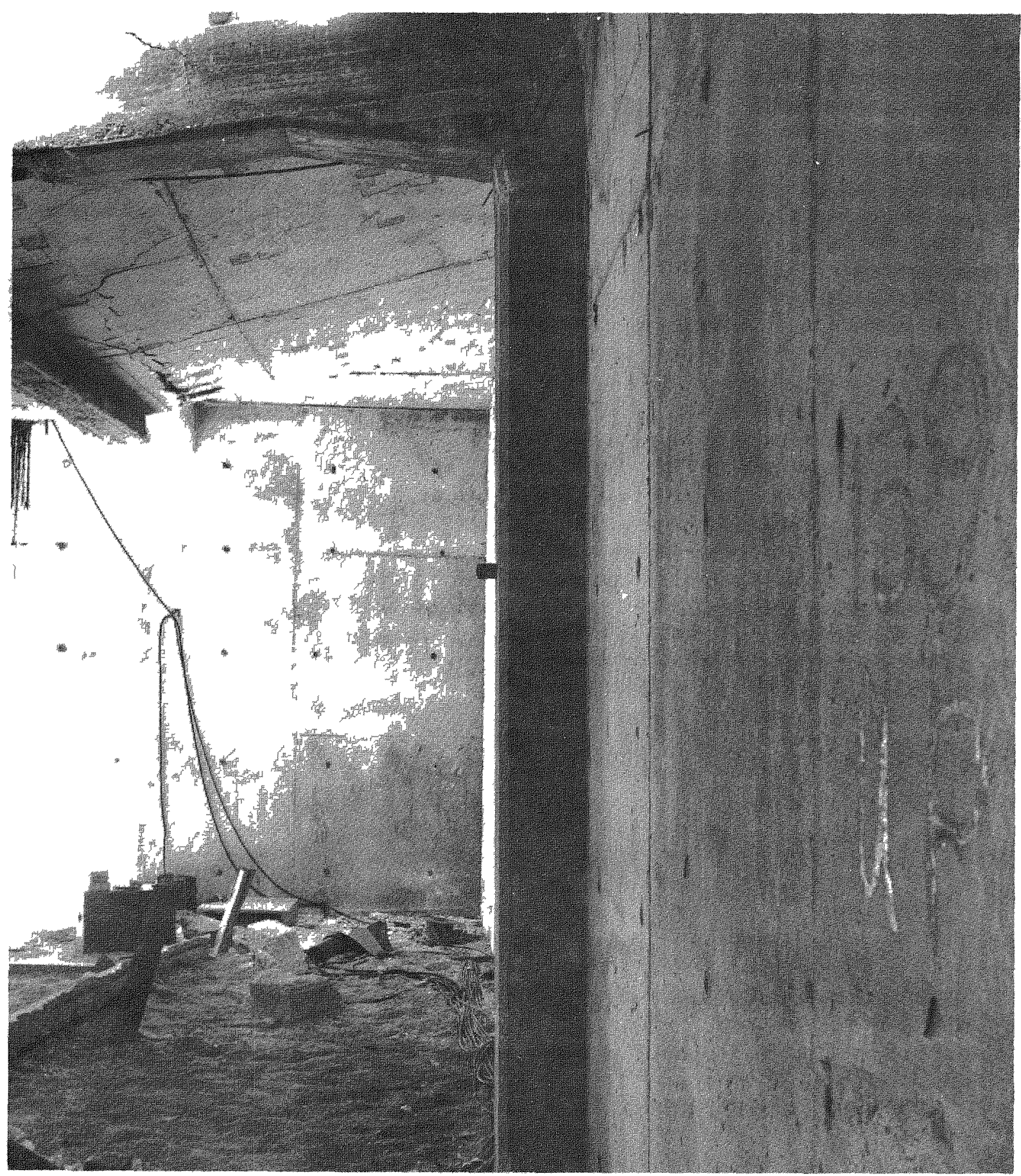

Fig. 6112 Detall View of Rotation of Haunch at Rear Wall 


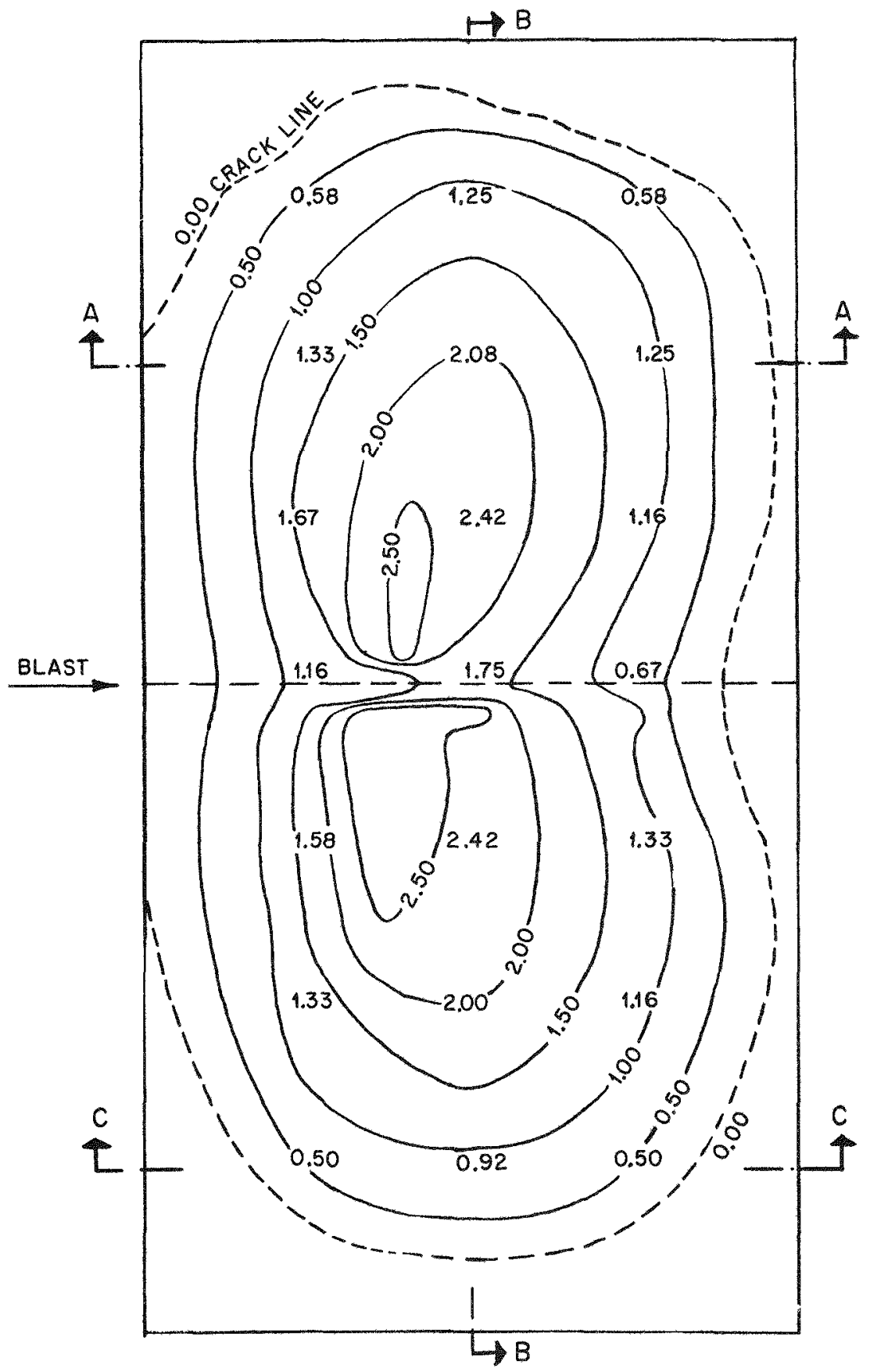

Fig. 6.113 Roof Deflections, Structure 3.2.7b. Deflections are given in feet. 

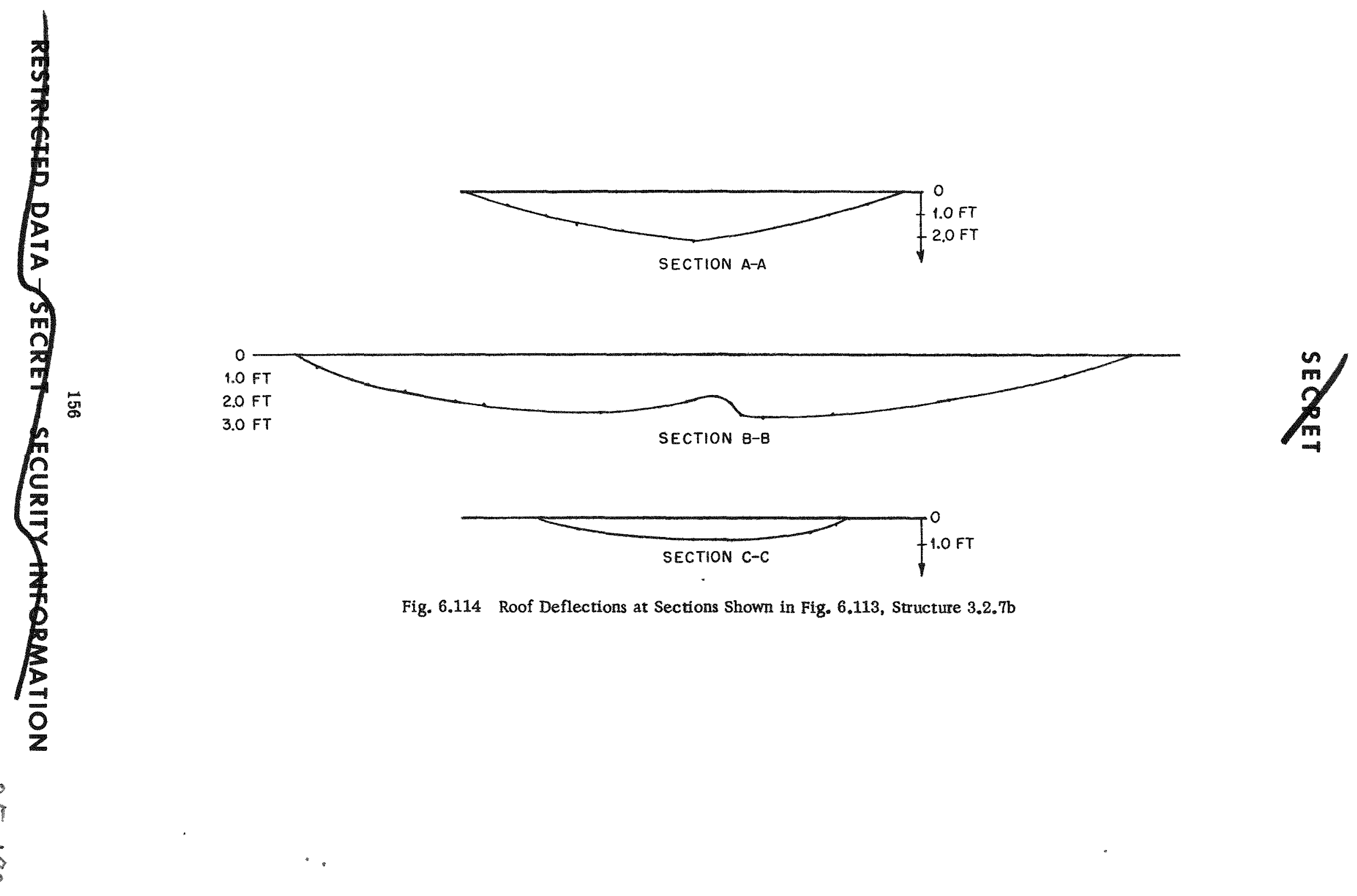

Fig. 6.114 Roof Deflections at Sections Shown in Fig. 6.113, Structure 3.2.7b 

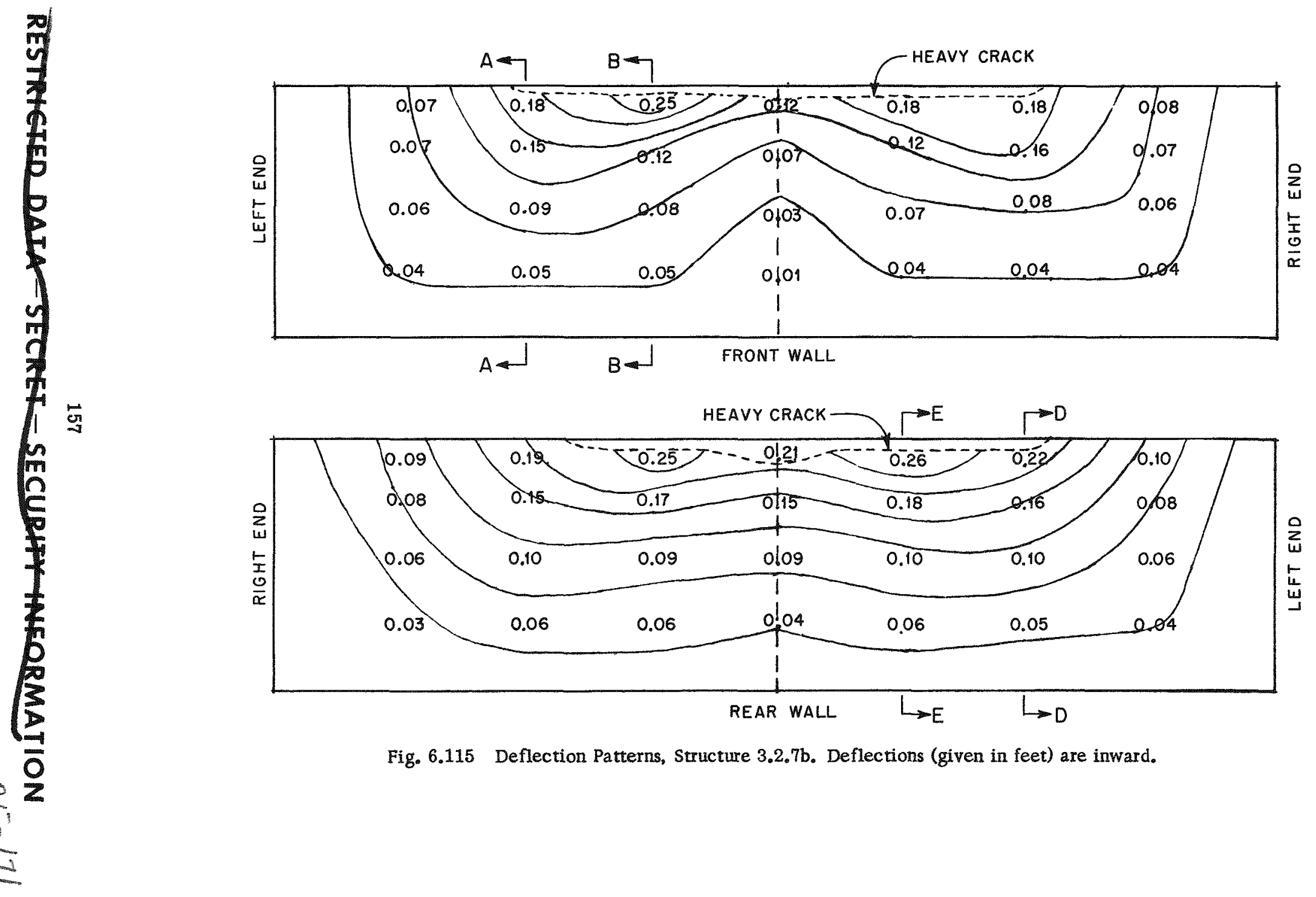

Fig. 6.115 Deflection Patterns, Structure 3.2.7b. Deflections (given in feet) are inward. 
SECRET

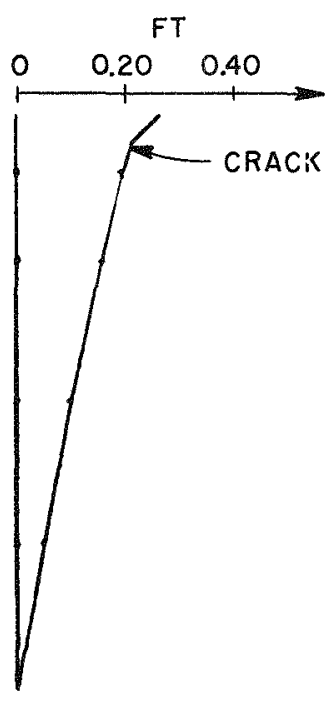

SEC. ADA

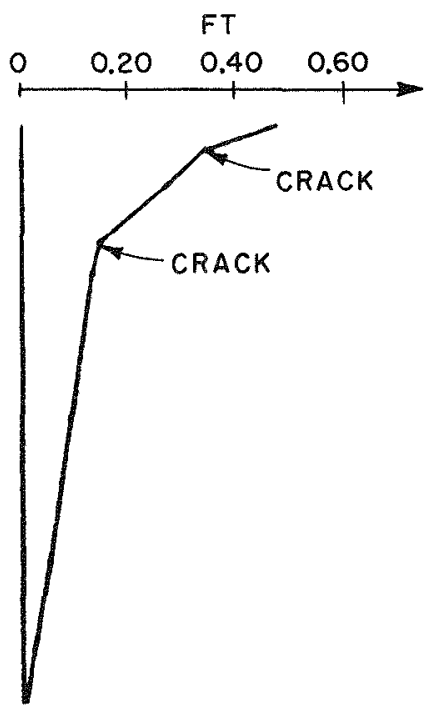

SEC. $B-B$

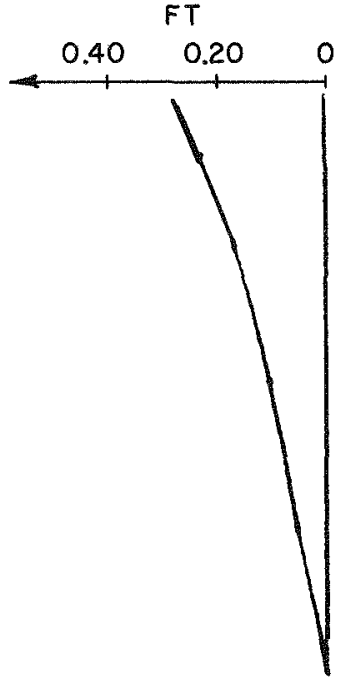

SEC. DOD

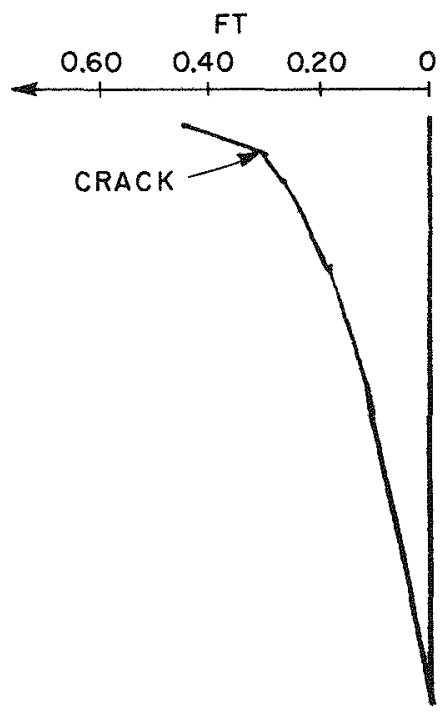

SEC. $E-E$

Fig. 6.116 Wall Deflections at Sections Shown in Fig. 6.115, Structure 3.2.7b

158

RESTRICTED DATA SECRET - SECURITY INFORMATION

$25-172$ 

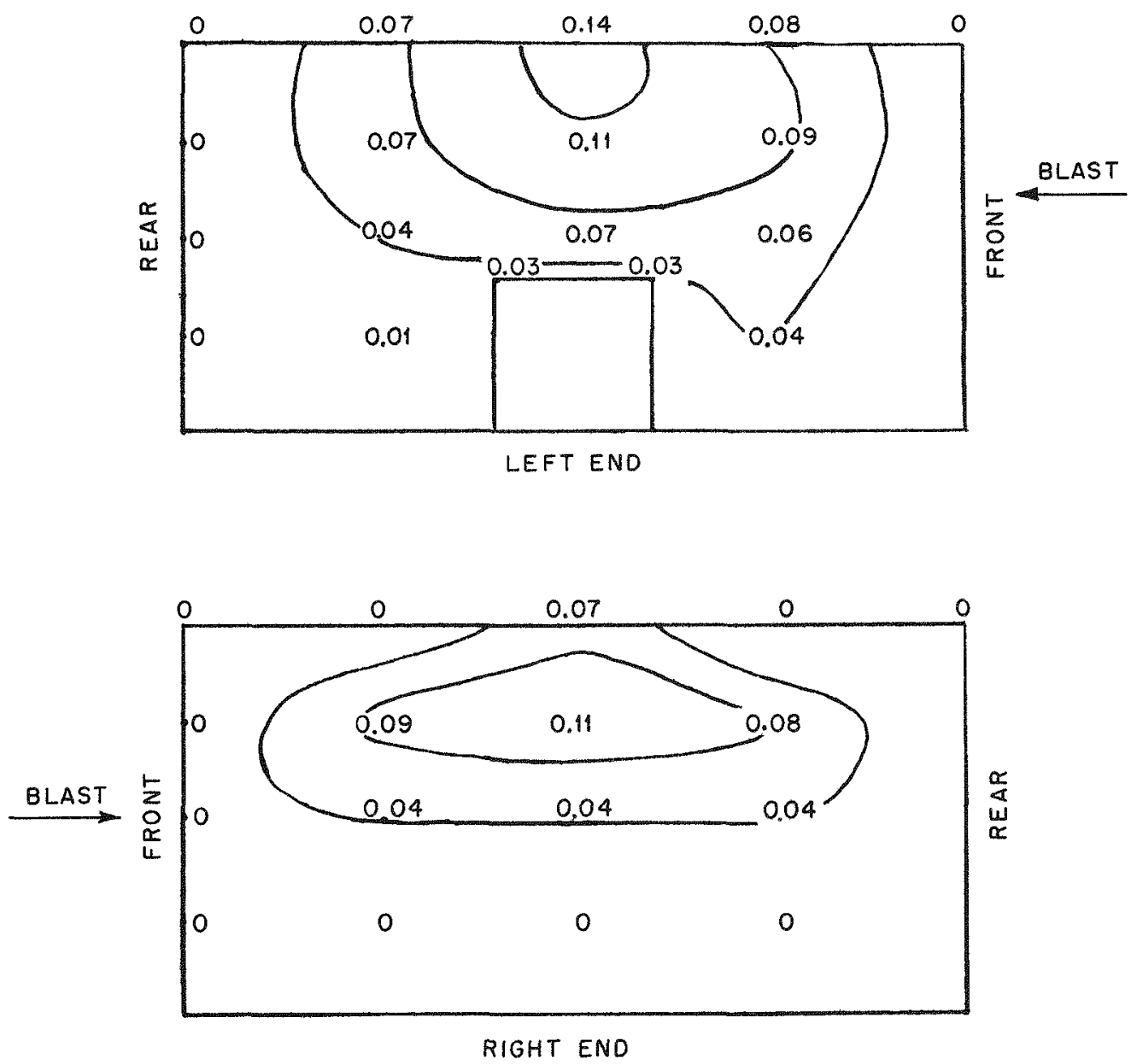

Fig. 6.117 End-wall Deflection Pattern, Structure 3.2.7b. Deflections (given in feet) are outward. 

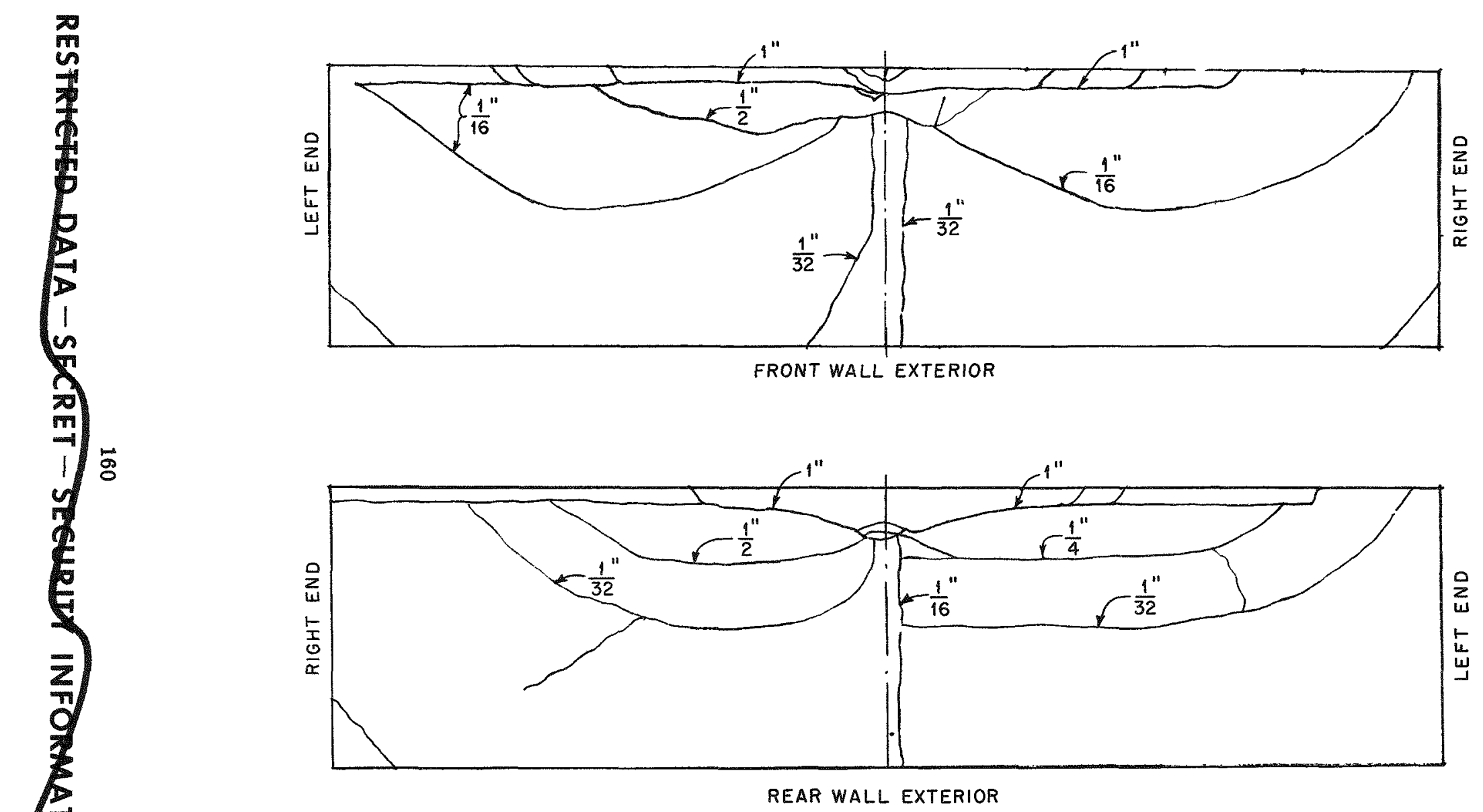

$\prod_{-1}^{m}$

Fig. 6.118 Crack Pattern, Structure 3.2.7b 

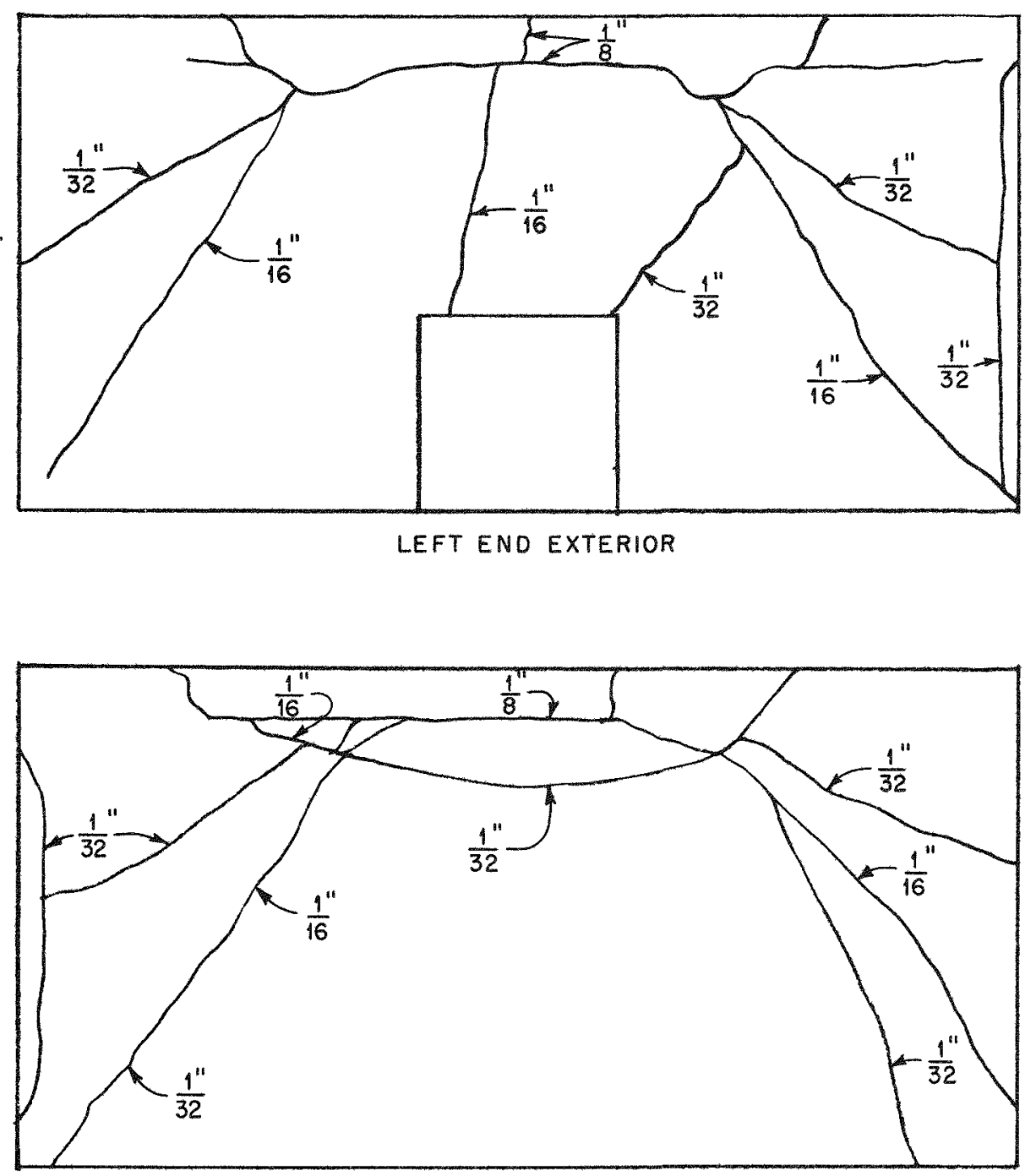

RIGHT END EXTERIOR

Fig. 6.119 Crack Pattern, Structure 3.2.7b 

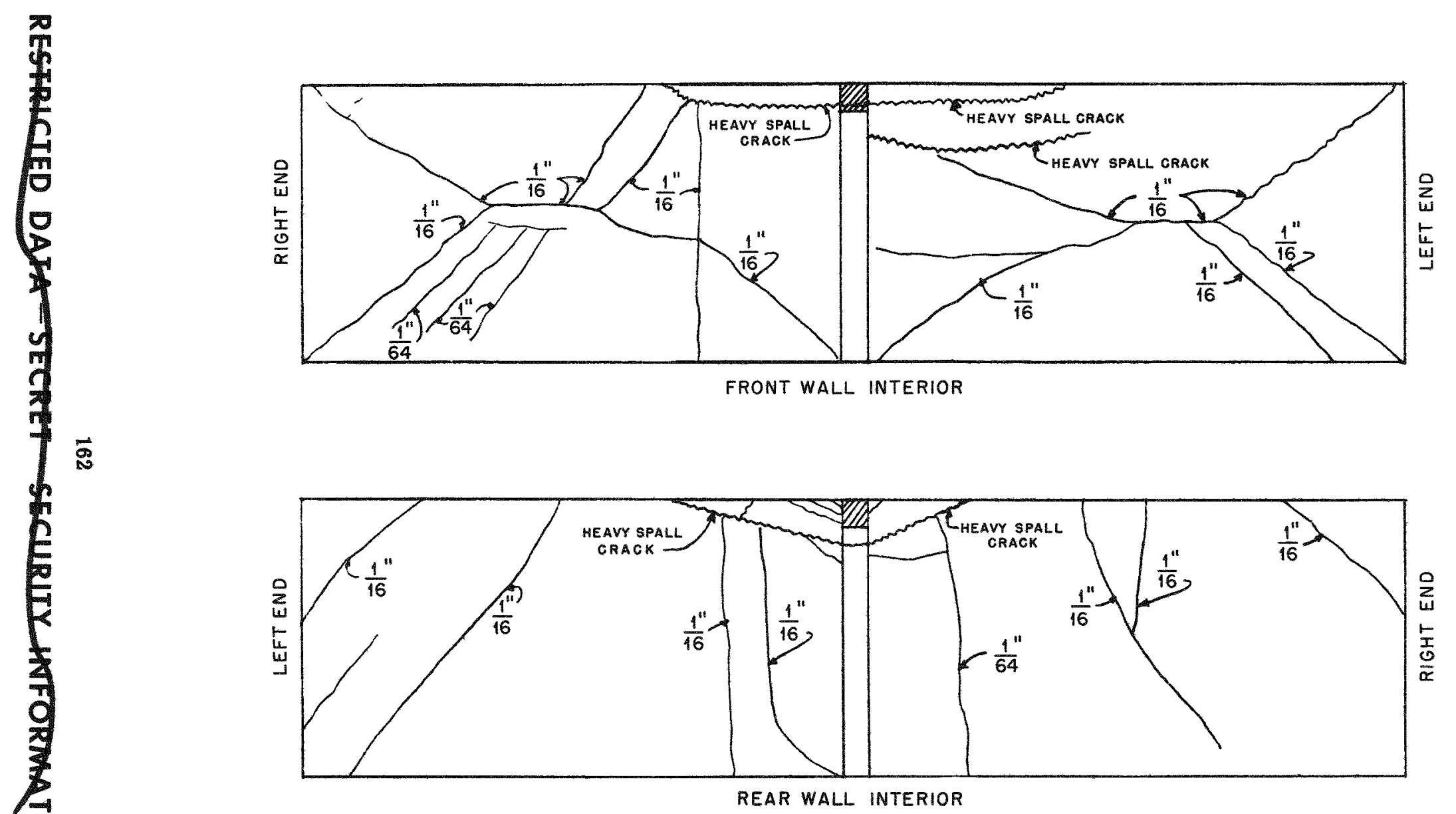

Fig. 6.120 Crack Pattern, Structure 3.2.7b 

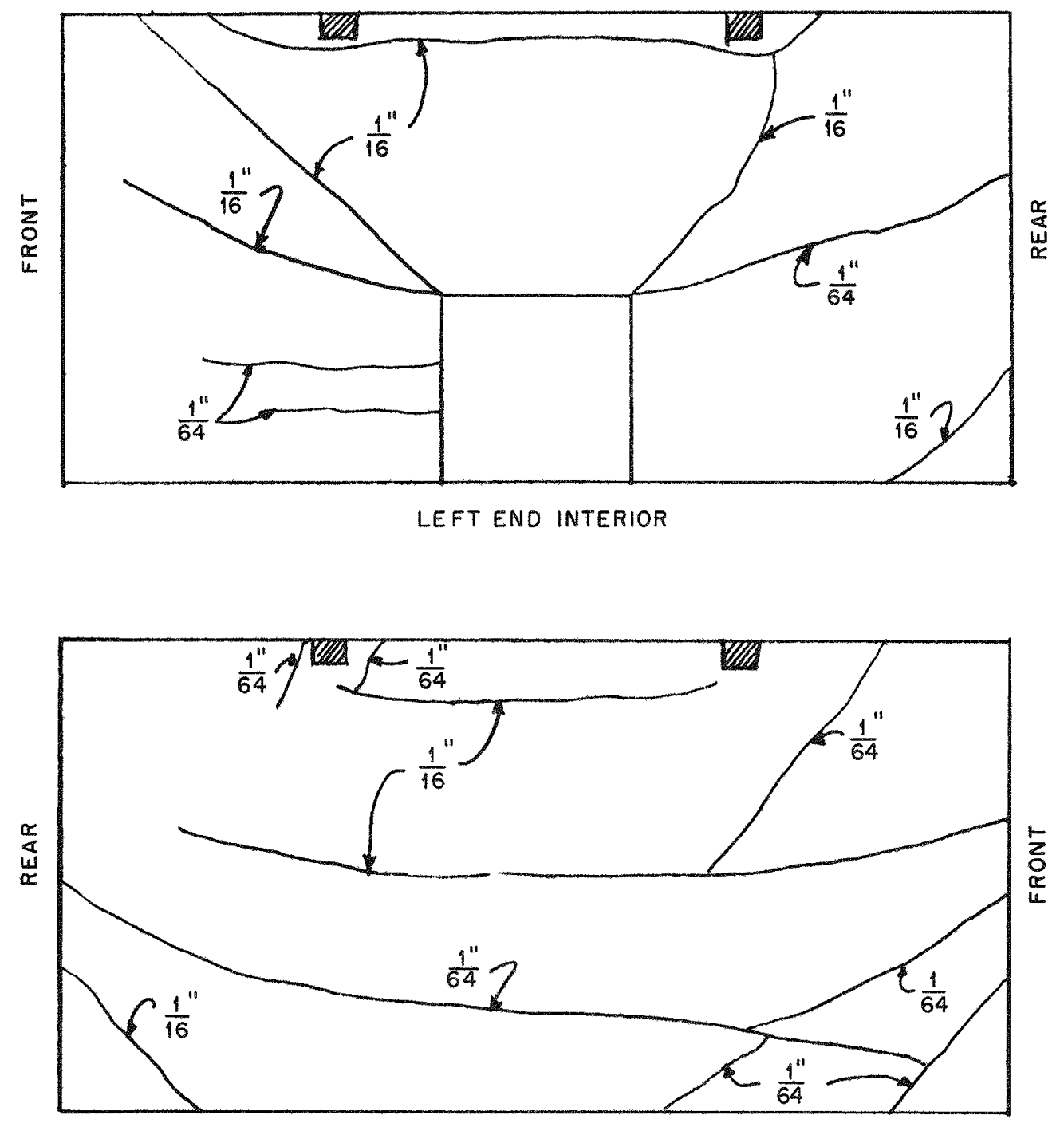

RIGHT END INTERIOR

Fig. 6.121 Crack Pattern, Structure 3.2.7b 

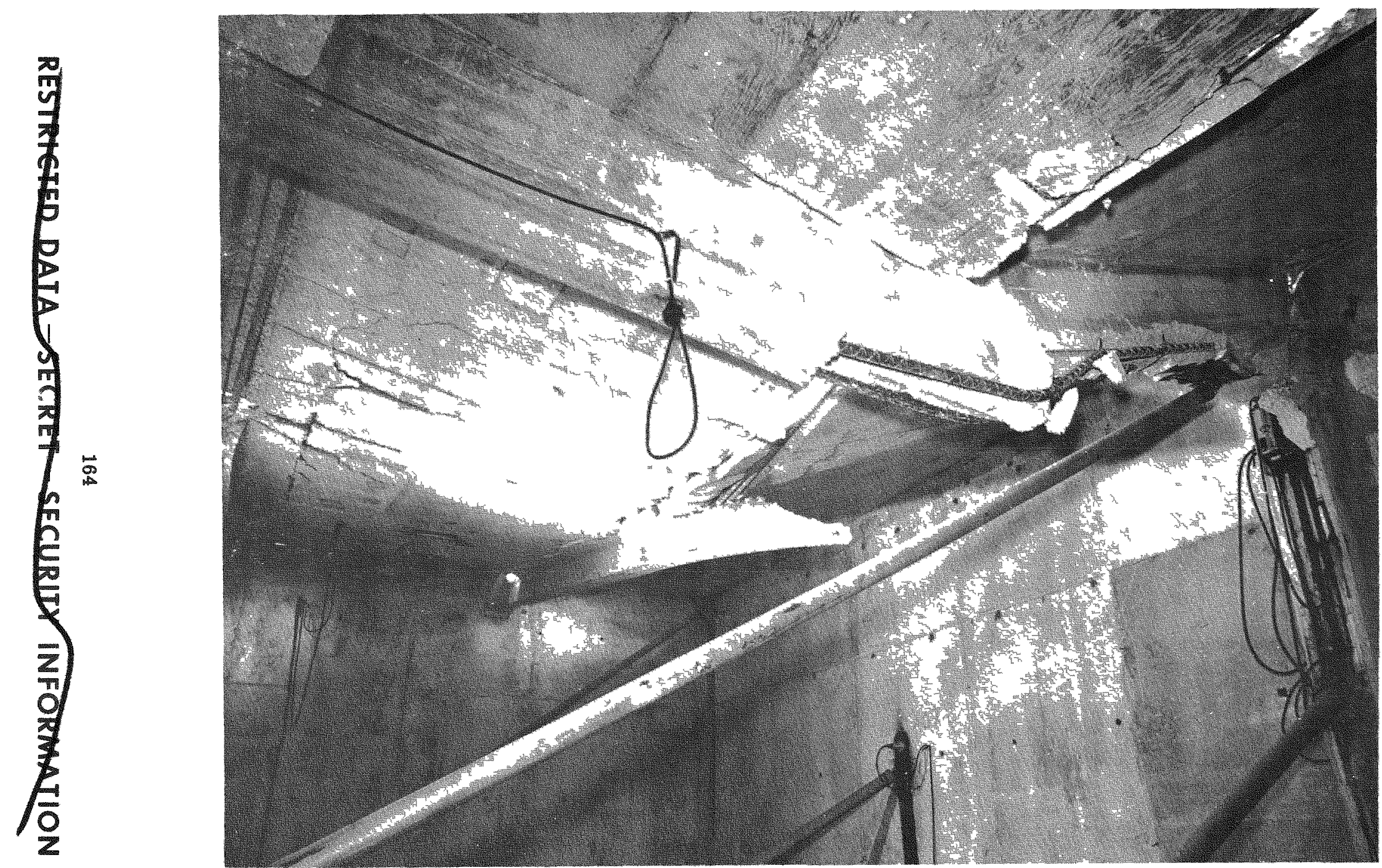

$\prod_{m}^{m}$

3

Fig. 6.122 Diagonal Shear Farlure in Roof Girder 
TABLE 6.1 MAXIMUM DISPLACEMENTS

\begin{tabular}{|c|c|c|}
\hline Gauge & Location & Value (in.) \\
\hline & Structure $3.2 .2 \mathrm{a}$ & \\
\hline $\mathrm{D}-1$ & Center right front wall; center foundation & 10.6 \\
\hline D-2 & Front right bent; rear foundation & 0.59 (peak) \\
\hline D-3 & Center roof; rear foundation & 4.37 (peak) \\
\hline $\mathrm{D}-4$ & Center roof; front foundation & 1.86 (peak) \\
\hline \multirow[t]{2}{*}{ D-5 } & Center bent; center foundation & 0.64 (peak) \\
\hline & Structure $3.2 .2 \mathrm{~b}$ & \\
\hline$D-1$ & Center roof; rear foundation & 5.8 (peak) \\
\hline $\mathrm{D}-2$ & Center roof; front foundation & 3.0 (peak) \\
\hline \multirow[t]{2}{*}{ D-3 } & Center front wall; center foundation & 2.1 \\
\hline & Structure $3.2 .3 a$ & \\
\hline $\mathrm{D}-1$ & Center roof; front foundation & 2.0 (peak) \\
\hline$D-2$ & Center roof; rear foundation & 3.3 \\
\hline$D-3$ & Top center front wall; rear foundation & 7.9 \\
\hline \multirow[t]{2}{*}{$\mathrm{D}-4$} & Center right front wall; center foundation & 9.0 \\
\hline & Structure $3.2 .3 \mathrm{~b}$ & \\
\hline$D-1$ & Center roof; rear foundation & 7.9 (peak) \\
\hline $\mathrm{D}-2$ & Center roof; front foundation & 1.65 \\
\hline$D-3$ & Top center front wall; rear foundation & 8.0 \\
\hline \multirow[t]{2}{*}{ D-4 } & Center right front wall; center foundation & 8.7 \\
\hline & Structure $3.2 .4 a$ & \\
\hline$D-1$ & Left end roof; front foundation & 0.56 (peak) \\
\hline \multirow[t]{2}{*}{$\mathrm{D}-2$} & Left end roof; rear foundation & -0.12 (peak) \\
\hline & & 0.90 (peak) \\
\hline $\mathrm{D}-3$ & Center roof; front foundation & 2.2 (peak) \\
\hline \multirow[t]{3}{*}{$\mathrm{D}-4$} & Front roof; center foundation & -0.52 (peak) \\
\hline & & 0.25 (peak) \\
\hline & & -1.52 (peak) \\
\hline \multirow[t]{2}{*}{$D-5$} & Center roof; rear foundation & NG \\
\hline & Structure $3.2 .4 \mathrm{~b}$ & \\
\hline$D-1$ & Right end roof; front foundation & 1.9 \\
\hline $\mathrm{D}-2$ & Right end roof; rear foundation & 2.6 \\
\hline$D-3$ & Left front fold; rear foundation & 5.3 \\
\hline$D-7$ & Right front fold; rear foundation & 5.6 (peak) \\
\hline D-8 & Right front roof; center foundation & 1.25 (peak) \\
\hline$D-9$ & Right roof; front foundation & 1.85 \\
\hline \multirow[t]{2}{*}{$\mathrm{D}-10$} & Right roof; rear foundation & -0.75 (peak) \\
\hline & & 0.55 (peak) \\
\hline
\end{tabular}


TABLE 6.1 (Continued)

\begin{tabular}{|c|c|c|}
\hline Gauge & Location & Value (ins) \\
\hline & Structure 3.2 .5 & \\
\hline D-1 & Left end peak; front foundation & 2.2 \\
\hline$D-2$ & Left end peak; rear foundation & 0.1 \\
\hline$D-3$ & Left peak; front foundation & 3.8 (peak) \\
\hline \multirow[t]{3}{*}{$D-4$} & Left peak; rear foundation & 0.8 (peak) \\
\hline & & -0.5 (peak) \\
\hline & & 0.6 (peak) \\
\hline$D-5$ & Left front center; center foundation & 2.8 (peak) \\
\hline $\mathrm{D}-6$ & Left rear center; center foundation & 1.8 (peak) \\
\hline \multirow[t]{2}{*}{$\mathrm{D}-9$} & Right front center; center foundation & 2.3 (peak) \\
\hline & Structure $\$ 3.2 .6$ & \\
\hline$D-1$ & Left B-ring; center floor & 0.72 (peak) \\
\hline $\mathrm{D}-2$ & Right B-ring; center floor & 0.7 (peak) \\
\hline D-3 & Front C-ring; center floor & 1.08 (peak) \\
\hline $\mathrm{D}-4$ & Front B-ring; center floor & 0.88 (peak) \\
\hline$D-5$ & Peak; center floor & 0.9 (peak) \\
\hline \multirow[t]{2}{*}{$\mathrm{D}-6$} & Rear B-ring; center floor & 0.6 (peak) \\
\hline & Structure $3.2 .7 \mathrm{a}$ & \\
\hline$D-1$ & $\begin{array}{l}\text { Middle center column; rear two-thirds } \\
\text { foundation }\end{array}$ & 0.75 (peak) \\
\hline \multirow[t]{2}{*}{$D-2$} & $\begin{array}{l}\text { Center right front wall; rear two-thirds } \\
\text { foundation }\end{array}$ & 7.8 \\
\hline & Structure $3.2 .7 \mathrm{~b}$ & : \\
\hline \multirow{3}{*}{ D-1 } & Middle center column; rear two-thirds & -0.1 (peak) \\
\hline & foundation & 0.63 (peak) \\
\hline & $\Rightarrow$ & -0.55 (peak) \\
\hline $\mathrm{D}-2$ & $\begin{array}{l}\text { Center right front wall; rear two-thirds } \\
\text { foundation }\end{array}$ & 1.4 (peak) \\
\hline
\end{tabular}




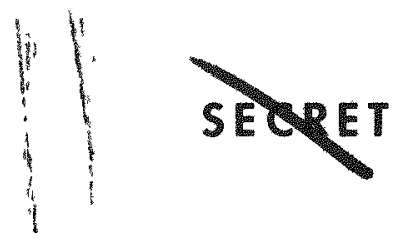

\section{Chapter 7}

\section{Discussion of Results}

\subsection{COMPARISON OF TEST RESULTS WITH PRETEST PREDICTIONS}

The discussions in this chapter are based upon preliminary studies and investigations. Although the complete postshot structural analysis is not ready for inclusion in this report, all the test structures will eventually be analyzed and the results published. The complete postshot analysis for Structures $3.2 .4 \mathrm{~b}$ and 3.2 .5 is included in Sec. 7.3 .

\subsubsection{Loading}

As mentioned in Chap. 2, certain simplified assumptions were made regarding structural loading. Some of these assumptions were found to be valid; others require modification.

Table 7.1 presents a comparison of predicted and observed loading data The measured yield or $0.7 \mathrm{kt} /$ was not sulficiently different from the predicted yield of $50 \mathrm{kt}$ to account for the appreciable variations in the side-on pressures, the $\sqrt[3]{46.7 / 50.0}$ equaling 0.977 .

Thejlection Factors. The observedreflection factors were also less than predicted. This disparity may be rationalized as follows:

1. A reduced reflection factor would be expected under the lesser overpressures observed.

2. Theoretical reflection factors are based on a true shock, i.e., one which rises to the peak pressure almost instantaneously. However, appreciable rise times were observed - up to $46 \mathrm{msec}$ at $2400 \mathrm{ft}$. Apparently, beyond $4000 \mathrm{ft}$ the blast rearranged itself into more of a "textbook" form. This accounts for the closer correlation between predicted and actual reflection factors at $6950 \mathrm{ft}$. Also, at this range the overpressure was as predicted. Fortunately the factor of 2 used in the Navy analysis was close to that observed. This would not have been the case had a true shock existed. It may be concluded that predicted reflection factors, in addition to being based on shock strength and angle of incidence, must also be related to the rise time.

3. On Structure 3.2.2b, a reflection factor of 1.54 was observed, whereas a value of 2.55 was predicted. It is believed that the considerable lateral movement of the front wall may have reduced the factor. In other words, something less than an infinitely rigid reflection surface was avallable. It will manifestly be very difficult to correlate the velocity of a reflecting surface with the expected reflection factor.

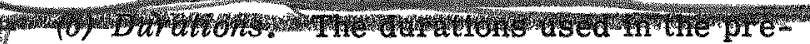
shot analysis (Fig. 2.1) were taken directly from Fig. 3.13e on page 54 of "The Effects of Atomic Weapons." This curve is based on a nominal bomb. These times should have been multiplied by $\sqrt[3]{50 / 20}=1.37$ to extrapolate to $50 \mathrm{kt}$.

\section{(c) Rzse 12 me.} of $46 \mathrm{msec}$ at $2400 \mathrm{ft}, 39 \mathrm{msec}$ at $2640 \mathrm{ft}, 12$ msec (average) at $3630 \mathrm{ft}$, and $3 \mathrm{msec}$ at $6950 \mathrm{ft}$. The finite time of rise seems to be related to the double pressure-wave generation from the explosion. The second wave has a higher velocity than the first, which results in its catching up and coalescing with the first at some range between 3630 and $6950 \mathrm{ft}$. It is believed that the $r$ ise time is a function of the separation between these two pressure waves.

On structural elements whose natural period is considerably in excess of the blast rise time, it may still be sufficiently accurate to assume an instantaneous rise time when computing response. However, a serious error may result in the case of smaller members whose natural period may actually be less than the time of rise. This is true of the subpanels of Structure 3.2.2a. 
TABLE 7.1 LOADING COMPARISON*

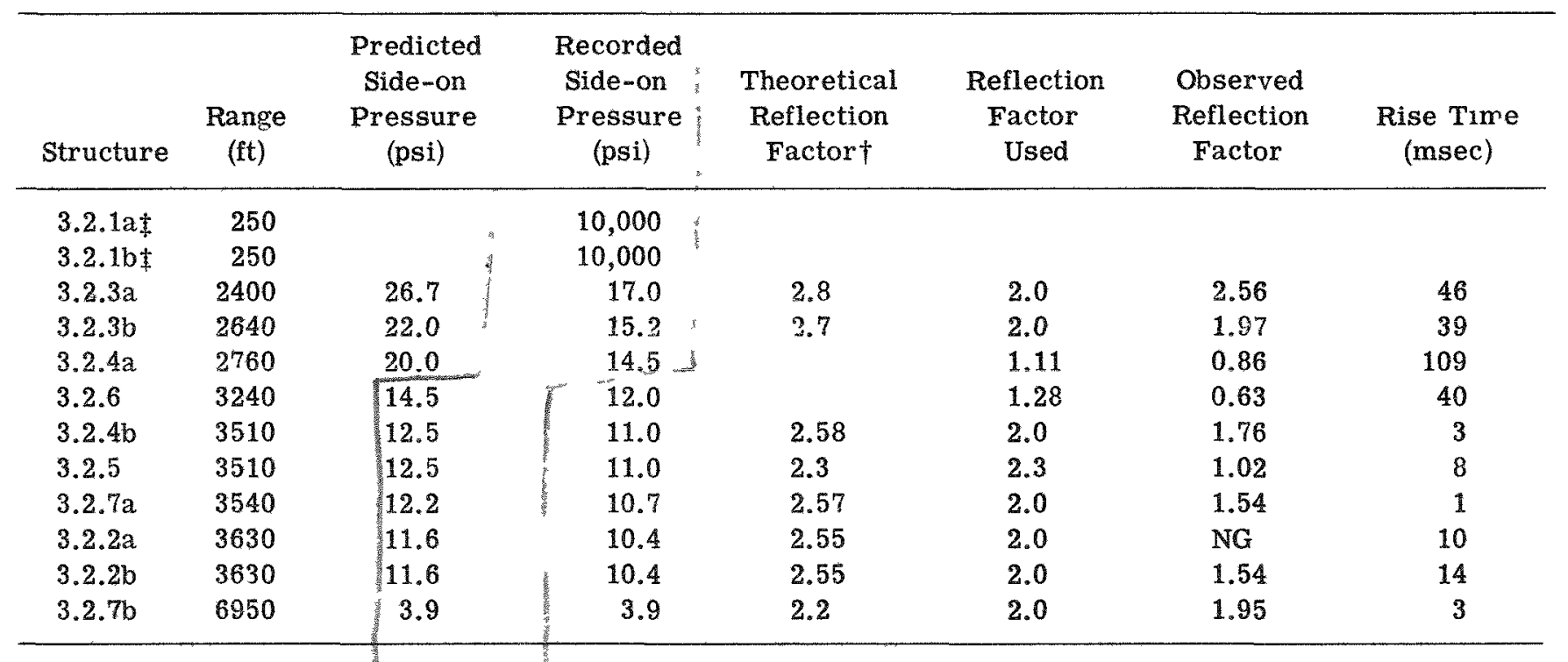

* Reflection factors and rise times refer to vertical or near-vertical front-wall surfaces.

† From "The Effects of Atomic Weapons," p. 123, Los Alamos Scientific Laboratory and U. S. Government Printing Office, Washington, D. C., 1950.

Ball-crusher-gauge results, Propram 1.

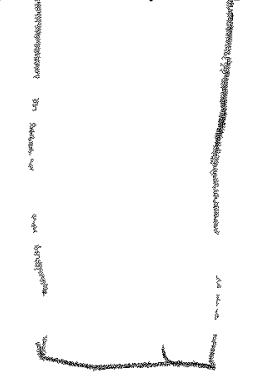


Here it is necessary to use a pressure-vs-time curve with a $10-\mathrm{msec}$ rise time in order to obtain proper estimates of deflection. Failure to do this results in estimates of deflection far in excess of those observed.

(d) Asymmetry. It has been assumed that the blast would propagate uniformly in all quadrants. Program 1 results on two blast lines indicate discrepancies. However, this effect will probably remain indeterminate as far as assumed loading for structural-response calculations is concerned.

(e) Decay Assumpitions. Chapter 2 presents certain general assumptions for the manner in which the shock decays after its initial rise. In most cases the slow rise time modified the loading pattern sufficiently to make difficult a check on the general validity of these assumptions. In cases where there was a sharp rise, as in Figs. $6.6,6.11$, and 6.12 , a comparison can be made. The predicted front-wall loading curves seem to be reasonably good. With some modification of reflection factors, they stand as sufficiently accurate.

The roof pressures decayed less rapidly than predicted by the two-dimensional shock-tube experiments. Apparently the action of vortices is less prominent in three dimensions than in two. A decay to $2 / 3 \mathrm{p}_{0}$ in time $t_{\mathrm{x}}$ in Fig. 2.3 is recommended as being closer to observed values.

Rear-wall pressures were also slightly higher than predicted. Using the full $p_{0}$ rather than $2 / 3$ $\mathrm{p}_{0}$ in Fig. 2.4 would give a more conservative loading estimate.

(f) Conclusions on Loading. The following conclusions regarding loading seem to be valid.

1. The reflection factor is a function of the time of rise.

2. The assumption that duration of loading must be scaled to the yield is confirmed.

3. Shock-tube predictions of pressures for roof and rear walls of a rectangular structure are low, whereas the predictions for front walls are quite good.

4. Rise time is an important factor in computing the response of members with high natural frequencies.

\subsubsection{Response}

The variations in predicted and observed loading curves make it difficult to assess pretest predictions for response. In order to draw firm conclusions, it is necessary to recalculate the deflections in accordance with the actual loading. This is done for Structures $3.2 .4 \mathrm{~b}$ and 3.2 .5 in Sec. 7.3. It is possible to observe obvious critical points on the structural design, however, as discussed in Sec. 7.2.

In general, where the difference between observed and predicted loading was not too great and where connections were adequate, deformations of structural elements fell within the predicted range. The allowable 10 per cent deformation criterion is apparently valid for relatively ductile members. It would probably have to be reduced for structural elements more rigid than those used in the Navy test structures.

\subsubsection{Structure 3.2.1a}

As explained in Appendix C, Structure 3.2.1a was not analyzed prior to the test because no dependable data regarding loading were available. Rather, this roof slab was designed, under standard Bureau of Yards and Docks procedures, to resist the impact effect of a $2000-1 b$ projectile. The results can be considered very satisfactory, since the slab withstood close-in atomic pressures successfully. Had the structure been oriented with the roof normal to the blast, the roof would have been subjected to pressures 1.3 times as large, but a slightly deeper slab would provide for this eventuality.

\subsubsection{Structure 3.2.1b}

Structure 3.2.1b was not analyzed prior to the test because dependable loading data were unavailable. Owing to the vented type construction, this roof slab was expected to behave somewhat better than the solid slab (Structure 3.2.1a) in resisting blast. However, the vented slab failed predominantly from the horizontal component of the blast; it was designed only for a vertical load. Had the roof been oriented normal to the blast, a better test might have resulted.

\subsubsection{Structure 3.2.2a}

Damage to Structure $3.2 .2 a$ was consiaerably greater than anticipated, owing primarily to connection failures which prevented the front panels from performing as designed. The center panels on the front face were expected to receive the heaviest damage, i.e., extensive cracking in the $r$ ibs and some separation between ribs and skin. 


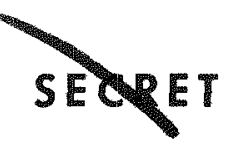

These panels actually failed, with a rather sharp break, near the center in moment. Some rib cracking occurred, but there was no separation between skin and rib. The other front panels failed similarly and released the blast wave inside the structure. The remainder of the panels failed from their weak side. Anchor bolts acted about as expected, being bent inward.

Damage to the bents, which occurred prior to the failure of the front wall, was about as predicted with heavy cracking at the haunches of the center bent. However, the expected separation between the channels forming the bent did not occur. 'Damage to the end bents was relatively less, as predicted.

\subsubsection{Structure $3.2 .2 \mathrm{~b}$}

Damage to Structure $3.2 .2 \mathrm{~b}$ was different from that predicted, owing to the rotation of the front wall and uplift of the panel footing. No restraining moment developed at the base of the front wall; therefore no damage occurred to the anchor bolts or plates. Similarly, the rotation of the front wall relieved the stresses on it, and panel damage was negligible. The roof failed unexpectedly, owing to the impulse it received, which was much larger than expected. The masonry failed through the bricks rather than through the mortar as predicted. Cracks in the brick end walls resulted from slight outward dishing rather than from action as shear walls. No damage occurred in brick walls around the bolts and washers tying them to the panels. Panels on end walls and the rear wall were damaged less than predicted.

\subsubsection{Structures $3.2 .3 a$ and $b$}

Structures 3.2.3a and b sustained over-all damage far in excess of, and in a manner somewhat different from, the predictions. It was thought that the front wall would receive a vertical compressive stress from the roof as the roof became loaded. Instead, the front wall deflected so much at the center that it actually applied a tension force to the front edge of the roof, tending to pull this edge down, but the roof itself successfully resisted this force with extremely limited deflection.

In addition, it was predicted that the base of the front wall would fail first and break away from the foundation, maintaining its connection to the roof. An exactly reverse situation oc- curred. In both structures the connection at the roof was broken first, and in Structure 3.2.3b the front wall collapsed, but the base remained anchored to the foundation.

The roof body was severed from the end walls along the predicted planes of weakest connection, but at the middle it split down the center of the panel rather than at the edges of the center panel. The grouted joints along the edge of this panel were intact, even after the impact of landing behind. The other half of the roof and the rest of the center panel flipped over as they landed and suffered severe damage. Even here, the joint between panels was still intact, even though the grout was broken loose.

\subsubsection{Structure 3.2.4a}

The earth cover on Structure 3.2.4a, especially the heavy embankments against the vertical faces of the side walls, caused the structure to respond in a manner slightly different from the predictions. It was thought that the pressure loading would produce a response similar to that obtained in an uncovered arch type structure, namely, a slight flattening out of the front panels with tension stresses on the inside and compressive stresses on the outside, as well as a tendency to squash the rear panels with tension on the outside and compression on the inside. However, the flat sloping roof portion of the front panels received heavier load than the vertical face, and the sloping portion attempted to move downward, introducing large moments at the knee of the panel with consequent cracks on the outside of the knee and none on the inside. On the rear-wall panels, tension cracks appeared on the inside face near the base and also at the fold lines. The end panels that remained in place developed shear stresses and cracks as predicted and to just about the extent predicted.

\subsubsection{Structure $3.2 .4 \mathrm{~b}$}

Except for the complete failure of the end walls, Structure $3.2 .4 \mathrm{~b}$ responded as predicted. In general, the end-wall failure probably did not influence the damage to the remainder of the structure. The gable bents had reached maximum deflection before the pressure inside the structure became a factor. Damage to edge beams was most severe at the crown and at the haunch, as predicted. Slab or skin 


\section{SECRET}

failure was in the concrete along the edge beams and was through cracks.

Foundation failure did not occur as predicted. The foundation cracked at the rear third point in the end-wall foundations instead of outside the toe of the panels in the rear foundation. The anchor bolts in the front wall were not deformed. It is indicated, therefore, that the toe of the wall panels was anchored well enough to resist the loads imposed and to pass the load to the endwall foundations.

The panels without intermediate ribs appeared to resist the loading as well as those with intermediate panels.

\subsubsection{Structure 3.2.5}

With the exception of the end walls, damage to Structure 3.2.5 was very close to that predicted. Rib damage was greatest at the crown and foundation, and some shear cracking occurred, as predicted, in the skin near the ribs. However, the panels without crossribs were damaged no more severely than those with crossribs. As expected, the panels with skin out were the strongest.

\subsubsection{Structure 3.2.6}

Structure 3.2.6 resisted the loading with less damage than predicted. No bolt deformation was noted. Cracking was similar in points of occurrence but was of very small magnitude. D-ring panel damage, although very slight, was greater than damage to the upper rings.

\subsubsection{Structure 3.2.7a}

The points of occurrence of failure in Structure 3.2.7a were well predicted; however, the degree of damage sustained was much greater than expected. The front wall received the greatest damage, occurring in the two rectangles outlined by the end walls, roof, column, and foundation. The failure of the front walls and the unpredicted stringer failure caused the roof to collapse. Heaviest cracking in all cases was as predicted.

The damage to the end walls was mainly in the form of shear cracks. The left end wall actually had brittle compression failures near the rear corner, where shear stresses were highest.
Column loadings were influenced by the failure of the front wall and roof. The front column failed as predicted; the rear column did not.

\subsubsection{Structure 3.2.7b}

Structure $3.2 .7 \mathrm{~b}$ responded about as predicted, with the exception of the failure of the stringer beams (a design weakness) and the excessive rotation of the haunches of the main girder. The haunches of the stringer beams were improperly designed in so far as the steel was concerned, and the haunches of the main girder, although properly laid out, were underdesigned for the loads that they were called upon to resist. The action of the front wall was almost precisely according to predictions; the rear wall sustained deflections about equivalent to those of the front wall, instead of the lesser amount that had been predicted. The end walls, which had been expected to deflect inward, actually deflected outward.

\subsection{CRITICAL POINTS IN DYNAMIC DESIGN}

\subsubsection{End Walls}

Although the end walls for the Greenhouse structures were designed to withstand only freeair pressure, preliminary evidence indicates that side-on pressure was somewhat greater than predicted free-air pressure during most of the positive phase. Since the direction of blast would not be known, future test structures should have end walls designed to withstand the full front-wall reflected pressure. Stronger end walls will then be capable of relieving more of the load imposed on the front wall.

\subsubsection{Connections on Rectangular Structures}

A common point of weakness in the rectangular structures was either the connection between the front wall and the roof or the weakness of the roof itself to the applied load. The latter is discussed in Sec. 7.2.4. In Structures 3.2.3a and $b$, the front wall broke loose from the roof through the welded connections at the trusses. In Structure 3.2.7b, the connection of the girder to its columns and the stringer beams to the walls by means of haunches proved to be inadequate. In Structure 3.2.2a, the rear haunch of the column-to-girder connection failed. In Structure 3.2.7a, the stringer haunches pulled bodily 


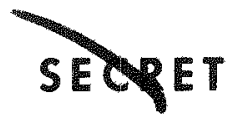

out of the end walls. In Structures 3.2.1a and b, the short stub walls sheared away from the roof sections. This consistent tearing or shearing inward of the front wall indicates that most of the front-wall action takes place before the roof can transmit appreciable downward forces to the wall.

\subsubsection{Panel Framing}

The basic analysis for resistance used for the Navy structures depended upon the development of large tensile forces acting through a catenary shape. This required a high degree of restraint at the connections of diaphragms to ribs, and of ribs to frames or adjacent ribs. In general, these forces had appreciable components in two directions, but in many cases the necessary restraint was not provided in both of these directions, and sometimes sufficient restraining was not provided in either direction. All the failures of the diaphragm-and-rib type can be traced to this shortcoming. Observations at the site indicate that the catenary action predicted by the analysis was developed, but in many cases the restraint for the resultant forces was not provided.

\subsubsection{Roofs}

Roofs were loaded to as much as 100 per cent over the design load. High moment stresses were developed at the center of the span because of this loading. The walls did not provide enough roof panel and restraint to develop the catenary type resistance; therefore failure of the roof resulted. Another action which caused the roof overload was axial compression of the roof panels when the structure was enveloped by the blast wave. Forces from the front and rear toward the center of the building placed an axial load on the roof panels after they were deflected, and this action accelerated failure.

\subsubsection{Front Walls}

Every case of front-wall failure led to complete collapse of the structure because the pressure was then allowed to enter and explode the building. Consequently the front wall is the most critical surface of the entire structure.

\subsection{COMPARISON OF RECORDED DEFLEC- TIONS WTH THOSE COMPUTED ON THE BASIS OF RECORDED LOADING}

\subsubsection{Structure 3.2.5 (Quonset)}

The analytical and experimental study of Structure 3.2.5 had the following objectives:

1. Comparison of the over-all pressure dis tribution assumed in design with that obtained in the test.

2. Study of the effect of the projecting ribs and stiffeners on local intensities of pressures.

3. Determination of the relative strength of panels having inward-projecting $x$ ibs (skin out) vs panels having outward-projecting ribs.

4. Determination of the relative strength of panels having stiffening crossribs vs panel without crossribs.

5. Determination of adequacy of the $2-\mathrm{in}$. slab thickness chosen in design.

6. Determination of adequacy of strength of the rib system of the panel as a unit.

7. Comparison of structural behavior anticipated in the original analysis with that recorded by the instrumentation and observed after the test.

In general, sufficient data were obtained for formulating conclusive opinions regarding all the foregoing objectives. A summary of conclusions, together with a brief discussion of resuits, follows.

The pattern or shape of the pressure curve enveloping the arch contour as obtained from the test is about the same as that given by shocktube experiments and used in design. In intensity the design pressures were somewhat greater than those recorded by the test instruments. The comparisons of over-all pressures are shown in Figs. 7.1 and 7.2. The differences, such as the subpanels in the front face of the arch, are more significant locally. The maximum pressures occur in the subpanel with $15^{\circ}$ inclination. The two pressure curves corresponding to this location are shown in Figs. 6.7 and 6.8. A peak of 29 psi was predicted against the maximum recorded of 11.4 psi.

Contrary to expectation, the pressures in comparable panels with outward-projecting ribs were of lesser intensity than in panels having a smooth contour, i.e., ribs projecting inward. This was probably due to pressure relief from vortices 

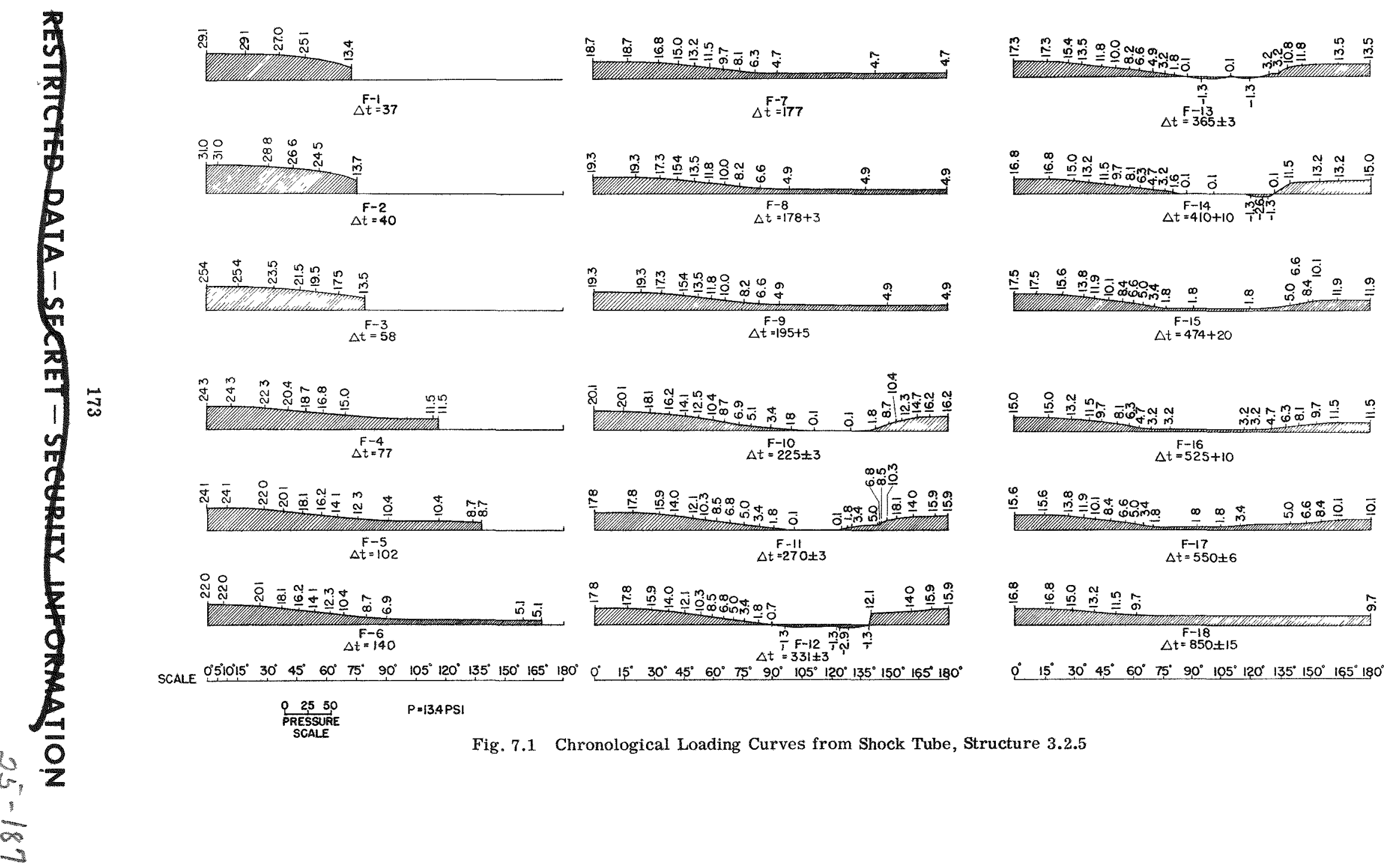

SCALE $0^{\circ} 5^{\circ} 10^{\circ} 15^{\circ} 30^{\circ} 45^{\circ} \quad 60^{\circ} \quad 75^{\circ} \quad 90^{\circ} 105^{\circ} 120^{\circ} 135^{\circ} 150^{\circ} 165^{\circ} 180^{\circ} 0^{\circ} \quad 15^{\circ} \quad 30^{\circ} 45^{\circ} \quad 60^{\circ} 75^{\circ} \quad 90^{\circ} 105^{\circ} 120^{\circ} 135^{\circ} 150^{\circ} 165^{\circ} 180^{\circ}$

$0^{\circ} \quad 15^{\circ} \quad 30^{\circ} 45^{\circ} \quad 60^{\circ} 75^{\circ} \quad 90^{\circ} 105^{\circ} 120^{\circ} 135^{\circ} 150^{\circ} 165^{\circ} 180^{\circ}$

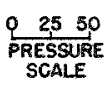
$P=13.4$ PSI

Fig. 7.1 Chronological Loading Curves from Shock Tube, Structure 3.2.5 


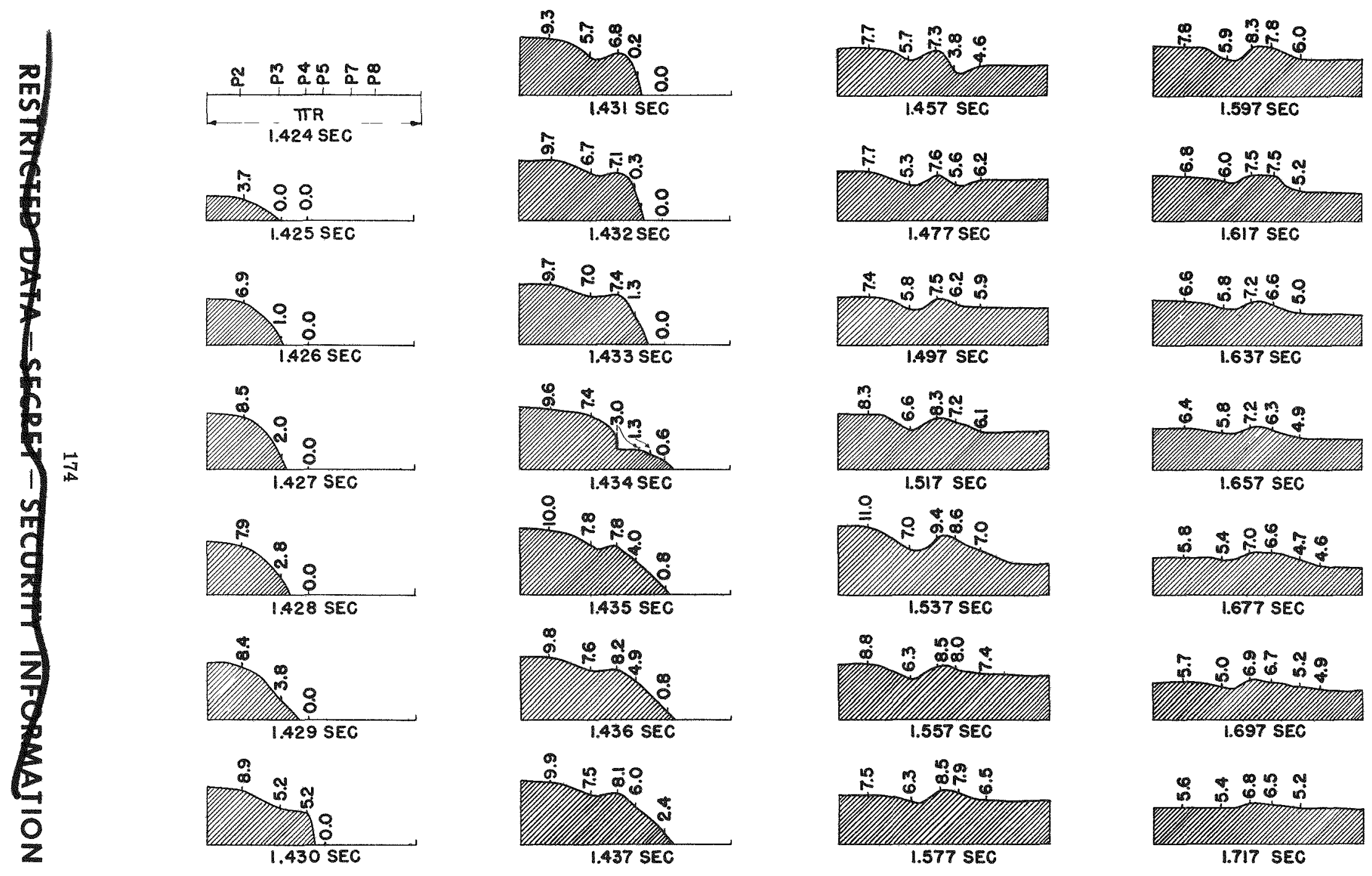

Fig. 7.2 Recorded Chronological Loading Curves, Left Half of Structure 3.2.5 
formed by the ribs. At a later time, pressures in the ribs-outward panels were slightly greater, possibly due to entrapment of the blast wave by the ribs.

There were slight differences in physical damage, as evidenced by the extent of cracking and permanent deflections, which showed a small advantage in strength of arch panels with inward-projecting ribs over those with outwardprojecting ribs. It is quite possible that the small advantage in strength of the ribs-inward panels was offset by their relatively higher pressures.

No appreciable advantage was obtained by the use of crossribs in either type of panel. This was due to the fact that local pressures were transmitted to the foundations principally by direct arch action through the shell rather than to the ribs by slab action.

The test verifies the design feasibility of minimum shell thickness. For an arch with a 20-ft span having its edge ribs $4 \mathrm{ft}$ apart, a 2 -in. shell, reinforced with a $2-$ by 2 -in. 8 -gauge mesh, appears to be entirely adequate for resisting reflected peak pressures of up to $20 \mathrm{psi}$. Assuming a reflection factor of 2 for the middle front panels, this will correspond to a side-on peak pressure of $10 \mathrm{psi}$.

The test verifies the adequacy of design proportions of the edge ribs. For a $20-\mathrm{ft}$ arch span and 4-ft panel width, an 8-in. rib depth is apparently adequate to sustain the pressure condition outlined. The chosen reinforcement consisting of a $7 / 8$-in.-diameter bar in the stem and $a \frac{3}{8}$-in.-diameter bar in the flange also is demonstrated to be sufficient.

There is a considerable divergence in the anticipated and observed structural behavior of the various framing elements of the shelter. Except for the vertical end-wall panels, the design predictions have proved to be on the conservative side.

The end panels failed primarily because of an error in the orientation of the ribs. According to the design, the ribs were to project inward. However, when drawing the details, the ribs were shown to project outward. As a result of this error, the strength of the panel in resisting an inward-acting force was greatly reduced. The weakness'was brought about in two ways: (1) By reversal of direction of the ribs, the $3 / 8$-in.diameter bar called for in design as compression reinforcement had now become the tensile reinforcement in lieu of a $\% / 8$-in.-diameter bar placed in the stem, thus resulting in a 75 per cent reduction in the flexural strength of the vertical ribs. (2) The support afforded by the middle ribs to the slab was now confined to the tensile strength of concrete through a plane connecting the slab to the rib. The failure of the latter section then resulted in increasing the span length of the slab from about $3 \mathrm{ft} 6$ in. to $7 \mathrm{ft}$ 0 in. Even with the presence of these significant weaknesses, the end panels developed considerable resistance prior to complete fallure, as evidenced by the very slow rise of pressure within the shelter. Unfortunately, no gauges were placed on these panels to register the intensities of the imposed pressures. Since the intensities are unknown, no conclusions can be reached regarding the structural behavior of end panels with correctly oriented supporting ribs.

The analysis and design of the arch panels were predicated on some rather conservative assumptions. In the case of the shell it was assumed that each of the arch panels would act as a one- or two-way slab in accordance with arrangement, transmitting the entire loading to the edge and transverse ribs by local bending. With this concept it was anticipated that the slabs would crack extensively and have permanent deflections from 2 to 3 in. However, except for minor cracking along the supports in some of the subpanels, the slabs showed no evidence of strain beyond their elastic capacity. Accordingly, only a small portion of the imposed loading was absorbed by local slab action. Analyzed as a shell, for the dimensions and sectional proportions used in the design, it can be shown that only about one-sixth of the load is carried to the ribs, the remainder being transmitted to the foundation supports by arched-shell action.

Using the pressure curve obtained by the instrumentation (Figs. 6.7 and 6.8), the analysis indicates that the maximum deflection of a strip of slab of unit width located at $15^{\circ}$ inclination in the third arch panel from the end was only 0.0006 ft with reference to its rib supports and that the motion had stopped at the end of the period $t=$ $0.004 \mathrm{sec}$. During this short period of time no change in pressure could have occurred within the shelter to affect the flexure of the slab, since, even assuming an instantaneous failure of the 


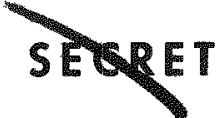

end walls, it would have required approximately 0.010 sec for the shock wave to reach the rear of the slab.

The absence of observable cracks at the supports indicates that the necessary resistance of the slab was developed by end elastic moments. Assuming that the strip flexed as a homogeneous section, the resulting maximum tensile fiber stress in the concrete was about $800 \mathrm{psi}$, or a resisting moment of $6400 \mathrm{in.-1b}$ per foot of slab. In comparison, the strip could have developed a maximum resisting moment of about 9000 in. Ib as a cracked section at the yield value of the steel reinforcement.

The observed behavior of the arch panels as a unit differed somewhat from that anticipated in design. Owing to the relatively weak jointing details, it was assumed that the pairs of bolted arch segments would act essentially as a threehinged arch framing. The deformations predicted on this basis were accordingly greater than those obtained in the test. However, in the absence of large rotational movements or openings at the crown and base connections and in view of the recorded small deflections, it may be concluded that the assembly acted as a rigid arch. With this understanding a new analysis was made for determining the revised deflections. The results of the analysis are shown graphically in Figs. 7.3 to 7.6 together with the recorded values.

In the elastic range of behavior, the arch goes through four modes of deformation (with cor- responding changes in resistance) as a series of four plastic hinges are formed successively with increased strains. For a segment with inward-projected ribs, the initial condition of a rigid arch prevails for about $11 \mathrm{msec}$, at which time the first hinge is developed at the front base. The second hinge is formed at the rear base; a third hinge is formed at approximately midway between the crown and rear base; and the fourth and final hinge is developed at a corresponding point in the front arch segment. At this last stage the behavior of the arch may be considered as fully plastic, with a constant resistance. For a segment with outward-projecting ribs, the sequence of hinge formation is reversed, the first hinge being formed at the rear base, the second at the front base, the third in the front quarter, and the fourth in the rear quarter.

The computations were made on the basis of five sets of values for dynamic modulus of elasticity of concrete, dynamic yield values of structural-steel-grade bolts, intermediate-grade reinforcing steel, and wire mesh. The combinations are shown in Table 7.2.

The values in set 5 are yield values increased by 60 per cent over set a, the assumed static strengths. Laboratory tests had indicated strength increases of this order of magnitude. Set 3 is identical with set 5 , except that a more realistic increase in $\mathrm{E}_{\mathrm{c}}$ of 10 per cent was utilized on the basis of tests conducted for the Bureau of Yards and Docks by the National Bureau of Standards. Later laboratory tests of actual steel used in

TABLE 7.2 STRENGTHS OF MATERIALS

\begin{tabular}{|c|c|c|c|c|c|}
\hline \multirow[b]{2}{*}{ Set No. } & \multirow{2}{*}{$\begin{array}{l}\mathbf{E}_{\mathbf{C}} \\
\text { (psi) }\end{array}$} & \multicolumn{3}{|c|}{ Yield Values of Steel (psi) } & \multirow{2}{*}{$\begin{array}{c}\text { Increase } \\
\text { over } \\
\text { Static } \\
(\%)\end{array}$} \\
\hline & & Bolts & Reinforcing Steel & Wire Mesh & \\
\hline \multicolumn{6}{|l|}{ Dynamic } \\
\hline 1 & $4,000,000$ & 40,000 & 56,000 & 72,000 & $b+28$ \\
\hline 2 & $5,000,000$ & 50,000 & 70,000 & 90,000 & $b+60$ \\
\hline 3 & $5,000,000$ & 50,000 & 80,000 & 120,000 & $a+60$ \\
\hline 4 & $8,000,000$ & 50,000 & 70,000 & 90,000 & $b+60$ \\
\hline 5 & $8,000,000$ & 50,000 & 80,000 & 120,000 & $a+60$ \\
\hline \multicolumn{6}{|l|}{ Static } \\
\hline$a$ & $5,000,000$ & 31,000 & 50,000 & 75,000 & 0 \\
\hline $\mathrm{b}$ & $5,000,000$ & 31,000 & 44,000 & 56,000 & 0 \\
\hline
\end{tabular}



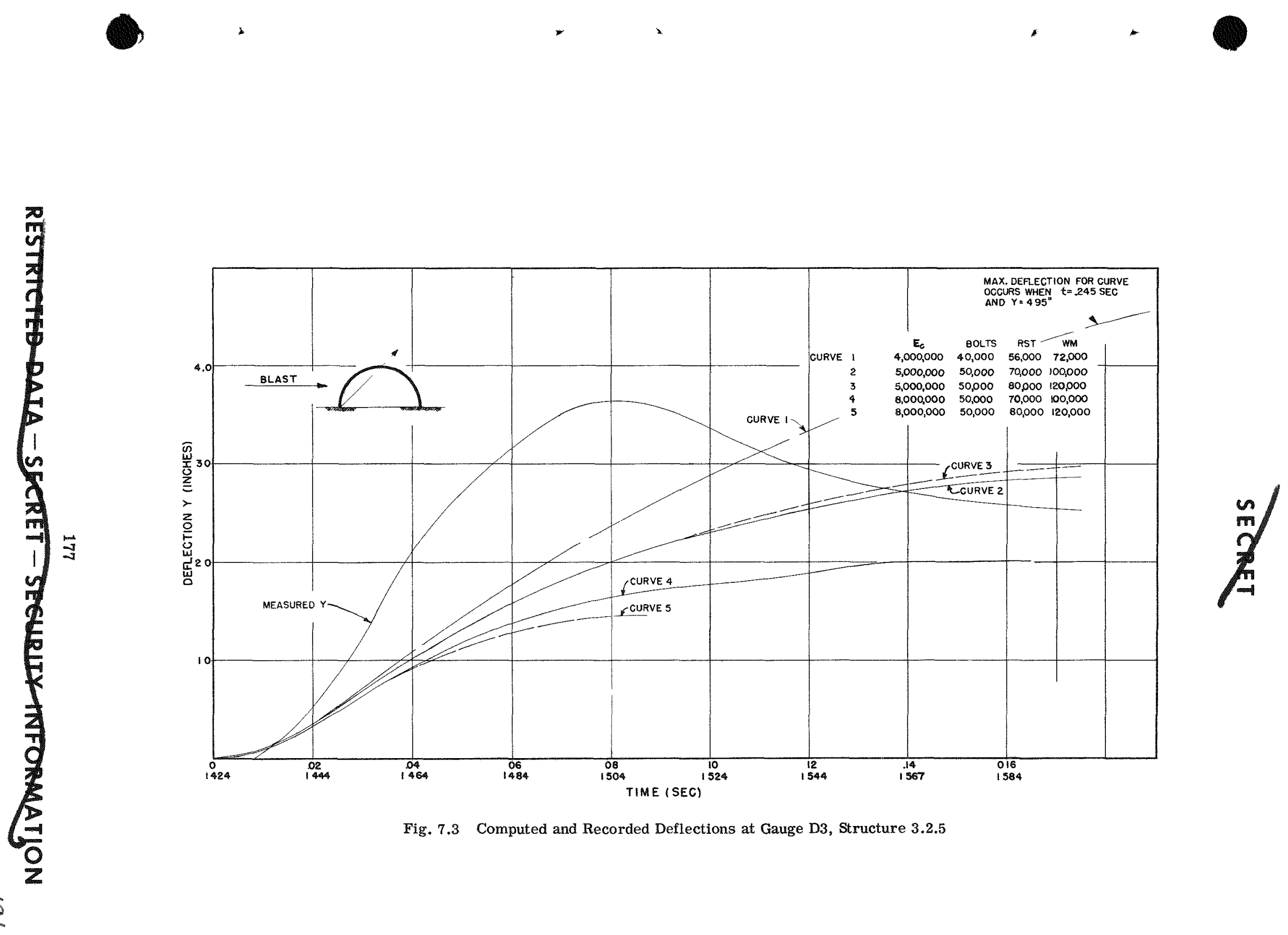

Fig. 7.3 Computed and Recorded Deflections at Gauge D3, Structure 3.2.5 

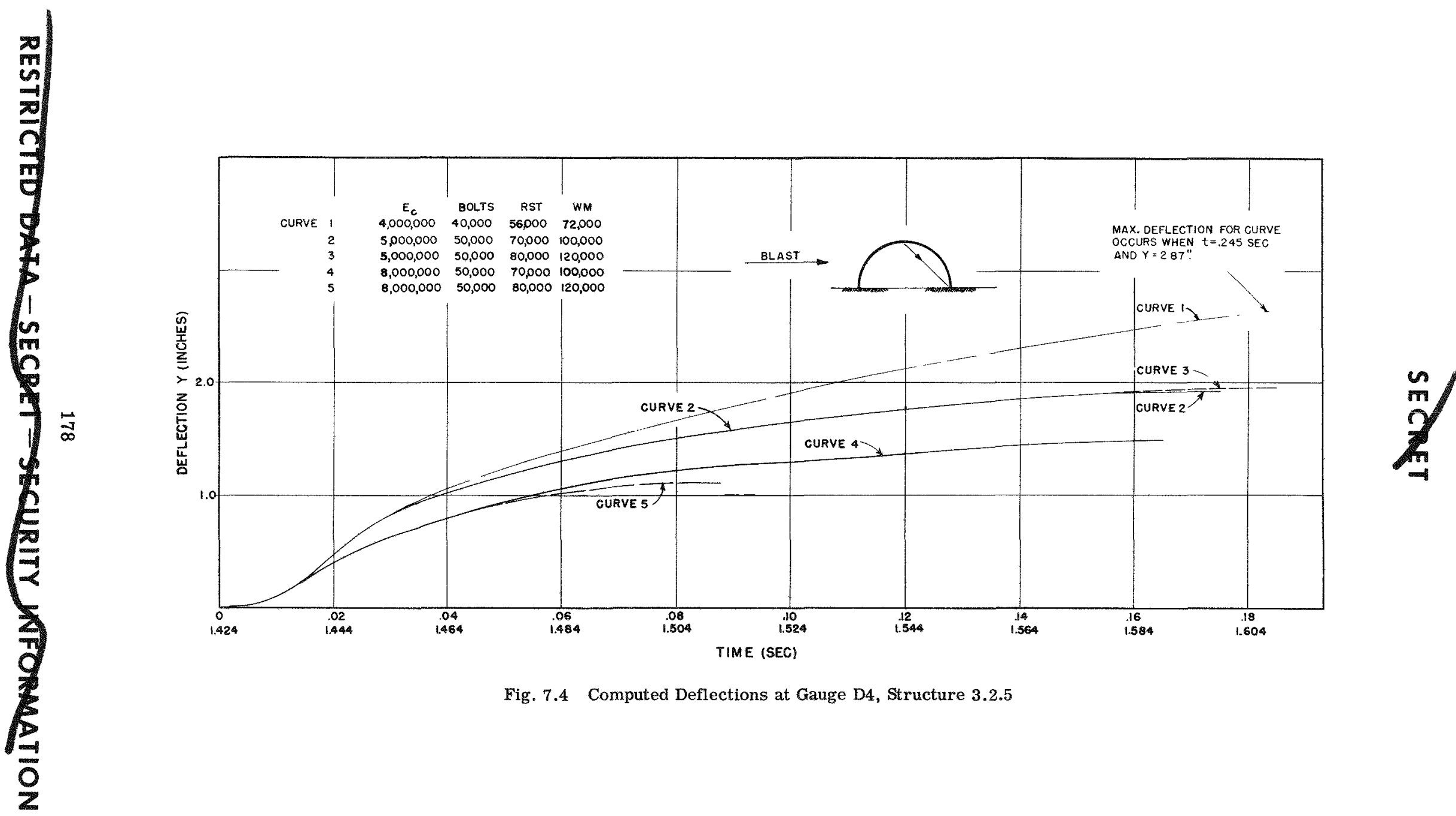

Fig. 7.4 Computed Deflections at Gauge D4, Structure 3.2.5 

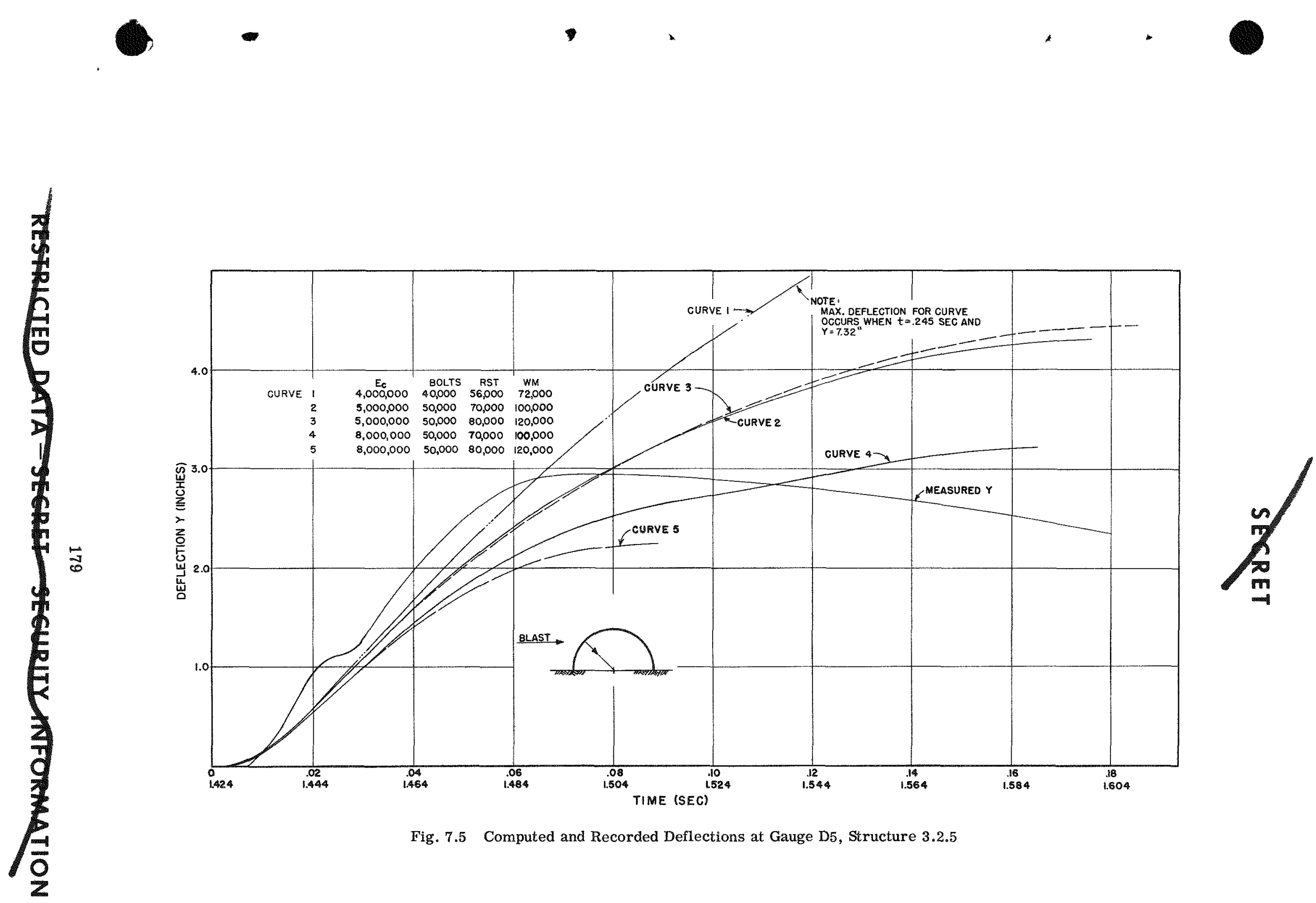

Fig. 7.5 Computed and Recorded Deflections at Gauge D5, Structure 3.2.5 

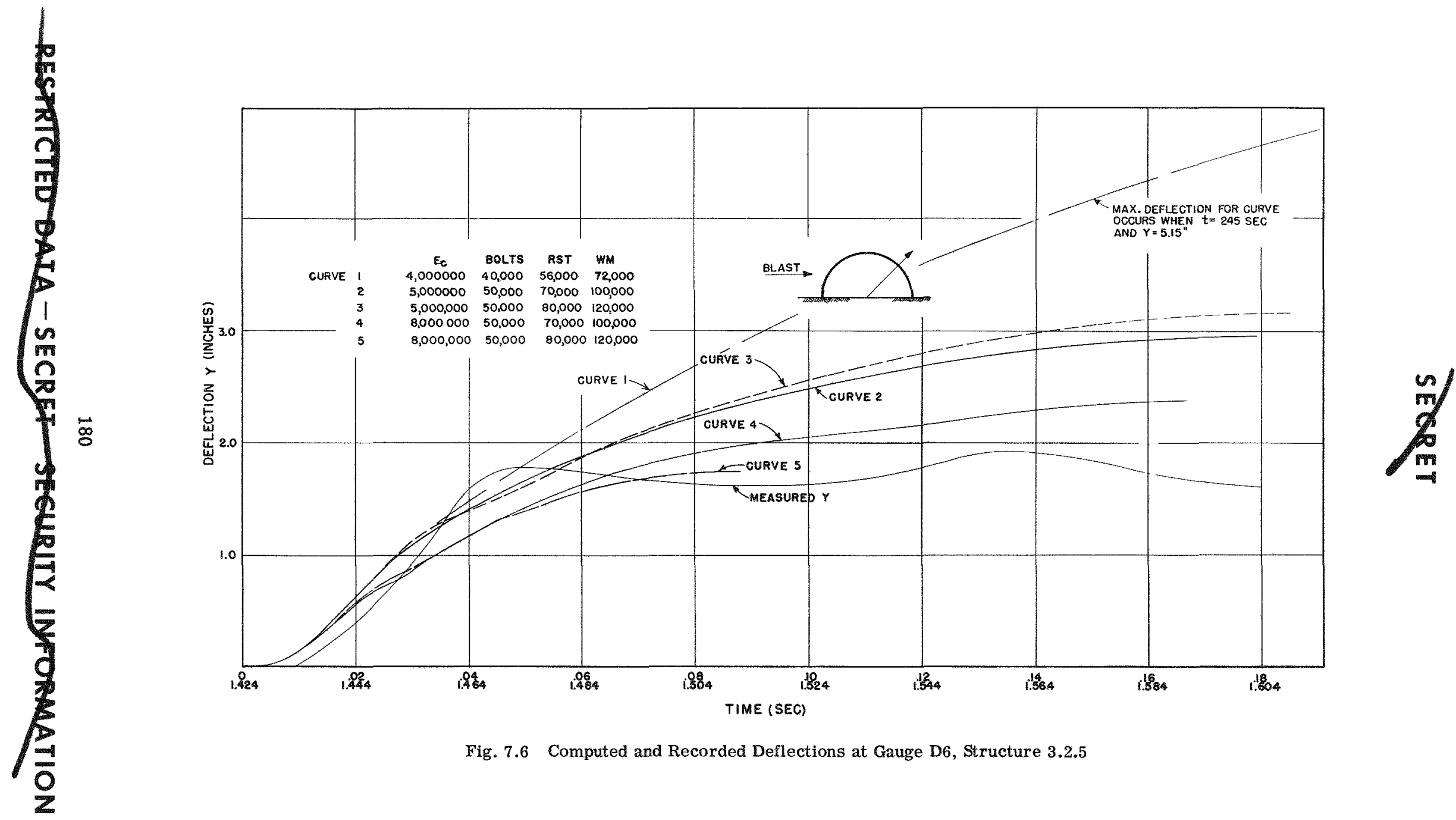

Fig. 7.6 Computed and Recorded Deflections at Gauge D6, Structure 3.2.5 
the precast panels indicated softer (set b) reinforcing steel and wire mesh than had been assumed. Accordingly, sets 2 and 4 were calculated with the new values to give a comparison with sets 3 and 5 . Later set 1 was arbitrarily selected as 80 per cent of the values in set 2 in an effort to reach better agreement between the recorded and calculated deflections on Structure 3.2.4b. This was successful, as shown in Fig. 7.7 , although the same values do not produce satisfactory correspondence on Structure 3.2.5, as shown in Fig. 7.3. This indicates that different strain rates on the two structures produced different dynamic strengths.

Deflections for gauges D3, D4, D5, and D6 are shown in Figs. 7.3 to 7.6. From these curves it appears that the best agreement between computed and observed values of deflections is given by gauges 5 and 6 . For the same gauges, curve 4 appears to approach the observed deflections most closely. For gauge 3 no satisfactory coincidence is obtained between the observed and computed values, especially in the earlier stages of deflection. However in the final stages curves 2 and 3 tend to approach the observed deflection. Because of an apparent injury to gauge 4 , the recorded values have not been plotted in the figure. It is quite possible that the readings of this gauge may have been affected by the impact of flying missiles caused by failure of the end walls.

\subsubsection{Structure 3.2.4b (Gable)}

The objectives of this study were the same as those described for Structure 3.2.5 in Sec. 7.3.1. In general, the comments and conclusions given for the quonset arch are applicable to the gable arch (Structure 3.2.4b). The order of formation of plastic hinges of the gable is about the same as that of the quonset, except that in the rear face the third hinge forms just above the knee and the fourth hinge occurs in the front face about midway between the top of the knee and the apex of the gable.

The deflection record of only one gauge for this structure was available. The computed and observed values for this deflection gauge are shown in Fig. 7.7. It will be noted that curve 1 appears to provide the most satisfactory coincidence. In Fig. 7.8 computed values for deflections corresponding to pauge D2 are given. Either curve 1 or 2 may be considered satisfactory.

\subsection{COMPARISON OF SHAPED WITH REC- TANGULAR STRUCTURES}

\subsubsection{Loading}

Table 7.3 presents a comparison of maximum loading conditions on the front surfaces of two shaped structures $(3.2 .4 \mathrm{~b}$ and 3.2 .5$)$ to maximum conditions on the front wall of a rectangular structure (3.2.7a) at the same range.

By geometry, a component of the blast pressure on an arch-shaped structure is downward, adding to the stability of the building. The pressure is also more evenly distributed over the building after complete envelopment. The advantages of shape seem to be directly proportional to the amount of streamlining.

\subsubsection{Structural-resistance Characteristics}

The advantages known for arch shapes in static-loading design are also apparent for dynamic-loading conditions. The absence of corners decreases the dangers of local points of overstressing. In other words, the stress patterns are uniform across the arch. Within the arch panels, stress concentrations may occur at the point of attachment between skin and ribs, but this is apparently not a serious objection.

\subsection{COMPARISON OF CONVENTIONAL WITH PANELED STRUCTURES}

In the justification for Structures 3.2.7a and b, it was stated that these structures were placed in the project as a comparison of conventional with panel type structures. Actually, Structures 3.2.7a and $b$, as indicated previously in this report, gave considerable information as to the response of materials. Changes in conventional design for dynamic loadings are indicated from this information, such as carrying reinforcing bars to supports and providing continuous reinforcing throughout a structure. Comparisons may be made, however, and are considered important in the evaluation of the structures. Structures $3.2 .7 \mathrm{a}$ and $3.2 .4 \mathrm{~b}$ can be assumed to have the same loading. Structure $3.2 .7 \mathrm{a}$ was $30 \mathrm{ft}$ farther from ground zero and about $75 \mathrm{ft}$ from Structure 3.2.4b.

During construction it was demonstrated that the construction time for paneled buildings was 

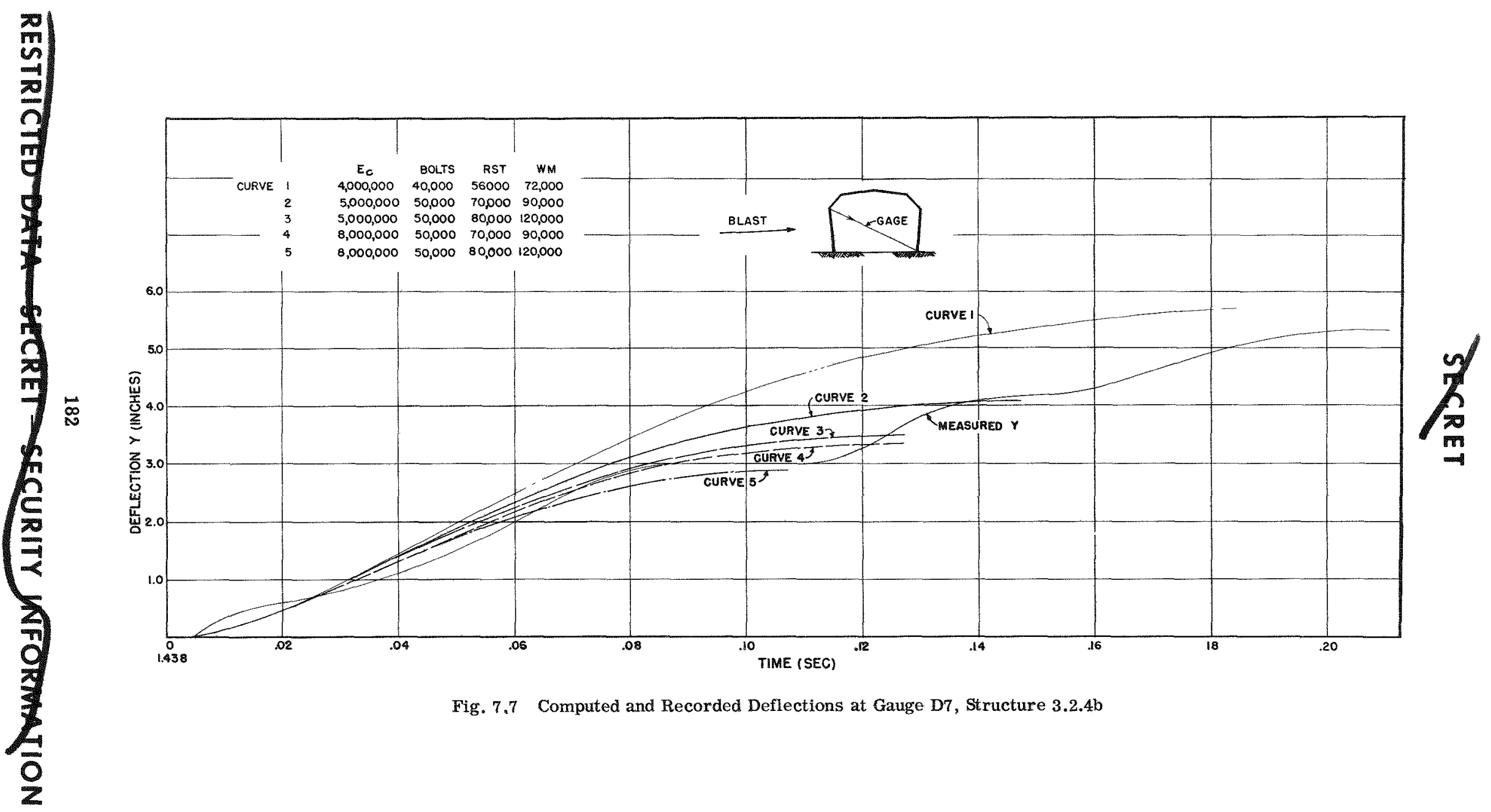

Fig. 7.7 Computed and Recorded Deflections at Gauge D7, Structure 3.2.4b 


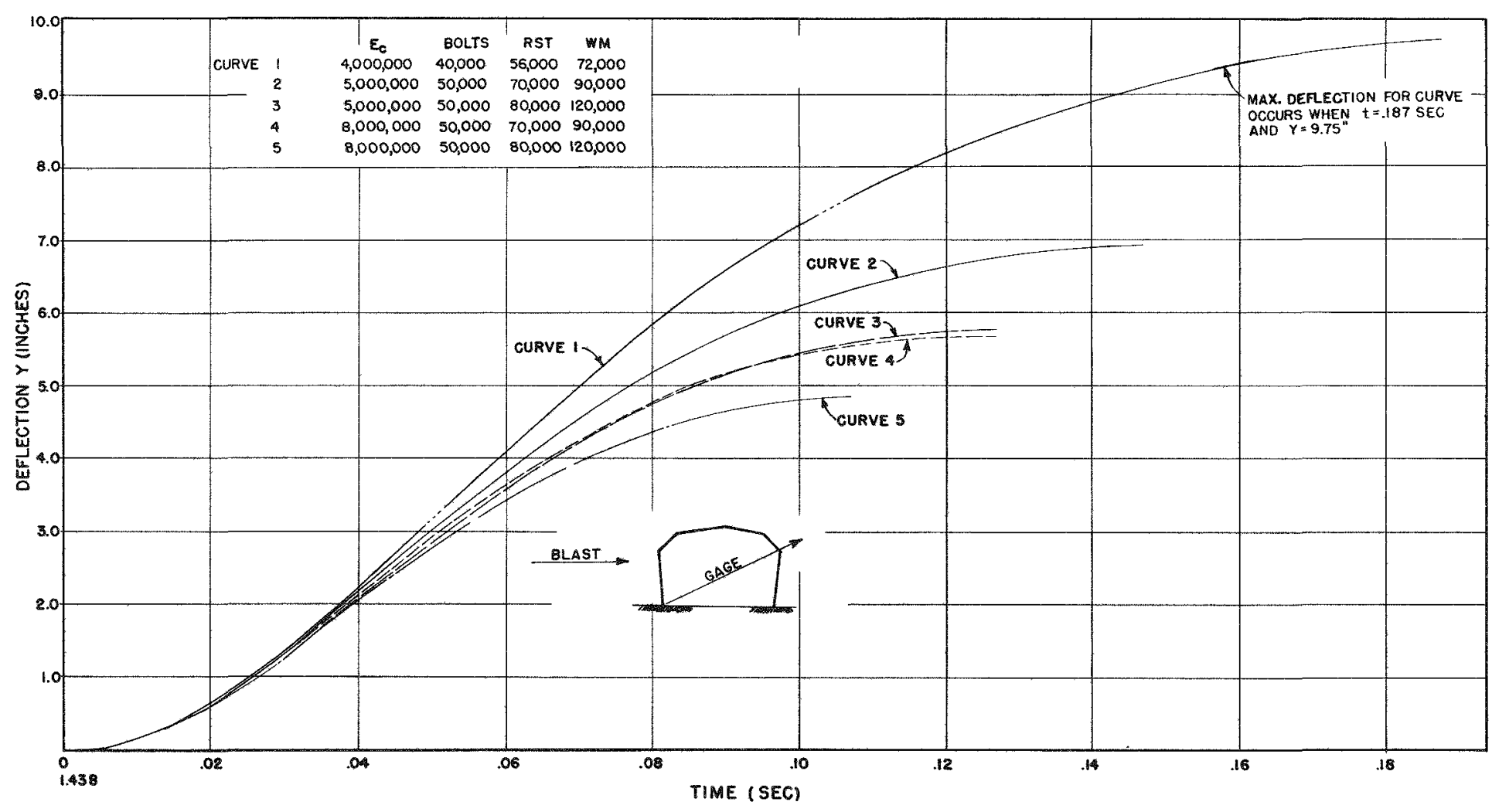

Fig. 7.8 Computed Deflections at Gauge D2, Structure 3.2.4b 
TABLE 7.3 EFFECT OF SHAPE ON REFLECTED PRESSURES

(CONSTANT RANGE)

\begin{tabular}{|c|c|c|c|c|}
\hline \multirow[b]{2}{*}{ Structure } & \multicolumn{4}{|c|}{$\begin{array}{l}\text { Maximum Loading Condition } \\
\text { on Front Surface }\end{array}$} \\
\hline & Gauge & $\begin{array}{l}\text { Pressure } \\
\quad \text { (psi) }\end{array}$ & $\begin{array}{l}\text { Angle with } \\
\text { Horizontal }\left({ }^{\circ}\right)\end{array}$ & Shape \\
\hline \multirow[t]{3}{*}{$3.2 .4 \mathrm{~b}$} & Front wall & 18 & 90 & \multirow[t]{3}{*}{ Gable bent } \\
\hline & Front fold & 13.3 & 45 & \\
\hline & Front roof & 15.25 & 20 & \\
\hline \multirow[t]{3}{*}{3.2 .5} & Front lower & 11.4 & 75 & \multirow{3}{*}{$\begin{array}{c}\text { Circular } \\
\text { arch }\end{array}$} \\
\hline & Front top & 9.1 & 40 & \\
\hline & Peak & 7.5 & 5 & \\
\hline $3.2 .7 \mathrm{a}$ & Front wall & 16.0 & 90 & Rectangular \\
\hline
\end{tabular}

considerably less than for conventional buildings. Labor savings can also be shown when precasting labor is included, if a large order is made for each type of building.

In general, Structure $3.2 .4 \mathrm{~b}$ withstood the loading with less damage than Structure 3.2.7a. The front wall of the latter failed first; therefore comparison in this discussion will be limited to front walls in order to eliminate supposition in later loading and response. The front-wall slab of Structure 3.2.7a was 6 in. thick with twice the steel required for structures built to withstand normal static loadings. The wall deflected to failure; the steel at the break and along the foundation was necked down, indicating tension failure. The slab was therefore too weak to withstand the loading imposed. The connections to the foundation were also too weak in tension.

On the other hand, the front wall of Structure 3.2.4b suffered local rib failure in on'y one panel. The slab in these panels was 2 in. thick with 2 - by 2 -in. 8-gauge mesh reinforcing or, by weight, the same amount of steel per square foot as that in Structure 3.2.7a. The paneled sections contained only 50 per cent as much concrete as was used in a similar section of Structure 3.2.7a. This comparison indicates the order of material saving which is inherent in the use of thin-slab construction, with no sacrifice in strength.

Further detailed and specific comparison will be made when the analysis of the structures is completed.

\subsection{DISCUSSION OF COMPARISON PANELS}

During the planning phases of the project, it was decided to design panels of two shaped structures in various ways in order to determine strength characteristics. Structures 3.2.4a and 3.2 .5 were chosen for this experimentation.

\subsubsection{Ribs In vs Ribs Out}

One-half of the panels on each structure were designed with the ribs out, the other half with ribs in. The half with the ribs in gave a more streamlined structure; thus theoretically the pressure gauges were more reliable. The response of these panels provided a great deal of information. In Structure $3.2 .4 \mathrm{~b}$ the vertical sections of the ribs-out panels were deflected considerably. Actually, since the tensile strength of the concrete is the mesh end restraint for $2 \frac{1}{2}$ in. of the rib width, the span of the slab or skin is 5 in. more in the ribs-out panels. The concrete failed, causing through cracks along the edge beams. The ribs-in panels, on the other hand, suffered no damage to the skin except hairline cracks. Practically all these cracks were in the vertical section of the panels.

In Structure 3.2.5, damage was not so severe to the ribs - out panels; however, a comparison can still be made favoring the ribs-in panels.

The end-wall panels of Structures 3.2.4a and $b$ and 3.2.5 were designed with ribs out. It is apparent from the preceding discussion that the 
end walls would have been stronger if the ribs had been in. It will be noted on the drawings that the end-wall panels were about twice the width of the front and rear panels. A center rib was provided, but the mesh was not tied to this rib. The mesh span was therefore the full width of the panel after the concrete failed in the center rib. Had the ribs been inward, the center rib would have served as a support for a continuous slab and would have provided additional strength.

\subsubsection{Value of Intermediate Ribs}

The panel in the center of each half of Structures 3.2.4b and 3.2.5 did not have intermediate ribs. The panels were simply thin slabs supported by ribs on the periphery. It was predicted that these panels would receive more damage owing to the lack of intermediate support. There was no visible or measurable difference in the response of these panels, however. Based on this test alone, it is considered that intermediate ribs may not be necessary, but further tests should investigate this possibility.

\subsubsection{Welded Panel Connections vs Bolted Connections}

Many of the precast-concrete panels which were displaced failed at connection points; therefore an examination of the merits of welded and bolted connections is in order. In the case of connections of the panel to the end wall or foundation and in the case of peak panel connections by bolts through the edge ribs there were very few failures in the bolts themselves. Rather, the concrete around the pipe sleeves through which the bolts passed failed in punching shear, freeing the bolt. In order to develop properly the strength of the bolt, it must be firmly affixed to the reinforcement. It is not safe to depend on compression between the reinforcing movement at connections. Indeed, sometimes the movement occurs in both directions.

In the other type of connection where plates were welded to the panel reinforcement and secured to a similar plate on an adjacent panel by a splice-plate weld, connection failures normally occurred by a $45^{\circ}$ shear failure in the weld around the splice plate. Hence the full design strength of the connection was developed. The connections should be modified to provide additional strength.

\subsection{EFFECTS OF EARTH COVER}

Although little experimentation has been conducted with the specific purpose of determining the mechanism by which structures are strengthened by the addition of earth cover, it is considered that one or all of the effects discussed in Secs. 7.7.1 to 7.7.3 are factors.

\subsubsection{Mass Effect}

Under a constant dynamic force the acceleration given a body without restraint is inversely proportional to its mass $\left(F=M_{a}\right)$. Hence, increasing the effective mass of an element by adding cover should reduce its movement and consequent damage under blast. In actuality, all structural elements have resistance, which is a function of displacement. When the resistance of an element in the elastic range exceeds the dynamic force, motion in the direction of blast will cease, and the element will tend to move in the opposite direction, releasing some of the energy it has received. Then the momentum of the cover increases the force on the element in direct proportion to the quantity of cover and to the initial acceleration. That is, initially,

$$
F_{e}=F_{a}
$$

when $M=$ mass of earth cover

$a=$ acceleration given structural element and cover

$F_{\mathrm{a}}=$ force due to air pressure

$F_{\mathrm{e}}=$ force on element

$Q=$ resistance of element

However, when the motion of the element reverses direction $\left(Q>F_{a}\right)$,

$$
\mathrm{F}_{\mathrm{e}}=\mathrm{F}_{\mathrm{a}}+\mathrm{M}_{\mathrm{a}}
$$

In the case of Structure 3.2.6, which had a minimum of $2 \mathrm{ft}$ of earth cover as radiation protection, the free-air pressure gauges outside the cover recorded a maximum of 10 psi with a second plateau of $7.8 \mathrm{psi}$ about $10 \mathrm{msec}$ later. Corresponding earth pressure gauges at the surface of the structure recorded a maximum of $16 \mathrm{psi}$, and there was subsequent attenuated oscillation during the time of the plateau of the free-air pressure recording. The period of the elastic oscillation was about $60 \mathrm{msec}$, and the 


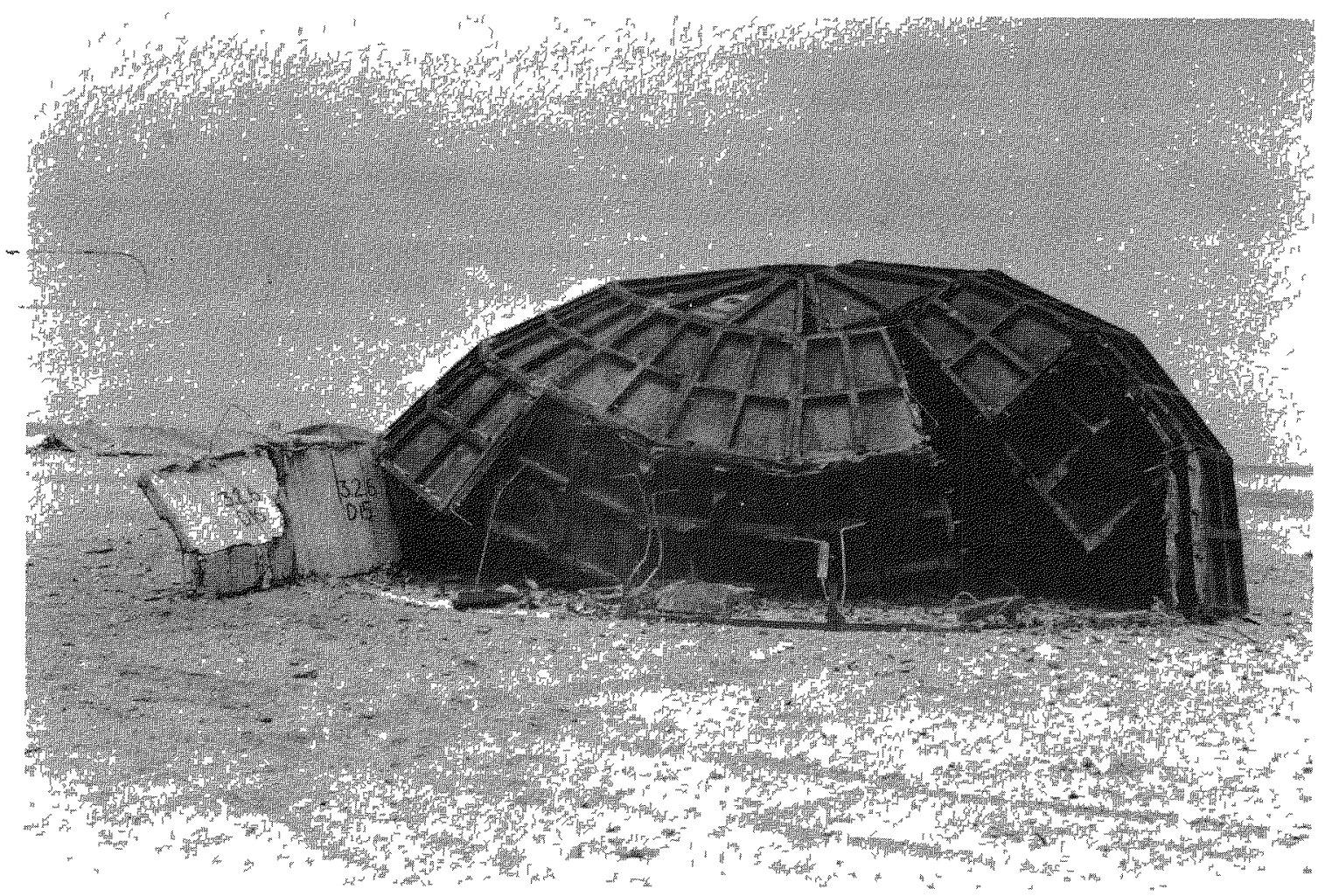

Fig. 7.9 Damage to Structure 3.2.6 After Item Shot, Looking from Direction of Blast 


\section{SECRET}

maximum points were coincident with maximum acceleration toward the exterior. In other words, the structural vibrations modulated the impressed loading. These oscillations are not indicative of the natural frequency of the structure because the vibration is forced. The high degree of damping prevents oscillatory motion after the blast has passed. Elements of the struc ture were subjected to about twice the pressure which existed at the surface of the cover. Use of the $F=M_{a}$ equation verified the suspicion that the additional 8 psi pressure on the top panel was caused by the change in the direction of movement of the panel and the subsequent additional pressure exerted on it by the $2 \mathrm{ft}$ of cover.

However, the true yardstick when considering damage is not loading but response, which can be roughly determined by initial acceleration. Had the 2 ft of cover been absent from the top of the dome, the effective mass would have been reduced by a factor of approximately 8 so that acceleration would have been increased considerably.

A limit is placed on the depth of cover by the static strength of the structure. Also, sufficient reserve strength must be maintained to absorb the dynamic live load. An optimum balance must be sought between live and dead load to determine optimum cover depth.

The foregoing discussion of the value of cover on a roof applies equally well to the front face of a vertical walled structure. Here the angle of repose of the earth provides greatest mass addition where it is most needed, i.e., at the usually vertical junction between foundation and front wall, without adding much dead load to the structure.

In the case of the rear wall of a covered structure which is attempting to deform away from the blast, the cover behind the rear wall opposes deformation and, by the passive strength of the earth, increases the pressure on the wall. Structures 3.2.4a and 3.2.6 had their highest earth pressure not on the front wall but on the rear wall.

\subsubsection{Pressure Attenuation}

A pressure wave is attenuated as it passes through any medium. The amount of this attenuation is not well known at the time of writing. There was no apparent loss of pressure in the $2 \mathrm{ft}$ of cover on top of Structure 3.2.6. However, decreased earth pressures were observed on the walls, depending on the gauge location and the amount of earth before it (Fig. 6.9).

\subsubsection{Streamlining Effect}

Although the total presentment of a structure is increased by cover, the pressures are favorably altered. Reflection factors are much lower than on a vertical wall, and the pressures over the structure are more evenly distributed. Structure 3.2.6 survived the Easy Shot practically undamaged, except for perrorifent vertical deformations of $3 / 4$ in. maximum. After the shot, the structure was completely uncovered, and the earth was leveled down to the foundation. The structure was then subjected to a second loading during the Item Shot. Similar conditions of range and pressure existed The thents were much different from the Casy test Four of the lower panels on the side of the structure facing the shot were demolished. The pressure wave then entered the structure and forced the panels on either side of the damaged ones to move out from the building interior and separate from the next higher ring of panels. These higher panels then dropped until they rested on the building foundation as shown in Fig. 7.9. The rest of the structure was essentially undamaged.

Althqugh the structure was not instrumented for the tem Shot the value of cover in protecting and stremingrical front surfaces was clearly demonstrated. Other advantages will become manifest following future, more thoroughly instrumented, cover tests. 


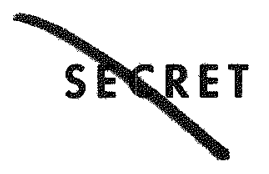

\author{
Chapter 8
}

\title{
Conclusions and Recommendations
}

\subsection{GENERAL CONCLUSIONS}

Certain conclusions may be drawn from the survey and the studies completed to date. The value of the test to the Navy is evident, as indicated by the following discussion.

\subsubsection{Fundamental Data}

Many data were collected. Enough data were obtained to prepare new designs and to reanalyze the structures tested. The amount and type of data collected were satisfactory and valuable. However, the test made evident that further data are required in some fields, for example, earth-cover and shaped structures.

\subsubsection{Observation of Physical Behavior}

Design assumptions were generally verified. In instances where response was greater than predicted, the reasons are being determined and may result in refinements either to the design of the structure or to the method of analysis.

\subsubsection{Relative Merit of Types}

Shaped structures, namely, the gable arch (3.2.4a and b), the arch (3.2.5), and the dome (3.2.6), were far superior to the rectangular structures. These three types of shaped structures can be used immediately for protective purposes, if modified as discussed. The test of the heavy bombproof roof (3.2.12) demonstrated the near-absolute protection of the Navy conventional heavy bombproof structure. The paneled rectangular structures when modified will provide protection at ranges where heavy conventional type buildings are otherwise required.

\subsection{SPECIFIC CONCLUSIONS}

As a result of studies to date, certain conclusions can be made about specific areas of work. These conclusions may be revised upon completion of the analysis.

\subsubsection{Validity of the Method of Analysis}

Preliminary studies have resulted in tentative conclusions regarding the concepts used in the method of analysis.

(a) Concept of Loading. The assumed-loading curves proved to be reasonably accurate as to quality for purposes of design, considering particularly the simplicity of application. Exceptions have been discussed in Chap. 7. Further laboratory and shock-tube studies are necessary to determine diffraction effects and reflection factors more accurately under various conditions such as slow rise time and nonrigid reflecting surfaces.

(b) Concepts of Resistance. The basic concepts of resistance as promulgated in the analysis used for checking the Navy structures appear to be sound. However, the structural qualities required to provide the necessary degree of restraint for these forces were lacking in many instances; this restraint could have been provided in practically every case by the use of improved connections - connections that actually would carry the stresses as assumed in the analysis. This would allow structural elements to develop full design resistances before failing in bending. Further testing of these improved connections will be required.

(c) Concept of Deformation. Two assumptions were made in the concept of deformation as a tool of analysis. The first assumption was that during full plasticity the member took the 
shape of a catenary. The second assumption was that the reinforcement would sustain over-all elongation. As judged from visual observations, the actual response of elements approached these two assumptions. It is necessary, however, to complete the analysis before these assumptions can be fully evaluated.

\subsubsection{Modifications to Analysis in Light of Test Results}

The postshot analysis of the structures has not been carried to the point where the necessity for modifications is evident. It is considered premature to form conclusions on the work accomplished to date even though the results are promising.

The need for revisions in the assumed loading curves is evident. Further analysis of test data and shock-tube data is required before definite conclusion can be made.

\subsubsection{Conclusions on Greenhouse Structures}

General conclusions may be made regarding the test of the structures. These conclusions are not dependent on the completion of the analysis and may be regarded as final. Amplification of these and addition of others may result from the completed analysis.

(a) Use of Thin Concrete Sections. A thin diaphragm section of reinforced concrete, properly tied to supporting ribs, can be effectively used to provide protection against atomic blast at distances where much heavier sections of conventionally designed concrete elements would otherwise be required.

(b) Shaped Structures. Very definite advantages are attached to the use of shaped structures as opposed to rectangular structures. The basic reason for this unfavorable position of the rectangular structures is the requirement for extremely strong and probably massive connections at the $90^{\circ}$ intersections throughout. The less the angularity of the stress path of the structure, the stronger it will be. With this concept, the sphere will probably be the most resistant of all basic shapes.

(c) Earth Cover. The use of earth embankment provides a valuable asset to the response of structures. The mechanics by which the earth embankment aids a structure are as yet not completely known, but the favorable effects are evident. A contractor has been commissioned to study this particular phenomenon.

(d) Protection of Existing Structures. Although Structure 3.2.2b was the only structure erected at Greenhouse to test the possibility of protecting existing structures, this field of study is a very large one. The use of precast panels for this purpose shows considerable promise. With a stronger roof, the brick building would have been completely protected. Japanese experience indicates that an unprotected masonry structure of similar design would have been completely destroyed at this range.

(e) Bombproof Structures. The heavy slab tested on the edge of the fireball at Greenhouse was eminently successful. Although designed to resist large impact missiles (for lack of information regarding close-in pressures), this ....... structure withstood short-time pressures surpassing the ultimate static compressive strength of the concrete. The possibility of providing above-ground personnel protection against blast on the edge of the fireball from a surface burst has thus been demonstrated.

(f) Foundations and Footings. The small observed footing movements indicate that foundations and footings are not a critical part of the structure when designing against blast.

\subsubsection{Revised Designs Based on Analysis}

Several revisions to designs are indicated as a result of the preliminary study. The qualitative revisions listed here can be applied to conventional design with little increase in cost of construction. Quantitative revisions will be made on completion of the analysis.

Conventionally arranged reinforcement apparently has a number of weaknesses which require modification. Suggested studies for modifications are as follows:

1. Continuity of reinforcing steel throughout structure.

2. Redistribution and relocation of reinforcing steel throughout.

3. Doweling or ties from wall to foundation. Revisions in the new type or paneled structures are as follows:

1. End-wall ribs should project inward rather than outward. Intermediate ribs are unnecessary. 
2. Rib steel should be continuous.

3. Steel should have sufficient anchorage to transmit local load to the support.

4. Mesh edges should be wrapped around rib reinforcing bar.

5. Rib steel should be equal in the stem and flange.

\subsection{GENERAL RECOMMENDATIONS}

The recommendations included here are based on conclusions reached in the preliminary study. Most of them may be considered final; some may be revised upon completion of the analysis. It is recommended that some structural types of the Navy project be tested further in order to obtain additional fundamental data and to service-test the various structural types. An order of priority of testing is recommended as follows:

1. Existing structure protection.

2. Gable arch.

3. Panel on bents.

\subsection{SPECIFIC RECOMMENDATIONS}

Recommendations are made here to cover specific areas of work.

\subsubsection{Recommended Overpressures}

The following classification of damage is used in Table 8.1.

Severe Damage - damage severe enough to prevent completely the accomplishment of any useful military function and the repair of which is essentially impossible.

Moderate Damage - damage sufficient to prevent any military use until extensive repairs are effected.

Light Damage - damage which will not seriously interfere with the immediate military operation of an item but which will require some repair to restore the item to complete usefulness.

The pressures listed in Table 8.1 apply to Greenhouse type structures with obvious weaknesses corrected.

\subsubsection{New Type Structures}

The novel cellular panels in Structures 3.2.3a and $b$ exhibited great skin strength. However, the welded panel connections were weak, and the large amount of field welding increased construction costs. Prestressing may solve both of these problems. Erection would consist of building up slabs from cells using prestressing cables and then securing these slabs together to form a structure. Use of cells with thicker skins would bring the slab strength up to the strength of the built-up panels of Structures 3.2.3a and $b$. With stronger connections, such a structure should be capable of withstanding the 22-psi free-air pressure that Structure $3.2 .3 \mathrm{~b}$ was designed to withstand.

Other new structures showing promise in resisting atomic blast should be tested as they are developed.

\subsubsection{Studies of Earth Cover and Shapes}

The value of both earth-cover and shaped structures was apparent in this test. The data collected on Greenhouse and other information should be studied car efully in order to develop theories of behavior of cover and effect of shape. Further full-scale tests are recommended.

\subsubsection{Instrumentation}

On the basis of instrumentation results on Greenhouse, it is recommended that structures in all future tests be instrumented and that instrumentation be employed in the transverse as well as longitudinal direction. Much of the information reported here would have been lost had it not been for the excellent instrumentation results.

\subsubsection{Shock-tube Studies on Shaped Sections}

Arrangements should be made to have shocktube data collected on the shapes used in this project. The present data on the Structure 3.2.4 type shapes could be supplemented in tubes currently used. Three-dimensional studies are necessary to study end-wall effects.

\subsubsection{Laboratory}

It is believed that valuable data could be collected in the laboratory by subjecting panels to a dynamic load. The edges of the panels when loaded should be restrained. Data concerning these tests would be very valuable. 
TABLE 8.1 RECOMMENDED OVERPRESSURES

\begin{tabular}{|c|c|c|}
\hline Structural Type & Damage & $\begin{array}{l}\text { Air Shock (psi) } \\
\text { Free-air Pressure }\end{array}$ \\
\hline $\begin{array}{l}\text { Heavy bomb-resistant shelter, } \\
\text { 3.2.1a }\end{array}$ & $\begin{array}{l}\text { Severe } \\
\text { Moderate } \\
\text { Light }\end{array}$ & $\begin{array}{r}12,000 * \\
10,000 \dagger \\
8,000 \dagger\end{array}$ \\
\hline $\begin{array}{l}\text { Precast panels on bents, } \\
\text { 3.2.2a }\end{array}$ & $\begin{array}{l}\text { Severe } \\
\text { Moderate } \\
\text { Light }\end{array}$ & $\begin{array}{r}10 * \\
7 \dagger \\
5 \dagger\end{array}$ \\
\hline $\begin{array}{l}12 \text {-in. brick walls protected by } \\
\text { precast panels, } 3.2 .2 \mathrm{~b}\end{array}$ & $\begin{array}{l}\text { Severe } \\
\text { Moderate } \\
\text { Light }\end{array}$ & $\begin{array}{r}14 \dagger \\
11 * \\
8 \dagger\end{array}$ \\
\hline Matchbox shelter, 3.2.3 & $\begin{array}{l}\text { Severe } \\
\text { Moderate } \\
\text { Light }\end{array}$ & $\begin{array}{r}13 * \\
9 \dagger \\
7 \dagger\end{array}$ \\
\hline $\begin{array}{l}\text { Gable shelter (with cover add } 2 \mathrm{psi} \text { ), } \\
\text { 3.2.4 }\end{array}$ & $\begin{array}{l}\text { Severe } \\
\text { Moderate } \\
\text { Light }\end{array}$ & $\begin{array}{l}14 \dagger \\
12 \dagger \\
10^{*}\end{array}$ \\
\hline $\begin{array}{l}\text { Cylindrical arch shelter (with cover add } 2 \text { psi), } \\
\text { 3.2.5 }\end{array}$ & $\begin{array}{l}\text { Severe } \\
\text { Moderate } \\
\text { Light }\end{array}$ & $\begin{array}{l}16 \dagger \\
13 \dagger \\
10 *\end{array}$ \\
\hline $\begin{array}{l}\text { Dome shelter (without cover subtract } 3 \text { psi), } \\
\text { 3.2.6 }\end{array}$ & $\begin{array}{l}\text { Severe } \\
\text { Moderate } \\
\text { Light }\end{array}$ & $\begin{array}{l}16 \dagger \\
14 \dagger \\
12 *\end{array}$ \\
\hline $\begin{array}{l}\text { Conventional reinforced-concrete structure, } \\
3.2 .7 \mathrm{~b}\end{array}$ & $\begin{array}{l}\text { Severe } \\
\text { Moderate } \\
\text { Light }\end{array}$ & $\begin{array}{l}6 \dagger \\
4 * \\
3 \dagger\end{array}$ \\
\hline $\begin{array}{l}\text { Conventional reinforced-concrete structure with } \\
\text { double reinforcement, } 3.2 .7 \mathrm{a}\end{array}$ & $\begin{array}{l}\text { Severe } \\
\text { Moderate } \\
\text { Light }\end{array}$ & $\begin{array}{r}10 * \\
8 \dagger \\
6 \dagger\end{array}$ \\
\hline
\end{tabular}

*Test results.

†Consensus of qualified persons.

191 
It is recommended that testing of materials be accelerated in order to determine yield strengths of all structural materials under dynamic loads. Particularly desired are data on structural-grade bolts, high-yield mesh, and intermediate-grade reinforcing steel.

\subsubsection{Theoretical Studies}

Several theoretical studies are necessary to explore feasibility phases of the structure types.

(a) Economics of Precast vs Poured-inplace Structures. Even though studies have been made on this subject, it is recommended that the precast types used in this test be com- pared economically with conventional buildings. It is considered very likely that precast shelters with a layer of earth cover to provide additional mass, as well as radiation protection, may be more economical than conventional poured-inplace shelters where the mass is an integral part of the structure. Mass production of precast shelters would reduce the cost of precasting by a factor of 2 or 3 .

(b) Advantages of Shaped Structures. Since shaped structures are inherently more satisfactory, it is important to study the utility of this type of structure. Comparisons of floor area, volume, costs, etc., should be made with conventional buildings of similar resistance to dynamic loads. 


\section{Chapter 9}

\section{Summary}

The structures of the Navy project represented a variety of types developed by the Bureau of Yards and Docks. The various types afforded studies of shape, earth cover, protection of existing buildings, degrees of strength, comparisons to conventional design, and many local comparisons. Thin concrete elements were used extensively, representing designs which provided considerable savings in on-site labor and material. The objectives of the test were to obtain fundamental data from the various types when subjected to blast loadings in order to check the method of analysis, and to observe the response of the various types under blast loadings.

The structures were designed and analyzed for dynamic loading under the direction of $A$. Amirikian, Consultant on Special Structures for the Bureau. Theoretical-loading curves were prepared by Amirikian based on the shock-tube studies conducted by W. Bleakney of Princeton University.

The precast-concrete elements were fabricated in the United States by Barrett and Hilp, San Francisco. On-site construction was accomplished by Holmes and Narver, Los Angeles. LTJG D. G. Iselin, CEC, USN, represented the Project Officer on the site during construction.

The structures were instrumented to record transient changes. Measurements of pressure, acceleration, and displacement were made. The work was done by the Sandia Corporation.

Before and after the test a thorough measurement survey was made. The purpose of the survey was to determine and record permanent changes in the structures and the structural elements. Survey instruments and still photography were used extensively during this phase of the operation. The survey measurements were made by LT C. L. Hayen, CEC, USN; LTJG D. G. Iselin, CEC, USN; and LTJG P. J. McEleney, CEC, USN. A. Amirikian was at the site as technical consultant.

After returning to the United States, project personnel evaluated the data collected. Complete studies were made to determine the history of response and the methods of failure of the structures. In every case of failure the reason was determined. During these studies the instrumentation results were invaluable in that transient measurements were available.

The postshot analysis was also initiated immediately on return from the Forward Area. Shock-tube data were available on the arch, Structure 3.2.5, and in addition 24 instruments were used in the structure, giving a great deal of information. It was therefore chosen as the first to be analyzed. Structure $3.2 .4 \mathrm{~b}$ was analyzed next for similar reasons.

As a result of the studies and the analysis, several conclusions may be made. The most important is the demonstration of the satisfactory use of thin concrete elements in protective construction. The objectives were met in that many of the design assumptions were corroborated and sufficient data were collected to confirm the analysis, while the relative merit of the structures was established.

The necessity for further full-scale testing is apparent. Shock-tube studies, earth-cover studies, and dynamic strength-of-materials tests should be expanded. 


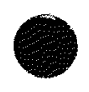

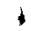

$\wedge$

$+$

$-$

3 
APPENDIXES 


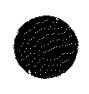

)

$\star$

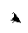

$-$

- 


\section{Appendix A}

\section{Notations}

The following notations are used generally throughout the report.

\section{A.1 DIRECTIONS}

When standing with back to blast and facing structure, directions are as indicated in Fig. A.1.

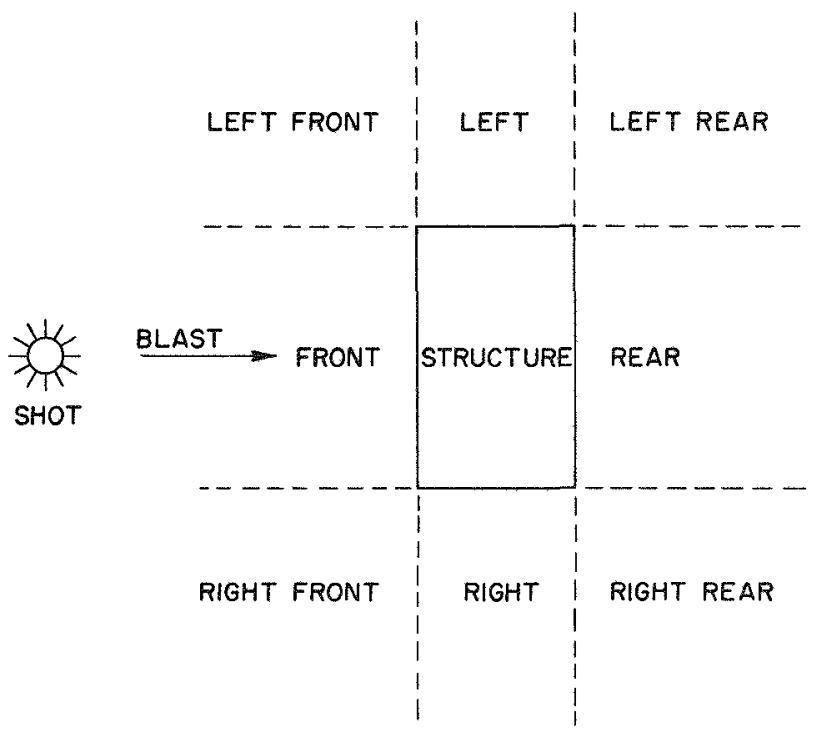

Fig. A.1 Plan View, Showing Directions

\section{A.2 NOTATIONS USED IN ANALYSIS}

$\begin{aligned} A= & \text { surface area of slab or beam } \\ A_{S}= & \text { area of tensile reinforcement } \\ c_{f}= & \text { coefficient of sliding friction of } \\ & \text { structure on ground } \\ d= & \text { width or depth of rectangular struc- } \\ & \text { ture } \\ d^{\prime}= & \text { extension of footing outside of wall }\end{aligned}$

$\mathrm{E}_{\mathrm{C}}=$ modulus of elasticity of concrete

$F=$ total force acting to move structure or component

$f=$ net force causing motion of unit area

$f_{c}^{\prime}=$ ultimate compressive strength of concrete

$\mathrm{h}=$ height of rectangular structure

$\mathrm{h}^{\prime}=$ depth of footing

$\mathbf{I}_{\mathrm{c}}=$ moment of inertia of unit width of concrete members

$I_{m}=$ mass moment of inertia of structure about an axis of rotation

$L=$ length of rectangular structure

$l=$ length of one-way slab or beam

$l_{1}=$ length of short side of two-way slab or plate

$l_{2}=$ length of long side of two-way slab or plate

$M_{p}=$ total moment of roof pressure about front edge of roof

$M_{r}=$ resisting moment at yield stress per unit width of slab or beam

$\mathrm{M}_{\mathrm{T}}=$ total overturning moment on structure

$\mathbf{P}_{\mathrm{H}}=$ total pressure on front wall

$P_{\mathrm{H} 1}=$ total pressure on rear wall

$\mathbf{P}_{\mathrm{V}}=$ total pressure on roof

$p=$ unit pressure, above atmospheric, on a surface

$\mathrm{p}_{0}=$ peak pressure, above atmospheric

$\mathrm{q}=$ modulus of resistance

$\mathbf{R}=$ total resistance to motion of structure in translation

$r=$ ratio of volume of reinforcing steel to volume of concrete, also a constant used in the solution of equations of motion

$S=$ stress per unit width of resisting steel in slab or beam

$t=$ time measured in seconds 
$t_{1}=$ time for reflected pressure on front face to drop to $p_{0}$

$t^{\prime}$ = time for shock wave to travel from front face to center of rear face

$\mathrm{v}=$ velocity

$v_{1}=$ velocity at time $t_{1}$

$v^{\prime}=$ velocity of shock wave

$\mathrm{v}_{\mathrm{a}}=$ allowable unit shearing stress in concrete

$v_{\mathrm{c}}=$ unit shearing stress in concrete

$\mathrm{W}=$ total weight of structure or component part

$\mathrm{w}=$ unit weight

$\mathrm{x}=$ displacement of structure in direction of shock wave $y=$ displacement of center of slab or beam relative to its supports

$\mathrm{y}^{\prime}=$ displacement of any point on slab or beam relative to its supports

$\alpha=$ acceleration

$\beta=$ reduction factor for area

$\beta_{1}=$ reduction factor for weight

$\gamma=$ resistance factor

$\Delta_{1}=$ displacement at time $t_{1}$

$\delta=$ maximum uplift at front footing

$\theta=$ angular displacement of structure

$\tau=$ duration of positive phase of shock

wave 
Appendix B

\section{Method of Analysis for Resistance to Blast}

\section{B.1 PROCEDURE OF ANALYSIS}

\section{B.1.1 General Phases of Investigation}

The analysis of a structure under blast involves two main investigations: strength and stability.

The strength computation, in turn, may be divided into two parts: (1) local strength or the resistance of individual members and (2) overall strength of the framing or assembly.

The investigation of stability will include (1) a study for stability against sliding and (2) a study for stability against rotation or overturning.

\section{B.1.2 Concept of Deformation}

In order to ascertain the strength of a framing arrangement, the strength of each individual member must first be considered. Assuming that the member will have adequate supports for transfer of its load, then the problem becomes a study of anticipated deformations of the member relative to its supports. The possibility of shear failure in short deep members should not be overlooked, however. A check for shear is given in Sec. B.3 (Eqs, B.37 and B.38). Under an impulse loading, the strength behavior of the member, or its capacity to absorb an impulse loading, will be governed in a large measure by its ductility. That is to say, the larger the deformation or axial elongation of the member and the larger the corresponding sag or deflection, the greater is the capacity of the member to absorb the imposed loading. The ductility of a reinforced-concrete member to produce desired deformations for resistance is governed by the ductility of its reinforcement.

When a fully fixed reinforced-concrete member is subjected to an impulse loading many times greater than its elastic resistance, the member will pass through three stages of deformations: (1) an initial stage corresponding to elastic behavior, (2) an intermediate stage of partly elastic and partly plastic behavior, and (3) a final stage of wholly plastic behavior. In the first stage, the member will behave as a fully restrained element, developing maximum resisting moments at the supports. This period of elastic behavior terminates when the end moments reach the ultimate elastic capacity of the section.

As the deformations increase, the resisting moments at the supports will increase to the plastic capacity of the section, and the reinforcement will deform locally to form plastic hinges at these locations. As a result, the ends will rotate and the member will deflect, as in the case of a simply supported beam. This is the second stage of deformation.

When the plastic moment capacity of the section at the center of the span is reached, the member enters into its final stage of deformation, characterized by extensive cracking and over-all elongation of the reinforcement. The passage from the intermediate to the final stage of deformation is accompanied by a loss in moment capacity and an increase in axial tension.

With continued deformations, the moment resistance rapidly diminishes to a negligible value, and the member axially elongates in the form of a simple parabolic curve. Failure will generally occur by rupture of the reinforcement similar to a bar in tension. If a factor is applied against the maximum deflection to prevent such failure, then the resulting deformation may be considered as a limiting condition in obtaining a practical or working resistance in 
design. This deformation may be stated in terms of axial elongation, or by unit strain. Although the reinforcement does not elongate uniformly, the average unit strain can be obtained by dividing the total elongation of the reinforcement by the over-all length of the member. A maximum deflection of one-tenth of the span length is suggested as a limiting value, corresponding to an average elongation of about 2.8 per cent. This value may be modified after further experimentation.

Explanation of the notations used in the following discussion may be found in Appendix A.

\section{B.1.3 Modulus of Resistance}

Figure B.1 illustrates the foregoing concept of deformation of a member. The deflection curve shown in Fig. B.1a, corresponding to the first stage of deformation, may be considered as that due to a uniformly distributed load $\mathrm{q}_{2}$. The deflection at the center of the span, $y_{a}$, will then equal

$$
\mathrm{y}_{\mathrm{a}}=\left(\frac{1}{384}\right)\left(\frac{\mathrm{q}_{\mathrm{a}} l^{4}}{\mathrm{E}_{\mathrm{c}} \mathrm{I}_{\mathrm{C}}}\right)
$$

in which $E_{c}$ is the modulus of elasticity and $I_{c}$ is the moment of inertia per unit width of member. Then

$$
q_{a}=\frac{384 E_{c} I_{c}}{l^{4}} y_{a}
$$

In Fig. B.1b, the deformation indicated by the dashed line represents the beginning of plastic deformation, where the moments at the supports have reached their ultimate plastic or yield value, $\mathrm{M}_{\mathrm{r}}$. The full line represents the beginning of the transitional period. At this point the deflection is $y_{b 1}$, which again may be considered as produced by the load $\mathrm{q}_{\mathrm{b} 1}$. The relation between $q_{b}$ and $y_{b}$ is then given by

$$
\mathrm{q}_{\mathrm{b} 1}=\frac{192 E_{c} I_{c}}{l^{4}} \mathrm{y}_{\mathrm{bI}}
$$

Figure B.1c shows the transitional stage in which it is assumed that the member continues to deflect under a constant load $q_{c}$. The value of this load may be expressed either in terms of $M_{r}$ obtained at the beginning of the period or in terms of a reduced moment, $\mathbf{M}_{\mathbf{r}}^{\prime}$, and an axial tension, $\mathbf{S}^{\prime}$. It is known that the total stress in the reinforcement resulting from both sources of strain will remain constant and equal to the yield-value strength of the steel in this period. However, since the relation between $\mathbf{M}_{r}^{\prime}$ and $\mathbf{S}^{\prime}$ cannot be clearly defined and conveniently expressed, the value of $\mathrm{y}_{\mathrm{c}}$ may be obtained from Mralone. Thus

$$
q_{\mathfrak{c}}=\frac{16 \mathbf{M}_{\mathbf{r}}}{l^{2}}
$$

Figure B.1d shows the final stage of deformation where, owing to extensive cracking, no appreciable resisting moments exist. The relation between deflection and load will then become

$$
\mathrm{q}_{\mathrm{d}}=\frac{8 \mathrm{~S}}{l^{2}} \mathrm{y}_{\mathrm{d}}
$$

in which $S$ is the ultimate yield strength of the reinforcement per unit width.

In the relations given above, the load $q$ is a measure of strength of the member and accordingly may be called the modulus of resistance of the member, or simply the resistance.

The relation between resistance and deflection throughout the full range of deformations is shown diagrammatically in Fig. B.2. Here the line $O A$ indicates the first or elastic stage; $A B$, the partly elastic and partly plastic stage; $B C$, the transitional period; and $C D$, the final or fully plastic stage of deformation. At point $C$, $q_{c}$ is equal to $q_{d}$. Hence, from Eqs. B.2 and B.3

$$
\frac{16 \mathbf{M r}_{\mathbf{r}}}{l^{2}}=\frac{8 \mathrm{~S}}{l^{2}} \mathrm{y}_{\mathrm{c} 1}
$$

from which

$$
\mathrm{y}_{\mathrm{c} 1}=\frac{2 \mathrm{Mr}}{\mathrm{s}}
$$

If the effect of resisting moments is neglected, then the deflection-load relation will be represented by the straight line OCD, Fig. B.2. This is the case for a relatively thin element supported on two ends.

In the case of a thin framing element supported on four sides (Fig. B.3), such as a re- 


\section{SEQRET}

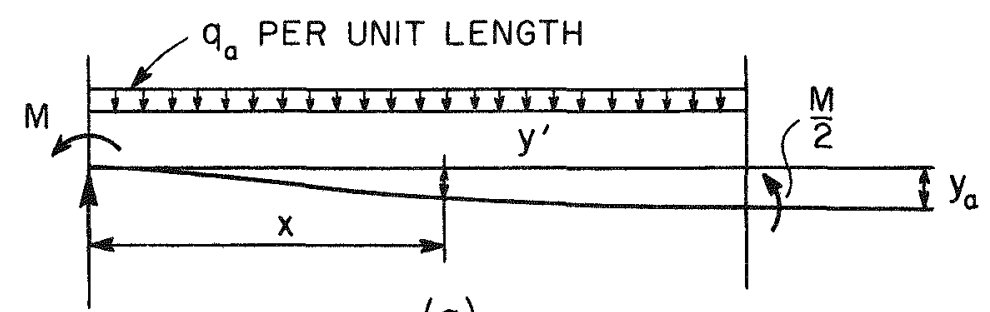

(a)

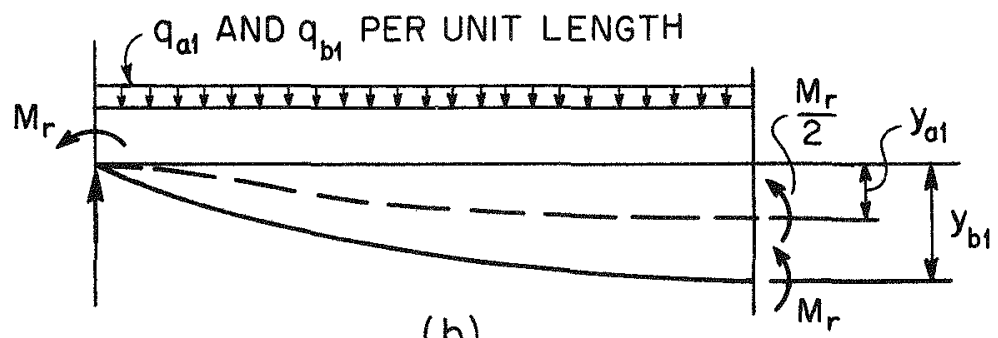

(b)
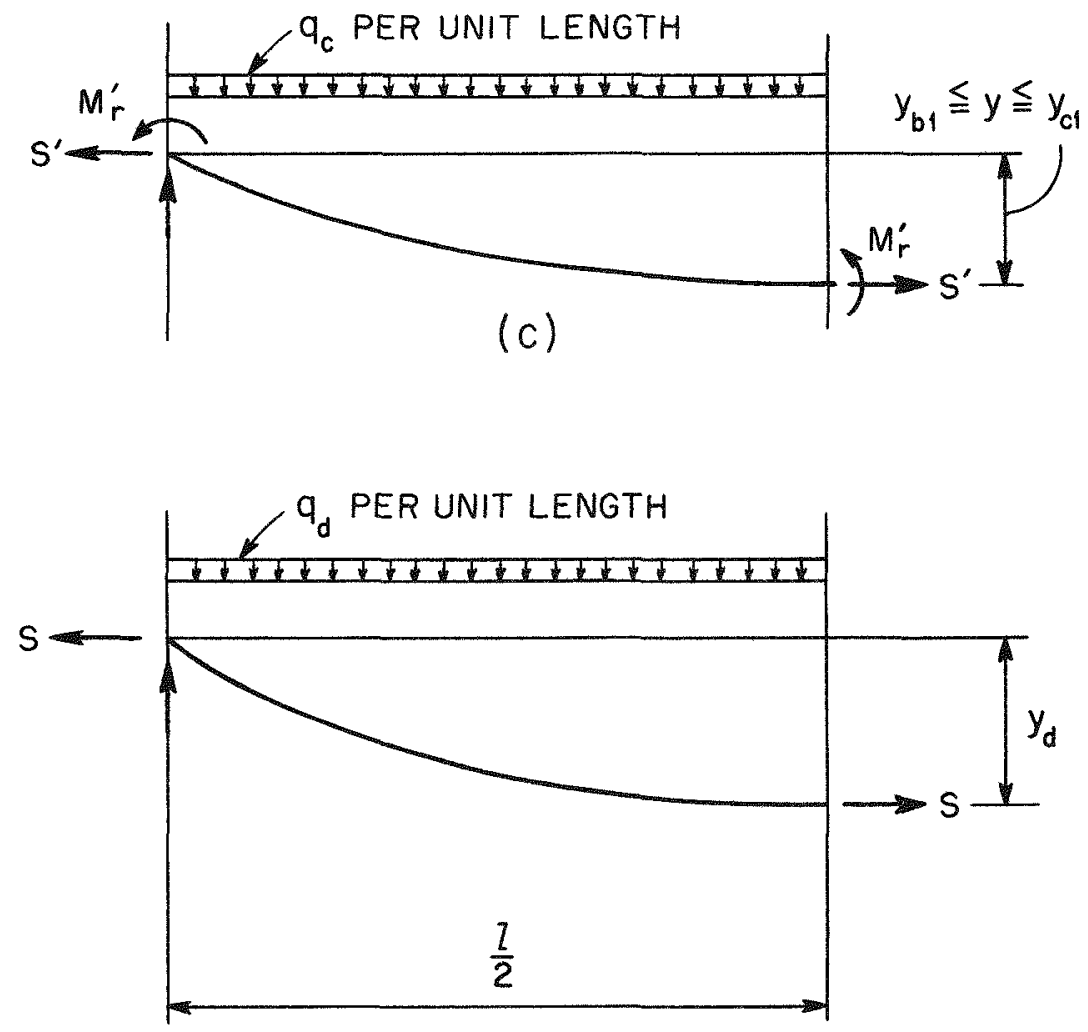

(d)

Fig. B.1 Deformations of a Beam Under a Uniform Loading. (a) for $0 \leq t \leq t_{a}, q_{a}=\left(384 E_{c} I_{c} y_{a}\right) / l^{4}$; (b) for $t=$ $t_{b 1}, q_{b 1}=\left(192 E_{c^{1}} y_{b^{1}}\right) / l^{4} ;$ (c) for $t_{b l} \leq t \leq t_{c 1}, q_{c}=\left(16 M_{r}\right) / l^{2}$; (d) for $t \geq t_{c 1}, q_{d}=\left(8 S y_{d}\right) / l^{2}$. 

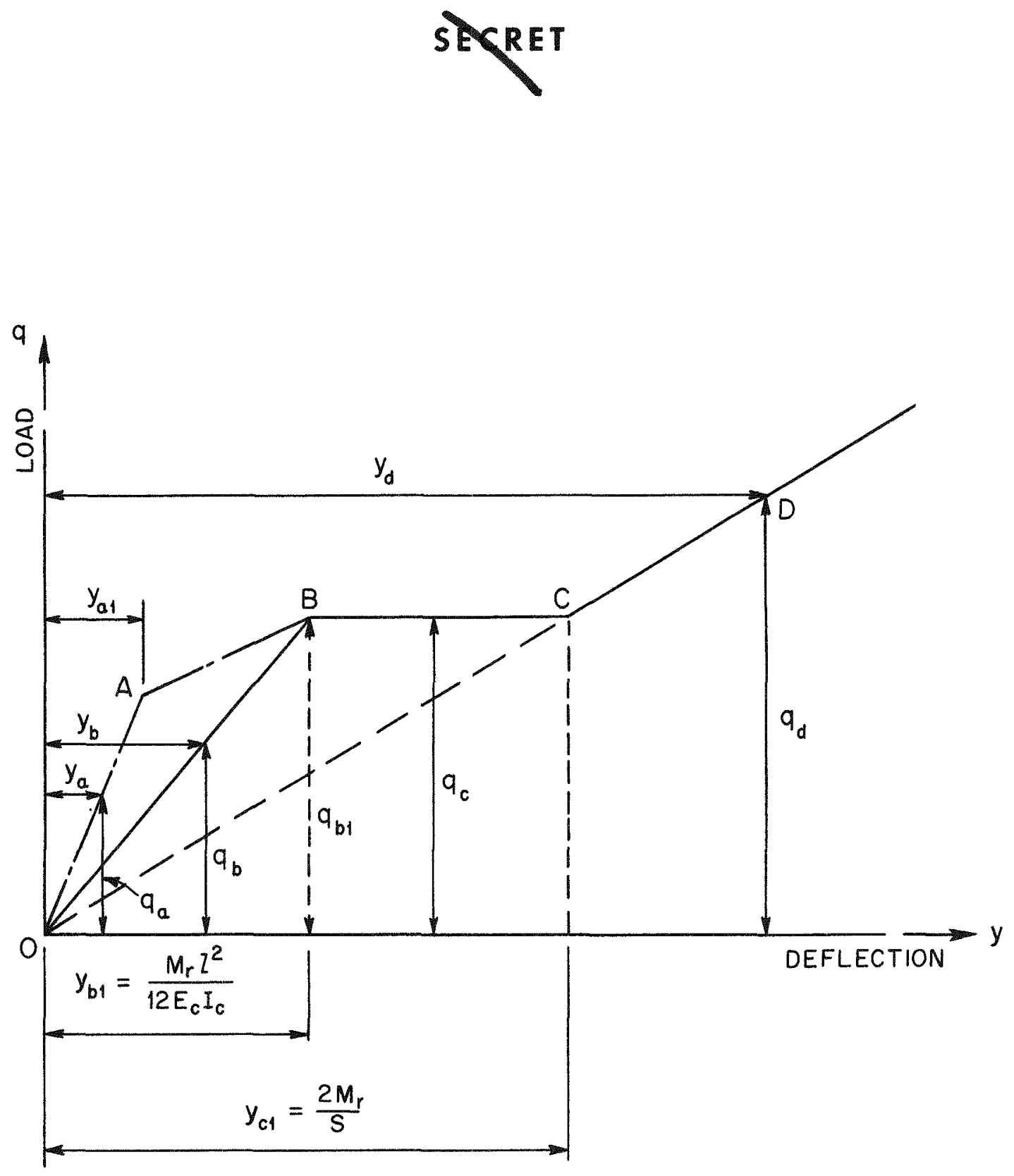

Fig. B.2 Resistance-Deflection Relation for a Reinforced-concrete Member. For $0 \leq y \leq y_{b 11}, q_{b}=$ $\left(192 E_{c} I_{c} y_{b}\right) / l^{4} ;$ for $y_{b 1} \leq y \leq y_{c 1}, q_{c}=\left(16 M_{r}\right) / l^{2}$; for $y \geq y_{c 1}, q_{d}=\left(8 S y_{d}\right) / l^{2}$.

\section{RESTRLCIED DATA SECRET-STEURITY INFORMAIION}




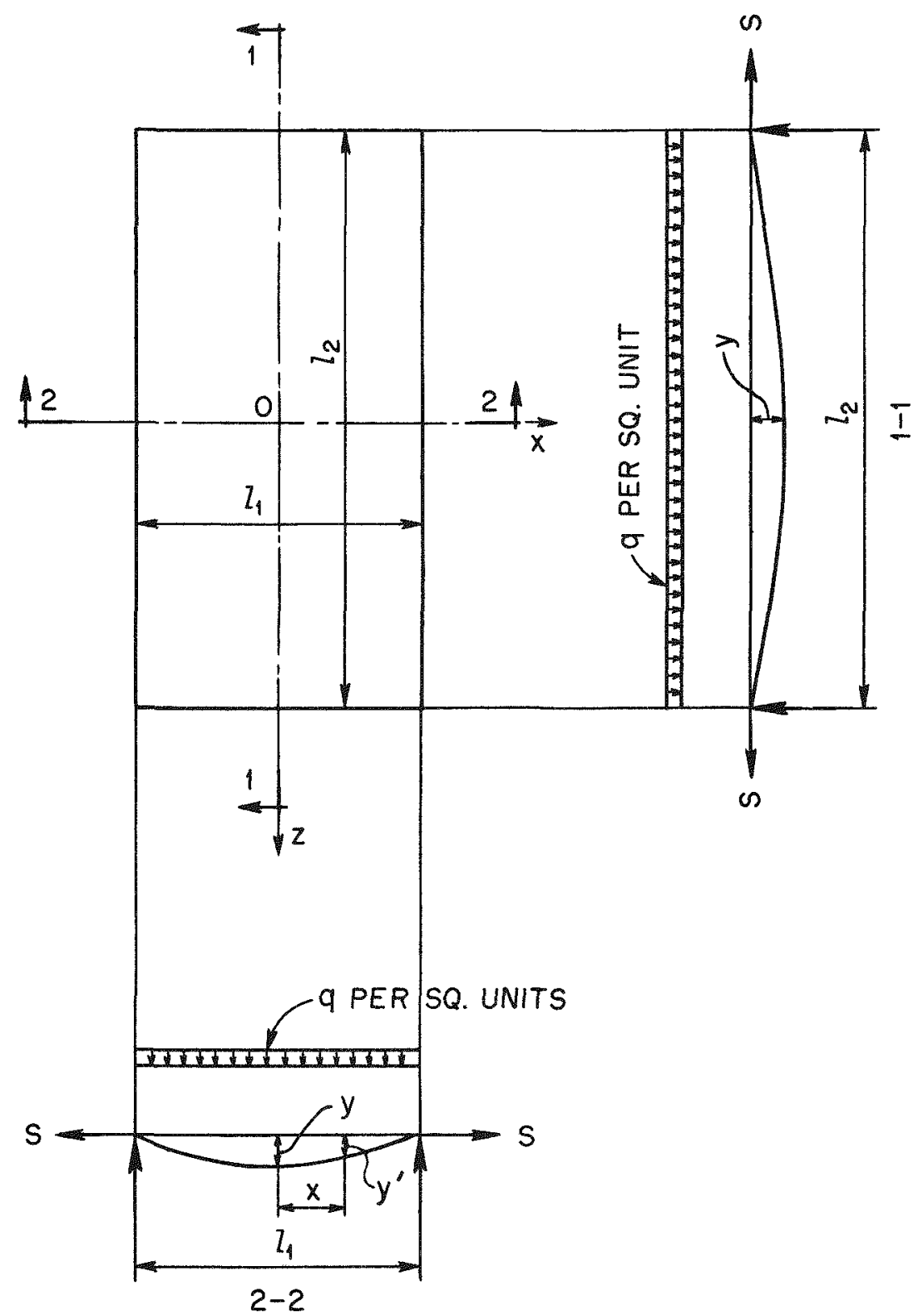

Fig. B.3 Plastic Deformation of a Two-way Thin Slab Under a Uniform Loading q. $q=\left(\gamma / l_{1}^{2}\right)$ Sy. 
inforced-concrete slab of small depth, or a steel plate, the moments $M_{\boldsymbol{r}}$ will have only a negligible effect on the resistance of the member and hence may be omitted in the resistance equation. Under large plastic deformations such an element will deflect as a membrane. The deflection $\mathrm{y}^{\prime}$ at any point $(\mathrm{x}, \mathrm{z})$ is given by

$$
\begin{aligned}
& y^{\prime}=\frac{4 q l_{1}^{2}}{\pi^{3} s} \sum_{n=1,3,5}^{n=\infty} \frac{(-1)^{(n-1) / 2}}{n^{3}} \\
& {\left[1-\frac{\cosh \left(\mathrm{n} \pi \mathrm{z} / l_{1}\right)}{\cosh \left(\mathrm{n} \pi l_{2} / 2 l_{1}\right)}\right] \cos \frac{\mathrm{n} \pi \mathrm{x}}{l_{1}}}
\end{aligned}
$$

and at the center

$$
y=\frac{4 \mathrm{q} l_{1}^{2}}{\pi^{3} S} \sum_{n=1,3,5}^{\mathrm{n}=\infty} \frac{(-1)^{(\mathrm{n}-1) / 2}}{\mathrm{n}^{3}}\left[1-\frac{1}{\cosh \left(\mathrm{n} \pi l_{2} / 2 l_{1}\right)}\right]
$$

From which the modulus of resistance, $q$, is obtained as

$$
\mathrm{q}=\frac{\pi^{3} \mathrm{Sy}}{4 l_{1}^{2} \sum_{\mathrm{n}=1,3,5}^{\mathrm{n}=\infty} \frac{(-1)^{(\mathrm{n}-1) / 2}}{\mathrm{n}^{3}}\left[1-\frac{1}{\cosh \left(\mathrm{n} \pi l_{2} / 2 l_{1}\right)}\right]}
$$

or

$$
q=\frac{\gamma \text { Sy }}{l_{l}^{2}}
$$

Values of the resistance factor $\gamma$ are given in Fig. B.4.

\section{B.1.4 Fundamental Relation of Motion}

The effect of $q$ is that of a negative force, acting in an opposite direction to the applied load $p$. The net force $f$, equaling $p-q$, will then represent the accelerating force of a unit mass, w/g. Thus

$$
\mathfrak{f}=p-q=\frac{w}{g} \alpha
$$

which is the fundamental relation of motion.

For a unit area located at a distance $\mathrm{x}$ from the supports, the displacement $\mathrm{y}^{\prime}$ will diminish from $y$ to 0 . Assuming that the ratio of $y^{\prime}$ to $y$ during the period of motion remains constant, it is then possible to express the motion of any point in terms of the motion at the center line by means of a reduction factor applied to the unit area and the unit mass at that point. That is to say, the equation of motion for a unit area having a displacement $\mathrm{y}^{\prime}$ may be written as that of an equivalent reduced area having the same displacement $y$ at the center and an equivalent reduced mass having the corresponding acceleration $\alpha$. Thus

$$
\mathbf{f}^{\prime}=\beta(p-q)=\beta_{1} \frac{w}{g} \alpha
$$

where $\beta$ is the reduction factor for area, and $\beta_{1}$ is the reduction factor for mass. Then the expression of motion for the entire member becomes

$$
F=\beta A(p-q)=\beta_{1} \frac{W}{g} \alpha
$$

in which $A$ is the total surface of the member, $W$ its total weight,

$$
\beta=\frac{\int \mathrm{y}^{\prime} \mathrm{dA}}{\mathrm{yA}}
$$

and

$$
\beta_{1}=\frac{\int\left(y^{\prime}\right)^{2}}{y^{2} W} d w
$$

For a one-way slab, or beams, $\beta=2 / 3$ and $\beta_{1}=$ 8/15. For two-way slabs, values of $\beta$ and $\beta_{1}$ for various length-to-width ratios are given in Fig. B.4.

\section{B.2 APPLICATIONS OF ANALYSIS FOR RESISTANCE TO BLAST}

Having established the fundamental relation of motion pertaining to a local element, the next step of the analysis consists in the application of the relation to various conditions of blast loading. For this purpose, use will be made of a simple rectangular building having vertical walls and a flat roof, as shown in Fig. B.5. The critical condition of each wall would be an orientation or exposure to frontal attack of the blast wave. 


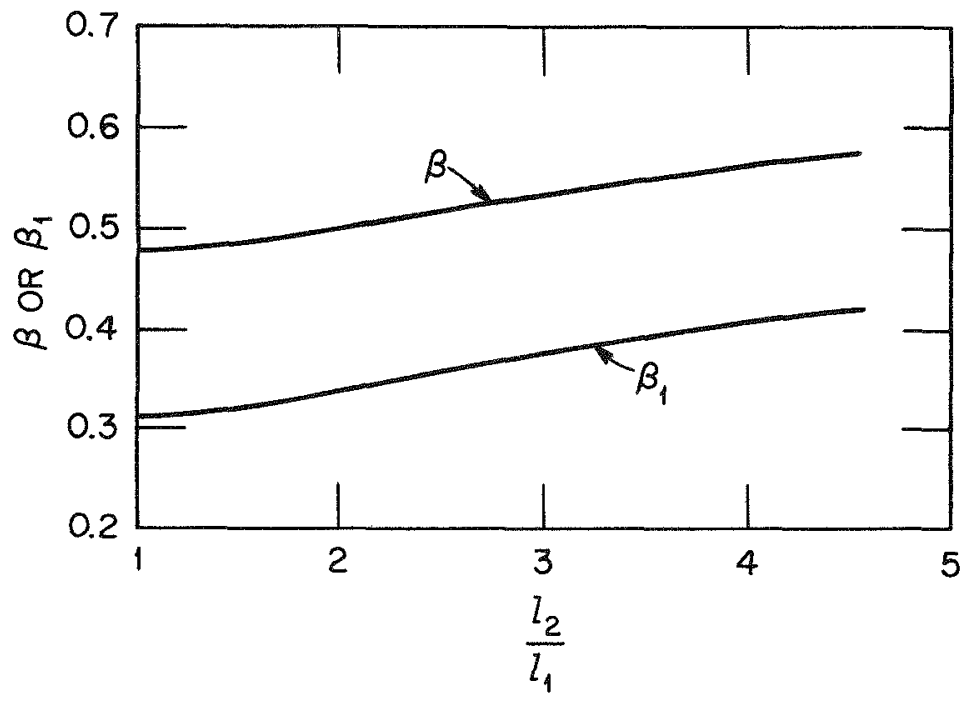

A

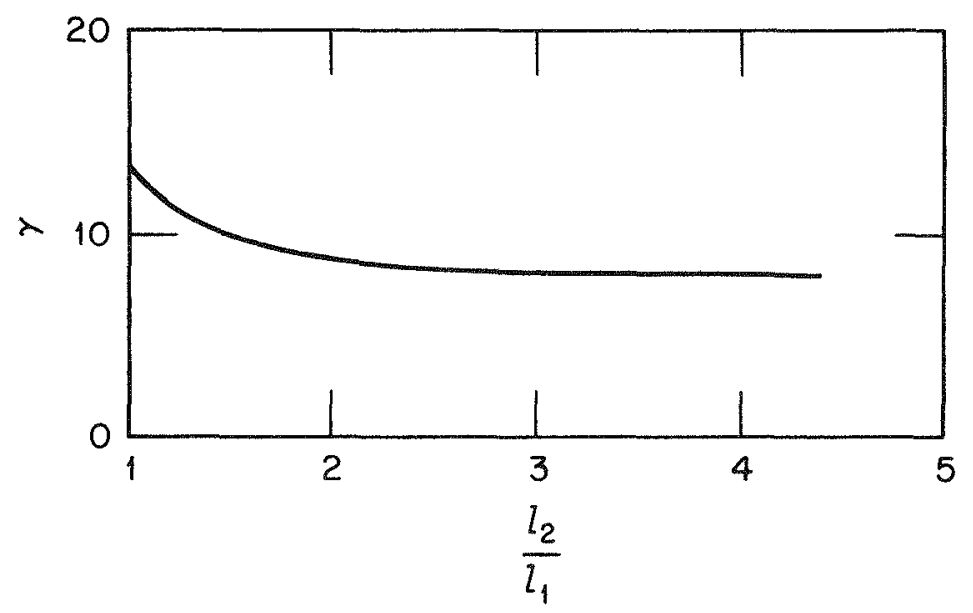

Fig. B.4 Reduction Factors and Resistance Factor for Two-way Slabs 


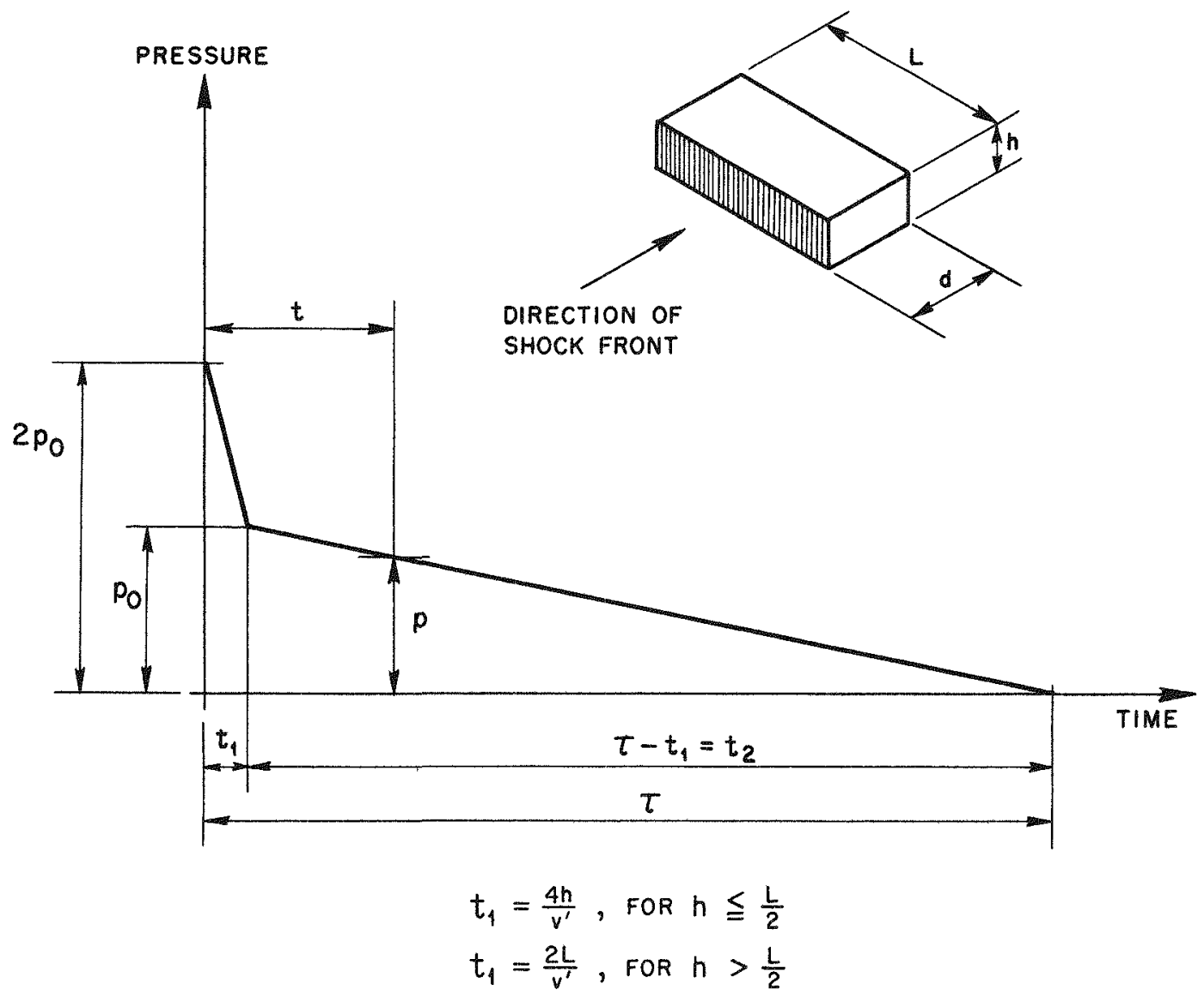

Fig. B.5 Pressure-Time Relation for Front Face of Structure 


\section{B.2.1 Case I: Front Wall}

(a) Condition 1, Moment Resistance Neglected. The relation between load and deformation is given by the straight line $O D$ of the resistance diagram shown in Fig. B.2. The pressure-time curve for this case is shown in Fig. B.5. The pressure $p_{1}$ in period $t_{1}$ is given by

$$
p_{1}=p_{0}\left(3-2 \frac{t}{t_{1}}\right)
$$

and that in period $t_{2}$ is

$$
\mathrm{p}_{2}=\mathrm{p}_{0}\left(\frac{\tau-\mathrm{t}}{\mathrm{t}_{2}}\right)
$$

Assuming that the wall framing consists of a slab reinforced in one direction (in the direction of $h$ ), the equation of motion corresponding to the two time periods is then obtained by substitution in Eq. B. 6 of the values of $p$ given by Eqs. B. 7 and B.8 and the value of $q$ given by Eq. B.3.

$$
\begin{gathered}
\beta A\left[p_{0}\left(3-2 \frac{t}{t_{1}}\right)-\frac{8 S}{h^{2}} y\right]=\beta_{1} \frac{W}{g} \alpha \\
\beta A\left[p_{0}\left(\frac{\tau-t}{t_{2}}\right)-\frac{8 S}{h^{2}} y\right]=\beta_{1} \frac{W}{g} \alpha
\end{gathered}
$$

or in the general form

$$
\frac{d^{2} y}{d t^{2}}+r^{2} y=a-b t
$$

in which $\mathrm{d}^{2} \mathrm{y} / \mathrm{dt}^{2}$ is the acceleration $\alpha, \mathrm{r}^{2}=$ $8 \beta \mathrm{gAS} / \beta_{1} \mathrm{~h}^{2} \mathrm{~W}$, and $\mathrm{a}$ and $\mathrm{b}$, for the periods $t_{1}$ and $t_{2}$, are

$$
\begin{array}{ll}
a_{1}=\left(\frac{\beta g A}{\beta_{1} W}\right) 3 p_{0} & b_{1}=\left(\frac{2 \beta g A}{\beta_{1} W t_{1}}\right) p_{0} \\
a_{2}=\left(\frac{\beta g A}{\beta_{1} W}\right)\left(\frac{\tau}{t_{2}} p_{0}\right) & b_{2}=\left(\frac{\beta g A}{\beta_{1} W t_{2}}\right) p_{0}
\end{array}
$$

The general solution of this ordinary differential equation is in the form

$$
y=c_{1} \sin r t+c_{2} \cos r t+\frac{a-b t}{r^{2}}
$$

$$
\frac{d y}{d t}=r\left(c_{1} \cos r t-c_{2} \sin r t\right)-\frac{b}{r^{2}}
$$

The values of the two constants $c_{1}$ and $c_{2}$ are obtained from the consideration $t=0, y=0$; $\mathrm{t}=0, \mathrm{dy} / \mathrm{dt}=0$; which gives

$$
c_{1}=\frac{b_{1}}{r^{3}} \quad c_{2}=-\frac{a_{1}}{r^{2}}
$$

Substituting these values in Eqs. B.12 and B.13, the displacement and velocity equations,

$$
\begin{gathered}
y=\frac{1}{r^{2}}\left[b_{1}\left(\frac{\sin r t}{r}-t\right)+a_{1}(1-\cos r t)\right] \\
\frac{d y}{d t}=\frac{1}{r^{2}}\left[b_{1}(\cos r t-1)+a_{1} r \sin r t\right]
\end{gathered}
$$

are obtained. Similarly, in the period $t_{2}$,

$$
\begin{aligned}
& y=c_{3} \sin r t+c_{4} \cos r t+\frac{a_{2}-b_{2} t}{r^{2}} \\
& \frac{d y}{d t}=r\left(c_{3} \cos r t-c_{4} \sin r t\right)-\frac{b_{2}}{r^{2}}
\end{aligned}
$$

The constants $c_{3}$ and $c_{4}$ are determined from the fact that at the beginning of this period the displacement and velocity will be the same as the respective values at the end of the first period, as given by Eqs. B.14 and B.15, and where $t=t_{1}$. Let $\Delta_{1}$ indicate the displacement $y$, and $v_{1}$ the velocity dy/dt at the end of the period $t_{1}$; then

$$
\begin{gathered}
c_{3} \sin r t_{1}+c_{4} \cos r t_{1}=\Delta_{1}-\frac{a_{2}-b_{2} t_{1}}{r^{2}} \\
c_{3} \cos r t_{1}-c_{4} \sin \mathrm{rt}_{1}=\frac{v_{1}}{r}+\frac{b_{2}}{r^{3}}
\end{gathered}
$$

from which

$$
\begin{aligned}
c_{3}=\sin r t_{1}\left(\Delta_{1}-\frac{a_{2}-b_{2} t_{1}}{r^{2}}\right) & \\
& +\cos r t_{1}\left(\frac{V_{1}}{r}+\frac{b_{2}}{r^{3}}\right)
\end{aligned}
$$

and

$$
c_{4}=\cos r t_{1}\left(\Delta_{1}-\frac{a_{2}-b_{2} t_{1}}{r^{2}}\right)-\sin r t_{1}\left(\frac{v_{1}}{r}+\frac{b_{2}}{r^{3}}\right)
$$


The motion may stop in either the first or the second period. Assuming that the latter is the case, the value of $t$, the time in the period $t_{2}$ when motion stops, can be obtained from $\mathrm{Eq}$. B.17.

$$
\frac{d y}{d t}=r\left(c_{3} \cos r t-c_{4} \sin r t\right)-\frac{b_{2}}{r^{2}}=0
$$

or an approximate value from the relation

$$
\cos \mathrm{rt}=\frac{1}{ \pm \sqrt{1+\left(\frac{\mathrm{c}_{3}}{\mathrm{c}_{6}}\right)^{2}}}
$$

In general, the motion of walls reinforced in one direction will stop in the second period. On the other hand, in the case of a thin slab or a steel plate supported on four sides, the motion will generally stop in the first period. However, an investigation should be made in all cases to ascertain whether or not the motion stops during the first period. This can be accomplished by equating $\mathrm{dy} / \mathrm{dt}$ in $\mathrm{Eq}$. B.15 to zero and solving for $t$. If the smallest value of $t$ thus obtained is less than $t_{1}$, then the motion stops in the first period, and the magnitude of the final displacement is obtained from Eq. B.14.

In the case of a slab supported on four sides, the derivations presented above apply, with due allowance for the changes in the resistance factor $\gamma$ and reduction factors $\beta$ and $\beta_{1}$.

(b) Condition 2, Moment Resistance Considered. The relation between load and deflection for this case is shown by the broken line $O A B C D$ of the resistance diagram in Fig. B.2. It is to be noted that part $O A B$ is predicated on the use of a constant moment of inertia $I_{c}$. Obviously this condition of constant moment of inertia cannot prevail throughout this range of the deformation because of the continued cracking of the concrete. If $\mathbf{I}_{c}$ at each stage of the deformation is modified to its actual value, line $O A$ would tend to shift toward line $O B$; that is to say, for the same load there would be larger deflections than indicated by the diagram. Since it is not practicable to determine the true position of the resistance line, it may be taken as the straight line $O B$, using a constant value for $I_{c}$ predicated on the full section of the member. In the period represented by the line $O B$, the relation between deflection and load is then given by

$$
u_{b}=\frac{192 E_{c} I_{c}}{l^{4}} y_{b}
$$

The purpose of the analysis is to determine the extent of maximum deflection which, as explained above, occurs when the motion in the direction of the applied pressure stops, i.e., when $\mathrm{dy} / \mathrm{dt}=0$. If the resistance-deflection and pressure-time relations were continuous functions, it would be possible to determine the maximum deflection in one operation by placing the value of $\mathrm{dy} / \mathrm{dt}$ in $\mathrm{Eq} . \mathrm{B.15}$ equal to zero and solving for $y$ by Eq. B.14. However, due to the discontinuity of the resistance line at points $B$ and $C$, it becomes necessary to determine the time and the attained velocity at these two points before proceeding to the next stage of deformation.

As in the previous case, owing to the discontinuity in the pressure-time curve, it will also be necessary to determine the deflection and the attained velocity at the time $t_{1}$.

The analysis of motion corresponding to the resistance line $O B$ in Fig. $B .2$ is the same as in the preceding case. During this period the resistance $q$ is given by $\mathrm{Eq}$. B.20. Accordingly

$$
\mathbf{r}^{2}=\left(\frac{\beta \mathrm{gA}}{\beta_{1} W}\right)\left(\frac{192 \mathrm{E}_{\mathrm{c}} \mathrm{I}_{\mathrm{c}}}{\mathrm{h}^{4}}\right)
$$

and the values of $a_{1}$ and $b_{1}$ remain the same as given by Eqs. B.11. Substituting the value of $\mathrm{y}_{\mathrm{b} 1}$ for $\mathrm{y}$ in $\mathrm{Eq}$. B.14

$$
\begin{aligned}
y_{b 1}=\frac{1}{r^{2}}\left[b_{1}\left(\frac{\sin r t_{b 1}}{r}-t_{b 1}\right)\right. & \\
& \left.+a_{1}\left(1-\cos r t_{b 1}\right)\right]
\end{aligned}
$$

From this equation the value of $t_{b 1}$ is $o b-$ tained by trial. The velocity $V_{b 1}$ at the end of this period is determined by substituting the value of $t_{b 1}$ in Eq. B.15.

In the period corresponding to the resistance line $\mathrm{BC}$, the resistance is constant, and the equation of motion takes the form

$$
\beta A\left[p_{0}\left(3-2 \frac{t}{t_{1}}\right)-\frac{16 M_{r}}{h^{2}}\right]=\frac{\beta_{1} W}{g} \alpha
$$


If the discontinuity in the pressure-time relation should occur in this period, then, during the interval $t_{2}, E q . B .23$ becomes

$$
\beta A\left[\mathrm{p}_{0}\left(\frac{\tau-\mathrm{t}}{\mathrm{t}_{2}}\right)-\frac{16 \mathrm{M}_{\mathrm{r}}}{\mathrm{h}^{2}}\right]=\frac{\beta_{1} \mathrm{~W}}{\mathrm{~g}} \alpha
$$

Equations B.23 and B.24 may be written in the general form

$$
\frac{d^{2} y}{d t^{2}}=a-b t
$$

in which $b$, for the periods $t_{1}$ and $t_{3}$, is given by Eqs. B.11 and a is given by

$$
\begin{aligned}
& \mathrm{a}_{1}=\frac{\beta \mathrm{gA}}{\beta_{1} \mathrm{~W}}\left(3 \mathrm{p}_{0}-\frac{16 \mathrm{M}_{\mathrm{r}}}{\mathrm{h}^{2}}\right) \\
& \mathrm{a}_{2}=\frac{\beta \mathrm{gA}}{\beta_{1} \mathrm{~W}}\left(\frac{\tau}{\mathrm{t}_{2}} \mathrm{p}_{0}-\frac{16 \mathrm{Mr}_{\mathrm{r}}}{\mathrm{h}^{2}}\right)
\end{aligned}
$$

The general solution of the ordinary differential equation is in the forms

$$
y=c_{1}+c_{2} t+\frac{a t^{2}}{2}-\frac{b t^{3}}{6}
$$

and

$$
\frac{d y}{d t}=c_{2}+a t-\frac{b t^{2}}{2}
$$

The values of the constants $c_{1}$ and $c_{2}$ are obtained from the consideration $t=t_{b 1}, y=y_{b 1}$, and $\mathrm{dy} / \mathrm{dt}=\mathrm{V}_{\mathrm{b} 1}$, which gives

$$
c_{1}=y_{b 1}-c_{2} t_{b 1}-\frac{a t_{b 1}^{2}}{2}+\frac{b t_{b 1}^{3}}{6}
$$

and

$$
c_{2}=v_{b 1}-a t_{b 1}+\frac{b t_{b 1}^{2}}{2}
$$

The values of the displacement $\Delta_{1}$ and the velocity $V_{1}$ are found by substituting $t_{1}$ for $t$ in Eqs. B.15 and B.17.

The time $t_{c 1}$ and the velocity $V_{c 1}$ corresponding to the end of this period, at point $C$ on the resistance line, are obtained as in the preceding step by replacing the constants $c_{1}$ and $c_{2}$ by new constants $c_{3}$ and $c_{4}$. Thus

$$
y=c_{3}+c_{4} t+\frac{a_{2} t^{2}}{2}-\frac{b_{2} t^{3}}{6}
$$

and

$$
\frac{d y}{d t}=c_{4}+a_{2} t-\frac{b_{2} t^{2}}{2}
$$

The values of $c_{3}, c_{4}, t_{c 1}$, and $V_{c 1}$ are obtained in the same manner as before.

In the final period of deformation, indicated by the resistance line $\mathrm{CD}$, the equation of motion is

$$
\frac{d^{2} y}{d t^{2}}+r^{2} y=a_{z}-b_{2} t
$$

in which

$$
\mathrm{r}^{2}=\frac{8 \beta \mathrm{gAS}}{\beta_{1} \mathrm{~h}^{2} \mathrm{~W}}
$$

and $a_{2}$ and $b_{2}$ are given by Eqs. B.11. The solution of Eq. B. 25 is

$$
y=c_{5} \sin r t+c_{6} \cos r t+\frac{a_{2}-b_{2} t}{r^{2}}
$$

and

$$
\frac{d y}{d t}=r\left(c_{5} \cos r t-c_{6} \sin r t\right)-\frac{b_{2}}{r^{2}}
$$

Values of the constants $c_{5}$ and $c_{6}$ are determined from the condition at the beginning of this period, when $y=y_{c 1}, t=t_{c 1}$, and $d y / d t=V_{c 1}$. The maximum deformation is then found by determining the time at which $d y / d t=0$ in Eq. B.32 and by solving Eq. B.31 for y using the obtained value of $t$.

In the foregoing analysis it was assumed that the point of discontinuity of the pressure-time curve, corresponding to time $t_{1}$, would occur in the period defined by the resistance line $\mathrm{BC}$ in Fig. B.2. However, it may occur in any one of the three periods. As the time in each step is determined, a comparison with the time $t_{1}$ will indicate whether the pressure discontinuity occurs in that period.

It is to be noted that the motion may stop in any one of the three periods of resistance. Should it occur in the first period of resistance, indicated by line $O B$ in Fig. B.2, the member 
may be considered as overdesigned, necessitating a revision of the section. If the motion should stop in the second period of resistance, indicated by line $\mathrm{BC}$, the design may be considered conservative. For an economical design it would be desirable to so proportion the section that the motion will stop in the third period of resistance, indicated by line $C D$, provided that the maximum allowable deformation is not exceeded.

For an approximate analysis the resistance line OD in Fig. B.2 may be substituted for the broken line $\mathrm{OBCD}$, in which case Condition 1 will apply.

\section{B.2.2 Case II: Roof}

The pressure-time curve for this case is shown in Fig. B.6. The pressure $p_{1}$, in period $t_{x}$, is given by

$$
p_{1}=\frac{p_{0}}{3}\left[3+\frac{2}{t_{x}}\left(\frac{x}{v^{\prime}}-t\right)\right]
$$

and in the period $\tau-t_{1}$ by

$$
p_{2}=\frac{p_{0}}{3}\left(\frac{\tau+\frac{x}{v^{\prime}}-t}{\tau-t_{x}}\right)
$$

It will be expedient, in this case, to measure the time from the instant the shock wave reaches the section $\mathrm{x}$ under consideration. That is, for $t=0, p_{1}=p_{0}$, and Eqs. B.33 and B.34 become

$$
\mathrm{p}_{1}=\frac{\mathrm{p}_{0}}{3}\left(3-\frac{2 \mathrm{t}}{\mathrm{t}_{\mathrm{X}}}\right)
$$

and

$$
\mathrm{p}_{2}=\frac{\mathrm{p}_{0}}{3}\left(\frac{\tau-\mathrm{t}}{\tau-\mathrm{t}_{\mathrm{x}}}\right)
$$

The analysis is carried out in the same manner as for Case $I$. The time $t_{1}$ now becomes $t_{x}$, and $t_{2}$ becomes $\tau-t_{x} ;$ Eqs. B.35 and B.36 replace Eqs. B. 7 and B. 8 in computing the values of the constants $a$ and $b$.

Since the drop in pressure is a function of $t_{x}$ which, in turn, varies directly with the distance $x$ measured from the front face of the building, the most severe condition of loading will occur over the area of the roof adjacent to the rear wall.

If the main reinforcement is parallel to the short dimension of the roof, $d$ in Fig. B.6, the orientation of the blast wave should be parallel to the long sides. The dimension $\mathrm{x}$ will then be taken as $L$. Since the roof slab will receive support from the end wall, the value of $\mathrm{x}$ should be taken as somewhat less than L, say, I minus six times the thickness of the roof slab.

It should be noted that the pressures shown in Fig. B.6 are for transverse sections of the roof and that for the unit strip used in the analysis the pressure will, in reality, be variable across the width of the strip. This variation could be neglected in the analysis, and the pressures as given by Eqs. B.35 and B.36 may be assumed constant across the width of the strip. Numerical examples may be cited, as follows:

Example 1-Front Wall, Moment Resistance Neglected. Let $\mathrm{h}=10 \mathrm{ft}, \mathrm{d}=20 \mathrm{ft}, \mathrm{L}=40 \mathrm{ft}$, and $\mathrm{p}_{0}=10$ psi or 1440 psf. From Figs. B.7. and B.8, $\tau=0.58 \mathrm{sec}$, and, from Fig. B.9, $t_{1}=$ $1 / 35$ sec.

Assuming a 6-in.-thick concrete wall with one-way reinforcing of $3 / 4$-in. round bars spaced vertically at 6 -in. centers at the center of the slab, then, for a strip $1 \mathrm{ft}$ wide, $A=10 \mathrm{sq} \mathrm{ft}$, $W=750 \mathrm{lb}, A_{S}=0.88 \mathrm{sq}$ in., and, using a yield value of $50,000 \mathrm{psi}, \mathrm{S}=44,000 \mathrm{lb}, \beta=2 / 3, \beta_{1}=$ $8 / 15$, and $\mathrm{g}=32.2 \mathrm{ft} / \mathrm{sec}^{2}$.

Then $\mathrm{r}^{2}=1889, \mathrm{a}_{1}=2318, \mathrm{~b}_{1}=54,096, \Delta_{1}=$ $0.6359 \mathrm{ft}, \mathrm{v}_{1}=31.086 \mathrm{ft} / \mathrm{sec}, \mathrm{a}_{2}=813, \mathrm{~b}_{2}=1401$, $c_{3}=0.4512$, and $c_{4}=-0.6198$. From Eq. B.19 the motion stops when $\sin r t=0.6064$ and $\cos r t=-0.7952$, from which $t$ is found to be $0.0573 \mathrm{sec}$, and the final value of $\mathrm{y}$ is $1.18 \mathrm{ft}$, which is slightly over the allowable value.

For comparison, the same member will be reviewed taking into consideration the resisting moments.

Example 2-Front Wall, Moment Resistance Considered. Assuming $\mathrm{E}_{\mathrm{c}}=4,000,000 \mathrm{psi}$ and $\mathrm{f}_{\mathrm{C}}^{\prime}=4000 \mathrm{psi}, \mathrm{E}_{\mathrm{c}} \mathrm{I}_{\mathrm{c}}=6,000,000 \mathrm{ft}^{2}-\mathrm{lb}$, and $\mathrm{Mr}_{\mathrm{r}}=$ $9000 \mathrm{ft}-\mathrm{lb}$, then $\mathrm{y}_{\mathrm{bl}}=0.0125 \mathrm{ft}, \mathrm{q}=115,200 \mathrm{y}$, $r^{2}=61,824, a_{1}=2318$, and $b_{1}=54,096$. Solving Eq. B.22 by trial, $t_{b 1}=0.003433 \mathrm{sec}$, and, from Eq. B.15, $\mathrm{V}_{\mathrm{b} 1}=6.7263 \mathrm{ft} / \mathrm{sec}$.

Then $\mathrm{y}_{\mathrm{c}}=0.4091, \mathrm{q}_{\mathrm{c}}=1440, \mathrm{a}_{1}=1546, \mathrm{~b}_{1}=$ 54,096, $c_{1}=-0.0022$, and $c_{2}=1.7377$. Placing 


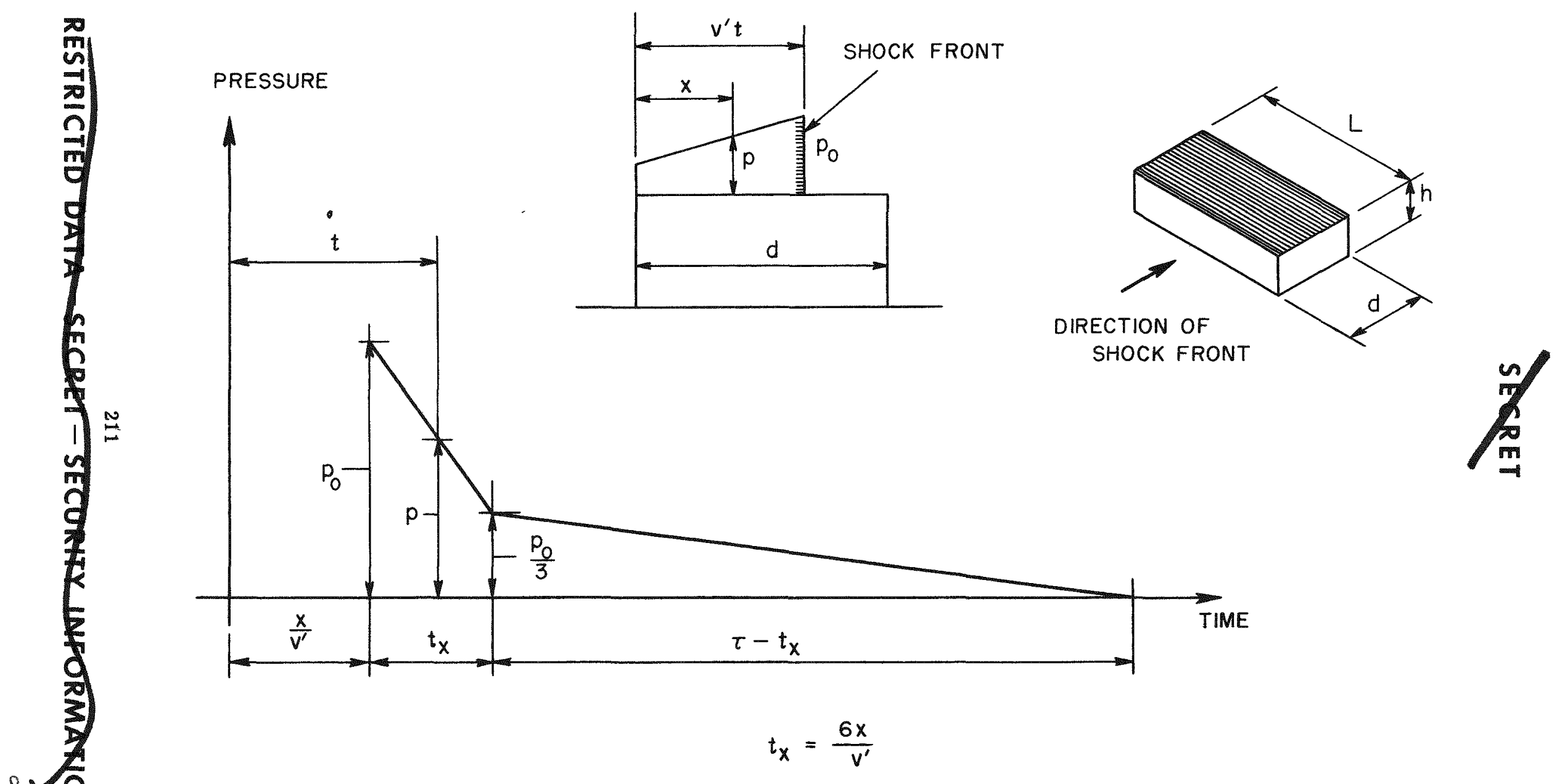

Fig. B.6 Pressure-Time Relation for Roof of Structure 


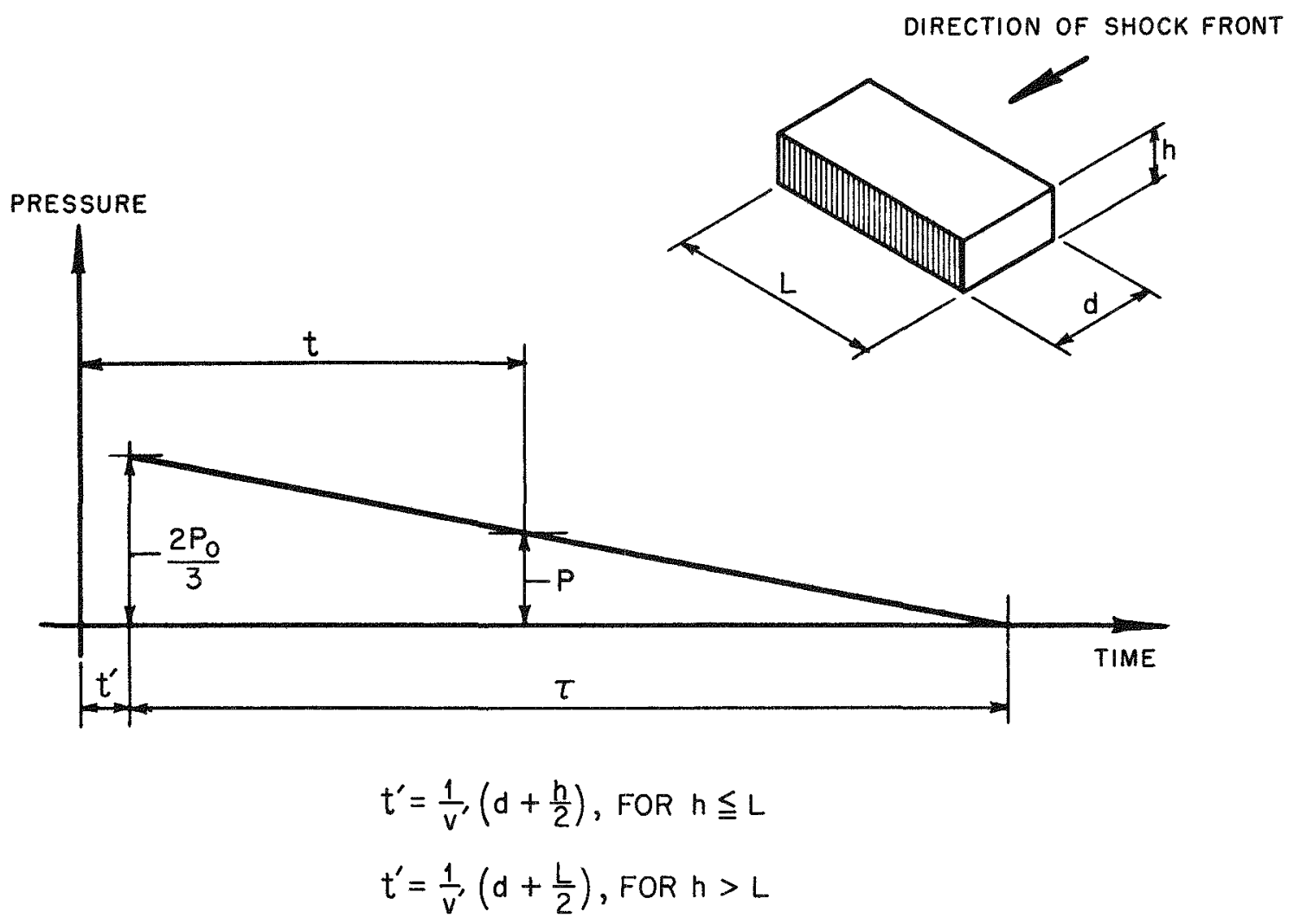

Fig. B.7 Pressure-Time Relation for Rear Face of Structure 

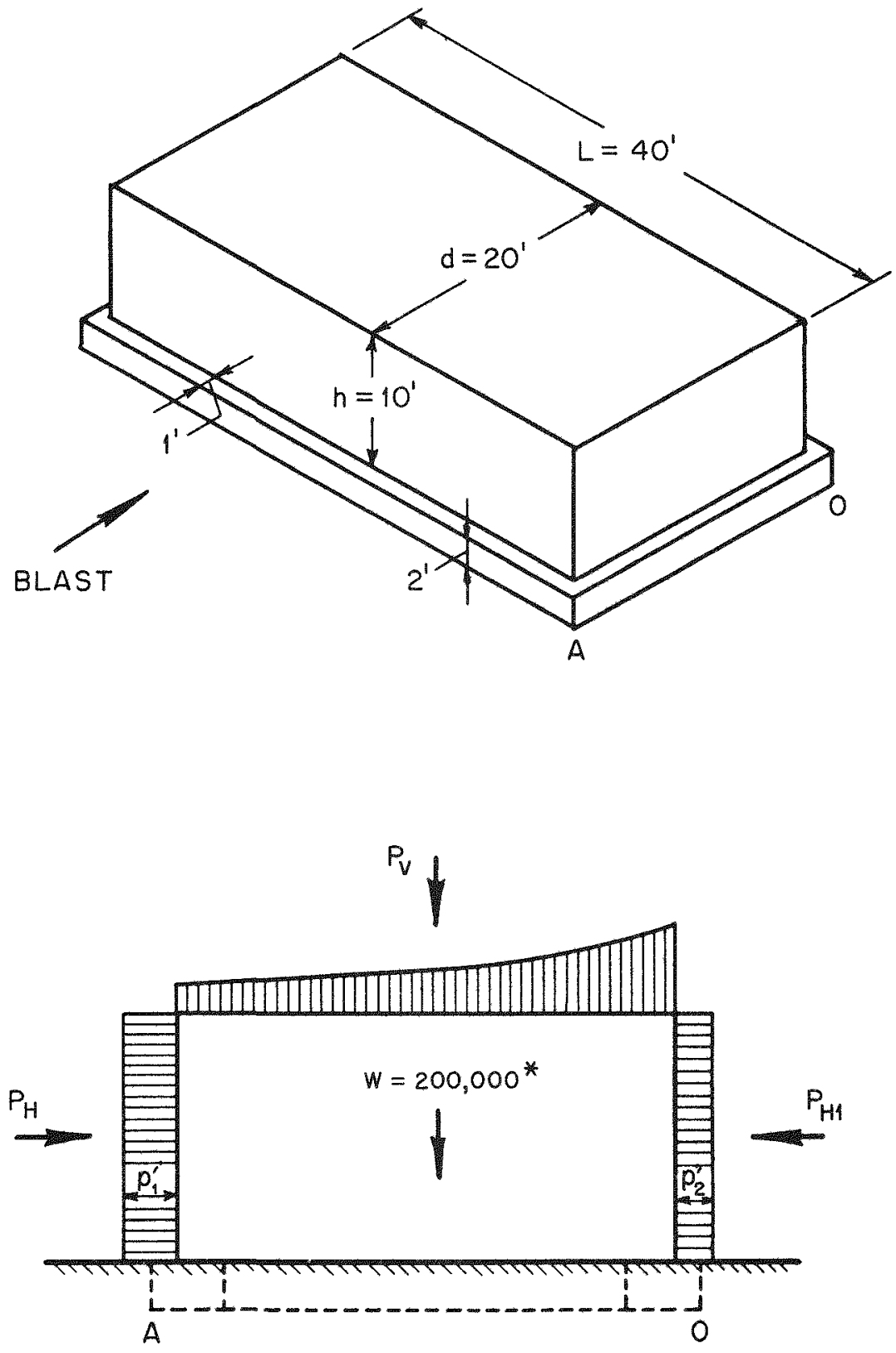

Fig. B.8 Typical Structure in Shock Wave 


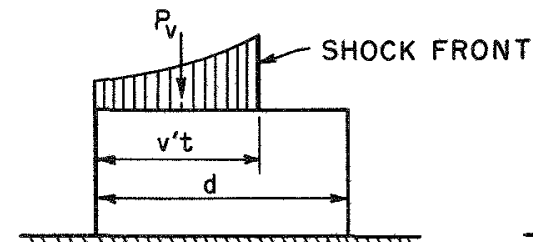

$0 \leqq v^{\prime} t \leqq d$

CASE I

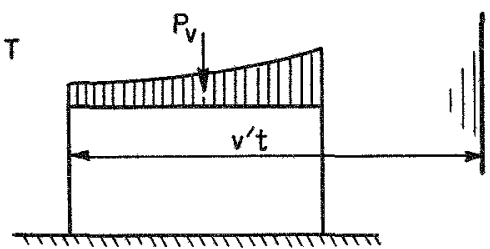

$d \leqq v^{\prime} t \leqq 7 d$

CASE II

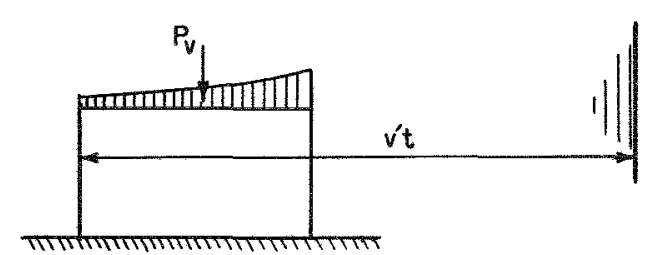

$v^{\prime} t \geqq 7 d$

CASE III

\begin{tabular}{|c|c|c|}
\hline CASE I & 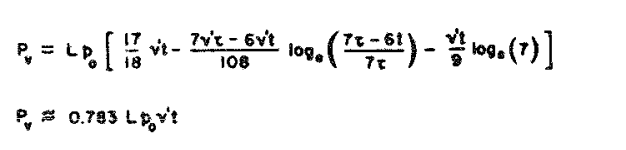 & $\begin{array}{l}M_{p}=L p_{0}\left\{\frac{113}{252}(v i)^{2}-\frac{7 v \tau-6 v i}{100}\left[\frac{v_{t}}{7}+\frac{v_{t}}{6} \log _{0}\left(\frac{7 \tau-8 t}{7 \tau}\right)\right]\right\} \\
M_{B} \approx 0.452 L p_{9}(v t)^{2}\end{array}$ \\
\hline CASE'II & 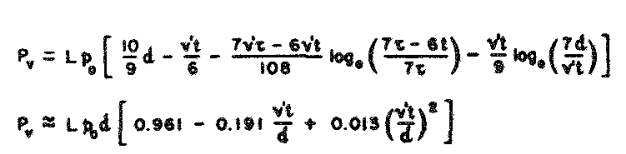 & $\begin{array}{l}M_{p}=L p_{0}\left\{\frac{(v t)^{2}}{252}-\frac{7 v t-6 v t}{108}\left[\frac{v t}{7}+\frac{v t}{6} \log _{\theta}\left(\frac{7 r-\sigma t}{7 r}\right)\right]+\frac{d}{3}(s d-v t)\right\} \\
M_{p} \approx L p_{0}\left[\frac{d}{3}(s d-v t)+\frac{(v t)^{2}}{130}\right]\end{array}$ \\
\hline CASE III & $\begin{array}{l}P_{v}=L P_{0}\left[-\frac{d}{18}-\frac{7 \psi t i-6 v t}{108} \log _{g}\left(\frac{i t-\delta d}{v t}\right)\right] \\
P_{v} \approx L P_{0} d\left[0.408-0.014 \frac{v i t}{d}\right]\end{array}$ & 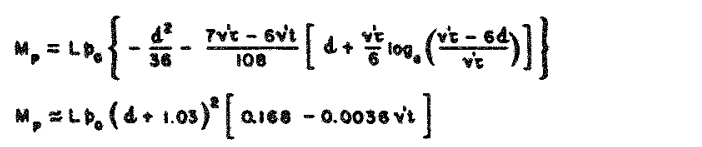 \\
\hline
\end{tabular}

Fig. B.9 Total Roof Pressures and Movements of Total Pressures. $P_{v}=$ total pressure on roof; $M_{p}=$ moment of $P_{\mathrm{v}}$ about front edge of roof. Approximate values are for $\mathrm{v}^{\prime}=1400 \mathrm{ft} / \mathrm{sec}, 0.5 \leq t \leq 0.75 \mathrm{sec}, d \leq 50 \mathrm{ft}$. Shock wave moves from left to right. $L=$ length of structure. 


\section{SECRET}

$\mathrm{y}=\mathrm{y}_{\mathrm{c}}=0.4091$ in Eq. B.26, $\mathrm{t}=0.02609 \mathrm{sec}$, which is smaller than $t_{1}$; hence the point of discontinuity of the pressure-time curve occurs in the final period of deformation. From Eq. B.27, $\mathrm{dy} / \mathrm{dt}=26.6615$ at point $\mathrm{C}$. The value of $\mathrm{r}^{2}$ in the final period is 1880 , and, from Eqs. B.11, $a_{1}=2318, b_{1}=54,096, a_{2}=813$, and $b_{2}=1401$.

The values of the constants, determined from the conditions at the beginning of this period, are $c_{3}=0.4450$ and $c_{4}=-1.1203$. For $t=t_{1}$, $\Delta_{1}=0.4680 \mathrm{ft}$ and $v_{1}=23.6883 \mathrm{ft} / \mathrm{sec}$. The constants $c_{5}$ and $c_{6}$ are then determined from Eqs. B.31 and B.32, using the known values of $y$ and $\mathrm{dy} / \mathrm{dt}$ at the time $\mathrm{t}_{1}$, from which $\mathrm{c}_{5}=0.2373$ and $c_{6}=-0.5130$. The motion stops when $t=$ $0.0616 \mathrm{sec}$, and the final value of $\mathrm{y}$ is $0.95 \mathrm{ft}$. Since this value is less than one-tenth of the span, the design is adequate.

Example 3-Front Wall, Slab Supported by Heavy Members on Four Edges. Let $\mathrm{h}=10 \mathrm{ft}$, $\mathrm{d}=20 \mathrm{ft}, \mathrm{L}=40 \mathrm{ft}$, and $\mathrm{p}_{0}=20$ psi or 2880 psf. It is then found that $\tau=0.49$ and $t_{1}=1 / 35 \mathrm{sec}$. Assuming a $3 / 16$-in. steel plate $8 \mathrm{ft}$ high and $4 \mathrm{ft}$ wide in the front wall, $A=32 \mathrm{sq} \mathrm{ft}, \mathrm{W}=244.8$ $\mathrm{lb}, \mathrm{S}=67,50 \mathrm{n} \mathrm{bb} / \mathrm{ft}$ (yield value of $30,000 \mathrm{psi}$ is taken for plate steel); $1_{2} / 1_{1}=2.0$, and, from Fig. B.4, $\gamma=8.8, \beta=0.5$, and $\beta_{1}=0.338$. Then $\mathrm{r}^{2}=231,128, \mathrm{a}_{1}=53,790$, and $\mathrm{b}_{1}=1,255,100$. Equating dy/dt in Eq. B.15 to zero, $t=0.00633$, which is less than $t_{1}$. Hence the motion stops in the first period, and $y$ at the end of motion is $0.43 \mathrm{ft}$. Since this value of $y$ is only slightly larger than one-tenth of the short span, the design is considered to be adequate.

\section{B.3 ANALYSIS FOR OVER-ALL STRENGTH AGAINST BLAST}

In the local investigation of strength, it was assumed that the members would have adequate support and anchorage to justify the concept of deformation and the mode of failure outlined in the preceding analysis. This requirement will be met by making the reinforcing of the member continuous, or spliced for full strength, between its supports and by providing an end anchorage capable of development of the full or ultimate strength of the reinforcing.

In addition, it was assumed that the supports would not displace during local bending of the member and that there would be no appreciable participation in the over-all bending of the framing as a whole. In so far as the first condition is concerned, it is a conservative and wholly justifiable assumption for members framed to strong elements, such as transverse walls and floors. The other assumption will be satisfied if the framing is so arranged that under a lateral loading the deformations of frames composed of floors and transverse walls become very small in comparison with the corresponding deformations of bents composed of local elements.

In connection with the latter consideration, it is to be noted that in order to provide the necessary strength to resist strong atomic blast the use of strong frames comprising structural floors and transverse walls becomes almost mandatory. The analysis presented here contemplates the use of this type of framing.

In conformity with the foregoing concept, floors are considered as girders, transmitting the loads from local members to the transverse walls. These loads are then carried to the foundations through the walls, by either frame or cantilever action. If the transverse walls are placed no farther apart than, say, three times the width of the floor, then the problem of strength will be primarily that of shear. Accordingly, the needed investigation may be confined to shear strength only.

There is little information available regarding the shear strength of materials under dynamic loading. Until such data are obtained, use will be made of values deduced from static tests. For reinforced concrete an allowable working value for shear is given by the formula

$$
v_{a}=f_{S}(0.005+r)
$$

where $v_{a}=$ allowable unit shearing stress

$\mathrm{f}_{\mathrm{S}}=$ allowable stress in steel

$\mathrm{r}=$ ratio of volume of steel to volume of concrete

In this investigation $f_{S}$ may be taken as the yield value of the steel, and the unit shear is computed by dividing the total shear by the cross-sectional area of the floor or wall.

The maximum shears in the floors and walls occur at the instant the shock wave strikes the front wall. In obtaining the total load, the maximum value of the reflected pressure is used. 
To illustrate, consider the building shown in Fig. B.8. The total maximum load $\mathrm{P}_{\mathrm{H}}$ obtained from the reflected pressure is

$$
\mathbf{p}_{\mathrm{H}}=3 \mathrm{p}_{0} \mathrm{hL}
$$

Assuming that this total load is carried to the foundations by the two end walls only, the corresponding unit shear in the concrete, $\mathrm{v}_{\mathrm{c}}$, will then be

$$
\mathrm{v}_{\mathrm{c}}=\frac{3 \mathrm{p}_{0} h \mathrm{~L}}{2 \mathrm{dT}}
$$

where $\mathbf{T}$ is the thickness of the wall.

\section{B.3.1 Stability Against Sliding}

When a shock wave hits the front face of a structure, the reflected pressures will tend to move it by bodily displacement and rotation. The tendency to displacement will be resisted first by the developed friction under the base or foundations and the passive pressures of the surrounding earth; then, as the blast wave envelopes the structure, by the additional aid of the blast pressures on top and on the rear face.

In order to develop the relations of motion needed for this investigation, consider the simple rectangular building shown in Fig. B.8. The applied force tending to move the building is the total blast pressure $P_{H}$ on the front wall, and the total force resisting sliding, $R$, is given by

$$
\mathbf{R}=\left(\mathbf{P}_{\mathrm{H} 1}+\mathbf{R}_{\mathrm{e}}+\mathrm{c}_{\mathrm{f}}\right)\left(\mathbf{W}+\mathbf{P}_{\mathrm{V}}\right)
$$

where $R_{e}=$ passive resistance of the earth (assumed to be constant during the motion)

$c_{\mathrm{f}}=$ coefficient of friction

$\mathrm{W}=$ total weight of structure, including footings

$\mathrm{P}_{\mathrm{V}}=$ total pressure on the roof

The resulting equation of motion is

$$
\frac{d^{2} x}{d t^{2}}=\frac{g}{W}\left(P_{H}-R\right)
$$

in which $\mathrm{x}$ is the distance moved by the structure. The forces $\mathrm{P}_{\mathrm{H}}$ and $\mathrm{P}_{\mathrm{H} 1}$ are given by

$$
\mathbf{P}_{\mathrm{H}}=\mathrm{hLp}
$$

and

$$
\mathbf{P}_{\mathrm{H} 1}=\mathrm{hLp} \mathrm{p}_{2}^{\prime}
$$

in which $p_{1}^{\prime}$ and $p_{2}^{\prime}$ are obtained from the pressure-time curves shown in Figs. B.5 and B.7.

The expressions for $\mathrm{P}_{\mathrm{H}}, \mathrm{P}_{\mathrm{H} 1}$, and $\mathrm{P}_{\mathrm{V}}$ will vary for the various time intervals. These time intervals may be defined as follows:

$$
\begin{aligned}
t_{a}= & \text { time for wave to reach rear edge of roof } \\
t_{b}= & \text { time for wave to reach center of rear } \\
& \text { wall } \\
t_{c}= & \text { time for pressure on front face to drop } \\
& \text { to value of } p_{0} \text { (which is equivalent to } t_{1} \text { in } \\
& \text { in Fig. B.5) } \\
t_{d}= & \text { time for wave to reach } 7 d
\end{aligned}
$$

where all times are measured from the instant the shock wave strikes the front wall. Accordingly

$$
\left.\begin{array}{l}
t_{a}=\frac{d}{v^{\prime}} \\
t_{b}=\frac{2 d+h}{2 v^{\prime}} \\
t_{c}=\frac{4 h}{v^{\prime}} \\
t_{b}=\frac{2 d+L}{2 v^{\prime}} \\
t_{c}=\frac{2 L}{v^{\prime}} \\
t_{d}=\frac{7 d}{v^{\prime}}
\end{array}\right\} \text { for } h<\frac{L}{2}
$$

The values of $\mathrm{P}_{\mathrm{V}}$ for the various time intervals are given in Fig. B.9. Here Case $I$ is for $0 \leqq t \leqq t_{a} ;$ Case $I$, for $t_{a} \leqq t \leqq t_{d}$; and Case III, for $t>t_{d}$.

Since $\mathrm{P}_{\mathrm{H}}, \mathrm{P}_{\mathrm{H} 1}$, and $\mathrm{P}_{\mathrm{V}}$ are functions of $t$ and $t^{2}$, the general equation of motion, Eq. B.40, may be expressed as

$$
\frac{d^{2} x}{d t^{2}}=a_{2}+b_{2} t+c_{2} t^{2}
$$

The solution of this equation is

$$
x=c_{2 n-1}+c_{2 n} t+\frac{a_{2} t^{2}}{2}+\frac{b_{2} t^{3}}{6}+\frac{c_{2} t^{4}}{12}
$$


in which $c_{2 n-1}$ and $c_{2 n}$ are constants of integration.

By differentiating Eq. B.20,

$$
\frac{d x}{d t}=c_{2 n}+a_{2} t+\frac{b_{2} t^{2}}{2}+\frac{c_{2} t^{3}}{3}
$$

If $\Delta_{\mathrm{n}}$ and $\mathrm{V}_{\mathrm{n}}$ represent the displacement and velocity, respectively, at the beginning of any period at the time $t_{n}$, then the constants of integration for the equation of motion during that period are found from the relations

$$
\begin{gathered}
c_{2 n}=v_{n}-a_{2} t_{n}-\frac{b_{2} t_{n}^{2}}{2}-\frac{c_{2} t_{n}^{3}}{3} \\
c_{2 n-1}=\Delta_{n}-c_{2 n} t_{n}-\frac{a_{2} t_{n}^{2}}{2}-\frac{b_{2} t_{n}^{3}}{6}-\frac{c_{2} t_{n}^{4}}{12}
\end{gathered}
$$

The motion stops when $\mathrm{dx} / \mathrm{dt}=0$. The total distance moved may then be determined by equating the right side of Eq. B.26 to zero, solving for $t$, and substituting this value of $t$ in Eq. B.23.

It is to be noted that the pressures on those parts of the footing which extend beyond the wall lines are not included in the foregoing analysis. Inclusion of these areas is not warranted except in unusual cases.

Numerical Illustration. The building shown in Fig. B. 8 will be investigated for stability against sliding under a peak overpressure of $10 \mathrm{psi}=1440 \mathrm{psf}$, which corresponds to a distance of approximately $1 / 2$ mile from the center of explosion of a $20-\mathrm{kt}$ bomb. The coefficient of friction is assumed to be 0.6 , and the total passive resistance of the earth is assumed to be $39,000 \mathrm{lb}$. From Fig. B.10, $\tau=0.58 \mathrm{sec}$. The values of the time intervals are $t_{a}=1 / 70$ sec, $t_{b}=1 / 56 \mathrm{sec}, t_{c}=1 / 35 \mathrm{sec}$, and $t_{d}=1 / 10 \mathrm{sec}$. The numerical work is given in Table B.1. It is to be noted that the motion stops in the time interval $1 / 35 \leqq t \leqq 1 / 10$. The time when the motion stops is found from Eq. B.26.

$$
\frac{d x}{d t}=c_{8}-98.7 a t+713 t^{2}-2363 t^{3}=0
$$

from which $t=0.0774$ sec. By substituting this value of $t$ in Eq. B.23, the total sliding motion is found to be $0.10 \mathrm{ft}$, or about $1 \frac{1}{5} \mathrm{in}$.

\section{B.3.2 Stability Against Overturning}

The reflected pressures on the front face in addition to causing the structure to slide will tend also to rotate the structure as a unit about the rear edge of the footing. In reference to Fig. B.8, the force tending to produce rotation about an axis through 0 is $\mathrm{P}_{\mathrm{H}}$, and the forces tending to resist such motion are $\mathbf{P}_{\mathrm{V}}, \mathbf{P}_{\mathrm{H}}$, and the total weight of the structure W. For small angles of rotation, $\theta$, expressed in radians, the overturning moment $\mathbf{M}_{\mathrm{T}}$ causing the rotation is given by

$$
\begin{aligned}
\mathbf{M}_{\mathrm{T}}=( & \left.\frac{\mathrm{h}}{2}+\mathrm{h}^{\prime}\right)\left(\mathbf{P}_{\mathrm{H}}-\mathbf{P}_{\mathrm{H} 1}\right) \\
& +\mathbf{M p}_{\mathrm{p}}-\left(\mathrm{d}+\mathrm{d}^{\prime}\right) \mathbf{P}_{\mathrm{V}}-\left(\frac{\mathrm{d}}{2}+\mathrm{d}^{\prime}\right) \mathrm{W}
\end{aligned}
$$

where $h^{\prime}=$ depth of rear footing below ground level

$$
\begin{aligned}
d^{\prime}= & \text { extension of rear footing beyond } \\
& \text { rear wall } \\
M_{p}= & \text { moment of } P_{V} \text { about front edge of } \\
& \text { roof (see Fig. B.9). }
\end{aligned}
$$

The general equation of motion is given by

$$
\frac{d^{2} \theta}{d t^{2}}=\frac{M_{T}}{I_{m}}
$$

in which $I_{m}$ is the mass moment of inertia of the structure about an axis through 0 .

As explained in the preceding section, $\mathrm{P}_{\mathrm{H}}$, $\mathrm{P}_{\mathrm{HI}}, \mathrm{MV}$, and $\mathrm{PV}$ are functions of $t$ and $\mathrm{t}^{2}$. Accordingly, Eq. B.47 will take the form

$$
\frac{d^{2} \theta}{d t^{2}}=a_{3}+b_{3} t+c_{3} t^{2}
$$

The solution of this equation is found in the same manner as that given for sliding (Eq. B.41). The maximum value of $\theta$ occurs when $\mathrm{d} \theta / \mathrm{dt}$ changes sign or when $\mathrm{d} \theta / \mathrm{dt}=0$. The maximum uplift, $\delta$, at the front edge is then simply

$$
\delta=\left(d+2 d^{\prime}\right) \theta
$$

Numerical Illustration. The building shown in Fig. B. 8 will now be investigated for stability against overturning under the same peak 


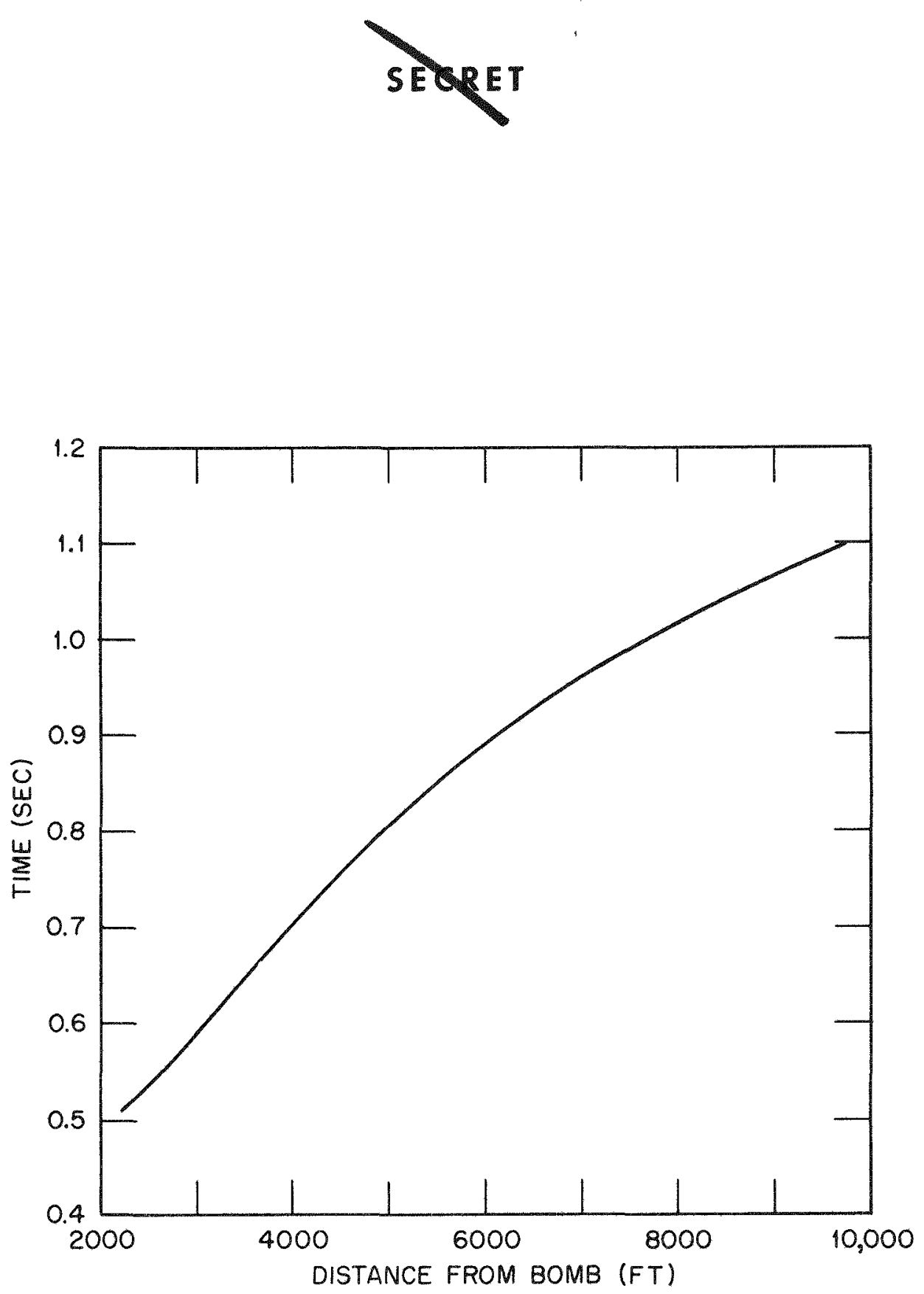

Fig. B.10 Duration of Positive Phase of Shock Wave 
TABLE B.1 COMPUTATIONS FOR STABILITY AGAINST SLIDING

\begin{tabular}{|c|c|c|c|c|}
\hline \multirow{2}{*}{ Term } & \multicolumn{4}{|c|}{ Time Interval (sec) } \\
\hline & $0 \leqq t \leqq \frac{1}{70}$ & $\frac{1}{70} \leqq t \leqq \frac{1}{56}$ & $\frac{1}{56} \leqq t \leqq \frac{1}{35}$ & $\frac{1}{35} \leqq t \leqq \frac{1}{10}$ \\
\hline $\begin{array}{l}\mathrm{P}_{\mathrm{H}} \times 10^{-6} \\
\mathrm{P}_{\mathrm{H}} \times 10^{-6} \\
\mathrm{PV} \times 10^{-6} \\
\mathrm{R} \times 10^{-6} \\
\left(\mathrm{P}_{\mathrm{H}}-\mathrm{R}\right) \times 10^{-6} \\
\text { Equation of } \\
\text { acceleration, } \\
\mathrm{d}^{2} \mathrm{x} / \mathrm{dt}^{2} \\
\text { Equation of dis- } \\
\text { placement, } \mathrm{x} \\
\text { Equation of } \\
\text { velocity, dx/dt } \\
\text { Values at beginning } \\
\text { of period } \\
\mathrm{x} \\
\mathrm{dx} / \mathrm{dt} \\
\text { Values of constants } \\
\text { in equations } \\
\text { Values at end of } \\
\text { period } \\
\mathrm{x} \\
\mathrm{dx} / \mathrm{dt}\end{array}$ & $\begin{array}{c}1.728-40.32 t \\
0 \\
63.141 t \\
0.159+37.885 t \\
1.569-78.205 t \\
252.62-12591 t \\
\\
c_{1}+c_{2} t+126.31 t^{2}-2098.5 t^{3} \\
c_{2}+252.62 t-6295.5 t^{2}\end{array}$ & $\begin{array}{c}1.728-40.32 t \\
0 \\
1.107-15.402 t+73.382 t^{2} \\
0.823-9.241 t+44.029 t^{2} \\
0.905-31.079 t-44.029 t^{2} \\
145.71-5004 t-7089 t^{2} \\
c_{3}+c_{4} t+72.855 t^{2}-834.0 t^{3}-590.75 t^{4} \\
c_{4}+145.71 t-2502 t^{2}-2363 t^{3}\end{array}$ & $\begin{array}{c}1.728-40.32 t \\
0.396-0.662 t \\
1.107-15.402 t+73.382 t^{2} \\
1.219-9.903 t+44.029 t^{2} \\
0.509-30.417 t-44.029 t^{2} \\
81.95-4897 t-7089 t^{2} \\
\\
c_{5}+c_{6} t+40.975 t^{2}-816.17 t^{3}-590.75 t^{4} \\
c_{6}+81.95 t-2448.5 t^{2}-2363 t^{3}\end{array}$ & $\begin{array}{c}0.606-1.045 t \\
0.396-0.662 t \\
1.107-15.402 t+73.382 t^{2} \\
1.219-9.903 t+44.029 t^{2} \\
-0.613+8.858 t-44.029 t^{2} \\
-98.70+1426 t-7089 t^{2} \\
\\
c_{7}+c_{8} t-49.35 t^{2}+237.67 t^{3}-590.75 t^{4} \\
c_{8}-98.70 t+713 t^{2}-2363 t^{3}\end{array}$ \\
\hline
\end{tabular}


TABLE B.2 COMPUTATIONS FOR STABILITY AGAINST OVERTURNING

\begin{tabular}{|c|c|c|c|}
\hline \multirow[b]{2}{*}{ Term } & \multicolumn{3}{|c|}{ Time Interval (sec) } \\
\hline & $0 \leqq t \leqq \frac{1}{70}$ & $\frac{1}{70} \leqq t \leqq \frac{1}{56}$ & $\frac{1}{56} \leqq t \leqq \frac{1}{35}$ \\
\hline $\begin{array}{l}\mathrm{P}_{\mathrm{H}} \times 10^{-6} \\
\mathrm{P}_{\mathrm{H} 1} \times 10^{-6} \\
\mathrm{P}_{\mathrm{V}} \times 10^{-6} \\
\mathrm{M}_{\mathrm{p}} \times 10^{-6} \\
\mathrm{M}_{\mathrm{T}} \times 10^{-6} \\
\text { Equation of acceleration, } \\
\quad \mathrm{d}^{2} \theta / \mathrm{dt}^{2} \\
\text { Equation of displacement, } \theta \\
\text { Equation of velocity, } \mathrm{d} \theta / \mathrm{dt} \\
\text { Values at beginning of period } \\
\quad \theta \\
\quad \mathrm{d} \theta / \mathrm{dt} \\
\text { Values of constants in } \\
\text { equations } \\
\text { Values at end of period } \\
\theta \\
\mathrm{d} \theta / \mathrm{dt}\end{array}$ & $\begin{array}{c}1.728-40.32 t \\
0 \\
63.141 t \\
51029 t^{2} \\
9.896-1608.2 t+51029 t^{2} \\
6.597-1072 t+34019 t^{2} \\
c_{1}+c_{2} t+3.2985 t^{2}-178.67 t^{3}+2835 t^{4} \\
c_{2}+6.597 t-536 t^{2}+11340 t^{3} \\
0 \\
0 \\
c_{1}=0 \\
c_{2}=0 \\
0.000270 \text { radian } \\
0.017915 \text { radian/sec }\end{array}$ & $\begin{array}{c}1.728-40.32 t \\
0 \\
1.107-15.402 \mathrm{t}+73.382 \mathrm{t}^{2} \\
12.8-179.2 \mathrm{t}+868.43 \mathrm{t}^{2} \\
-0.551-138.0 \mathrm{t}-672.59 \mathrm{t}^{2} \\
-0.367-92 \mathrm{t}-448 \mathrm{t}^{2} \\
\mathrm{c}_{3}+\mathrm{c}_{4} \mathrm{t}-0.1835 \mathrm{t}^{2}-15.33 \mathrm{t}^{3}-37.37 \mathrm{t}^{4} \\
\mathrm{c}_{4}-0.367 \mathrm{t}-46 \mathrm{t}^{2}-149.5 \mathrm{t}^{3} \\
0.000270 \mathrm{radian} \\
0.017915 \mathrm{radian} / \mathrm{sec} \\
\mathrm{c}_{3}=-0.000117 \\
\mathrm{c}_{4}=0.032981 \\
0.000322 \mathrm{radian} \\
0.010908 \mathrm{radian} / \mathrm{sec}\end{array}$ & $\begin{array}{c}1.728-40.32 t \\
0.396-0.662 t \\
1.107-15.402 \mathrm{t}+73.382 \mathrm{t}^{2} \\
12.8-179.2 \mathrm{t}+868.43 \mathrm{t}^{2} \\
-3.323-133.364 \mathrm{t}-672.59 \mathrm{t}^{2} \\
-2.215-88.9 \mathrm{t}-448 \mathrm{t}^{2} \\
\mathrm{c}_{5}+\mathrm{c}_{6} \mathrm{t}-1.1075 \mathrm{t}^{2}-14.82 \mathrm{t}^{3}-37.37 \mathrm{t}^{4} \\
\mathrm{c}_{6}-2.215 \mathrm{t}-44.5 \mathrm{t}^{2}-149.5 \mathrm{t}^{3} \\
0.000322 \mathrm{radian} \\
0.010908 \mathrm{radian} / \mathrm{sec} \\
\mathrm{c}_{5}=-0.000406 \\
\mathrm{c}_{6}=0.065490 \\
0.000192 \mathrm{radian} \\
-0.037576 \mathrm{radian} / \mathrm{sec}\end{array}$ \\
\hline
\end{tabular}


overpressure as used in the investigation for sliding, namely $10 \mathrm{psi}$. The mass moment of inertia about an axis through 0 is assumed to be $1.5 \times 10^{6} \mathrm{lb}-\mathrm{sec}^{2}-\mathrm{ft}$. The numerical work is given in Table B.2. It can be seen that the maximum value of $\theta$ occurs in the time interval $1 / 56 \leqq t \leqq 1 / 35$. The time when $\theta$ is a maximum is found from the relation

$$
\frac{\mathrm{d} \theta}{\mathrm{dt}}=\mathrm{c}_{6}-2.215 \mathrm{t}-44.46 \mathrm{t}^{2}-149.46 \mathrm{t}^{3}=0
$$

From this equation, $t=0.0205 \mathrm{sec}$, and $\theta_{\max }=$ 0.000337 radian. The maximum uplift at $A$, Fig. B.8, is found to be $0.0074 \mathrm{ft}$ or about $1 / 10 \mathrm{in}$.
From the small values obtained in these examples, it may be concluded that the structure possesses adequate stability against sliding and overturning. Obviously the extent of displacements which may be deemed as permissible will vary with the type and functional requirements of the structure.

\section{REFERENCE}

1. F. E. Turneaure and E. R. Maurer, "Principles of Reinforced Concrete Construction," p. 103, John Wiley \& Sons, Inc., New York, 1936. 


\section{Appendix C \\ Design and Analysis of Structures}

\section{C.1 STRUCTURE $3.2 .1 \mathrm{a}$}

Structure 3.2.1a simulates the roof slab of a bomb-resistant building, designed in accordance with the Bureau of Yards and Docks criteria of protection. ${ }^{1}$ The details of design and the method of construction conform to Bureau practice used in protective construction. during the last war.

The purpose of this test was to ascertain the efficacy of this structure, originally designed to provide protection against conventional weapons, in resisting atomic blast at rather close range.

Owing to the lack of dependable design data regarding pressures and duration of the blast wave at such a close distance, no satisfactory analysis of structural behavior could be made.

Details of design are shown in Fig. D.1.

\section{C.2 STRUCTURE 3.2.1b}

Structure 3.2.1b also simulates the roof slab of a bomb-resistant building, designed in accordance with the Bureau's newly developed construction technique of cellular framing. It consists of a three-layer precast cell assembly, arranged in a checkerboard pattern to form a honeycomb framing. The framing is reinforced by a special system consisting of welded trusses and bars. The middle layer of cells is filled with concrete, and the assembly is topped with a poured 21 -in. reinforced-concrete slab.

The aggregate thickness of the roof slab being about the same as for Structure 3.2.1a, it will have an equal protective value against weapons of impact. However, owing to its vented assembly, a greater degree of protection against blast is anticipated.
Details of the design are shown in Figs. D.2 to D.4.

\section{C.3 STRUCTURE $3.2 .2 \mathrm{a}$}

\section{C.3.1 Framing Arrangement}

Structure 3.2.2a, of rectangular shape approximately 11 by 21 by $41 \mathrm{ft}$, is of precastconcrete construction comprising three singlespan rigid-frame type bents, and roof and wall panels which are attached to the bents.

The bents are identical and are composed of three component framing members. Each member, in turn, is composed of two channelshaped elements bolted together to form a hollow-box section. The channels are provided with special details at each end to facilitate the interconnection of the members by welding of the reinforcing steel and by grouting. Connection to the foundations is made by pouring concrete into the lower portion of the hollow legs around dowels extending from the footings. The concrete is poured through holes in the columns provided for this purpose.

Roof slabs, $19 \mathrm{ft} 11 \frac{3}{4}$ in. by $2 \mathrm{ft} 7 \%$ in. in plan, are in the form of ribbed panels. The slab is $1 \frac{1}{4} \mathrm{in}$. thick and is reinforced with welded-wire fabric of 2-in. mesh. The ribs consist of edge beams of 6-in. depth and 4-in, cross beams dividing the panel into approximately square subpanels. Insert plates are welded to the reinforcement of the edge beams at the ends of the beams on the bottom and at the corners and at four other locations along the long edges at the top. The roof slabs span from the center to the end bents and are connected to the bents and to each other by plates welded to the insert plates. 


\section{SECRET}

The long walls are composed of panels identical to the roof panels except for minor variations. These panels are connected to the bents and to the roof panels by welding and to each other by bolting through pipe sleeves cast in the edge beams.

The end-wall panels are similar to the sidewall panels, but their long dimensions are in the vertical direction. These panels are connected to each other and to the roof panels by welding and are bolted to the foundation. Entrance to the structure is provided by means of a removable panel which forms a part of one of the end panels.

The foundation is composed of six 5 - by 5 by $2-\mathrm{ft}$ poured-in-place footings at each of the columns of the bents and a continuous pad $2 \mathrm{ft}$ 6 in. wide and $1 \mathrm{ft}$ deep supported on the footings. A 6-in. curb poured integrally with the pad extends above grade and supports the bottom edges of the wall slabs. The footings under the center bent are connected to each other with a reinforced-concrete strut. Similar struts used for instrumentation connect the foundation pads on the long sides at the quarter points.

Plans, elevations, and details of design for this structure are shown in Figs. D.5 and D.6.

\section{C.3.2 Design}

The structure was designed for a roof live load of $40 \mathrm{psf}$ and for winds of $70 \mathrm{mph}$ intensity. Connections of the slabs other than at the ends were dictated by the analysis for blast as described below.

Precast concrete was specified to have a maximum aggregate of $1 / 4$ in. and a 28-day strength of 5000 psi; foundation concrete was to have a maximum aggregate of $1 \mathrm{in}$. and a 28day strength of 2500 psi. Reinforcing steel was specified to be structural-grade deformed bars, and mesh reinforcing was to be weldedwire fabric having a minimum yield strength of 70,000 psi. Welding was in accordance with Yards and Docks Specifications $22 \mathrm{Yb}$.

\section{C.3.3 Analysis for Blast}

This structure was oriented so that the long walls were parallel to the shock front. Pressure-time curves for the long walls and roof of this structure were assumed to be the same as those shown in Figs. B.5 to B.7.
In Appendix $\mathrm{B}$, the peak overpressure $\mathrm{p}_{0}$ is assumed, and the analysis is made to determine the maximum deformation resulting from this shock loading. If the deformation thus found exceeds the allowable or is too small, the design is changed accordingly. For the test structure a peak overpressure $p_{0}$ was sought that would produce a deflection of about one-tenth the span of the element investigated. This was done by trial. The smallest value of $p_{0}$ thus found for the various elements was used to determine the location of the structure in the test with reference to ground zero.

It is apparent that the framing elements receiving the greatest shock load are the wall panels on the front or long wall. The analysis of these panels was made in two parts: (1) an investigation of the approximately square subpanel formed by the cross ribs and edge ribs and (2) an investigation of the panel as a whole, spanning from center to end bent.

The values of the constants pertaining to the structure as a whole are $L=41 \mathrm{ft}, \mathrm{h}=11 \mathrm{ft}$, $d=21 \mathrm{ft}$, and $f_{c}^{\prime}=4000$ psi. The yield strengths of the reinforcing steel and welded-wire mesh are 50,000 and $90,000 \mathrm{psi}$, respectively.

The increased yield values used for the reinforcement is due to the extremely short duration of the sustained strains.

Since $h<L / 2$, the value of $t_{1}$ is

$$
\mathrm{t}_{1}=\frac{4 \mathrm{~h}}{\mathrm{v}^{\prime}}=\frac{4(11)}{1400}=0.0314 \mathrm{sec}
$$

The investigation for the square subpanels of the front-wall elements was made in the same manner as for the panel of Example 3 of Sec. B.2.2. Here the values of $\beta, \beta_{1}$, and $\gamma$ are 0.48 , 0.31 , and 13.5 , respectively. The values of the other needed constants are $W=75 \mathrm{lb}, \mathrm{A}=4.5$ $\mathrm{sq} \mathrm{ft,} \mathrm{S}=8600 \mathrm{lb} / \mathrm{ft}$, and $l_{1}=2.12 \mathrm{ft}$.

The equations of motion corresponding to the time periods $t_{1}$ and $t_{2}$ are

$$
\beta A\left[p_{0}\left(2-\frac{t}{t_{1}}\right)-\frac{13.5 \mathrm{~S}}{(2.12)^{2}} \mathrm{y}\right]=\beta_{1} \frac{\mathrm{W}}{\mathrm{g}} \alpha
$$

and

$$
\beta \mathrm{A}\left[\mathrm{p}_{0}\left(\frac{\tau-\mathrm{t}}{\mathrm{t}_{2}}\right)-\frac{13.5 \mathrm{~S}}{(2.12)^{2}} \mathrm{y}\right]=\beta_{1} \frac{\mathrm{W}}{\mathrm{g}} \alpha
$$


The method of solving the foregoing equations is given in Appendix B.

The value of $p_{0}$ must now be found by trial so that the value of $\mathrm{y}$, when $\mathrm{dy} / \mathrm{dt}=0$, is $l_{1} / 10$ or $0.212 \mathrm{ft}$.

This solution is predicated on the element's having end anchorage capable of developing the full strength of the reinforcement. For the element in question, the reinforcement consists of mesh embedded in the edge beams and is continuous over the subbeams. The $S$ forces at the edge beams act toward the inside, and this inward pull is resisted by the subbeams. Using a length of $2 \mathrm{ft} 6 \mathrm{in}$. between the subbeams, the total force on each'subbeam is $2.5 \mathrm{~S}$ or $\mathbf{2 1 , 5 0 0}$ 1b. Since the area of subbeam, including the part of the slab contiguous with it, is about 8.5 sq in., the compressive stress in the concrete is equal to $21,500 / 8.5$ or $2530 \mathrm{psi}$, which is a value much less than the ultimate for the concrete used.

The $S$ forces at the subbeams will be balanced by similar forces from the next subpanel except at the ends, where a condition exists similar to that of the edge beams. Here, however, the tension is resisted by compression in the edge beams.

The intermediate wall panels marked A3 on Fig. D.5 are the most critical on the front wall, since the top panels, A2, are supported along the top edge by the roof slabs, and the bottom panels, A4, are supported along the bottom edge by bolting to the foundations. Panels A3 may be considered as simply supported at the bents, and the effect of the bolts along the edge beams may be neglected.

The analysis of these elements under blast was performed in a manner similar to that for beams fixed at the ends, as given in Appendix B. However, since the panels are simply supported, the resistance diagram shown in Fig. B.2 is not applicable. The resistance diagram for this case is shown in Fig. C.1, which is applicable to simply supported beams.

Since the roof and end-wall panels are subject to much smaller normal blast pressure than the front-wall panels, an investigation similar to that for the front panels was not needed. These panels, however, are subject to large shearing forces, as is explained in the following discussion.

The investigation for the over-all strength of this structure is rather involved and requires a study of the interaction of the various parts during the time intervals of changing pressure conditions. Immediately after the shock front strikes the front face, the structure as a whole will deform away from the blast. The end bents cannot deform laterally without distortion of the end-wall panels, thus greatly increasing the resistance of these bents to lateral bending. In addition, the reaction at the center bent is twice the reaction at each end bent. As a result, the center bent will have larger lateral deformations than those at the ends. This differential motion is resisted by the roof panels and by the torsional rigidity of the end bents.

It is assumed that the deformations are symmetrical with respect to the transverse center line of the building. It is further assumed that the lateral deformation of any point on the center or end bents bears a constant relation to the lateral deformation of the center bent which is taken as the deformation of reference, $y$. The problem then becomes one of determining the modulus of resistance, $\mathrm{q}$, as $\mathrm{y}$ is increasing in value. Then the equation of motion will take the form

$$
\beta^{\prime} A(p-q)=\beta_{1}^{\prime} \frac{W}{g} \alpha
$$

where $A=$ area of the front face

$\mathrm{p}=$ net pressure on the structure tending to move it in the direction of the blast

$\mathrm{W}=$ total weight of structure

$\beta^{\prime}$ and $\beta_{1}^{\prime}=$ constants similar to $\beta$ and $\beta_{1}$ of Appendix B

Before the constants $\beta^{\prime}$ and $\beta_{1}^{\prime}$ can be determined, it is necessary to find the ratio $\mathrm{k}$ of the lateral deflection $\mathrm{y}_{\mathrm{e}}$ of the top of the end bent to the deflection $y$ of the center bent due to a uniform load $q$ applied to the front wall.

Observing that the front panels which carry the applied load $q$ to the bents are simple spans, then the center bent will have twice the load of each end bent, if the effect of load transfer to the foundation through the bolts in the edge beam of the lower panels is neglected. If $Q$ is the total shear in the roof at each side of the center bent, then the loads producing the deflection $y$ at the center bent are as shown in Fig. C.2a. If it is assumed that the deformation $y$ produces stresses in the center bent within 


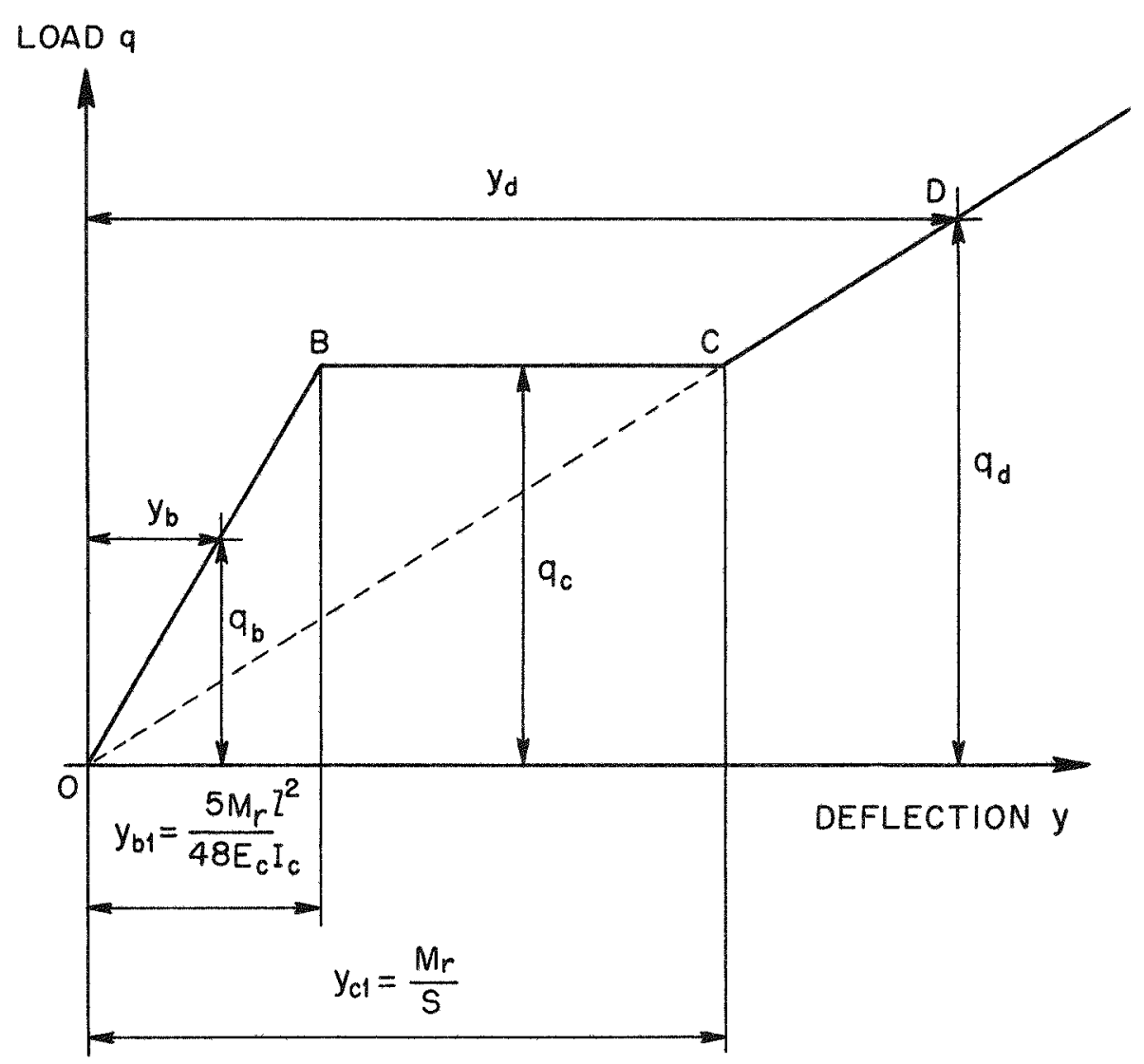

Fig. C.1 Resistance-Deflection Relation for a Simply Supported Reinforced-concrete Member. For $0 \leq y$ $\leq y_{b 1}, q_{b}=\left(384 E_{c} I_{c} y_{b}\right) / 5 l^{4} ;$ for $y_{b 1} \leq y \leq y_{c 1}, q_{c}=\left(8 M_{r}\right) / l^{2}$; for $y>y_{c 1}, q_{d}=\left(8 S y_{d}\right) / l^{2}$. 


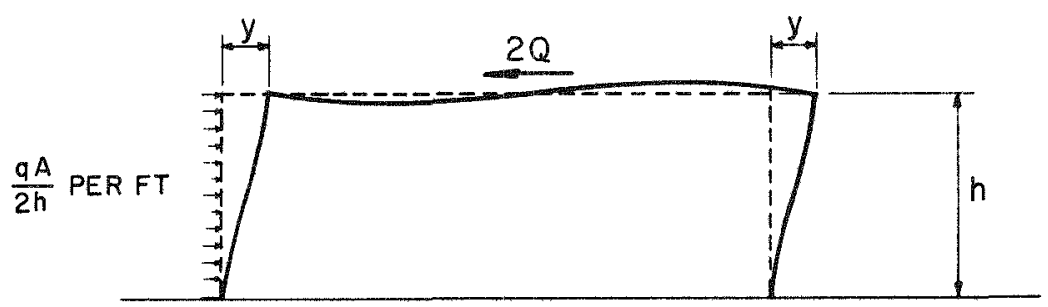

CENTER BENT LOADING AND DEFORMATION

(a)

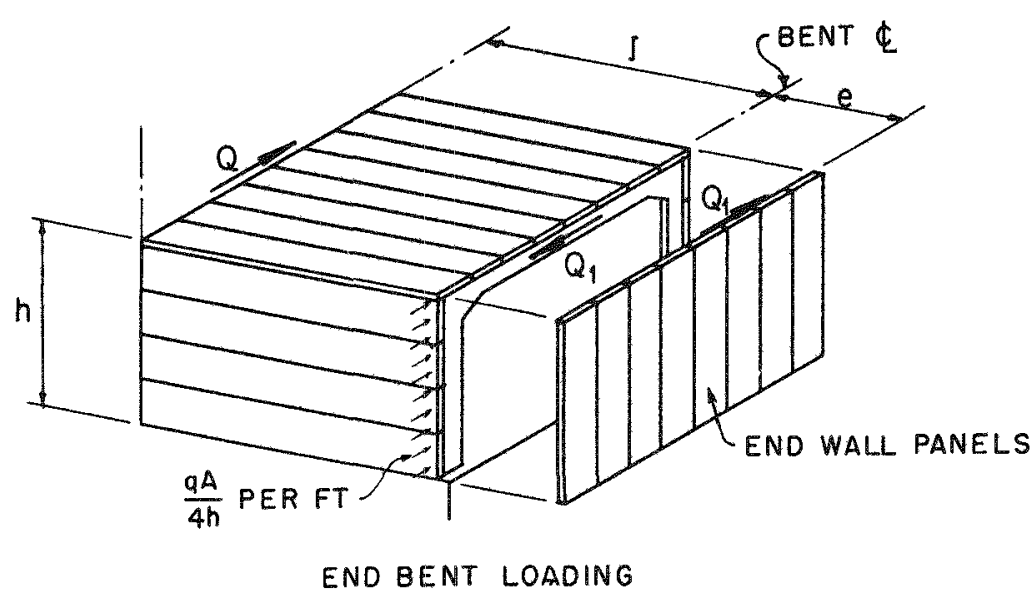

(b)

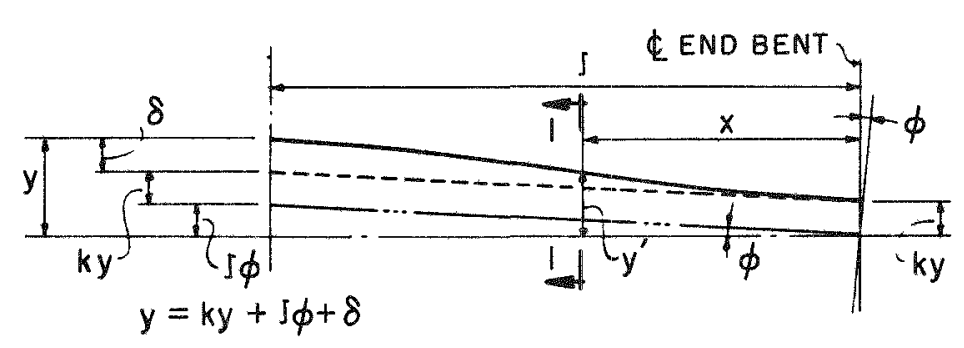

(c)

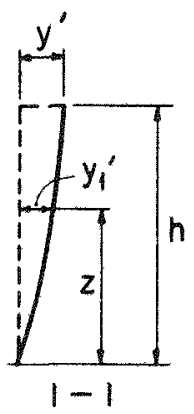

然

Fig. C.2 Deformations and Loadings for Bents of Structure $3.2 .2 \mathrm{a}$ 


\section{SERET}

the elastic limit, then the deformation y can be expressed in terms $q, Q$, and two constants $c_{1}$ and $c_{2}$, using any of the usual methods for determining the deflections of a rigid frame. Then

$$
y=c_{1} q-c_{2}(2 Q)
$$

in which $c_{1}$ and $c_{2}$ are constants depending on the physical and geometrical properties of the frame.

The loads on the end bent are shown in Fig. C.2b, and the deformation is shown in Fig. C.3. Let $\phi$ be the angle, expressed in radians, through which the end bent rotates; $\delta$, the deflection, due to the load $Q$, of the roof slabs acting as a cantilever with the free end partially guided so that the deflection here is the average of a free and guided cantilever; and $y_{e}$, the lateral deflection of the end bent. Then the deflection $y$ at the center bent is given by

$$
\mathrm{y}=\mathrm{y}_{\mathrm{e}}+l \phi+\delta
$$

Let $Q_{1}$ be the total shear between the endwall panels and the end bent. The relation between $Q_{1}$ and $y_{e}$ can be found by assuming that the end-wall panels will act together as a short cantilever with a partially guided free end. Then

$$
y_{e}=\frac{5 Q_{1} h^{3}}{24 E_{c} I_{p}}=c_{3} Q_{1}
$$

in which $I_{p}$ is the moment of inertia of the end wall acting as a unit. Equation C.4 is valid as long as stresses remain in the elastic range. With increasing values of $Q_{1}$ the yield-point stress will be reached first in the bolt nearest the front wall, connecting panel B1 to the foundation. With further increase in the value of $Q_{\hat{f}}$, the bolts, as well as the plates connecting the panels together, will progressively yield. The panels will then begin to act as individual units, and the maximum value of $Q_{1}$ can be found from a consideration of the forces acting on the individual panels, as shown in Fig. C.3c.

In the end panel $B 1, T_{1}$ represents the yield strength of the anchor bolt, and $\mathrm{C}_{1}$ represents the total stress of the concrete at the corner of the panel. Let $\mathrm{S}$ represent the yield strength in shear of the connecting plates between the slabs. Then the value of $\mathrm{Z}_{1}$, the length of the compression zone in the concrete for the end panel, is found from the consideration that $\mathrm{C}_{1}+2 \mathrm{~S}=\mathrm{T}_{1}$. For the intermediate panels, $\mathrm{C}=\mathrm{T}$, since the $\mathrm{S}$ forces are balanced. The resisting moment $\mathrm{M}_{1}$ of the end slab is then found by taking the moments of $S$ and $T_{1}$ about $C_{1}$. The maximum value of $Q_{1}$ is then equal to the sum of the individual resisting panel moments divided by the height of the panels.

As in the case of the center bent, $y_{e}$ can be expressed in terms of $q, Q$ and $Q_{1}$, and two constants. Since the center and end bents are identical, the relation is

$$
y_{e}=\frac{c_{1}}{2} q-c_{2}\left(Q_{1}-Q\right)
$$

The angle of the twist, $\phi$, through which the end bent rotates is expressed by the relation

$$
\phi=\mathrm{c}_{\mathrm{q}} \mathrm{M}_{\mathrm{t}}
$$

in which $M_{L}$ is the twisting moment and $c_{4}$ is a constant depending on the physical and geometrical characteristics of the bent and which may be computed in the usual way, assuming that the stresses are within the yield values. In this case, see Fig. C.2b

$$
\mathbf{M}_{\mathrm{t}}=\mathrm{Q} l+\mathrm{Q}_{\mathrm{1}} \mathrm{e}
$$

and Eq. C.6 takes the form

$$
\phi=c_{5} Q+c_{6} Q_{1}
$$

The value of $\delta$ is expressed by the relation

$$
\delta=\frac{5 Q l^{3}}{24 \mathrm{E}_{\mathbf{c}} \mathrm{I}_{\mathbf{r}}}=c_{7} \mathrm{Q}
$$

in which $I_{r}$ is the moment of inertia of the roof as a whole. From Eqs. C.4 and C.5

$$
c_{3} Q_{1}=\frac{c_{1}}{2} q-c_{2}\left(Q_{1}-Q\right)
$$

or

$$
Q_{1}=\frac{c_{1} q+2 c_{2} Q}{2\left(c_{3}+c_{2}\right)}
$$




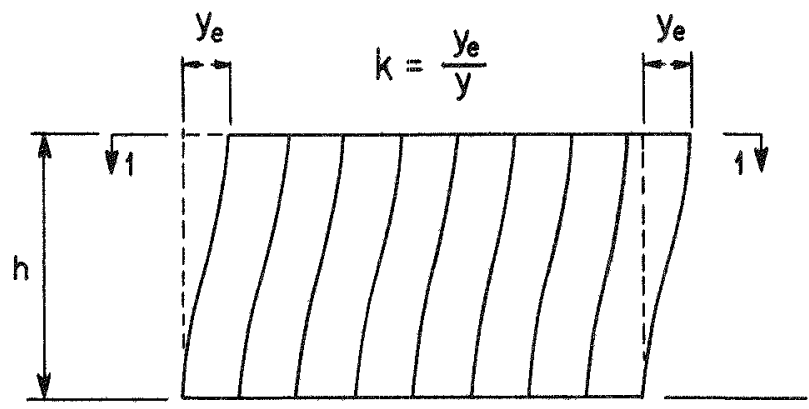

\section{ELEVATION}

(a)

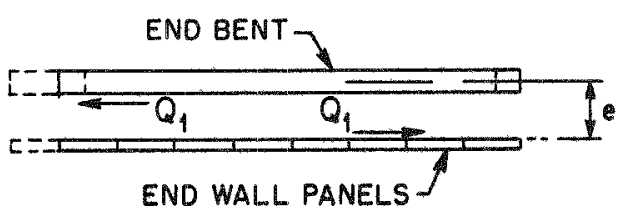

VIEW 1-1

(b)

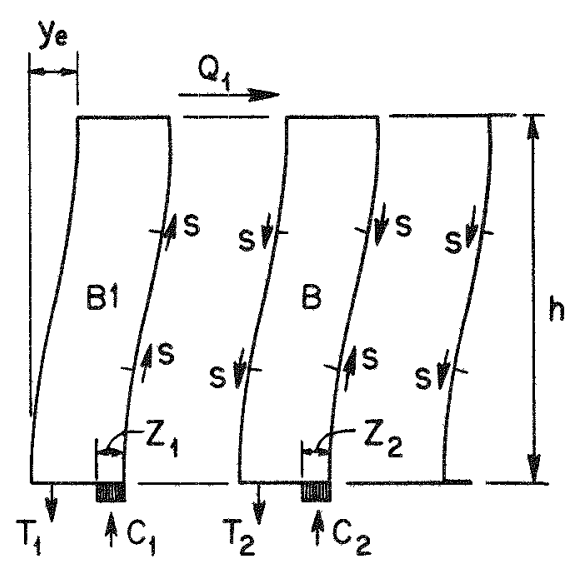

(c)

Fig. C.3 Deformations and Loadings for End Walls of Structure $3.2 .2 \mathrm{a}$ 
Then substituting Eqs. C. 4 and C.8 in Eq. C.3

$$
\mathrm{y}=\mathrm{c}_{3} \mathrm{Q}_{1}+l\left(\mathrm{c}_{5} \mathrm{Q}+\mathrm{c}_{6} \mathrm{Q}_{1}\right)+\mathrm{c}_{7} \mathrm{Q}
$$

and replacing y by its value as given by Eq. C.2

$c_{1} q-c_{2}(2 Q)=c_{3} Q_{1}+l\left(c_{5} Q+c_{6} Q_{1}\right)+c_{7} Q$

Equations C.9 and C.10 may now be solved for $Q$ and $Q_{1}$ in terms of $q$ and constants determined from the physical and geometrical properties of the bents and slabs. It is now possible to eliminate $Q$ and $Q_{1}$ from Eqs. C.3 and C.4 and to express $y$ and ye in terms of $q$ and a single constant. The ratio $\mathrm{k}$ is

$$
k=\frac{y_{e}}{y}
$$

If the lateral deformations of the roof are assumed to be linear from $y_{e}$ to $y$, then the lateral deformation $y^{\prime}$ of any point on the roof at a distance $\mathrm{x}$ from the end bent, Fig. C.2c, is given by

$$
\mathrm{y}^{\prime}=\mathrm{ky}+\mathrm{yx} \frac{(1-\mathrm{k})}{l}
$$

Again assuming a straight-line variation in lateral deformations at any vertical section of the front section of the front wall, the deflection of $y_{1}^{\prime}$ of a point at a distance $z$ above the foundation is given by

$$
\mathrm{y}_{1}^{\prime}=\frac{\mathrm{zy}^{\prime}}{\mathrm{h}}
$$

The value of $\beta^{\prime}$ is then determined by

$$
\beta^{\prime}=\frac{2 \int_{0}^{l} \int_{0}^{\mathrm{h}} \mathrm{y}_{1}^{\prime} \mathrm{dz} d \mathrm{x}}{\mathrm{yA}}
$$

or

$$
\beta^{\prime}=\frac{k+1}{4}
$$

In order to determine the value of the mass reduction factor $\beta_{1}^{\prime}$, it is necessary to treat the end and side walls, the bents, and the roof separately. If $W_{e}$ is the total weight of the end walls, then $\beta_{1}^{\prime}$ for this part of the structure is given by

$$
\beta_{1 \mathrm{e}}^{\prime}=\frac{\int_{0}^{\mathrm{h}}\left(\mathrm{y}_{1}^{\prime}\right)^{2} \mathrm{dW}}{\mathrm{y}^{2} \mathrm{~W}}
$$

in which $y_{1}^{\prime}$ varies from 0 to $k y$, and $W$ is the total weight of the structure. Integrating the right side of Eq. C.16

$$
\beta_{1 \mathrm{e}}^{\prime}=\left(\frac{\mathrm{k}^{2}}{3}\right)\left(\frac{\mathrm{W}_{\mathrm{e}}}{\mathrm{W}}\right)
$$

$\beta_{1}^{\prime}$, for the front and rear walls, is given by

$$
\beta_{\mathrm{If}}^{\prime}=\frac{2 \int_{0}^{l} \int_{0}^{\mathrm{h}}\left(\mathrm{y}_{\mathrm{f}}^{\prime}\right)^{2} \mathrm{dW_{ \textrm {f } }}}{\mathrm{y}^{2} \mathrm{~W}}
$$

in which $W_{f}$ is the total combined weight of front and rear walls. Performing the integration

$$
\beta_{1 f}^{\prime}=\frac{W_{f}}{9 W}\left(1+k+k^{2}\right)
$$

For the roof, $\beta_{1}^{\prime}$ is given by

$$
\beta_{\mathrm{ir}}^{\prime}=\frac{2 \int_{0}^{l}\left(\mathrm{y}^{\prime}\right)^{2} \mathrm{dW} \mathbf{r}}{\mathrm{y}^{2} \mathrm{~W}}
$$

or

$$
\beta_{1 \mathrm{r}}^{\prime}=\frac{\left(1+\mathrm{k}+\mathrm{k}^{2}\right) \mathrm{W}_{\mathrm{r}}}{3 \mathrm{~W}}
$$

in which $W_{r}$ is the total roof weight.

The center bent is divided into two parts, $W_{c}$ representing the weight of the columns and $W_{b}$ representing the weight of the horizontal beam. Then

$$
\beta_{1 \mathrm{c}}^{\prime}=\frac{\mathrm{W}_{\mathbf{c}}}{3 \mathrm{~W}}
$$

and

$$
\beta_{\mathrm{ib}}^{\prime}=\frac{\mathrm{W}_{\mathrm{b}}}{\mathrm{W}}
$$

For the end bents

$$
\beta_{1 c^{\prime}}^{\prime}=\frac{W_{c^{\prime}} K}{3 W}
$$


and

$$
\beta_{1 b^{\prime}}^{\prime}=\frac{W_{\mathcal{C}^{\prime}} \mathrm{K}^{2}}{W}
$$

in which $W_{\mathrm{c}^{\prime}}$ is the total weight of the columns for both end bents, and $W_{b^{\prime}}$ is the weight of the horizontal member of both end bents.

The value of $\beta_{1}^{\prime}$ for the entire structure is then the sum of the $\beta_{i}$ values for the individual parts or

$$
\begin{array}{r}
\beta_{1}^{\prime}=\frac{1}{3 W}\left[k^{2} W_{e}+\left(1+k+k^{2}\right)\left(\frac{W_{f}}{3}+W_{r}\right)\right. \\
\left.+W_{c}+W_{c^{\prime}} k^{2}+3\left(W_{b}+W_{b} \prime k^{2}\right)\right]
\end{array}
$$

In the above analysis for $\beta^{\prime}$ and $\beta_{1}^{\prime}$, the deformations at intermediate points were assumed to bear a linear relation to the coordinates of each point measured from the end bent and height above foundation. In reality the deformation relations are not linear. However, in view of the complications introduced by the nonlinear relation, as well as its probable small effect, its use is not warranted.

Having determined the values of $\beta^{\prime}$ and $\beta_{1}^{\prime}$ the equation of motion, Eq. C.1, is solved in the same manner as shown in Appendix B, with due allowance for the change in the pressure constants.

In this analysis the value of $p_{0}$ used is the smaller of the values determined from the preceding analysis of the front-wall slabs. Having determined the value of $y$ when the motion stops, the value of $y_{e}$ is then determined from Eq. C.12. Values of $Q$ and $Q_{1}$ and an equivalent load $q$ for the final value of $y$ are determined by solving the simultaneous Eqs. C.2, C.9, and C.11. The resulting shears in the roof and endwall-panel connections are then computed in the usual manner.

The value of $\mathrm{k}$ from which the constants $\beta^{\prime}$ and $\beta_{1}^{\prime}$ are obtained is based on stresses in the elastic range of the bents, end walls, and roof. However, inasmuch as $\mathrm{k}$ is a ratio, it is reasonable to assume that its value will not materially change when stresses in parts of the structure are in the plastic range.

In the investigation for the front-wall panels as a whole, acting as simple spans between the center and end bents, the resistance to motion in the final stage of deformation was provided by tension forces $S$ equal to the yield strength of the reinforcing steel. The $\mathbf{S}$ force acting on one side of the center bent will be balanced by a similar force acting on the other side of the bent. At the end bent, however, there is no such balancing force acting, and the forces are resisted by bending and twisting of the column of the end bent adjacent to the front wall. It will be noted that the motion of the top of the bent in the direction of applied forces is prevented by the roof panels acting as a strut. Tension forces in the roof panels similar to the $S$ forces in the front-wall panels are not developed, owing to the relatively low pressures here.

Computations for overturning and sliding, made in a manner similar to those shown in Appendix $\mathbf{B}$, indicate small motions for these effects.

\section{C.3.4 Anticipated Damage}

Damage to this structure resulting from the test was expected to be most severe on the panels forming the front walls. Extensive damage to concrete slab and to the edge beams of front face panels, marked A3 on Fig. D.5, Appendix $D$, was expected. Damage to the slab was expected to be most severe at the center portions of panels, whereas the concrete edge beams were expected to be damaged along their entire length. At bolt locations adjacent to the upper panels A2 and the lower panels A4, separation of the concrete of the slabs from the edge beams was expected to occur to the extent that the mesh reinforcing would be visible.

The upper edge beams of front-wall panels A4 and the lower beams of panels A2 were expected to be damaged to about the same extent as those for panels A3, but cracking of the slabs was expected to be less severe. The concrete in the edge beams adjacent to the anchor bolts was expected to be severely cracked, and the anchor bolts were expected to be pushed away from the blast and pulled upward. It was thought that the two anchor bolts near the center of panels A4 might possibly shear off at the top of the foundation.

It was anticipated that the end-wall panels would be most severely damaged at their connections, with possible pulling out of the insert plates at these locations. The end-wall panels adjacent to the front walls were to suffer the 


\section{SERRET}

greatest damage. Here the end anchor bolt would be elongated and bent in the direction of the blast. This bolt, however, was not expected to fail in shear. Elongation and bending of alternate anchor bolts along the end walls were expected, the amount of elongation being less for those bolts toward the rear of the building. Little damage was expected in the slabs of endwall panels due to bending, but shear cracks radiating from the points of connections were believed to be possible.

The top insert plate at the front wall of the end-wall panels, together with reinforcement attached to these plates, was expected to pull away from the short edge beam at this location. Damage to the roof panels would be most severe at the edge beam of the panels adjacent to the front wall. Cracks in the slab adjacent to the insert connection plates were expected, increasing in severity toward the ends of the building.

Damage to the panels of the rear wall would be minor and confined largely to the connections to the roof panels and bents.

The center bent was expected to be damaged most at the columns just below the haunches, the damage at the front wall being most severe. Here large cracks were expected at the inside face of the front column and on the outside face of the rear column. Separation of the channels forming the bent was expected to occur throughout and would be most severe at the front column. The bolt at the front face shown just below Sec. 13-13 in Fig. D.5 was expected to exhibit the greatest elongation and possibly to fail in tension. In the case of the horizontal member, the opening between the channels was expected to be on the top. At the footings a separation of the precast elements from the foundation concrete was expected to take place, particularly at the front column where, in addition, a small amount of uplift was also expected. Lateral shifting of both columns was expected to be small.

It was thought that damage to the end bents would be similar to that of the center bent but would be less severe owing to the rigidity provided by the end-wall panels. It was anticipated, however, that the channels forming the frontwall columns of these bents might separate more than those of the center bent, because of the twisting effect of the load transfer from the front-wall panels.
Had the anticipated pressures been 20 per cent greater, the damage would have been much more severe than just described, causing failure of the panels marked $\mathrm{A} 3$ and the roof panels and possible collapse of the structure.

\section{C.4 STRUCTURE $3.2 .2 \mathrm{~b}$}

\section{C.4.1 Framing Arrangement}

Structure $3.2 .2 \mathrm{~b}$ is a typical one-story brick building with a timber roof. The entire structure is covered with precast-concrete panels to afford protection against atomic blast. This structure was included in the program to determine the extent of protection afforded by precast panels.

This structure, rectangular in plan, has a length of $43 \mathrm{ft}$, a width of $21 \mathrm{ft}$, and a height of $11 \mathrm{ft} 6$ in. above grade. Brick walls, 12 in. thick, extend $2 \mathrm{ft} 6$ in. below grade and are supported on a continuous footing pad $2 \mathrm{ft} 6 \mathrm{in}$. wide and $1 \mathrm{ft}$ thick. A 12 - by 12-in. reinforcedconcrete strut joins the long sides of the footing pads at about the center of the structure.

The roof of the primary structure consists of 1-in. sheathing supported by 3 - by 12 -in. joists spaced 16 in. on centers and spanning the short direction of the brick walls. The joists are stiffened by typical bridging at the third points; they are connected to the brick wall by means of short 2- by 6-in. members embedded in the wall and by toenailing into a continuous 3 - by 6 -in. plate which is anchored into the brick wall.

Precast ribbed roof panels $2 \mathrm{ft} 73 \%$ in. wide span the roof in the short direction and are supported on the roof sheathing along the edge beams and at the ends rest on the precast wall panels. The edge beams are 6 in. deep and, with the 4-in.-deep subbeams, form approximately square subpanels of the $1 \frac{1 / 4}{4}$-in. slab. Each slab is connected to the timber roof framing by means of two $\% / 8$-in. bolts spaced at the third points of the slab. Each bolt passes through a boss cast in the slab and extends through the sheathing to a continuous 3 - by 6 in. member which is below, and attached to, the joists. The roof panels are connected to each other and to the wall panels by welding connection plates to insert plates cast in the slabs and welded to the reinforcement. 
The precast wall panels are of the same type as the roof panels and have their long edges in the vertical direction. They are supported by and connected to a curbing which rests on the foundation pad and extends 6 in. above grade. The curb connection to the panel is made by welding an angle, 3 by $2^{1 / 2}$ by $1 / 2$ in., to insert plates cast in the panels. The angle is anchored to the curb by means of two $3 / 4$-in. anchor bolts. Connections to the brick wall are made in the same manner as in the case of the roof panels to the timber roof, except that here the bolts have 6 - by 6 -in. washers bearing on the inside surface of the brick walls.

Entry to the interior of the structure is provided by means of a door panel cast in one of the end-wall panels at an opening in the brick wall provided for this purpose.

Plans, elevations, and details of design for this structure are shown in Figs. D.7 and D.8.

\section{C.4.2 Design}

The basic structure comprising the brick walls and the timber-framed roof was designed for a live load of $40 \mathrm{psf}$. The wind loading did not govern any part of the design. The precast panels used to cover the basic structure were made similar to those of Structure 3.2.2a. Connections of the panels to each other were designed for the expected blast loading.

Specifications for concrete, reinforcing bars, wire mesh, and welding are the same as for Structure 3.2.2a.

\section{C.4.3 Analysis for Blast}

Pressure-time curves for the shock wave are identical with those used for the analysis of Structure 3.2.2a. Inasmuch as the structure was oriented so that the long walls are normal to the shock front, the panels receiving greatest load are those on the front wall. The analysis for these panels was made in the same manner as for the front-wall panels of Structure 3.2.2a. Here, however, the weight of the brick wall adjacent to the panel is included in the total weight, since the panels cannot deform without moving the bricks behind it. In the case of a subpanel, deformations can take place without motion of the brick wall, and the mass associated with the subpanel is that of the $1 / 4$-in. slab between beams only. Since these panels are of shorter length than similar panels for Structure 3.2.2a, it is apparent that the strength here is governed by the strength of the subpanels.

In the analysis for the motion of a vertical front-wall panel, the additional resistance afforded by shear in the brick wall was neglected. The $\mathbf{S}$ forces developed in the reinforcement of the edge ribs, when deformations reach the plastic stage, are assumed to be resisted by compression in the brick wall. This is admissible since the computed deformations were not large enough to destroy the load-carrying capacity of the wall in compression.

Since the main reinforcement in the roof is parallel to the blast, the analysis for roof panels given in Appendix B is not applicable. The analysis for the roof panels was based on a pressure-time curve in which the ordinates were average pressures over the entire roof in terms of the peak pressure $p_{0}$. The data for plotting this curve were obtained from Bleakney's shock-tube experiments at Princeton University. The curve was approximated by a number of straight lines so that the pressure could be readily expressed in terms of the time and thus simplify the resulting equations of motion. The curve used is shown in Fig. C.4. It is assumed that the pressure drops linearly to atmospheric at the end of the period of overpressure. The analysis is made in the same manner as for the front-wall panels, with due allowance for the change in pressures.

The analysis for the structure as a whole is not so involved as that for Structure 3.2.2a, since no complications are introduced by the bents. Resistance to motion is afforded by the rigidity of the end walls, together with the roof acting as a horizontal girder. The torsional resistance of the end-wall framing is small and was neglected in the analysis.

That part of the resistance to motion contributed by the brick end walls was assumed as constant and its value taken at 100 psi as shear in mortar joints. The resistance of the endwall panels and the roof panels to lateral motion was computed in the same manner as for Structure 3.2.2a.

\section{C.4.4 Anticipated Damage}

Damage to the structure from a bomb of the strength predicted for the test was estimated to 

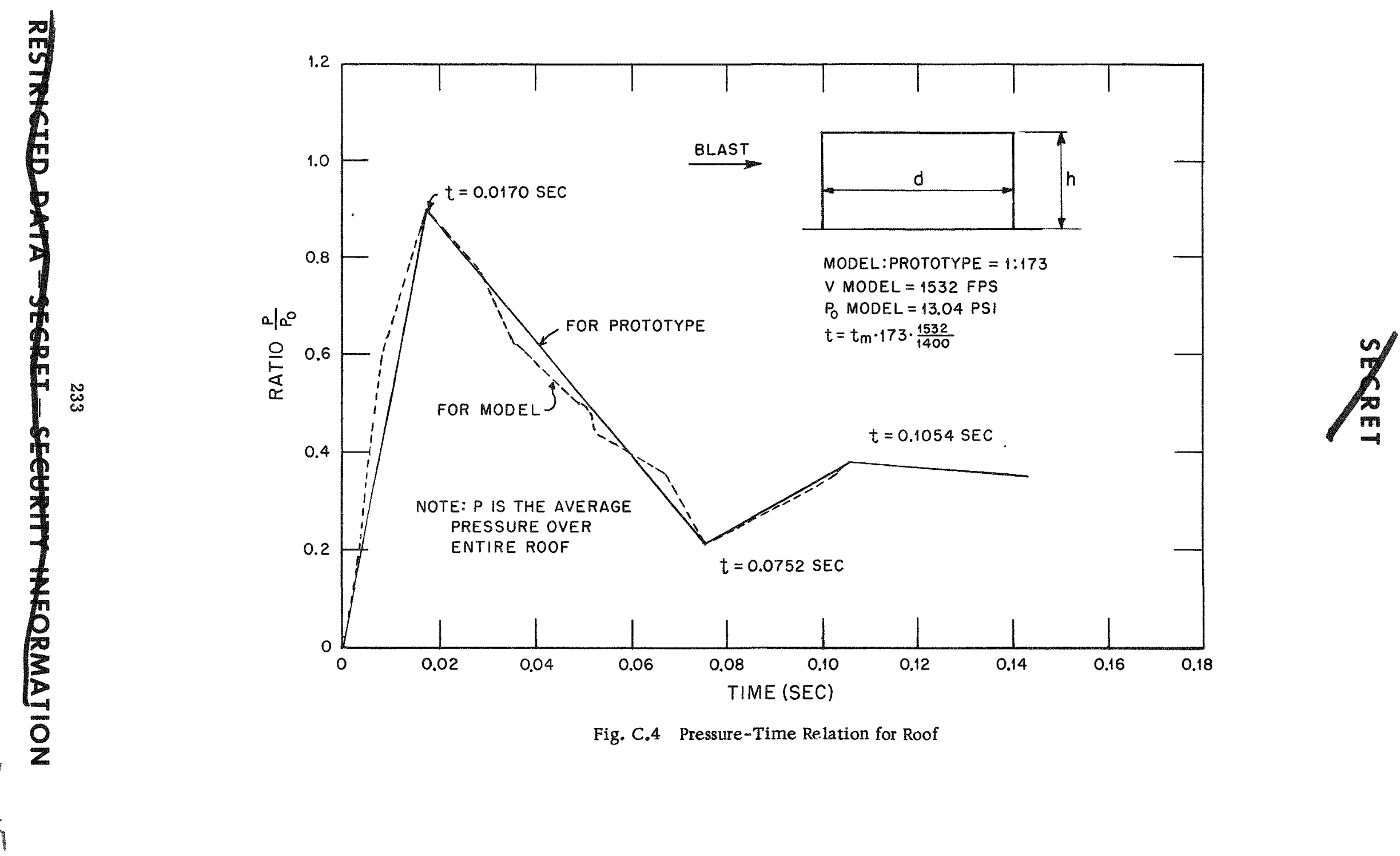

Fig. C.4 Pressure-Time Relation for Roof 
be most severe on the front face. Extensive cracking of the concrete of the edge beams and of the slabs adjacent to the edge beams was expected to occur. Breaking of the concrete with possible pulling out of the insert plates adjacent to the anchors in the foundations, particularly for the front-wall panels adjacent to the end walls, was expected. Anchor bolts near the ends of the front wall were expected to elongate and bend because of the forces producing uplift and also because of the tendency of the angle at the anchor bolts to rotate. Shearing off of nuts at these locations was thought to be a possibility. Damage to anchor bolts and to the concrete surrounding the insert plates adjacent to the anchors was expected to be less severe toward the center of the front face.

The edges of the end-wall panels near the front wall were expected to move upward, producing large shearing stresses between adjacent panels and possibly dislodging some plates from the surrounding concrete. This condition was expected to be most severe in the end-wall panel adjacent to the front wall.

Only minor damage was expected to occur to the roof panels with the possible exceptions of the short edge beams to which the front-wall panels were connected. It was expected that cracks would occur here and that the concrete would break up to some extent in the slabs next to the inside face of the end edge beams. Damage of this type was expected to be most severe in the panels nearest the end walls. Cracks around the insert plates connecting roof panels were expected to occur, with possibly some breaking out of the plates on the panels nearest the end walls.

It was thought that damage to the primary structure would be confined to the walls. Little or no damage to the timber framing, with the possible exception of the connections to the front and rear brick walls, was anticipated. The front brick wall was expected to dish inward, with large shear cracks occurring in the mortar joints. The walls were expected to remain intact except at the locations of the bosses on the precast slabs of the front wall, where individual bricks or a small section of bricks adjacent to the connection was expected possibly to fall. Damage to the brickwork of the side walls was expected to consist of large shear cracks in the mortar and some motion of the upper layers of brick relative to the lower portion in the direction of the blast. Damage to the rear brick wall was expected to be minor and confined to the regions of the brickwork around the washers holding the precast slabs to the walls.

If the anticipated pressures had been 20 per cent greater, the damage would have been much more extensive and severe than just described. Elongation and bending would occur in all the anchor bolts along the front wall instead of in those nearest the end walls only. In addition, damage to the edge beams would be more severe, and breaking up of some subpanels, particularly those near the center of the frontwall slabs, would occur. The greatest difference in the extent of damage from that described for the bomb strength used, however, would be to the brick walls. There would be a possibility of large areas of bricks near the top of the front walls falling inward, with consequent partial collapse of the roof. It is expected that the timber framing, because of its large resilience, would not be damaged except indirectly by failure of the front brick wall.

\section{C.5 STRUCTURES 3.2.3a AND b}

\section{C.5.1 Framing Arrangement}

Buildings 3.2.3a and $b$, constructed of precast-concrete elements, conform to a new type of protective structure developed by the Bureau of Yards and Docks of the Navy Department.

The precast panels which, in assembly, form the structure were composed of precast-concrete cells cast between two slabs of concrete. Each cell is a rectangular box-shaped unit of $5 / 8$-in.-thick concrete, open at two opposite faces, having outside dimensions of 16 by 16 by $8 \mathrm{in.}$ Three of the faces have openings or holes, and the fourth face, one of the 16- by 16-in. faces, has a recess of the same size as the hole in the opposite face, but extending only about half the thickness of the concrete shell. Reinforcement for the cells consists of $2-$ by 2-in. 12 -gauge welded-wire mesh, placed in the center of the cell walls and continuous across the openings.

A typical panel assembly in the position in which it is cast consists of a bottom concrete slab $1 \frac{3}{8}$ in. in thickness, four rows of cells 
with the recessed faces on the top, and a top slab of concrete also $13 / 8$ in. in thickness, making the total depth of the panel $10^{3} / 4$ in. The cells are oriented in a checkerboard pattern, with the open ends of adjoining cells alternating in direction. The cells are spaced $13 / 8$ in. between rows. Running in the long direction of the panel is a steel bar truss. The trusses extend beyond the ends of the cast panels and are connected to similar trusses on other panels forming the structural assembly. Reinforcement for the upper and lower slabs consists of 2- by 2-in. 12-gauge welded-wire mesh, alternate wires of which are spot-welded to the top and bottom chords of the trusses. This mesh extends out from the sides and ends of the panels to serve as anchorage in the completed assembly.

A concrete stop of sheet metal is welded to the diagonal members of the truss near the top to prevent the concrete from filling the spaces between cells in the long direction. In the short direction between cells, the concrete stops consist of short pieces of wood. The cells are pushed into the bottom slab concrete as it is poured, so that the concrete is forced into the bottom openings and between the cells flush with the inner surface of the bottom face of the cells. The top slab is poured on the surface formed by the cells and the concrete stops. The holes in the bottom of the cells and the depressions in the top of the cells serve to key these elements into the slabs.

In assembling the panels to form the structure, a bar truss identical with those cast into the panel is placed between the precast panels; alternate projecting wires from each adjoining panel are spot-welded to the truss; and the space between panels is filled with grout.

The structural assembly consists of seven roof panels, spanning in the short direction, supported on similar panels in the long walls. The wall panels have their long edges vertical, and the trusses of these panels are welded to the trusses in the roof panels. The end-wall panels are also placed in a vertical position, and the vertical trusses here are welded to short trusses which extend out from the end roof panels. These short trusses are, in turn, welded to the long trusses of the end roof panels before the casting of these panels. A bar truss (T-7 in Fig. D.12), with chords twice the area of the typical truss, extends for the full length of the structure on each of the long edges of the roof. These trusses are welded to both the roof and wall trusses at their intersections.

All edges of the roof where the trusses extend out of the precast slabs are enclosed with concrete, poured in place during the assembly. The extending wires of the mesh are spliced by similar mesh extending along the upper edges of the roof. The treatment of the vertical corners is the same as at the roof edges.

The foundations under the walls consist of continuous pads of reinforced concrete $3 \mathrm{ft}$ deep, $2 \mathrm{ft} 9 \mathrm{in}$. wide on the long walls and $2 \mathrm{ft}$ 8 in. wide on the short walls. A 6-in. -thick slab, poured on a rolled surface and reinforced by $3 / 8$-in. bars at 6 in. on centers both ways, is connected by dowels to the concrete foundation pads.

The vertical wall panels are assembled in a recess $5 \frac{1}{2}$ in. deep in the foundation pad and are connected to the foundations by means of two $7 / 8$-in. anchor bolts at each wall truss. The wall trusses are welded at their bottom ends to a reinforced channel which fits over the anchor bolts. After assembly of the panels the recess in the foundation is filled with grout.

Structures 3.2.3a and $\mathrm{b}$ are identical. Plans, elevations, and details of the design are shown in Figs. D.9 to D.12.

\section{C.5.2 Design}

The framing arrangement of Structures 3.2.3 $a$ and $b$ is similar to that of Structure 3.2.1b. In this case the elements contain a single-layer cell assembly and thus offer small resistance to impact penetration. However, the arrangement is expected to provide high resistance to blast.

The roof trusses, except for trusses T-7, were designed in the usual manner for live loads of 40 psf. The connections, however, were increased in strength above that required in normal construction.

Truss $\mathrm{T}-7$ at the rear wall on the long side of the building is required to resist tension in the roof acting as a girder under the blast loading. A similar truss is used at the front wall to make the roof framing symmetrical.

Specifications governing the materials of the framing are as described for Structure 3.2.2a. 


\section{SAYRET}

\section{C.5.3 Analysis for Blast}

Pressure-time curves for Structures 3.2.3a and $b$ are the same as for Structure 3.2.2a. Here again the long walls of the structures are normal to the blast wave, and a factor of 2 is used with the peak overpressure $p_{0}$ to obtain the initial reflected pressure.

The resistance of the front-wall panels to blast was determined by the method described in Appendix B. Inasmuch as the beams of the front edge of the roof, formed by trusses T-7 and the poured-in-place concrete, cannot develop the full value of the $S$ forces of the wallpanel vertical trusses, the resistance-deflection diagram for this case was modified from that shown in Fig. B.2. It was assumed that the resistance of a front-wall panel would remain constant throughout the deformation, after the resisting moments at yield-point strength had been reached at the ends and center of the panel. In other words, the resistance line $\mathrm{BC}$ of Fig. B.2 does not change direction at $\mathrm{C}$ but continues to be horizontal.

Since the main reinforcing of the roof is parallel to the blast, the analysis for roof panels was made in the same manner as that given for Structure $3.2 .2 \mathrm{~b}$.

In the analysis of the structure as a whole, the point of reference for $y$ was taken at the top of the front wall at the center of the building. Values of the constants $\beta^{\prime}$ and $\beta_{1}^{\prime}$ were determined on the assumption that the relative motion of the center of the roof, in the direction of the blast, with respect to the ends of the roof would be small in comparison with the total over-all motion of the roof in relation to the foundation.

With this assumption $\beta^{\prime}$ becomes $1 / 2$ and $\beta_{1}^{\prime}$ is determined from the following relation:

$$
\beta_{1}^{\prime}=\frac{1}{W}\left(W_{\mathrm{r}}+\frac{W_{W}}{3}\right)
$$

where $\mathrm{W}=$ total weight of structure

$\mathrm{W}_{\mathrm{r}}=$ total weight of roof

$\mathrm{W}_{\mathrm{W}}=$ total weight of walls

The equation of motion (Eq. C.1) is then

$$
\beta^{\prime} A(p-q)=\beta_{1}^{\prime} \frac{W}{g} \alpha
$$

where $A=$ area of front wall

$$
\begin{aligned}
\mathrm{p}= & \text { net pressure on structure in the } \\
& \text { direction of motion } \\
\mathrm{q}= & \text { resistance }
\end{aligned}
$$

The value of $\mathrm{p}_{0}$ used to determine $\mathrm{p}$ in the equation just given is that found from the analysis of the front-wall panels.

An approximate value for the resistance $q$ in Eq. C. 1 may be found by assuming that the end walls act as short cantilevers having flanges of a portion of the long walls, assumed as $5 \mathrm{ft}$ wide at each end. The relation in the elastic range is then given by

$$
q=\frac{8 E_{c} I^{\prime}}{A h^{3}} y
$$

where $I^{\prime}$ is the moment of inertia of cantilevers, and $A$ is the surface area of the front wall. In the plastic range the resistance $q$ is independent of $y$ and may be expressed by

$$
\mathrm{q}=\frac{2 \mathrm{M}_{\mathrm{r}}}{\mathrm{Ah}}
$$

in which $\mathrm{M}_{\mathrm{r}}$ is the resisting moment at yieldpoint strength of the beams formed of the end walls as webs and the 5 - $\mathrm{ft}$ portions of long walls as flanges. This approximate method, employing various lengths of flanges, was used to estimate the maximum motion of the building as a whole.

It is to be noted that Eq. C.1 is an exact expression for the motion of the structure, provided that $\beta^{\prime}, \beta_{1}^{\prime}$, and $q$ are exact, and the equation becomes approximate to the extent of the approximations made in the values of the constants. In order to arrive at a more exact value of these constants than those employed above, an analysis of the deformations of the roof and all walls due to a uniform load on the front wall in the elastic and plastic ranges would have to be made. Such an analysis would require assumptions as to conditions of restraint at the boundaries of the slabs and other physical characteristics. Although admittedly such an analysis might result in better approximations for the constants, the rather involved work required for it is not warranted, particularly since the strength of the front-wall panels, and not the motion of the structure as a 


\section{SERET}

whole, is the criterion of the ability of this structure to resist atomic blast.

Maximum lateral shears in the roof were computed on the assumption that the reaction of the wall loads at the roof followed a cosine curve, with a maximum ordinate at the center line of the building. It was further assumed that pressure loads on the transverse or vertical center line of the front wall were carried equally to the roof and foundations. Then the maximum ordinate of the reaction curve is $2 \mathrm{p}_{0} \times \mathrm{h} / 2$ or $\mathrm{p}_{0} \mathrm{~h}$, where $\mathrm{p}_{0}$ is the peak overpressure and $h$ is the height of the building. The maximum shear, $V$, in the roof is then given by

$$
\mathrm{V}=\mathrm{p}_{0} \mathrm{~h} \int_{0}^{l} \cos \frac{\pi \mathrm{x}}{\mathrm{L}}
$$

or

$$
\mathrm{V}=\frac{\mathrm{L}}{\pi} \mathrm{p}_{0} \mathrm{~h} \sin \frac{\pi l^{\prime}}{\mathrm{L}}
$$

where $\mathrm{x}=$ displacement measured from center line of building

$\mathrm{L}=$ total length of building

$l^{\prime}=$ distance from center line of building to inside face of end wall

The maximum shear at the base of the end wall, $v_{1}$, is given by

$$
\mathrm{V}_{1}=\mathrm{p}_{0} \mathrm{hL}\left(1-\frac{1}{\pi}\right)=0.682 \mathrm{p}_{0} \mathrm{hL}
$$

If the ends of the roof acting as a girder are assumed to be 50 per cent fixed and subject to the load defined by the cosine curve given above, the lateral deflection $\mathrm{y}^{\prime}$, including deformations due to shear, at any point of the roof can be computed in terms of $p_{0}, h, E_{c}$, and I, where $E_{c}$ and I have their usual meaning. In addition, the moment $M_{X}$ and shear $V_{X}$ can also be determined for any point. If $\mathrm{k}_{\mathrm{x}}$ represents the ratio of the deflection at any point to the center-line deflection and if $w$ represents the weight of the roof per unit length, the kinetic energy $K$ of the roof during motion may be expressed as

$K=\left(\frac{d y}{d t}\right)^{2} \sum \frac{\left(k_{x}\right)^{2} w d x}{2 g}=c_{k} \frac{W}{2 g}\left(\frac{d y}{d t}\right)^{2}$ where $W$ is the total weight of the roof and $C_{k}$ is a constant. The strain energy $U$ is given by

$$
\mathrm{U}=2 \int_{0}^{l / 2} \frac{\mathrm{M}_{\mathrm{X}}^{2}}{2 \mathrm{EI}} \mathrm{dx}+2 \int_{0}^{l / 2} \frac{\mathrm{V}_{\mathrm{X}}^{2} \mathrm{dx}}{2 \mathrm{~A}_{\mathbf{r}} \mathrm{G}}
$$

or

$$
U=\frac{\left(p_{0} h\right)^{2} I^{5}}{2 E I \pi^{4}}\left(\frac{1}{2}-\frac{3}{\pi^{2}}\right)+\frac{\left(p_{0} h\right)^{2} L^{3}}{4 A_{r} G \pi^{2}}
$$

in which $A_{r}$ is the cross-sectional area of the roof and $G$ is the shear modulus. Since the center-line deflection $\mathrm{y}$ may be expressed in terms of $p_{0}, h, L, E, I, A_{\mathbf{x}}$, and $G, E q . C .32$ may be written in terms of $y^{2}$ as

$$
\mathrm{U}=\mathrm{c}_{\mathrm{u}} \mathrm{y}^{2}
$$

where $c_{\mathrm{u}}$ is a constant. The work $\mathrm{dW}$ done on the roof by the pressure load in the distance dy is given by

$$
d W=\left(\sum k_{x} p_{0} h \cos \frac{\pi x}{L} d x\right) d y
$$

or

$$
d W=c_{W} p d y
$$

in which $\mathrm{c}_{\mathrm{W}}$ is another constant and $\mathrm{p}$ is the pressure on the front wall or the net pressure on the front and rear walls tending to move the roof in the direction of the blast.

The change in the kinetic energy during the interval $\mathrm{dy}$ is found by differentiating $\mathrm{Eq}$. C.31, or

$$
d K=c_{k} \frac{W}{2 g} 2 \frac{d^{2} y}{d t^{2}} d y
$$

and the change in the potential energy is given by

$$
d U=c_{u} 2 y d y
$$

Since the work done in the interval dy is equal to the change in kinetic and potential cyergies, it may be seen from Eqs. C.35 to C.37 that

$$
c_{w} p=c_{k} \frac{W}{g} \frac{d^{2} y}{d t^{2}}+2 c_{u y}
$$


Equation C. 38 is the equation of motion of the roof, relative to the end walls, in the elastic range under the assumed conditions of loading and restraint and is solved for $y$ by methods explained in Appendix B.

Motion in the plastic range will begin after the ultimate resisting moment is reached at the center of the span. The equations of motion in this range are then determined by the same methods as explained in Appendix B.

Equation C. 38 expresses the motion of the center of the roof with relation to the end walls. The total motion of the center of the roof is then the motion as given by this equation plus the motion of the end walls as given by Eq. C.1.

The foregoing analysis was made for Structure $3.2 .3 \mathrm{~b}$ to determine its distance from ground zero. Structure 3.2.3a was arbitrarily placed at a closer distance.

\section{C.5.4 Anticipated Damage, Structure 3.2.3b}

Damage to Structure 3.2.3b was expected to be most severe on the front wall. Here cracking of the concrete was expected to occur over the whole wall; the largest cracks or breaking of concrete were expected to occur on the inside faces of the wall panel at midheight and on the outside faces near the top and bottom. It was thought that the concrete cover over the vertical trusses would be lost at these locations and the trusses would be bent; Panels P-3a and $P-3 b$ would be sheared from their connections to the end walls; and the separation or lateral shift would be greatest at midheight, tapering off toward the roof and the foundation. Cracking and breaking out of the poured-in-place concrete at the corner of the building was expected to occur at these locations. It was thought that the mesh reinforcement here might be sheared off or pulled out to some extent.

Vertical joints of the front wall were expected to be most severely damaged on the inside faces of the panel connections. Some of this concrete was expected to spall and fall by the force of the initial blast impact.

It was anticipated that grout poured in the foundation slot would crack and dislodge on the front side and crush on the inside. The channels to which the vertical trusses were welded were expected to be bent at the anchor bolts. It was expected that the outside line of anchor bolts on the front wall would be pulled out slightly and bent in the direction of the blast; the inside line of anchor bolts would be pushed inward and bent. The ends of the front wall at the foundations were expected to rise slightly, exposing the dowels and mesh at these locations.

Damage to the roof was expected to be much less severe than that to the front wall. The largest cracking or destruction of concrete of the roof was expected on the upper part of the panels near the front wall. Less severe cracking was expected on the inside faces of the panels near the center of the building. The two transverse grouted joints near the center of the building were expected to remain intact or show only slight cracks near the rear wall. However, the other joints in the roof were expected to show cracks throughout or possibly separate on the inside surfaces of the panels. In addition, shear cracks in the $1 / 8$-in.-thick slab concrete of the panels were expected to occur, the roof panels near the ends of the buildings suffering most damage of this type.

The end-wall panels were expected to be damaged in a manner similar to those of the front wall but only to a minor degree. Cracking of the concrete here was expected to be most severe at the outside faces of the panels near the roof.

Damage to the precast-concrete cells was expected to be slight. Only those cells adjacent to the poured-in-place vertical edges, to the front edge of the roof, and to the front wall at the foundation were expected to have through cracks or be otherwise damaged.

Had the anticipated pressures been 20 per cent greater, the result would have been a corresponding increase in the damage to the structure as described above, but this would not have caused the buildings to collapse or the front-wall elements to fail, except for possible separation of individual cells of panel assemblies.

\section{C.5.5 Anticipated Damage, Structure 3.2.3a}

Damage to Structure 3.2.3a was expected to be very severe. It was anticipated that the nature of the damage would be as described for Structure $3.2 .3 \mathrm{~b}$, except that it would be greater in extent and there would be more failures in the concrete. Opening of all the grouted joints in the roof on the underside of the panels and 
breaking out of concrete at the top face adjacent to the poured-in-place edge beams were both expected to occur. In addition, some of the anchor bolts at the front face were expected to fail by combined shear and bending.

Had the anticipated pressures been 20 per cent greater, the result would have been the collapse of the structure by failure of the frontwall panels. These panels would have been pushed inward, shearing their connections to the foundation, and some of the cells would have been bodily dislodged. Connections of the front-wall panels to the roof panels would probably not have been broken, but the inward motion of the front wall would have pulled the roof panels down. The truss connections of the side-wall panels to the roof trusses nearest the end walls would have caused the roof to break apart at these locations, and the side walls would have leaned toward the center of the building but would probably have remained standing.

\section{C.6 STRUCTURE 3.2 .42}

\section{C.6.1 Framing Arrangement}

Structure 3.2.4a, of precast-concrete design, was recently developed by the Bureau of Yards and Docks for use as a magazine. The main framing consists of pairs of cast panels with wedge-shaped edge beams, bolted together at the center or crown of the building and also bolted to the foundation. The precast panels have a nominal width of $4 \mathrm{ft}$, and 10 pairs are used to form a structure $40 \mathrm{ft}$ long, $20 \mathrm{ft}$ wide on the inside between the vertical portions of the slabs, and $12 \mathrm{ft} 6 \mathrm{in}$. high at the crown.

The panel slabs are 2 in. thick and are reinforced with 2 - by 2 -in. 8 -gauge welded-wire mesh. End edge beams and subbeams divide the slab into approximately square subpanels. Connections of the panels to each other are made by means of bolts passing through pipe sleeves in the edge beams.

The structure is covered with an earth fill to a depth of $2 \mathrm{ft}$ over the roof. The fill follows the slope of the roof panels and at the sides and rear of the building has a slope of 1.5 to 1.0 . The earth fill is retained from the front of the building by wing walls.
The rear wall consists of three flat precast panels having a 2-in. -thick slab stiffened by 10-in.-deep edge beams and by a 10-in.-deep vertical beam in the center. The top edges of the assembled panels follow the outline of the frames. The front wall consists of similar panels with 6-in.-deep edge and stiffening beams. These panels extend about $2 \mathrm{ft}$ above the roof to retain the fill and are contiguous with wing-wall panels. The wing-wall panels are buttressed by means of precast panels set normal to the plane of the wing walls and covered by the fill. All end-wall panels are bolted to each other and to the building frame and foundations through pipe sleeves cast in the edge beams.

The foundation consists of a continuous reinforced-concrete pad $2 \mathrm{ft}$ deep and $2 \mathrm{ft} 6 \mathrm{in}$. wide. The precast panels making up the frames are placed in 2 -in.-deep slots in the foundation, whereas end-wall panels are set flush with the top of the foundation pad. A reinforced-concrete tie or strut connects the long sides of the pad near the center of the structure.

The floor slab, consisting of precast panels framing in the short direction of the building, is supported and attached to the foundation pad by bolting. The floor panels have 2 -in.-thick slabs reinforced with wire mesh and 6-in. -deep edge and subbeams.

Plans, elevations, and details of the design are shown in Figs. D.13 and D.14.

\section{C.6.2 Design}

The analysis of the main framing for the design loads was made on the assumption that the frames were hinged at the crown and at the supports. The weight of the earth cover was assumed to be $100 \mathrm{lb} / \mathrm{cu} \mathrm{ft}$, and lateral pressures due to the fill were computed in the usual way. The design of the slabs of the panels was governed by the earth pressure near the base, and the required thickness and reinforcing here were made uniform throughout the remainder of the panel. The main tensile reinforcement for the frames is placed in the edge beams, and the depth of these beams roughly follows the stress pattern.

The rear end-wall panels and the wing walls were designed to resist the earth pressure at those locations, and the front-wall panels were 
made similar except for the depth of the edge beams. The size of bolts used in the connections was increased above that required for ordinary construction.

Specifications for the materials of construction are the same as those described for Structure 3.2.2a.

\section{C.6.3 Analysis for Blast}

The variation of pressure with time due to atomic blast for the walls and roof of a structure of this shape and covered by an earth fill is not known. It was assumed that the reflected pressures on the vertical portions of the long side, oriented so that they would be normal to the blast wave, would be similar to those for a rectangular structure. Here, however, the earth cover would reduce the effective pressure acting on the structure. It was assumed that the pressure on the vertical portion of the front wall was equal to the reflected pressure times the cosine of the angle made by the fill with the vertical. For the sloping roof surface above the haunch, the maximum pressure was assumed to be the peak overpressure.

Pressures on the front vertical wall were assumed to vary as indicated in Fig. B.5 but modified as described in the preceding discussion. The time $t_{1}$ was computed as before, assuming $\mathrm{h}$ in this case to be the total height of the structure plus the fill. On the sloping surface the pressure was assumed to vary uniformly from the peak overpressure to zero at the end of the period of overpressure.

On the back side of the structure, pressures for the sloping roof surface were taken as indicated in Fig. B.7. For the rear vertical wall the same pressures were used except that they were modified by the slope of the earth fill as in the case of the front wall.

The strength of the local subpanels of the frames was determined as described for Structure 3.2.2a. Here the most critical panels were located on the sloping surface of the front part of the roof. In the computations the mass of the earth cover was included in the mass of the panel.

Resistance to motion of the structure as a whole is provided by the end-wall panels acting together, by the passive resistance of the earth fill, and by the frames. An analysis of the mo- tion of the center frames was made on the assumption that they received no help from the end walls. The analysis was made in the same manner as described for the roof of Structure 3.2.2b, except that deformations due to shear were not considered here. In this analysis it was assumed that pressures on the front wall and the sloping portion of the roof were applied simultaneously. The mass of earth moving with the structure included only the earth on the roof.

\section{C.6.4 Anticipated Damage}

It was anticipated that damage to this structure resulting from the test would be most severe on the frames near the crown of the roof. Cracking and breaking out of concrete in the edge beams at the crown was expected to be greatest at the bolt locations. The bolts here were anticipated to be bent and elongated and possibly fractured. Less severe cracking of edge beams was expected in the region of the haunches. Cracks on the inside faces of the edge beams and for a portion of the slabs were expected to occur on the side facing the blast. On the side away from the blast, cracks at the haunches were expected to occur at the outside edges of the beams.

Cracking of the 2-in. concrete slabs was expected to be most general in the sloping portions of the roof where the earth cover was smallest. At the knees of the frames, cracking of the panels was expected to be greatest on the front side.

The vertical-wall panels were not expected to be severely damaged. The concrete of the edge beams here was expected to be cracked at the connections to the frames and foundations, and shear cracks were expected in the 2-in.thick panels. The wing-wall panels were expected to be pushed out slightly away from the fill and to be cracked at the edge-beam connections. Damage to the floor panels was expected to be minor and confined to a small amount of cracking at the connections to the foundation pad.

Had the anticipated pressures been 20 per cent greater, the damage would have been more severe than just described, but a collapse of the structure would not have been anticipated. 


\section{C.7 STRUCTURE 3.2.4b}

\section{C.7.1 Framing Arrangement}

Structure 3.2.4b is similar to Structure 3.2.4a, having the same framing arrangement and outside dimensions, but it has no earth cover or wing walls. Of the 10 frames comprising the main structure, five have edge beams or ribs extending outward from the slabs of the precast panels, and five have ribs extending inward. Frames with outward ribs are on one side of the transverse center line of the building, and those with inward ribs are on the other side of the center line. In the center frame of each group the transverse stiffening ribs are omitted.

The foundation consists of a continuous pad similar to that for Structure 3.2.4a and has two reinforced-concrete struts connecting the long sides at about the third points. Floor panels are omitted at the strut locations.

Plans, elevations, and details of design are shown in Fig. D.15.

\section{C.7.2 Design}

Frames of this building are of the same type as those designed for Structure 3.2.4a.

\section{C.7.3 Analysis for Blast}

Analysis for blast was made in the same manner as for Structure 3.2.4a, except that the effects of the earth fill were omitted.

\section{C.7.4 Anticipated Damage}

As in the case of Structure 3.2.4a, damage to the concrete was expected to be most severe at the crown and haunches of the structure. Through cracks in the edge beams were expected to occur at these locations. Cracking of edge-beam concrete was also expected at the connection to the foundations. A lateral shift in the direction of the blast was expected at the foundations, accompanied by breaking of the concrete at the corners of the slot in the foundation away from the blast and by bending and elongation of the front anchor bolts.

Damage to the 2-in. panels was expected to be most severe in those sections where the stiffening ribs were omitted. Extensive damage to the concrete slabs along the edge beams was expected to occur. Large through cracks were expected at these locations.

Damage to the end-wall panels was expected to be similar to that described for Structure 3.2.2a but more severe in this case, particularly at the connections to the frames.

Had the anticipated pressures been 20 per cent greater, the damage would have been much more extensive than just described, with possible collapse of the center portion of the structure.

\section{C.8 STRUCTURE 3.2.5}

\section{C.8.1 Framing Arrangement}

Structure 3.2.5 represents another type of precast-concrete magazine developed by the Bureau of Yards and Docks. As in the case of Structure 3.2.4a, the main framing comprises 10 pairs of frames bolted together at the crown and to the foundations. Here, however, the assembled frames form a semicircle having a radius of about $10 \mathrm{ft}$, and the edge beams have a constant depth of 6 in. throughout. As in the case of Structure $3.2 .4 \mathrm{~b}$, five of the 10 frames have the ribs extending outward and the remaining five inward. Here, also, stiffening ribs are omitted on one section of each type. Stiffening ribs are of the same depth as the edge beams and divide the panel of each half frame into four approximately equal subpanels.

The end walls consist of three precast panels with their upper ends rounded to follow the curve of the frames. These panels are bolted to each other, to the frames, and to the foundation pad. Entrance to the structure is provided by a door panel inserted in the center panel at one end of the building.

The foundation consists of a continuous pad $2 \mathrm{ft} 6 \mathrm{in}$. wide and $2 \mathrm{ft}$ deep, connected at about the third points of the long sides by reinforcedconcrete struts. Floor panels, similar to those for Structure 3.2.4a, span in the short direction; they are supported and bolted at the ends in a recess in the foundation pad and are connected to it by means of three $3 / 4$-in. anchor bolts in each panel.

Plans, elevations, and details of design are shown in Fig. D.16. 


\section{C.8.2 Design}

The design of the structure was made on the basis of an earth fill covering the crown to a depth of $2 \mathrm{ft}$. The design assumptions were the same as those made for Structure 3.2.4a.

\section{C.8.3 Analysis for Blast}

The structure is oriented so that the long axis is normal to the blast wave. Shock-tube investigations by Bleakney at Princeton University, in which the disturbance to flow had a semicircular shape, provided some of the necessary pressure-time relations. The data presented by Bleakney give the pressure distribution for the shock wave passing over the obstacle and for a very short time thereafter. It was assumed that the pressures for the remainder of the positive phase would drop to atmospheric at the end of this period, varying directly with the time.

Maximum reflected pressures of about 2.3 times the peak overpressure occur on the side facing the blast up to an angle on the arc of the section of about $30^{\circ}$. (Angles are measured from the horizontal, starting from the ground line on the side in the direction of the blast.) Accordingly, the most critical section for a subpanel is a slab located in this region. A curve showing variations in the ratio of reflected pressure to peak pressure with time was constructed from Bleakney's data for a section having an angle of $15^{\circ}$, and this curve was approximated by straight lines (Fig. C.5). The total time covered by the curve was 850 $\mu$ sec for the model used in the Princeton tests, which corresponds to a time of about $0.113 \mathrm{sec}$ on the actual structure, when the velocity of the shock front is assumed at $1400 \mathrm{ft} / \mathrm{sec}$. For the time from $0.0482 \mathrm{sec}$ to the end of the period of overpressure $\tau$, the pressure was assumed to decay lineally.

For the time periods thus described, the pressures $p$ on the slab are expressed in terms of $p_{0}$ and $t$ in a manner similar to that given by Eqs. B.7 and B.8. The slab analysis was made assuming a one-way reinforced beam of $1-\mathrm{ft}$ width between the edge beams subject to the pressures as determined above. This is somewhat conservative since the effect of two-way supports afforded by the crossbeams is neg- lected. For the structure as a whole, analysis was made in a manner similar to that made for Structure 3.2.4b.

\section{C.8.4 Anticipated Damage}

Damage to this structure resulting from a bomb of the strength proposed for the test was expected to be somewhat similar to that to Structure 3.2.4b. Damage to the ribs was expected to be most severe at the crown, foundations, and quarter points. Damage to the panels was expected to be greatest in frames without cross-ribs.

Had the anticipated pressures been 20 per cent greater, the center portion of the structure probably would have collapsed. The elements near the end walls probably would not have collapsed, but they would have been severely damaged.

\section{C.9 STRUCTURE 3.2 .6}

\section{C.9.1 Framing Arrangement}

With the exception of the entrance and wing walls, Structure 3.2 .6 is built entirely of precast panels bolted together to form a dome. In plan the structure is a regular polygon of 16 sides circumscribing a circle with a radius of about $16 \mathrm{ft} 3$ in. Radial lines from the center to the vertices outline the meridian edges of the planes of the panels except for the center or top panel.

Around the center panel are four rings, each containing 16 identical precast panels, except for the two bottom rings where one of the panels in each ring is replaced by the pouredin-place entrance section. The plane of the central panel is horizontal, and its inner face is $14 \mathrm{ft}$ above the floor slab. The centers of the upper and lower edges at the inside faces of the other panels are on a vertical circle having a $14-\mathrm{ft}$ radius and a center $2 \mathrm{ft}$ off the center of the structure as shown in plan.

The edge beams of the panel are 6 in. deep and are inclined to the plane of the panels so that in assembly they fit tightly against adjacent beams. The panels are held in position by bolting through the width of the edge beams and are fastened to the foundation and entrance section by means of anchor bolts. 

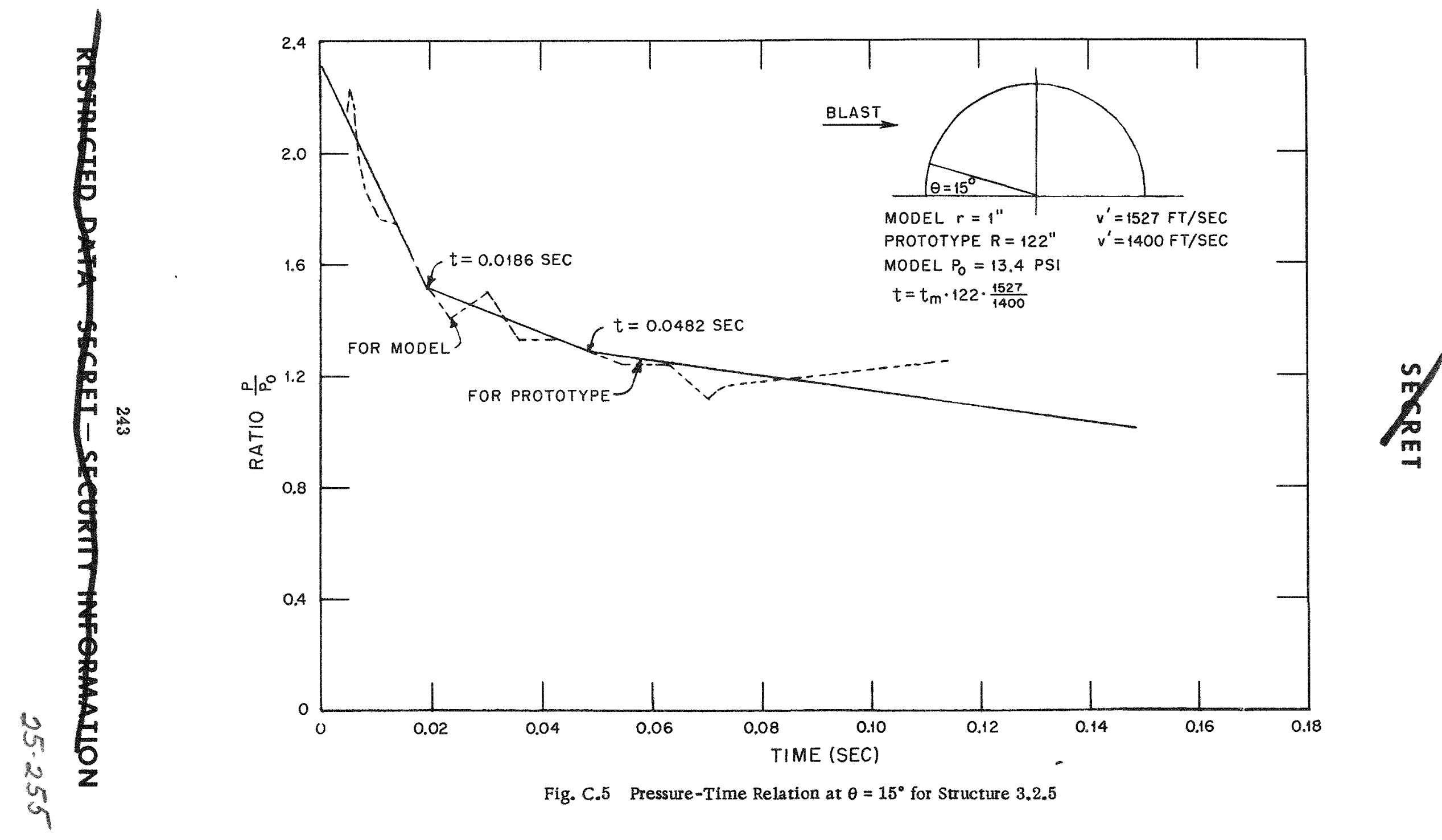

Fig. C.5 Pressure-Time Relation at $\theta=15^{\circ}$ for Structure 3.2 .5 
The structure is covered with an earth fill $2 \mathrm{ft}$ deep at the crown. The fill follows the curve of the roof until the slope is 1.5 horizontal to 1.0 vertical where it continues uniformly to grade.

The foundation consists of a continuous reinforced-concrete pad $2 \mathrm{ft} 3$ in. deep and $2 \mathrm{ft}$ 9 in. wide. A 6-in. slab poured on a rolled subgrade is doweled into the pad and made flush with its top surface.

Plans, elevations, and details of the design are shown in Figs, D.17 and D.18.

\section{C.9.2 Design}

The design of the panels was based on supporting the fill plus a nominal 10-psf live load. Since compressive stresses exist between all panels, the bolts would be required to resist components of stress parallel to the planes of separation at the edge beams. These bolts, however, were made heavier than necessary for the design loads in order to provide greater stability against blast. Panels $B, C$, and $D$ were originally designed with a vertical stiffening rib, and the thickness of the slab varied for each ring. After a preliminary blast analysis was made, the design was changed so that panels B, C, and D had slabs of the same thickness, and a horizontal stiffening rib was added. The addition of this stiffening rib permitted the thickness of the slabs to be reduced from that contemplated in the original design.

Specifications governing the materials of the design are as described for Structure 3.2.2a.

\section{C.9.3 Analysis for Blast}

Pressure-distribution curves and pressuretime curves for an atomic blast striking a structure of this shape and under an earth fill have not been determined. It was assumed that the most critical panels were those whose planes were normal to the direction of the shock wave. For these panels the pressuretime relation was assumed to be the same as for a structure of cylindrical shape.

In the analysis for the slabs of the precast panels, it was assumed that the edges did not move and that the mass of the panel was increased by the earth fill moving in the same direction as the panel. For panels $\mathrm{C}$ and $\mathrm{D}$, the amount of earth moving with the panel was assumed to be uniformly distributed over the panel, having a depth equal to the depth of fill normal to the panel at its center line. The analysis was made in a manner similar to Example 3 of Sec. B.2.2, using an average value of the span for the sloping sides.

No analysis was made of the over-all bending of the assembly. Owing to absence of pressuredistribution data applicable to this case as well as to the indeterminate nature of the structural behavior of the assembly, the magnitude of the moments produced by the unsymmetrical loading could not be determined.

\section{C.9.4 Anticipated Damage}

Damage to this structure was expected to be greatest for the upper panels. The center panel was expected to be cracked around the base of the circular edge beam on the upper side; on the lower, or inner, side it was expected to be cracked near the center. The center panel as a whole was expected to be pushed inward, and the bolts connecting it to the $A$ panel were expected to be bent. It was thought that the edge beams of panels $A$ would be cracked most severely near the top and the slabs near the center, on the inside. Panels $B$ were expected to exhibit similar cracks but to a lesser degree than on panels A. Damage to panels $C$ and $D$ was expected to be minor.

Had the anticipated pressures been 20 per cent greater, the damage to the upper panels would be correspondingly more severe than just described, and panels $\mathrm{C}$ would crack on the upper edges. Panels $D$ would be damaged to a minor degree.

This theory was predicated on the assumption that the over-all bending moments produced by the unsymmetrical loading were not large enough to cause the connecting bolts to fail and the structure to collapse. As explained, these moments could not be satisfactorily computed. It appeared that the over-all strength of this structure could best be determined by the test.

\section{C.10 STRUCTURES 3.2.7a AND b}

\section{C.10.1 Framing Arrangement}

Structures $3.2 .7 \mathrm{a}$ and $\mathrm{b}$ are conventional onestory poured-in-place concrete buildings. The 
structures are identical except for the main reinforcing steel, the amount of steel for Structure 3.2.7a being twice that for Structure 3.2.7b.

The structure is 41 by $21 \mathrm{ft}$ in plan and is $11 \mathrm{ft} 6 \mathrm{in}$. high above the foundation. The 3 -in.thick roof is supported by two beams, placed at the third points, which frame into a transverse girder at the center of the building. The main reinforcement for the roof is parallel to the short sides of the building and is bent up at the beam locations. The girder is supported by columns which are poured integrally with the 6-in. walls. The principal wall reinforcement runs in the vertical direction and consists of $3 / 8$-in. bars placed in the center of the wall on 6-in. centers for Structure 3.2.7a and on 12-in. centers for Structure $3.2 .7 \mathrm{~b}$.

The foundation, which is carried to a depth of $3 \mathrm{ft}$ below grade, is in the shape of an inverted $T$ in cross section and is made continuous. The foundation is widened at the column locations. A reinforced-concrete tie at the top of the foundation connects the long sides at the transverse center line. A second tie, used for instrumentation, is placed at the quarter point.

Plans, elevations, and details are shown in Fig. D.19.

\section{C.10.2 Design}

The design criteria for these structures were the same as for Structure 3.2.2a.

\section{C.10.3 Analysis for Blast}

The analysis for these structures was made in the same manner as for Structure 3.2.3a, except for loads normal to the roof surface. For these loads the analysis given in Appendix $B$ was used. Since the main reinforcement is parallel to the direction of blast, the value of $x$ used in the expressions for the time and pressure was taken to the center of the panel formed by the roof beam and the rear wall; an average pressure, varying with time, was used over the span.

\section{C.10.4 Anticipated Damage, Structure 3.2.7a}

Damage to Structure 3.2.7a was expected to be most severe on the front wall. On the outside face, cracking of concrete was expected to be greatest along the edges of the rectangles formed by the end walls, the column, and the underside of the roof. Principal cracking of concrete on the outside faces was expected to occur near the center of these rectangles.

On the roof the concrete was expected to crack over the beams along the front edge and at the edges of the girders. Cracking was expected to be less severe at the rear edge of the roof. Damage to the side walls was expected to be mainly in the form of shear cracks. It was thought that damage to the rear wall would be minor.

It was anticipated that cracking of the column on the front wall would be most severe at the top of the inside face and at the bottom of the outside face. The column on the rear wall was expected to be similarly cracked, but the cracks were expected to occur on the outside face at the top and on the inside face at the bottom. It was thought that the transverse girder would be cracked mainiy at the ends and would have shear cracks near the beams.

Had the anticipated pressures been 20 per cent greater, the damage would have been much more extensive and severe than just described, but a collapse of the structure would not have been expected.

\section{C.10.5 Anticipated Damage, Structure 3.2.7b}

Damage to Structure 3.2.7b was expected to be similar to that of Structure 3.2.7a but less severe in extent.

\section{REFERENCE}

1. C. A. Trexel, CAPT, CEC, USN, "Bombproof Structures," U. S. Government Printing Office, Washington, D. C., Sept. 30, 1941. 


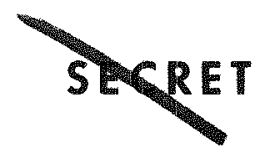

\section{Appendix D \\ Design Drawings and Specifications}

\section{D.1 GENERAL CLAUSES}

\section{D.1.1 General Description}

The work for the test structures includes concrete work, masonry, steelwork, woodwork, and field painting.

\section{D.1.2 Drawings}

The following drawings accompany this speci.. fication and are a part of it. Where "as shown," "as indicated," "as detailed," or words of similar import are used, it shall be understood that reference to these drawings is made unless stated otherwise. The drawings are the property of the Government and shall not be used for any purpose other than that contemplated by the specification.

\section{Fig. $\quad Y \& D$}

No. Dwg. No.

Title

\begin{tabular}{|c|c|c|}
\hline D.1 & 481343 & Type $3.2 .1 \mathrm{a}$, structu \\
\hline D.2 & 481344 & Type $3.2 .1 b$, gen \\
\hline D.3 & 481345 & Type $3.2 .1 \mathrm{~b}$, tru \\
\hline D.4 & 481 & $1 \mathrm{~b}$, for \\
\hline D.5 & 47 & Type 3 \\
\hline D.6 & 481 & Type $3.2 .2 \mathrm{a}, \mathrm{st}$ \\
\hline D. 7 & 48 & Type $3.2 .2 b$, str \\
\hline .8 & 50 & Type $3.2 .2 b$, str \\
\hline .9 & 48 & Type 3.2.3, general plans \\
\hline 10 & 48 & Type 3.2 .3 , joi \\
\hline 11 & 48 & Type 3.2 .3 , \\
\hline .12 & 48 & Type $3.2 .3, \operatorname{tr}$ \\
\hline D.13 & 481 & Type $3.2 .4 \mathrm{a}$, structural details \\
\hline D. 14 & 481356 & Type $3.2 .4 a$, structural details \\
\hline D.15 & 481357 & Type $3.2 .4 b$, plans and details \\
\hline D.16 & 481 & Type 3.2 .5$, plans and details \\
\hline D.17 & 481358 & Type 3.2 .6 \\
\hline D.18 & 481359 & Type 3.2 .6 , structural details \\
\hline D.19 & 481361 & Type 3.2 .7$, structural details \\
\hline
\end{tabular}

\section{D.1.3 Standard Specifications}

Except as provided otherwise by this specification and/or its accompanying drawings, the standard specifications given in the following list or mentioned elsewhere herein (including the addenda, amendments, and errata listed) shall govern in all cases where references to standard specifications are made. Special care shall be exercised to refer in requests for quotations, in orders, and in subcontracts to the standard specifications and to all modifications thereof.

\begin{tabular}{|c|c|c|}
\hline $13 Y c$ & October 1935 & $\begin{array}{l}\text { Concrete construc- } \\
\text { tion, including } \\
\text { addendum No. } 1 .\end{array}$ \\
\hline $22 Y b$ & October 1939 & $\begin{array}{l}\text { Structural-steel } \\
\text { welding, including } \\
\text { addendum No. } 2 .\end{array}$ \\
\hline $43 \mathrm{~B} 11 \mathrm{~d}$ & Jan. 15,1946 & $\begin{array}{l}\text { Bolts, nuts, studs, } \\
\text { and tap-rivets } \\
\text { (and material for } \\
\text { same) including } \\
\text { amendment } 1 .\end{array}$ \\
\hline$Q Q-S-741$ & Dec. 9,1942 & $\begin{array}{l}\text { Steel: structural } \\
\text { (including welding) } \\
\text { and rivet (for) } \\
\text { bridges and build- } \\
\text { ings, including } \\
\text { amendment } 3 \text {. }\end{array}$ \\
\hline SS-C-192 & May 20, 1946 & Cement: portland \\
\hline SS-C-621 & Apr. 28, 1931 & $\begin{array}{l}\text { Concrete units: } \\
\text { masonry, hollow, } \\
\text { including amend- } \\
\text { ment } 1 .\end{array}$ \\
\hline $\mathrm{TT}-\mathrm{P}-40$ & $\operatorname{May} 19,1943$ & $\begin{array}{l}\text { Paint: oil, exterior, } \\
\text { ready-mixed light } \\
\text { tints and white, } \\
\text { including amend- } \\
\text { ment } 2 .\end{array}$ \\
\hline
\end{tabular}


TT-P-86a May 4, 1949

Paint: red-lead base, ready-mixed.

\section{D.2 CONCRETE WORK}

\section{D.2.1 General Requirements}

Concrete work shall be in accordance with specification No. $13 Y$ c, except as indicated and except as specified herein. Portland cement shall be type I in accordance with specification No. SS-C-192. Ready-mixed concrete will be permitted. Concrete poured in place may be compacted by means of approved internal vibrators.

\section{D.2.2 Additional Classes of Concrete}

Concrete indicated 3000 psi with $3 / 4$-in. maximum coarse aggregate, concrete fill, grout concrete, and precast concrete, designated herein as $\mathrm{E}-3 / 4, \mathrm{E}-3 / 8, \mathrm{E}-1 / 4$, and $\mathrm{H}-1 / 4$, respectively, shall be proportioned in accordance with paragraph 3-01x of specification No. $13 Y \mathrm{Yc}$ and the data shown in Table D.1.

The slump for precast concrete, $\mathrm{H}-1 / 4$, shall be not less than $1 \frac{1}{2}$ in. and not more than $4 \frac{1}{2}$ in. The coarse aggregate for the additional classes of concrete shall be graded so that the percentages by weight passing standard laboratory sieves having square openings will be as shown in Table D.2.

\section{D.2.3 Precast Concrete}

Wire fabric shall conform to ASTM specification No. A185-37, except that the wire shall have a minimum yield point of 70,000 psi. Precast panels, sections, and cells shall be cast in strong, accurately constructed mortar-tight forms or in concrete molds. The concrete shall be vibrated mechanically when placed. Care shall be taken to produce precast material with smooth surfaces of dense concrete and to retain the reinforcement in its proper position. The precast material shall be water-cured for not less than 3 days and shall not be subjected to load for 7 days after the concrete is placed. Castings preferably shall be removed from concrete molds by the use of suction lifting devices; before removal from mold the casting shall have attained a strength of not less than 2000 psi. Forms may be removed $24 \mathrm{hr}$ after placing the concrete. Members of structure shall be matchmarked as indicated. Before starting the work, the contractor shall submit for approval the proposed method and procedure for casting, handling, and shipping precast-concrete framing members.

(a) Dimensions of Precast-concrete Members. Dimensions shall be within the limits shown in Table D.3.

(b) Cracks in Precast Concrete. Precast concrete containing hair cracks which are visible but not measurable by ordinary means may be accepted. Cracks of widths measurable by ordinary means may be cause for rejection of precast concrete, depending on the location and magnitude of the cracks.

\section{D.2.4 Concrete Surfaces}

Exposed exterior and interior concrete finished surfaces, except wearing surfaces, shall be smooth and uniform and practically free from joint marks, fins, depressions, bulges, sand streaks, and other defects. The concrete shall be placed so that the forms for exposed surfaces will not be spattered, using spouts or elephant trunks, with the lower end at the approximate level of the fresh concrete. Concrete shall be compacted by means of approved internal vibrators as required by specification No. $13 \mathrm{Yc}$, and, in addition, the forms for exposed concrete surfaces at the level of the concrete being placed shall be vibrated sufficiently with light air hammers to provide smooth dense concrete but not to produce sand streaks. Care shall be exercised not to loosen or damage the forms.

\section{D.3 MASONRY}

\section{D.3.1 General Requirements}

Where brick or concrete-block wall is indicated, wall shall be constructed of brick or of concrete units of the following types. Brick shall be hard-burned clay or shale brick. Concrete units shall be type $\mathbb{I}$, weight $b$, in accordance with specification No. SS-C-621. Mortar for wall construction shall be mixed in the proportion of 1 part portland cement, 1 part hydrated-lime paste, and 6 parts clean sharp sand; the mortar shall be used so that it will be in place before the initial setting of the cement 
TABLE D.1 CONCRETE SPECIFICATIONS

\begin{tabular}{|c|c|c|c|c|c|c|}
\hline \multirow[b]{2}{*}{$\begin{array}{l}\text { Class of } \\
\text { Concrete }\end{array}$} & \multirow{2}{*}{$\begin{array}{l}\text { Estimated } \\
\text { 28-day Com- } \\
\text { pressive } \\
\text { Strength (psi) }\end{array}$} & \multirow{2}{*}{$\begin{array}{c}\text { Cement Factor, } \\
\text { Sacks* of } \\
\text { Cement per } \\
\text { Cubic Yard of } \\
\text { Concrete, } \\
\text { Freshly Mixed }\end{array}$} & \multirow{2}{*}{$\begin{array}{l}\text { Maximum } \\
\text { Water per } \\
\text { Sack* of } \\
\text { Cement (gal) }\end{array}$} & \multirow{2}{*}{$\begin{array}{c}\text { Fine Aggre- } \\
\text { gate Range } \\
\text { in Per Cent } \\
\text { of Total } \\
\text { Aggregate } \\
\text { by Weight }\end{array}$} & \multicolumn{2}{|c|}{$\begin{array}{l}\text { Approximate Weights of } \\
\text { Saturated Surface-dry } \\
\text { Aggregates per Sack * } \\
\text { of Cement }\end{array}$} \\
\hline & & & & & $\begin{array}{l}\text { Fine Aggre } \\
\text { gate }(\mathrm{lb})\end{array}$ & $\begin{array}{c}\text { Coarse Aggre- } \\
\text { gate (lb) }\end{array}$ \\
\hline$E-3 / 4$ & 3000 & 6.2 & $6^{1 / 2}$ & $37-45$ & 203 & 293 \\
\hline$E-3 \%$ & 3000 & 6.7 & $6^{1 / 2}$ & $39-47$ & 192 & 255 \\
\hline $\mathrm{E}-1 / 4$ & 3000 & 6.8 & $6 \frac{1}{2}$ & $40-48$ & 191 & 242 \\
\hline $\mathrm{H}-1 / 4$ & 5000 & 9 & 5 & $34-42$ & 116 & 189 \\
\hline
\end{tabular}

* Sack weighs $94 \mathrm{lb}$.

$\dagger$ Figures denote size of coarse aggregate in inches. 
TABLE D.2 AGGREGATE SIEVE SPECIFICATIONS

\begin{tabular}{lc}
\hline & $\begin{array}{c}\text { Percentage by Weight } \\
\text { Passing Sieve }\end{array}$ \\
\hline 1 in. & Class E- $3 / 4$ \\
$3 / 4$ in. & 100 \\
$3 / 8$ in. & $90-100$ \\
No. 4 & $20-55$ \\
No. 8 & $0-10$ \\
& $0-5$ \\
$1 / 2$ in. & \\
$3 / 8$ in. & 100 \\
No. 4 & $85-100$ \\
No. 8 & $10-30$ \\
No. 16 & $0-10$ \\
& $0-5$ \\
Classes E- $1 / 4$ and H- $1 / 4$ \\
$3 / 8$ in. & 100 \\
No. 4 & $85-100$ \\
No. 8 & $10-40$ \\
No. 16 & $0-10$ \\
No. 50 & $0-5$ \\
\hline
\end{tabular}

TABLE D.3 PRECAST-CONCRETE TOLERANCES

\begin{tabular}{lccc}
\hline Item & $\begin{array}{c}\text { Length } \\
\text { (in.) }\end{array}$ & $\begin{array}{c}\text { Width } \\
\text { (in.) }\end{array}$ & $\begin{array}{c}\text { Thickness } \\
\text { (in.) }\end{array}$ \\
\hline Panel & $\pm 1 / 8$ & $\pm 1 / 16$ & $\pm 1 / 16$ \\
Cell & $\pm 1 / 8$ & $\pm 1 / 8$ & $\pm 1 / 16$ \\
\hline
\end{tabular}

has taken place; retempering of mortar in which cement has started to set will not be permitted.

\section{D.3.2 Workmanship}

All beds on which brick or concrete units are to be laid shall be clean. Brick or concrete units shall be built level, plumb, and true; bats shall be used only for closures. Brickwork shall be laid in common bond with a through header course at every sixth course. Joints shall be about $1 / 2$ in. thick; joints exposed in the interior of the test structure shall be troweled neatly. Where bolts, built in as the work progresses, occur within the cells of the units or between the joints, such cells shall be filled with concrete or with cement mortar. Where concentrated loads occur on masonry, the voids in the units shall be filled solidly with masonry concrete or with 1-to-4 cement-sand mortar. When directed, tops of exposed walls shall be covered with watertight material while work thereon is not in progress.

\section{D.4 STEELWORK}

\section{D.4.1 General Requirements}

Steelwork includes the furnishing and installing of structural-steel trusses, doors, shapes and plates, inserts, and all fastenings indicated or necessary for securing concrete, steel, and woodwork in place. Welding, including the welding of reinforcing steel for concrete specified hereinbefore, fabrication, shop painting, erection, and inspection shall be in accordance with specification No. $22 \mathrm{Yb}$, except that fabrication of bolted work shall be in accordance with good practice in modern structural shops, that zinc-coated surfaces shall not be painted, and that fastenings shall be painted as specified hereinafter. Members of structures shall be matchmarked as indicated. Welding electrodes and rods shall be on the current approved list of the Department of the Navy.

\section{D.4.2 Structural Steel}

Structural steel shall be type II, grade B, in accordance with specification No. QQ-S-741, except that tolerances in rolling and cutting shall conform to the current editions of the Manual of the American Iron and Steel Institute.

\section{D.4.3 Inserts}

Inserts shall be structural steel. Threads shall be as specified hereinafter for bolts, shall not be painted, and shall be coated thoroughly with an approved preservative grease.

\section{D.4.4 Fastenings}

Bolts and nuts shall be in accordance with specification No. 43B11d and, except bolts and nuts in concrete, shall be zinc-coated. Bolts and nuts shall be unfinished commercial steel. 
Anchor bolts and other bolts where indicated shall have hexagonal nuts. Threaded rods and through bolts shall have standard threads and nuts; bolts shall have square heads, unless otherwise indicated. Bolts and threaded rods shall be of lengths such that not more than one washer will be necessary under each head or nut to provide a rigid connection. Threaded rods and eyebolts shall be in accordance with the applicable requirements of specification No. 43B11d for uncoated bolts of unfinished commercial steel.

Washers shall be structural steel and, except washers in concrete, shall be zinc-coated. Zinc coating shall be as specified for bolts and nuts.

\section{D.4.5 Pipe}

All pipe shall be of zinc-coated standardweight steel pipe. Pipe sleeves shall be provided for anchor bolts and where indicated.

\section{D.5 WOODWORK}

\section{D.5.1 General Requirements}

All woodwork shall be protected from the weather until placed in the building. Lumber shall be well seasoned. Spiking, nailing, and bolting shall be done in a substantial manner. Timbers shall be drilled accurately for bolting; suitable washers shall be provided; and all bolts shall be drawn up tight. Plates shall be lapped at splices and shall be bolted through the laps, or the ends shall be butted and bolted not more than 6 in. from the ends. Plates shall be bedded solidly in 1-to-3 cement mortar to form a level and continuous bearing. Roof joists shall be of uniform widths; they shall have full bearing on plates. The spacing of roof joists shall not exceed those indicated. After joists have been set in position and crossbridged, the tops shall be level. Wood chips, shims, or other shrinkable material shall not be used for leveling joists. Sheathing shall be 6 to 8 in. wide, tongued and grooved or straightedged, having a uniform thickness of not less than $25 / 32$ in.; it shall be driven up close and double-nailed at each bearing. Except for tongue-and-groove ends, joints shall occur only over bearings and shall be staggered.

\section{D.5.2 Grades}

Grades shall be in accordance with the grading rules of the association applicable for the species as follows:

Roof joists, plate, and blocking under and at end of joists shall be of the following grade and species.

\begin{tabular}{ll}
\hline \multicolumn{1}{c}{ Grade } & \multicolumn{1}{c}{ Species } \\
\hline $\begin{array}{c}\text { No. 2 dimension, or } \\
\text { No. 2 small timbers, or } \\
\text { No. 2 utility timbers and } \\
\text { heavy joists }\end{array}$ & $\begin{array}{c}\text { Any species } \\
\text { permitted for } \\
\text { sheathing }\end{array}$ \\
\hline
\end{tabular}

No. 1 small timbers and No. 1 utility timbers and heavy joists shall be medium grain and shall have a slope of grain not exceeding 1 in 10 .

Sheathing, cross-bracing for joists, and wood stops for concrete shall be of the following grade and species.

\begin{tabular}{|c|c|}
\hline Grade & Species \\
\hline No. 2 common & $\begin{array}{l}\text { Western red cedar } \\
\text { Douglas fir } \\
\text { West coast hemlock } \\
\text { Sitka spruce } \\
\text { White fir (W.C.L.A.) } \\
\text { Port Orford cedar }\end{array}$ \\
\hline No. 3 common & $\begin{array}{l}\text { Eastern hemlock } \\
\text { Southern pine } \\
\text { Eastern spruce } \\
\text { Redwood } \\
\text { Cypress }\end{array}$ \\
\hline No. 4 common & $\begin{array}{l}\text { White pine } \\
\text { Norway pine } \\
\text { Ponderosa pine } \\
\text { Larch } \\
\text { Engelmann spruce } \\
\text { Lodgepole pine } \\
\text { White fir (W.P.A.) }\end{array}$ \\
\hline $\begin{array}{l}\text { No. } 2 \text { construction } \\
\text { boards }\end{array}$ & $\begin{array}{l}\text { Aspen } \\
\text { Basswood } \\
\text { Chestnut } \\
\text { Cottonwood } \\
\text { Magnolia } \\
\text { Poplar (yellow) } \\
\text { Willow, gum, and tupelo } \\
\text { Buckeye }\end{array}$ \\
\hline
\end{tabular}


Plywood stops for open ends of precast-concrete cells shall be Douglas fir plywood, grade B-B, exterior.

\section{D.6 FIELD PAINTING}

D.6.1 General Requirements

Paint shall be applied only to dry and thoroughly clean surfaces and shall be worked thoroughly into all joints, crevices, and open spaces. Colors and shades of colors shall be approved. Finished surfaces shall be smooth, even, and free of defects. Metal surfaces shall be free of rust, dirt, loose and disintegrated paint, grease, and scale before the field coats are applied. Where shop coats have been damaged, the exposed metal surfaces shall be retouched with red-lead paint in accordance with specification No. TT-P-86a. Samples of all finishes shall be submitted for approval. The number of paint coats specified shall be in addition to the shop priming coats.

\section{D.6.2 Materials}

Materials shall be in accordance with the standard specifications listed under Sec. D.1.3; those not covered by such standards shall conform to the requirements given hereinafter and shall be of approved brands. Paints and materials therefor shall be delivered in unbroken original packages bearing the manufacturer's name and brand designation.

\section{D.6.3 Lead-and-oil Paint}

Except for zinc-coated surfaces and anchor bolts, priming and one finishing coat shall be applied to all exposed exterior and interior wood and metal surfaces. Lead-and-oil paint shall be type II in accordance with specification No. TT-P-40. All surfaces or fastenings and structural steel that are accessible for painting after erection shall be given one coat of redlead paint in accordance with specification No. TT-P-86a before being made inaccessible or concealed by other work. Exposed ends of anchor bolts set in concrete shall be coated with red-lead paint after setting.

\section{D.7 DESIGN DRAWINGS}

Figures D.1 to D.19 comprise the design drawings for the test structures. 


\section{STKRET}
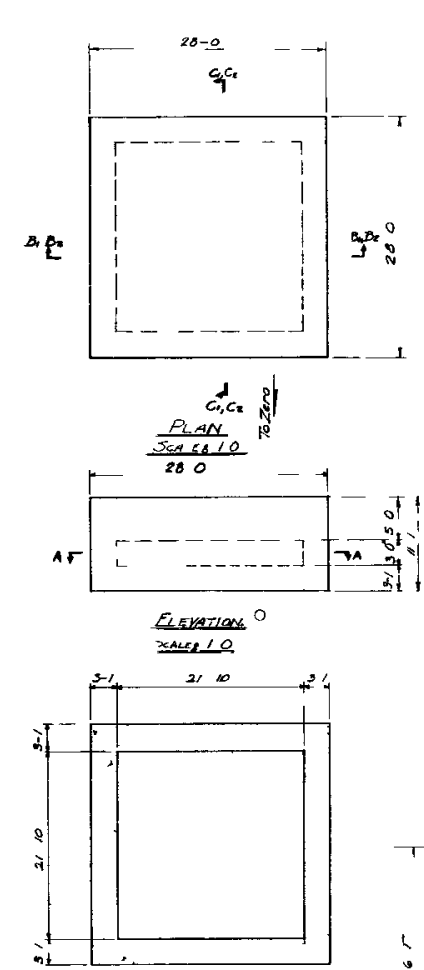

$\frac{\text { Fondegrion Llan }}{\operatorname{san} 10}$

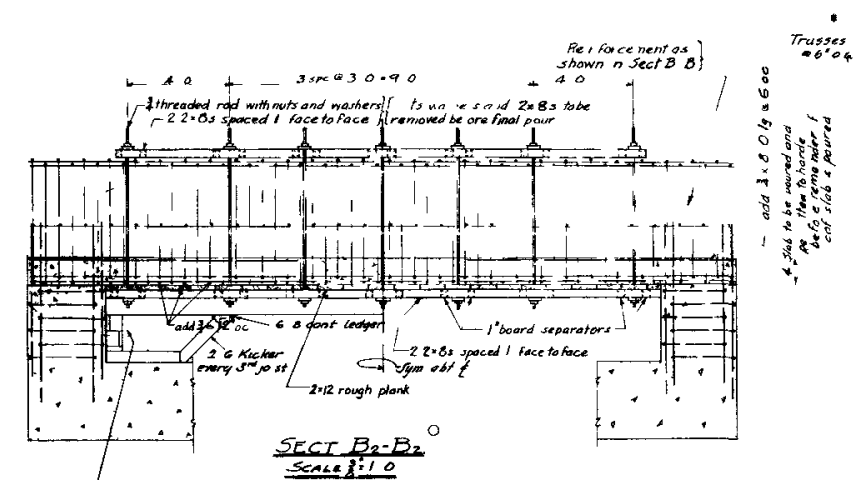

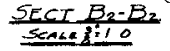

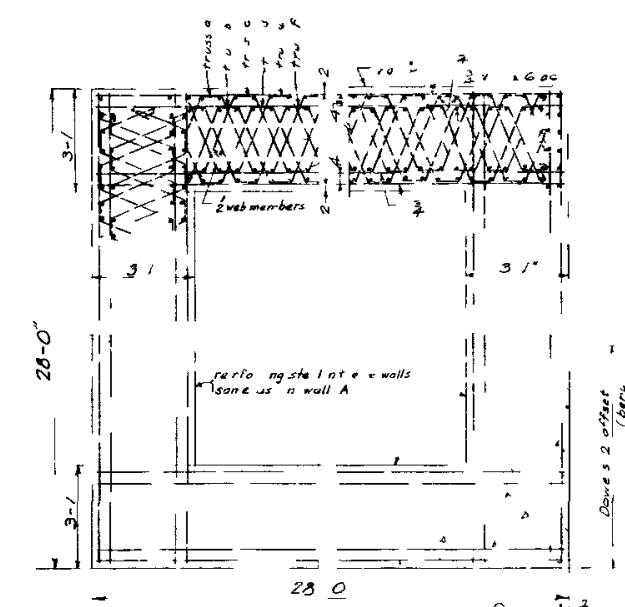

Horrzan- $280-1 A_{1}^{\circ} \mathrm{t}^{2}$ trusses no $\left\{\begin{array}{l}1 \\ 5 \\ 4 \\ 3 \\ 3 \\ 1-\end{array}\right.$

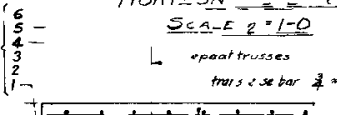

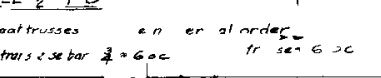

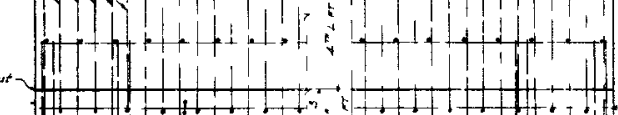

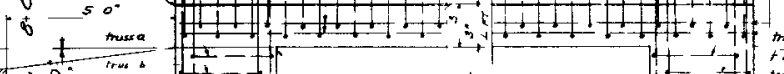

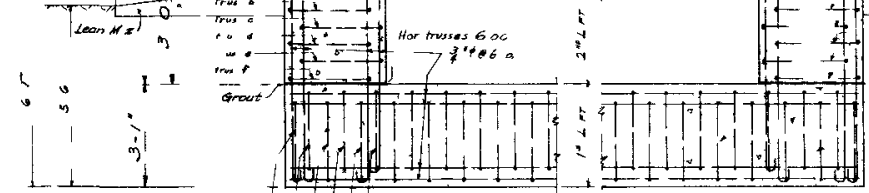

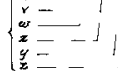

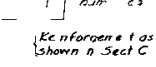

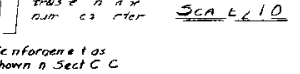

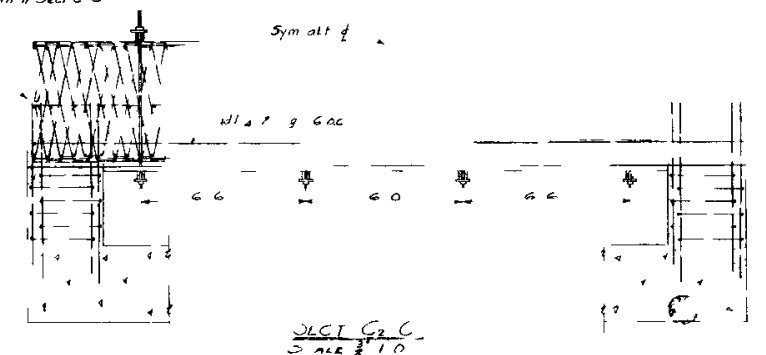

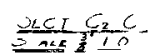

SUGGESTED METHQD OF CONSTRUCTION

Fig. D.1 Structural Details, Type 3.2.1a

252

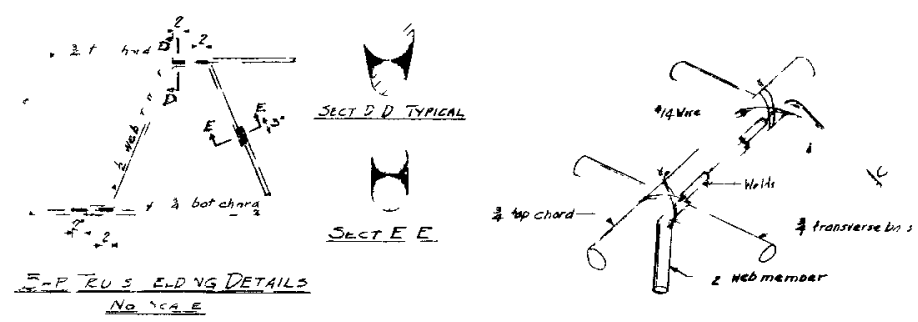

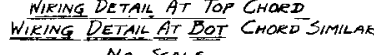

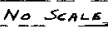

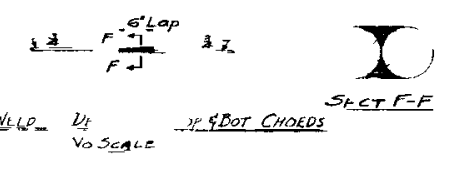

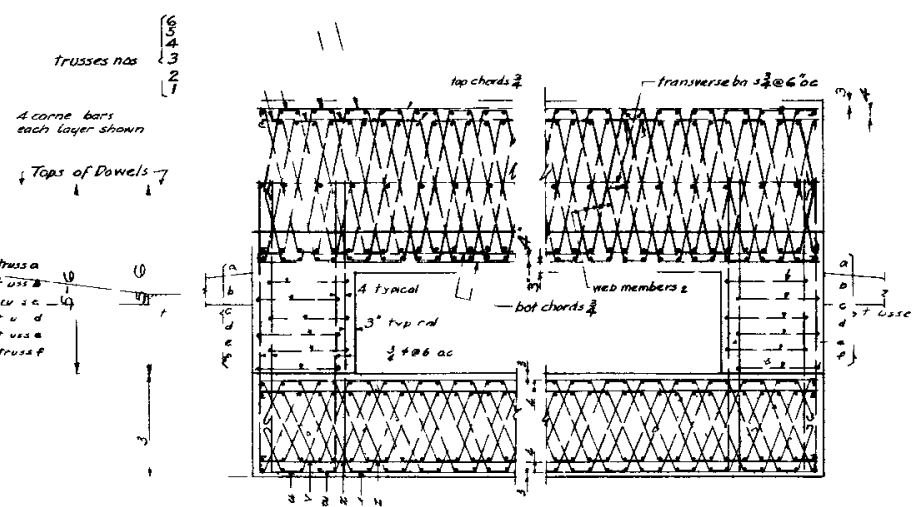

.

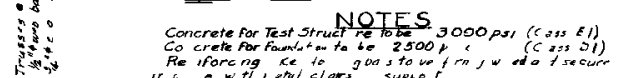

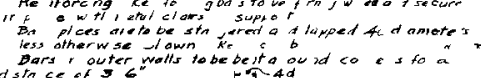

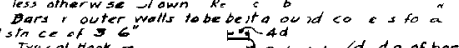

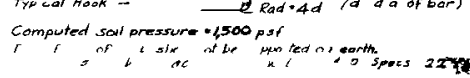

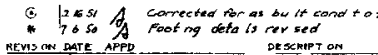
些 


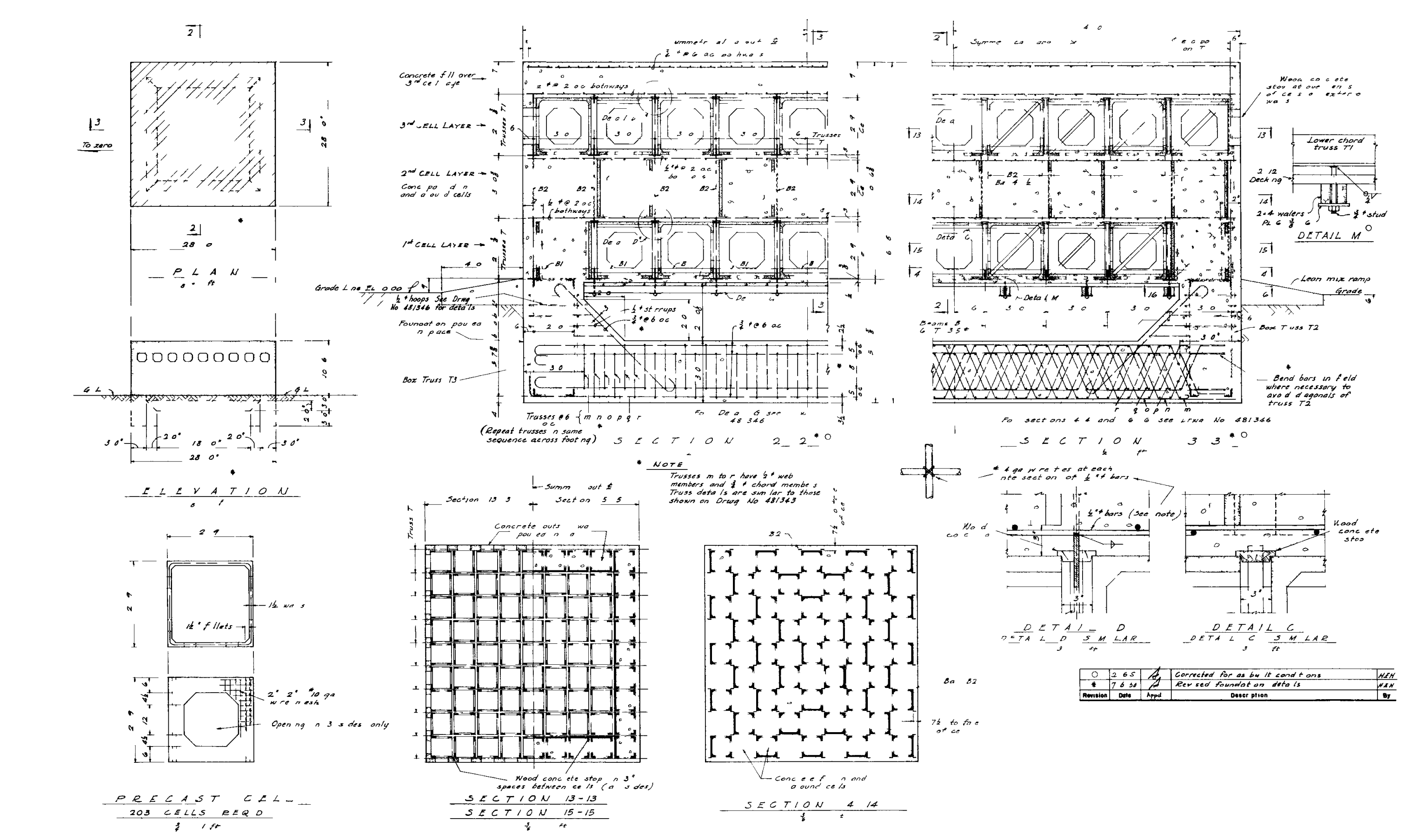

Fig. D.2 General Plans, Type 3.2.1b 


\section{STYKeT}
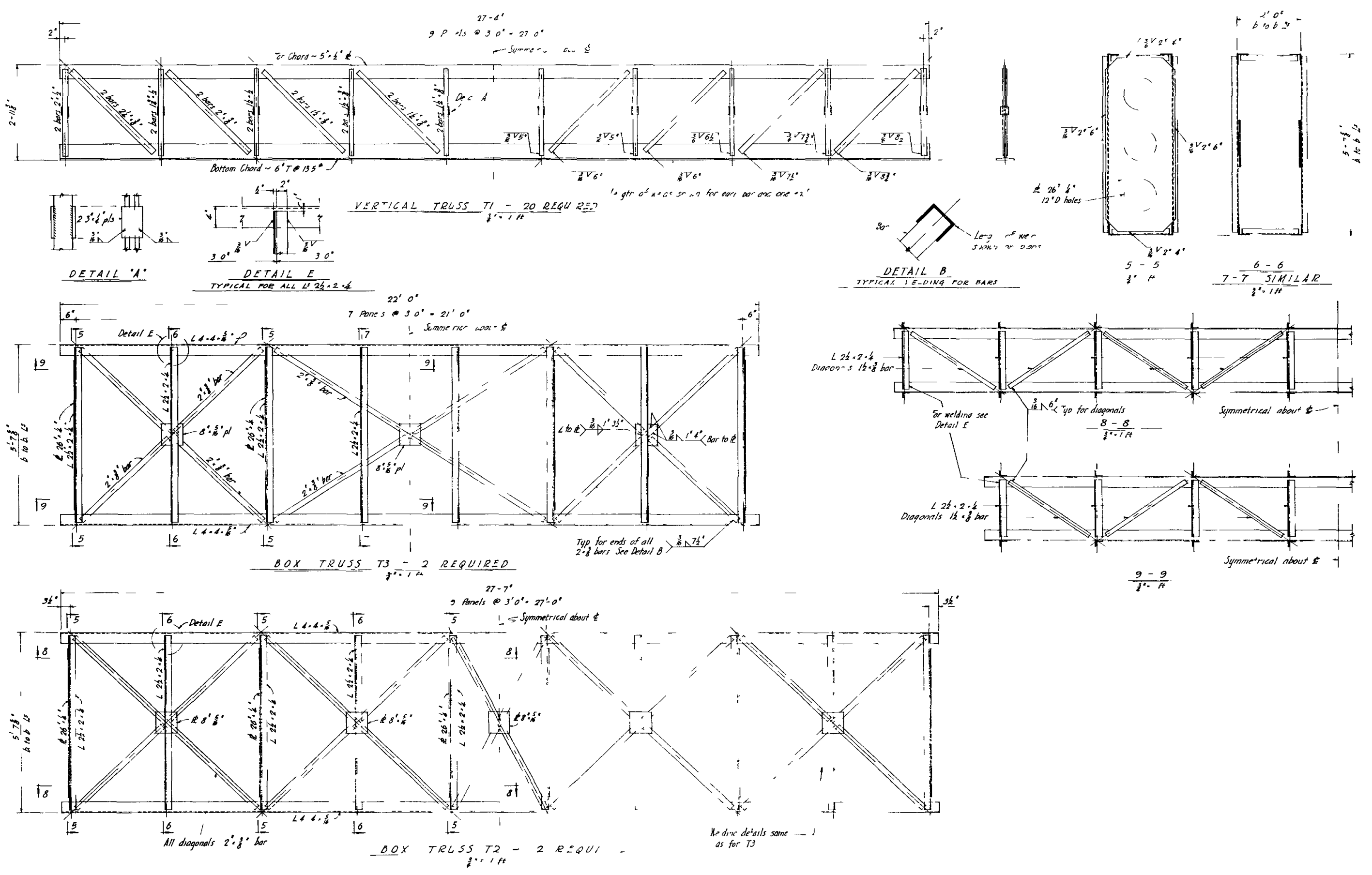

Fig. D.3 Truss Details, Type 3.2.1b 


\section{Jiget}

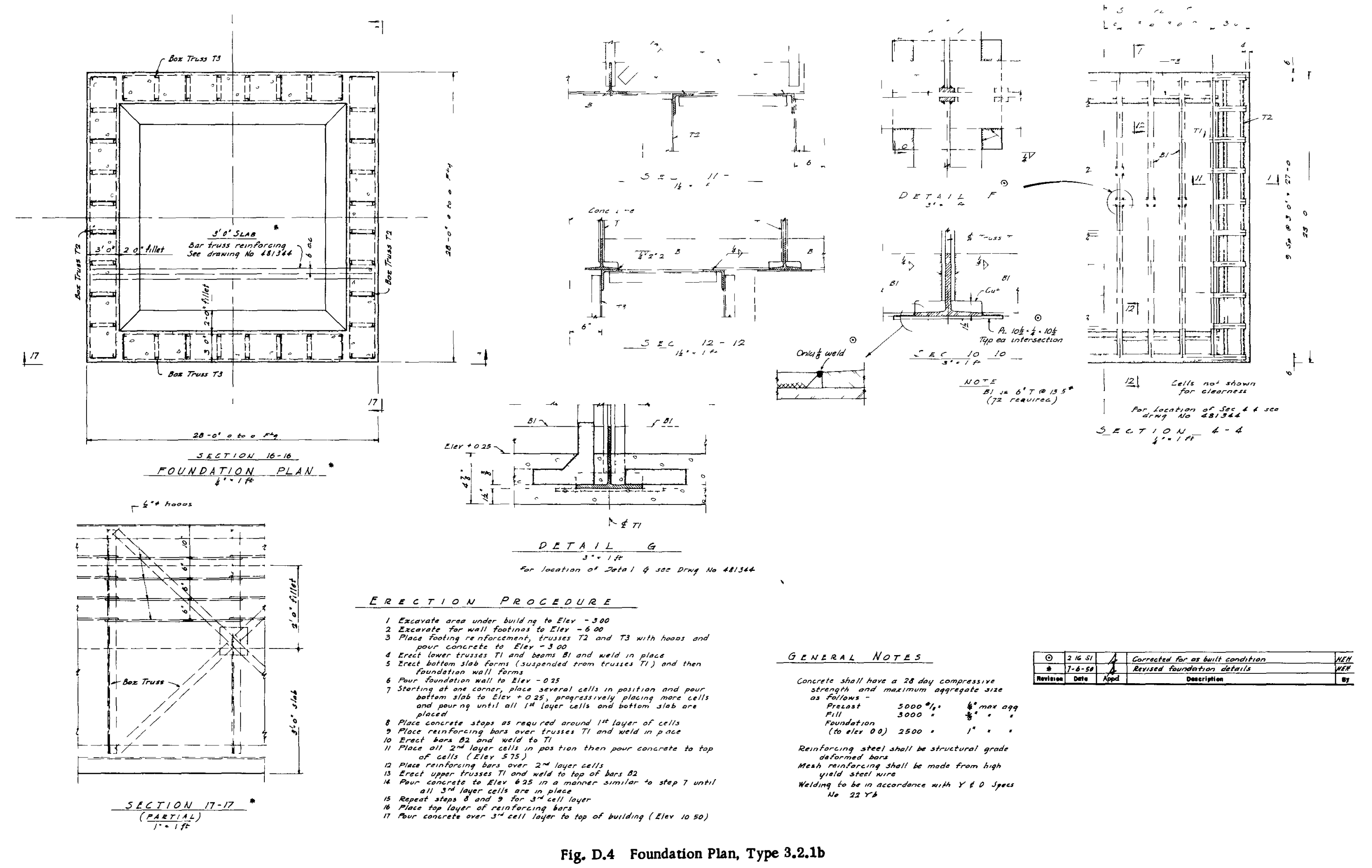

Fig. D.4 Foundation Plan, Type 3.2.1b 


\section{STKRE}

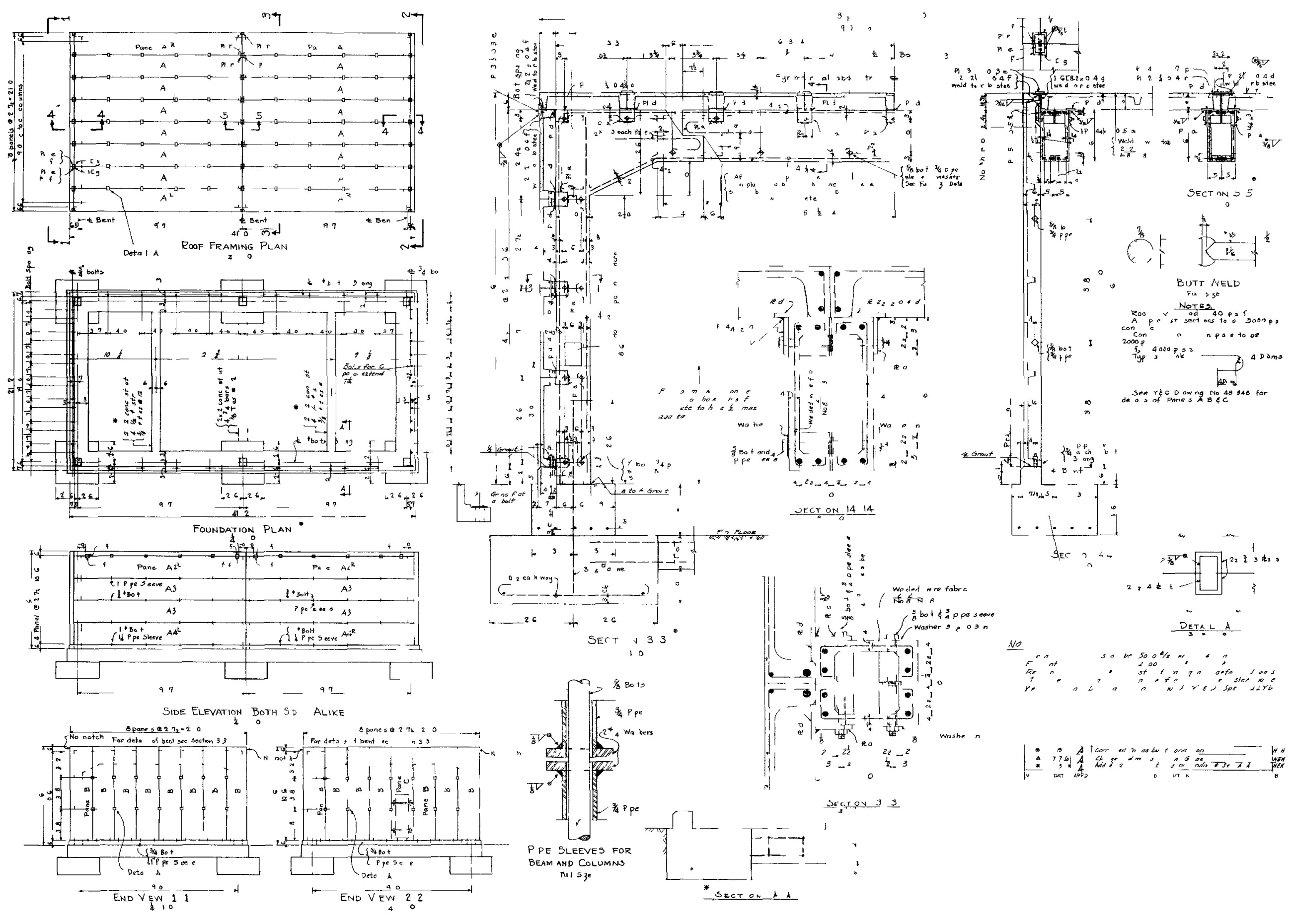

Fig. D.5 Structural Details, Type 3.2.2a 


\section{StKRE}
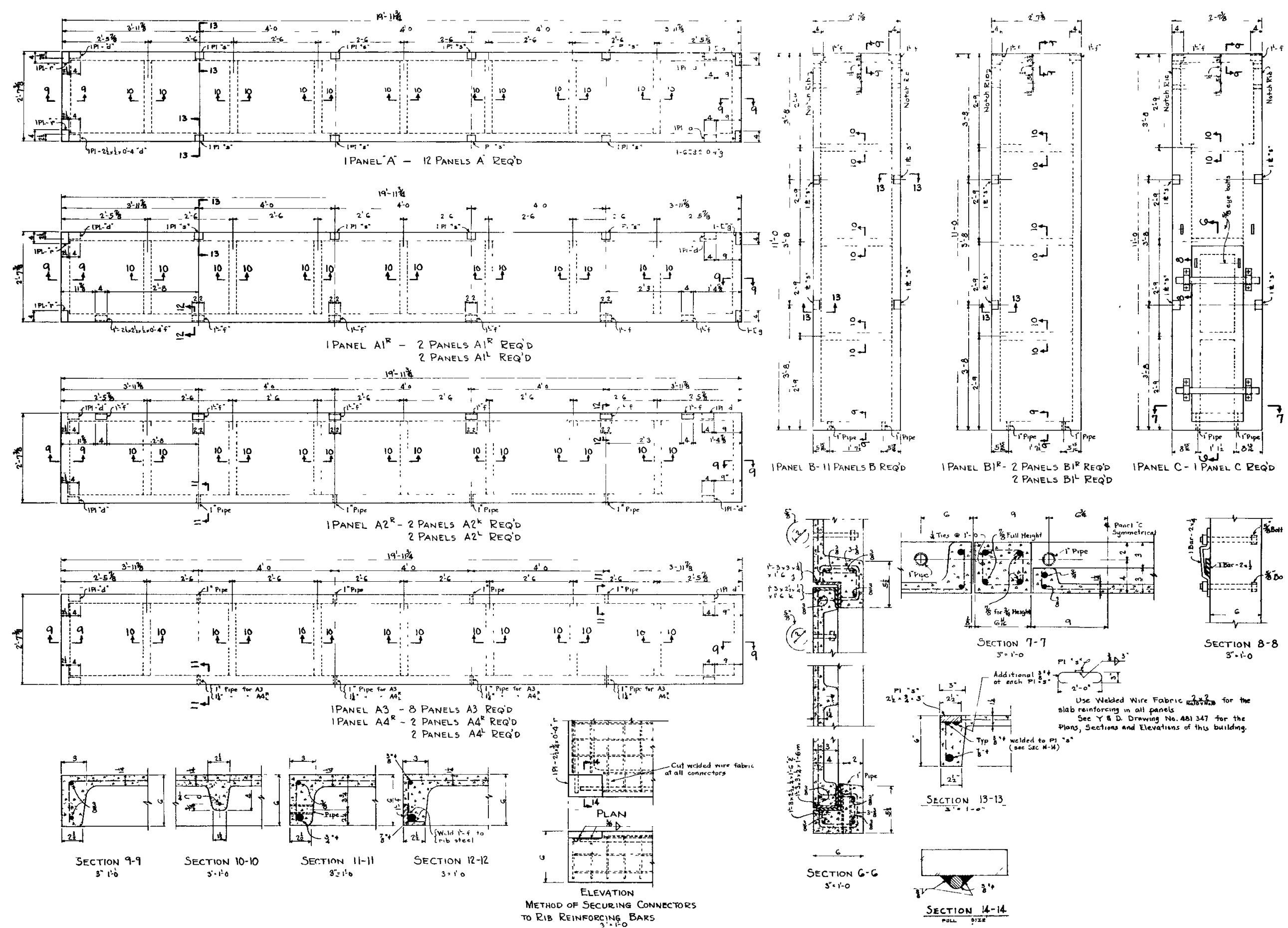

Fig. D.6 Structural Details, Type 3.2.2a 


\section{SEgret}

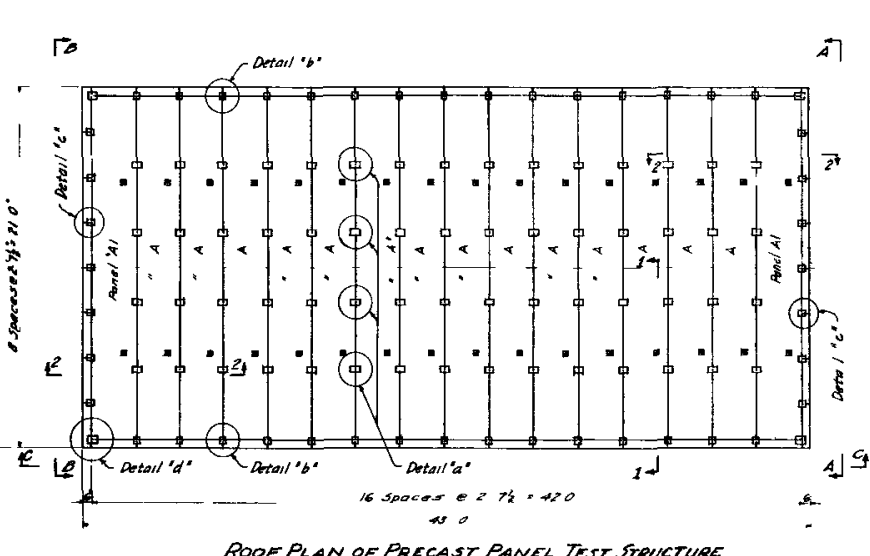

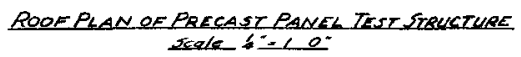

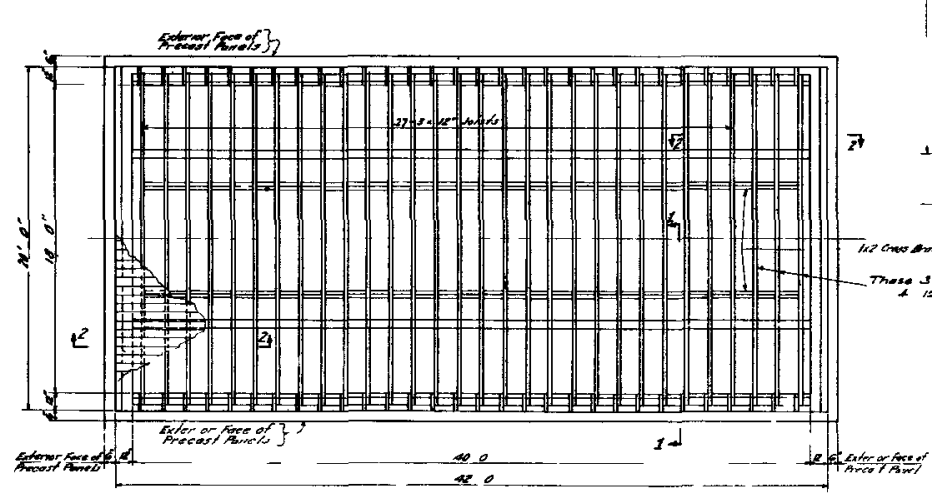

ROOF PLAN OF BRICK TEST TTRUETURE

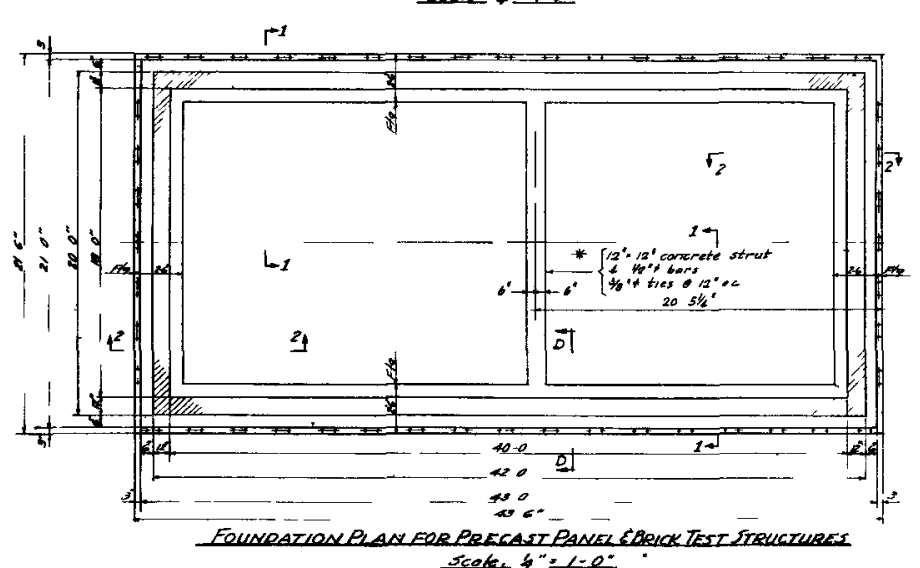

Fat
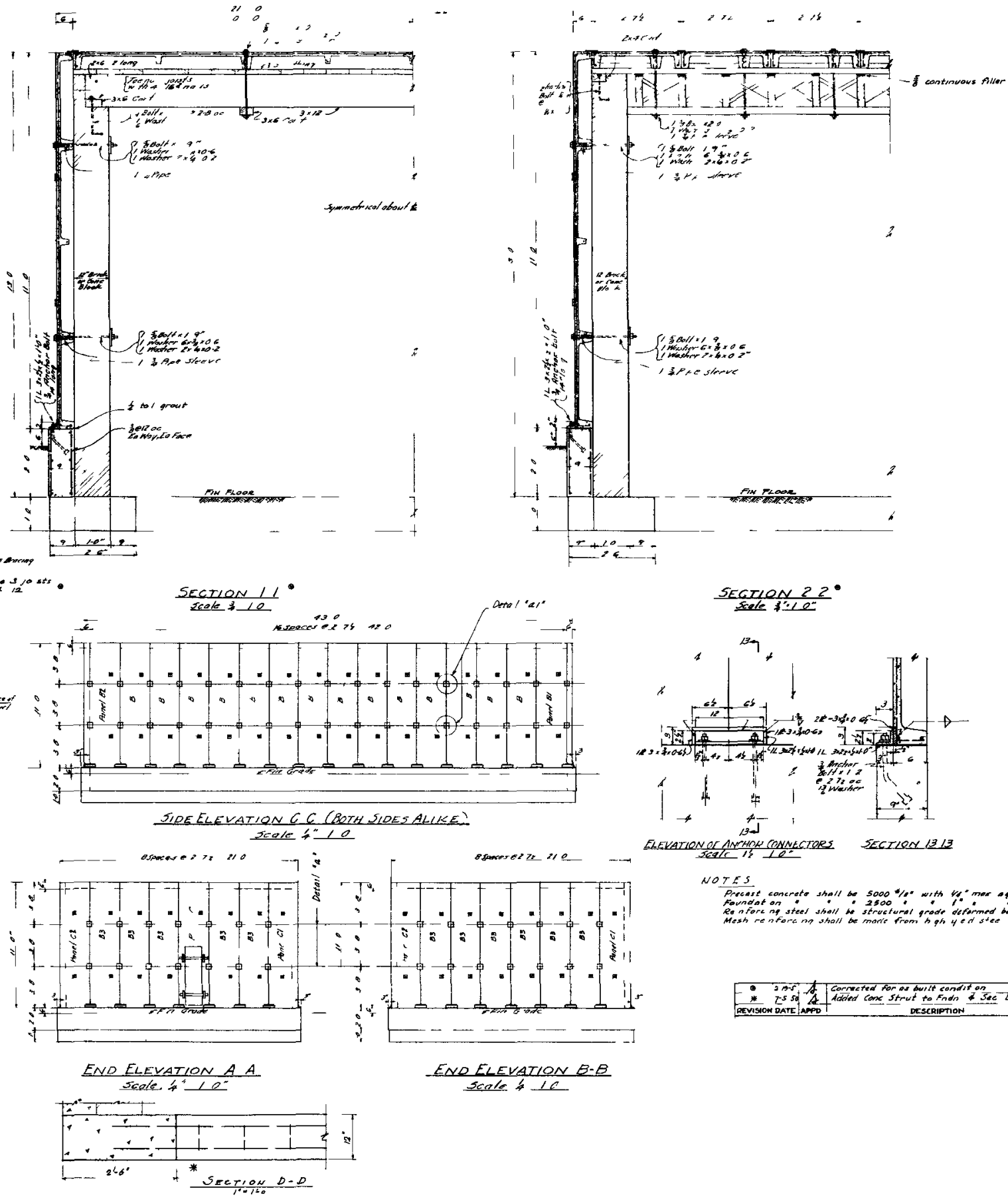

$\frac{\operatorname{secten} 22^{\circ}}{\text { sede }}$
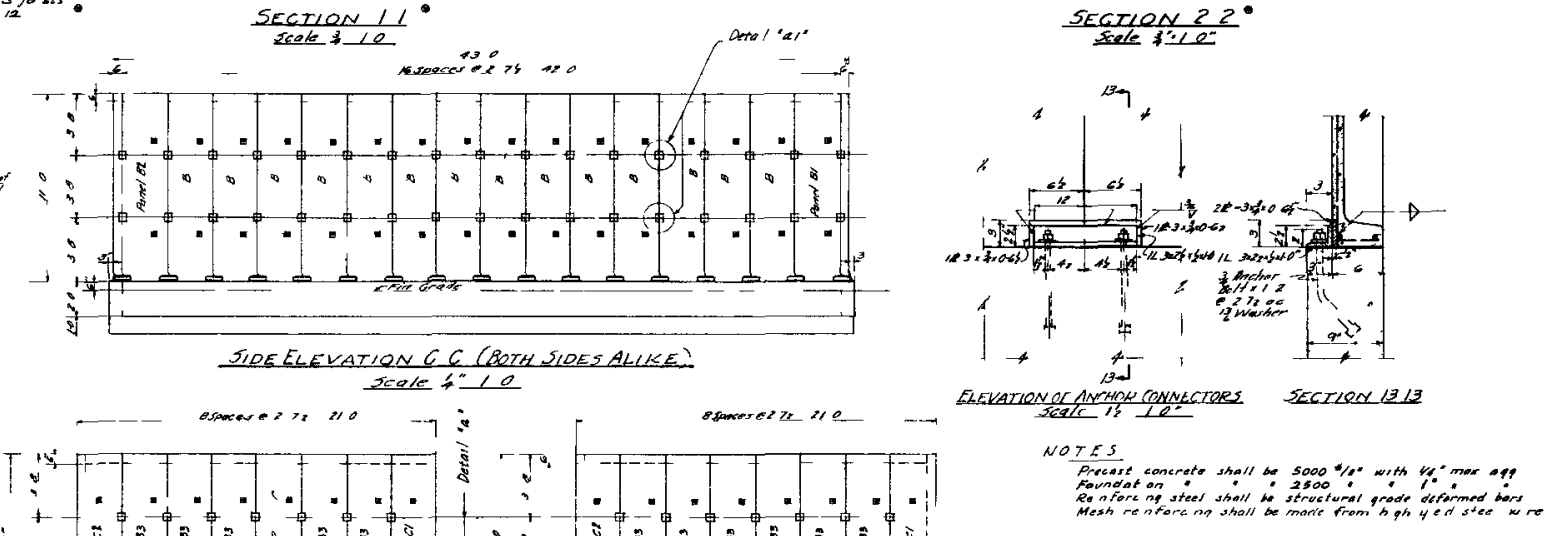

Fig. D.7 Structural Details, Type 3.2.2b 


\section{J}
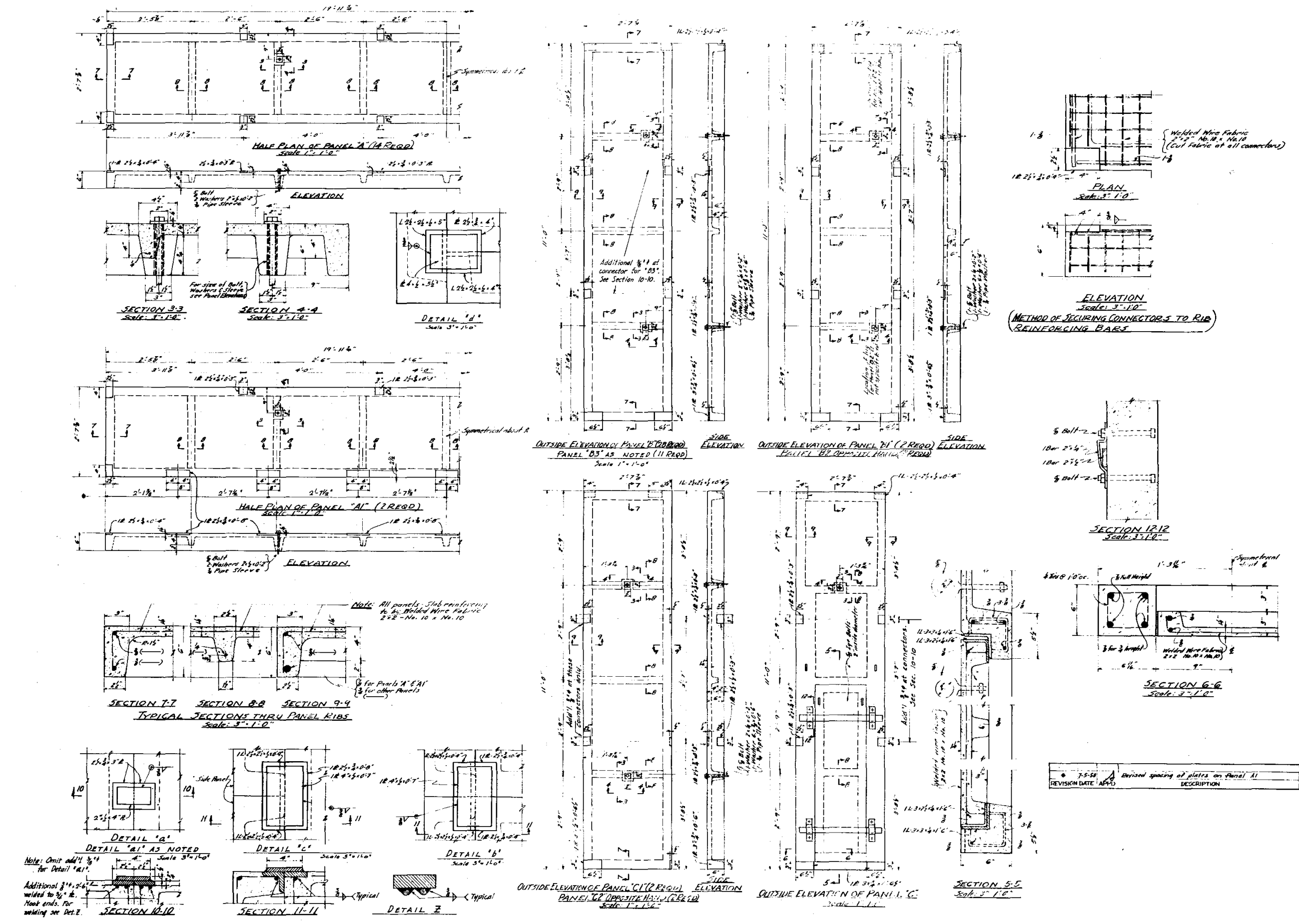

Fig. D.8 Structural Detaik, Type 3.2.26 

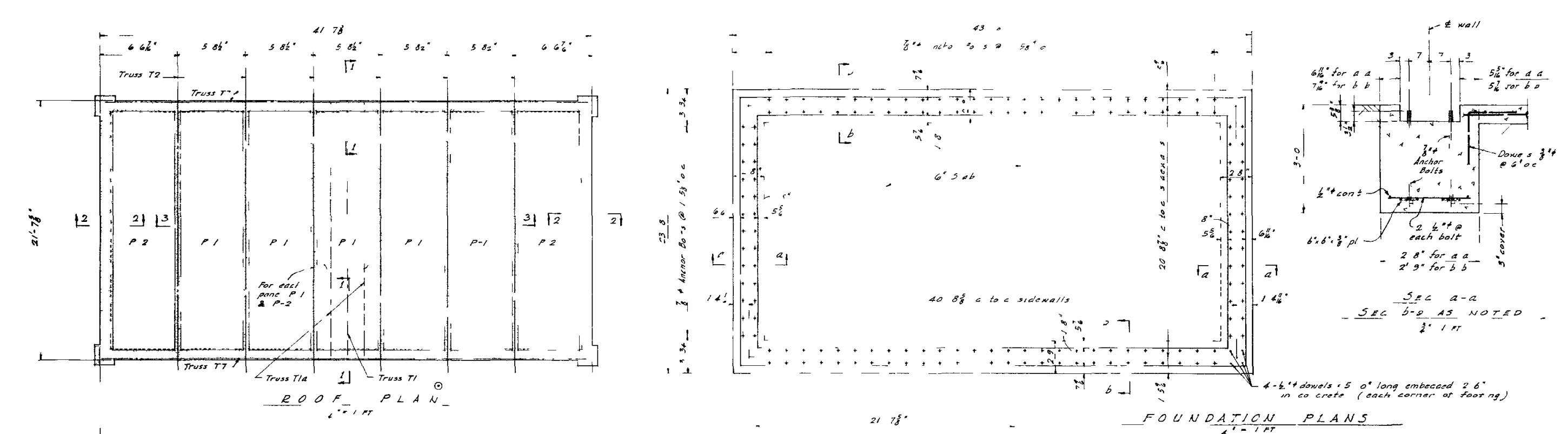
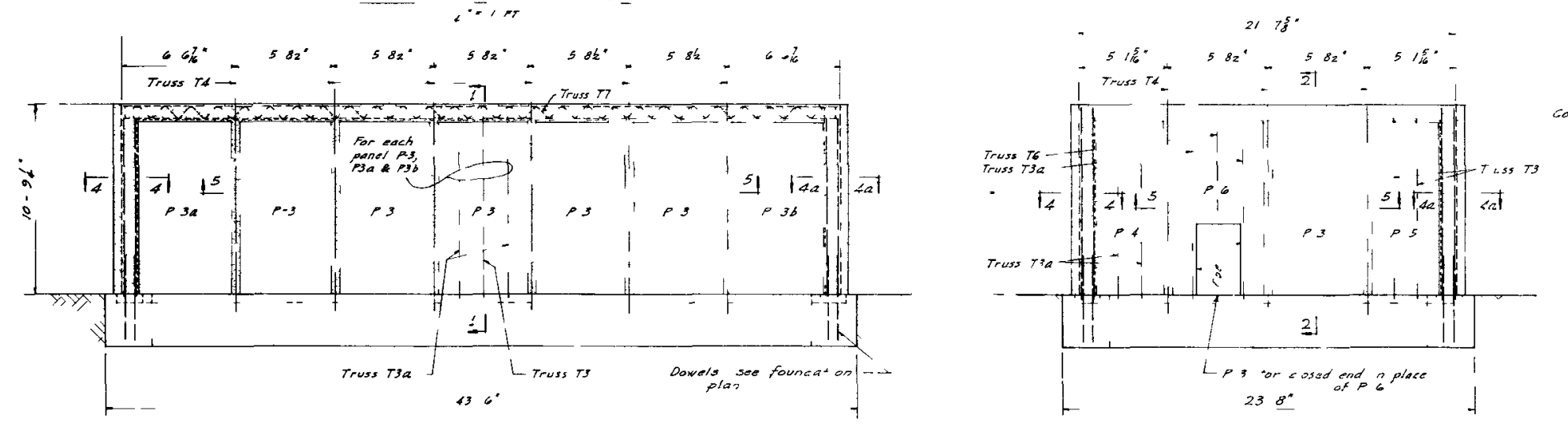

END E E EYTATION
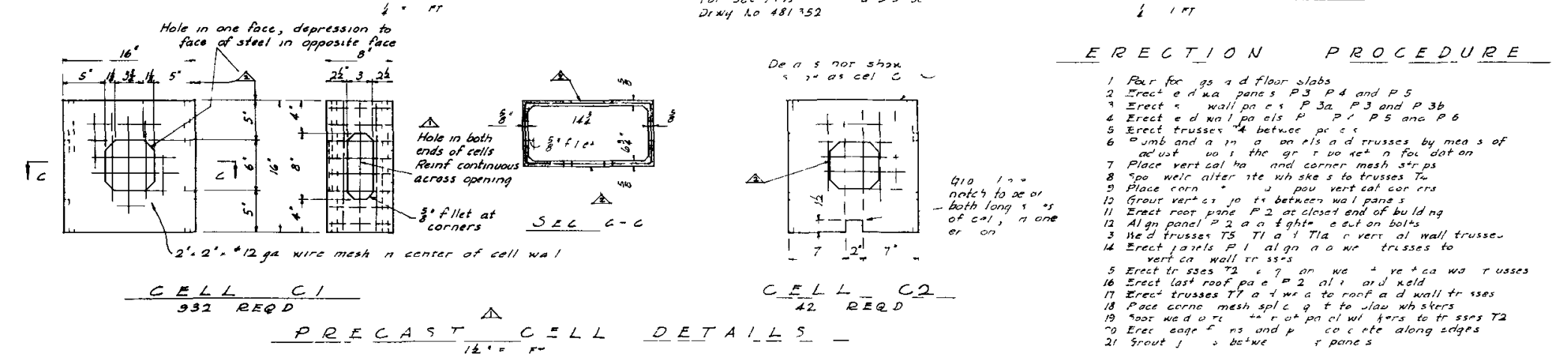

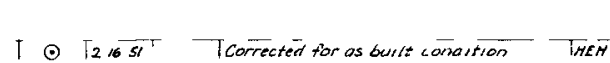

Fig. D.9 General Plans, Type 3.2.3
-

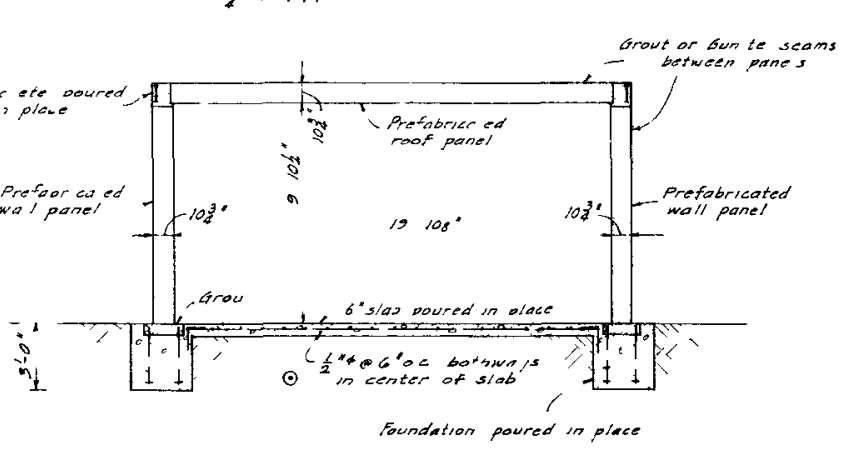

YPPICA L

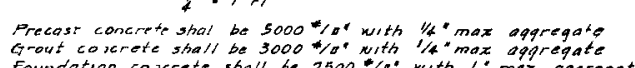

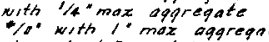

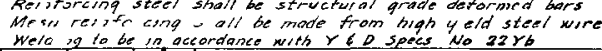

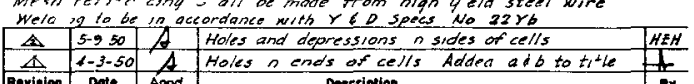




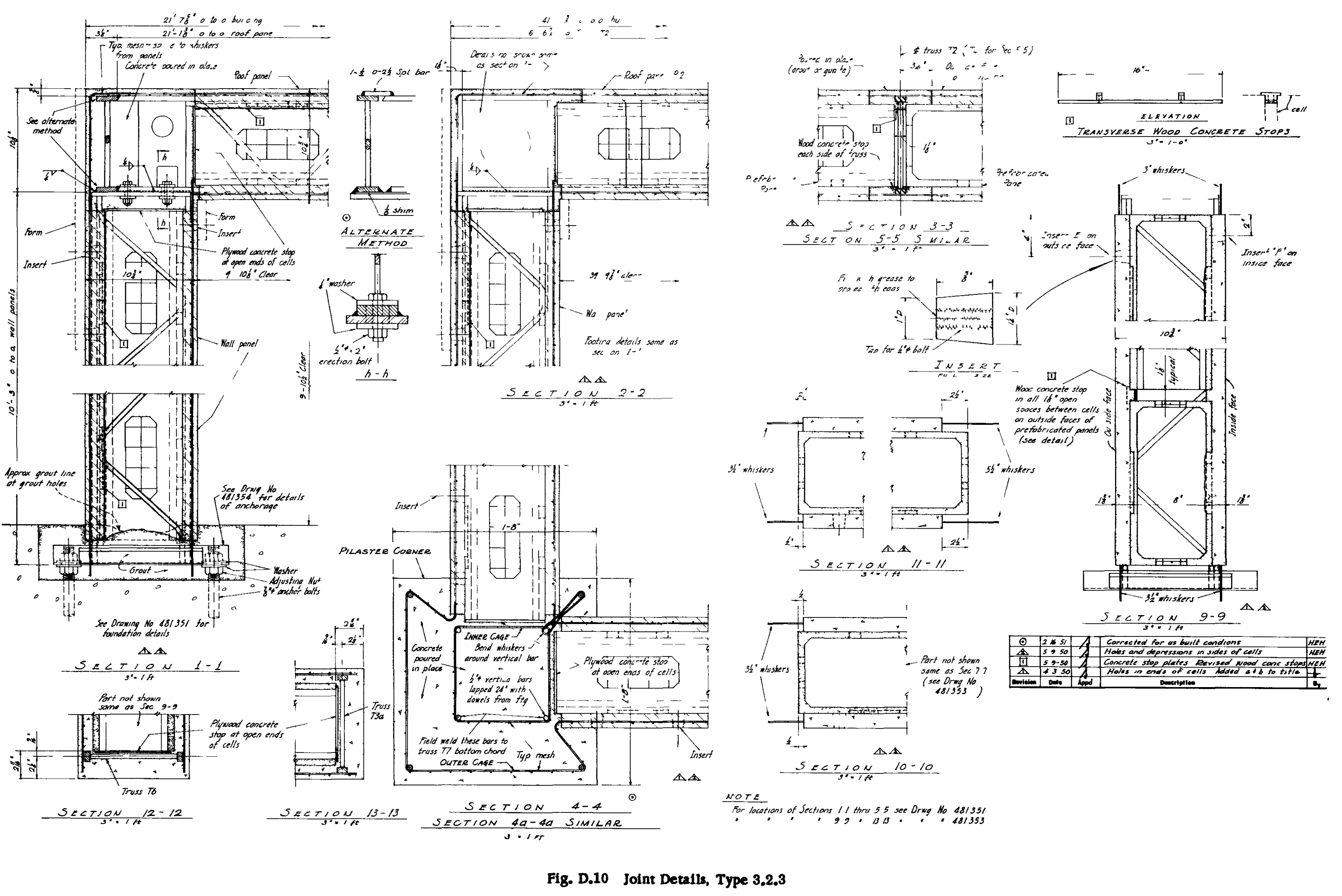




\section{STCRET}

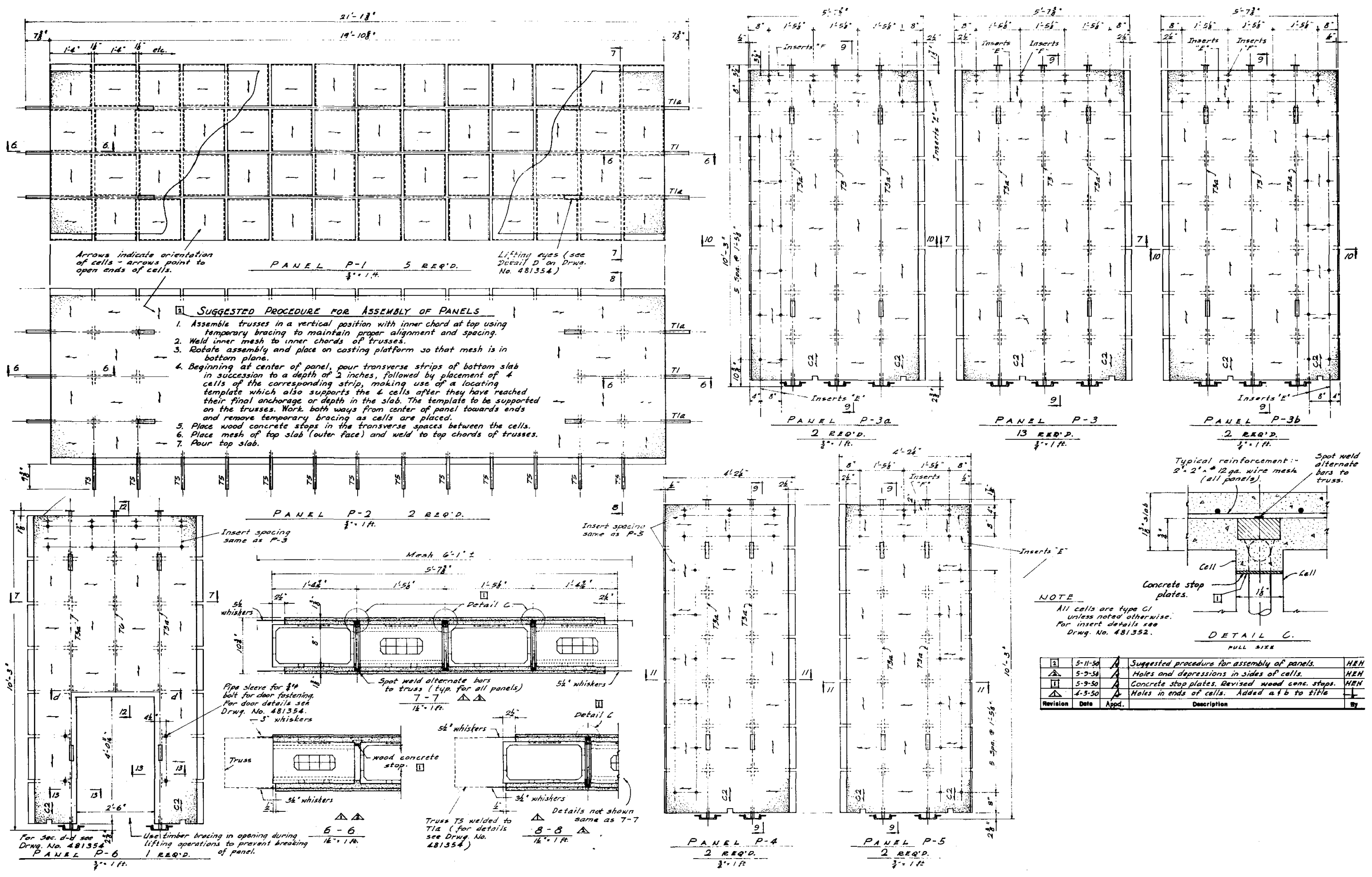

Fig. D.11 Panel Details, Type 3.2.3 


\section{STKET}
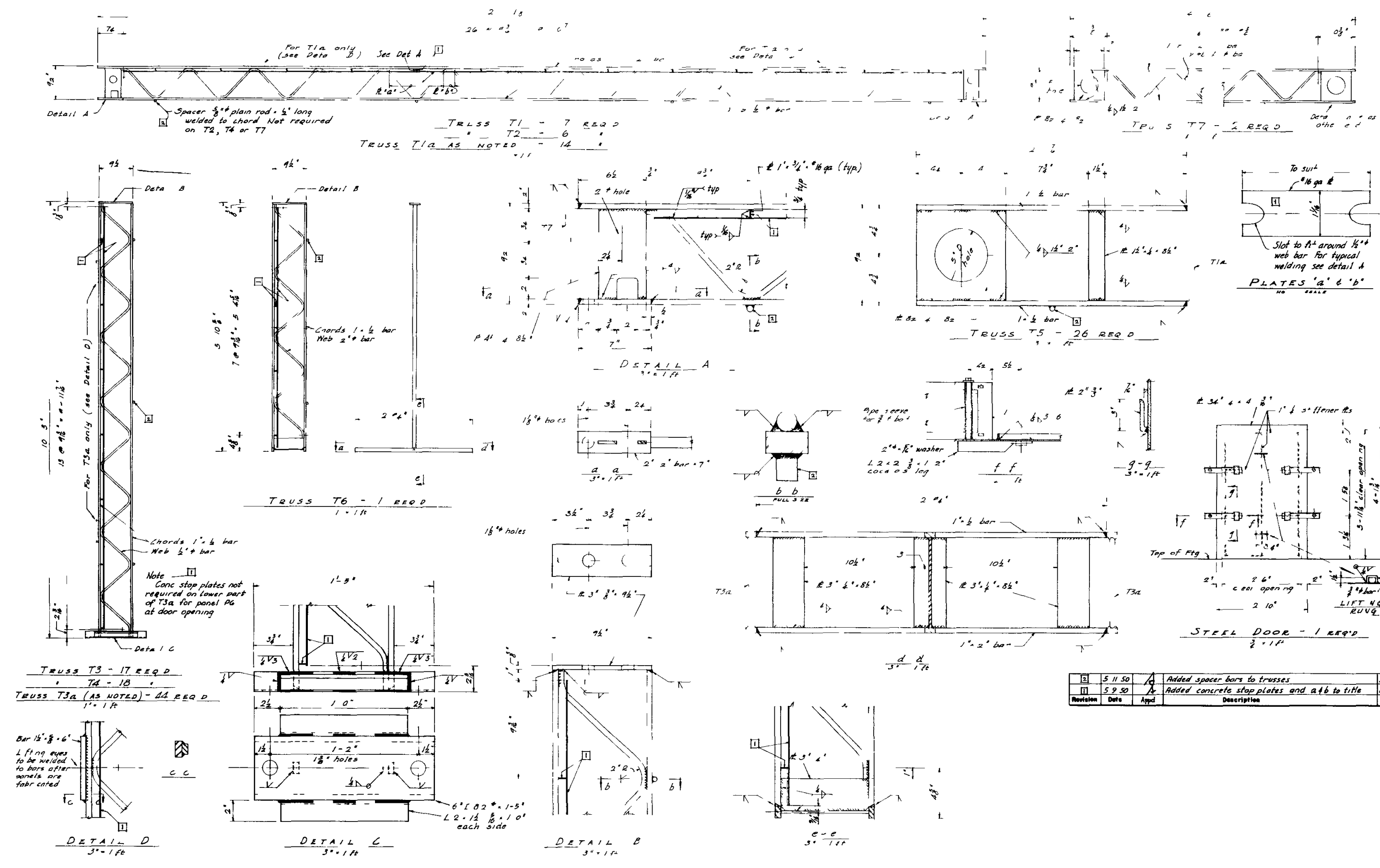

Fig. D.12 Truss Details, Type 3.2.3 


\section{S.KRET}
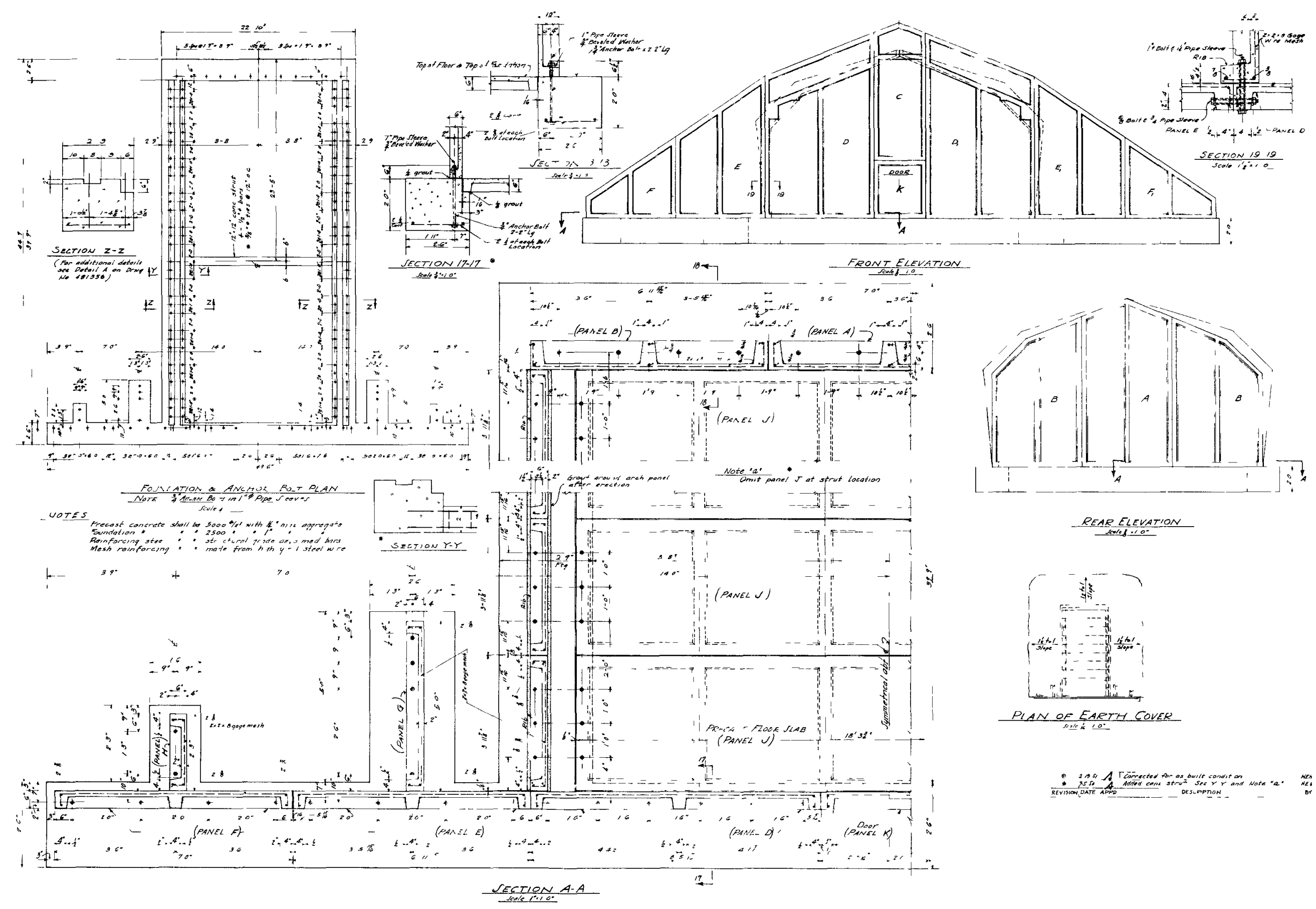

Fig. D.13 Structural Details, Type 3.2.4a 


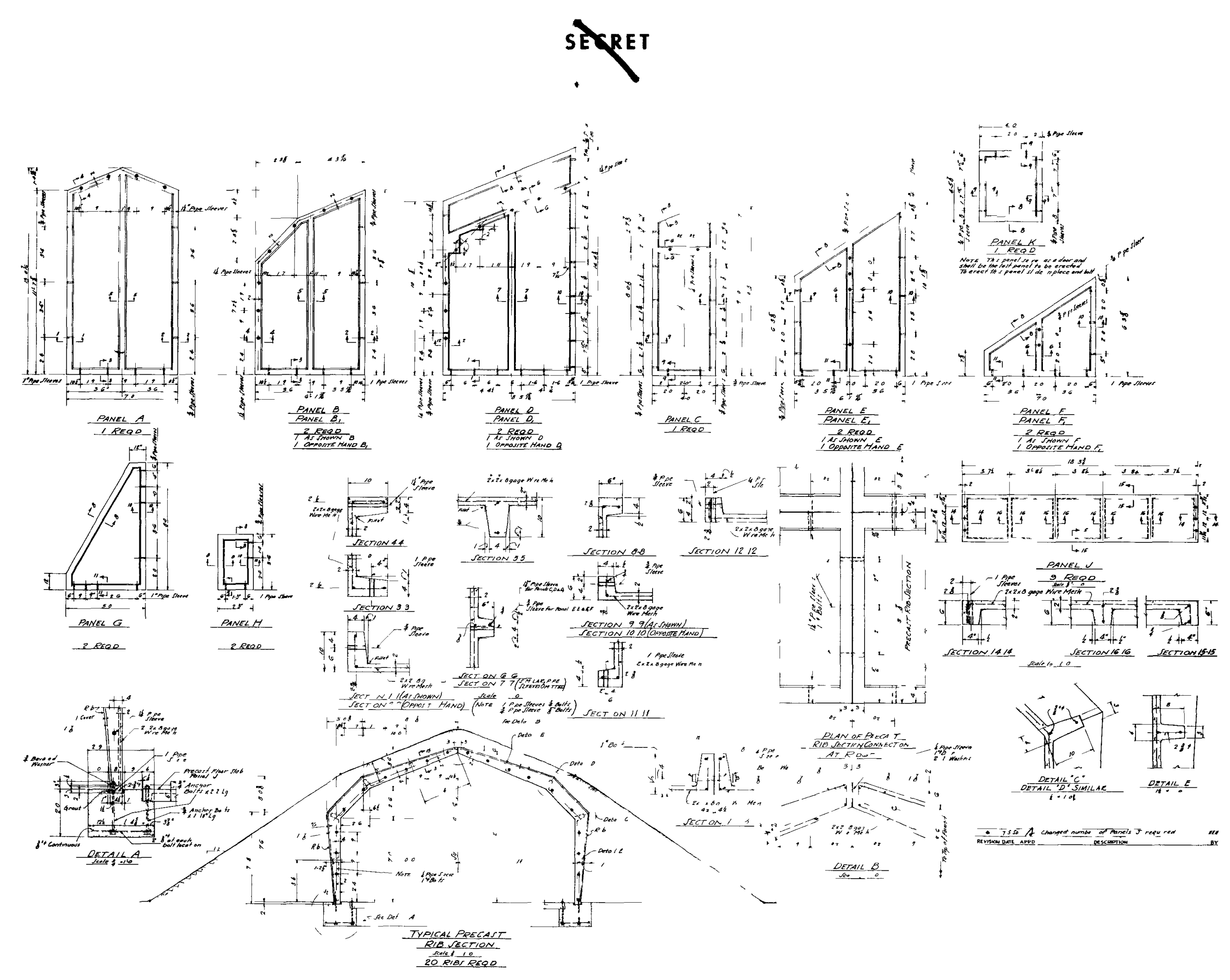

Fig. D.14 Structural Details, Type 3.2.4a

265 


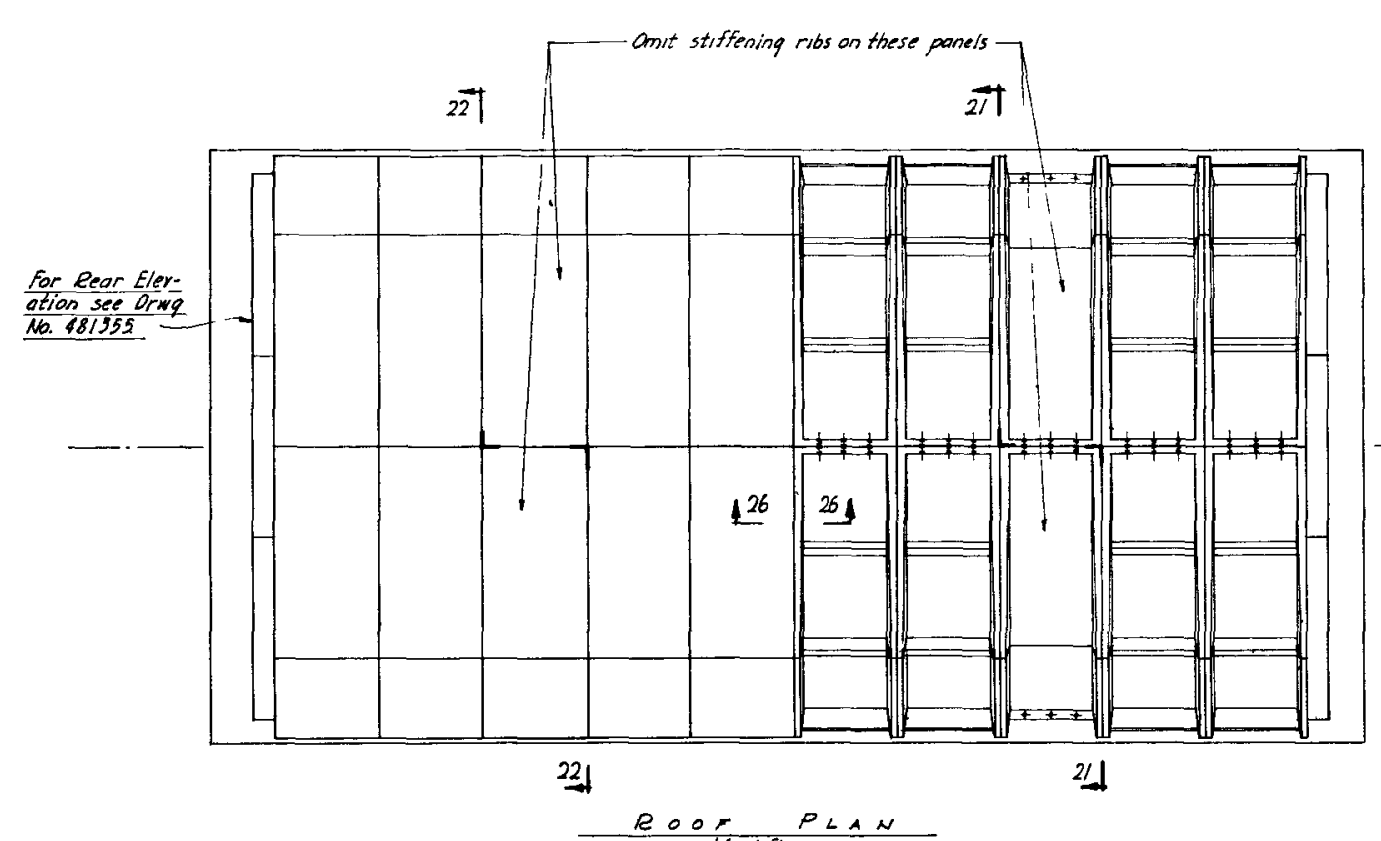

\section{डोरret}
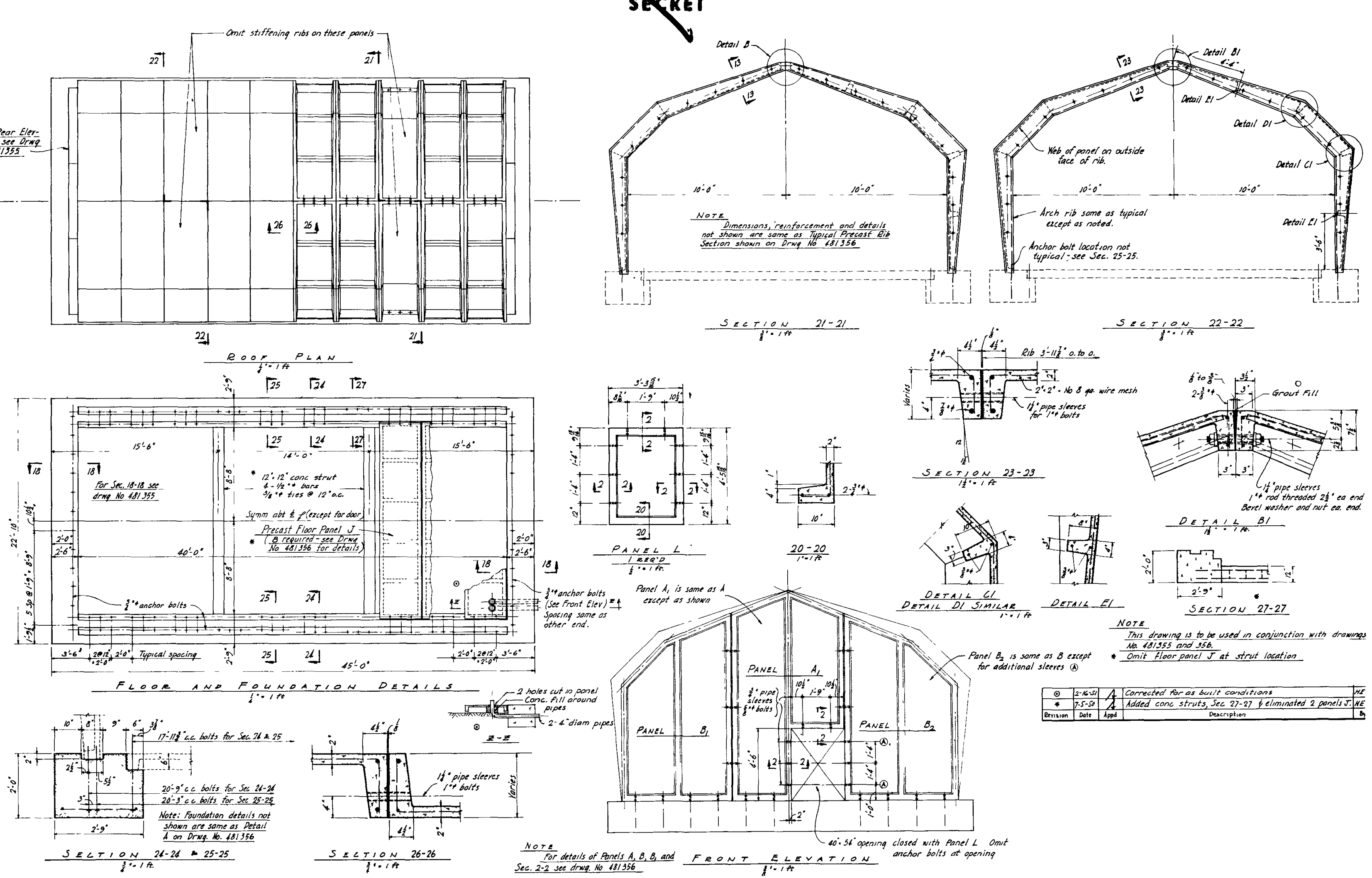

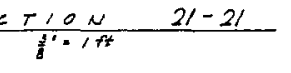

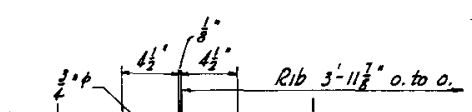

$=1+2$

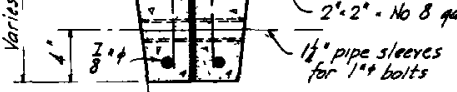

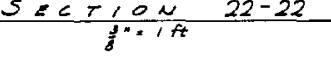

$\sqrt{25} \quad \sqrt{24} \quad \sqrt{27}$
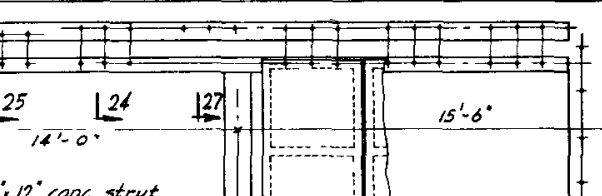

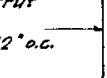

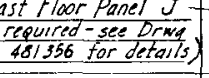

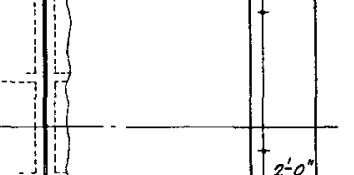

$$
\text { if } 20
$$

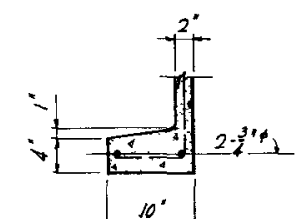

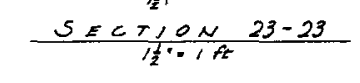

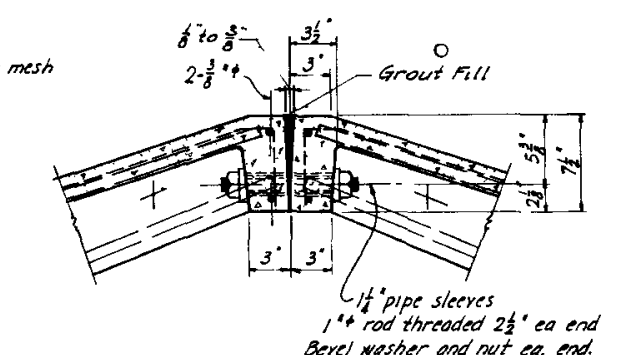

\section{6: $181 \frac{P_{A N E L}}{-\frac{N E S Q D}{2}}$ \\ $\frac{20-20}{101+t}$}
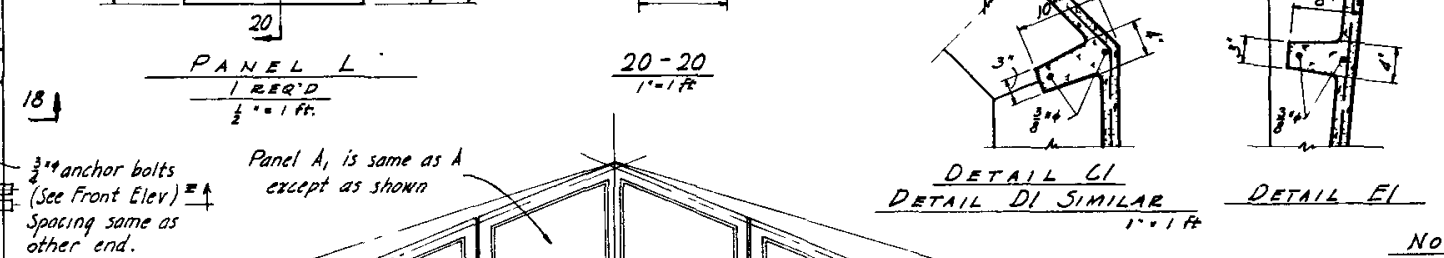

DETA $1 \leq B$ BI

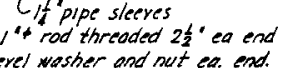

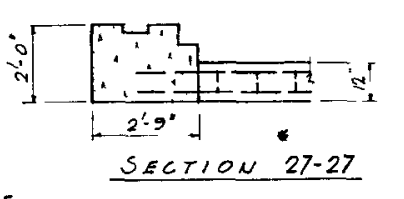

SECTION 27-27

NoTE This drowing is to be used in conjunction with drawings Panel $B_{2}$ is some as $B$ except
for additional sleves $\$$

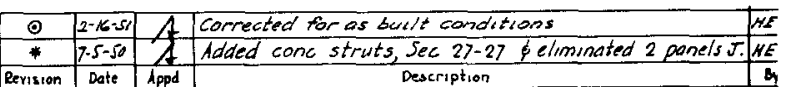

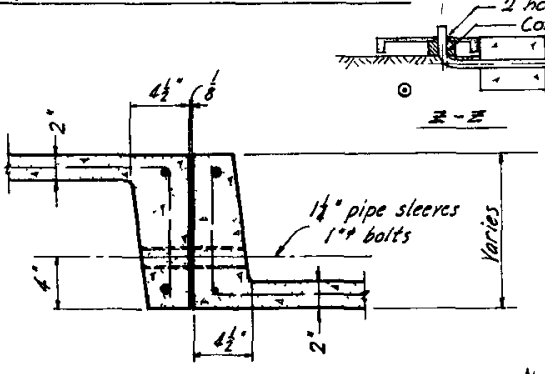

$5 \leq \frac{\pi 10 N 26-26}{3 \% 14}$

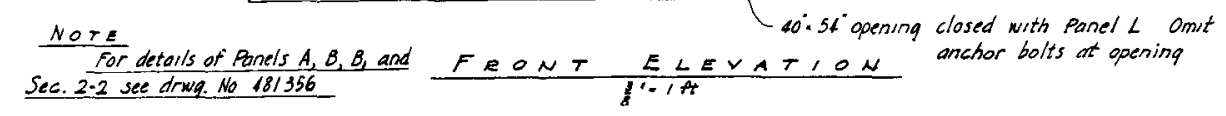

Fig. D.15 Plans and Detalls, Type 3.2.4b 


\section{SEYRET}
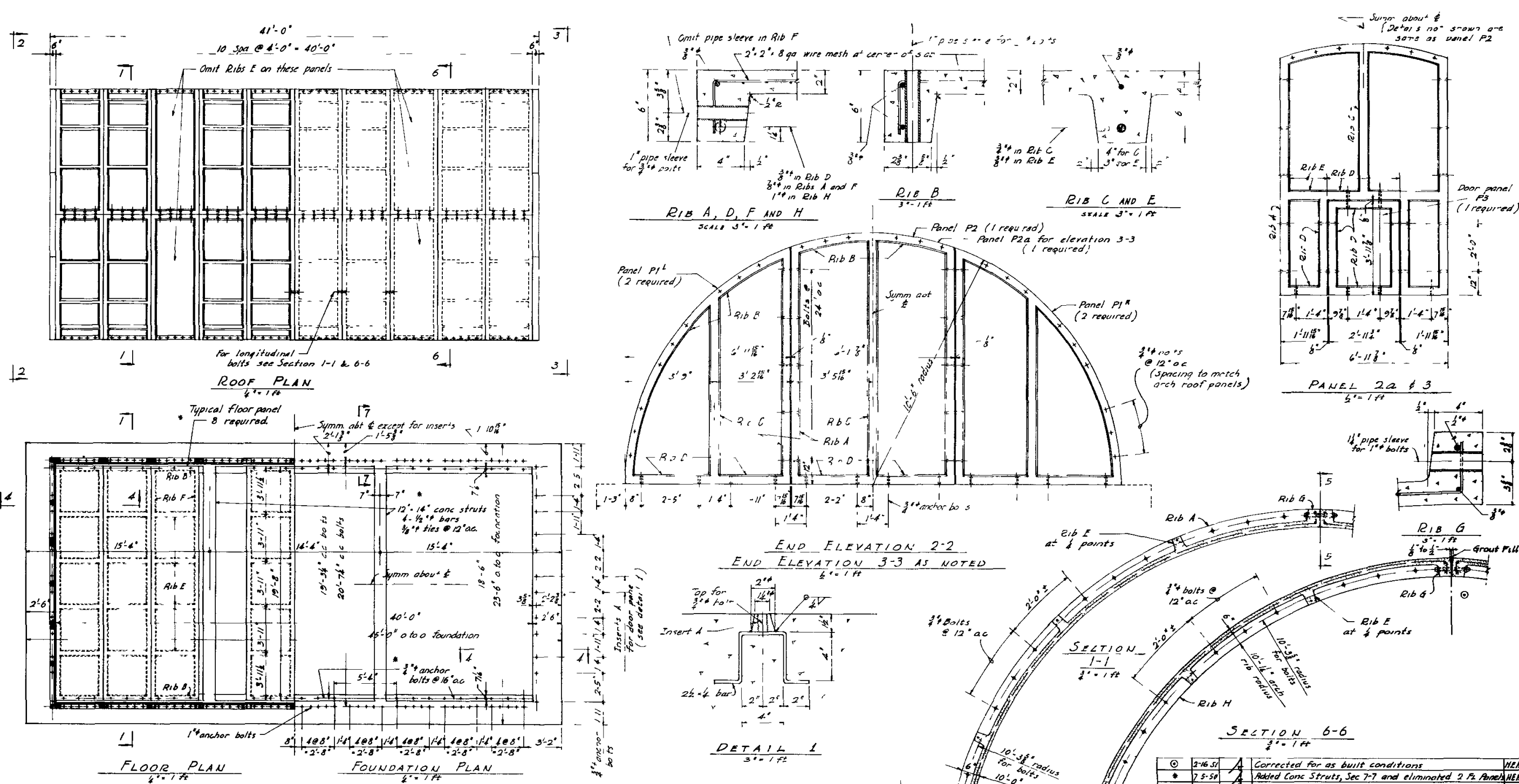

$$
\text { L f } 6^{2}-118 .-1
$$$$
\text { PANEL } 2 a \notin 3
$$

$s^{\prime \prime}=1$ ft

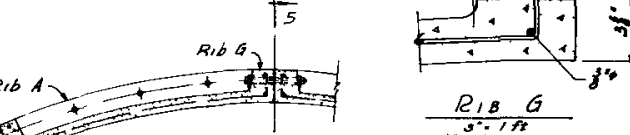
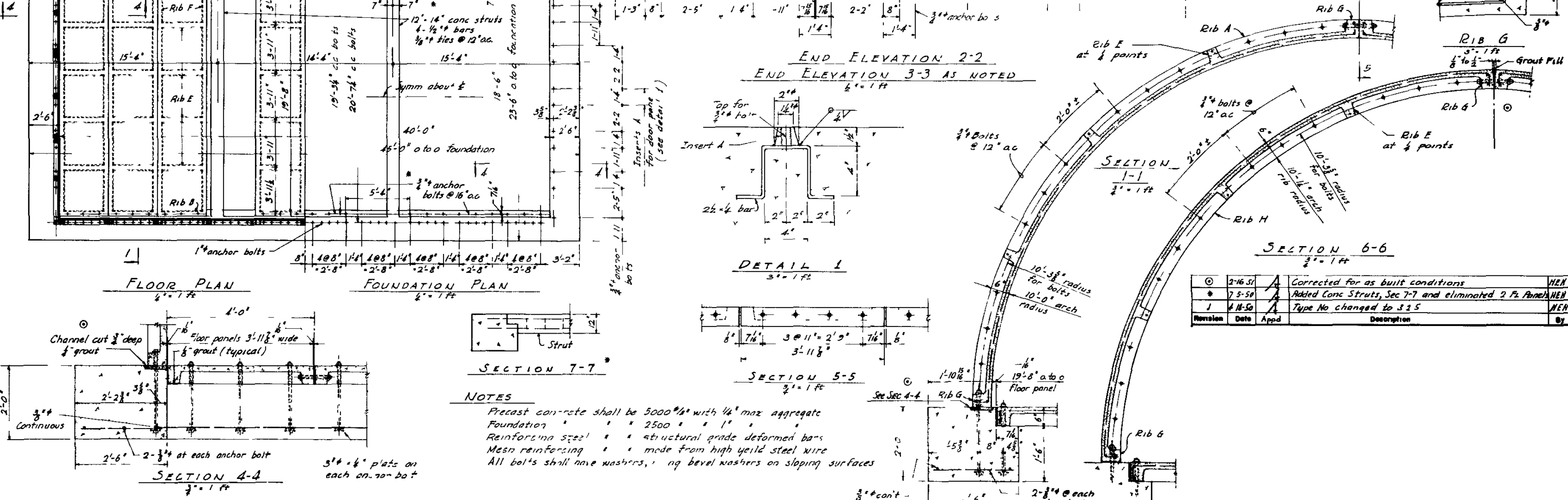

section 5-5

"moz aggregate

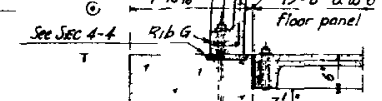

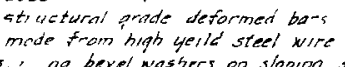

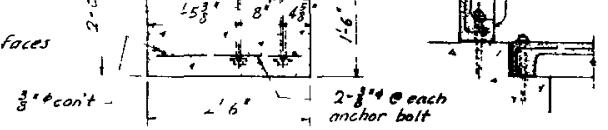

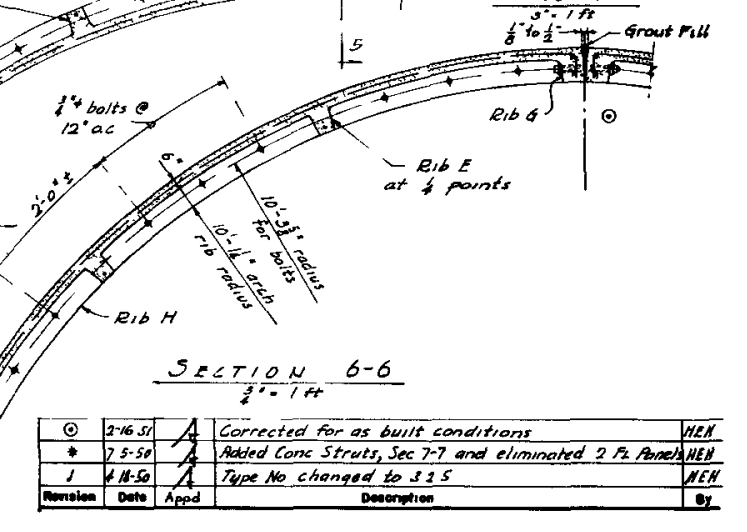

Fig. D.16 Plans and Details, Type 3.2.5

267 


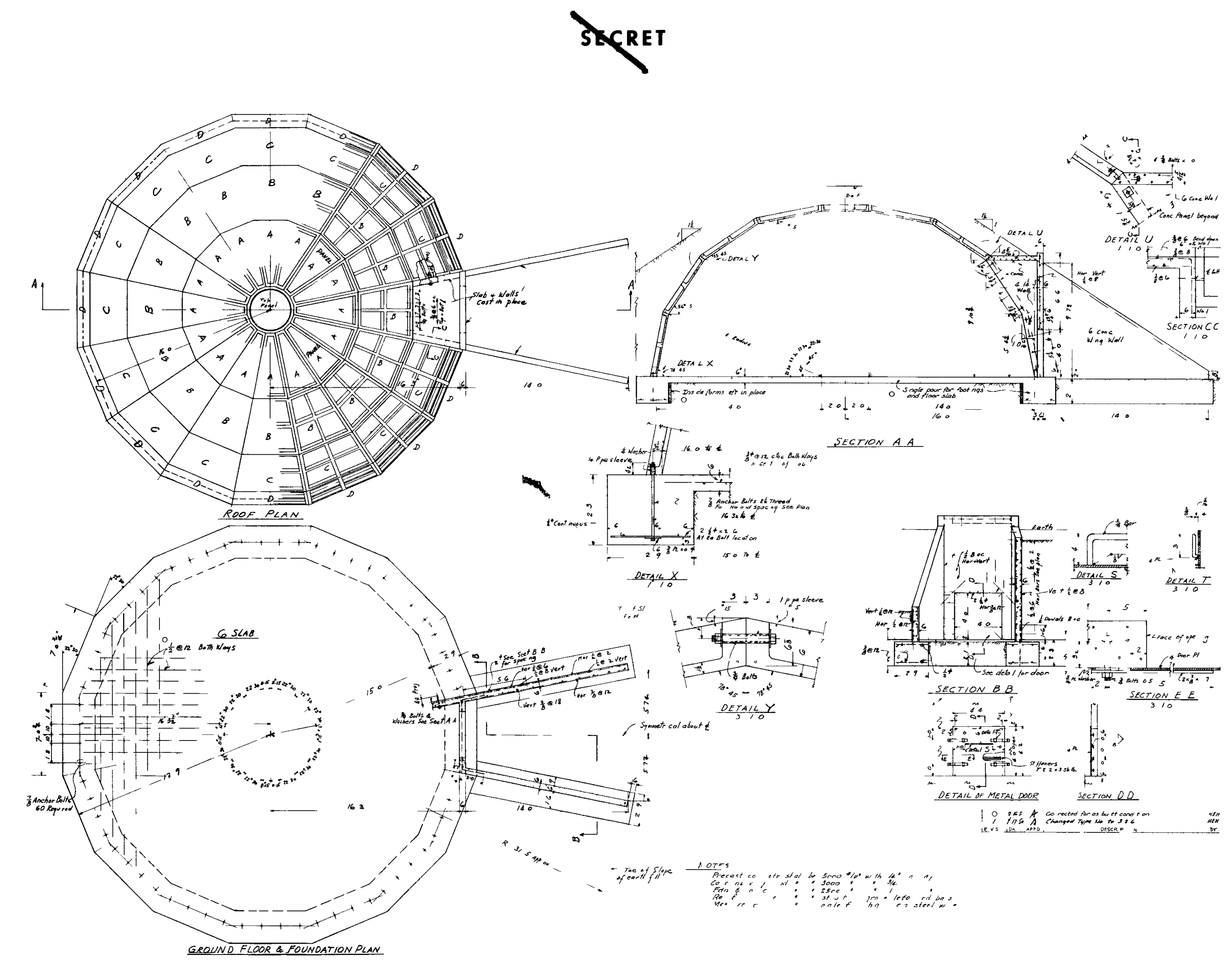

Fig. D.17 Structural Details, Type 3.2.6 


\section{UNCLASSFFIED}
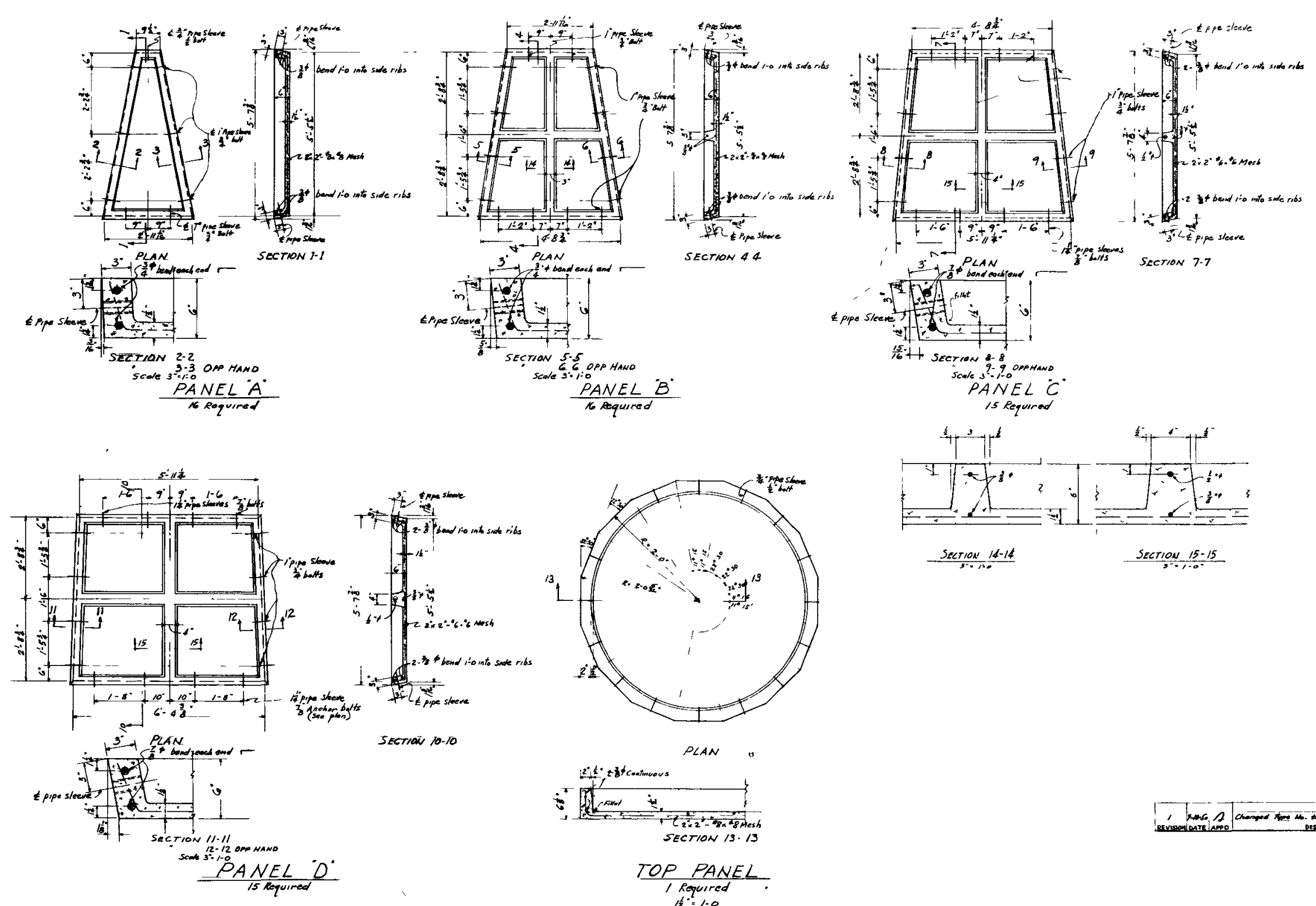

SECroũ 10.10

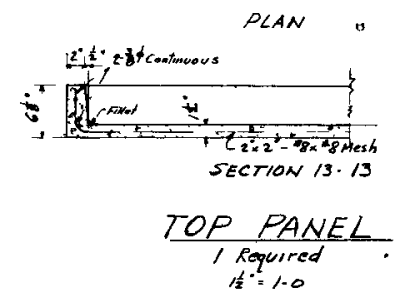

Fig. D.18 Structural Details, Type 3.2.6

\section{UMSLASSIFIED}




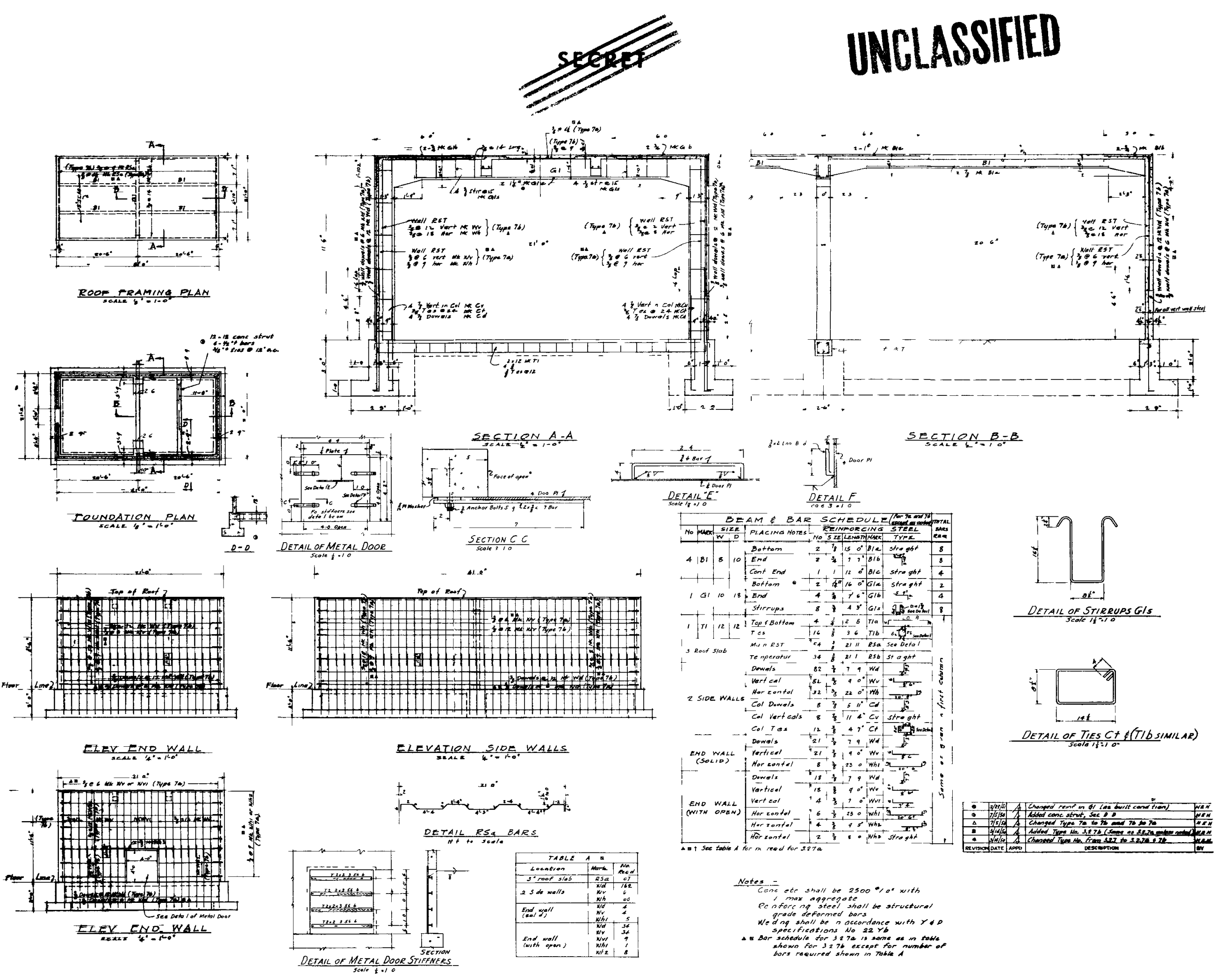




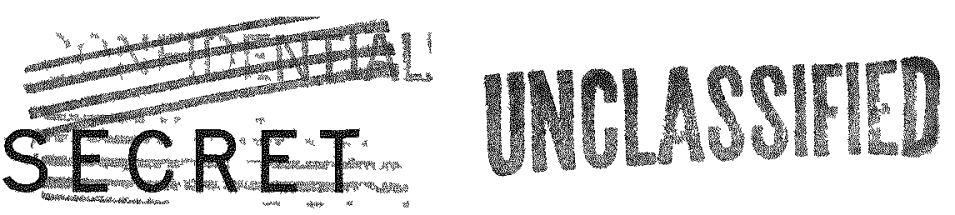

\section{Bibliography}

Amirikian, A., Design of Protective Structures (A New Concept of Structural Behavior), NAVDOCKS Report P-51, August 1950.

Amirikian, A., Precast Concrete Storehouses, J. Am. Concrete Inst,, 18 (10): 1097-1116 (1947).

Bleakney, W., "The Diffraction of Shock Waves Around Obstacles and the Transient Loading of Structures," Princeton University, Department of Physics, Mar. 16, 1950.

Bureau of Yards and Docks, Interim Report - Participation by Bureau of Yards and Docks, Navy Department, in Operation Sandstone.

Dames and Moore, Report of Foundation Investigation, Los Angeles, Mar. 9, 1951.

Holmes and Narver, Inc., Final Report, Foundation Investigations, Los Angeles, Apr. 6, 1951.

Iselin, D. G., LTJG, CEC, USN, Field Construction Report of Program 3.2 Structures, Dec. 15, 1950.

Los Alamos Scientific Laboratory, “The Effects of Atomic Weapons," Los Alamos Scientific Laboratory and U. S. Government Printing Office, Washington, D. C., 1950.

Trexel, C. A., CAPT, CEC, USN, "Bombproof Structures," U. S. Government Printing Office, Washington, D. C., Sept. 30, 1941.

Turneaure, F. E., and E. R. Maurer, "Principles of Reinforced Concrete Construction," John Wiley \& Sons, Inc., New York, 1936.

U. S. Naval Proving Grounds, Final Report on Model Tests of Concrete Cellular Construction, Jan. 18, 1950.
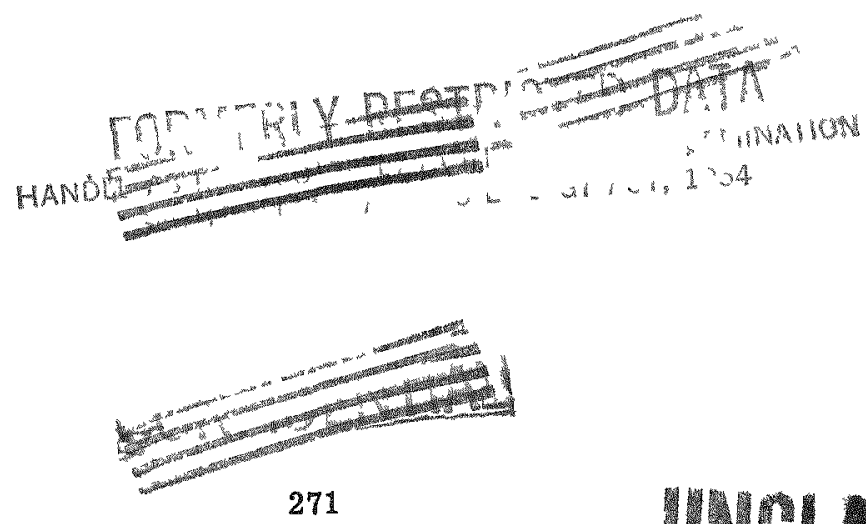

271

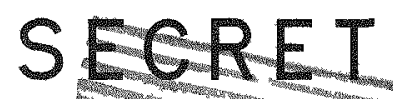

